RUCKERS. A HARPSICHORD AND VIRGINAL BUILDING TRADITION

by

George Grant O'Brien

Doctor of Philosophy

University of Edinburgh

1983

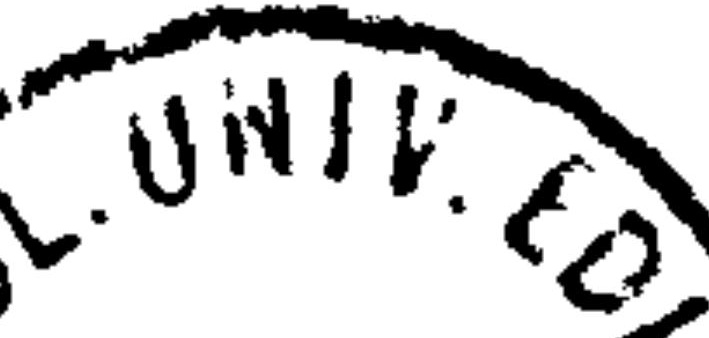




\section{BEST COPY}

AVAILABLE

Variable print quality 


\section{Declaration}

I declare that this thesis is entirely of my own composition and that the work is entirely my own, and based on my own research.

- G. Grant O'Brien Edinburgh

Dec. 29, 1983 


\section{Volume I}

Declaration

Table of Cont onts

Abstract

Int roduct $10 n$

Chapter 1 - Ruckors Family Hstory and tho Gulld of St. Luko ....................... 9

Antwerp and the Notherlands at tho time of tho Ruckors family

Ruckers family hlstory

llans Ruckers

Ioannes Ruckers

Andreas I Ruckers 22

Androas II Ruckers

Ioannes Couchet

The Couchot sons

'CR'

Ruckers and the other Antwerp artists

The Gulld of St. Luke

Conditions of work in the Guild workshops

Tho Couchots and tho Ruckers tradition

Chapter 2 - The Pro-Ruckers Instruments and Traditions

The early Italian tradition

The early Germanic tradition

Early Flemish instruments

Early Flemish double-manual harpsichords 
Chapter 3 - The Types of Instruments Bullt by the Ruckers, and the Ruckers Numbering

systen ........................... 86

Introduction - Tho numbers found on the differont models of Ruckers Instrument

Tho modols of Ruckers virginal

The standard types of harpsichord

Spoctal modols of Ruckers harpstchord

Tho Interprotation of tho Ruckers numbering syst on

Chapter 4 - Tho Stringing and Pitches of Ruckers Inst ruments

The pltches of Ruckers Instruments 146

Ruckers stringlng materials 158

Ruckers string gauges 161

The pitch scheme of Ruckers instruments 174

Chapter 5 - The Construction of Virginals 180

Introduction 180

Virginal baseboards 184

virginal outer case and framing 186

Virginal wrestplanks and hitchpin rails 194

Virginal 11d and keywell flap

Virginal toolbox

virginal soundboards 200

virginal soundboard barring 204

Virginal bridges 210

The harplchordium stop 213

Virginal registers 216

Bridge-plnning in virginals 220

Gluelng the virginal soundboard into the case 
Chapt or 5 (cont'd)

V1rginal koybods and keyboards

V1rglnal jacks and jackrall

Chapter 6 - Construction of Ruckers Harpsichords .... 247

lhrpslchord basoboards 247

llurpsichord case sides and Intermal framing 251

Tho maln 11d, 11d flap and koywell flap in harpsichords

Tho harpslchord wrostplank $\quad 274$

Hurpstchord soundboards 285

Soundboard barring and hitchpln ralls in

harpsichords

llarpsichord bridges 301

llarpsichord reglsters 322

Koyboards and keybods in harpsichords 338

Ruckers Jacks 362

Harpsichord jackralls 377

$\begin{array}{ll}\text { Harpsichord stands } & 378\end{array}$

\section{Volume II}

Chapter 7 - The Decoration of Ruckers Instruments ... 384

Flemish printed papers $\quad 384$

The wood-block pattorn books 391

Catalogue of the Flemish paper patterns found on Ruckers instruments

Types of Flemlsh block-printed paper patterns.

404

Ruckers painted soundboards $\quad 418$

Pattern books for Ruckers soundboard paintings 419 
Chapt or 7 (cont'd)

Stylos and poriods of Ruckers soundboard decoration

Early lans Ruckors style

Early Ioannes stylo

Tho oarly indreas stylo

440

The late Ioannes/Couchet style

Tho lato Androas stylo

Soundboard proparation, palnting modium and ploments

Ruckers roses

Lid and keywell flap decoration

Out er caso decoration

Mouldings

Key arcades

Locks and strap hinges

Chapter 8 - The Determination of the Original Compass and Disposition of Ruckers Harpsichords

Chapter 9 - Trademarks of the Ruckers Instruments . 525

Ruckers instrument authentification

Soundboard construction features

Soundboard decoration

The use and type of Ruckers roses

Features of case construction and materials

Differences in the constructional methods between the varlous members of the Ruckers family

Ruckers instruments in paintings

The value and Importance of fake and counterfolt Ruckers instruments 
Chapt or 10 - The Influence of the Ruckers/Couchet Tradition on Lat er Harpsichord

Bulld1ng Pract1co ................. 560

Ioannes Couchet and the beginning of change 562

Tho Couchot sons and tho doveloping tradition 565

Tho Ruckors tradition in England in tho 18th

contury

570

The Ruckors tradition in 18th century Franco 574

Tho offoct of tho Ruckers tradition in the rost of Northorn Europo

Chapt or 11 - Tho Ravaloment of Ruckors and Couchet Instruments ...................... 592

Ravalement of virginals 592

Ravalenont of Ruckors harpsichords 596

Pot it ravalement of single-manual

harpsichords

Grand ravalement of single-manual harpslchords

602

Converston of singlo-manual harpsichords to double-manual harpsichords

Allgnment of doublo-mamual harpsichords

Pet lt ravalement of Ruckers double-

manual harpsichords

Grand ravalement of Ruckers doublemanual harpsichords

\section{Volume III}

Catalogue of the Authentic Ruckers Instruments ...... 630

Introduction $\quad 630$

Hans Ruckers 631

Ioannes Ruckers (with HR roses) 639

Ioannes Ruckers (wth IR roses) 659

$\begin{array}{ll}\text { Andreas Ruckers } & 703\end{array}$

$\begin{array}{ll}\text { Ioannes Couchet } & 768\end{array}$

Ioseph Ioannes Couchet (or attributable to him) 783 
Appendices

Appond1x 1 - Tho duim

Appondix 2 - Tho lagaerts 5-voot splnett virginal

Appond1x 3 - The $2 \frac{1}{2}$-voet virginal

Appond1x 4 - Tho stringing of instrument types not in Douwes

Appondix 5 - Douwos scalos and Ruckers Instrumonts

Appond1x 6 - Classification of Ruckers Instrumonts according to tholr orlginal stato

Appendix 7 - Transposition by a tone in meantono tuning

Appond1x 8 - Grond15 Ondersoek van de Toonen dor lusifk, 1099, by Claas Douwes

Appendix 9 - 'Harpsichord' from the Muzikaal Kunst-woordenbook, 1795, by Joos Verschuere Reynvaan

Append1x 10 - 'Of the llarpsichord' from Elementa Musica, 1739, by Quirinus van Blankenburg

Appendix 11 - Contract between Joos and Goosen harest

Appendix 12 - Regulations of the Guild of St. luke pertaining to the clavecimbel builders

Appendix 13 - Extract from the Encrclopedie

Appendix 14 - The preparation of bone for keyboards

Appendix 15 - Ruckers Instruments sold in Paris sales during the 18 th century

Append1x 16 - Gerbler-W1ndebank correspondence concerning a Ruckers harpsi dord

Appendix 17 - Correspondence between G.F. Duarte and Constantijn Huyghens 
Appendices (cont'd)

Appendix 18 - Correspondence from Ioannes

Couchet to Constantijn Huyghens

909

Blbllography

912 
Ruckers. A Harpsichord and Virginal Building Tradition.

\section{Abstract}

The harpsichords and virgtnals made by the Flemish fam1l1es of Ruckers and Couchet in Antwerp at the end of the 16th contury and in the first half of the 17 th century ostablishod a tradition whlch was carrlod on in most of Northern Europo during the socond half of the 17th contury and throughout the 18 th century. The oconomic and polit1cal conditions in dntwerp and the regulations of the Guild of St. Luke were lmportant factors affecting the output of the Ruckers and Couchet workshops. The personal historles of llans Ruckers, Ioannos Ruckers, Andreas I Ruckers, Andreas II Ruckers, Ioannes Couchet and the Couchet sons are outIIned In so far as the detalls relate to the production of thelr instruments. The tradition which the Ruckers establ1shod was strongly affected by the earlier Itallan, Germanic and Flcmish traditions. Many different types and models of harpsichord and virginal were built, and each was mubered to indicate both the type of instrument and the serlal number with the instrument category. An analysis of the numbering system enables some undated instruments to be dated and also gives an 1dea of the production rates of the Individual workshops. Using archival sources, the original scalings of the instruments, and measurements of old strings surviving on some instruments, it is possible to determine the pitches and string plans of most of the models of Ruckers 1nstruments. Instruments at 8 different pitches are founa 
to axist and thoso can bo dividod into two families a tono apart, with each family consisting of 4 instruments soparatod in pltch from ono anothor by intervals of a fourth and a f15th. A dotallod oxamination 13 mado of tho materials usod In, and tho mothod of construction of tho case, Ifd, soundboard, brldges, roglsters, keybods and keyboards, and tho jacks and Jackrall of both tho Ruckers harpslchords and virglmals. The Ruckors/Couchot instruments woro very olaboratoly docorat od with block-print od papors, painted casos, paint od soundboards into which glit roses were set, o1l palntings Inside tho 11ds, caso mouldings, and plorcod koy arcados. Tho most rolovant tradcmarks which can bo usod to authont Icato a gomulno Ruckers/Couchot instrument aro out11ined. Tho Influence of tho Ruckers tradition on later harpsichord bullding in tho rest of Europo was very important, especially in England and France. Tho Couchots aro shown to have been very innovative and to have introduced many changes to the stable tradition alroady establishod by tho Ruckers. Aftor tho dems so of tho Ruckers and Couchets, tho Instruments they bullt were altered to enable them to play the later music. The process of alteration, called ravalement, is discussed for virginals, single-manual harpsichords and double-manual harpsichords. The genutne instruments of each of the members of the Ruckers and Couchet Instrument-bullding ramily are catalogued and individually described. There are elghteen appendices relating mostly to thooretical aspects arising out of the text, and to archtval sources. Thore is a complete bibliography of 
works consulted and of relevant material, and tho toxt is liborally 1llustratod with tablos, diagrams and photographs. 
In approachlng a study of tho Ruckors family and tholr Instruments, tho primary phllosophy I have adopted has boon to got as much information as possiblo from tho 1nstruments. Thls mothod of approach has 1 nvolvod not only a study of the materials usod in tho instruments and tho Ruckers construction mothods, but also a close examination of the scalings and pltch of the lnstruments, the decoration, numbering and the types of instruments made. of nocessity this has also involvod a study of the original state of each type of Instrument, and of tho subsequent states of many of the instruments as they were adapted for later musical use. Although no less important than tho actual Instruments, I have used documents and the archives only socondarily to confirm or elucidate features found from a study of the instruments. Thus generally there is littlo reforence made throughout this work either to archival sources or the work of other authors.

The study of the instruments of a given builder is greatly affected by the mumber of extant examples of his work. The task of somoone studylng the kirkman family, with over 150 surviving instruments is vastly different from that of someone studyling the 10 or so remalning instruments attributed to Baffo. Boalch 11 sts altogether 190 instruments under the headings 'Couchet' and 'Ruckers'. But if one doletes those which are listed twice, are unauthentic or have disappearod, one is left with 
the genuine products of the Ruckers/Couchet family workshops. Fifty nine of these instruments are harpsichords, with the distribution of single- and double-manual instruments being roughly equal. The remaining instruments are all virginals of a number of different sizes and types. Although the instrument production of the Ruckers family is spread over a period of about 100 years covering the end of the $16 \mathrm{th}$ century until the end of the 17th century, and although this production is divided among the output of 6 different individuals, a comparison of all these instruments reveals an extremely stable and conservative building tradition. The differences across this time span and from builder to builder are so few as to make the Instruments of any one type almost identical except in the details of the decoration. It is the relatively large number of surviving instruments and the conservative building tradition that make a comparative study of the Ruckers instruments particularly valuable and meaningful.

During the course of this work it became clear that a number of new terms had to be defined, the meaning of terms already in use had to be restricted or altered slightly, and new words and terms introduced. Most of these terms are defined or made clear in the text. A word adopted specially for this work is clavecimbel. This word (sometimes spelled beginning with a ' $\mathrm{k}^{\prime}$ ) was used in $16 \mathrm{th}, 17 \mathrm{th}$, and 18th century Flanders to mean 'plucked stringed keyboard instrument'. It was a generic term which could mean either virginal or harpsichord. Because, in the transla- 
tion of documents, it could not be translated directly, and because it avoided the inelegant use of 'plucked stringed keyboard instrument' in the main text, I have used it with its old classical meaning (in modern Flemish klavecimbel means harpsichord only, and not either or both virginal and harpsichord).

Two other Flemish words used throughout the text are voet (foot) and duim (thumb) and their plural forms voeten and duimen. These are the 16th, 17th and 18th century Antwerp units of measure and are discussed in the text and appendices. Lengths are quoted in millimetres (mm) and where applicable nominal lengths are also quoted in duimen and vo eten. String scalings are measured from centre-to-centre from one bridge pin to the other. Plucking points are measured from the centre of the nut pin to the centre of the quill plucking the string in question. String scalings and plucking points are always quoted in millimetres even when not stated.

I have used a short-hand notation to refer to particular instruments. This consists simply of the date of the instrument and the initials of the rose in the soundboard (or the initials of the maker if the rose is missing). This is the same system used in the 'Ruckers' article in the sixth edition of Grove's Dictionary: The New Grove's Dictionary of Music and Musicians published in 1980. For example, 1639 IR refers to the harpsichord made in 1639 by Ioannes Ruckers. If more than one instrument was made in a single year by a maker, then the date is followed by 
a lower case letter of the alphabet, eg. 1620a AR, 1620b AR, 1620c AR, etc. When the date of an instrument is uncertain it has been placed in parentheses: eg. (1626) AR is an undated virginal by Andreas Ruckers whose date has been estimated from its Ruckers number. A fold-out page giving the date, builder, present type of instrument and its location has been included as a condensed catalogue of all of the authentic Ruckers instruments. This page has been placed at the end of Vol. I and Vol. II, and at the end of the appendices in Vol. III and can be left open for reference when reading the main text.

When referring to keyboard compasses and to notes within the compass, a modified Praetorius/Helmholtz notation similar or identical to that currently-adopted by most modern authors has been used. Using this notation 'cello c is 'C and the diatonic notes above it are D, E, F, G, A, $B, c, d, e$, etc. The octaves above are labelled $c^{1}, c^{2}$, $c^{3}$, etc. The $\underline{f}$ below $C$ is called $F_{1}$, and the diatonic notes above it are $G_{1}, A_{1}$ and $B_{1}$. Accidentals are given their meantone names, eg. $e^{b}$ and not $d^{\#}, c^{\#}$ and not $d^{b}$, etc. On instruments at transposed pitch, or when referring to the 4' stop, the notes are always named according to the played key and not the sounded pitch. Pitch $c^{2}$ refers to the length and pitch of the note $c^{2}$ for the 6-voet virginals and normal single-manual harpsichords. The length of a string for any other note can be referred to pitch $c^{2}$ as outlined in Chapter 4.

The convention used here for referring to the order 
of the registers for describing the disposition is exemplified as follows:

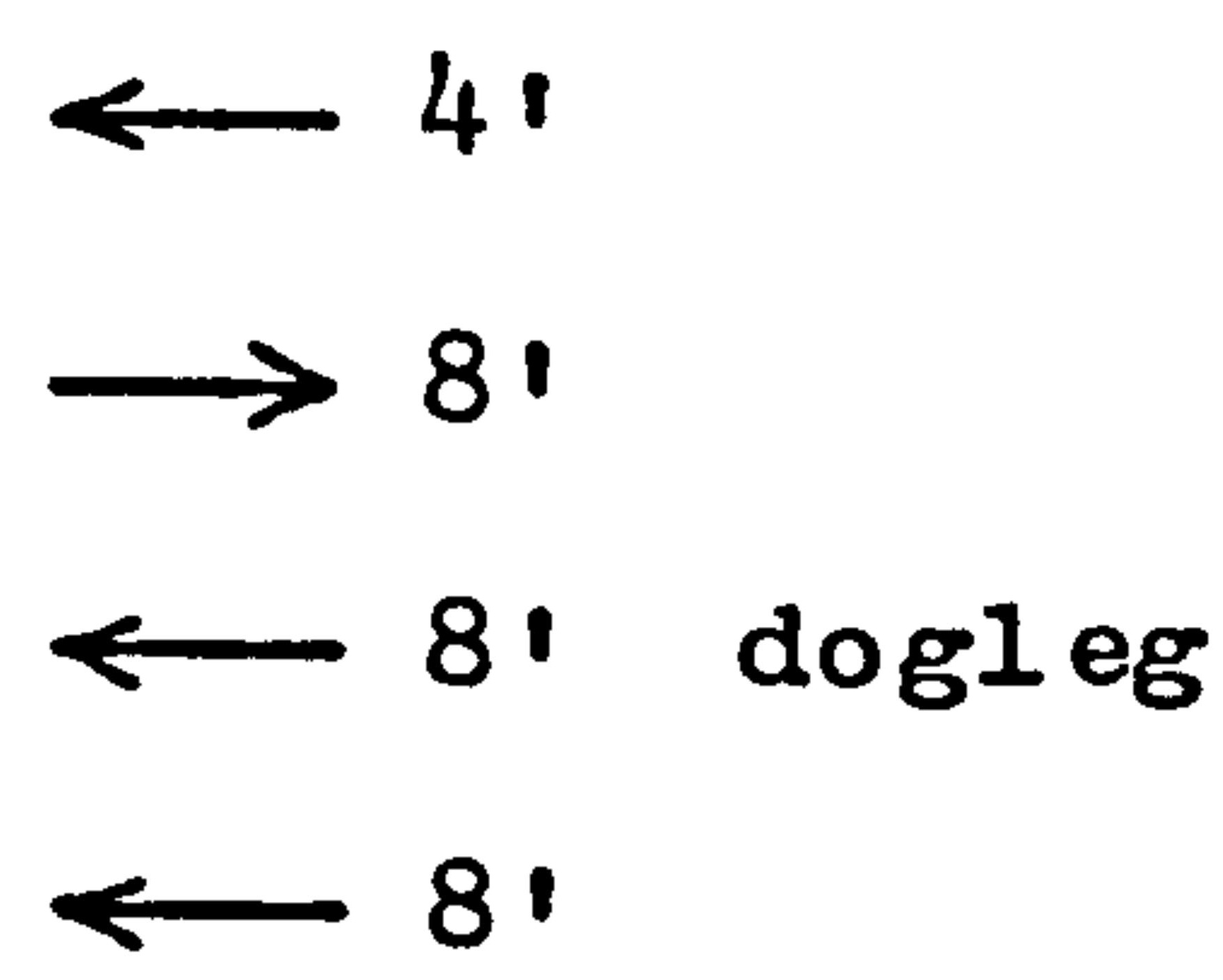

Here the 4' register is furthest from the player and plucks to the left. There are two 81 registers near the player and they both pluck to the left. The second register from the player is a dogleg register and can be played from either manual. The order of the registers in this convention is the opposite to that used by Hubbard.

Generally references to the work of other authors or to archival sources are given at the end of each chapter. Exceptions to these are the three 'standard' works which are referred to without notes. These are the books by Boalch, Russell and Hubbard which are respectively:

Donald Boalch, Makers of the Harpsichord and Clavichord, 1440-1840, London (1956, revised edition, 0xford 1974).

Raymond Russell, The Harpsichord and Clavichord, London (1959) (reprint ed. Howard Schott, London, 1973). Frank Hubbard, Three Centuries of Harpsichord Making, Cambridge, Mass. (1965).

Authentic Ruckers/Couchet instruments are always referred to using the short-hand notation already described. Unauthentic instruments are referred to according to their number in the listing under 'Ruckers' or 'Couchet' in the second revised edition of Boalch's book. Thus, for 
example, B.57 refers to the false 1636 Hans Ruckers harpsichord in the Palace of Holyroodhouse in Edinburgh.

This study was made possible only through the cooperation and help of the many owners and museum personnel in charge of the instruments examined during the course of this study. I would like to thank them and the many others whose help and friendly advice and assistance have enabled me to complete this work. My thanks and gratitude go out to:

Dr. Jeanette Abery, Florence Abondance, Dr. Rob van Acht, Dottoressa Clelia Alberici, Dr. Horst Appuhn, Lode Bauwens, Hubert Bédard, Josianne Bran-Ricci, William Bright, Dr. John Catch, Dottoressa Louisa Cervelli, the late Madame de Chambure, Christopher Clarke, Richard Clayson, William Dowd, Leonard Elmhirst, Philippe Fritsch, Andrew Garrett, Sheridan Germann, Kenneth Gilbert, Dr. Clemens von Gleich, Martha Goodway, Bert11 Grahn, Goran Grahn, Fri edemann Hellwig, Dr. Hubert Henkel, Christianne Jaccottet, Dr. Jean-Pierre Jelmini, Dr. Robert Johnson, Cary Karp, Andreas Kilstrom, John Koster, Dr. Di et er Krickeberg, Barbara Lambert, Dr. Jeannine Lambrechts-Douillez, Michael Latcham, David Ley, Laurence Libin, Dr. Mark Lindley, Tom McGeary, René de Maeyer, Peter Maxwell-Stuart, Dr. John van der Meer, Dr. Nicolas Meeus, Claude Mercier-Ythier, François Meyer, Mette Muller, Vere Pilkington, Stewart Pollens, Jerome Prager, Scott Odell, Dr. Nicholas Renouf, Richard Rephann, Dr. Rudolf Reuter, J.J.K. Rhodes, Dr. J. van Roey, Comte Xavier de Sade, the late Dr. Konrad Sasse, Martin-Christian 
Schmidt, Dr. Jim Tate, Fritz Thomas, Michael Thomas, W.R. Thomas, Pet er Thornton, The Lord Tollemache, Raymond Touyere, Ma van Va erenbergh, Dr. Christian Vaterlein, Kurt Wittmayer, and Denzil Wraight.

Eddi e Clark has very kindly typed most of the manuscript for me. I would certainly not have been able to complete this work without his help. I also greatly appreciate the help of the many friends who helped with the proofreading, photographs, and collating in the final stages.

I would particularly like to record my thanks to John Barnes whose systematic and methodical approach has been the model for carrying out the research involved in this study. I would also like to thank Dr. Rita McAllister who read Chapters 3 and 7 and offered many helpful suggestions. Finally I would like to thank Professor Peter Williams who initially suggested that this study might take the form of a doctoral dissertation, who has read all of the manuscript, and who has offered innumerable suggestions for its improvement. His guidance and support have been invaluable.

Some of the conclusions and results of this work have been published by me previously:

'The Numbering System of Ruckers Instruments', The Bulletin of the Brussels Museum of Musical Instruments, 4 (1974) 75-89.

The Determination of the Original Compass and Disposition of Ruckers Harpsichords' and 'The Stringing and Pitches of Ruckers Instruments', Colloquium. Ruckers 
klavecimbels en copiesn, Antwerp (1977) 36-47 and 48-71. All of this previously published material has been completely re-worked and up-dated before it was included here. 
Chapter 1 - Ruckers Family History and the Guild of

Antwerp and the Netherlands at the time of the Ruckers Family

Toward the end of the 15th century, with the silting of the Zwijn, Bruges lost her port and, with shipping greatly restricted, her cultural and economic decline was inevitable. Almost concurrent with the silting of the Zwijn, a series of floods and Innundations deepened and widened the Scheldt, and Antwerp on its east bank, which was even then an excellent port, became the home of the shipping, trade guilds and banks formerly centred in Bruges. Europe's first real bourse or stock exchange was founded in Antwerp in 1460. In the early. decades of the 16 th century the diamond industry was established and expanded greatly when the Jewish diamond craftsmen, expelled from Portugal, settled in Antwerp. Gradually Antwerp became the chief port and the commercial and cultural centre of the Netherlands and western Europe. Charles I of Spain (1516) succeeded to the throne of the Holy Roman Empire as Charles V in 1519. Born and educated in the Low Countries he ruled with a powerful but benevolent hand. Antwerp's life was stimulated by the Spanish and Portuguese discoveries in the New World and the riches brought back to Europe. Commerce flourished and a wealthy middle-class developed who were eager to adorn their new houses with the best paintings, fine furniture, 
sculpture, bronzes, rugs and drapery, and their appetite for fine silver and gold, books, pottery, medallions and jewellery was insatiable. Trade and culture flourished and by 1550 Antwerp had surpassed even Venice in commerce and the arts.

Like the rest of Europe, however, Antwerp was beset by religious strife in the second half of the 16 th century. Charles $V$ was a champion of the Roman Catholic faith and he vigo rously repressed the Protestant heresy. Despite this the number of Calvinists grew. In 1556 Charles' son, Philip II of Spain acceeded to power. Unlike his father, Phil ip II had little sympathy or understanding of the attitudes and wishes of the Lowland's populace. His heavy taxation and fanatical suppression of the Protestants made him very unpopular. In 1567 an open revolt took place in which the united efforts of the Catholics and Protestants were forced against the Spanish. The Duke of Alva was sent in and under orders from Phil ip II, a period of bloody and enforoed repression took place. In order to establish Spanish dominance over the local population Alva built a fortified citadel on the southerm ramparts of the Antwerp city wall to garrison his Spanish troops.

In 1576 these troops, after enduring a long period of hardship and lack of pay, stormed out of the citadel and ran mad through the streets. In the resultant sacking of Antwerp - the so-called "Spanish Fury" - hundreds of buildings and homes were burned and plundered, women raped, works of art were destroyed and an estimated 8,000 
Iives were lost. Antwerp never really recovered from the disaster.

In the disorder after the "Fury" the Calvinists seized and held power and destroyed Alva's citadel. However, in 1585, after an extended seige, Antwerp again fell to the Spanish under Alessandro Farnese, Duke of Parma. Under Parma the Protestants were sent into exile, and much of the population, capital and enterprise emigrated, mostly to the Dutch United Provinces to the North.1-1) During the years following 1585 Antwerp's population fell from over 80,000 to 42,000. Economic, political and religious freedom were sharply curtailed. However, by 1595 the population in Antwerp had increased to 47,000 and a renewed period of peace and prosperity ensued without the crowding and the resultant plague, disease and fires of the earlier years.

Under Albert of Austria and Isabella, daughter of Phil 1p II, who made their state entry into Antwerp in 1599, the city experienced a continued period of peace and splendour. In 1609 the Twelve Years Truce was signed with the Protestant held United Provinces, and Antwerp entered into its second Golden Age. By 1612 Antwerp's population was 53,000 and it maintained itself at this level until well into the 18 th century. Commercial and cultural life again flourished. Rubens, Jacob Jordaens and Pieter Breughel executed major painting commissions and established an intermational reputation. The printing presses of Plantin were as busy as they had ever been. And the two Ruckers' sons Andreas and Ioannes entered the 
Guild of St. Luke and established themselves as instrument builders of the highest order.

In 1621, with the expiry of the Twelve Years Truce, tension increased somewhat between the Protestant Dutch Provinces and the Spanish Netherlands, but outright conflict was avolded, in great part due to the skilful diplomatic efforts of Ruckers' contemporary Peter Paul Rubens. After 1635, with the death without an heir of Isabella, sporadic fighting took place with the Calvinist Northern Provinces. Nonetheless, the difficulties were not serious enough to affect greatly the artistic and economic life in Antwerp. Then, finally, in 1648 the Treaty of Munster and the Peace of Westphalia recognised the independence of the United Provinces. It also gave the Dutch full control of the estuary of the Scheldt and therefore of Antwerp's port. The Amsterdam merchants demanded that the river be closed to navigation and this ensured tho. final cultural and economic decline of Antwerp. By 1655 to 1660 the last important members of the Ruckers family had died and, like Antwerp's commercial and artistic life, the production of Ruckers instruments ceased. Instruments continued to be build in the Ruckers style by the Couchets who were the heirs to the old tradition. These later instruments exhibit considerable innovation, but the number produced was very small, probably as a result of the lack of a local market and the removal of the commercial focus of Northwestern Europe from Antwerp to Ámsterdam. By 1706 the last of the harpsichord building Couchets was dead, and 
the Golden Age of harpsichord building in Antwerp came to an end.

\section{Ruckers Family History}

The biographical details of the Ruckers family have been of interest to researchers for over a century now, and in the course of this time a great deal has been learned about its various members. One of the earliest, and still one of the best contributions to the field was published in 1859 by Genard ${ }^{1-2}$ and further details were added in $1863^{1-3)}$ and $1864^{1-4}$ ) Somewhat more recently a publication of $1942^{1-5)}$ has made further contributions, and the indefatigable energy of Dr. Jeannine LambrechtsDouillez has brought this research together and added much new information to our knowledge of the Ruckers family!-6) Most of the information about the family history that follows has been taken from one or other of her publications. But despite the large amount of work that has been done, and is still being done, there are a number of important gaps in our knowledge of the histories of almost all of the members of the Ruckers family. The features of some of the instruments built by the Ruckers and Couchets enable us to make conjectures about some of these details, but a more complete picture of the lives of the Ruckers can only come from a careful and complete study of the Antwerp church and city archives and the other historical sources in Belgium and Holland. The continuation of this work is being carried out by Dr. Lambrechts-Douillez.

The name Ruckers itself comes from the Christian name Ruka ert or Rycka ert (English, Richard). 'Ruckers' is 
thus a foreshortening of the patronymic Ryckaertszoon or Ruckaerts (in English, Richardson or Richards). In the archives of the Antwerp cathedral and the Guild of St. Luke, the name appears written in the forms Ruyckers, Rueckers, Rieckers, Rueckaers, Rycardt, Rickaert, Ruckeerts, Ryckers, Ricaert and Ruckaert. As with many of the names associated with instrument building in Antwerp, the family seems to have come to the Lowlands from Germany. 1-7) Albrect Durer, on a trip to the Netherlands and Antwerp in 1520 depicted a Master Arnold of Seligenstadt (near Frankfurt am Main): 1-8) It has been possible to show that the person sketched by Durer was one Arnold Rucker or Rttcker who, although he also worked in Mathias Grtnewald's workshop in Aschaffenburg as a woodcarver, was best known to his contemporaries as an organ bullder. Arnold Rucker built organs in Marburg-an-derLahn, Aschaffenburg, Wurzburg, Amorbach and probably in other Franconian towns including his native Seligenstadt in the period from 1508 to 1536. No direct connection has yet been discovered between Arnold Rucker of Seligenstadt and the Ruckers family of Antwerp, but the similarity in the name, and the fact that all of the Flemish Ruckers were also involved with the repairs and tuning of the church organs in Antwerp, strongly suggests that there is a family relationship between the two. Hanns_Rückerers_

The founding member of the Ruckers family was Hans kuckers. He was born in Mechelen (Malines) and his father 
was Frans Ruckers, but the exact date of his birth is not known. On June 25, 1575 Hans Ruckers married Adriana (Naenken) Knaeps (or Cnaeps) in the cathedral (Onze Lieve Vrouwekerk) in Antwerp, and Marten van der Biest, who was also another clavecimbel builder, and one Adam Boest were witnesses to the ceremony. It is known that on 5 July, 1597 he was still alive, but also that, according to the will of his great-great-grand-daughter Rebecca Ruckers, he died "in the century of 1500 in the years of $90 "$, so that he must have died in 1597,1598 or 1599. 1-9) Recent work by Dr. Lambrechts-Doulilez has shown that he was already dead on the 14th of September, 1599. The cathedral records from Christmas 1597 to Christmas 1599 give:

"Received as the dues for the funeral, 1598. Hans Rycardt. 4 gulden, 1 stuijver, 6 den." 1-10)

and, although the spelling of the surname is unusual, it seems clear that the entry refers to Hans Ruckers and that the time of his death can be placed during 1598. From this and the date of his marriage it seems likely that Hans Ruckers was born about 1550, since he would then have been about 25 at the time of his marriage and just under 50 at the time of his death. Two factors have contributed to a certain amount of confusion about the assignment of the death date of Hans Ruckers. In the first place, both Hans and his eldest son Ioannes were referred to/bythers, and called themselves, by any one of the different forms of the name Ioannes, Joannes, Johannes, Jan and Hans. Thus in the will of Rebecca Ruckers, Hans Ruckers and Ioannes 
Ruckers, father and son, are both referred to as Ioannes. Also in the cathedral records for 1598 and 1599 we find;

"Tn Hans Ruckers, for the maintenance of the organ

- at his salary for two years at the rate of 6 pounds Flemish per year paid for the years, 1598, 1599 at St. Bavon's, 12 pounds Flemish." 1-11)

Here it soems certain that since Hans Ruckers died in 1598, his son Ioannes had succeeded his father in the upkeep of the cathedral organ.

A second source of confusion has arisen because of the fact that Ioannes Ruckers used a rosette in the soundboard of his instruments from 1598 until at 1 east 1616 which used the initials "HR"i.e. Hans Ruckers. This rosette (in fact several different castings were used) is, however, slightly different and quite distinguishable from the HR rosette used by Hans Ruckers the father from 1579 to 1598 (see further p. 456). 1-12) In order to avoid confusion in this work, I will refer to the father as Hans, and to his eldest son as Ioannes.

Hans Ruckers joined the Guild of St. Luke in 1579. The painters, engravers, printers, glaziers, and other Antwerp artists all belonged to the Guild of St. Luke and, in 1557, ten clavecimbel makers banded together to form an autonomous group within the Guild whose profesion would be recognised like that of painter or goldsmith. Counting the original clavecimbel builders, Hans was the nineteenth to be inscribed in the Guild records after 1557 as Claversinbalmakerre. Thus in 1579, in a town with a population of only about 80,000 there were probably about 15 to 20 master clavecimbel makers in Antwerp, 
probably each having his own workshop, apprentices, workers and servants.

After 1579 Hans Ruckers' name appears regularly in the membership accounts and in the Bussenboek, the register of the contributors to the emergency relief fund for the members of the Guild of St. Luke. After 1591 Hans Ruckers was engaged on a yearly basis to tune and maintain the cathedral organ, and his name appears regularly in the cathedral accounts. In 1593 he even installed and tuned 14 or 15 ranks of pipes (registers) in the cathedral organ, for which a special payment was made. ${ }^{1-13)}$.

In 1594, on the last day of February, he was made a poorter or citizen of Antwerp. It is still a mystery why Hans Ruckers registry as a poorter came so late as it would normally have been impossible for him to join the Guild of St. Luke without already being an Antwerp citizen. It has been suggested that the original documents relating to Hans Ruckers' citizenship may have been lost during the 'Spanish Fury' of 1576 or the Spanish seige and occupation of 1584-85, and that this loss was then later corrected in 1594.

Also in 1594, Hans Ruckers is recorded as having been involved in a civil suit with one of his former employees Staes van Bueren. In the proceedings of the case we find that Staes van Bueren built a case for a harpsichord which was then finished and sold by Hans Ruckers. It is not clear whether Ruckers paid van Bueren for the building of the case after the completion and sale of the instrument. Also involved was the loan of money by Hans Ruckers' wife 
to Staes van Bueren's wife after the latter's purse containing money was stolen in the Antwerp fish market. An interesting sidelight of the case is that Staes van Bueren went north for a time around 1587 to work in Amsterdam for Marten van der Biest.

On July 5, 1597 Hans Ruckers bought a house called 'The Little Clavecimbel' (de cleyn clavecingel) on the north side of the Jodenstraat. This was a large house between the house of the late Goosen Karest and the House of God of the Carmelites. It is described as being in the beginning of the Jodenstraat, and as having 'a gate, large courtyard, pump, cistern, drains, store rooms, kitchen, business premises and all appurtenances thereto situated and located in the Jodenstraat.... (see Fig. 1-1).

The document dealing with the purchase of the house in the Jodenstraat seems to be the last that exists relating to the life of Hans Ruckers. The house was transferred to Hans Ruckers' widow Adriana Kna eps on September 14, 1599, and became the sole property of their eldest son Ioannes on October 31,1608 (see below) and seems to have served as workshop and living quarters at least until the death of Ioannes Ruckers in 1642. It may also have belonged to Ioannes Couchet and was the property of Hans Ruckers' great-grandson, a cloth merchant, in 1656.

Hans Ruckers and Adriana Kna eps had in all eight children of whom only 5 survived into adulthood. All of these children were baptised in the cathedral and this, plus the fact that several of the grand-children and great- 


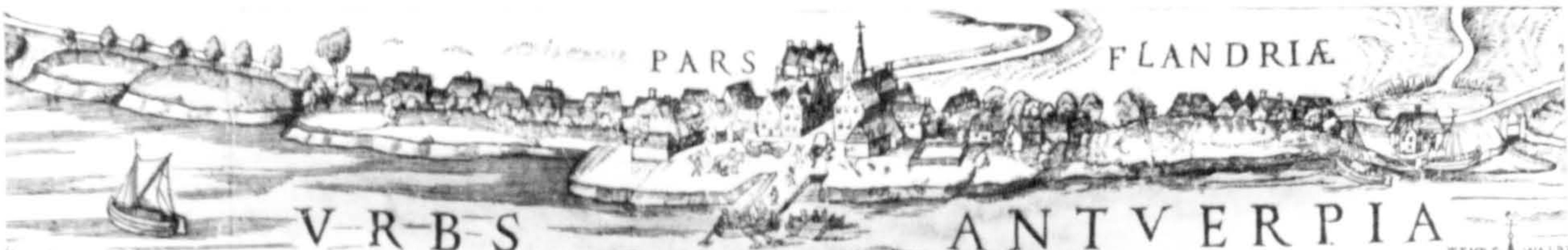

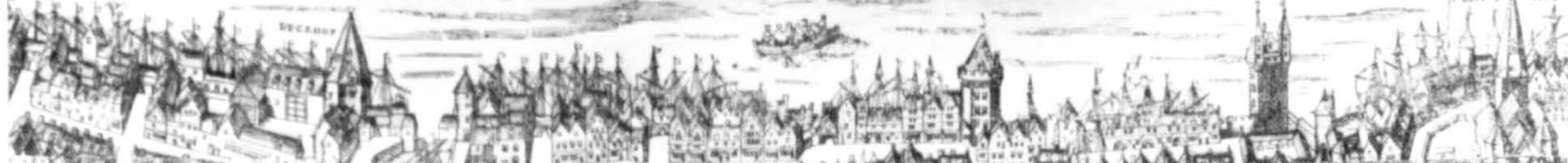

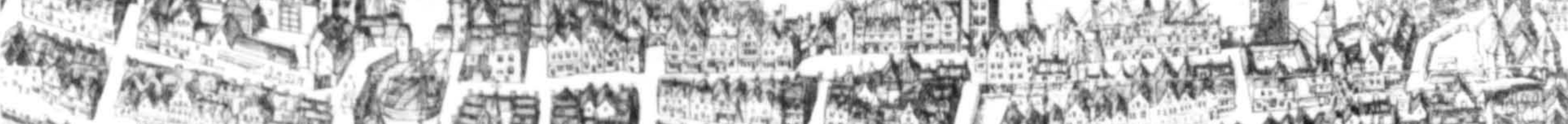

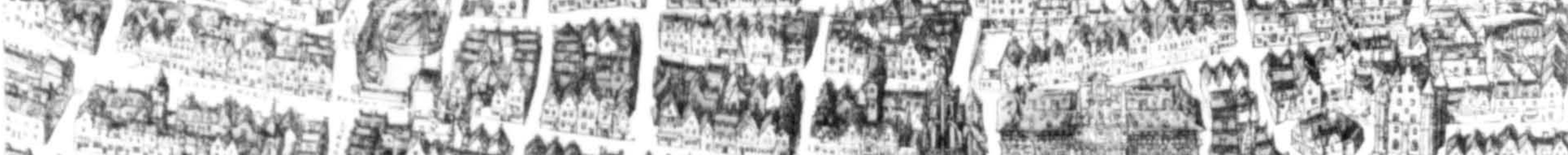

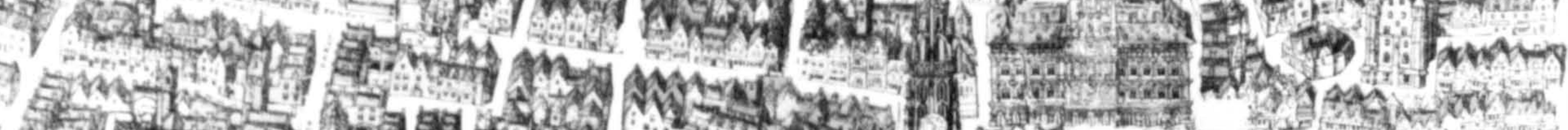

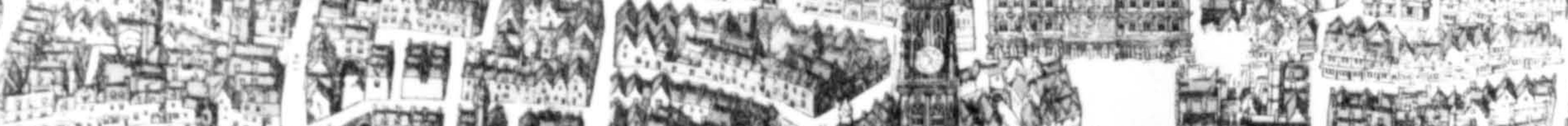

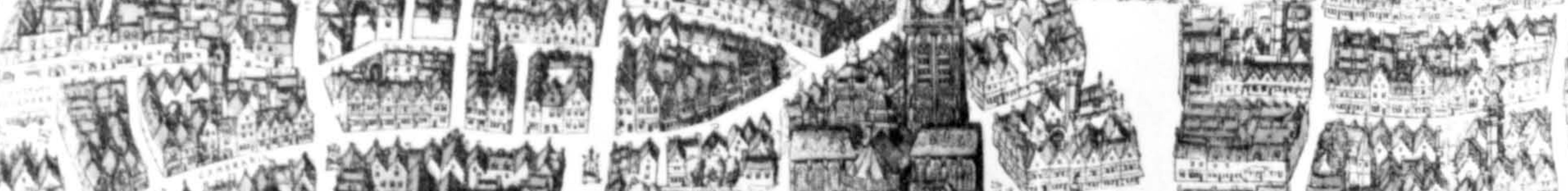

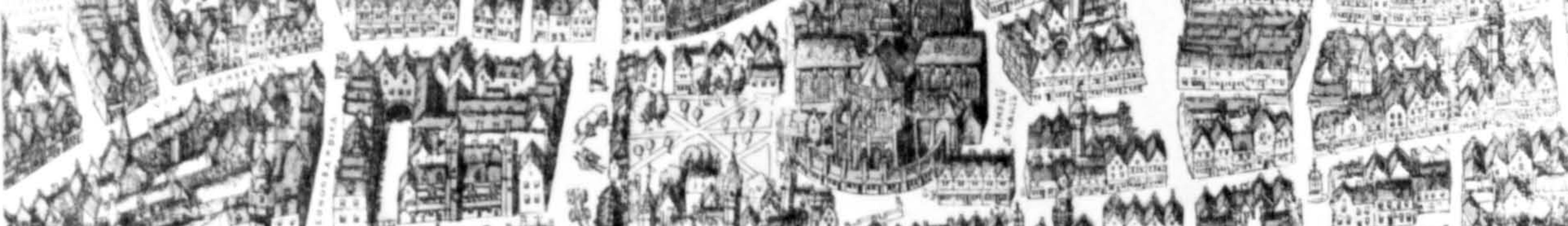

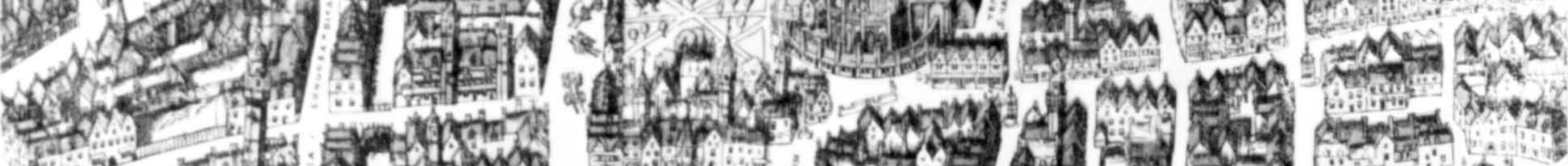

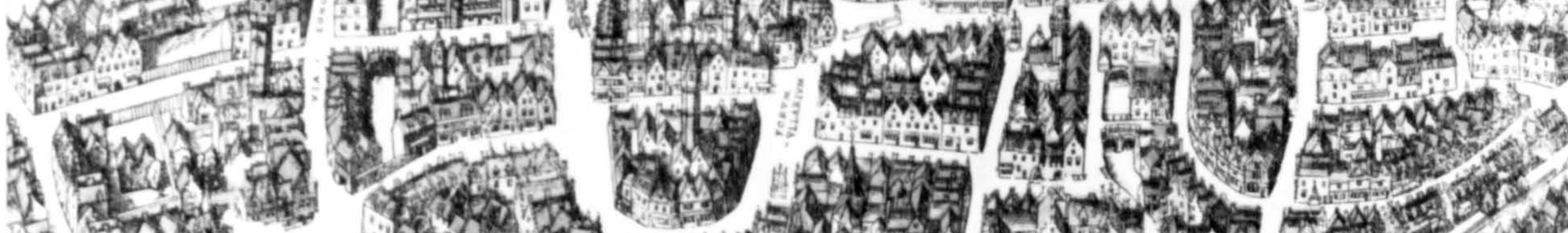

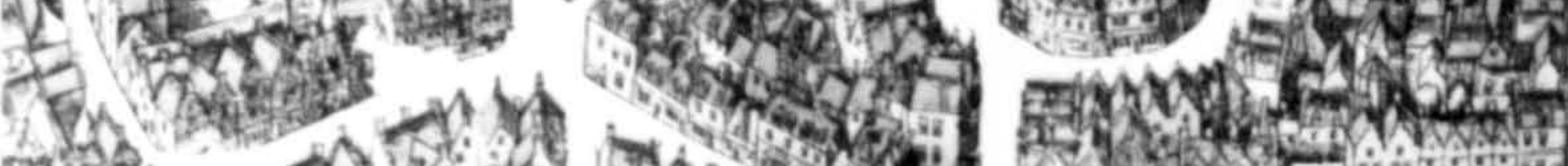

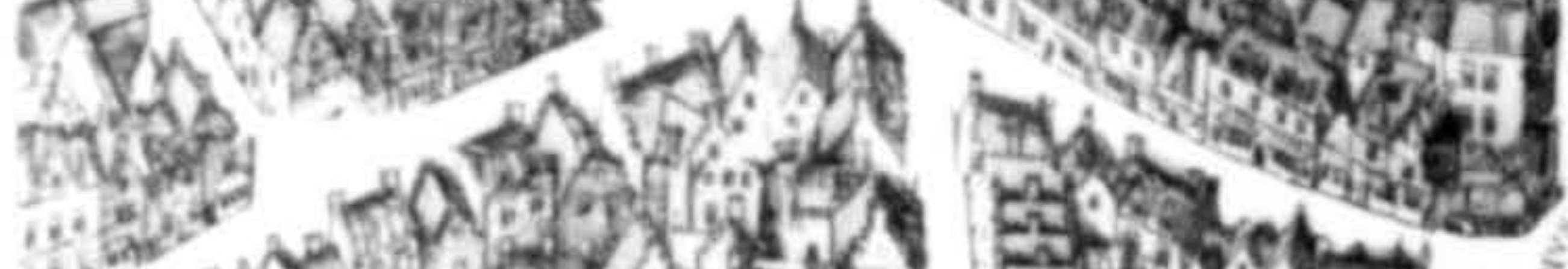

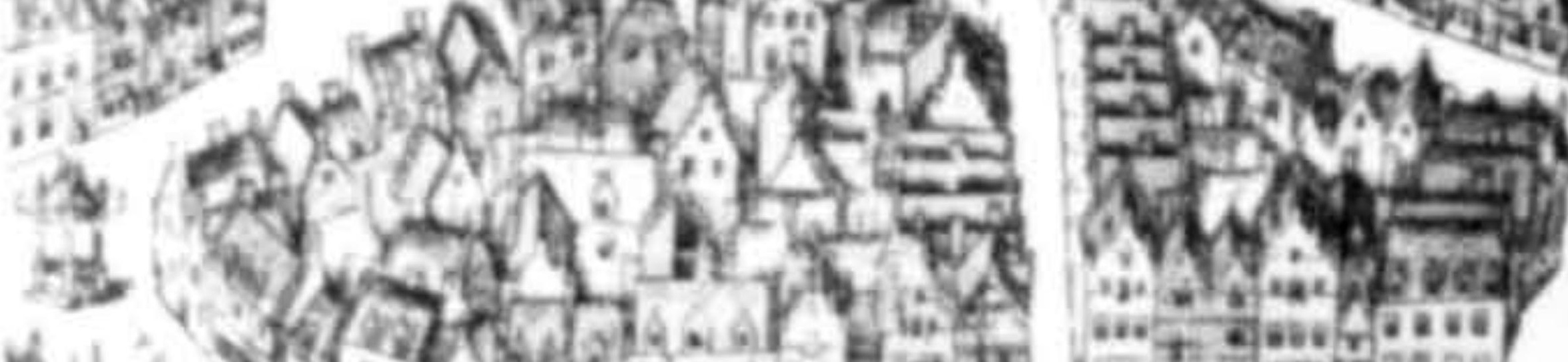

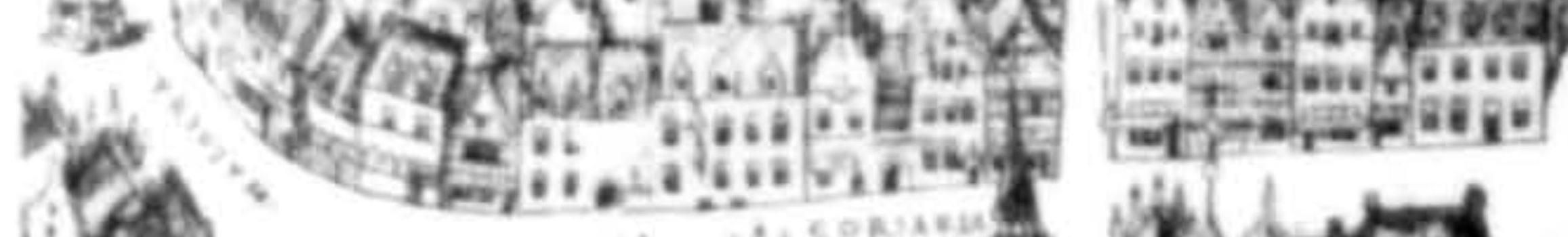

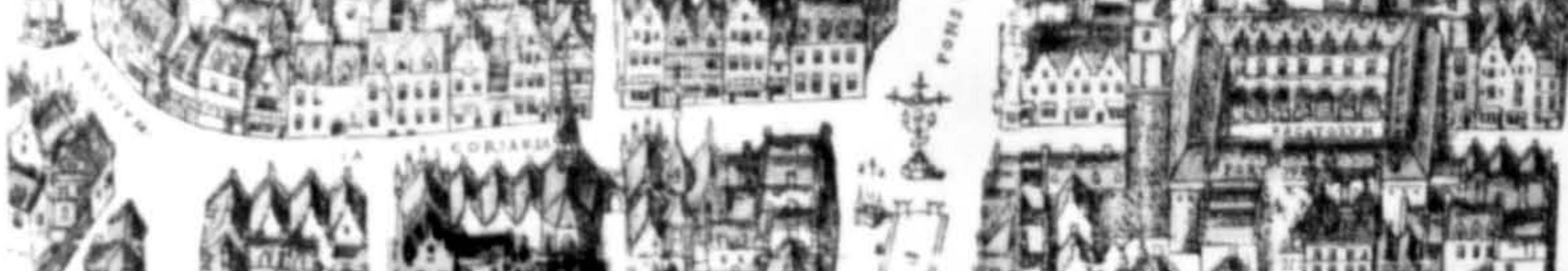

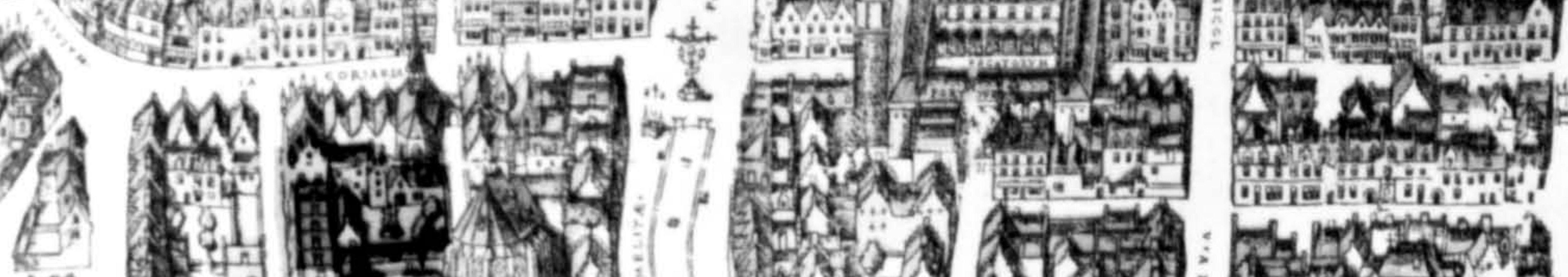

13 a r.

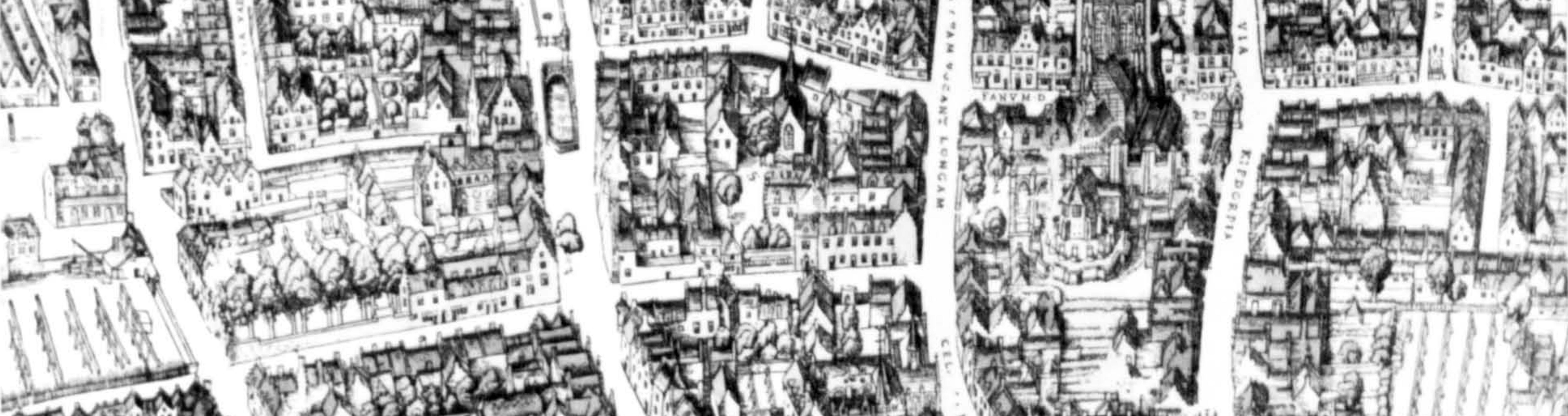

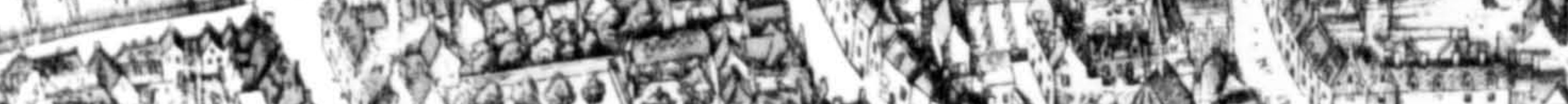

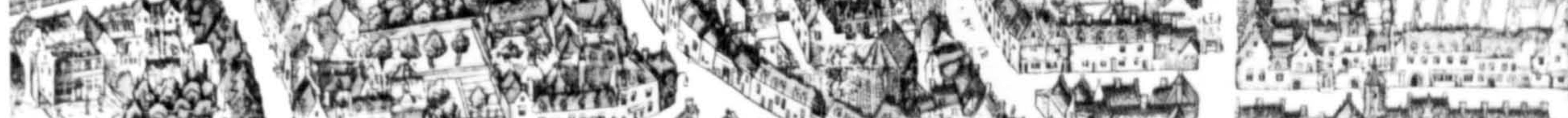

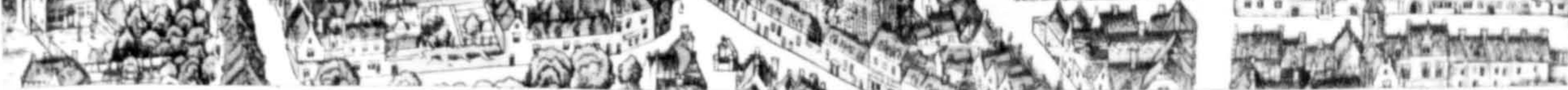

Fig. 1-1 Detail of a map of the City of Antwerp. Virgilius Boloniensis $(1565)$. The darkened area shows the site of Hans Ruckers' workshop with a 'gate, large courtyard, pump, cistern, drains, store rooms, etc.' This later became Ioannes Ruckers' workshop, and also probably that of Ioannes Couchet. 
grand-children became priests or nuns, suggests that the family maintained its Roman Catholic faith throughout the period of religious strife in Antwerp. The three children of Hans Ruckers and Adriana Knaeps of interest to us here are Ioannes Ruckers, Andreas Ruckers (the elder), and Catharina Ruckers who became the wife of Carel Couchet and the mother of Ioannes Couchet. Hans Ruckers' widow Adriana Knaeps died on March 29, 1604. Ioanne요 Ruckerers

Ioannes Ruckers was the first of Hans Ruckers' children, the heir to the Ruckers tradition and probably the greatest of the members of the harpsichord and virginal building family. He was baptised on the 15th of January, 1578. 1-14) In 1598 and 1599, and in practically every year until 1642, his name appears in the Antwerp cathedral accounts for the tuning and maintainence of the organ; inftially at the rate of 6 gulden per year, and increasing to 42 gulden by 1625. He also tuned the organ of the St. Jacobskerk in Antwerp after 1617 where his yearly salary varied from 28 to 30 gulden.

In March 1604, Ioannes' mother died and, as eldest son he would have taken over the running of the family home and workshop at the age of 26. Later on in the same year on November 14, 1604 Ioannes Ruckers married Maria Waelrant, daughter of Hubert Waelrant the organist and composer who helped to formalise the extension of the hexachord and the method of solmisation to include the note si $(i . e, \underline{b})$. Ioannes and Maria Waelrant were 
married in Antwerp cathedral and had at least two daughters, Maria and Elizabeth. It was probably because they had no surviving male children that Ioannes Ruckers took on his nephew Ioannes Couchet as an apprentice to carry on the virginal and harpsichord building business.

The virginal dated 1604 and signed iIOANNES ET ANDREAS RVCKERS FECERVNT' now in the Brussels Museum of Musical Instruments (No. 1917) indicates that the two brothers were working together in partnership in 1604 although neither is known to have been a member of the Guild of St. Luke at that time. On the 31 st of october, 1608, an agreement was drawn up between the brothers Ioannes Ruckers and Andreas Ruckers whereby the family home on the Jodenstraat became the sole property of Ioannes, although even before this Andreas was building, numbering and signing his own instruments (see below p.23 and Chapt. 3 p. 127). The date of Ioannes Ruckers' entry into the Guild of St. Luke is not certain but the registers of the Guild for 1611 give:

"Hans Ruckers, sone, claversigmaker" and this is generally accepted as referring to Ioannes Ruckers. This may be substantiated by the first appearance of an IR rosette in a Ioannes Ruckers instrument in 1612 (however Ioannes Ruckers-continued to use the old HR rosette at least until 1616 , and the dating of the 1612 instrument is not at all certain (see the catalogue entry (1612)IR, p. 661)).

From 1616 until his death he was the organ and harp- 
sichord builder to the archducal court in Brussels. 1-15) It may well have been this court appointment which inspired Ioannes to have the three rather sophisticated IR rosettes cast for use in his instruments. At any rate after 1616 he ceased using the somewhat primitive HR rosette and used only the more elegant IR rosettes. Also connected with his court appointment is a document dated 1623 in which Jan Ruckaerts, Peter Paul Rubens, Jan Brueghel, Robrecht de Nole, and Rombout Rasiers were all, because they were in the service of the court, exempted from carrying out the civic watch duties around the town walls. When in 1636 his onlyrviving later dean of the Guild of St. Luke, the wedding dowry was considerable, indicating that Ioannes was by then a very wealthy person. In 1642 Ioannes Ruckers was involved in a court case with the civic aldermen who challenged not his exemption from personal watch duty, but whether he had been freed from making the usual tax contribution to the maintenance of the watch. The outcome of the case is not stated. Ioannes Ruckers died on the 29th of September 1642 and the burial took place on October 1, 1642. The direction of the workshop and the continuation of the Ruckers tradition was then undertaken by Ioannes Couchet. Andreas $\underline{\text { I }}$ Ruckerer

Andreas Ruckers (the elder) was second son of Hans Ruckers and Adriana Knaeps. He was 'baptised on August 30, 1579 and on January 25, 1605 was married to Catharina de Vries (Catharina was the sister-in-law of the painter 
Jacob Jordaens). As was mentioned before Andreas was working with his brother Ioannes in 1604, and the numbering of the Andreas instruments indicates that he was probably signing and numbering his own instruments from 1605 onwards (see Chapt. 3, p. 127) . Perhaps the two brothers initially shared their father's old workshop until, in 1608, 'de cleyn clavesingel' became the sole property of Ioannes, at which time Andreas and his family must have been living elsewhere. Although there is no record or Andreas' entry into the Guild of St. Luke his extant instruments indicate that from 1608 he signed his instruments himself, and used his own individual AR rosette. In 1616 Andreas Ruckers is described as living "bij kerckhof, bij scoenkramen", that is, near the cathedral churchyard (now the Groenplaats with the impressive bronze of Rubens) and the shoemarket (schoemarkt). This was only about 500 metres from the Jodenstraat and Ioannes Ruckers' workshop, which itself was only about 200 metres from Ruben's house and studio. Andreas Ruckers and Catharina de Vries had at least 5 children, among whom were Andreas II, who carried on the harpsichord building tradition in the Ruckers family, and Anna, who became the second wife of Johann Davidszoon de Heem, the most famous of all the Antwerp still-life and flower painters. Although the Ruckers soundboard paintings and the oil paintings of de Heem have a kindred aesthetical spirit, the quality of the painting and the excellence of the technique of de Hemm far exceeds that exhibited on the Ruckers soundboards and there is 
no indication at all that Ruckers soundboards were painted by anyone with the skill and competence of de Heem. Around 1644 Andreas I Ruckers was living in the Huidevetterstrat (The Tanner's Street) adjoining the Jodenstraat and therefore probably just a few metres from Ioannes Ruckers' workshop. It is not clear at what stage Andreas II Ruckers began to work in his father's workshop, nor what their commercial relationship was after Andreas II joined the Guild of St. Luke in 1637/38. The problem is made greater because we also do not know the exact date of Andreas I Ruckers' death, and thus the point at which the production of the elder Andreas stops is also unknown. However, the 1644 single manual harpsichord signed "ANDREAS RVCKERS DEN OVDEN ME FECIT ANTVERPIAE" suggests that the two were building instruments in separate workshops at this date. The (1651)a AR single harpsichord signed "ANDREAS RVCKERS AND(REAS) F(ILIUS) ME FECIT ANTVERPI $n$ logically implies that Andreas I was still alive in 1651, and also that the two Andreases were working separately. ${ }^{1-16)}$ However it may also indicate simply that Andreas II signed himself effectively "Andreas Ruckers, Jr." after his father's death. Andreas I is known to have been alive on 22 September, 1645, and although an Andreas Ruckers is mentioned in the archives in 1651 and 1654, these may refer to Andreas II. Andireas II_Ruckẹers_

Little is known of the life of Andreas II except that he was baptised on the 31st of March, 1607. His exact death 
date is also not known although he was already dead in 1667 and perhaps still living in 1661. In about 1637 he was married to Joanna Haechts (Haegts) probably in Mechelen (Malines). The couple had three children, one of whom was. called Ioannes, presumably after Ioannes Ruckers (his greatuncle) who was his godfather at the baptism on February 6 , 1642 .

Also in 1637/38 Andreas II became a member of the Guild of St. Luke and a master harpsichord builder. It seems likely that this is connected with his marriage and with his probable establishment as an independent harpsichord builder with his own workshop separate from that of Andreas I. Because the date of Andreas I's death is unknown, and because the two Andreases were working concurrently it is difficult to distinguish the late work of Andreas I from the early instruments built by Andreas II. It may be possible to distinguish them on the basis of the style of the decoration, but such a distinction is both difficult and hypothetical (seo p. 451).

Ioanñes Couch het

Catharina Ruckers was a daughter of Hans Ruckers and a sister of Ioannes Ruckers and Andreas I Ruckers. In 1611 she married Carel Couchet, and Ioannes Couchet was their son, born February 2, 1615. According to a letter from G. Duarte to Constantijn Huygens, Couchet went to work for and apprenticed with his uncle Ioannes Ruckers in about 1627 (see Appendix 17, p. 904). But he probably went to work with Ruckers in 1625, as his mother Catharina 
died about May 30, in that year. Couchet worked with his uncle until Ruckers' death in 1642. In about 1635 he married Angela van den Brant, and three of their sons Petrus E. Ioannes, Ioseph Ioannes and Maria Abraham, all became members of the Guild of St. Luke and carried on the harpsichord building tradition.

In $1642 / 43$, the Registers of the Guild of St. Luke record, along with the death and death dues received for Ioannes Ruckers, the entry of Ioannes Couchet as a master harpsichord builder. In $1646 / 47$ Couchet is recorded in the accounts of the Antwerp cathedral as having carried out special repairs to the organ. Ioannes Couchet died on March 30, 1655, but the workshops seem to have continued to function after his death under the direction of his widow Angela van den Brant who entered into a business relationship with Simon Hagaerts (Haquaerts). 1-17) The Couchenet Sons

Of the three sons of Ioannes Couchet and Angela van den Brant, little more is known of them than the dates of their entry into the Guild of St. Luke. Petrus E. Ioannes Couchet joined the Guild in 1655/56, the year in which his father Ioannes died (this was also the year in which Joris Britsen joined the Guild). Petrus Ioannes is known to have married Sara de Vrise. Both Ioseph Ioannes and Maria Abrahaim joined the Guild in $1666 / 67$, but nothing more is known of them except that Ioseph Ioannes was already dead in 1706. The Couchet sons were great-grandsons of Hans Ruckers and thus carried on the clavecimbel 
building tradition of the Ruckers family into the fourth generation.

ICR'

Two virginals of a type and construction very similar to those built by the Ruckers family survive with a rosette bearing the initials CR, but otherwise without any sign-

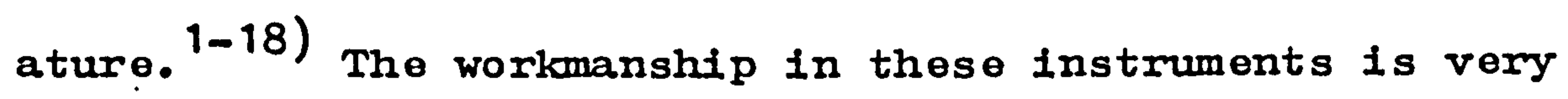
rough and suggests to me that the instruments are the work of an apprentice learning his craft. These instruments have been linked with the 16th-century organist Christoffel Ruckers from Dendermonde between Antwerp and Brussels. However the $\mathrm{C}$ to $\mathrm{d}^{3}$ chromatic compass and details of the decoration found on these instruments point to a date of construction in the second half of the 17th century so that there can be no connection whatever between these virginals and Christoffel Ruckers. The chi ef interest of these virginals thus seems to be that they were not built by any of the Ruckers, although built at the end of the period when the Ruckers family were still active. Ruckers and ofther Antwerp artists

As has already been mentioned the members of the Ruckers family were related to or connected with a number of the other well-known figures in Antwerp's highly active cultural history. Marten van der Biest, another clavecimbel builder, was a witness at Hans Ruckers' wedding and took a workman from Ruckers' workshop after moving to Amsterdam. Ioannes Ruckers' father-in-law was Hubert Waelrant, the composer, and Andreas I Ruckers 
was related by marriage to Jacob Jordaens, the painter. And Johann Davidszoon de Heem, the still life painter, was Andreas II Ruckers' brother-in-law. Joos Karest, whose brother had owned the property adjoining 'de cleyn clavesingel' on the Jodenstraat may also have been related to the Ruckers by marriage. On March 18, 1542, Karest was married to Christine Rughers whose relationship with the Ruckers family, although unknown, is at least a possibility. She was Karest's second wife but did not survive long, as Karest was married a third time on November 18, 1545.

Another interesting relationship with the Antwerp harpsichord building fraternity occurs through willem Gomparts, who became a master harpsichord builder in the Guild of St. Iuke in 1560, 19 years before Hans Ruckers. In 1593 Gompaerts was godfather to Catharina Ruckers who was later to marry Carel Couchet and to become the mother of Ioannes Couchet. Also on October 31, 1610 Gompaerts took part with Elizabeth Waelrant in the baptismal ceremony of a daughter of Ioannes Ruckers and Maria Waelrant. These two connections suggest that Gompaerts, if not actually related to the Ruckers, must have been a longstanding friend of the family.

The Ruckers sons must have been on familiar terms with both Rubens and Breughel, and Ioannes and the latter two must have been amongst the most respected of Antwerp's citizens since all three were exempted from the town watch duty and $\operatorname{tax}$ in consideration of their services to the 
court. Ioannes Ruckers' and Rubens' houses were within a minute's walk of one another, and although it is known that Rubens sometimes painted the lids of Ioannes' instruments, unfortunately no harpsichord or virginal lid painted by Rubens is known to have survived (see Gerbier-Windebank correspondence, Appendix 16 p. 899). Their relationship was probably not just commercial. They would 11kely have known one another soclally, been of comparable class and led comparable and inter-connected lives. For example, Rubens received commissions for the high altar painting and the 'Descent from the Cross' from the cathedral where Ioannes Ruckers maintained and tuned the organ. Jan Breughel is credited with the lid painting of the 1612 IR harpsichord along with van Balen and Paul Brill. Also the 1608 AR harpsichord has a lid painting ascribed to Pieter Godde, a member of the Rubens school.

The Ruckers were thus acquainted socially and artistically with many of the important people in Antwerp's cultural 1ife. They took part in and contributed to the second economic and artistic flowering in Antwerp. The Guild of st. Luke

The existence of the Guild of St. Luke in Antwerp can be traced back as early as 1382. The apostle Luke was the patron saint of the painters, and throughout its entire history in Antwerp the Guild of St. Iuke was predominated mainly by the painters of fine art. But other groups of artists and artisans also belonged to the Guild including sculptors, engravers, printers, gold- and silver- 
smiths, potters, chest makers, craftsmen in glass, etc. By no means all of these were creative artists. Even among the painters, many members of the Guild churned out the same uniform product to the: same pattern day in and day out. Others were clearly artisans and craftsmen - the chest makers, bookbinders, cabinet makers - and still others, the booksellers, printsellers, and art dealers had a solely commercial interest in the products produced by the rest of the membership in the Guild of St. Luke. There were also a small number of outsiders whose relationship to the Guild is not certain. Among these are, for example, the drapers, carpet merchants, pedlars, schoolmasters, doctors (St Luke isalso the patron saint of the medical fraternity), brushmakers, grocers and even a varmish maker, a 'geographist' and a seller of pens.

The main purpose of the establishment of the Guilds, and membership in them, seems to have been to prevent outside competition. The Guild regulations enabled the number of people engaged in any one trade to be strictly controlled. All people who were members of the Guild also had to be citizens of Antwerp, and this meant that a travelling artist or artisan could not suddenly set up in business in Antwerp in competition to the Guild members unless he planned to settle there permanently and take up citizenship. Prices of the Guild products could be established and regulated so as to be favourable to the Guild members.

But the Guild system also helped to maintain stand- 
ards. Normally one was not admitted to the Guild without submitting a 'masterpiece' for approval by the other masters. Usually this test piece was the product of a long apprenticeship under one of those who was already a master in the Guild. If the exhibition piece did not meet the standards of the other masters, membership could be refused or with-held until a further period of apprentIceship had been served.

There was, however, a great deal of discrimination and nepotism within the Guilds. The fees charged to the apprentices and journeymen were very high indeed and the registration charges roso much more rapidly than the general rate of inflation in Antwerp. By making the conditions of entry in the Guild more and more difficult, the masters assured themselves of the inexpensive labour of their apprentices for a longer period of time. Ioannes Couchet, for example, worked in his uncle's workshops for 16 years, and didn't become a journeyman builder until the eventual death of his master. Also the sons of the established masters were admitted as 'wijnmeesters' usually at a fraction of the cost of the regular member, and often without submitting a 'masterpieco'. This inbred cliquish system meant that entry into the Guild was either impossible or at least very difficult for those without influence or money or both.

Also, as in any system where human activity is regulated by a set of inflexible rules, innovation and inventiveness were stifled and the products of the Guild 
workshops tended to become standardised. New ideas took a long time to become accepted and established since the system fostered the situation in which the product of the student was like that of his master. For example, although the number of Instrument models from the Ruckers workshops is quite large, each model is highly uniform from builder to bullder, and shows virtually no development or evolution through three generations of building and across a time span of about 80 years.

During the period in which the Ruckers family were active, membership in the Guild for harpsichord and virginal builders was compulsory. This had, however, not always been the case. Before 1557 the building of harpsichords and virginals was carried on freely without corporative restraint. Hence, before 1557, membership In the Guild was 'open' and only a few masters registered as clavesimbalmakere are to be found in the ledgers of the Guild. In 1557 ten clavecimbel makers applied to the Guild authorities for regulation and control of harpsichord and virginal building in Antwerp. The application was formally accepted in 1558, and after that time the trade was 'closed' and could only be carried on by those who were Guild members and recognised formally as either master or apprentice.

The regulations accepted by the Guild authorities: (seo Appendix 12 p. 874) exempted the 10 applicants from submitting a test piece as a condition for their membership in the Guild, but also laid down the conditions for 
the submitting and examination of test pieces produced by prospective members from 1558 onwards. The clavecimbel bullders were to have the same rights, responsibilities and froodoms (including partial exemption from watch duty) as the other members of the Guild of St. Luke, and above all they would be protected from outside competition since no one would be allowed to make or sell a clavecimbel in Antwerp without being a Guild member. The final stipulatIon accopted by the Guild was that each instrument should be provided with the maker's distinctive 'mark' or emblem displayed in an obvious place on the instrument.

There seems little doubt that the 'mark' referred to is the decorative rose placed in the soundboard. Although the rose usually displayed the initials of the builder, instruments by van der Biest and Grauwels, both signatories of the 1558 agreement, have geometrical rosettes. In fact instruments by these builders have identical geometIical rosettes, so that not only are the initials of the makers not displayed, but the rosettes are therefore also not characteristic of the builder. ${ }^{1-19)}$ Also the earliest Hans Ruckers instrument, the $1581 \mathrm{HR}$ double muselar mother and child virginal has 3 original goometrical parchment and wood rosettes, but lacks the usual lead rose with the HR initials and the angel playing the harp. It is also noteworthy that the early rose used by Ioannes Ruckers is almost indistinguishable from that of his father Hans, and that after 1637 the rose of the two Andreases, father and son, seem to be absolutely identical. Thus the way this 
final regulation was interpreted and exercised by the clavecimbel makers is not entirely clear. Conditions of work in the Guild workshops

Unfortunately very little is known about the nature of the Guild workshops during the period when the Ruckers were active. We do not know how big the workshops were, how many people worked in them, and we know very little about the actual conditions of work for apprentices, workers and servants. An analysis of the numbering system used by the Ruckers (see Chapt. 3) shows that about 35 40 instruments per year were being produced in the Andreas Ruckers workshop, and there seems little to indicate that the other Ruckers workshops produced fewer instruments than this. Thus, on the average, one new instrument came out of each workshop every week. Such a high rate of production seems to imply an industrial enterprise unlike even the largest harpsichord workshops of today.

A workshop of this size would, for example, have had to produce about 5000 jacks: in one year, and this in Itself may have been enough to keep one person employed full time (if indeed the jacks were produced on the premises - see, however, p. 376). By way of comparison, the workshops of both Plantin the printer, and Rubens, both of whom were contemporary with the Ruckers family, are still extant in Antwerp. These are both enormous, and it is easy to visualise the Ruckers' harpsichord and virginal workshops of a comparable size. It is known for example, that Plantin kept 16 printing presses busy full time, and 
employed about 80 people as compositors, printers, collators, proof-readers, binders and shop assistants.

A small insight into the working conditions in the clavecimbel workshops, albeit from a period considerably before the Gulld regulations of keyboard instrument production in Antwerp, is provided by a contract between Joos Karest and his brother Goosen. The Karest family (their father was called Jan (Ioannes)) came from Cologne, probably shortly before 1515. Goosen is recorded in the ledgers of the Guild of St. Luke as early as $1519^{\circ}$ as an apprentice painter studying under Peeter Mathijs. In 1529 he became a vrifmeester or journeyman painter. His brother Joos was already registered in 1523 as a master clavichordimaker and qualified to 'sculpt and paint' his own instruments. For some reason Goosen decided to become an instrument builder, and in 1537 (1538 new style) a contract (see Appendix 11 p.864) was drawn up outlining the conditions whereby Goosen would study under his brother Joos (if Goosen was about 16 when he began his apprenticeship in 1519, he must have been about 35 when he began his apprenticeship with Joos). Firstly, it is interesting that, although Goosen was already a master in the Guild of St. Luke and registered as such, he was required to undergo a further apprenticeship to qualify as a clavecimbel maker. Secondly, considering Goosen's age (Joos was presumably older than Goosen) and the fact that the two parties to the contract were brothers, the conditions of the apprenticeship seem unduly harsh. 
Although Joos supplied the necessary materials for Goosen to work with, Goosen had to supply his own tools. During the three years of his apprenticeship, Goosen could work only for Joos and not for himself or a third person, and he had at the same time to provide for his own live11hood. He was expected to work extremely long hours from 11 to 14 hours per day with only a $1 \frac{1}{2}$ to 2 hour midday break, and by candle-light if necessary. Any lost time had to be made up at the end of the three year period.

In return Goosen was paid 6 stuijvers per day by Joos who taught him the construction, tuning and playing of virginals and harpsichords. If either party broke their part of the contract a fine amounting to 40 times Goosen's dally wage was to be paid. It is difficult to assess the relative value of the wage paid to Goosen - it was probably at least sufficient to support him and perhaps his family. But otherwise the general conditions of the contract seem relatively severe - long working hours with no insurance against lost time through sickness or injury, difficult working conditions, including working by candlelight in the early morning and late evening. Also, considering the blood relationship between Joos and Goosen, one wonders at the conditions of work in the more usual cases of unrelated master and apprentice. The Couchets and the Ruckers tradition

As has already been made clear, the Couchets were directly related to the Ruckers family - Ioannes Couchet was Hans Ruckers' grandson. But it is also extremely 
important to note that the instruments built by the

Couchets - especially Ioannes Couchet - belong to the

Ruckers tradition as much as those of Andreas II Ruckers who was also a grandson of Hans. Ioannes Couchet worked in Ioannes Ruckers workshop for 16 years and the instruments of Couchet are built so much in the style of Ioannes Ruckers that instruments by the two builders are, aside from the rosette and signature, virtually indistinguishable. In fact, many of the late instruments signed by Ioannes Ruckers may be entirely the work of Couchet. Thus the product of the Couchet workshops is as much a part of the Ruckers tradition as those instruments signed by one of the Ruckers. In the subsequent part of this work I will therefore, for the sake of conciseness and readability, not always write 'Ruckers/Couchet tradition', or 'Ruckers/Couchet instruments'. But the contribution of the Couchets is always implied when I speak of the

'Ruckers tradition' and 'Ruckers instruments!.

\section{Footnotes:}

1-1) It was probably during this time that Marten van der Biest moved from Antwerp to Amsterdam, see J. Lambrechts-Douillez, 'Archi ef documenten betreffende de Ruckers familie', Bulletin of the Brussels Museum of Musical Instruments, IV (1974) 38 .

1-2) P. Genard, 'Les grandes familles artistiques d'Anvers: Ruckers', Revue d'histoire et d'archéologie, I Brussels, (1859) 458f.

1-3) L. de Burbure, 'Recherches sur les Facteurs de Clavecins et les Luthiers d'Anvers', Bulletins de l'Académie Rovale de Belgique, Series 2, Vol XV, No. 2, Brussels (1863) p.1.

1-4) P. Rombouts and $T$. van Lerius, De Iiggeren en andere 
historische Archieven der Antwerpsche Sint Lucasgilde, The Hague $(1864-1876)$ (facs. Amst erdam 1961).

1-5) J.A. Stellfeld, 'Bronnen tot de geschiedenis der Antwerpse clavecimbel-en-orgel-bouwers in de XVI en XVII eeuwen', V1amsch Jaarboek voor Muzi ekgeschiedenis, Antwerp (1942) 3-110.

1-6) J. Lambrechts-Douillez, 'Muzi ekinstrumenten te Antwerpen' Tijdschrift van de Stad Antwerpen, XIII Antwerpen (1967) 100-101. Ib1d, 'De klavecimbelbouw te Antwerpen: een Kunstambacht van wereldformaat (einde zestiende begin zeventi ende ouwe)', Antiek, Tijdschrift voor Liefhebbers en Kenners van oude Kunstnijverheid, III, Dec ember No. 5 (1968) 237-252.

Ibid, 'Biographical Notes on the Ruckers-Couchet Family', Galpin Soci ety Journal, XXII, (1969) 98-99. Ibid, Antwerpse Klavecimbels in hot Museum Vleeshuis, Antwerpen (1970).

Ib1d, 'Antwerpse Klavecimbels Oude Muzi ek Herleeft', Actuele Onderwerpen, AO 1310, Goes (1970).

Ibid, The Ruckers-Couchet Instruments in the Museum Vleeshuis; Restoration or Copy?', Colloquium. Restauratieproblemen van Antwerpse Klavecimbels, Antwerp (1971) 44-48.

Ibid, 'Documents Dealing with the Ruckers Family and Antwerp Harpsichord-Building', Keyboard Instruments. Studies in Keyboard Organology, Edinburgh (1971) 37-42.

Ibid, 'Archi of documenten betreffende de Ruckers familie' and 'Catalogus Ruckers: Documenten en Instrumenten', Bulletin of the Brussels Museum of Musical Instruments, IV (1974) 33-54 and 65-70. Ibid, The Ruckers family and other harpsichord makers', The Connoisseur, Vol. 194, No. 782 (1977) 266-273.

Ibid, 'Couchet', Algemene Muzi ekencyclopedie, Vol. 2 (1979) 262.

Ibid, 'Aperçu historique sur la facture de clavecin à Anvers au XVI et XVII siècles, La facture de clavecin du XV au XVIII ${ }^{e}$ siecle, Louvain-laNeuve (1980) 59-66.

Ibid, 'Stamboom der Klavecimbelbouwersfamilie Ruckers-Couchet', Mededelingen van het RuckersGenootschap, I $(19 \overline{82})$.

Ibid, 'Klavecimbelbouwersfamili e Hagaerts', Mededelingen van het Ruckers-Genootschap, II (1982).

1-7) Edwin M. Ripin, 'Antwerp. Harpsichord Building: the Current State of Research', Colloguium. Restauratieproblemen van Antwerpse Klavecimbels, Antwerp (1971) 12-23.

1-8) Friedrich Ernst, 'Master Arnold Rucker', Galpin 
Society Journal, XXII (1969) 35-39.

1-9) Ernest Classon, 'Quelle est l'année de la morte de Hans Ruckers, Ie vi eux?', Le Guide Musical, Vo. LVII, No. 38-39, (1911) 571-572.

1-10) 'Ontfanck van de rechten van de kerckelycken, $a(n n) 0$ 98. Hans Rycardt. 4-, 1-, 6'.

1-11) 'aen Hans Ruckers, van de orghel en te ondershouwen voer syn gagie van twee jaren tegen 61b. t'sjaers bet. pro annis 98, 99 te bamisse 12 1b'.

1-12) In particular the 5 voet virginal dated 1604 in the Brussels Instrument Museam No. 2927, 1 s signed "IOANNES ET ANDREAS RVCKERS ME FECERVNT" and uses the HR rosette otherwise used only by Ioannes from 1598 to 1616 .

1-13) A further interesting musical connection with the cathedral is that the cathedral organist Servaes van den Meulen was the godfather of Hans Ruckers' third son, who was called Servaes.

1-14) It is not entirely clear if this date is given in the style of Brabant or in the new style. Until roughly the third quarter of the 16 th century in Brabant, Flanders, etc. the New Year began, not on January 1, but at Easter. This date, could therefore be either January 15, 1578, or January 15, 1579. However, since Andreas Ruckers was born on August 30, 1579 (which is unambigous) it seems clear that Ioannes must have been born in January, 1578 since the period between January and August 1579 would be too short for the conception, gestation and successsful birth of a child at this time.

1-15) J.A. Stellfeld, 'Johannes Ruckers de Jongere en de Koninklijke Kapel to Brussel', Hommage a Charles van den Borren, Antwerp (1945) 289f.

1-16) Any argument based on this instrument is very flimsy since it is not entirely clear that the date is not 1641 instead of 1651 . The painting of the penultimate figure in the date was touched up in a recent restoration, and the result is a most unconvincing ' 5 ' - see catalogue entry p. 763.

1-17) . J Lambrechts-Douil1ez, 'Couchet', Algemeine Muziekencyclopedie, Vol. 2 (1979) 262.

1-18) One of these is in the Musée du Croix, Namur, the other is in the Metropolitan Museum, Now York.

1-19) The 1580 Marten van der Biest mother and child 
virginals in the Germanischen Nationalmuseum, Nuremberg (M1 85), and the Ioannes Grauwels 6-voet virginal (c. 1580) in the Brussels Museum of Musical Instruments (No. 2929). 
Chapter 2 - The Pre-Ruckers Instruments and Traditions

\section{The Early Italian Tradilition}

By about 1520, harpsichord and virginal building in Italy seems already to have developed into a mature tradition with its own characteristics and properties. Many regions and city-states had their own indivicual style of building which nonetheless fitted into the tradition of the peninsula as a whole. Unlike most instruments made in Northern Europe after about 1580 which have thick cases often of poplar or lime, the early Italian instruments have thin case-sides of cypress usually only about $6 \mathrm{~mm}$ thick. In order to add rigidity to these thin walls the top of the case is stiffened by the addition of a batten decorated with an elegant moulding. Because of the lack of strength in the case sides, the spine is too weak to support hinges and the weight of a lid. The instruments are therefore placed in a stout outer case, usually plainly decorated, which could be used to protect the entirely separate inner instrument.

From a constructional point of view the whole of the case and the internal framing in Italian harpsichords are built up from the baseboard. The wrestplank is attached at its ends to two heavy wooden bars which are, in turn, attached to the baseboard. Triangular shaped bracing blocks called 'knees' are placed at the edge of the baseboard around the inside of the instrument.: Normally the soundboard liner to which the soundboard is glued and to 
which the strings are attached along the bentside and tail is let into and attached to the top of the knees. The baseboard is usually reinforced with stiffening boards glued on their edge, and the bentside and tail liners which have to withstand the string tension are braced with buttresses running from the soundboard liners obliquely down to the baseboard. To this extremely rigid structure, which supports the soundboard and sustains the string tension, are attached the case sides. Because of the strength and rigidity of the internal framing these case sides can be made very thin, and indeed the thin walls serve only to enclose the internal framing and structure and add virtual1y nothing to the strength and rigidity of the existing framework. The case sides are attached to the knees and liners and characteristically overlap and are attached to the edges of the baseboard. The sides terminate at the front with scroll sawn cheeks beside the ends of the keyboard.

The thinness of the wood in Italian case sides greatly facilitates the bending of the bentside, which was probably attached to the instrument directly without first being exposed to a heat or moisture treatment. This is particularly important with Italian harpsichords which also characteristically have a much deeper and more constant curve to their bentsides than the North European instruments. This strongly curved bentside results from the short treble string scalings of the Italian instruments. Usually the length of the string sounded by the 
$c^{2}$ key is about 255 to $285 \mathrm{~mm}$ in Italian, in contrast to the 345 to $370 \mathrm{~mm}$ found in most North European harpsichords of the 16th century. Since the bass strings are of about the same length in both schools of instrument making, the shorter treble string lengths in the Italian instruments produces an acute bend in the treble part of the bentside.

The reason for the short scalings of the Italian instruments seems to be that they were intended for treble stringing in a copper alloy (brass) material whereas the North European instruments with their longer treble scalings were strung with iron strings. ${ }^{2-1}$ ) It must also be added, however, that there is a large number of early Italian instruments, which do have relatively long scalIngs of the order of 305 to $340 \mathrm{~mm}$. But these long-scaled instruments also usually (but not always) have a compass extending to $f^{3}$, a fourth higher than the short-scaled instruments which normally stop at $\left.c^{3} \cdot 2-2\right)$ Therefore both the long- and short-scaled instruments maintain the characteristic shape with a strongly curved bentside.

Generally, the scaling difference between the two types of instrument observed by Shortridge and Barnes was felt to correspond to an interval of a fourth difference in pitch. Thus they held that the $f^{3}$ key of the longscaled instrument would sound the same note and pitch as the $c^{3}$ key of the short-scaled one. However, both Barnes and Shortridge found that the difference it the scalings of the two types of instrument sometimes appeared to correspond to less than the expected interval of a 
fourth and was closer to a major or minor third.

The chief difficulty is that taking an average scaling for the two groups of instruments is a process of averaging over, not just one builder or tradition, but a number of different builders working in different times and locations. My most recent work ${ }^{2-3}$ ) suggests that the long and short scalings of the two groups of instruments do indeed correspond to less than an interval of a fourth, and that the real reason for the difference in the scalings is that a difference in stringing material is required.

The reason for the correlation between a long scaling and the top note of $\mathrm{f}^{3}$ is simply one of space constraints. For example, a virginal with a short scaling of, say, 285 $m$ at $c^{2}$ would have a scaling at $f^{3}$ of only $106 \mathrm{~mm}$. A top string this short leaves no space beside the box slide registers for the bridges to sit out over freely vibrating soundboard. Similarly a harpsichord with a 4' register cannot reach to $f^{3}$ using $c^{2}$ scalings of $285 \mathrm{~mm}$ - the strings in the extreme treble would be too short to allow space between the nut and bridge for two registers (for a. single row each of $8^{\prime}$ and $4^{\prime}$ jacks) and an area of freely vibrating soundboard. Thus a virginal which reaches to $f^{3}$, or a harpsichord with a 4' register reaching to this note, must have long treble scalings and this in turn means that they must be strung in iron. A virginal or harpsichord which only goes to $c^{3}$ in the treble can use short scalings intended for brass stringing and still produce a good sound in the extreme treble since the string lengths at $c^{3}$ still 
allow an area of freely vibrating area around the ends of the bridges near the registers. Using only brass to string the whole instrument has two distinct advantages over using brass bass strings and treble iron strings. Firstly the tuning stablifty is increased since all of the strings are of one material and so they all change equally if the temperature rises or falls. Secondly there is always a noticeable 'break' in the quality of the sound at the transition between brass and iron strings; instruments strung just in brass do not suffer the interruption in the tone quality caused by the transition from brass to iron stringing. 2-4)

As with the scalings, the compass and disposition of most 16 th century Italian harpsichords have been altered. Most extant Italian instruments now have one keyboard and two sets of unison 81 strings, with a compass and scalings typlcal of those harpsichords built in the late 17 th century. Although the disposition with two sets of unison strings does occur as an original feature of the earlier 16th century instruments, they often originally had only one set of strings, $2-5$ ) or sets of strings one of which was at the octave to the other. The strings are to the left of their corresponding jacks in the single-strung harpsichords, and analogously the low-pitched string is on the left, and the octave string is on the right of the jack in those instruments with an octave. This arrangement is characteristically Italian and the opposite of that found on the Flemish instruments disposed with $1 \times 8^{\prime}$ and $1 \times 4^{\prime}$. Unlike 
the Northern instruments, the Italian instruments with an octave stop often have no separate hitch-rail glued to the underside of the soundboard for the octave strings. Instead the octave strings are hitched to pins which were simply driven into the plank-sawn cypress soundboard and then reInforced underneath with a large drop of glue placed at the point where the hitchpin penetrated through the soundboard. There are very few Italian harpsichords originally built with two manuals, and none that I know of from the 16th century. 2-6)

The jack guides in Italian instruments were normally of the box-slide type. That is, each jack was guided in a single long slot morticed in a deep piece of wood. This guide often did not run parallel to the nameboard but rather, with the instrument viewed in plan, was angled so that the bass end of the jack guide(s) was further from the nameboard than the treble end, and the wrestplank was tapered to compensate for this. This gave the required bass plucking points and also tended to reduce the bentside curvature slightly. Often the angle of the registers was sufficient to necessitate the angling of the individual jack slots in the guides.

The key touchplates in Italian instruments are normally of box, except in the more elaborate, highly decorated instruments when they are of ivory. The sharps are usually of ebony, ebony topped fruitwood, or some other dark hardwood such as bog chestnut or bog oak. The keylevers are usually of a hardwood such as beech, chestnut 
or oak, and are gulded at their tails with slips of wood which move in a slotted diapason rack.

The bridges and nuts in Italian instruments are of a basically rectangular cross-section with parallel front and rear surfaces and/3elicate moulding along the top surface. These bridges are much smaller in cross-section than the type of bridge found on most North European harpsichords and virginal, but, like their northern counterparts, are tapered to give a larger cross-section in the bass than in the treble. Often the ends of the bridges are carved with delicate scrolls which extend the bridges toward the case sides beyond the top and bottom bridge and nut pins. These scrolls have a purely decorative function and often are detrimental to the tone at the extreme ends of the compass by stiffening the freely vibrating soundboard area near the ends of the bridges.

The Italian virginals of the 16th century are polygonal in shape and closely follow the principles of construction of the harpsichords regarding internal framing, case thickness, bridge shape and cross-sectional area, scaling, etc. Naturally the virginals are disposed with only one set of unison strings. The main feature which is characteristic of Italian virginals and which instantly distinguishes them from the early North European virginals also made with thin cases is in the position of the keyboards. The keyboards of the Italian virginals project out from the case of the instrument itself, whereas the keyboards of the northern instruments are recessed into the 
case. The cases of the Italian virginals are thus narrower front to back and perhaps somewhat more elegant in shape than those of the early North European instruments.

The sound of a brass-strung Italian instrument is pungent, powerful, immediate and engaging. Despite the totally different principles of construction it is remarkably similar to that of the 16 th and early 17 th century North European instruments. The chief difference is that the sound of the Italian instrument has a somewhat greater attack and slightly less sustaining power, both of these almost certainly due to the lighter bridge cross-section and the resulting greater flexibility of the bridge and. soundboard. That is, because the combined flexibility of the bridge and soundboard is greater than in the North European instruments, the energy of the string after.plucking is radiated into the air quickly during the initial stages of the sounding of the note. The note is therefore louder initially - 1.e. it has more attack, and it dies away quickly since the energy of the string is all dissipated in the initial attack of sound.

The Early Germanic Tradition

The earliest dated North European stringed keyboard instrument is not of Flemish origin, but Germanic. It is a single manual harpsichord in the Raccolta statale di Strumenti Musicali (formerly the Evan Gorga Collection) in Rome, and is signed "GOTTES WORT BLEIBT EWICK BEISTAN DEN ARMEN ALS DEN REICHEN DURCH HANS MULLER CV LEIPCIK IM $1537 "$ (The word of God remains forever to help the poor (as much) as the rich. (Made) by Hans Muller in Leipzig 


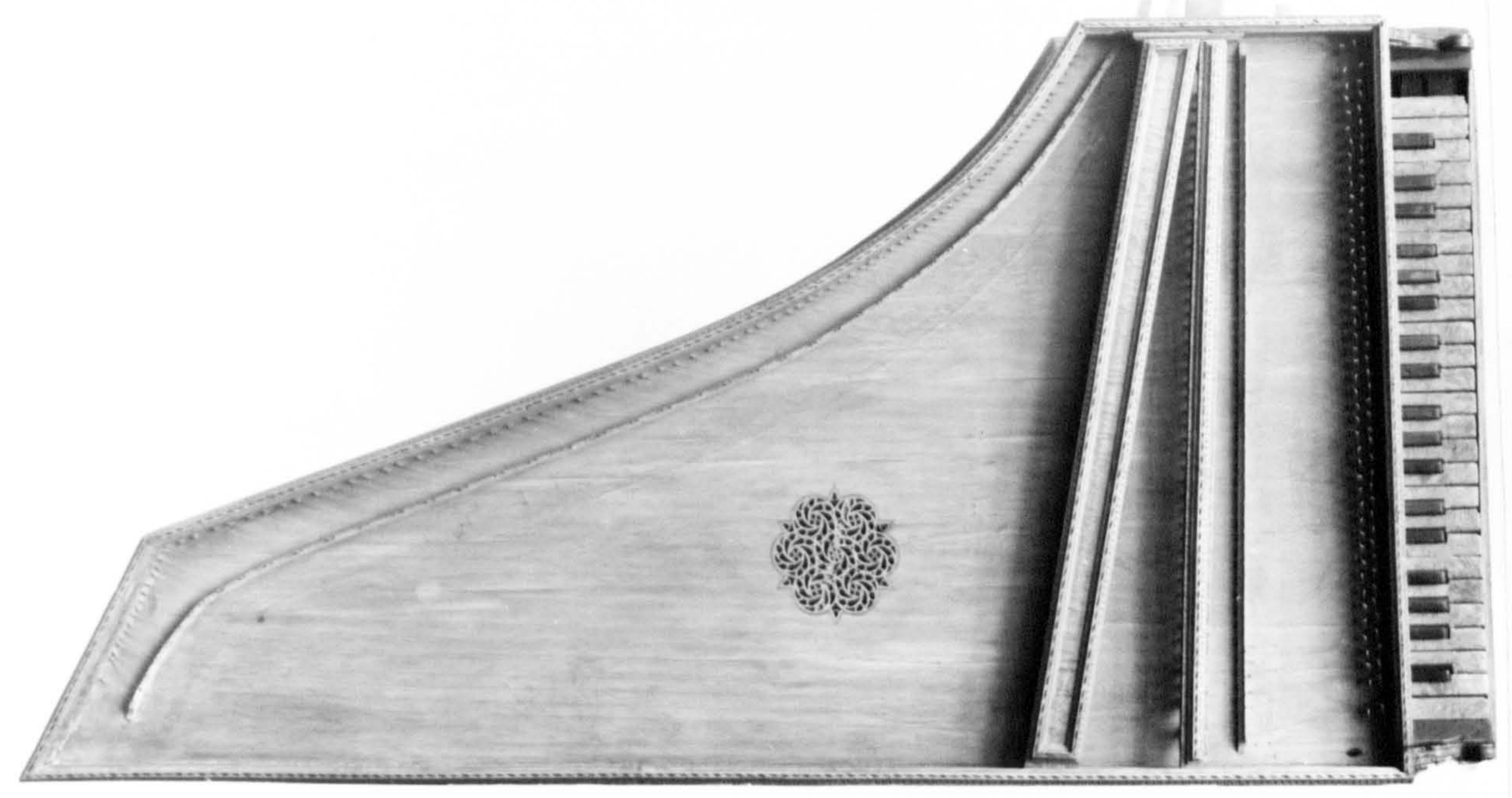

Photo 2-1 Plan view and spine side of the Hans Muller harpsichord of 1537. The original position of the bridge is clearly visible in the plan view. The keyboard is in its low-pitch position. The spine and case are made of figured 'Hungarian' ash, which was later imitated in the printed papers used to decorate the interior of the lid and flap of the Ruckers clavecimbels.

Scale 1:10 
in 1537). 2-7) This highly interesting and extremely rare instrument shows features which are characteristic both of the contemporary Italian school and of the later fully developed Flemish tradition. It is not clear however, whether the tradition in which the Mtller instrument was built grew out of the Italian tradition, or whether the Italian and Germanic traditions both are perhaps separate developments of some yet earlier common tradition.

The Muller harpsichord is $1494 \mathrm{~mm}$ long, $416 \mathrm{~mm}$ wide at the keyboards and $187 \mathrm{~m}$ high. Compared with other singlemanual harpsichords it is therefore rather small, and one is immediately led to suspect an instrument at a higher pitch than normal. The bentside, unlike those instruments built in the Italian tradition, has a shallow curve and this seems to suggest a long-scaled instrument intended originally for treble stringing in iron wire.

The original compass was $C$ to $\mathrm{a}^{2}$ without accidentals: $C^{\#}$ at the bottom and $g^{\# 2}$ at the top, 1.e. C, D. to $g^{2}$, $a^{2}, 44$ notes. The keyboards are arranged so that the tails of the top and bottom two keys are straight and parallel, with a space between for the 'missing' accidentals. The strings and jackslots also appear to be arranged with a gap at the top and bottom for the missing accidentals, but with altogether 46 pairs of strings and jackslots. However the arrangement of keys, strings, and jackslots results from the fact that the keyboard is capable of being shifted laterally by an amount equal to the width of one natural to achieve a transpoition of a tone. 
In either position of the keyboard two sets of strings are not required: one end set and the set third from the same end. The transposition by one tone produces certain problems in tuning which are discussed in relation to a Ruckers instrument in Appendix 7, p. 823.

The Mttler harpsichord is disposed with two sets of unison strings but throe rows of jacks. Two of these rows are placed in roughly the 'usual' position and one row of jacks is placed near the nut to give a nasal sounding register similar to the lute stop common on 18 th century English harpsichords. Clearly two sots of jacks originally plucked the same string and one set plucked the other, but it is now not possible to say what the original plucking direction of the jacks was.

As it presently stands the bridge is not in its original position (see photo. 2-1), but is displaced toward the bentside to lengthen the scalings. In this position the bridge is placed assymetrically between the cut-off bar and bentside, rather than in a more-or-less central position between the two. Also, because of the distortion of the scale produced by moving the bridge, the present treble string lengths do not double with each octave drop in pitch. With the bridge in its present position the scalings are approximately correct for brass stringing at a pitch corresponding to $\mathrm{a}^{1}=440 \cdot \mathrm{Hz}$. It would thus appear that the instrument was probably altered in Italy in the 18 th century to give scalings which would have 'modernised' the instrument to make it useful: for 
playing at the contemporary pitch.

Traces of the original position of the bridge, running along a roughly medial line between the cut-off bar and bentside are still visible, and in particular a number of bridge pin positions are visible where the original pins penetrated through the bridge into the soundboard. From these the original scalings of the harpsichord can be estimated. These yield treble string-lengths which double with each octave drop in pitch in a way which is much more accurate than the present scalings. The average scalings for the original position of the bridge are about $c^{1}=374\left(c^{2}=187 \mathrm{~mm}\right)$ with the keyboard in the lowpitch position, and $c^{1}=332 \mathrm{~mm}\left(c^{2}=166 \mathrm{~mm}\right)$ with the keyboard in the high-pitch position. These scalings immediately suggest iron treble stringing and a pitch an octave, and a ninth, above normal pitch (that is pitches of $R+8$ and $R+9$ in the pitch scheme suggested for the Ruckers instruments, see p. 177) .2-8)

From a constructional point of view the Muller harpsichord is framed and built quite differently from the contemporary Italian instruments, although still with some isolated Italianate features. The case sides of the Muller sit on top of the baseboard, rather than overlapping it as with instruments built in the Italian tradition. The baseboard itself is made like the later Flemish instruments with the grain of the wood running transversely under the keyboard, and lengthwise under the soundboard. The internal 'knees' of the Italian instru- 
ments are lacking, and the internal strengthening is achieved by means of upper and lower braces running just below the soundboard and at baseboard level respectively, from the bentside to the spine, in the manner of most later North European harpsichords.

The case-sides of the Mtller are very thin and are strengthened around the top edge of the instrument with a moulded batten, and in this respect the Miller is very Italianate. Also the scroll-sawn check pieces are very much in the Italian tradition. The rows of jacks are angled across the soundboard in the Italian way, but the jacks are guided by a series of holes pierced in the soundboard Itself and in a lower guide, rather than with a boxslide. The tradition of the jacks passing through holes plerced in the soundboard never ceased in the later Flemish virginal tradition and is also found in at least one early Anglo-Flemish harpsichord, namely that built. by Lodovijk Theouwes (see p. 67).

The soundboard is made not of spruce or fir as is. normal with North European harpsichords and virginals, but rather of cypress like many Italian instruments. Since the jackslots are pierced through it, the soundboard runs the full length of the instrument. The: wrest-. plank is a narrow bar of wood (beech?) only $32 \mathrm{~mm}$ wide behind the nameboard, and thus both the bridge and the nut are located over freely vibrating soundboard: The bridge and nut have a moulded top edge and scroll-carved ends in the Italian style. 
Most of the internal framing and the case of the Mtller harpsichord is of a coniferous wood. But one feature of the Maller which is typically individual to it, is the case veneer. This is of a highly figured wood called Hungarian ash, which was very popular in German and Swiss furniture and internal wood panelling during the Northern High Renaissance. Hungarian ash is ordinary European ash (Fraxinus excelsior) and is not particularly indigenous to Hungary. It is, instead, ash which is selected especially for this particular figure (just like fiddle-back maple or sycamore are not from a particular type of tree, but from specially selected or speclally grown trees). Ash sometimes grows with wavy, rather than circular, annular rings usually only on one side of the treo. If this wood is cut through the wavy rings in a roughly tangential direction, then the boards so obtained will have this extremely strong figure. The tradition of using Hungarian ash seems to have been carried to Flanders with the German speaking craftsmen who migrated there. The wood itself must have been lacking in Flanders, however, and this seems to have been the origin of the Hungarian ash wood-grain papers which were used as an imitation on the Flemish instruments (see further p. 396). The use of this wood on the cases of German instruments seems to have lasted for a long time since a doll's house virginal of about 1639 in the Germanisches Nationalmuseum has survived on which Hungarian ash decorates the outside of the case. 
There is no evidence on the spine of the instrument that the Muller ever had a lid, and this plus the thin case sides suggests that the instrument had an outer carrying case like its Italian counterpart. The tradition of this separate construction was probably also carried by the Germanic artisans to Flanders, and is to be found, for example, in the two earliest surviving Flemish virginals dated 1548 and 1550 by Ioes Karest which have separate outer cases for protection and transportation. Traces of abrasion on the lower surfce of the Muller baseboard discovered recently by Pletro Pattachiola seem to confirm the original existence of an outer case. This.case must have had 3 longitudinal battens on the inside lower surface which constantly abraded the baseboard of the inner instrument each time it was moved in and out of the outer case. There seem to exist no very early Germanic virginals built at about the same time as the MHller harpsichord. However, there are two virginals, both probably dating from the first half of the 17 th century, which exhibit many of the features exhibited by the early pre-Ruckers Flemish virginals. These two instruments are the doll's house virginal (already referred to) in tho Germanisches Nationalmuseum, Nuremberg, and a full-sized anonymous virginal of compass $\mathrm{C} / \mathrm{E}$ to $\mathrm{c}^{3}$ in the Museum Carolino Augusteum, Salzburg. 2-9) The latter instrument was probably intended to sound at a pitch one tone above normal, or $R+1$ (see p. 177).

Both of these instruments are hexagonal in shape, 
like the 1548 virginal by Ioes Karest. The keyboards are recessed, rather than projecting from the front of the case as is normal with Italian instruments as mentioned before, and this recessing of the keyboards is one of the most characteristic features common to all virginals built in the northern part of Europe. Like the virginals of Karest, but unlike the later Ruckers virginals, the nameboard above the keys is fixed and does not slide out. In order to be able to remove the keys, therefore, a small batten along the lower part of the nameboard is removeable, enabling the keyboard to be first lifted up to clear the front keywell moulding, and then withdrawn.

Features found on the Salzburg virginal which are not found on the later Ruckers virginals are the keyblocks at either end of the keyboard. Normally, even in the early Flemish virginals, there are no keyblocks between the ends of the keys and the keywell check pieces. However, the existence of these keyblocks on a virginal which at some stage was falsified to appear to be a Ruckers (see Boalch No. 23) but which was almost certainly made in Antwerp, shows that even this feature was carried over from the German tradition into some of the instruments built in Flanders.

Early Fllemish Instrument

The earliest Flemish clavecimbels are the two polygonal virginals by Ioes Karest. The earliest of these, dated 1548, is in the Brussels Instrument Museum and has been described in detail by Ripin ${ }^{2-10)}$ and Meeùs $2 \dot{11}$ ) 
The second Karest virginal, dated 1550, is located in the Raccolata Statale degli Strumenti Musicali 2-12)(Inv. No. 812) and it is mentioned in one of the catalogues of Franciolini. 2-13) Both of these instruments are signed 'IOES KAREST DE COLONIA', followed by the date $e^{2-14}$ )

Although these two instruments are quite different in size, and therefore probably intended to sound at a different pitch, they have many features in common. Both are polygonal in shape, although the larger Rome instrument has a curved 'bentside' running roughly parallel to the bridge. The case sides of both instruments are thin (about $7 \mathrm{~mm}$ ) and made of sycamore or maple. In order to protect the rather delicate structure of these instruments they were kept in a heavy protective outer case which was equipped with a lid and lockable front flap, and the outer cases of both instruments survive. The case sides are flush with the outer edge of the baseboard, although this feature is concealed beneath a moulded batten which surrounds the instrument along its lower edge. The top edge of each virginal is also reinforced with a moulded batten, and comparison of these mouldings on the two instruments show that they were made with the same moulding planes. The most prominent rounded feature of this moulding is decorated with stripes of black paint alternating with clear unpainted wood in a sort of 'barber pole' effect. Other parts of the mouldings are decorated with small squiggles and dots of black paint. Both theilnside and outside of the case of the Brussels virginal are inscrib- 


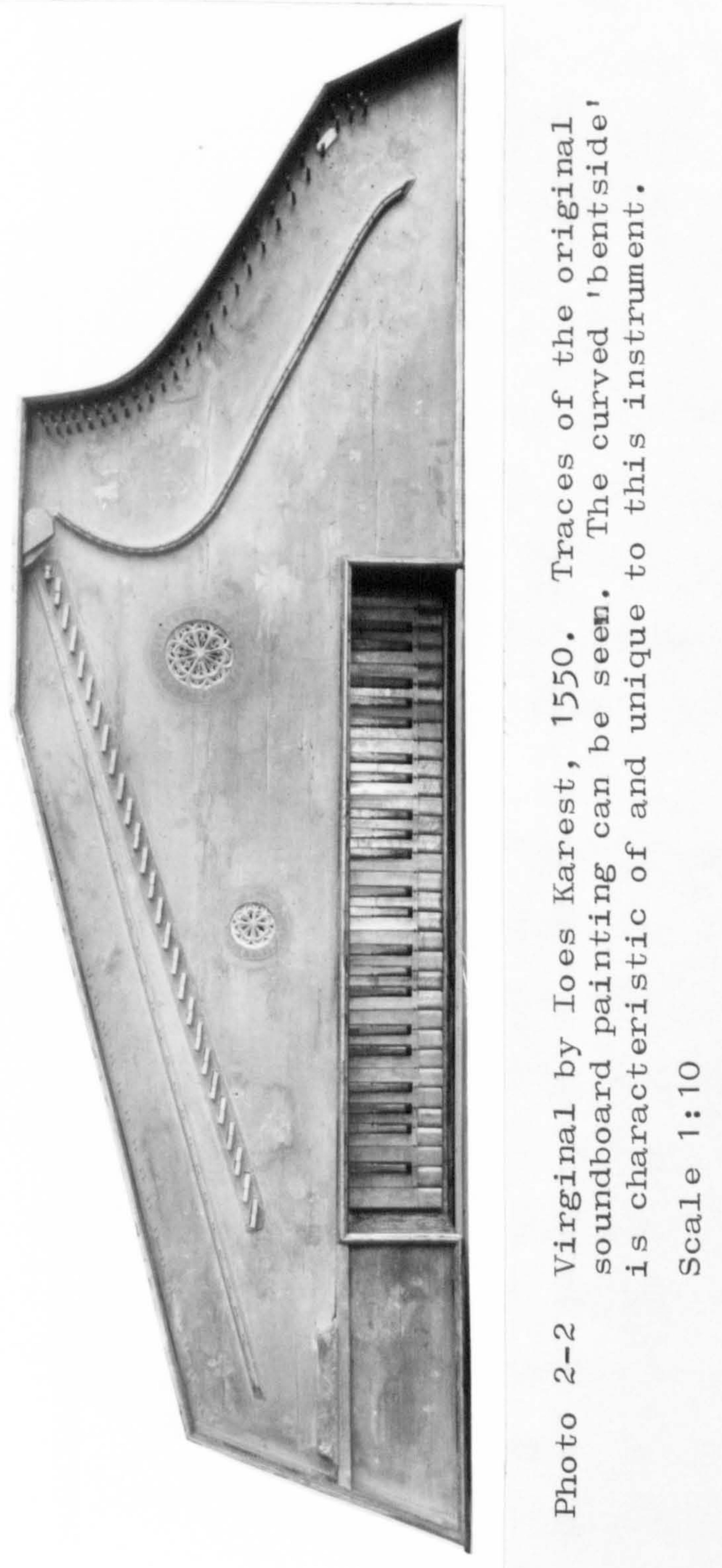


ed with Latin mottoes. The outside of the Rome Karest has a beautiful hand-painted Renaissance grotesque decoration in dark blue and black, with intertwined vines, leaves, fruits and flowers interspersed with, and sometimes connect to human and griffin heads. Although the dolphin does not feature in this decoration, the general impression is very similar to that of the later painted and block-printed-paper dolphin patterns. Both virginals probably originally had painted soundboards. But only traces of a soundboard painting are left on the Brussels Karest. The Rome Karest however has a soundboard painting with flowers and the usual blue borders and arabesques. It is thus the earliest instrument with its soundboard pattern still intact.

The Karest virginals have similar keyboards. The sharps are of bog oak decorated about half-way along the sharp with four scribed lines and a small edge nick between the two middle 1ines. These decorated sharps are typical of instruments built in Flanders until about 1580. The naturals, like those on the Muller, are of a highly figured dense wood, which is probably either briar or maple (sycamore) root. The poplar keylevers are guided at the back by a brass pin moving in a vertical slot in the rack, in a manner typical of that found in later Flemish virginals.

The soundboard in both virginals is a coniferous wood which is probably spruce. The bridges are made with rounded inward and flat outward facing surfaces, and a 
'step' moulding along the top of the bridge into which the bridge pins are driven. There are two roses in both virginals. The Brussels Karest has one large circular rose and a smaller rose in the shape of a Gothic window. These are filled with a gilded geometrical pattern of interlocking squares cut and embossed in vellum or heavy paper. The Rome Karest has two circular roses and they are both similar in style to the usual Italian pierced Gothic roses. The jacks are guided by a series of slots cut through the leather-covered soundboard, with the jacks in pairs two to a slot. A similar leather-covered board exteriding between the two keywell braces is used as a lower jack guide. This lower guide has sometimes been called a 'counter soundboard', but in fact it has no àcoustical function whatsoever. It might better be called a 'noiseboard' since it tends to amplify the sound of the jacks passing up and down through it, and it was soon replaced in instruments built slightly later by a narrow board stiffened along its edges to minimse the noise made by the jacks.

The chief differences between these two instruments lie in their compass, size and scalings. The compass of the Brussels instrument is $\mathrm{C} / \mathrm{E}$ to $\mathrm{c}^{3}, 45$ notes, and that of the Rome Karest is a full C,D to $f^{3}, 53$ notes, chromatic except for the missing bottom $C^{\#}$. Both of these compasses are unusual for instruments built during this period the Rome compass has no contemporary counterpart and even the compass of the Brussels Karest might have been expect- 
ed to be the more IImited $C / E$ to $a^{2}$ usual at this time. In order to assess the difference in pitch between the two virginals I have compared their scalings in the table below.

\begin{tabular}{|c|c|c|c|c|c|}
\hline \multirow[b]{2}{*}{ Note } & \multicolumn{2}{|c|}{$\begin{array}{c}\text { Rome Karest } \\
\text { of } 1550\end{array}$} & \multicolumn{2}{|c|}{$\begin{array}{c}\text { Brussels Karest } \\
\text { of } 1548\end{array}$} & \multirow{2}{*}{$\begin{array}{l}\text { Ratio of } \\
\text { Corrected } \\
\text { Scalings }\end{array}$} \\
\hline & $\begin{array}{l}\text { Measured } \\
\text { Scalings }\end{array}$ & $\begin{array}{l}\text { Corrected } \\
\text { Scalings }\end{array}$ & $\begin{array}{l}\text { Measured } \\
\text { Scalings }\end{array}$ & $\begin{array}{l}\text { Corrected } \\
\text { Scalings }\end{array}$ & \\
\hline $\mathrm{f}^{3}$ & $-114 \mathrm{~mm}$ & $111.7 \mathrm{~mm}$ & - & - & - \\
\hline$c^{3}$ & 166.5 & 169.8 & $139 \mathrm{~mm}$ & $136.2 \mathrm{~mm}$ & 1.247 \\
\hline$f^{2}$ & 273 & $267 \cdot 5$ & 211.5 & 215.7 & 1.240 \\
\hline$c^{2}$ & 346.5 & 353.4 & 286 & 280.3 & 1.260 \\
\hline$f^{1}$ & 488 & 478.2 & $388 \cdot 5$ & 396.3 & 1.205 \\
\hline$c^{1}$ & $592 \cdot 5$ & 604.4 & $511 \cdot 5$ & 501.3 & 1.205 \\
\hline $\mathbf{f}$ & 836 & $819 \cdot 3$ & 679 & 692.6 & - \\
\hline c & 990 & 1009.8 & 885 & 867.3 & - \\
\hline$F$ & 1229 & - & 1116 & - & - \\
\hline$C(/ E)$ & $1347 \cdot 5$ & - & 1163 & - & - \\
\hline
\end{tabular}

Here the lengths of the strings for the notes $c$ and $\underline{f}$ have been compared, and one immediately recognises another difference in the two instruments, arising because of their difference in compass. Because the jacks are placed together two to a slot, successive pairs of strings have to be moved apart to provide enough space for the jacks and quills. This means that alternate strings are successively slightly longer and slightly shorter than ideal. On the Brussels Karest ending with $c^{3}$ at the top the c strings are all slightly too, long and the $f$ strings 
all slightly too short, whereas on the Rome virginal ending with $\mathrm{f}^{3}$ at the top it is the $\underline{f}$ strings which are too long and the c strings which are too short as measured. The amount of lengthening or foreshortening amounts to about $2 \%$ (see p. 152), and each of the measured scalings has been corrected by this amount, taking care that the required amount is correctly added or subtracted in each case. It should be noted that, even as corrected, the scalings are not nearly as Pythagorean (i.e. they do not exactly halve with each octave rise in pitch) as those found in Ruckers instruments (p. 150).

Because one instrument has a short-octave bass and the other has an (essentially) chromatic bass compass, I have not compared the scalings below $c^{1}$ since the amount of and rate of foreshortening will be different for the two instruments. The ratio of the scalings is about 1.25 near $c^{3}$ and close to 1.20 around $c^{1}$, these corresponding to pitch differences of a major and minor third respectively when using the same stringing material. Thus the smaller Brussels virginal should probably be tuned about a major or minor third higher than the larger virginal by Karest in Rome. $2-15$ ) The Rome Karest has scalings (353.5 mm) similar to those of Ruckers (355 mm - see p. 156) and should probably be tuned to roughly the same pitch; that is to 'reference pitch' R. The smaller Brussels'virginal is thus at a pitch of $R+3$ (probably the best pitch comparison should be made in the extreme treble and therefore the pitch is a major third higher than R). "The"strings 
seem to be too long for it to have reached a pitch of $R+4$ without string breakage, so that this possibility can be exluded. The pitch $R+3$ does not belong to the scheme found for the Ruckers instruments (p. 177) and I have not been able to find any reference to the musical use of an instrument at this pitch.

The earliest extant rectangular Flemish virginal is the so-called 'Duke of Cleves' virginal in the Victoria and Albert Museum in London. 2-16) This is a highly decorated instrument and, although its shape derives partly from a purely decorative motive, it is built in a style which is quite different from the two Karest virginals just described, and more like the virginals and harpsichords which later became the typical product of the Flemish workshops. The case is of sarcophagus form with rounded sides sloping inwards toward the baseboard. The sides are thick and of walnut richly carved with figures of trophies and musical instruments. The impression is of a heavy chest, quite unlike the light delicate cases of the two Karest virginals just described. The fragile inner instrument has been combined with its heavy outer case in the Cleves virginal without, however, trying to counterfeit the impression of an inner instrument in an outer case as is common in many Italian instruments. Various parts of the case are decorated with Latin, mottoes, among which is included the date 1568, and the coat of arms of William, Duke of Cleves, Berg and JHlich (1516-1592). The soundboard is decorated with blue 
scallops and arabesques and naturalistic painted flowers. Although it has been suggested that these soundboard decorations date from a later period, iconographic evidence (see Ripin, above) showing instruments painted in the 1560's indicates that virginals during this period normally had this form of decoration, and the Rome Karest of some 18 years earlier also has its original painted soundboard. The keyboard is recessed into the case, in typical fashion. The keyboard is, however not original and the present compass of A to $\mathrm{f}^{3}$ (45 notes) is highly atypical. The most likely original compass is $C / E$ to $c^{3}$ also 45 notes. The compass and scalings seem to have been altered a number of times involving moving and repinning of the bridges and adding more jackslots to the soundboard and lower guide. However, the extreme treble and bass ends of the right-hand bridge are near their original positions, and the position of the middle sections of the bridge can be seen on the soundboard. Thus assuming a $\mathrm{C} / \mathrm{E}$ to $\mathrm{c}^{3}$ compass the scalings can then be estimated:

$$
\begin{aligned}
& c^{3}=170 \mathrm{~mm} \\
& c^{2}=325 \mathrm{~mm} \\
& c=1300 \mathrm{~mm}
\end{aligned}
$$

and these seem to suggest that the Cleves virginal'was originally intended to sound at a pitch of $R+1$.

One of the clearest links between the early Germanic and the Flemish traditions is provided by the harpsichord part of the claviorganum built by Lodowijk Theouwes in 1579 and now in the Victoria and Albert Museum; London. 2-17) 
Although the instrument was made in London in 1579 , it is probably more representative of instruments which would have been built in Antwerp 10 to 15 years earlier.

The Theeuwes harpsichord is built in a style which is intermediate between the German Muller harpsichord and the later Flemlsh instruments typified by those made by the Ruckers family. The case sides are about $12 \mathrm{~mm}$ thick, which is thicker than the earlier Muller and Karest instruments ( 7 to $9 \mathrm{~mm}$ ) but thinner than the 14 to $16 \mathrm{~mm}$ typical1y found in Ruckers instruments. The case of the Theeuwes is of oak instead of the usual poplar found in Flemish instruments, and this seems to be one of the English features of this harpsichord. On the other hand the case wood type seems generally to have been relatively unimportant to the classical builder - he seems to have used what was cheap and ready-to-hand. Inside the case one finds the mouldings applied to the main case walls in such a way as to counterfeit the appearance of a light inner instrument inside a protective outer case. This suggests that other Flemish (and perhaps English) builders used this integral construction to imitate instruments like the MHller which would have been stored in a protective outer case. However, in all later instruments of both the virginal and harpsichord type which are still extant, the cases are thick (i.e. about: $16 \mathrm{~mm}$ ) and there is no hint of a counterfeit inner instrument." The case sides are flush with the outer edge of the baseboard in typical fashion, and the internal framing is 
typically Flemish consisting of boards placed on edge on the baseboard and placed flatly under the liners running in both cases from the spine to the bentside.

The keys are missing, but the balance rail remains and the balance pins indicate that the original compass was $\mathrm{C}$ to $\mathrm{c}^{3}$ chromatic, 49 notes. This chromatic compass, although not always required for the music composed during the period in which the Theouwes was built, is often essential when playing English music of the late 16th century, and must be considered typical of instruments built in England at this time, when the $C / E$ short-octave seems to have been almost unfversal in most other parts of Europe.

The 4' nut and bridge are not original and thus the corresponding 4' scalings are unreliable. But, although the 8 ' bridge and nut are both original to the instrument, they are both slightly displaced from their original positions and the bridge pins do not fully relate to the position of the jackslots. However, the displacement of the bridge is greatest only in the extreme treble, and the scalings near $c^{2}$ are not appreciably different from the original. At present the long $c^{2}$ string is about $365 \mathrm{~mm}$, and this seems to suggest that the harpsichord (and organ) were originally intended to sound at a pitch slightly below $R$. The value of $R$ arrived at in Chapter 4, p. 173 is somewhere between 413 and $419 \mathrm{~Hz}$; corresponding to the Ruckers averaged scalings of $355: \mathrm{mm}$." The Theeuwes $c^{2}$ scaling of $365 \mathrm{~mm}$ suggests a pitch of about 
402 to $408 \mathrm{~Hz}$. This seems to be confirmed by John Koster's estimation of the pitch from one of the pipes remaining from the claviorganum which, referred to $a^{1}, g^{i v e s}$ about 392 to $404 \mathrm{~Hz}^{2-18)}$

The jacks are guided by slots cut in the soundboard like the Muller, and by three rows of separately moveable lower register slots which may be used to engage or disengage each of the rows of jacks with stop knobs located at the front of the instrument. Unlike the Muller, however, the three rows are all spaced close together and mun parailel to the nameboard in a position foreshadowing the position of the gap and registers in the later Flemish harpsichords. Like the Muller, the soundboard wood runs continuously for the full length of the instrument from the nameboard to the bentside and tail. The wrestplank is only about $50 \mathrm{~mm}$ square in cross-section, and therefore both the bridge and the nut sit on freely vibrating soundboard, a feature not found again on a later North European instrument.

There are three rows of tuning pins which, in conjunction with the three rows of jacks, suggests the disposition $2 \times 8^{\prime}, 1 \times 4^{\prime}$. However, in addition to the nonoriginal 4' nut and bridge there are other features of the $4^{\prime}$ stop which are somewhat dubious. The 4' hitchpin rail seems rather crudely made and there'is no cutoff bar on the spine side of the 4' bridge, and this has caused McGeary ${ }^{2-19)}$ to suggest that the 4':might not be original to the harpsichord. However, the upper belly 
rail, supporting the soundboard immediately behind the far row of jackslots is cut away in the treble to allow the 4' hitchpin rail to pass. This could only have been done before the soundboard was glued into the instrument. But conversely this does not prove that the $4^{\prime}$ stop is original since the hitchpin rail may originally have served only as a cut-off bar for the 8' bridge.

However, the hitchpin rail itself is cut away at the soundboard level to allow the 4 ' bridge to vibrate freely in the extreme treble. Also there are clear signs underneath the present $4^{\prime}$ nut of the original nut which must have been tall and narrow in the style of the present 8' nut and bridge. The three rows of tuning pins were marked out together, and it is necessary for one set of strings to pass through holes in the 8' nut. The holes for these strings are very neatly marked out and drilled suggesting that they consitute original work. It thus seems that the 4 ' is probably original and that the extremely advanced $2 \times 8^{\prime}, 1 \times 4^{\prime}$ disposition must also be accepted as original.

The remaining original section of the $8^{\prime}$ bridge of the Theeuwes harpsichord has a series of brass hooks, one for each note, whose function probably explains the apparently advanced disposition. These hooks have a handfiled thread on one end which is screwed into the top of the 8 ' bridge about half-way between the short and long strings. The top part of the hook is flattened and: slightly bent so that the flattened section is displaced 
about $5 \mathrm{~mm}$ from the axis of the section screwed into the bridge. As the hook is screwed into the bridge the flattened top section moves around from one side to another. This hook could have been positioned so that it was just touching the long $8^{\prime}$ string, and would produce a buzzing sound similar to the harpichordium found on the later Ruckers muselar virginals or the bray on Renaissance harps. However, unlike the harpichordium stop it could not have been engaged and disengaged for the whole (or a half) of the register at once. It is likely therefore that the long $8^{\prime}$ choir was permanently brayed, with the bray on each string in that choir having to be adjusted individually. The disposition should probably therefore be viewed as $1 \times 8^{\prime}$ (quili), $1 \times 8^{\prime}$ (brayed), $1 \times 4$, and not $2 \times 8^{\prime}, 1 \times 4 '$ in the sense of the later 17 th and 18th century instruments.

One complete jack and jack tongue (lodged. in a hole in the 8' nut) survive. The jack is well made and of a mature and sophisticated design. It has one oval damper hole similar to that found in Ruckers 4' jacks (seo p. 366). It is not clear that this jack belonged to a 4 ' register, however, as the jackslots in the soundboard are all of the same width so that all three rows probably had just one damper hole (unlike the Ruckers jacks which have:wider 8 ' jacks with two damper holes). The use of oval, holes for the dampers in this, the earliest extant harpsichord made in England, was not carried on into the later clavecimbel building tradition as it was in Antwerp where it 
appears often even in some 18 th century instruments. oblong damper holes are found in the jacks of only one isolated example of English keyboard instrument making, namely the John Crang spinet of 1758 in the Victoria and

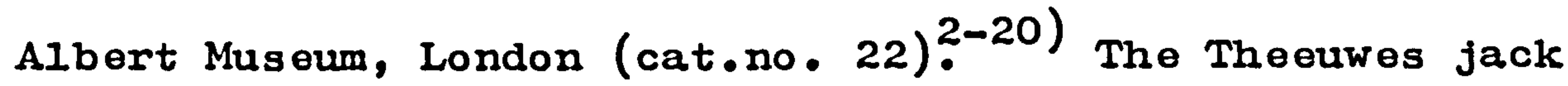
is slightly tapered in width and thi ckness, and the tongue is retained in its neutral position with the usual hog's bristle. The angled base of the tongue slot in the jack is covered with soft white (kid?) leather to prevent the tongue from clicking. Both the tongue in the complete jack, and the tongue lodged in the instrument have, most remarkably, iron quills which seem to be original. There are no signs that the quills have ever been replaced or tampered with and the quill slots are very small both in width and thickness, and this in itself suggests that the quills have always been of metal (and probably, being of metal, have managed to survive). Among other instruments, the clavicytherium dated c. 1480 at the Royal College of Music in London was reported by Hipkins ${ }^{2-21)}$ as having had traces of brass plectra in 1885. It is therefore possible that more of these early instruments may have been quilled with metal plectra, and that this is not just a feature of the early claviorgana where the harpsichord had to compete with an organ which was probably fairly loud and rich in harmonics.-22) The effect achieved with the harpichordium operating by metal-plucked strings combined with narrow-scaled pipe organ tone, would be unusual and surprising to the modern ear!. 
Vírginals builit at_a_time contemporary_with Hanss_Ruckerers_

By the time Hans Ruckers had joined the Guild of St.

Luke in 1579 and had started to build instruments, the style and construction of the virginals built in Antwerp had stabilized and become fairly uniform. These instruments differ little from the instruments built during the next 70 to 80 years by the various members of the Ruckers family and so will not be described in detail here (see Chapter 5). They were the typical heavy-cased, ironstrung, rectangular virginals built almost entirely out of poplar. But although these virginals are similar in their essentials to the later standard Ruckers models, they are slightly different in detail, and many of these details seem to characterize the instruments built during the period from about 1570 to 1590 .

By this time the keyboard compass had already become fairly standardized at $\mathrm{C} / \mathrm{E}$ to $\mathrm{c}^{3}$ (the most common exception is $\mathrm{C} / \mathrm{E}$ to $\mathrm{a}^{2}$ ), and this remained the usual virginal compass until the Ruckers family ceased building instruments at the beginning of the second half of the 17th century. The keys were made with the usual. bog oak sharps and bone natural touchplates. But the sharps on virginals during this period usually retained the extra decoration also found on the very earliest Flemish virginals. Instead of the plain sharps found on lat'er instruments built right up to the present day, these sharps were decorated with four scribed lines with a small edge nick filed on either side of the sharp 
between the 11nes. This decoration then matched the similar scribed lines and nicks found in the bone on the naturals touchplates just in front of the sharps. Virginals which have decorated sharps are the following:

Hans Bos (c. 1570), Monasterio de Santa Clara, Tordesillas, Spain.

Iohannes Grauwals (c. 1570) (compass $C / E$ to $g^{2}, a^{2}$ ), Brussels Museum of Musical Instruments.

Marten van der Biest, 1580 (mother and child), Germanisches Nationalmus eum, Nuremberg.

Hans Ruckers, 1581 (mother and child), Metropolitan Museum of Art, New York,

Hans Ruckers, 1583, Francois Meyer, Paris. The Artus Gheerdinck virginal built in 1605, and now in the Germant sches Nationalmuseum, Nuremberg also has decorated sharps but, being built in Amsterdam ${ }^{2-23)}$ out of the mainstream tradition, it is untypical of instruments built at. this late date.

Most of the instruments just mentioned also have slightly ornate bridges. The later Ruckers virginals have plain simply made bridges of an irregular crosssection, and with all of the surfaces planed flat (seo p. 304). The earlier virginals, however, usually have either or both of the front or rear surfaces planed to a rounded shape. The cross-section and strength of these bridges is roughly the same as that of the flat-surfaced 
bridges, so that rounding the sides of the bridges probably serves no acoustical purpose, and was done strictly from an ornamental point of view.

Another feature of the virginals built from about 1570 to 1590 concerns their roses. The later Ruckers virginals had a single lead rose with the figure of an angel playing a harp botwoen the maker's intials. It is usually assumed that this is the distinctive mark which the Guild regulations required each member to place in or on his instrument. However, many of the instruments built after the acceptance of the Gulld regulations in 1557 do not have such a lead rose. Also there is often more than one single rose decorating the soundboard. For example, the Hans Bos virginal does have a lead rose with a representation of a small pipe organ and the ititials $\mathrm{HB}$, but it also has a parchment geometrical rose, and a third empty rose hole which presumably also contained a geometrical rose.2-24) The Marten van der Biest mother and child.virginal has two geometrical parchment roses in the 'mother' and one in the 'child', but no lead rose. The Iohannes Grauwels virginal has a single parchment geometrical rose and, like the other instruments just mentioned, there is no doubt that these roses are original and they were not added as some later time.

All three of the van der Biest mother and child roses are completely different, but the slightly smaller lefthand rose in the mother virginal is identical in size and design with the Grauwels rose. It thus would seem that 
these parchment roses had a common origin and that different virginal makers used one and the same type of soundboard rose, perhaps purchased from a common supplier. Since these parchment roses are therefore not at all distinctive it seems unlikely that they qualify for the characteristic mark required by the Guild. Was the signature, usually on the jackrail, the required distinctive mark? Or was the Guild regulation simply ignored by the instrument builders, or perhaps the Guild itself was ineffective in enforcing the regulations?

Early Flemish double=manual harpsichords

The Brussels Instrument Museum has the good fortune to possess not only the earliest Flemish virginal by Ioes Karest, but also what is probably the earliest Flemish double-manual harpsichord:-25) The instrument bears the museum number 2934 and unfortunately is neither signed nor dated. It is in an extremely dilapidated and ruinous state, and appears at first sight to be a very uninteresting and unattractive instrument. It has undergone a number of alterations including a case ravalement to give the rather conservative $G_{1} / B_{1}$ to $c^{3}$ compass.2-26) However the original keybeds and most of the original keys remain, and from the pinning and re-pinning of the balance rail, and from the re-numbering of the keys it is possible to establish not only the original compass, but also the keyboard compass of three subsequent states. There seems no doubt that the instrument is of Flemish origin. It is of poplar construction with thick 


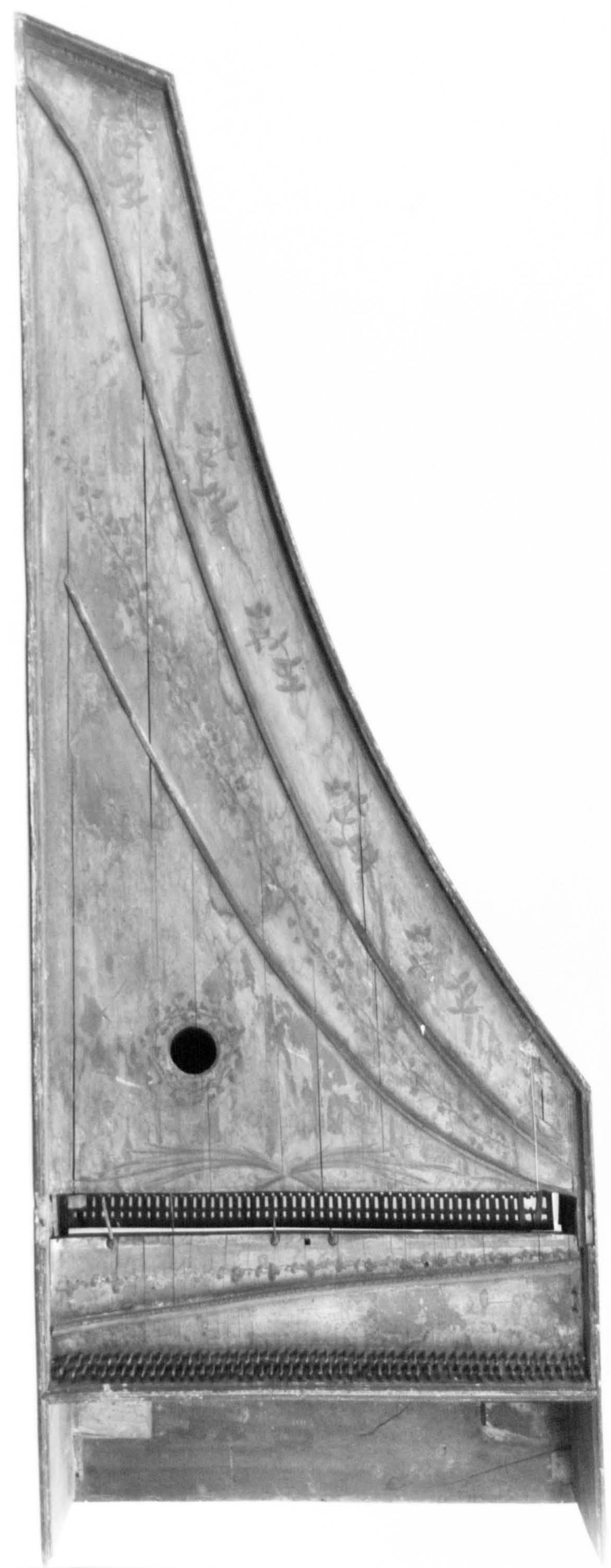

Photo 2-3 Anonymous early Flemish double-manual harpsichord. (Brussels Museum No. 2934) Scale 1:10 
case-sides sitting on the baseboard which is planed flush with the case walls around the bottom edge. The internal framing is in the general Flemish style having baseboard braces placed on their edge and upper level braces placed flat underneath the soundboard liners, with both types of bracing running from the spine to the bentside. The bridges are heavy and have the usual irregular crosssection, and the registers and buff stop originally projected through the chook in the usual way.

However, although it seems certain that the harpsichord is Flemish in origin, it seems equally certain that it is not by one of the Ruckers family:-27) The usual Ruckers construction marks on the soundboard above the 4 ' hitchpin rall are lacking and there are no positioning holes on either side of the bridges and nuts as is invariably found on Ruckers instruments (see Chapter 6, p. 532). Also there are no nails underneath the bridges securing them to the soundboard. Although the internal framing is in the style of Ruckers the rear toolbox brace is lacking. And the edges of the upper level braces and the soundboard liners are not broken with a chamfer as one finds on Ruckers instruments. Also the dimensions, such as the case height and the length of the tail, are not those typical of a Ruckers harpsichord. Part of the plan of the registers and string band is marked out on the original portion of the baseboard, but this is done in a quite different way from the $1594 \mathrm{HR}$ harpsichord (which, aside from being the only known harpsichord by 
Hans Ruckers, is also the only Ruckers instrument in which the string band is schematlcally marked out on the baseboard). All of these features point to a builder who had, in some aspects, a considerably different construction procedure from any of the members of the Ruckers family.

On the other hand, the bentside case joins are made like those found on Ruckers instruments (see p. 542), the original keyboard 3-octave span is $500 \mathrm{~mm}$ and the (now empty) rose hole diameter is $65 \mathrm{~mm}$, the base section of the 8' bridge was originally back-pinned from $C / E$ to $c$, and the original $81 \mathrm{c}^{2}$ bridge pin is $49 \mathrm{~cm}$ from the back of the nameboard (see p. 499). All of these latter are among the characteristic features of a Ruckers instrument. But the important deviations from the Ruckers usual practice seem. to me to suggest not only that the harpsichord is Flemish, but that it was made by one of Hans Ruckers contemporaries in Antwerp where the relationship between the various builders would be very strong, with slight but noticeable differences from workshop to workshop. Hence, keeping in mind that the instrument was probably built in Antwerp, and that it may have certain quite different features from those made by the Ruckers family, an attempt can be made to determine the original state of the harpsichord. The pinning of the balance rail on both manuals makes the original compass clear. The first three naturals in the bass of the upper man- : ual are missing and in their place traces remain, not of a solid block as is usual with Ruckers harpsichords; 
but of a small framed box, possibly with a lid originally. The upper manual then begins with a C/E short octave and reaches to a top note of $a^{2}$ (including $g^{\# 2}$ ). The lower manual also begins with a $\mathrm{C} / \mathrm{E}$ short octave and continues on to $d^{3}$ (with $c^{\# 3}$ ), the lower manual being pitched a fourth lower than the upper manual like the later Ruckers double-manual harpsichords. Identification of the pitch $c^{2}$ string using the $49 \mathrm{~cm}$ rule, and locating the original bridge pin positions from the $500 \mathrm{~mm}$ 3octave span (see Chapter 8) confirms the compass of both the upper and lower manuals. The important difference between the compass of this harpsichord and the Ruckers standard model double manual harpsichord is that the Ruckers reached a minor third higher. The shorter compass of the Brussels harpsichord is one of the features which points to an early dating since the $\mathrm{C} / \mathrm{E}$ to $\mathrm{a}^{2}$ compass was common on keyboard instruments built in the period between 1550 to 1580 or 1590 .

However, although the compass of this harpsichord seems quite clear, the original dispostion is not as easy to re-construct. A series of scribed lines is drawn on the original portion of the baseboard under the gap. Four lines running the full width of the instrument are traversed by a series of short lines which seem to indicate the positions of the $c$ and $\underline{f}^{\#}$ strings on both upper and lower manuals. The four lines underneath and parallel to the gap almost certainly indicate that the instrument was originally designed for 3 registers (Ruckers 
single-manual harpsichords have 2 registers and 3 similar Iines, and Ruckers double manual harpsichords have 4 registers and 5 lines drawn equispaced underneath the gap). The wrestplank was replaced in the course of the case ravelement, but there seems no indication that the gap width was altered in the process. This gives a present gap width of only $64 \mathrm{~m}$, whereas the gap width in a normal 4 register Ruckers double is $73 \mathrm{~mm}$. This and the narrow jackrail mortice (the jackrail is missing) all seem to confirm that the harpsichord was originally intended to have but 3 registers. Ripin has found iconographic evidence for a 3-register double manual Flemish harpsichord. 2-28) He attributes the harpsichord depicted by Brueghel to Ruckers, but if one accepts the accuracy of the painter in depicting the 3 registers correctly, then I feel that one must accept that a number of other features of the instrument in the painting are not in the style of Ruckers and that the instrument painted can at best be attributed only generally to the Antwerp school and not to one of the members of the Ruckers family.

However, acceptance of the fact that the Brussels harpsichord originally had only 3 registers, then leads immediately to the problem of the original distribution of three registers among two manuals.: Because of the alterations to the instrument and because the original: jacks have been lost, the original arrangement must of necessity remain conjectural. And yet I believe the instrument retains enough features that this original 
arrangement can be postulated with some certainty.

It is clear from the re-pinning of the bridges that the harpsichord orlginally had only one set of 81 strings and one set of 4 ' strings, $1 \times 81$, and $1 \times 41$. Furthermore, there is no evidence either on the $8^{\prime}$ or $4^{\prime}$ bridge or along the 4' hitchpin rail that there were doubled strings for the $e^{b} / g^{\#}$ notes. Thus when the player went from one manual to using the other he had to retune these strings to avold the meantone 'wolf'. Both the upper and lower manual key talls were marked out by using a punch through the upper and lower registers to leave an oblong indentation on the tail of the key at the future location of each jack in a similar way to that used by the Ruckers (see p. 351). It is clear from these marks that the upper manual keys have been shortened since only half of the oblong indentation is visible at the extreme end of the key. Since the mark therefore occurs at a position in the middle of the near row of jacks it seems clear that the upper manual was shortened to operate a dogleg register for the near row of jacks in the most recent state of the instrument. This would give the usual $1 \times 8^{\prime}$ on the upper manual and $2 \times 8^{\prime}, 1 \times 41$ on the lower manual. From the position of the indentations on the lower manual it seems clear that the upper manual keys have been shortened by an amount equal to one full register width. This would then mean that the middle row of jacks was originally a dogleg register which could then be operated from either manual. 
The most likely disposition is then;

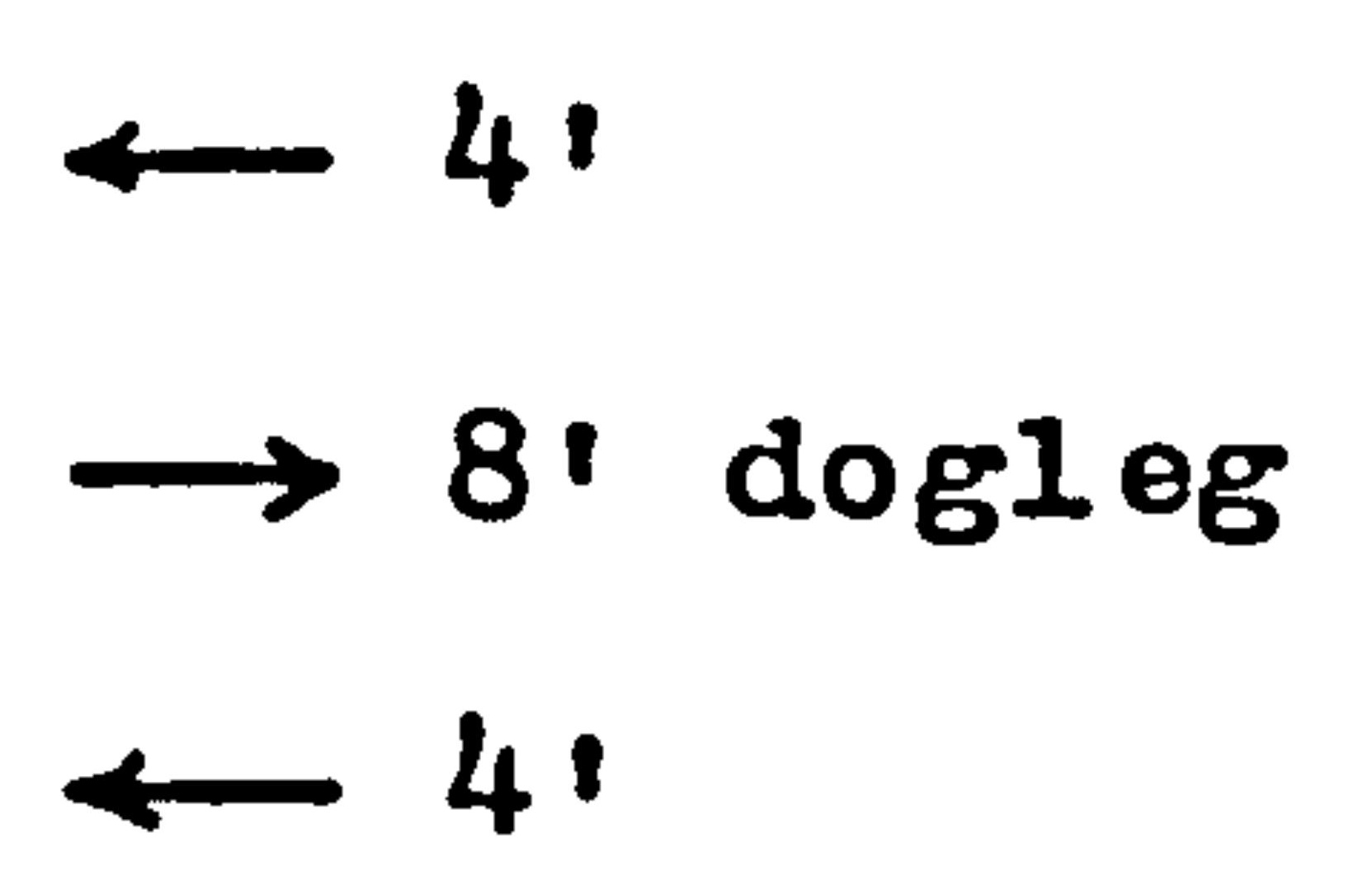

This would then mean that the $8^{\prime}$ strings would be played from either manual without altering the register. Probably the 8 ' register would be left on most of the time, except when using the $4^{\prime}$ as a solo stop. With the 8' register on, the appropriate 4' register (depending on the manual being used) could be added for added volume and brilliance. With such a system having only one row of 8' jacks the notes $e^{b} / g^{\#}$ must be re-tuned when moving from one manual to the other since the same jacks plucks the corresponding $8^{\prime}$ string on both manuals. But at this early period the range of modulation of the music was relatively small and the key signature of the pieces seldom involved more than one or two accidentals. So there would seldom have been the need to retune when changing manuals. The Ruckers doubled-string arrangement for the $e^{b} / g$ notes is surely a development arising out of a later musical need for pieces both to modulate further from their home key, and to involve a key signature itself with more accidentals. The Ruckers doubled string system could have been used on this harpsichord for the 4' stop, although there was probably little need for such a system when this instrument was built."

Whatever the reason for the lack of the doubled $e^{b} / g^{\#}$ strings on this instrument the Ruckers system is 
a distinct advance, since one can switch from one manual to the other immediately without re-tuning the troublesome $e^{b} / g^{\#}$ strings. Whether this advance can be attributed to Ruckers or not can never be confirmed because of the lack of instruments from this period and also the absence of relevant documentary evidence.

The earliest Ruckers double-manual harpsichord is dated 1599 (1599 HR), a year after Hans Ruckers had died, and must therefore have been made by one or both of Hans Ruckers' sons, Ioannes and Andreas. This harpsichord has been carefully examined and is discussed in more detall on page 504. In its original state it had doubled strings for the notes $e^{b}$ and $g^{\#}$, and therefore must originally have had 4 registers like the usual later models of Ruckers double. However this harpsichord is of particular interest since it originally had the same compass as the early anonymous Brussels instrument namely $\mathrm{C} / \mathrm{E}$ to $\mathrm{a}^{2}$ on the upper and $\mathrm{C} / \mathrm{E}$ to $\mathrm{d}^{3}$ on the lower manual.

\section{Footnotes:}

2-1) W.R. Thomas and J.J.K. Rhodes, 'The String Scales of Italian Keyboard Instruments', Galpin Society Journal', XX (1967) 49-62.

2-2) John Shortridge, IItalian Harpsichord Building in the 16th and 17 th centuries', Contributions from the Museum of History and Technology. United States National Museum Bulletin 225, Smithsonian Institution Paper 15, Washington (1960) 93-107. John Barnes, 'Pitch Variations in Italian Keyboard Instruments', Galpin Society Journal, XVIII (1965) 110-116.

J.H. van der Meer, 'Harpsichord Making and Metallurgy - a Rejoinder', Galpin Societ Journal, XXI (1968) $175-178$.

John Barnes, 'Italian String Scales', Galpin Society 
Journal, XXI (1968) 179-181.

John Barnes, 'The Specious Uniformity of Italian Harpstchords', Keyboard Instruments (ed. E.M. Ripin) Edinburgh (1971) 1-10.

John Barnes, 'The Stringing of Italian Harpsichords', Restaurierung von Saitenklavieren. Kongressbericht Graz, (1973), 35-40.

2-3) G.Grant O'Brien, 'Historical Harpsichord Stringing' which is due for publication by Cambridge University Press in the near future.

2-4) See Chapter 4 for a discussion of how iron and brass are used in Ruckers instruments, with typical scalings for each.

2-5) Friedemann Hellwig, 'The Single-strung Italian Harpsichord', Keyboard Instruments (Ed. E.M. Ripin) Edinburgh (1971) 37-41.

2-6) The Italians use of 2-manual harpsichord was quite different from that north of the Alps. Most of the surviving two-manual instruments have no manual coupler and have the 41 on the upper and the two unison 8's on the lower manual. Such a disposition might have been used for an echo or antiphonal treatment of fantasias.

2-7) This instrument is described in considerable detail in a booklet by L. Cervelli and J.H. van der Meer 'Conservato a Roma il piu antico clavicembalo tedesco', Edizioni Palatino, Rome (1967).

2-8) The other possibility is that the pitches involved might have been $R+4$ and $R+5$, a fourth and a fifth above normal pitch with treble stringing in brass. Using the ratio of the Ruckers brass to iron scalings (see p. 159) the scalings for the Milller would then be expected to be about $c^{2}=218 \mathrm{~mm}$ and $193 \mathrm{~mm}$, respectively. Even allowing for a considerable error in estimating the original scalings of the Mtller harpsichord, these long scalings seem to exclude this possibility.

2-9) J.H. van der Meer, 'Beitrage zum Cembalobau im Deutschen Sprachgebi et bis 1700', Anzeiger des Germanischen Nationalmus eums, Nur emberg (1966).

2-10) Edwin M. Ripin, Ion Joes Karest!s Virginal and the Origins of the Flemish Tradition', Keyboard Instruments, Edinburgh (1971) 65-73:"

2-11) Nicolas Meeùs, iLa facture de virginals à Anvers au

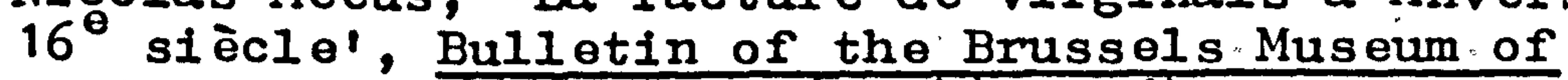
Musical Instruments, IV (1974) 55-64. 
2-12) Louisa Cervell1, 'Per un Catalogo degli Strumenti a Tastiera del Museo degli Strumenti Musicali', Accademie e Biblioteche d'Italia, XIIV, No. 4-5 (1976) $305-343$.

2-13) Edwin M. Ripin, The Instrument Catalogues of Leopoldo Franciolint', Music Indexes and Bibliographies, No. 9, New Jersey (1974) 10,25,50 and 58 .

2-14) The signature of the Rome virginal is not original although it apparently existed at the time that Franciolini compiled his catalogue.

2-15) As will be shown later (p. 173), the difference in scaling between instruments designed for iron and those designed for brass treble stringing corresponds roughly to an interval between a major and a minor third. It is thus remotely possible that the Brussels Karest should be strung throughout in brass and tuned to the same pitch as the larger Rome virginal strung with iron treble strings. There are two reasons for rejecting this possibility. Firstly there is considerable iconographic evidence showing contemporary small Flemish instruments with iron treble strings (E.M. Ripin, 'On Joes Karest's Virginal and the Origins of the Flemish Tradition', op. loc. cit.), and in view of the otherwise universal use of iron treble stringing in Flanders one is probably forced into excluding this possibility. Secondly, if the two instruments had been designed to sound at the same pitch, but with different treble stringing, then the scalings of the lowest notes should be the same since they would sound at same pitch and would be strung with the same material. But here the scalings of. bottom $C$ of the Brussels instrument are shorter in roughly the same proportion as the treble scalings. This indicates that the bass notes as well as the treble notes of the Brussels Karest should also be tuned higher than the Rome virginal by roughly a minor third.

2-16) Raymond Russell, Catalogue of Musical Instruments Keyboard Instruments, Vol. 1, London (1968) cat. no. 11, p. 40 .

See also: Thomas McGeary, 'Early English Harpsichord Building: A Reassessment', The (English) Harpsichord Magazine, Vol.1, No. 1 (oct. 1973) 7-19. John Koster, 'The Importance of the Early English Harpsichord', Galpin Society Journal, XXXIII (1980) 45-73.

Wilson Barry, 'Analysing the Theewes' to be published in the 1984 volume of The Organ Yearbook.

2-17) Raymond Russell, as $2-16$, cat. no. 16, p. 48. 
2-18) See John Koster, footnote 2-17), p. 54. Koster gets a pitch for c 3 of 933 to $960 \mathrm{~Hz}^{1}$, Calculating a from this (equal temperament) gives $a^{1}=392$ to $404 \mathrm{~Hz}$.

2-19) See Thomas McGearly, footnote 2-17).

2-20) This feature was pointed out to me by John Barnes.

2-21) A.J. Hipkins, The Planoforte, London (1896) 74. There seems to be no evidence at present of metal plectra in the jacks of this instrument.

2-22) From a careful examination of the remaining organ parts, and the space formerly occupied by the organ pipes, Wilson Barry (see footnote 2-16)) has found the following organ disposition:

Stopped diapason
Flute (stopped wood)
Principal (bass: stopped wood ${ }^{\prime}$
treble: open wood)
Cymbel (repeating metal)
Regal

2-23) Alan Curt1s, 'Dutch harpsichord makers', Tijdschrift van de Vereniging voor Nederlandse Musi ekgeschiedenis, Amsterdam, XIX, Vol. 1/2 (1960/61) 44-66.

2-24) See the illustrations 25 and 30 in Donald Boalch, Makers of the Harpsichord and Clavichord, 1440-1840, oxford (1974) second edition only.

2-25) The possible importance of this harpsichord was first noticed by Edwin M. Ripin, and pointed out to me by Nicolas Meeùs.

2-26) This was later crudely altered to $C$ to $f^{3}$ chromatic. A complete description of the intermediate states of this harpsichord will be the subject of a future paper by the author.

2-27) The instrument is, however, ascribed to Ruckers by both Boalch (number 26) and the 5th edition of Grove's Dictionary (Hans Ruckers number 21).

2-28) Edwin M. Ripin, 'The Two-Manual Harpsichord in Flanders before 1650', Galpin Society Journal, XXI (1968) 33-39. 
Chapter 3 - The Tvpes of Instruments Built by the Ruckers,

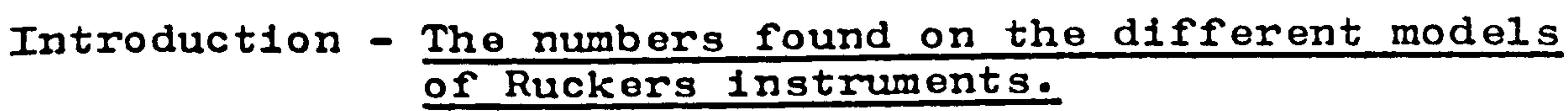

Unlike most of the 18 th century keyboard instrument bullders who bullt very few different models of instrument, the members of the Ruckers family built at least twenty clearly distinguishable models of harpsichord and virginal. Such a large number of different instrument types present a selection of different pitches, tone qualities, combinations of instrument types and keyboard compasses. Before going on to a discussion of the construction of the Ruckers instruments it is necessary to have a clear idea of the different model types which were built. Although many of these models will be described here, the complete identification and determination of all of the instrument types will be left to Chapters 4 and 8 .

Related to the different models of clavecimbel built by the Ruckers aro the marks and numbers written on many of them.-1) Unfortunately a great many Ruckers instruments have been so drastically modified in order to conform to later musical taste, that no part of them remains which bears this original marking. There are, however, several extant instruments which still retain at least one original marked part.

These marks and numbers are most commonly found 
on the action parts of the instruments: the upper and lower keylevers, the upper and lower jacks in each register, the registers themselves, and on the keyframe. In virginals, they are almost always found on the tail of the board at the bass end of the keyframe. The number is ofter additionally written on the baseboard below the keyframe, underneath the jackrail, in the case mortice for the jackrail, on the back of the nameboard in virginals, and on the rear of the namebatten and lower manual batten in doublo manual harpsichords. There are also isolated cases where the number is scratched with a sharp tool on one of the frames of the instrument, or, rarely the number is written in rather large red numerais $s^{3-2)}$

Photographs $3-1$ to $3-17$ show typical examples of these marks found in one of the above locations on various Ruckers and Couchet instruments. These can be seen to be written with quill or brush in ink, and they seem to be written in a hand characterlstic of each of the Ruckers workshops. On Ioannes Ruckers instruments, they seem to be in one type of hand-writing which is different from that found on Andreas Ruckers instruments, etc.

A characteristic feature of the markings is that the single virginals are always labelled with two numbers, one above the other: the upper number is always a numeral of low value and the lower one is usually somewhat higher in value (see Photographs $3-2,3,4,5,10,11$ and 12). The double virginals are labelled with an $\underline{m}$ on the large 

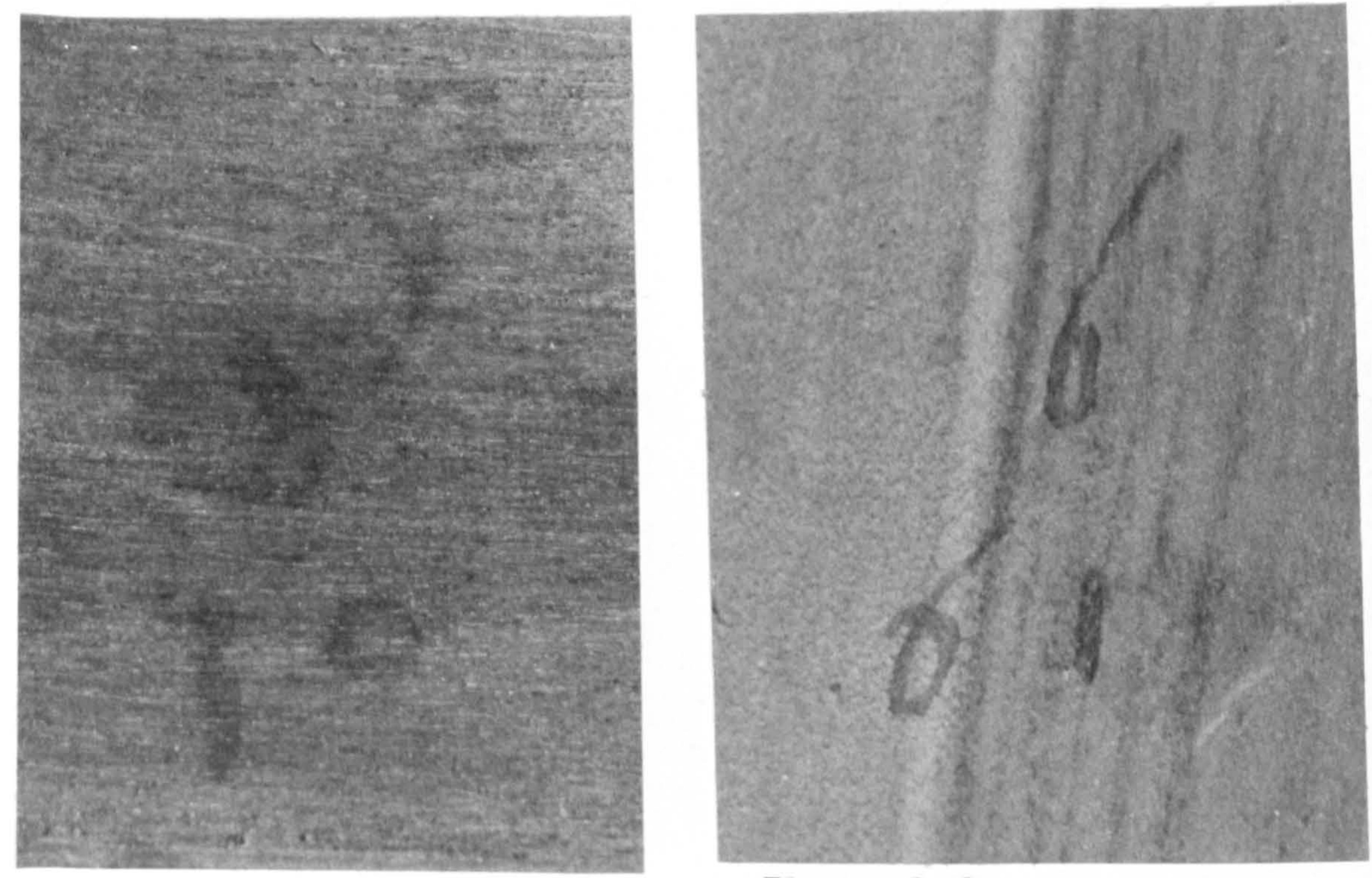

Pho to 3-2
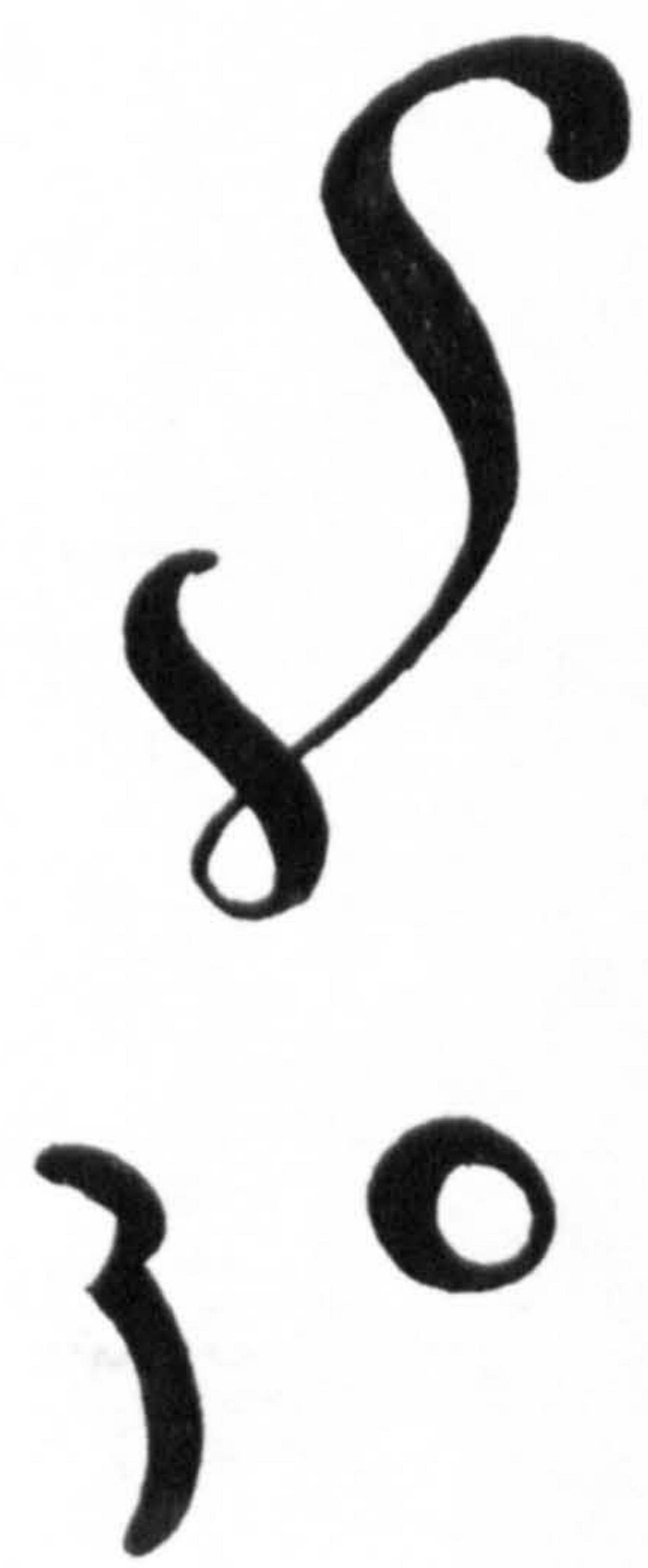

Photo 3-1

Hans Ruckers numbers:

Photo 3-1 1591aHR polygonal spinett virginal, with (below) a clearer view of the mark and number.

Photo 3-2 1598 HR 6-voet spinett virginal. 


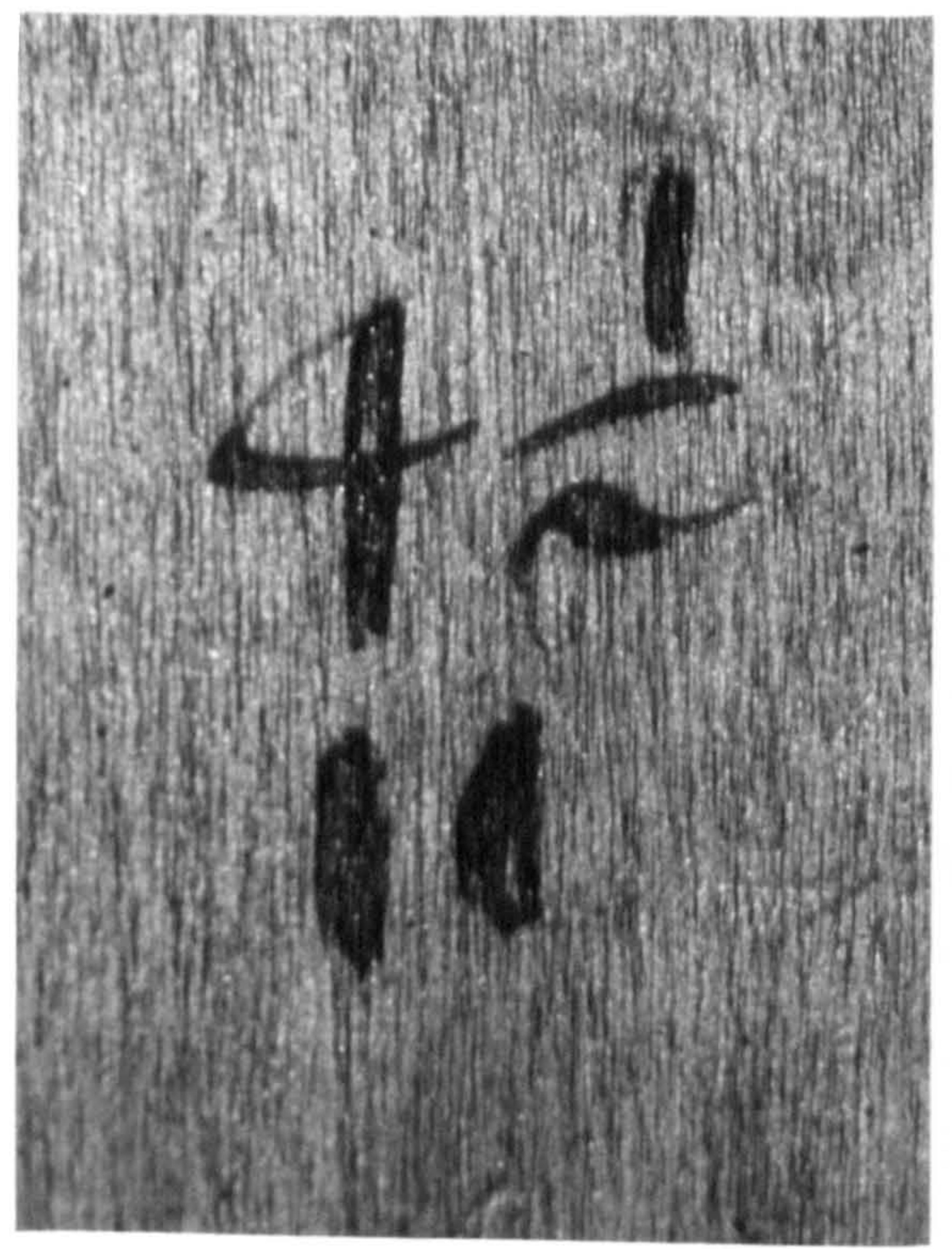

Pho to 3-3

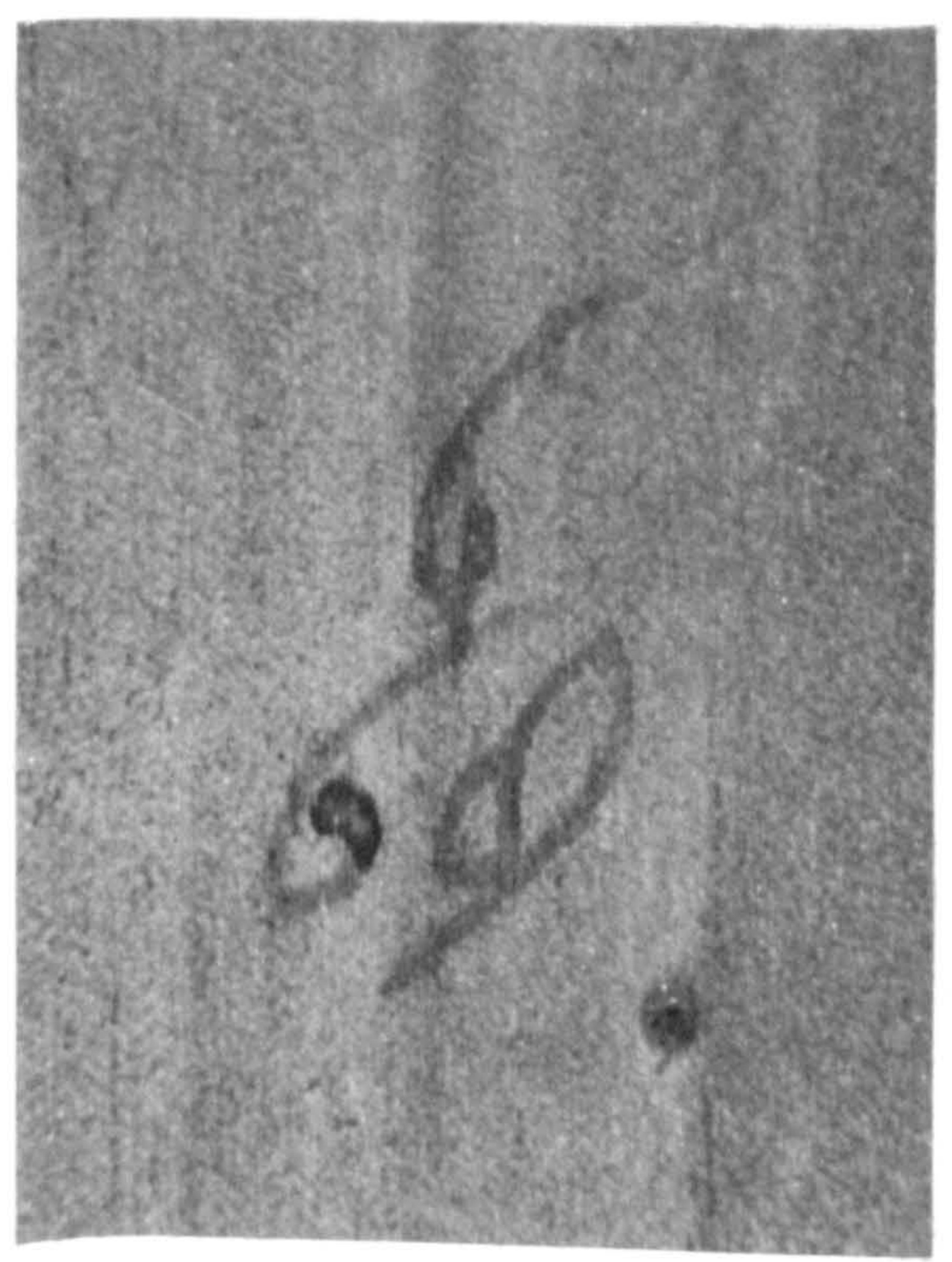

Photo 3-5

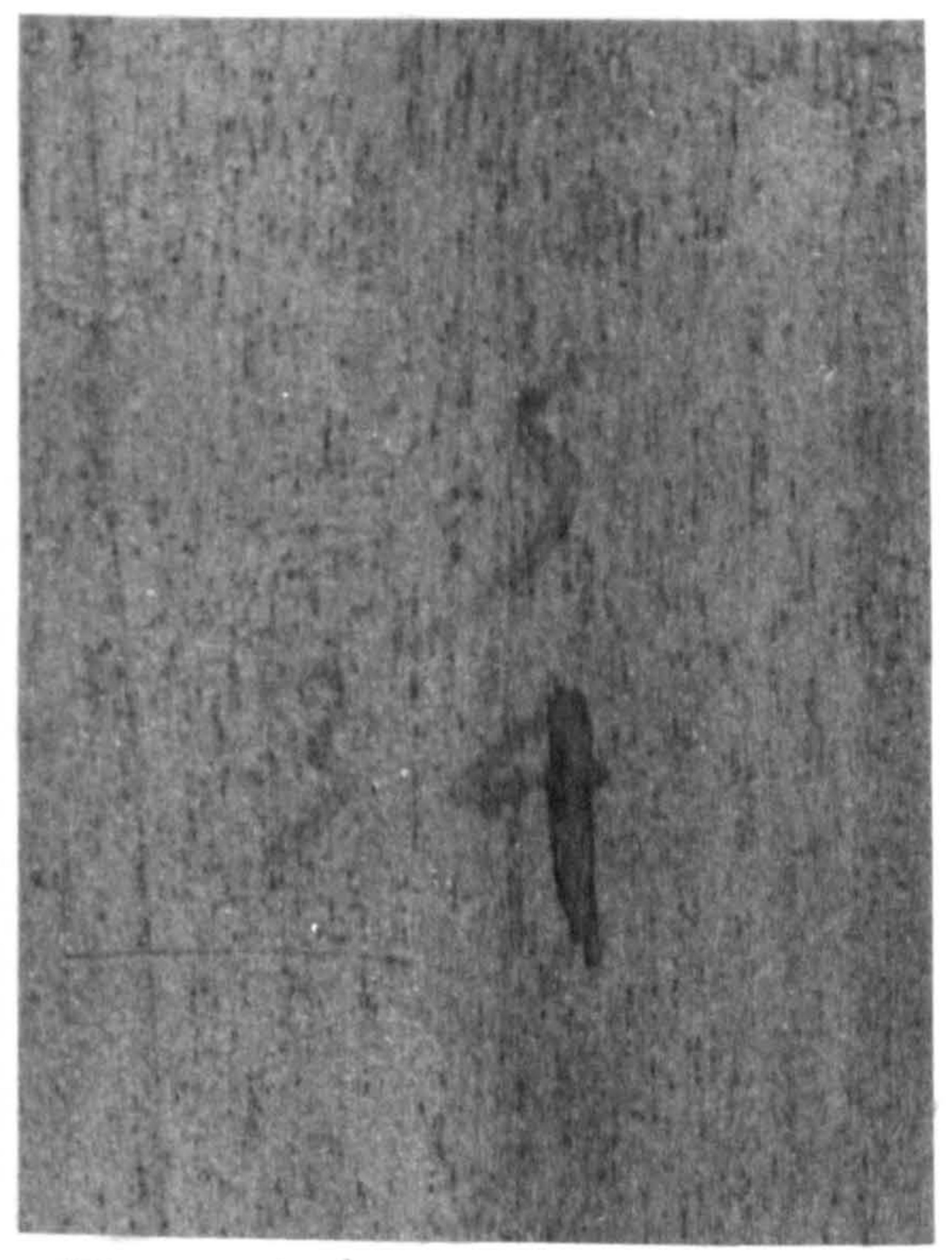

Pho to 3-4

Ioannes Ruckers numbers:

Photo 3-3 1629 IR $4 \frac{1}{2}$-voet virginal.

Photo 3-4 1604 HR 5-voet virginal.

Photo 3-5 1638a IR 6-voet virginal. 


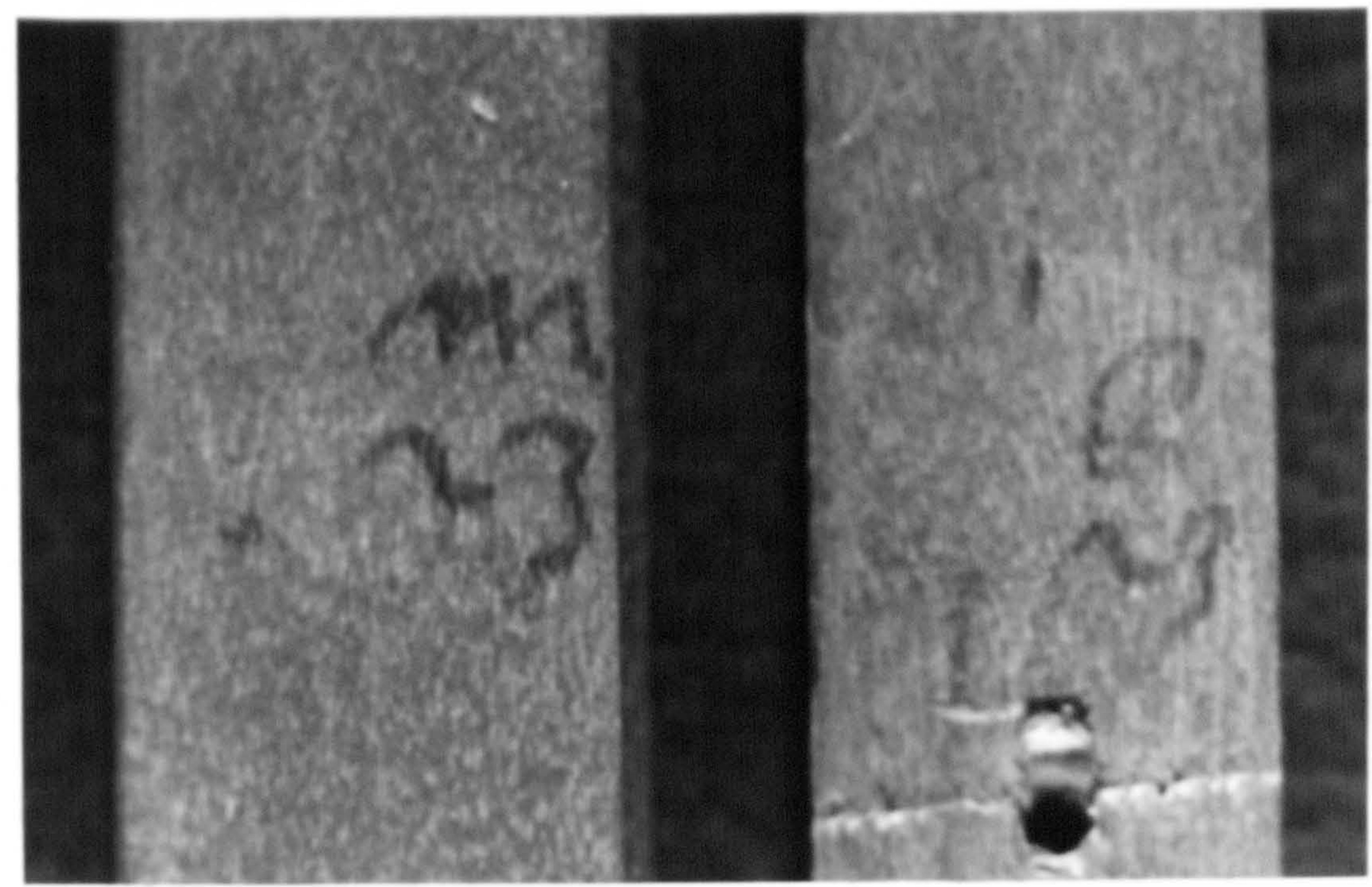

Pho to $3-6$

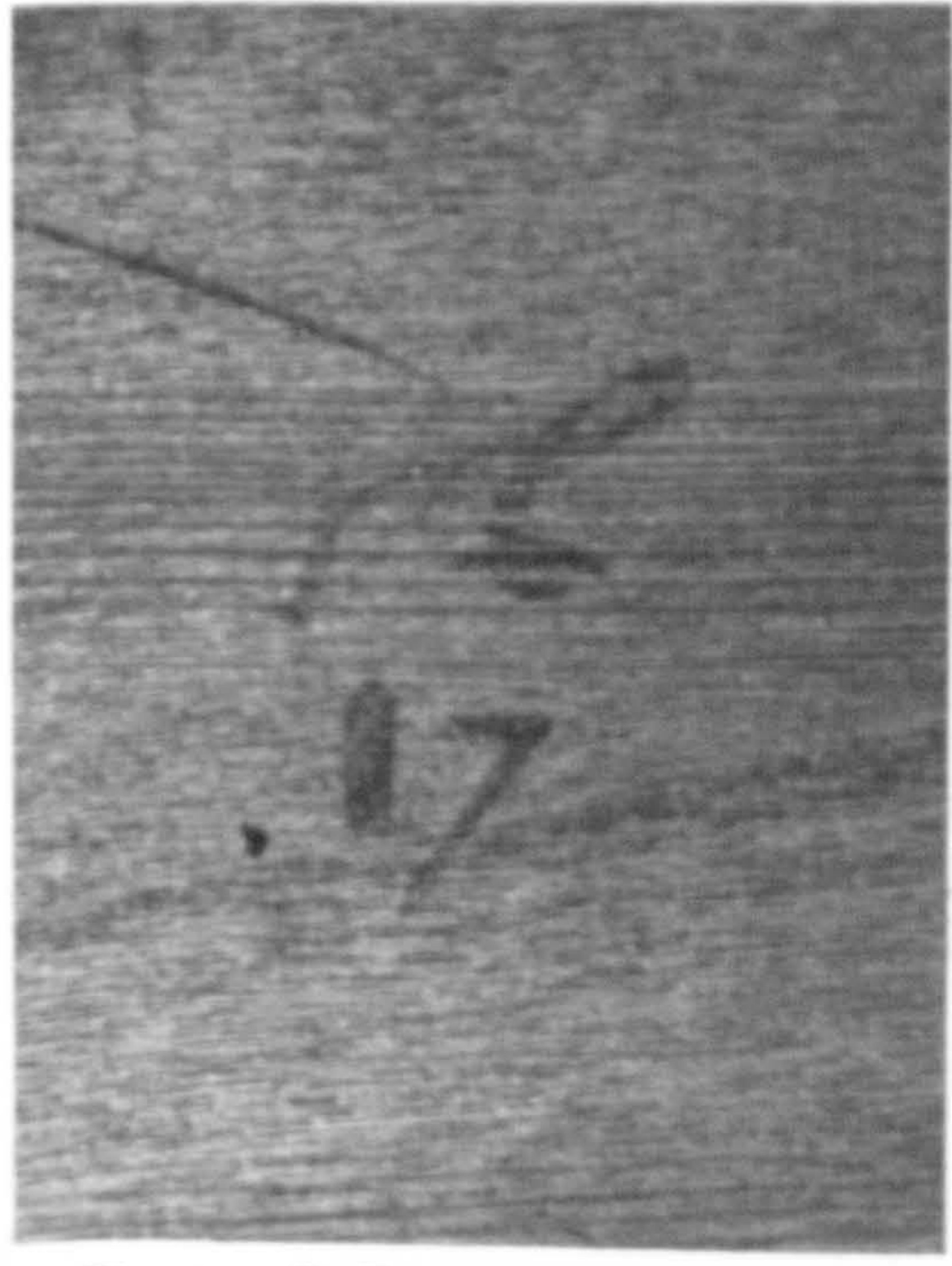

Pho to 3-7

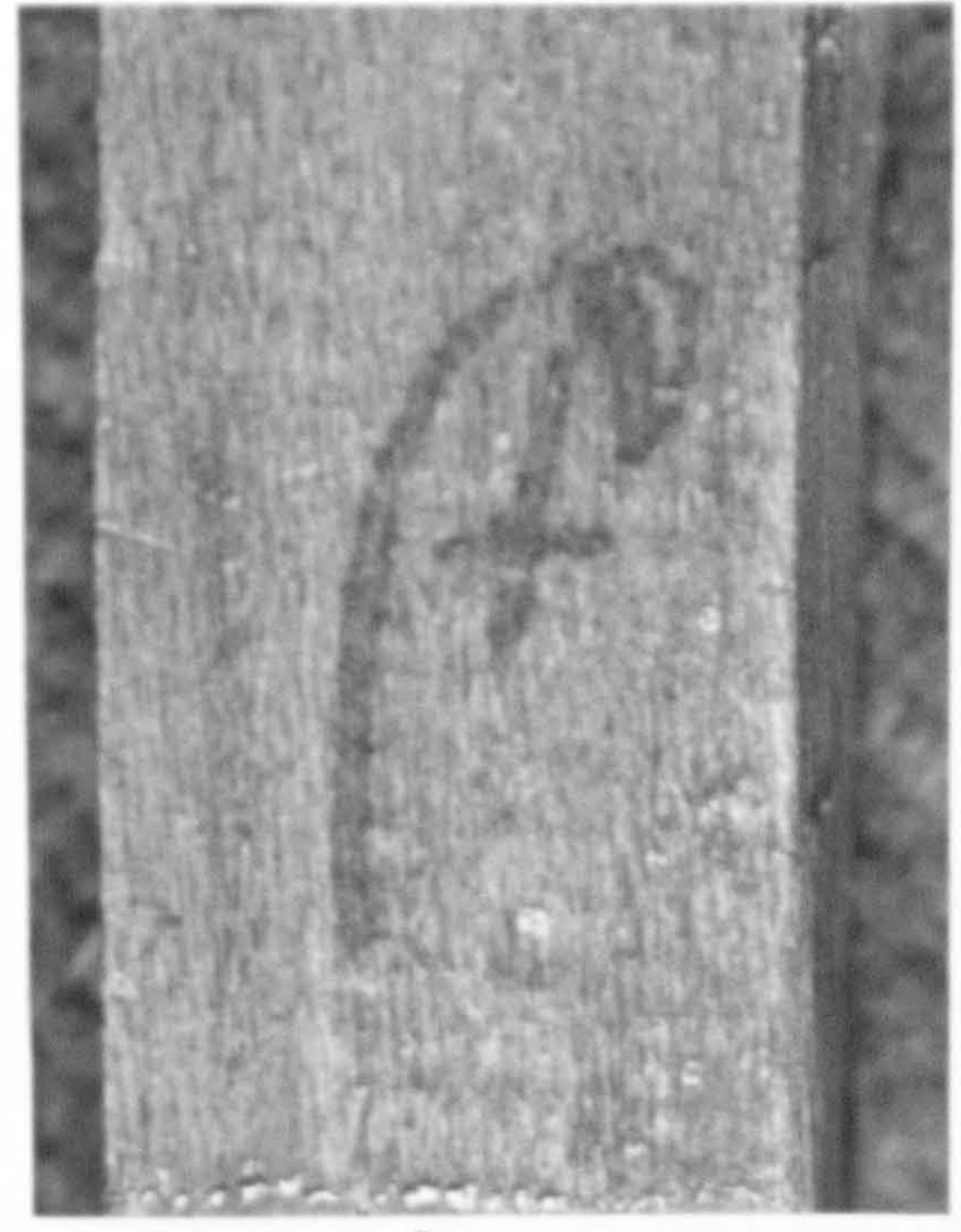

Pho to 3-8

Ioannes Ruckers numbers:

Photo 3-6 $1610 \mathrm{HR}$ mother and child virginals.

Photo 3-7 1616 HR 'French' double-manual harpsichord.

Photo 3-8 1619 IR double-harpsichord/virginal combination. 


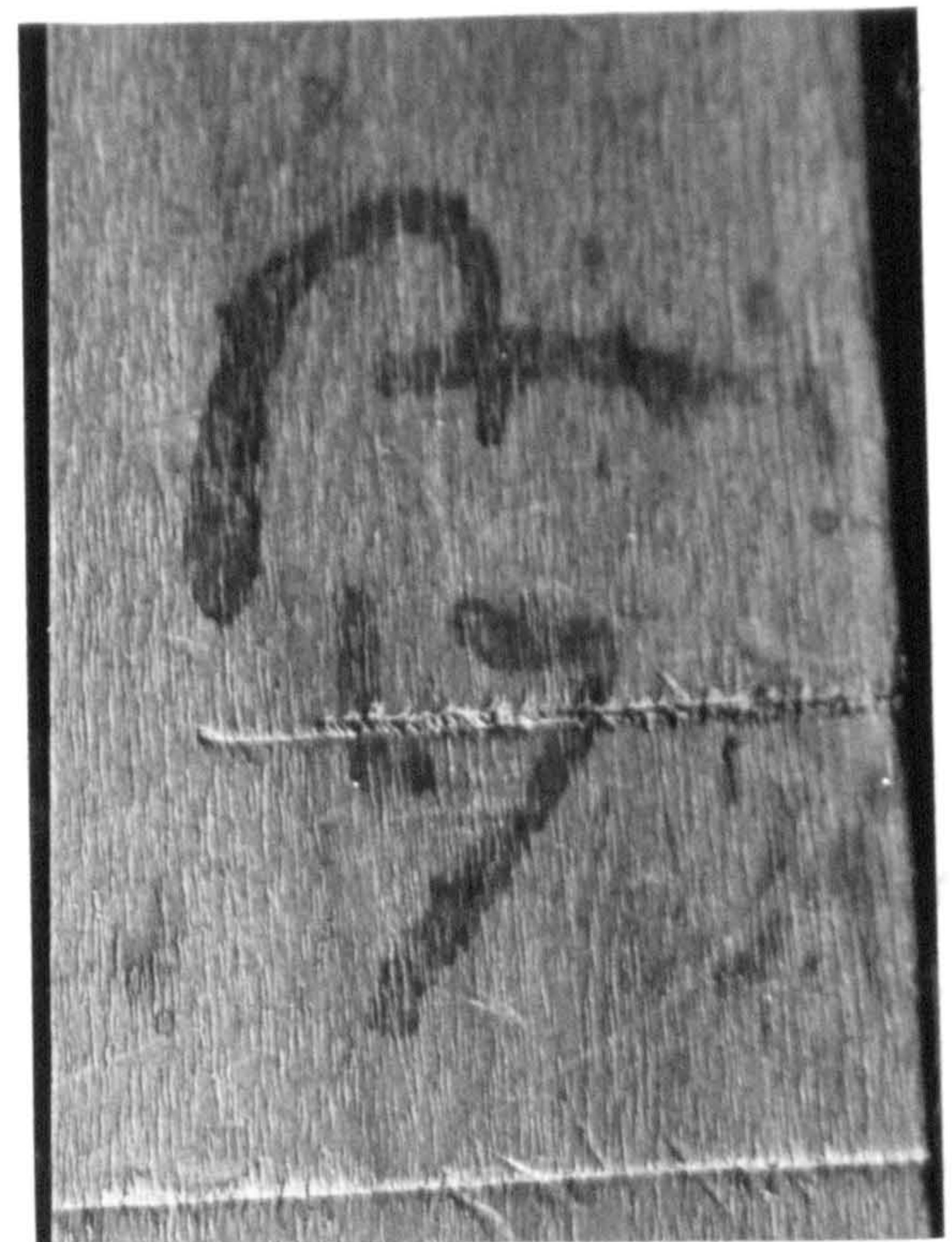

Pho to 3-9

Ioannes Couchet number:

Photo 3-9 1646 IC double-manual harpsichord.

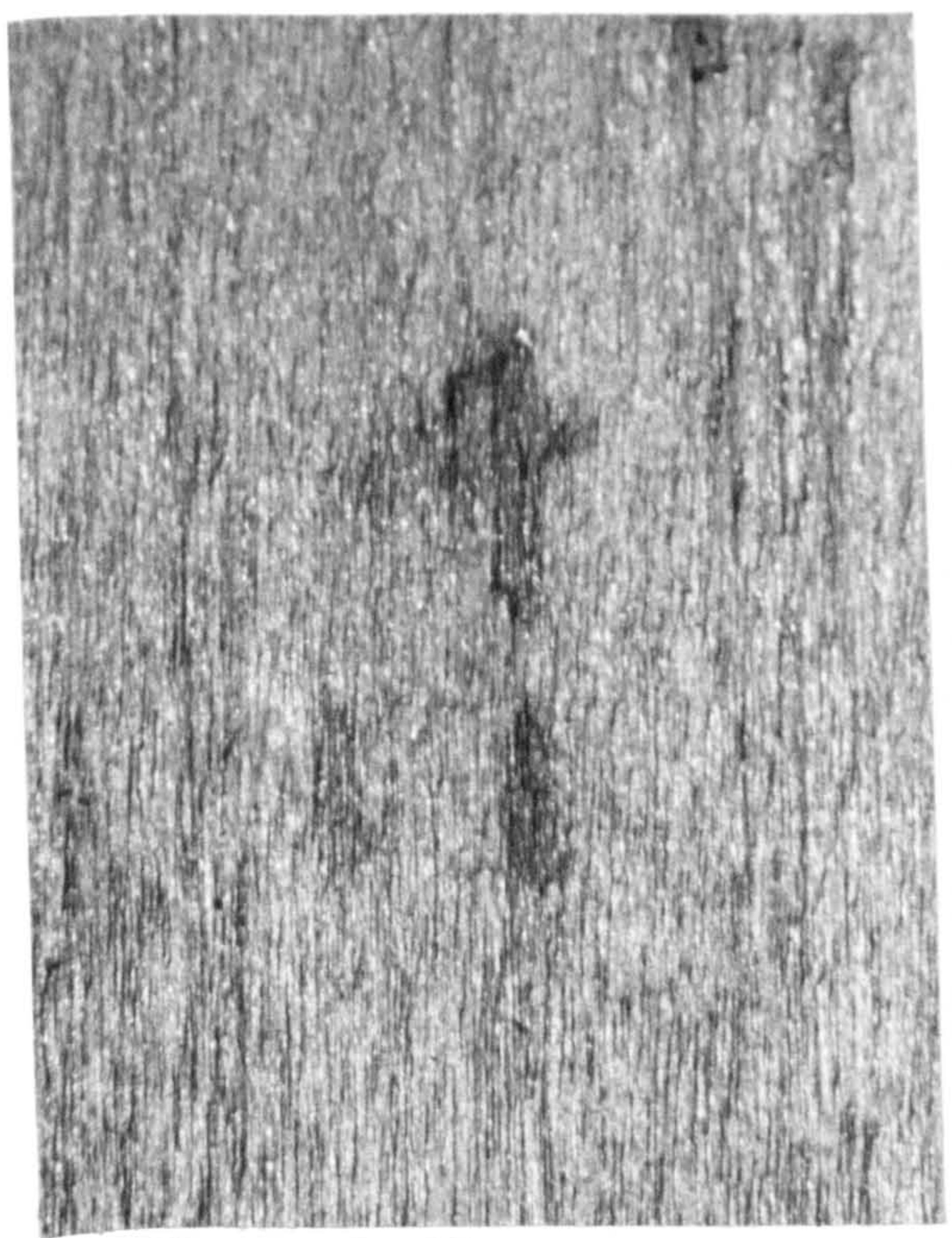

Pho to 3-10

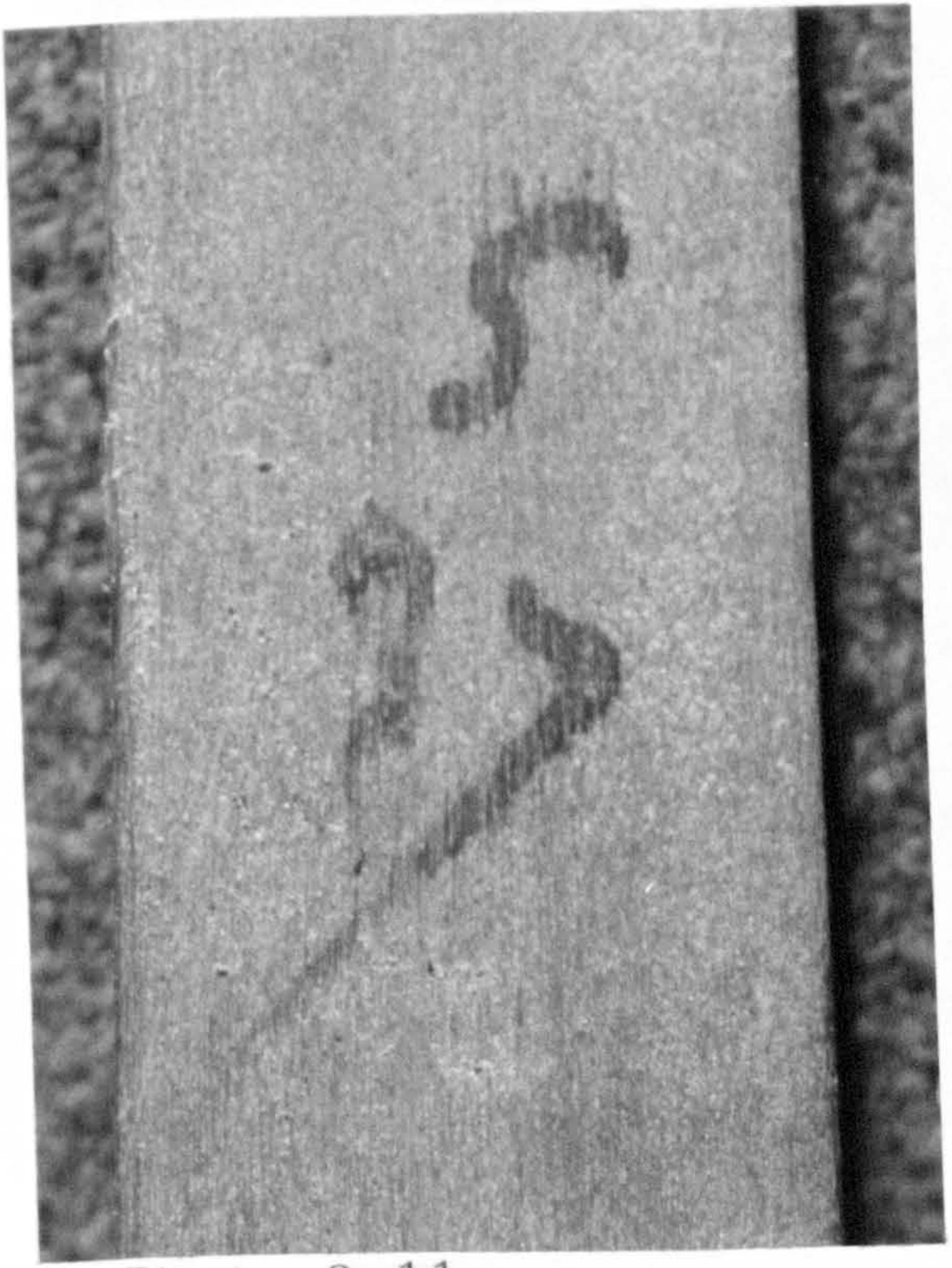

Photo 3-11

Andreas Ruckers number:
Photo 3-10 1613a AR 4-voet virginal.
Photo 3-11 1643a AR 5-voet vorginal. 


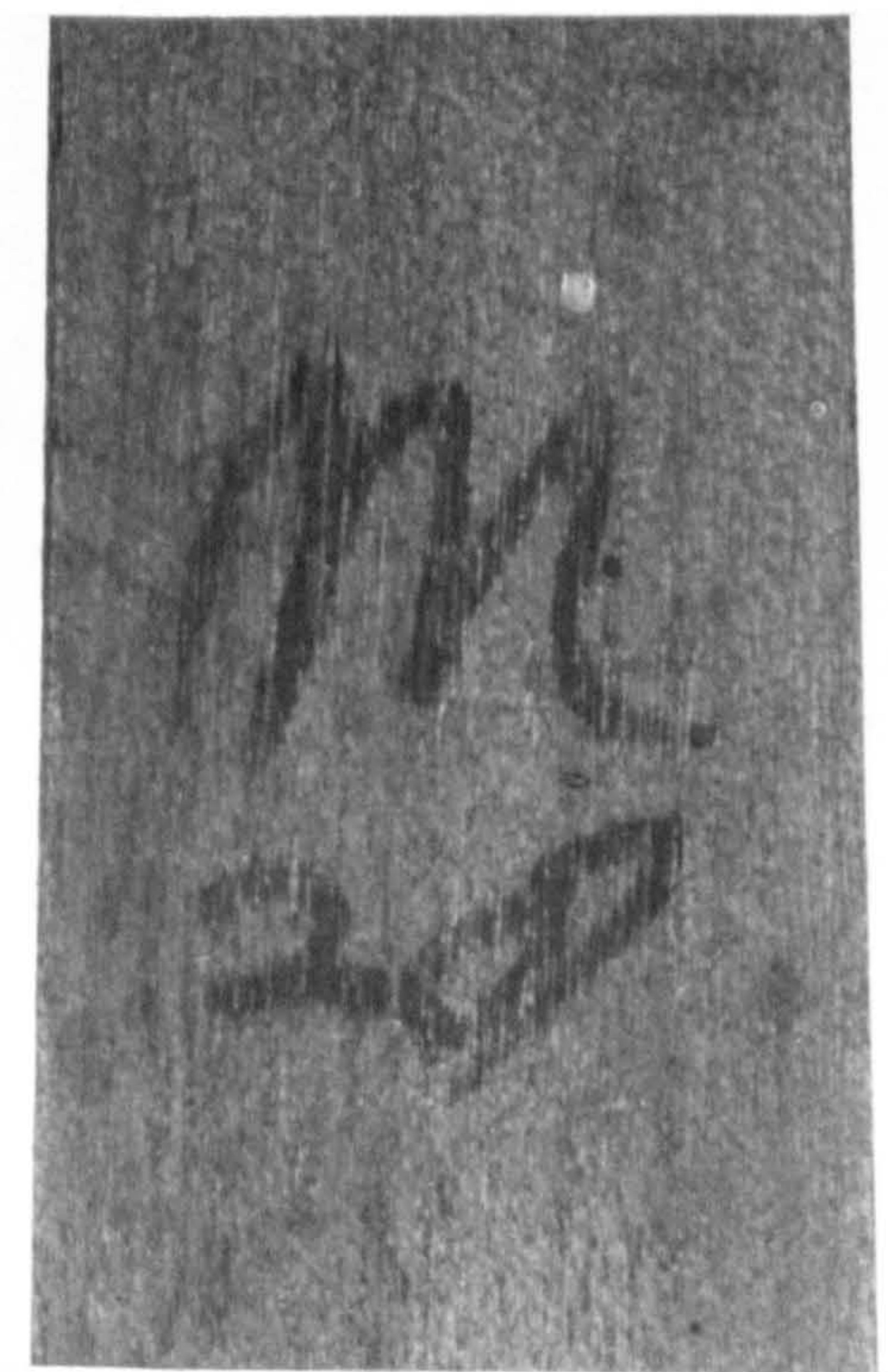

Pho to 3-12

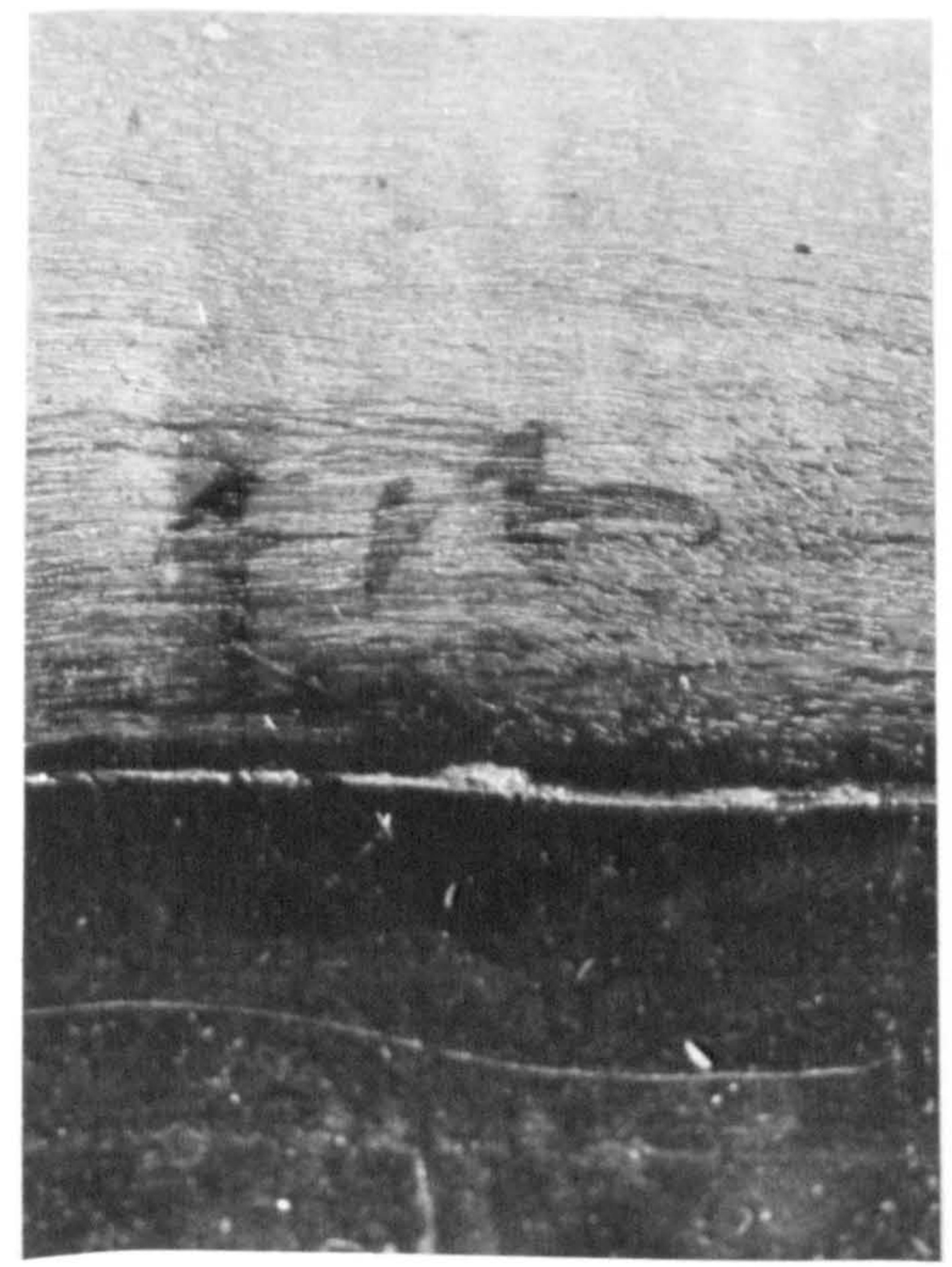

Photo 3-14

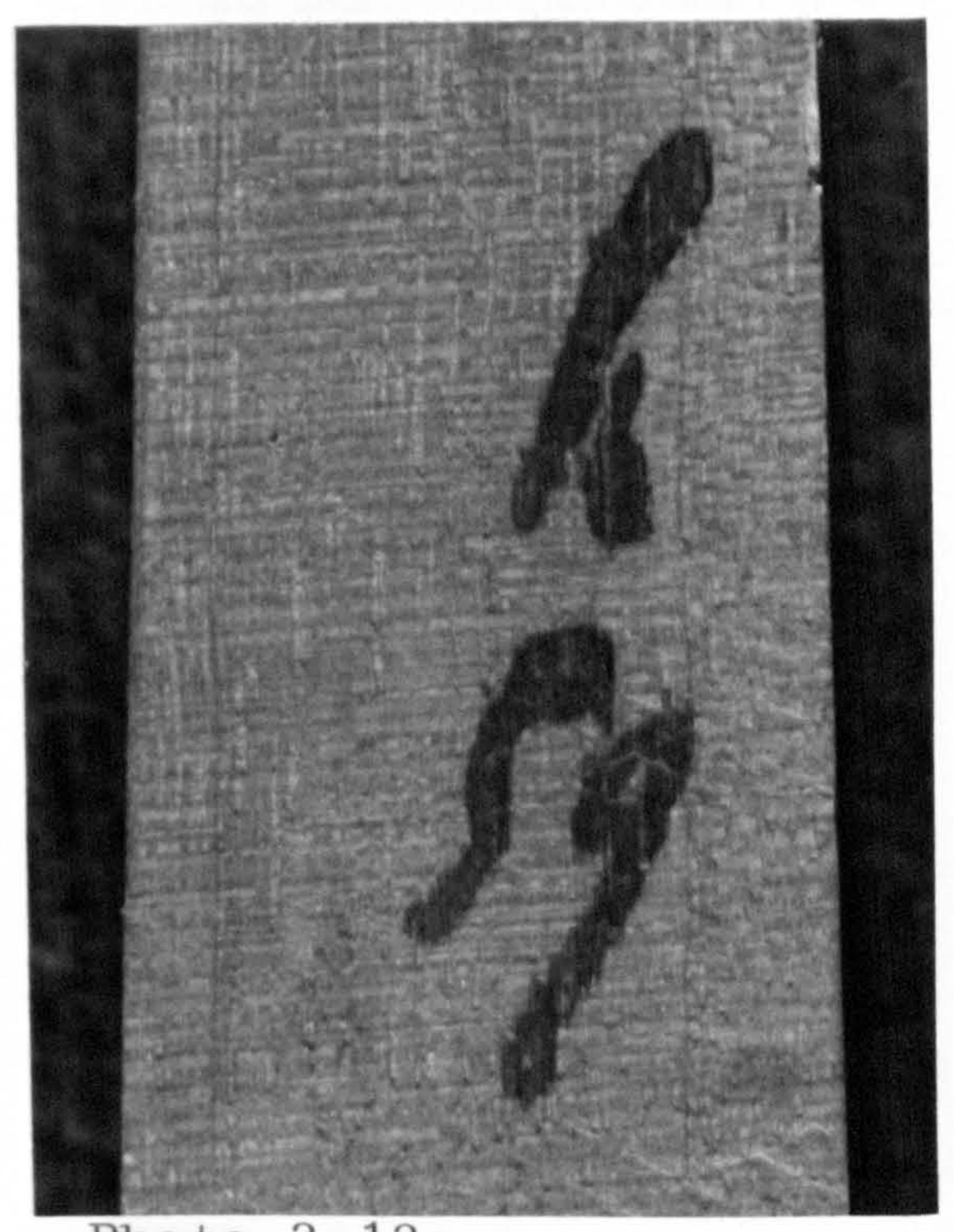

Pho to 3-13

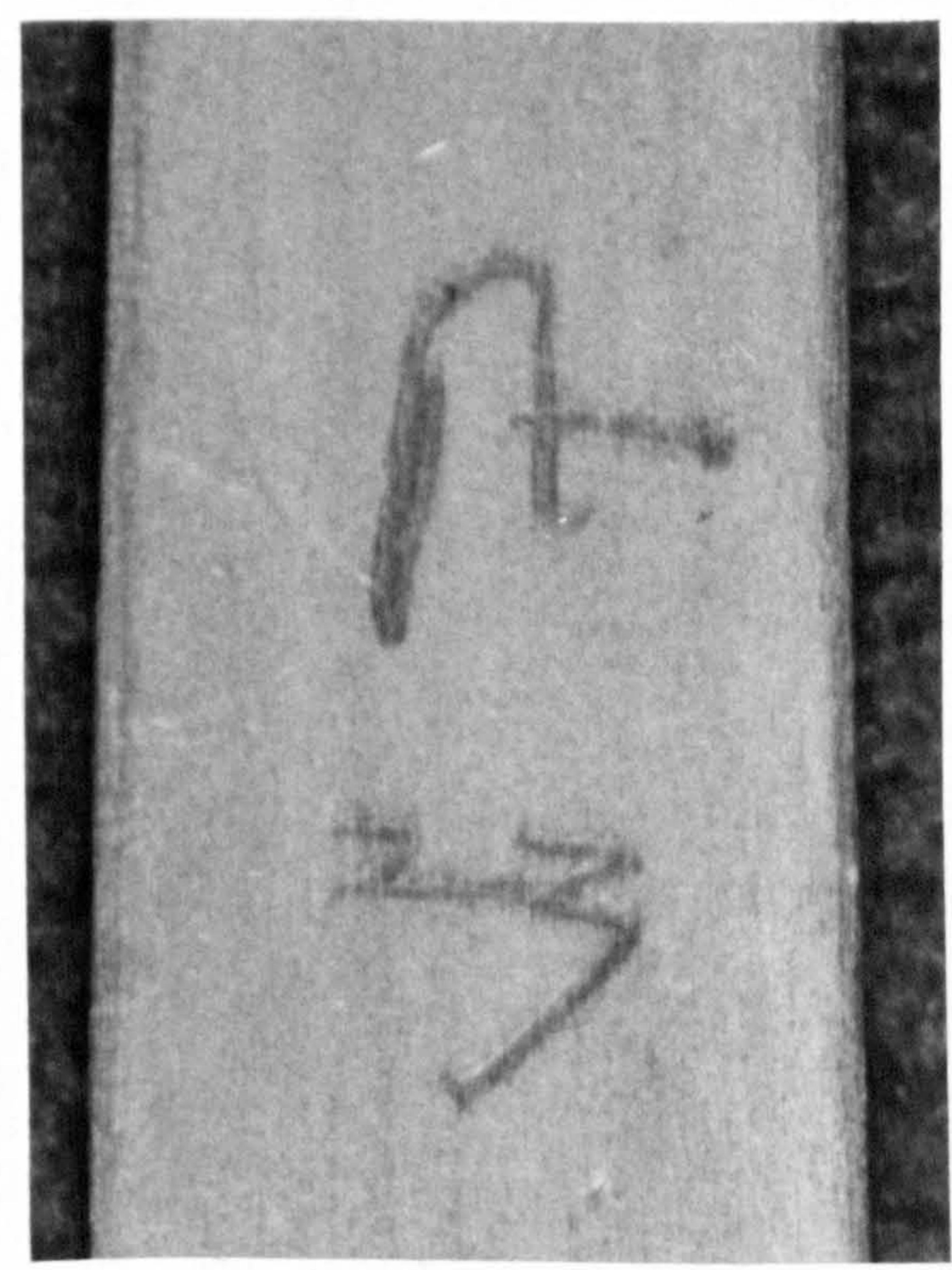

Pho to 3-15

Andreas Ruckers numbers:

Photo 3-12 1644b AR mother virginal.

Photo 3-13 1639a AR child virginal.

Photo 3-14 1627 AR 4-voet harpsichord.

Photo 3-15 1637 AR single-manual harpsichord. 


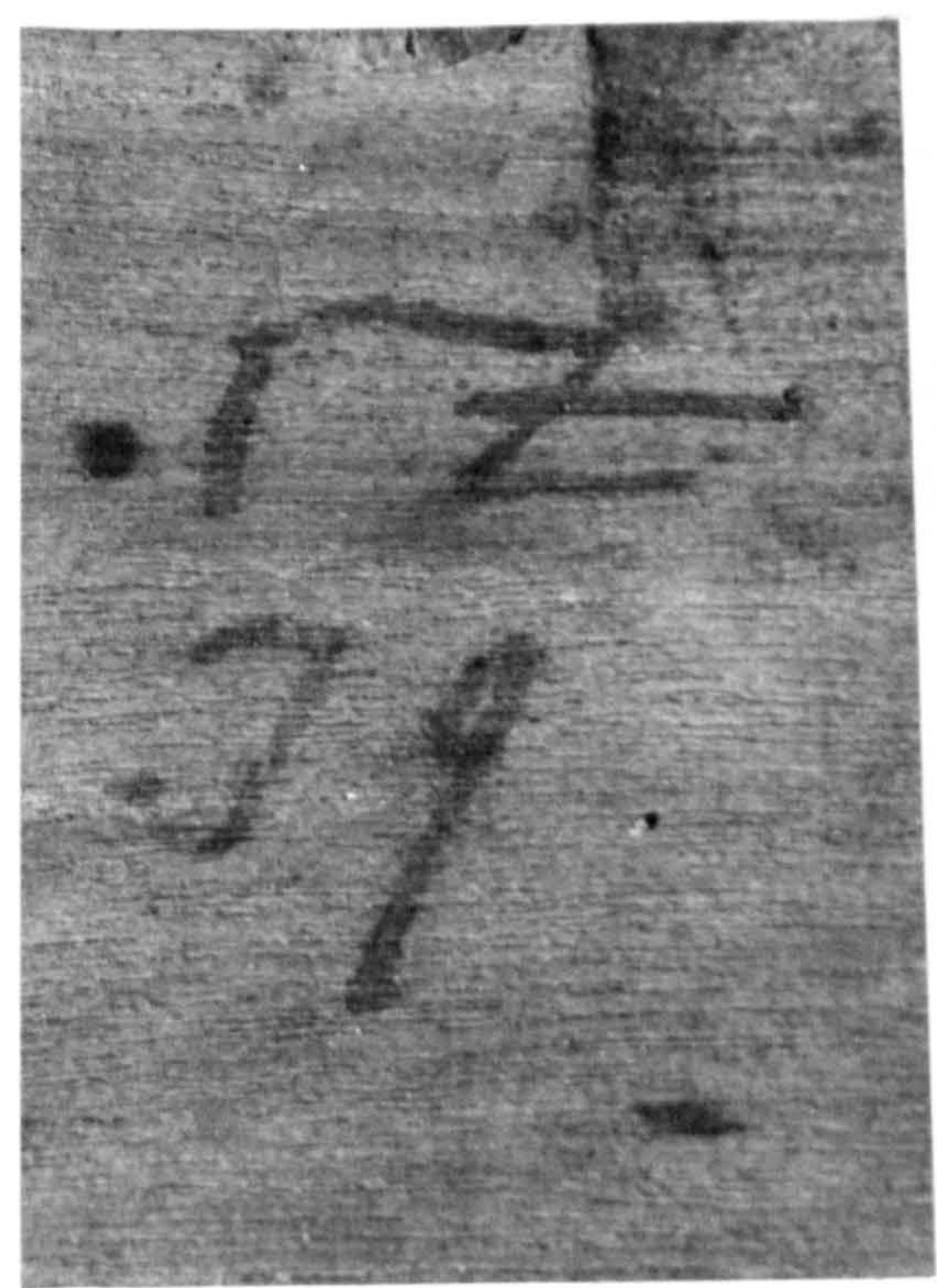

Pho to 3-16

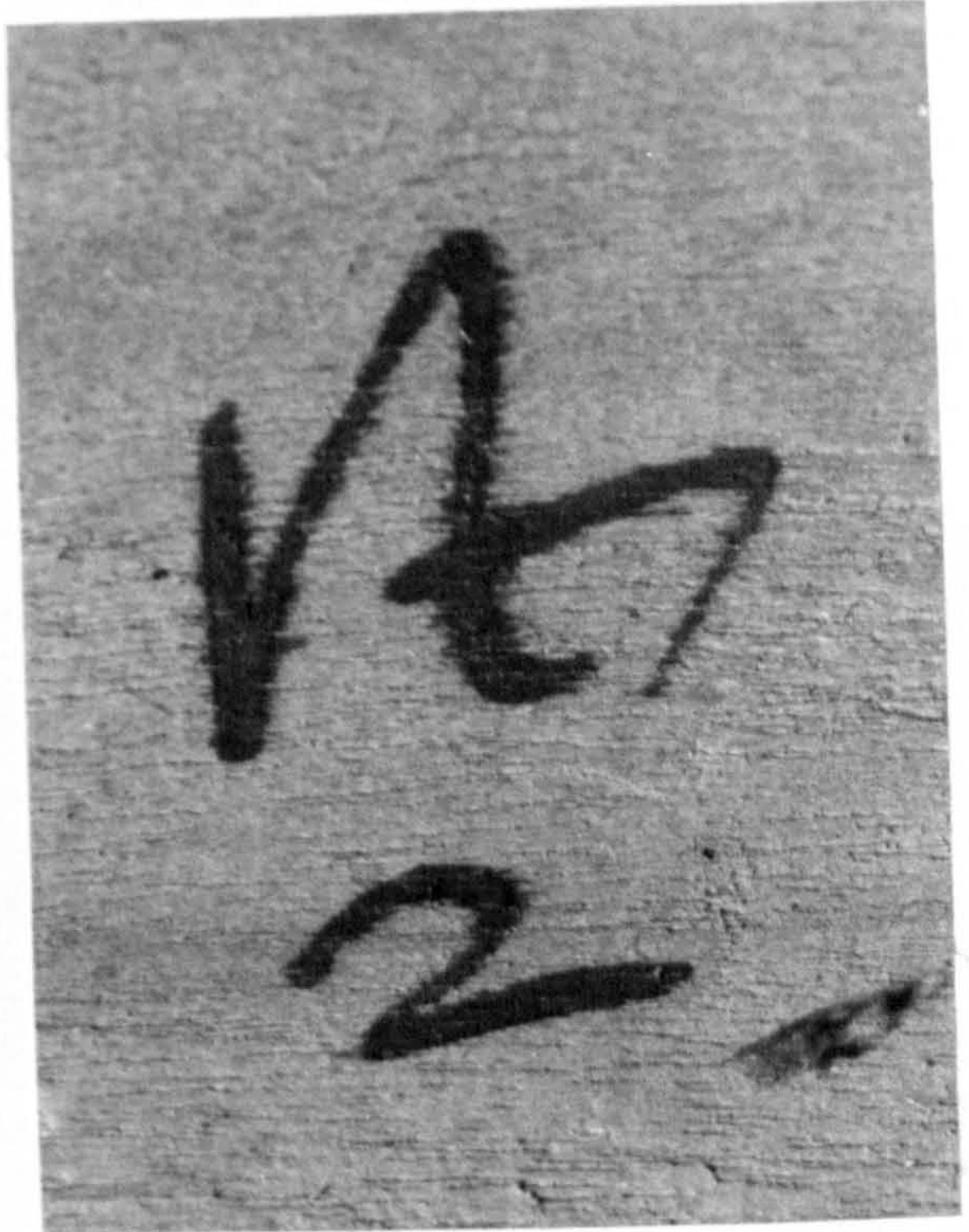

Photo 3-17

Andreas Ruckers numbers:

Photo 3-16 1608 AR double-manual harpsichord.

Photo 3-17 1640b AR double-manual harpsichord (Andreas the Younger?). 
instrument, and $a \underline{k}$ on the ottavino, but with the same lower numeral on both instruments (Photograph 3-6). The harpsichords, on the other hand, whether they are of one or two manuals, have a cipher with a number below it (photographs $3-7,9,15,16$ and 17 ).

The upper number on the virginals appears to be simply the overall length of the instrument in voeten or Flemish feet. Confirmation of this is provided in Table 3-1 below. The Flemish foot has been calculated here on the assumption that it contained eleven duimen, and that each duim - the equivalent of the modern inch contained $25.88 \mathrm{~mm}$. (see Chapter 5, p. 188) ${ }^{3-3}$ )

Table 3-1

\begin{tabular}{|c|c|c|c|c|c|c|}
\hline \multirow{3}{*}{ Instrument } & \multicolumn{5}{|c|}{ Length } & \multirow{3}{*}{$\begin{array}{l}\text { Ruckers } \\
\text { upper } \\
\text { No. }\end{array}$} \\
\hline & \multicolumn{3}{|c|}{ Modern } & \multicolumn{2}{|c|}{ Flemi sh } & \\
\hline & $\mathbf{m m}$ & inches & feot & duimen & vo et en & \\
\hline $\begin{array}{l}\text { (c1600) HR, Castello } \\
\text { sforzesco, Milan }\end{array}$ & 1709 & $6.7 \cdot 3$ & 5.61 & 66.0 & 6.00 & 6 \\
\hline $\begin{array}{l}1604 \text { HR, Brussels } \\
\text { Mus eum, No. } 2927\end{array}$ & 1424 & 56.1 & 4.67 & 55.0 & 5.00 & 5 \\
\hline $\begin{array}{l}1629 \mathrm{IR}, \text { Brussels } \\
\text { Museum, No. } 2511\end{array}$ & 1282 & 50.5 & 4.21 & $49 \cdot 5$ & 4.50 & $4 \frac{1}{2}$ \\
\hline $\begin{array}{l}\text { 1613b AR, Brussels } \\
\text { Museum, No. } 2928\end{array}$ & 1138 & 44.8 & 3.73 & 44.0 & 4.00 & 4 \\
\hline $\begin{array}{l}\text { (c1600) HR, Castello } \\
\text { Sforzesco, Milan }\end{array}$ & 820 & $32 \cdot 3$ & 2.69 & 31.7 & 2.88 & k \\
\hline $\begin{array}{l}\text { (c1610) AR, Private } \\
\text { Australia }\end{array}$ & 711 & 28.0 & 2.33 & $27 \cdot 5$ & 2.50 & $?$ \\
\hline
\end{tabular}

The practice of referring to the instruments according to their length must have been common in the 17th century. Klaas Douwes refers to the length of the virginals 
in the following way:

".. sommige Klavecimbels sijn ses voeten lang/sommige vi er voeten/somige drie voeten/end sommige noch kleiner'.3-4)

And other Antwerp builders also use this convention. George Britsen, for examplo, uses a ' 3 ' on the little 3 voet virginal No. 631 in the Brussels Museum of Musical Instruments.

The double virginals labelled with $\underline{m}$ and $\underline{k}$ are obviously de moeder met het kind - the mother with the child - referred to by Reynvaan ${ }^{3-5)}$ in his dictionary of music, the $\underline{m}$ on tho largo mother instrument and the $\underline{k}$ on the kind or child.

The cipher which appears as the upper part of the number on the harpsichords is the ligature $f$ composed of the two letters st, which run together in this way in ordinary Flemish handwriting of the 16th and 17th centurye ${ }^{3-6)}$ This cipher clearly stands for staartst uk or Staertstuk that is 'tail-piece' or harpsichord.

Having established the significance of the upper part of the Ruckers numbers for both virginals and harpsichords, it is necessary to describe the different models of each before going on to a discussion of the interpretation of the lower part of the Ruckers numbers. The Models of Ruckers Virginal

As well as being distinguished according to their lengths, the virginals are also differentiated according.. to their tone quality. Douwes was the first writer to. define the instrument types according to the sound they produce: $3-7$ ) 
"Clavecimbels are musical instruments which are very agreeable in their sound, and are therefore used mostly for pleasure and entertainment. They are best suited for playing all types of melodies and musical pieces. There are different types. In some the jacks are placed in the middle betwen the bridges, and these are the most common type. They are called Muselars. In some the jacks are placed close to the left hand bridge, and these are called Spinetten. The little ones are called Scherpen because they have a high and sharp sound."

Photographs 3-18 and 3-19 show the soundboards of two 6-voet Ruckers virginals, and distinguish clearly the muselar from the spinett virginal. These two instruments have the same scalings, and are therefore at the same pitch, but clearly the jacks attack the strings at different points and the resulting tone quality of the two types of virginal will be very different. The muselar virginal (Photograph 3-18) has its keyboard placed toward the righthand side of the instrument, and the jacks pluck the strings, not near their middle as Douwes suggests, but about $\frac{1}{3}$ of the way along their length. In muselar virginals both bridges are on freely vibrating soundboard, and the sound produced is bold, round and fluty - quite unique among the sound of plucked keyboard instruments. Also unique to the muselar virginal is the harpichordium stop. This consists of a series of soft metal hooks placed in a wooden bar underneath the right-hand ends of the strings. The bar with its hooks can be slid back and forth alongside the straight bass section of the bridge to engage and disengage the stop. When the stop is engaged the tops of the hooks just barely touch the ends of the strings and produce a rattling buzzing sound similar to that produced by 


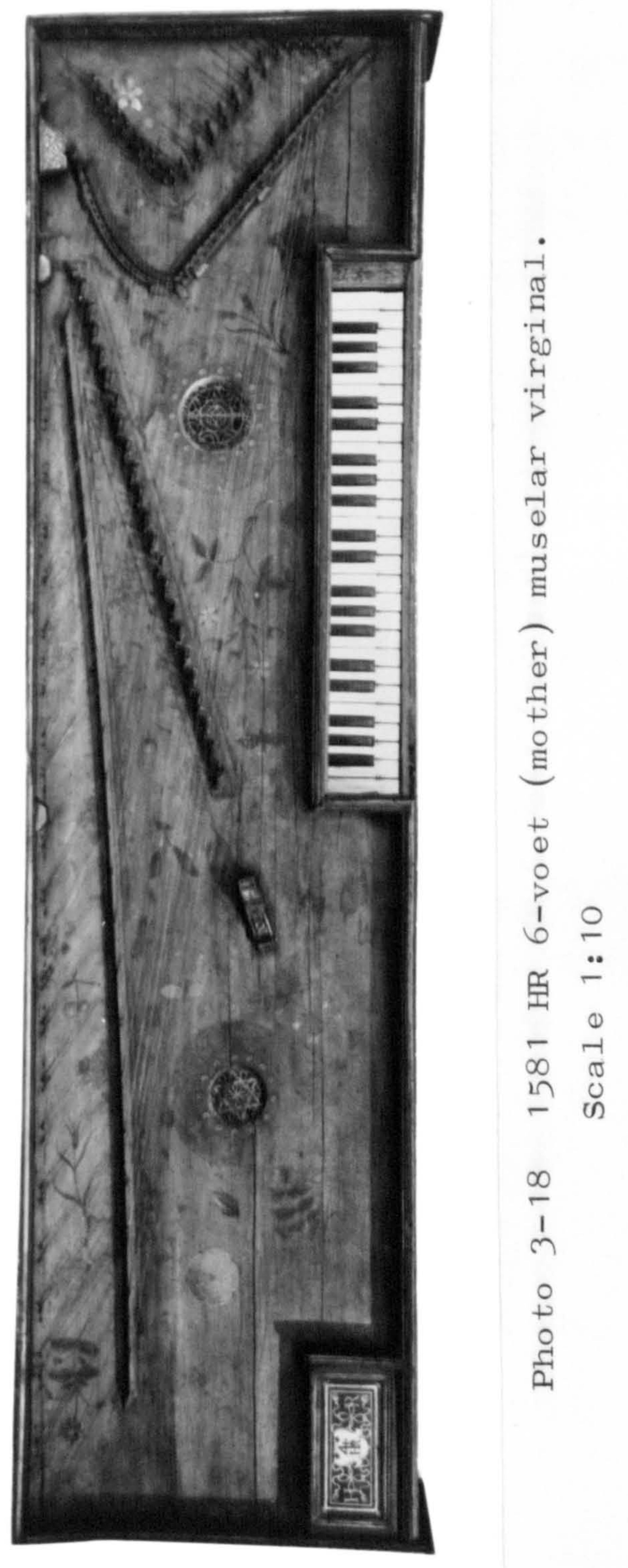




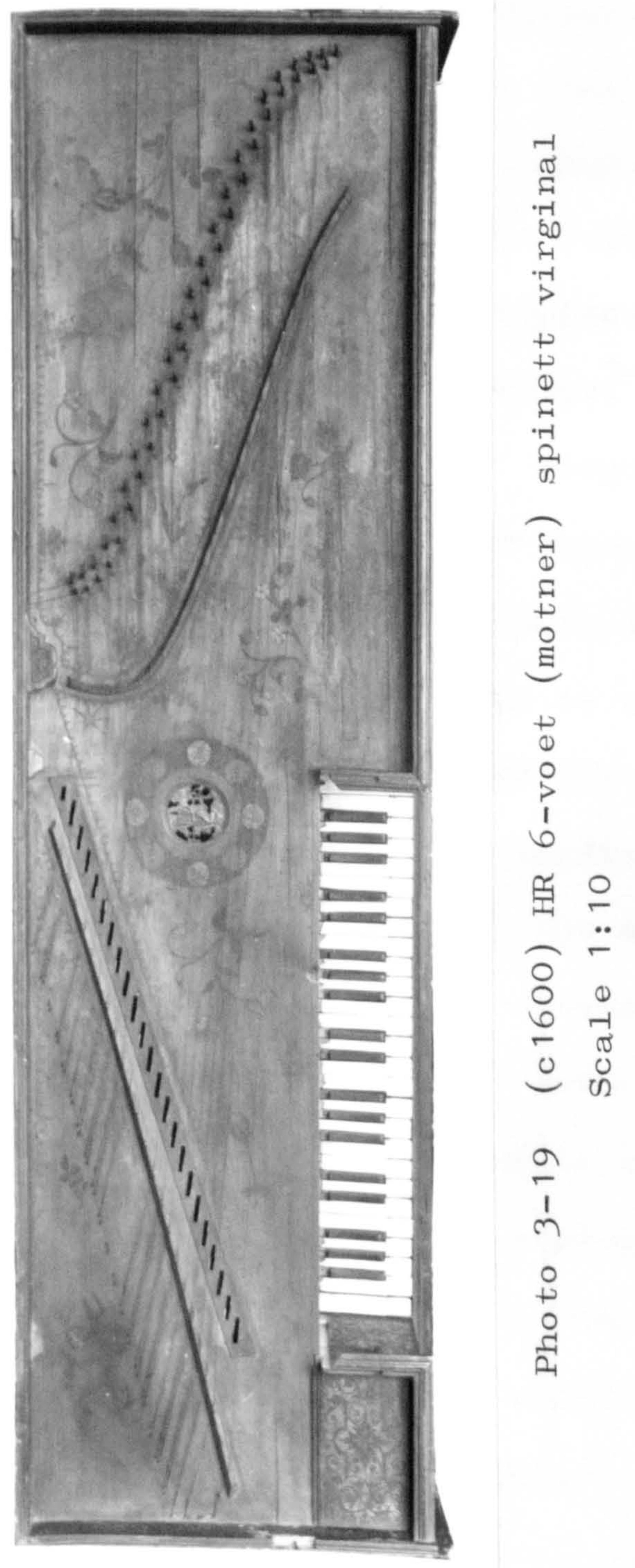


the bray on the Renaissance harp. The harpichordium operates only on the bass strings and provides an accompaniment of striking contrast to the fluty treble sound. The spinett virginal (Photograph 3-19) plucks the strings at roughly the same proportion of the string's length as in a harpsichord, and therefore has a tone that is more similar to the harpsichord than to that of the muselar virginal. The keyboard is placed near the lefthand side of the instrument and the left-hand bridge nearest the jacks rests on a solid piece of wood so that only the right-hand bridge can vibrate. $3-8$ ) Probably because the geometry of the larger spinett virginals imposes a smoothly curving shape on the right-hand bridge, there is no straight bridgo-section along which the harpichordium could operate. Therefore this stop is never found on the spinetten. But even on the muselar virginals the harpichordium stop is notoriously difficult to adjust and regulate despite the fact that the amplitude of vibration of the more centre-plucked strings is relatively great. The harpichordium would be even more difficult to regulate in the end-plucked spinett virginals where the amplitude of vibration of the string is relatively small, and this is doubtless also a reason why the harpichordium is found only on muselar virginals.

No 5-voet spinett virginal exists which is made by one of the Ruckers. However there is no particular reason to suppose that the Ruckers did not make 5-voet spinett virginals, and it is probably only a quirk of fate and 
probability that none now survives. If 5-voet spinett virginals were made at all by the Ruckers they would probably have beon produced in small numbers. Among the 20 extant 6-voet Ruckers virginals only 4 are of the spinett typo, or about 1 in 5 of the 6-voet virginals is a spinett virginal. Since only four 5-voet Ruckers virginals exist, it is not surprising that none of these is of the spinett type. 5-voet spinett virginals were, however, made in Antwerp. One example is the 1636 Cornelis Hagaerts virginal in the Rockox House in Antwerp ( see Appendix 2).

Douwes mentions clavecimbels of length 6-voet, 5-voet, 4-voet, 3-voet and 2 voet 4 duimen. But two Ruckers instruments exist which are $4 \frac{1}{2}$-voet in 1 ength and are marked as such (see Photograph 3-3). One of these is a spinett virginal (1629 IR) and the other is of the muselar type (1610b AR). There are no muselar virginals smaller than the $4 \frac{1}{2}$-voet spinett type. The reason for this is basically one of geometry. The bass strings of the 4-voet virginals, for example, are only about $920 \mathrm{~mm}$ long. To design a 4-voot muselar virginal the bass jacks would have to be placed about $\frac{1}{3}$ to $\frac{1}{2}$ of the way along the length of the string. The keyboard, which is about $650 \mathrm{~mm}$ wide for a $\mathrm{C} / \mathrm{E}$ to $\mathrm{c}^{3}$ compass, would then position the treble jacks to the right of the bass section of the right-hand bridge. In other words, a muselar of length 4 voet or smaller is a geometrical impossibility. 


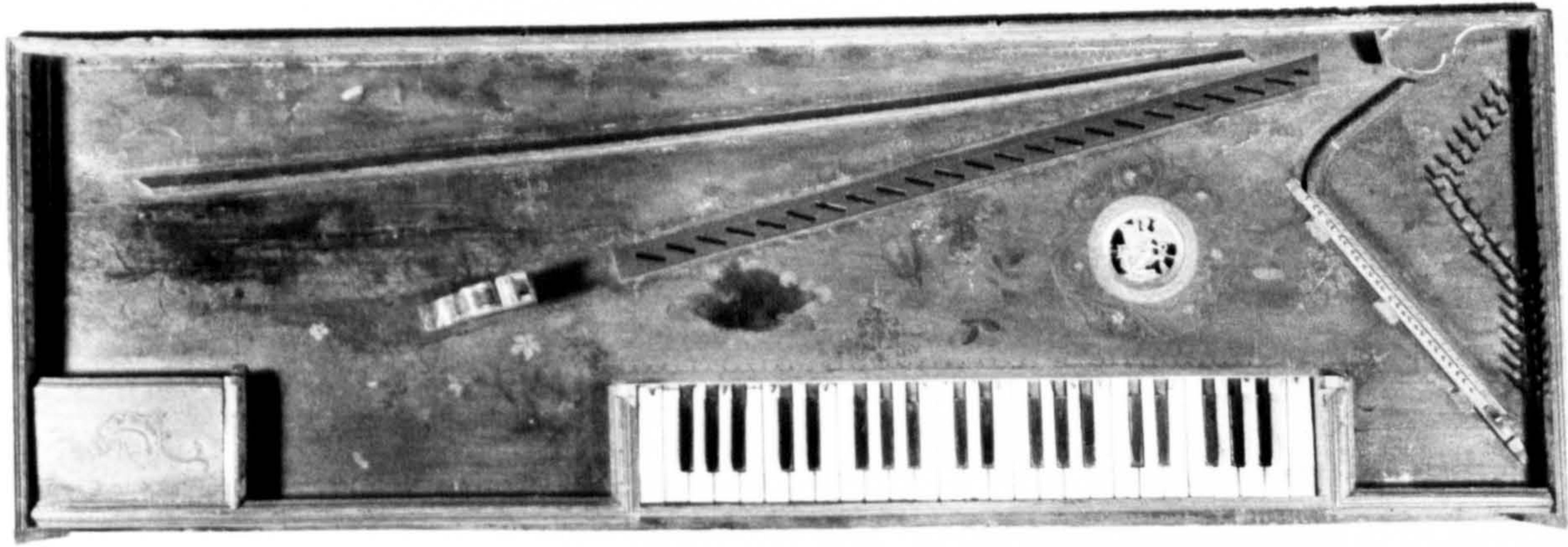

Photo 3-20 1604 HR 5-voet muselar virginal. Scale 1:10

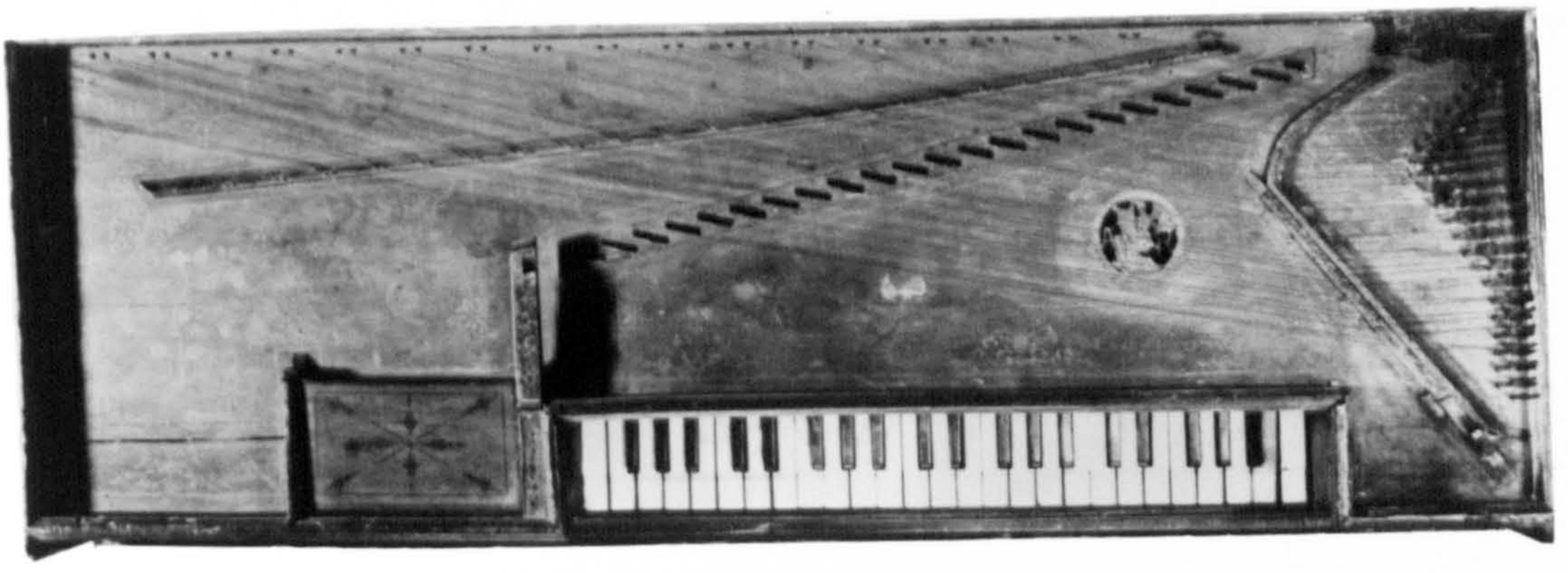

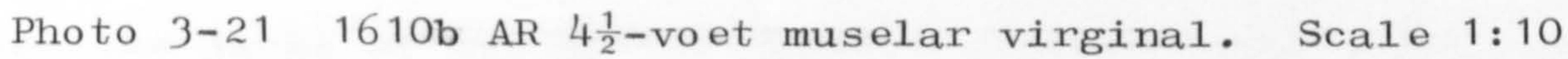

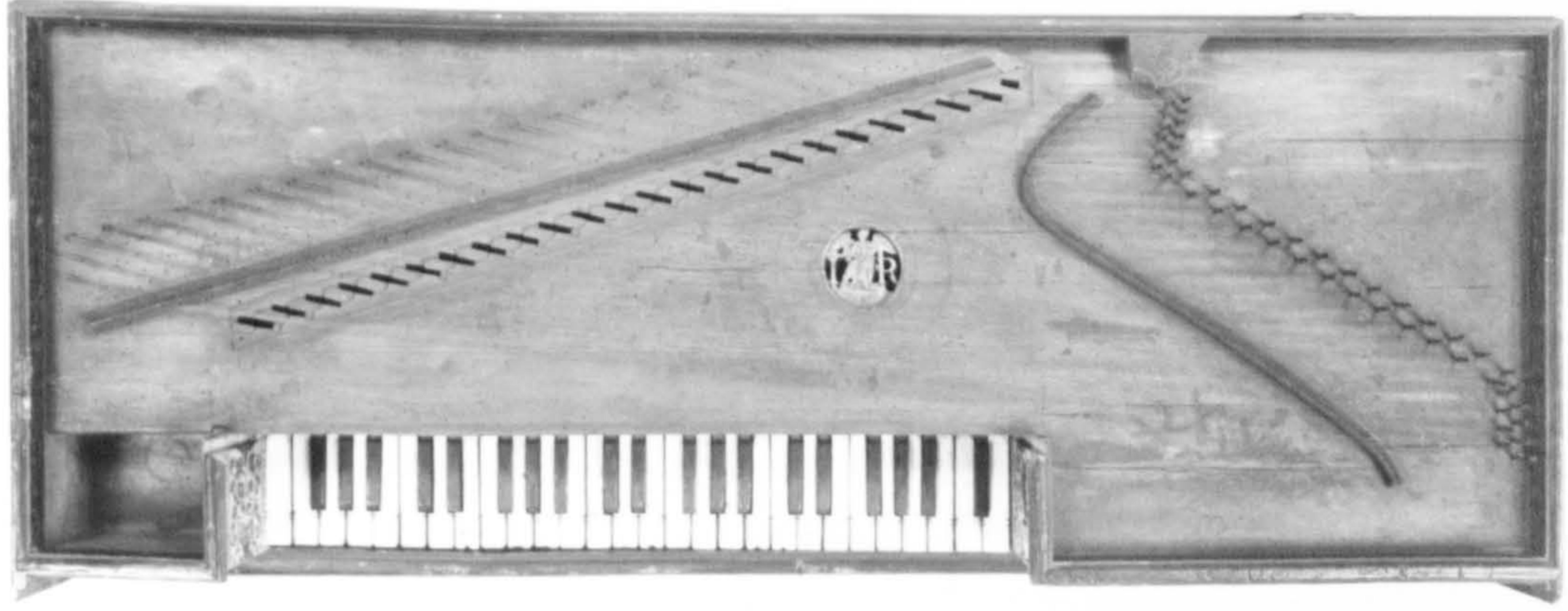

Photo 3-22 1629 IR 4 $\frac{1}{2}$-vo et spinett virginal. Scale 1:10 
The 3-voot virginals always occur in conjunction with the 6-voet instruments as a mother-and-child combination. Unlike other builders such as Britsen, the Ruckers never seem to have built any 3-voet virginals as separate instruments on thelr own. Also, probably bocause of space limitations in the mother instrument, the child instruments are not quite 3 voot in length, but are 2 or 3 duimen less: The child instruments fit into a space in the body of the mother virginal beside the keyboard. If the mother is a spinett virginal thochild fits to the right, if the mother is a muselar virginal, then the child fits to the left, of the keyboard of the mother instrument. But there is a slot in the baseboard of the child instrument under the tails of the keylovers enabling the child instrument to be played while sitting on top of the mother. To accomplish this the jackrail of the mother is removed, the child is positioned above the keyboard of the mother, and the jacks of the mother then operate the keys and jacks of the child through the slot in the baseboard. Because the child sounds an octave higher than the mother, this enables an octave and unison sound to be produced from the virginals in a way similar to that produced by the harpsichord with a $1 \times 8^{\prime}, 1 \times 4^{\prime}$ disposition. But clearly the possibility exists of playing the two instruments together side by side by two separate players, either with the child slightly withdrawn from the mother to make its keyboard accessible, or with the child instrument completely separated from the mother. 


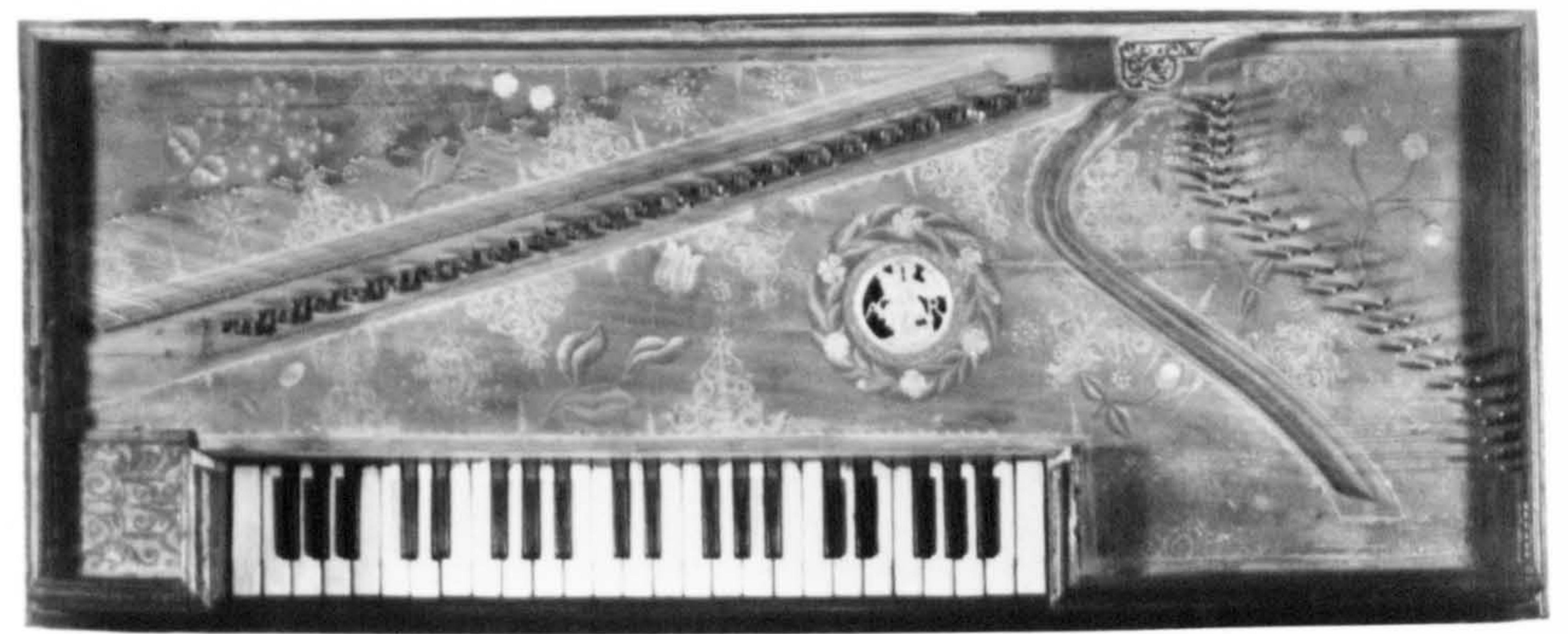

Photo 3-23 1620a AR 4-voet spinett virginal. Scale 1:10

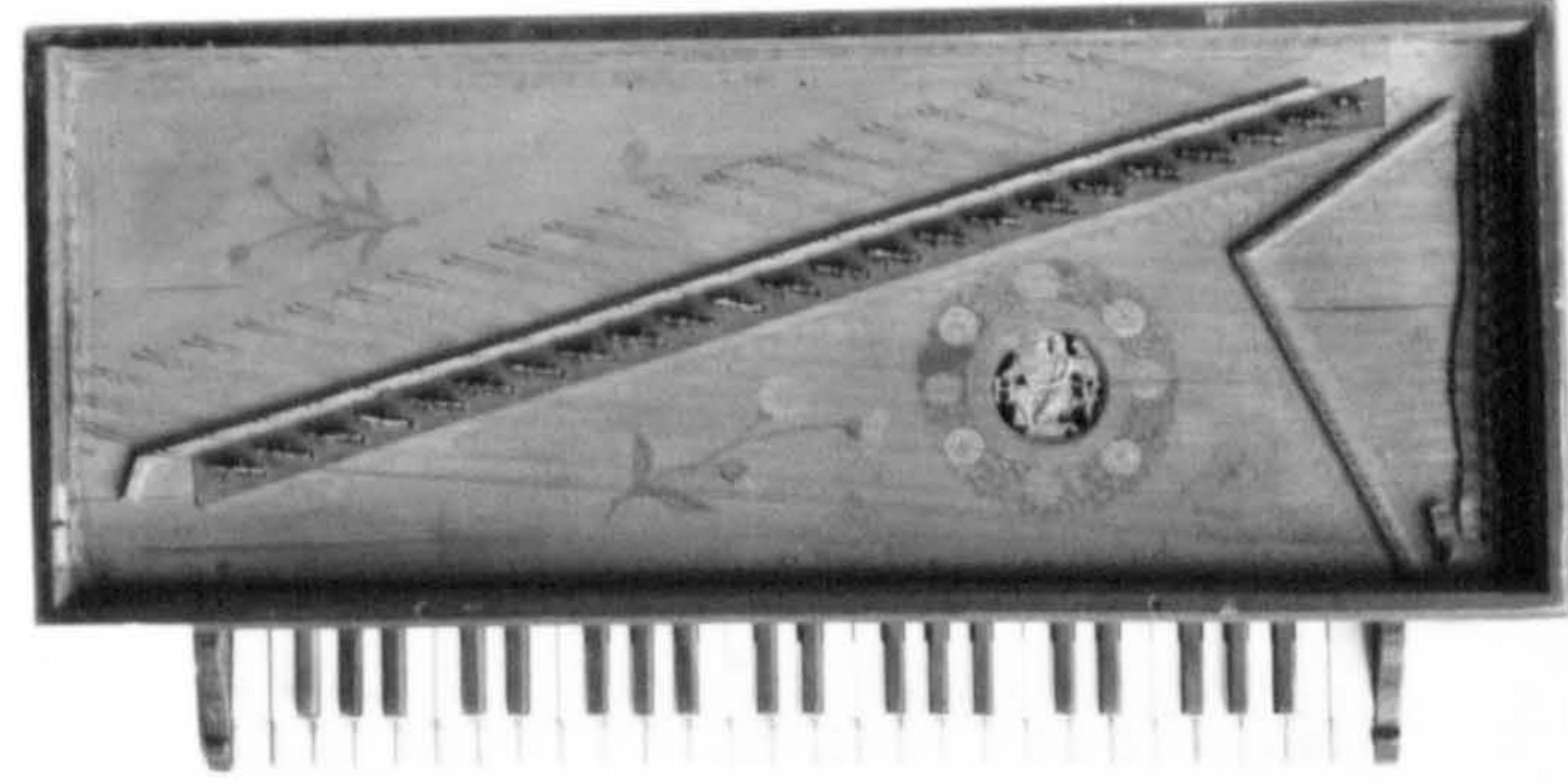

Photo 3-24 (c1600) HR child spinett virginal. Scale 1:10

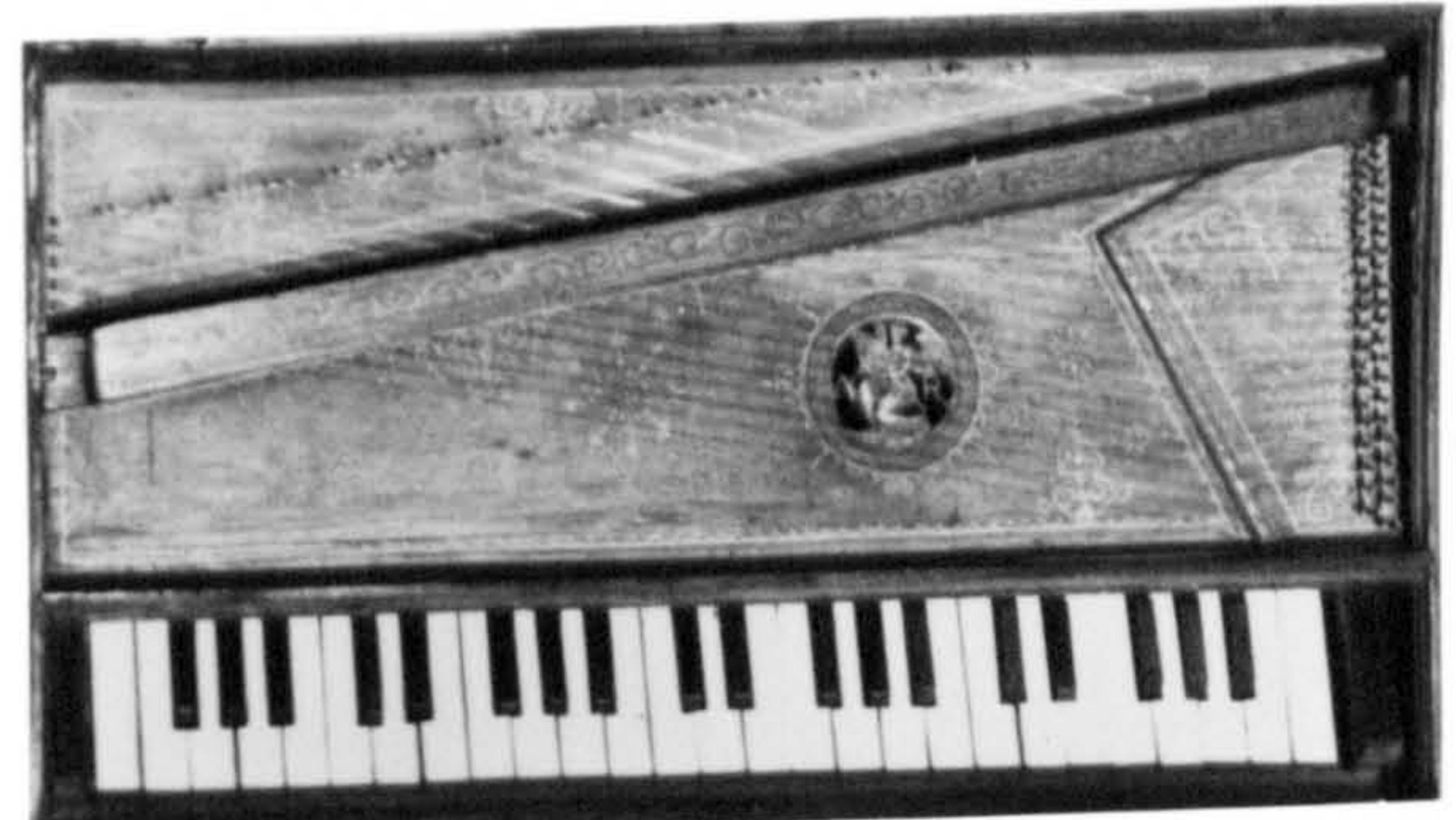

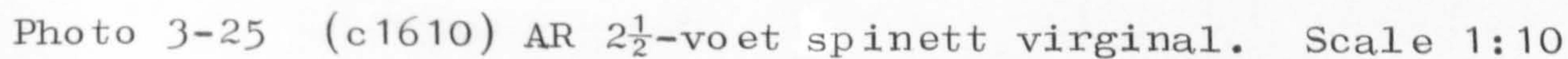




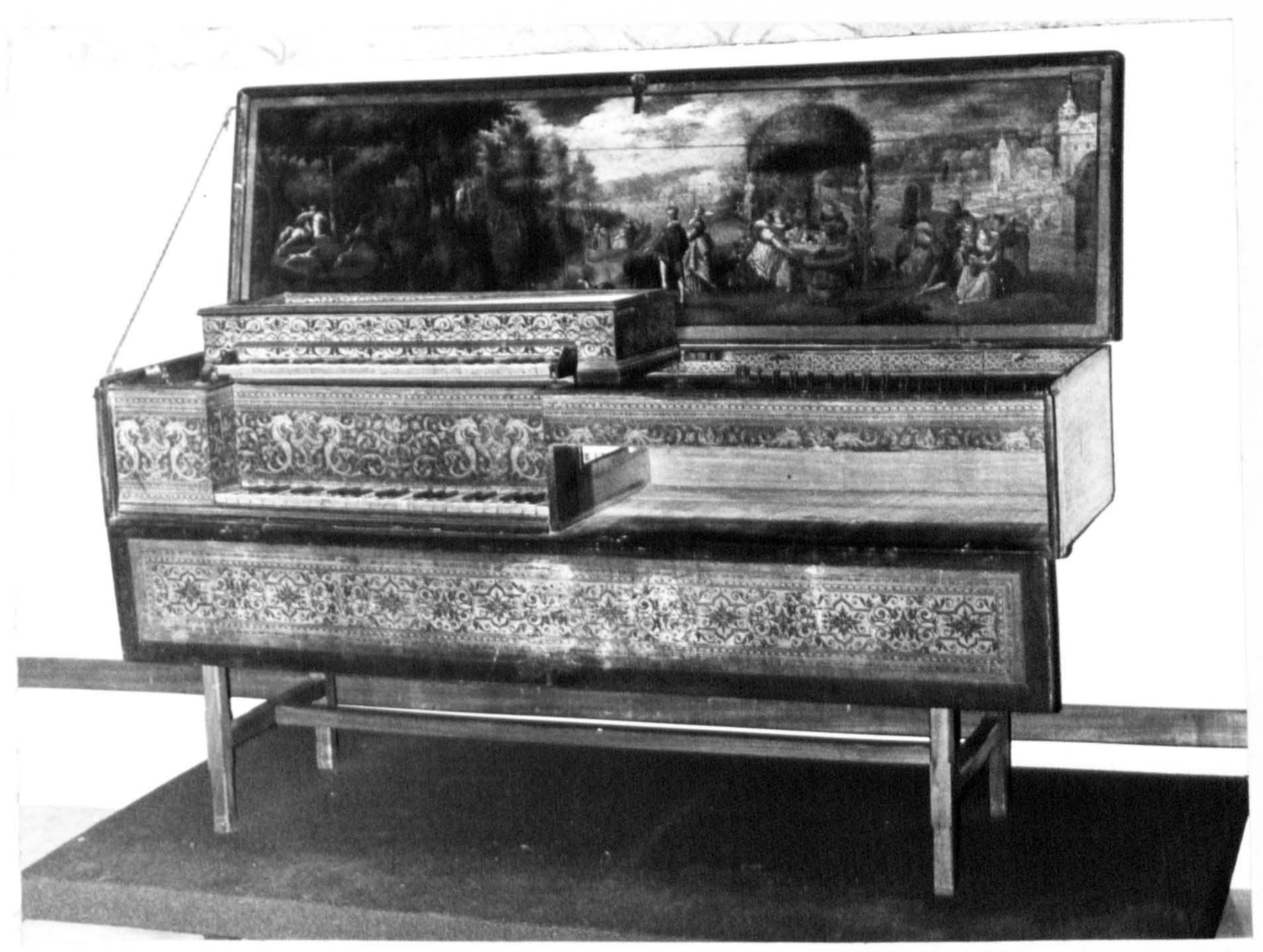

Photo 3-26 (c1600) HR mother and child spinett virginal. The child is in its coupled playing position with the jackrailof the mother removed. 
There is only one extant example (c1610a AR) of the little virginal which Douwes describes as being of length 2 voeten 4 duimen (see Appendix 3). It is at a pitch an octave above the 5-voet instruments (see p. 177) and is, in fact, not 2 voet 4 duimen in length, but is exactly half of the length of the 5-voet instrument, i.e. 2 voet $5 \frac{1}{2}$ duimen or $2 \frac{1}{2}$ voet long. This particular instrument does not have a slot in its baseboard, and this, along with the fact that it has very high and sloping sides, proves that it was not meant to be the child part of a 5-voet mother-and-child combination. At first glance it seems strange that no 5-voet mother-and-child combinations exist. The 6-voet 'mothers' are sometimes a few duimen longer than the nominal 6 voeten, the extra space being used to accommodate the child instrument. By adding on a similar amount of space, a 5-voet instrument could easily be made to hold a $2 \frac{1}{2}$-voet virginal. But such a combination has not been found.

The reason for this seems clear, and is again related to the geometry of the instrument and the width of the keyboard. The length of the bass note $C$ in such a child would be about $610 \mathrm{~mm}$ : the keyboard has a width of about $650 \mathrm{~mm}$, and so it is impossible to fit the jacks and keys into the space between the two bridges in the normal way. The problem was solved by cranking the keys of the small instrument in towards the centre of the string band and squeezing the jacks together into a space much narrower than usual by using jacks and jackslots which are them- 
selves narrower than normal. However this means that the tighter spacing of the jacks in such a putative 'child' would not match the normal spacing of the jacks in a 5voet 'mother', and so the two could not be used together in a way similar to the 6-voet mother and child. They can only be used separately.

The virginal models may be summarized as follows:

6-voet spinett mother and child

6-voot spinott virginal

5-voet spinett virginal*

$4 \frac{1}{2}$-voet spinett virginal

4-voet spinett virginal

child spinett virginal

$2 \frac{1}{2}$-voet spinett virginal 6-voet muselar mother and child

6-voet muselar virginal 5-voet muselar virginal. $4 \frac{1}{2}$-voet muselar virginal

*None now extant except for the 1636 Cornelius Hagaerts in the Rockox House, Antwerp.

The keyboard compass of the virginals is almost universally $\mathrm{C} / \mathrm{E}$ to $\mathrm{c}^{3}$. Some of the earlier 16 th century Hans Ruckers instruments have the more restricted $\mathrm{C} / \mathrm{E}$ to $a^{2}$ compass. Also one virginal, the $4 \frac{1}{2}$-voet spinett (1629 $I R)$, has the unusual compass $C / E$ to $d^{3}$. The reason for this large compass is not clear, but may have been taken this high so that the pitch of the top note was the same as the pitch of the top $c^{3}$ note of the smaller 4-voet instrument pitched a tone higher.

Only one Ruckers virginal is polygonal; all the others are rectangular. Like the earlier Karest virginals (see 
p. 56ff), the $1591 \mathrm{a} \mathrm{HR}$ is a six-sided spinett virginal. However, the lay-out of this instrument is exactly the same as the other Ruckers 6-voet spinett virginals the scalings, plucking points, keyboard compass, etc. are all identical with the usual rectangular spinett virginals. The difference is simply that the inactive parts of the soundboard of the rectangular instruments have been eliminated and a polygonal case has been fitted around the musical part of the instrument. Therefore, because the 1591a HR spinett virginal is neither acoustically nor musically different from the normal rectangular spinett type, I do not feel that it qualifies as a separate model of its own.

The different lengths of Ruckers virginals are each at a different pitch. In fact the different models of Ruckers virginal are at 6 clearly defined and different pitches (see Chapter 4). The pitch differences between the different models are not arbitrary, but correspond to the simple musical intervals of a tone, a fourth, a fifth and an octave. Nowhere else in the history of keyboard instrument building do we find such an array of virginal model types and pitches, and this must be considered amongst the most important contributions of the Ruckers to our knowledge of musical practice and instrument building of the $16 \mathrm{th}$ and 17 th centuries.

The Standard Types of Harpsichord

As with the virginals the Ruckers made a number of different models of harpsichord. However, these types 


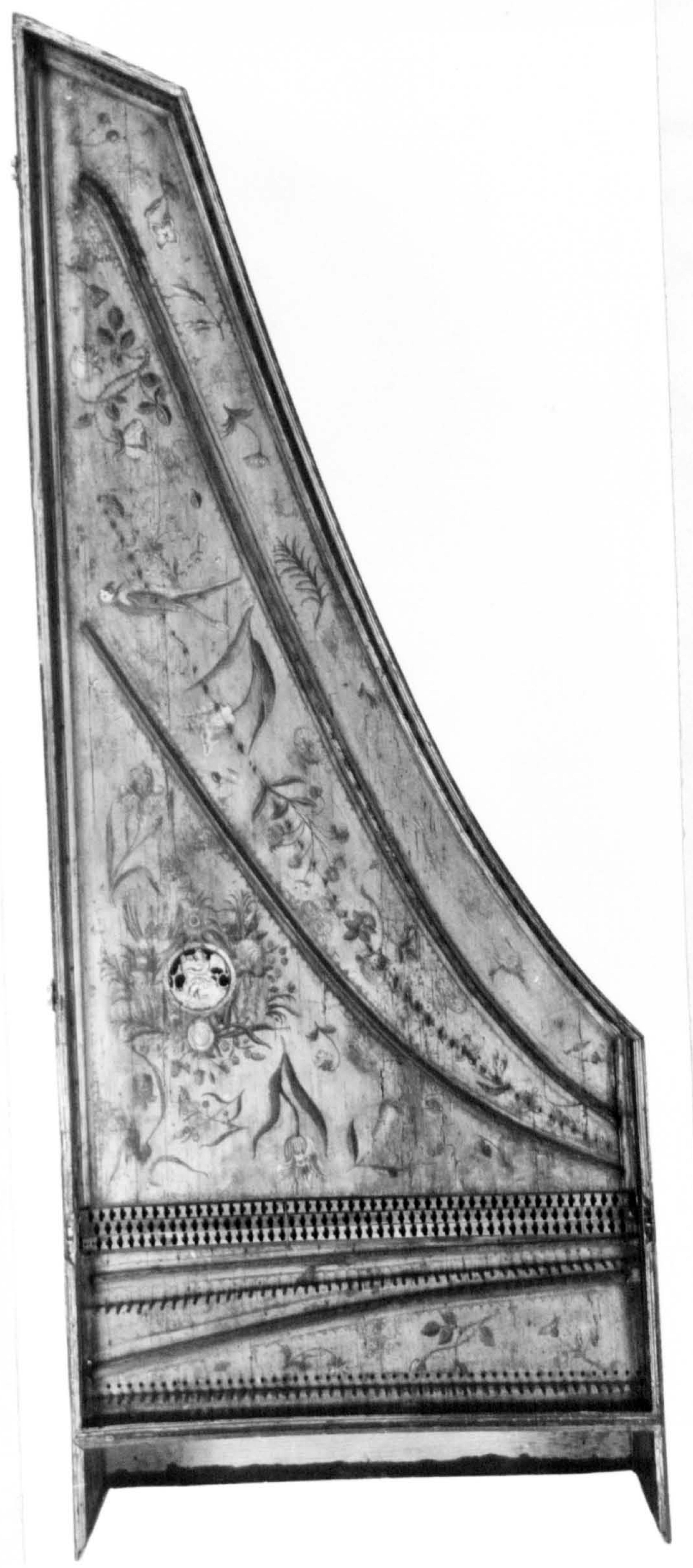

Photo 3-27 1645 IC standard single-manual harpsichord. Sca1e 1:10 
are at relatively few pitches, and their variety is more an indication that harpsichords with different keyboard compasses, and in a fow isolated cases different dispositions, were made.

By far the most common type of single manual harpsichord has the same scalings (and therefore sounds at the same pitch) as the 6-voet virginals, and is slightly longer than 6 voeten in length - usually about 6 voet 4 duimen $(1810 \mathrm{~mm})$. These harpsichords have only two rows of jacks and two sots of strings and are disposed $1 \times 8^{\prime}$, $1 \times 41:$

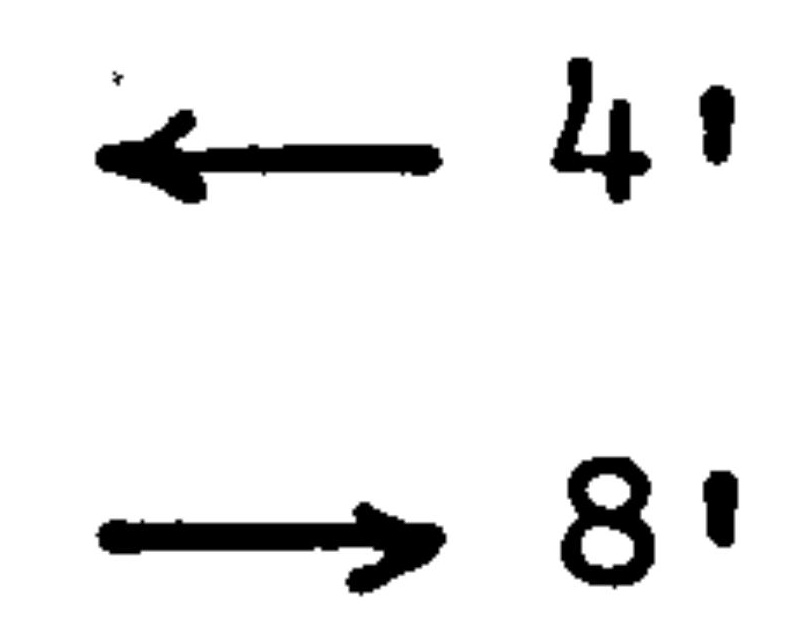

The original compass of these instruments is universally $\mathrm{C} / \mathrm{E}$ to $\mathrm{c}^{3}$.

The standard model of double is considerably longer than the single, at 8 voet or slightly less (average about $2240 \mathrm{~mm}$ ). The two keyboards are completely independent and not capable of being coupled, and each operates only two rows of jacks, as in the single manual harpsichords. There are only two sets of strings, one an octave above the other so that the four registers are disposed:

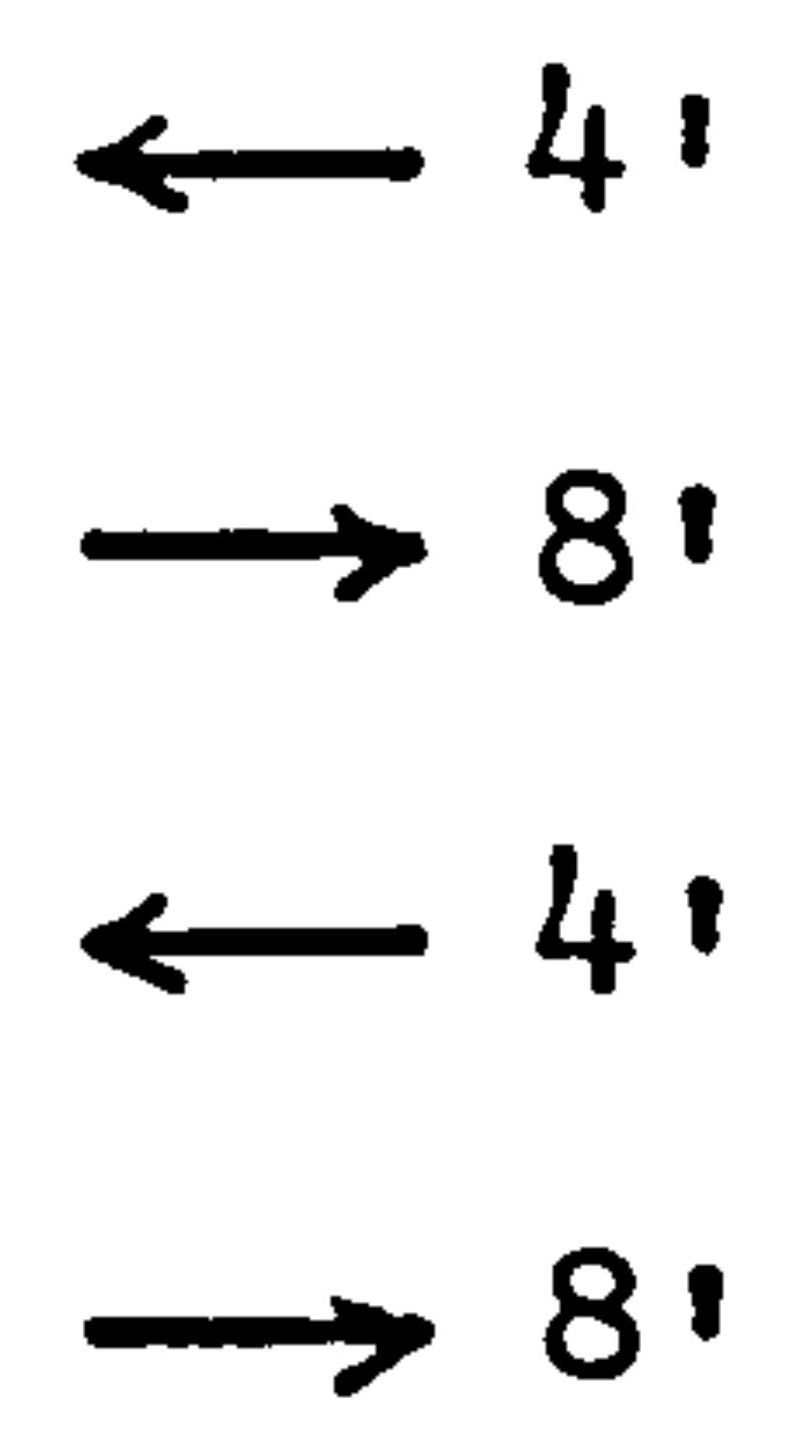

Since the jacks of both manuals operate on the same two sets of strings, only one manual can be used at a time, 


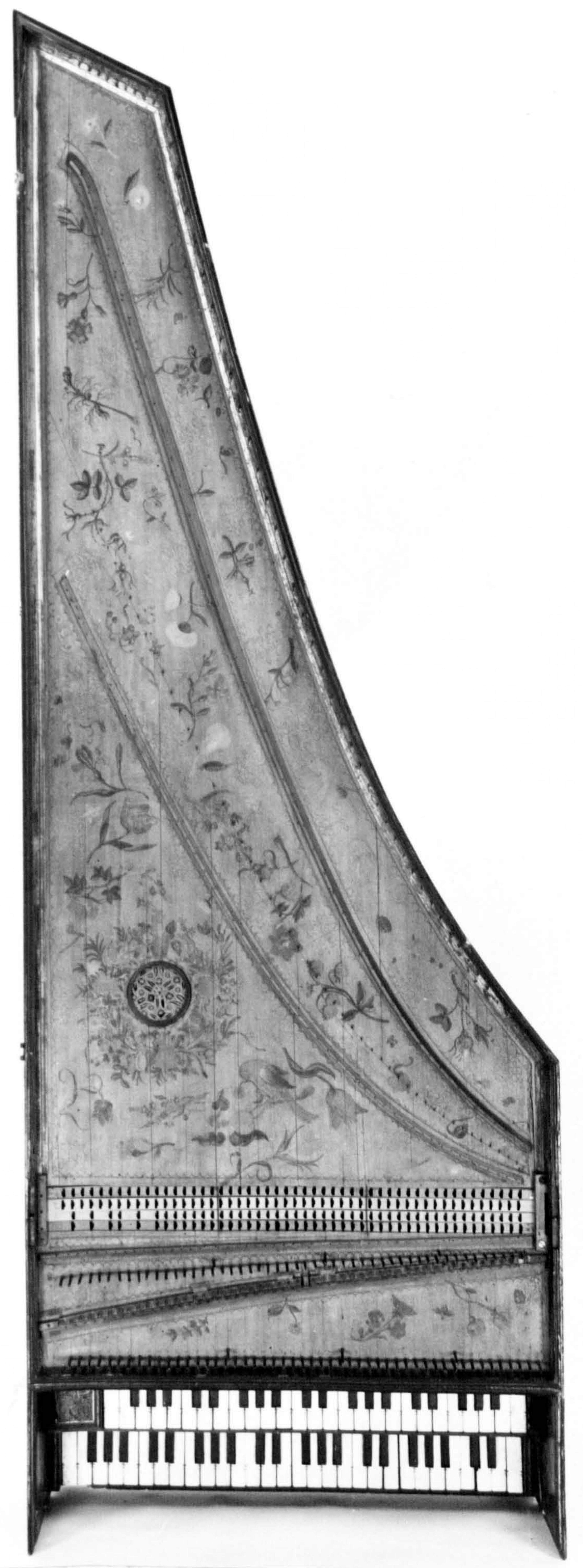

Photo 3-28 1638b IR standard double-manual harpsichord. Scale 1:10 
otherwise damper interference would occur (it is assumed that the dampers of all registers were cut so that when the register was withdrawn the dampers moved away from the strings to allow them to vibrate freely when plucked by the row of jacks on the other keyboard. See Chapter 6 p. 367 ).

The upper-manual keyboard consists of a block of wood three naturals in width followed by keys with a compass of $\mathrm{C} / \mathrm{E}$ to $\mathrm{c}^{3}$. The keyboard and jacks of the upper manual pluck strings whose scalings are the same as in the standard single-manual harpsichord and the 6voet virginal, and so the upper manual is at the same pitch as these instruments. The lower manual has a compass of $\mathrm{C} / \mathrm{E}$ to $\mathrm{f}^{3}$, and the keys are arranged so that they are displaced to the left by an interval of a fourth. Thus the c key on the lower manual plays the same string as the G key on the upper manual: the $c^{3}$ key on the upper manual plays the same string as the $f^{3}$ key on the lower manual, etc. (see Photo 6-12, p. 343).

Because the lower manual effects a transposition downwards of a fourth - or upwards of a fifth - relative to the upper manual, the Ruckers double-manual harpsichords have become known as transposing harpsichords?-9) Special models of Ruckers harpsichord

Single-manual Ruckers harpsichords were made at pitches higher than the standard ' 6 voet' harpsichord described above. One harpsichord exists (1627 AR) which is $1232 \mathrm{~mm}$ (about 4 voet 4 duimen) and is thus a nominal 
14-voet' harpsichord 3-10) This harpsichord has the same scalings and is at the same pitch as the 4-voet virginals. It has the usual $\mathrm{C} / \mathrm{E}$ to $\mathrm{c}^{3}$ compass and also the usual 2register unison and octave disposition. No smaller Ruckers harpsichord is known than the 1627 AR '4 voet' harpsichord $3-11$ )

As well as the standard short-octave singles, the Ruckers also made 6-voet single-manual harpsichords with a chromatic bass-octave to C. These have the same scalings and are at the same pitch as the standard 6-voet harpsichords and virginals. One of these harpsichords (1639 IR) originally had an extended treble compass to $d^{3}$, rather than the usual treble compass finishing at $c^{3}$. These instruments are the same length as the standard 6-voet singles but are wider by the amount occupied by the 'extra' naturals in the compass. All of these chromatic bass-octave singles are found in England, and this along with the fact that 16 th and 17 th century English music often requires a chromatic bass-octave, suggests that they were made as special export models for the English market. 16 th and 17th century English composers used to the chromatic bass-octave, and the contemporary English player would have wanted their instruments to have all of the chromatic and diatoric notes below $B^{b}$ (see Chapter 8, p. 516).

Although they are each unique examples of their ' type and are really all late instruments out of the mainstream Ruckers tradition, some interesting harpsichords 


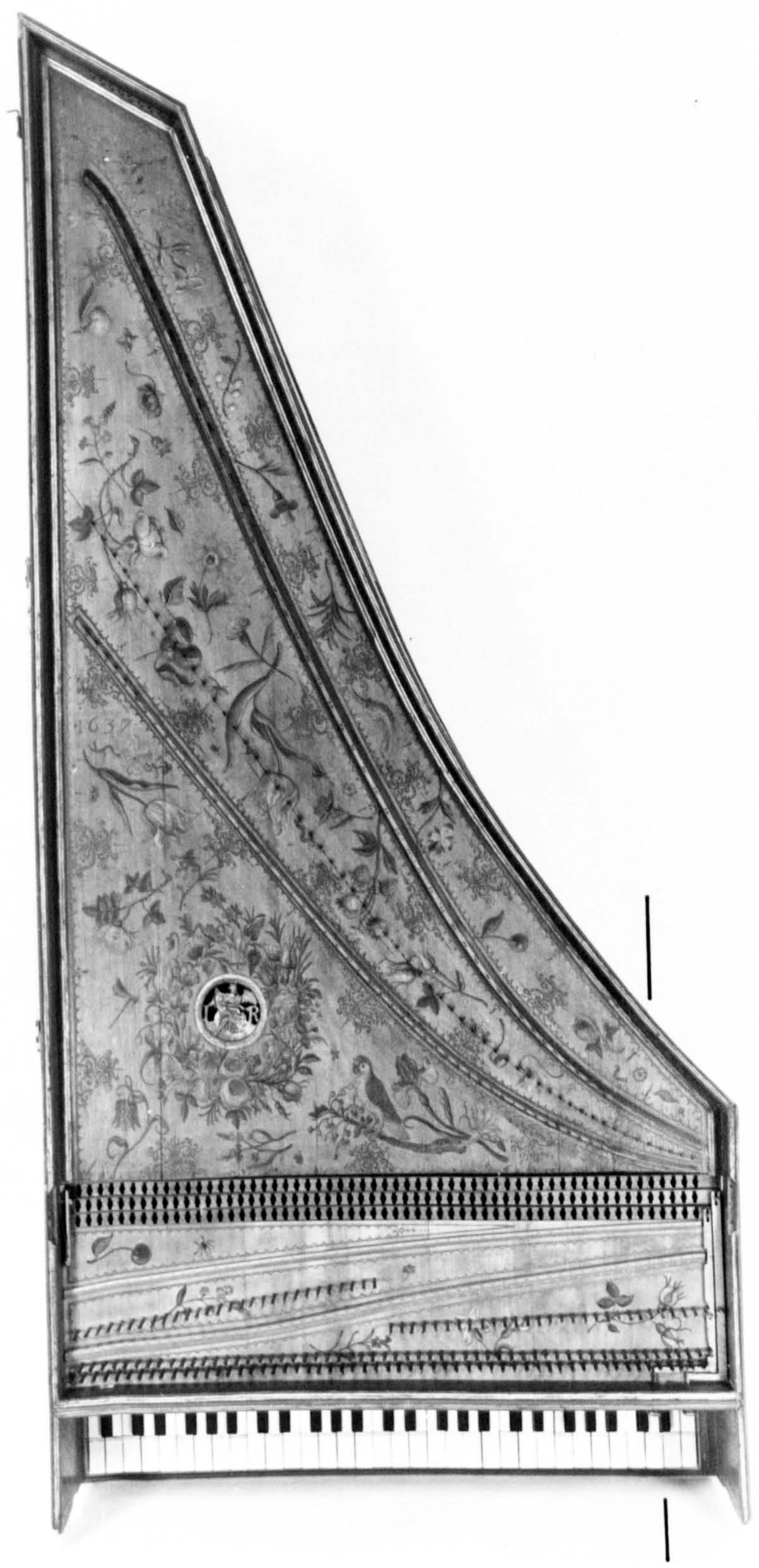

Photo 3-29 1637a IR wide single-manual harpsichord. The original width of the inside of the case is marked by the line.

Scale 1:10 
were built by the Couchets which indicate the way that musical taste was moving in the second half of the 17th century. The 1652 IC harpsichord was unusual in originally having a disposition of $2 \times 8^{\prime}$ with no $4^{\prime}$, and an original compass which was $\mathrm{C}$ to $\mathrm{d}^{3}$ chromatic. The (c1650)b IC harpsichord was originally a long single with the usual $1 \times 8^{\prime}, 1 \times 4^{\prime}$ disposition, but with an extended bass compass of $F_{1}, G_{1}, A_{1}$ to $c^{3}$. An instrument by Iosephus Ioannes Couchet (1679 IC) has a chromatic C to $\mathrm{c}^{3}$ compass, a disposition of $1 \times 8^{\prime}, 1 \times 4^{\prime}$, but 3 rows of jacks with two $8^{\prime}$ rows of jacks separated by by the $4^{\prime}$ row and both plucking the same string. And the 1680 IC as a single harpsichord, possibly also by Ioseph Ioannes, probably had a compass of $F_{1}, G_{1}, A_{1}$ to $d^{3}$ with an unknown disposition. The most unusual Couchet single is the n.d. IC harpsichord which was originally about $2630 \mathrm{~mm}$ long, and had a compass of almost 5 octaves from $F_{1}$ to $d^{3}, e^{3}$.

As with the singles, the Ruckers also made chromatic bass-octave double-manual harpsichords. In these instruments the disposition is the same as with the standard model double; the two keyboards differ in pitch by a fourth, but the pitch roke of the keyboards is reversed (see Chapter 8, p. 515). The lower manual, at the same pitch as the 6-voet virginals and harpsichords, has a chromatic compass of $G_{1}$ to $c^{3}$. The upper manual has a block at the bass end of the keyboard followed by keys with a compass of $F$ to $f^{3}$ chromatic which operate jacks plucking strings a fourth lower in pitch than the 

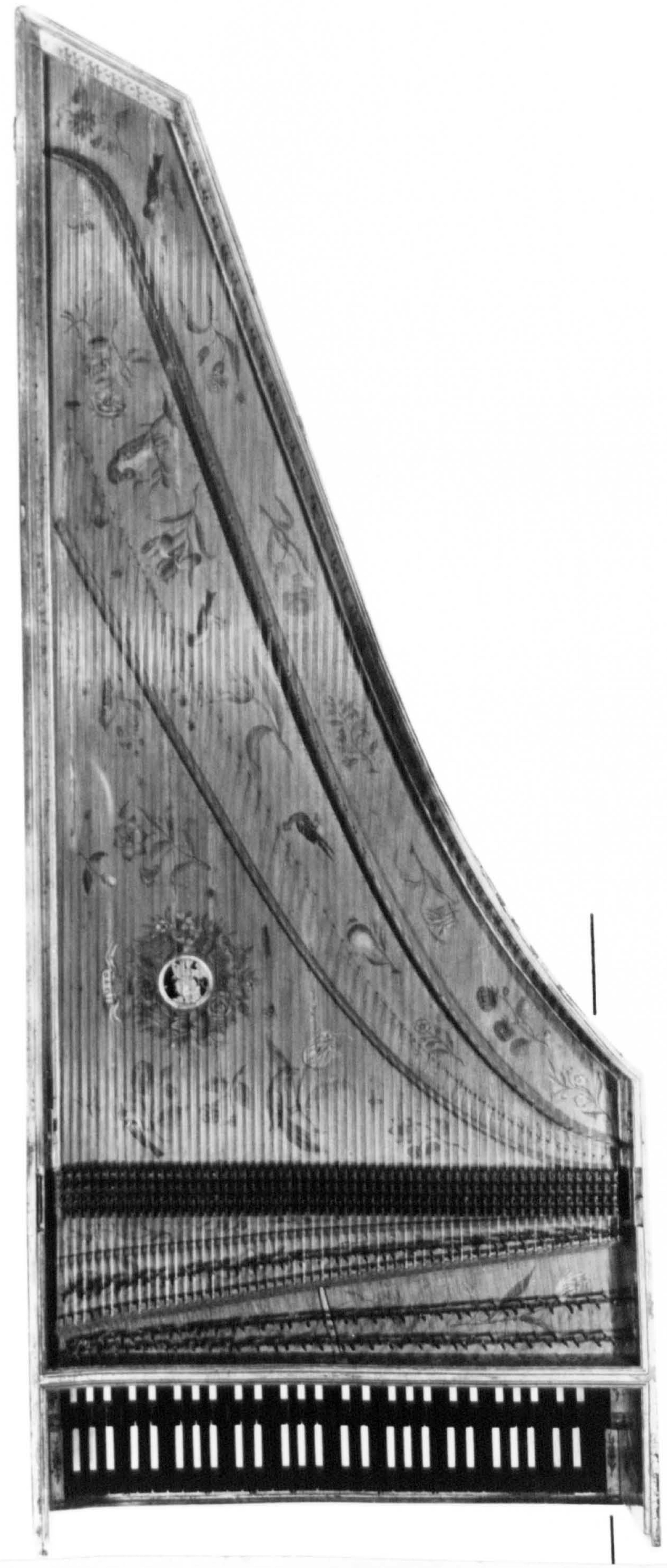

Photo 3-30 1646b AR wide double-manual harpsichord. The original width of the inside of the case is marked by the line. Scale 1:10 


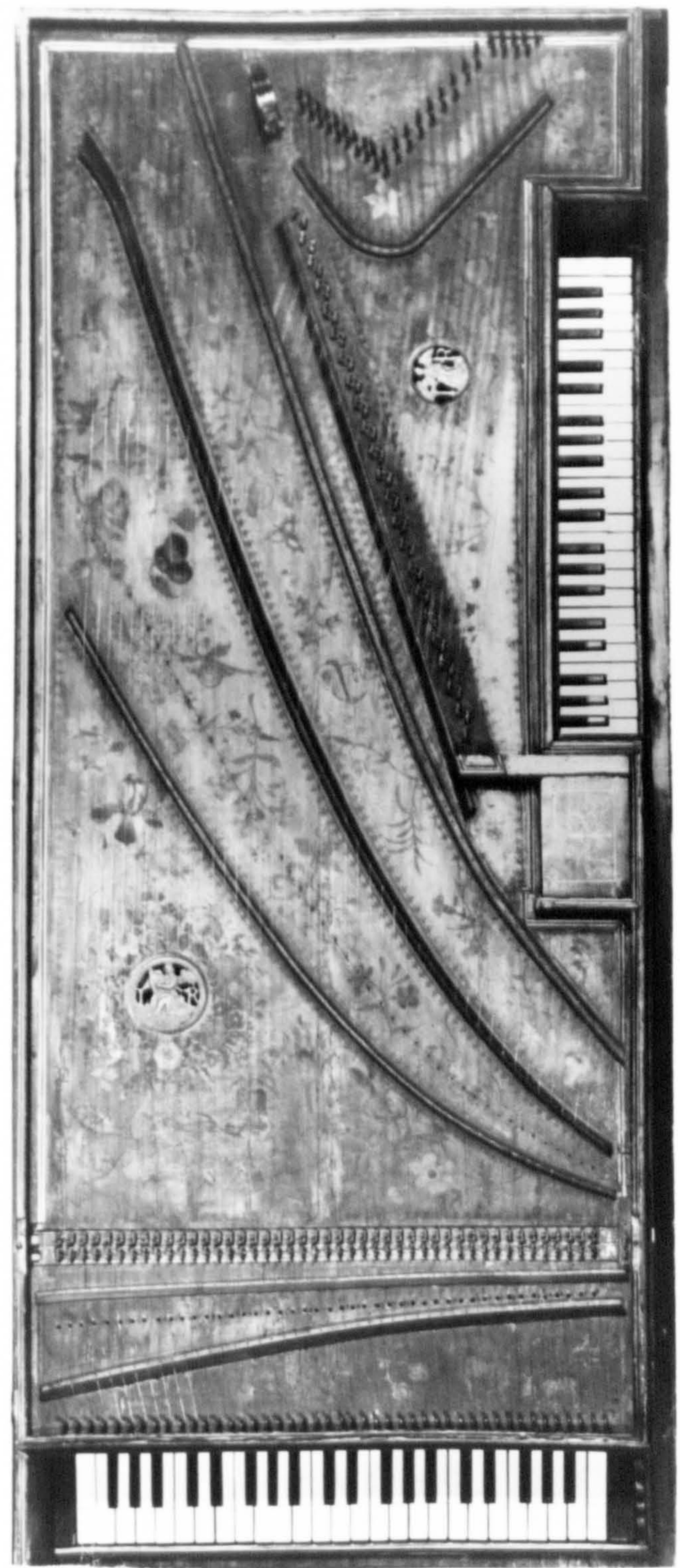

Photo 3-31 n.d. IR single-manual harpsichord/virginal combination.

Scale 1:10 
corresponding keys and jacks of the lower manual. These chromatic bass-octave doubles are the same length as the standard model short-octave doubles, but they are two natural notes wider.

Only one other non-standard type of double is known (1612a HR). Nelther the disposition, nor the compass of the second manual of this harpsichord is known, but one of the manuals must have had a compass of $C / E$ to $d^{3}$ at a pitch a fifth lower than the pitch of the 6-voet harpsichords and virginals (seo Chapter 8, p. 505).

One of the most unusual models of Ruckers instrument is the harpsichord/virginal combination. These are large rectangular instruments in which the virginal fills up the space beside the harpsichord bentside, with the virginal keyboard at the rear of the right-hand long-side of the instrument. These exist with the harpsichord part having both one and two manuals. In the single-manual version the virginal is at the octave to the harpsichord part. One double-manual harpsichord/virginal combination exists, and in this tho harpsichord is the standard model described above, and the virginal is an octave above the lower-manual keyboard (1.e. It is at the same pitch as the 4-voet virginals).

The extant Ruckers instruments of all types are classified in Appendix 6 according to their original states.

\section{The Interpretation of the Ruckers Numbering System}

The upper part of the Ruckers number clearly represents the length of the instrument in Flemish feet in the 
case of the single virginals, Moeder and kind in the case of the double mother and child virginals, and Staartstuk in the case of all models of harpsichord whether double or single.

The explanation of the lower number is not at first obvious since if all the numbers appearing on Ruckers instruments are arranged in chronological order a seemingly arbitrary arrangement of numbers results. However, if the numbers are arranged according to the type of instrument, and according to the member of the family who built the instrument, the numbers normally increase uniformly with the date in which the instruments were built. For example, if one considers the six-voet virginals of Andreas Ruckers:

$$
\begin{aligned}
& 1617 \text { AR }- 6 \\
& 23 \\
& 1620 \mathrm{BAR}- 6 \\
& 27 \\
& 1633 \mathrm{aAR}- 6 \\
& 70
\end{aligned}
$$

it can be seen that the lower number gradually increases with time.

It has been found to be very enlightening to plot these lower numbers on various instruments as a function of the date, and to do this separately for each type of instrument for the various members of the Ruckers family. Because the numbers can then be seen to increase with time for each type of instrument, one is forced to the conclusion that we are dealing here with serial numbers applied separately to each type. 
Graph 3-1 shows the numbers plotted for Hans and Ioannes Ruckers and for Ioannes Couchet, the unlabelled lines being for Ioannes Ruckers. Similarly, Graph 3-2 shows a plot of the numbers for the two Andreas Ruckers, father and son. The lines drawn through the points are, naturally, only approximate as the output of any workshop can hardly be expected to be completely uniform with time. Also many of the lines are drawn subject to many uncertainties. The problem arises because only 50 Ruckers instruments are numbered, and of these 50 only 34 are instruments in which the date and authorship are completely unambiguous. In some cases the serial number increases more or less uniformly over a long period of time such as in the example above and in the 6-voet virginals of Ioannes Ruckers. But in many cases it is clear that after the serial number had reached a value of 50 to 100 the numbering restarted again from one. With some instrument types this re-starting of the serial number occurs very frequently. This I have taken to mean a high rate of production for these types of instruments.

In drawing the lines and curves through the points of Graphs 3-1 and 3-2 I have tried to relate the production of instruments to the history of each of the members of the Ruckers family as far as we know it. But because of the paucity of reliable numbers, and the inadaquacy of our knowledge of the family history, many of the conclusions drawn are at best only tentative. In some cases so little data exists that lines could not be drawn through 


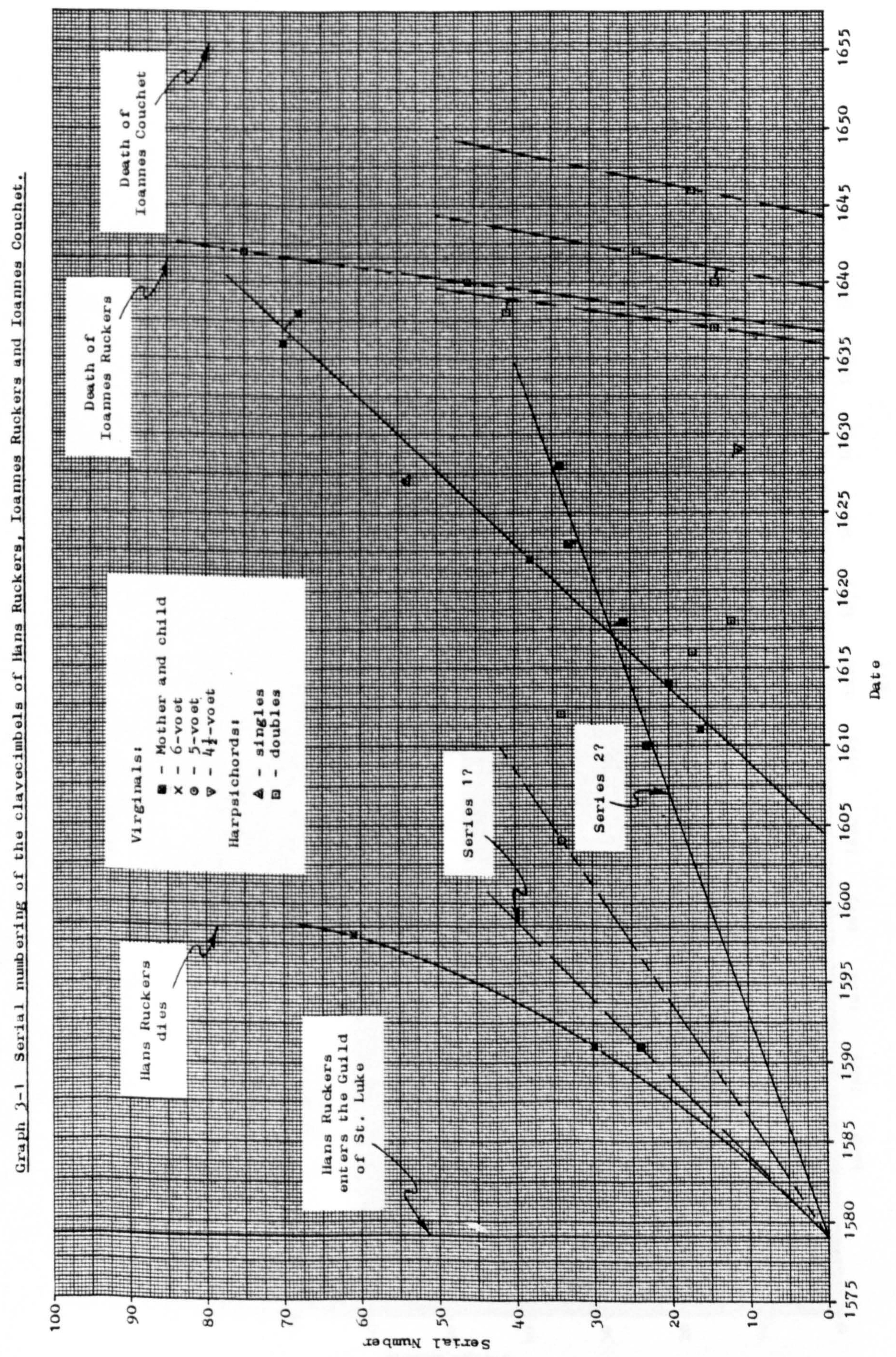




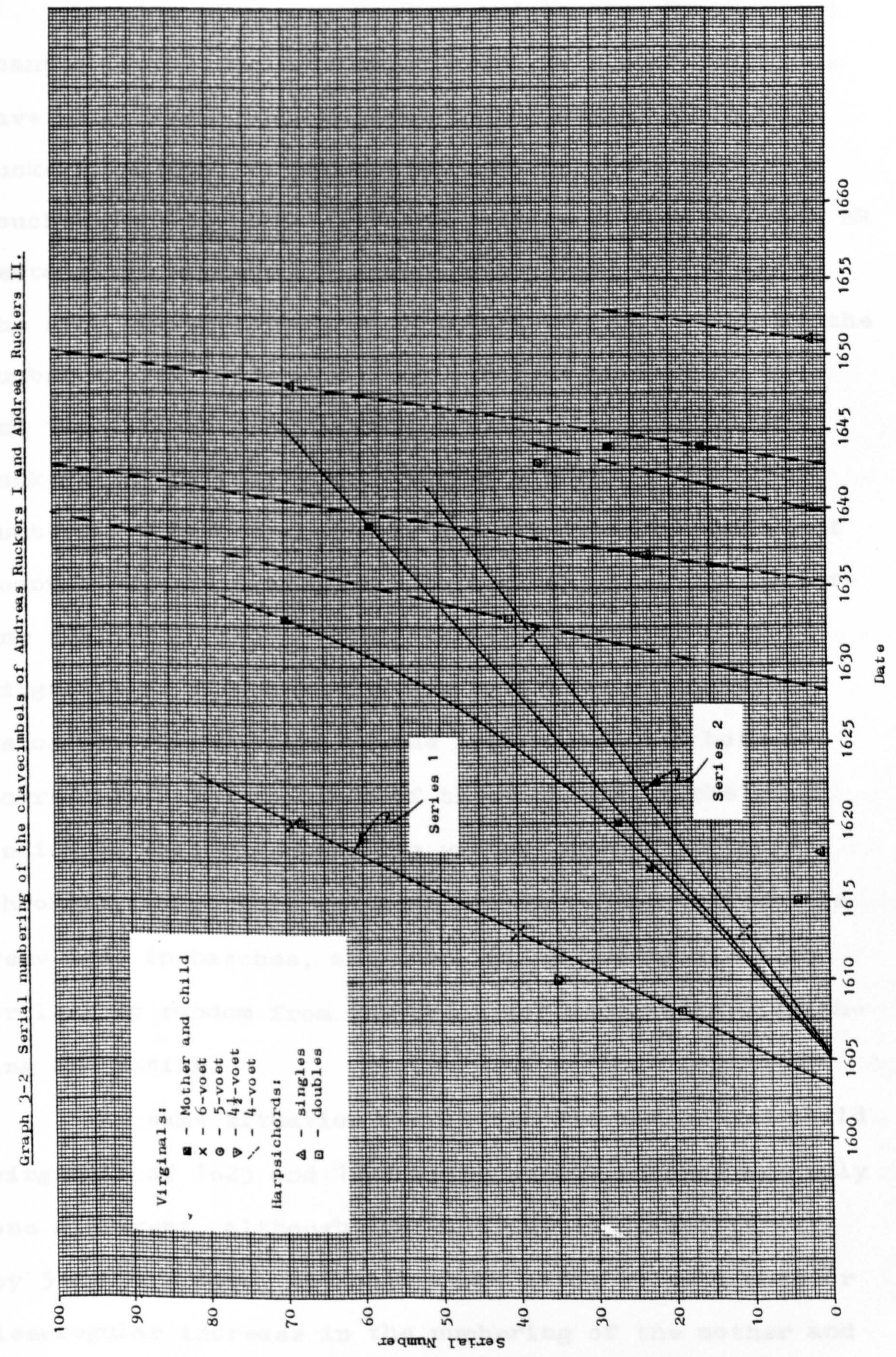


the points at all.

Looking first at the Hans and Ioannes Ruckers and Ioannes Couchet production in Graph 3-1, vertical lines have been drawn corresponding to the deaths of Hans Ruckers in 1598, to Ioannes Ruckers in 1642, and to Couchet in 1655. The 1591a HR polygonal, and the $1598 \mathrm{HR}$ rectangular spinett virginals both appear to belong to the same number serial, even though the upper part of the number on the 1591a HR is not a 6 (see Photograph 3-1) and the $1598 \mathrm{HR}$ virginal was probably made by Ioannes Ruckers in the year of his father's death. The other numbers for 6-voet virginals are all from the output of Ioannes Ruckers, and appear to indicate that the numbering started in about 1598. The dates for the 6-voet virginals of 1636 and 1638 are both suspect as neither is on an original part of the instrument. If both are correct then the position of these points on the graph indicates that the numbering was not always strictly chronological. This may have arisen if the instruments were made in batches, and then pulled one by one more or less at random from the batch for decorating, finishing and dating.

The same situation occurs for the mother and child virginals of 1623 and 1628 - the serial numbers are only one different, although the instruments differ in date by 5 years. Also, although there seems to be a more or less regular increase in the numbering of the mother and child instruments beginning in 1579, the number 26 
in 1618 is somewhat lower than what one might expect. The $1591 \mathrm{~b}$ HR mother-and-child virginal is dated only indirectly through the dating of the lid painting. On the basis of the other mother-and-child numbers one would expect that it should be dated shortly before 1615 . However the style of the roses and the soundboard decoration all indicate that the instrument was made by Hans Ruckers so that the date must be sometime before Hans Ruckers' death in 1598. It thus seems that there were two series of numbers for the mother-and-child virginals, both probably originating in 1579 when Hans Ruckers joined the Guild. The Milan mother-and-child virginal has the number 15, and its date has been estimated to be about 1600 using the Series 2 numbers. Its soundboard decoration is in the style of the $1598 \mathrm{HR}$ 6-voet virginal, the 1610 HR mother-and-child virginal, and the $1612 \mathrm{a} \mathrm{HR}$ double harpsichord and this seems to corroborate this estimation of the date. The other possibility - that the 15 belongs to the earlier Hans Ruckers serial numbering can be eliminated on a number of grounds despite the lavish lid painting and the red-painted curved lower surface on the nameboard/faceboard double moulding, both of which are typical of Hans Ruckers instruments. The number 15 would put the date of this instrument at about 1586, and this is totally inconsistent with the soundboard decoration, the painting of the wreath and the signature $\cdots$ which uses IOHANNES and not HANS.

The production of double-manual harpsichords, where 
many serial numbers exist poses some interesting problems. The serial numbers 14 and 41 for the 1637 and 1638 doubles seem to indicate a very large production of double manual instruments. These are followed by the numbers 14 for 1640 and 24 for 1642, which seem to indicate that production had slowed down greatly. The discrepancy might be explained if the 1637 double were made at the beginning of the year and the 1638 double at the end, so that the average rate of production was about $\frac{41-14}{2}=\frac{27}{2}=13.5$ instruments a year. If then the 1640 had been numbered at the end of the year and the 1642 at the beginning (so that in fact only one year separated them) this would indicate a comparable production of $\frac{24-14}{1}=10$ instruments per year. Probably, like the virginals, the double manual harpsichords were also made in batches and the lack of precise chronology in the numbering, or the existence of an apparently variable rate of production, could bee explained if the instruments were not pulled from the batches for finishing in strict order.

At any rate the above analysis suggests that after reaching about 50, the serial number started again from 1 in 1639. If the serial again went to 50 and restarted from 1 in 1644 and the production was maintained at the same level then the production line coincides with the serial 17 for the 1646 Couchet double harpsichord. This is not surprising since Couchet had worked in Ioannes Ruckers' workshop since 1627 , and having probably worked on the instruments whose serial numbers are given above 
as belonging to the production of Ioannes Ruckers, it is natural that ho would continue the same serial system after Ruckers death in 1642.

Too few numbers exist to attempt to draw curves through the double-manual serial numbers 34 and 12 for 1612 and 1618 respectively. The anomalous number 17 for the 1616 double is probably a result of the fact that it is one of the large chromatic bass-octave doubles which were probably numbered with a different serial from the standard model bass short-octave doubles.

One of the surprising features of the production of Ioannes Ruckers is that $/$ one of his single-manual harpsichords is numbered, despite the fact that several of those singles that exist have their original baseboards on which one would expect to find a number. The reason for numbering the cases and parts of instruments must have been to avold mixing up the various pieces of otherwise identical instruments in a busy workshop with several instruments of the same type under construction simultaneously. The lack of a serial on the Ioannes singles suggests that he made very fow instruments of this type, possibly on a one-off basis so that there was no possibility of interchanging the action parts. This seems to be confirmed by the fact that of the extant Ruckers standard singles only two out of sixteen are by Ioannes Ruckers. The situation seems to have changed markedly for Ioannes Ruckers' successor Ioannes Couchet, at least as far as the special long single-manual harpsichords with 
a compass of $F_{1}, G_{1}, A_{1}$ to $c^{3}$ are concerned. The only extant example of this type of harpsichord, the (c 1650)b IC in the Metropolitan Museum, New York, has the serial number 34 , but is undated. The very fact that it was numbered indicates that this model was being produced in such large numbers that soveral were under construction in the workshop at the same time. Couchet refers to this model of harpsichord in a letter (see Appendix 18) which can be dated to the latter part of 1648:-12) In the letter Couchet says that he had only just begun to make this type of instrument. Such long singles were thus in production from 1648 until 1655 when Couchet died. Even if the Metropolitan Museum instrument was made in 1655, the serial number 34 would indicate an average production of about 7 of these long chromatic bass-octave singles every year. As it was probably much more than this we can conclude that Couchet had found himself a best-selling model which appealed to a clientele whose musical tastes were different from those of the first half of the 17th century. Graph 3-2 showing the serial numbers for Andreas Ruckers reveals several interesting features. There appear to be two series of numbers for the 4-voet virginals. Series 1 rises very sharply, indicating a high rate of production of about four instruments per year, and the other, Series 2, represents a much slower rate of production averaging about one and a half instrument per year. The reason for these two lines can only be guessed: does one of them represent the production of Andreas 
himself, and the other that of one of his apprentices? Or perhaps there were two workmen building cases and parts and each numbering his own instruments which were then later decorated and finished by someone else. The fact that they both seem to originate in the period around 1605 certainly seems to indicate that they are indeed two genuinely separate serials which mark the beginning of Andreas' active production.

The date of Andreas' entry into the Guild is not known. But he was married in 1605 and worked with Ioannes in the same workshop until 1608. The $1604 \mathrm{HR}$ 5-voet virginal is signed IOANNES ET ANDREAS RVCKERS FECERVNT, indicating that the two brothers were signing instruments together in 1604. However, the fact that the 6-voet and 4-voet virginal numbering serials both appear to start around 1604 to 1605 indicates that Andreas, although he was working together with Ioannes in the family workshop, then began to number (and probably to sign) his own instruments. Unfortunately no instruments by Andreas Ruckers from before 1608 exist to confirm whether or not Andreas and Ioannes were numbering and signing instruments independently during the period when they were sharing the same workshop. However a combined harpsichord and virginal by Andreas Ruckers of 1606 is listed among instruments for sale in Paris in the 18th century, ? $^{-13}$ ) and another harpsichord dated 1606 by Hans Ruckers (Ioannes used an $\mathrm{HR}$ rose at this date) is listed in an inventory of instruments confiscated from the French 
aristocracy ${ }^{3-14)}$ Thus it is not surprising to find that, after Andreas' marriage in 1605, the two brothers began to work on an independent basis: Ioannes continued his father's serial numbering and continued the serial he had restarted after Hans' death in 1598, and Andreas began his own serial numbering in about 1605.

Several single-manual harpsichords by Andreas are numbered, and from this their production rate can be estimated. The 1644b AR (serial so.16) and 1648 AR (serial no. 69) indicate a production of botween about 11 to 18 singles a year depending on when in these years the instruments were numbered and dated. Assuming a production of about 13 singles per year by drawing a line through the 1644 and 1648 points themselves, with the serial going up to 100 (instead of to 50 as for Ioannes) puts the serial numbers for the $1637 \mathrm{AR}$ and 1651a AR singles on the same production curves, with the serials beginning in about 1635, 1643 and 1650. The serial no. 1 on the 1618 AR single indicates that a serial started in this year, and suggests that another single-manual serial started in about 1627 or so, or roughly mid-wạy between 1618 and 1635 - i.e. a new singlo-manual harpsichord serial began about every $8 \frac{1}{2}$ years. This would mean that, at a slower initial rate of production, the first single-manual serial numbering could also have begun in about 1605.

Andreas' production of double-manual harpsichords, can be estimated only from the numbers of the $1615 \mathrm{AR}$ (serial 10, 4) and the 1620c AR (serial no. 68). Again 
depending upon whether these instruments were numbered at the beginning or end of these years the production rate could have been between about 11 to 16 instruments per year. The serial no. 19 on the 1608 AR double indicates that by 1608 Andreas' production was already well established, and had in fact begun before 1608. Assuming a somewhat slower inftial rate of production than in the 1615 to 1620 period, the 1608 serial also suggests that Andreas' production of double manual harpsichords began about 1605. The serial no. 41 of the 1633b AR indicates that there was probably an intermediate serial numbering (starting perhaps in about 1623?) but there are no other intermediate double manual serial numbers to confirm this.

Considering the present scarcity of $4 \frac{1}{2}$-voet virginals, the serial no. 35 for the 1610 AR virginal is very surprising. In view of the small number of surviving $4 \frac{1}{2}$ voet instruments, I feel that this serial cannot be interpreted to indicate that Andreas had a high rate of production after 1605 of $4 \frac{1}{2}$ voet virginals, but is most likely a continuation of Hans Ruckers' production and serialization which was maintained after Hans' death in 1598.

As only the 1643 5-voet instrument by Andreas Ruckers exists with a serial number nothing can be said about Andreas' production of 5-voet virginals.

It would appear from the previous analysis at least of the single-manual harpsichords that the serial numbers 
of Andreas II were a continuation of those of Andreas I. The 1644a AR single is signed ANDREAS RVCKERS DEN OVDEN ME FECIT, whereas the 1651a AR single is signed ANDREAS RVCKERS AND(REAS) F(IIIUS)ME FECIT, so that these can definitely be ascribed to Andreas I and Andreas II respectively. However, it seems that just as the Couchet double harpsichord numbering seems to continue the Ioannes Ruckers serials, so the Andreas II single serials continue those of Andreas I. It would therefore appear that the serial numbers cannot be used to distinguish the production either of Ioannes Couchet from Ioannes Ruckers, or of Andreas I from Andreas II Ruckers.

It has already been seen, one of the practical advantages of understanding the method by which the Ruckers numbered their instruments is that it enables one to estimate a date for an instrument which retains its number, but which has otherwise lost any trace of its date of manufacture. Such is the case with an undated Andreas Ruckers single manual harpsichord in the Vleeshuis Museum in Antwerp. This has the serial number 2 visible on the baseboard and, from the soundboard painting style, must date from sometime in the period 1605-1620. From Graph 2 it is clear that there is one single-manual serial starting in about 1618 , and presumably another in about 1605 . What little remains of the soundboard decoration is more consistent with the 1605 date than with 1618, and so the instrument has been tentatively assigned this date. 
The 'motherless' child virginal by Andreas Ruckers in the Sterckshof Museum, Deurne, is also undated but bears the serial no. 36. Thus, it must have been built about 1625, a date which is also consistent with the remaining traces of soundboard decoration.

One of the most interesting instruments which retains its sign given it by Ruckers, but which does not fit into any of the categories previously described, is the 1627 AR 'quint' harpsichord in the Gemeentemuseum, The Hague. This is a small instrument with the normal width of a Ruckers single-manual harpsichord, but it is only about $1231 \mathrm{~mm}$ long instead of the usual $1839 \mathrm{~mm}$ or so for a harpsichord at normal pitch. It is thus 4 voeten 3.6 duimen long. The inscription which appears on it is shown in Photograph 3-14. This is clearly 4 St, a fourvoet Staarstuk, and this corresponds exactly to the fourvoet virginal which has indeed the same scalings as the harpsichord. That the usual serial number is lacking suggests that this was an unusual, perhaps unique, instrument made to special order, which did not need to be distinguished from other instruments of a similar type in the workshop.

Also of interest is the sign on the combined doublew manual harpsichord with a virginal in the bentside, dated 1619, by Ioannes Ruckers, located in the Brussels Museum. A great deal of this instrument is not original, but it retains its original keyboards and keys. The top $c^{3}$ key of the upper manual of the harpsichord bears a cipher 
which is probably the usual st, but no serial number (see Photograph 3-8). This would also seem to indicate an instrument made to special order, or at least the absence in the workshop of other instruments of the same type, with which it could be confused.

The polygonal virginal of 1591 in the Gruuthuuse, Bruges, by Hans Ruckers, has a cipher written in a very flowing hand above tho sorial number 30 (Photograph 3-1). The exact meaning of this cipher is not understood, but it probably refers to the unusual polygonal shape of the instrument. The serial number, however, seems to fit in with the more usual rectangular six-voet virginals and it has therefore boen included with these in Graph 3-1. Among the six-voet virginals it should be noted that the two Hans Ruckers instruments and the 1617 Andreas Ruckers are all left-plucking spinett virginals. So far as their serial numbering is concerned at least, the Ruckers did not seem to distinguish between these and the more usual centre-plucking muselar virginals: they were all six-voet virginals.

Since the numbers of both the mother and child are the same, the numbers of the missing instrument in the case of the 'childless mothers' and the 'motherless children' can quite naturally be inferred. Also an instrument like the $1628 \mathrm{a}$ IR virginal in the Brussels Museum, which at first sight appears to be a normal 6voet virginal, is revealed originally to have been a double mother and child. The exterior of this instru- 
ment has been entirely veneered over and the keyboard compass has been extended into the space formerly occupied by the child, so that its original appearance has been completely disgulsed. However, the presence of an $\underline{m}$ on the keyframe instead of the 6 characteristic of a single virginal proves that it was originally a double mother and child instrument.

Only the first digit of the 1622 IR 6-voet virginal in Boston remains. A 2 is clearly visible on the original C/E keylever, but a second digit has been cut away during the process of a compass alteration. From Graph 3-1 it is clear that the number must have originally been about 33 to 35 .

Another advantage of understanding the Ruckers numbering system is that by extrapolating the curves obtained one can obtain a rough estimate of the number of instruments that the various members of the Ruckers family built. Because of the uncertainty caused by the scarcity of numbers for Hans Ruckers, Andreas Ruckers the Younger and Ioannes Couchet, and since there are no serial numbers with which to estimate the number of four-voet virginals or single-manual harpsichords for Ioannes Ruckers, I have therefore had to base my calculations only on the numbers available for Andreas the Elder. This results in a rough estimate of about 35 to 40 instruments of all types per year during the latter part of his active production.

At this rate Andreas was producing one new instrument in a little more than a week including one single- 
and one double-manual harpsichord every month. This is much greater than my original estimate of the Ruckers production rate, ${ }^{3-1} 5$ ) and seems to indicate that the Ruckers workshops were quite large employing a number of assistants and apprentices. It is likely that the Ioannes workshop produced as many, if not more instruments. And this represents the production of only 2 workshops in a town of only about 50,000 population. Antwerp's position as a port was clearly very important to the Ruckers, since such a high rate of production, supplemented by the output of the workshops of the other clavecimbel builders, would have soon saturated the local market.

Unfortunately we have no idea of the exact number of people working in the Ruckers workshops. From the Karest contract (see Appendix 11) it is clear that the workshop employees and apprentices worked long and hard hours. The instruments themselves indicate that such things as the jacks and sharps were not made in the workshop, but were bought from a common source of supply (see p. $356 \& 376$ and thus such items would not require workshop staff for their production. The decoration of the soundboard and case indicates that each workshop employed its own decorator, and personal experience suggest that a production rate of one instrument every 8 to 9 days or so is about the rate at which one person fluent in the style and technique could decorate a Ruckers instrument.

To the best of my knowledge, the only other makers who have both numbered and dated their instruments were 
all working in the 18th century. Baker Harris, Johannes Hitchcock, Johann Gottlob Horn, Johann Paul Krdmer, Longman and Broderip and Shudi-Broadwood are among those whose production can be calculated. By way of comparison, J.P. Krimer made about 23 clavichords per year; Shudi made only about 8 harpsichords per year at the beginning of his career, and this increased to a fairly steady rate of 26 harpsichords per year during the latter part of the ShudiBroadwood partnership. But the Ruckers were also producing about 26 harpsichords per year and in addition all of the different types of virginals as well. It is figures such as these which bring a workshop into focus more readily than any other implying, as they do, a large workshop and workshop staff, a vast number of tools and jigs, and a large reserve stock of well-seasoned wood for the cases and soundbaords.

Table 3-2 Ruckers Instrument Serial Numbers

Hans Ruckers

24 (1591) Mother-and-child muselar virginal, Yale University no. 242, New Haven, Conn., Date on lid painting.

301591 Polygonal 6-voet spinett virginal, Gruuthuuse Museum, Bruges.

$61 \quad 1598$

6-voet spinett virginal, Paris Conservatoire.

Ioannes and Andreas Ruckers

$34 \quad 504 \quad 5$-voet virginal, Brussels Museum no. 2927.

Ioannes Ruckers

15

Mother-and-child spinett virginal, Castello Sforzesco no. 595, Milan. 
Ioannes Ruckers (continued)

\begin{tabular}{|c|c|c|}
\hline 23 & 1610 & $\begin{array}{l}\text { Mother-and-child muselar virginal, } \\
\text { Brussels Museum, no. } 275 \text {. }\end{array}$ \\
\hline 26 & 1618 & Child virginal, Paris Conservatoire. \\
\hline 33 & 1623 & $\begin{array}{l}\text { Mother-and-child muselar virginal, } \\
\text { Wurt embergisches Landesmuseum, Stuttgart. }\end{array}$ \\
\hline 34 & 1628 & $\begin{array}{l}\text { Mother muselar virginal, Brussels Museum, } \\
\text { no. } 2926 \text {. }\end{array}$ \\
\hline 11 & 1629 & $\begin{array}{l}4 \frac{1}{2} \text {-voet spinett virginal, Brussels } \\
\text { Museum, no. } 2511\end{array}$ \\
\hline 46 & 1640 & $\begin{array}{l}\text { 5-vo et muselar virginal, Gemeent emuseum, } \\
\text { The Hague. }\end{array}$ \\
\hline 78 & 1642 & $\begin{array}{l}\text { 5-voet muselar virginal, Musikhistorisk } \\
\text { Museum, Stockholm. }\end{array}$ \\
\hline 16 & 1611 & $\begin{array}{l}\text { 6-voet muselar virginal, vleeshuis } \\
\text { Mus eum, Antwerp, no. } 2112 \text {. }\end{array}$ \\
\hline 20 & $(1614)$ & $\begin{array}{l}\text { 6-vo et muselar virginal, Brussels Museum, } \\
\text { no. 2930. Date on non-original soundboard } \\
\text { painting. }\end{array}$ \\
\hline $3 \pi$ & 1620 & $\begin{array}{l}\text { 6-voet muselar virginal, Museum of Fine } \\
\text { Arts, Boston. }\end{array}$ \\
\hline 38 & 1622 & $\begin{array}{l}\text { 6-voet muselar virginal, Metropolitan } \\
\text { Museum of Art, no. } 11.176 .1 \text {, New York. }\end{array}$ \\
\hline 68 & $(1638)$ & $\begin{array}{l}\text { 6-voet muselar virginal, Brussels Museum, } \\
\text { no. } 2933 \text {. Date on non-original soundboard. }\end{array}$ \\
\hline 70 & $(1636)$ & $\begin{array}{l}\text { 6-vo et muselar virginal, Harvard Univers- } \\
\text { ity, Cambridge, Mass. Date on non- } \\
\text { original lid papers and in a re-paint on. } \\
\text { the soundboard in an unusual position. }\end{array}$ \\
\hline 54 & 1627 & $\begin{array}{l}\text { Single-manual harpsichord, Hochschule fur } \\
\text { Musik, Berlin, no. } 2227 \text {. }\end{array}$ \\
\hline 34 & 1612 & $\begin{array}{l}\text { Double-manual harpsichord, Musée d'hist- } \\
\text { oire locale, Ami ens. }\end{array}$ \\
\hline 17 & 1616 & $\begin{array}{l}\text { Chromatic bass-octave double-manual harp- } \\
\text { sichord, Monsieur Nirouet, Paris }\end{array}$ \\
\hline 12 & 1618 & $\begin{array}{l}\text { Double-manual harpsichord, Schloss } \\
\text { Cappenberg, Westphalia. }\end{array}$ \\
\hline
\end{tabular}


Ioannes Ruckers (continued)

$\begin{array}{ccl}14 & 1637 & \begin{array}{l}\text { Double-manual harpsichord, Museo Stru- } \\ \text { menti Musicali, Rome. }\end{array} \\ 41 & 1638 & \begin{array}{l}\text { Double-manual harpsichord, Brussels } \\ \text { Collection, Edinburgh, no. } 6 .\end{array} \\ 14 & 1640 & \begin{array}{l}\text { Double-manual harpsichord, Erbdrostenhof, } \\ \text { Munster. }\end{array} \\ 24 & 1642 & \begin{array}{l}\text { Double-manual harpsichord, Hugh Gough, } \\ \text { New York. }\end{array}\end{array}$

\section{Ioannes Couchet}

$17 \quad 1646$

Double-manual harpsichord, Brussels Mus eum, no. 275.

34

Extended bass single-manual harpsichord, Metropolitan Museum of Art, no. 89.4. 2363, New York.

Ioseph Ioannes Couchet

1

1679

Andreas Ruckers

36

59

1639

28

1644

11

1613

38

1632

40

1613

69

1620

35

1610

37

1643
Chromatic bass-octave single-manual harpsichord, Smithsonian Institution, Washington.

Child virginal, Sterckshof Museum, Deurne.

Child virginal, Gemeent emuseum, The Hague.

Mother-and-child muselar virginal, University of Karl Marx, Leipzig, no. 1093. 4-voet virginal, Brussels Museum, no.274. 4-voet virginal, Brussels Museum, no. 1593. 4-voet virginal, Brussels Museum, no. 2928. 4-voet virginal, Smithsonian Institution, Washington.

4 $\frac{1}{2}$-voet muselar virginal, Museum of Fine Arts, Boston.

5-voet muselar virginal, Gemeentemuseum, The Hague. 


\begin{tabular}{|c|c|c|}
\hline 23 & 1617 & $\begin{array}{l}\text { 6-voet spinett virginal, Deutsches } \\
\text { Museum, Munich. }\end{array}$ \\
\hline 27 & 1620 & $\begin{array}{l}\text { 6-voet muselar virginal, Brussels } \\
\text { Mus eum, no } 1597 \text {. }\end{array}$ \\
\hline 70 & 1633 & $\begin{array}{l}\text { 6-voet muselar virginal, Brussels } \\
\text { Museum, no. } 4600 \text {. }\end{array}$ \\
\hline 2 & - & $\begin{array}{l}\text { Single-manual harpsichord, V1eeshuis } \\
\text { Museum, Antwerp, no. } 2136 \text {. }\end{array}$ \\
\hline 1 & 1618 & $\begin{array}{l}\text { Single-manual harpsichord, Hochschule } \\
\text { ftr Musik, Berlin, no. } 2224 \text {. }\end{array}$ \\
\hline $23 / 24$ & 1637 & $\begin{array}{l}\text { Single-manual harpsichord, Germanisches } \\
\text { Nationalmus eum MiR 1073, Nuremberg. }\end{array}$ \\
\hline 16 & 1644 & $\begin{array}{l}\text { Single-manual harpsichord, VIeeshuis } \\
\text { Museum, Antwerp, no. } 2137 \text {. }\end{array}$ \\
\hline 69 & 1648 & $\begin{array}{l}\text { Single-manual harpsichord, Musikhist- } \\
\text { orisk Museum, Copenhagen. }\end{array}$ \\
\hline 2 & $(1651)$ & $\begin{array}{l}\text { Single-manual harpsichord, Traquair House, } \\
\text { Innerleithen. }\end{array}$ \\
\hline 19 & $(1608)$ & $\begin{array}{l}\text { Double-manual harpsichord, Russell } \\
\text { Collection, Edinburgh, no } 3 \text {. }\end{array}$ \\
\hline 4 & 1615 & $\begin{array}{l}\text { Double-manual harpsichord, vieeshuis } \\
\text { Museum, Antwerp, no. } 2113 \text {. }\end{array}$ \\
\hline 68 & 1620 & $\begin{array}{l}\text { Double-manual harpsichord, Hochschule } \\
\text { fur Musik, Berlin, no. } 2230 \text {. }\end{array}$ \\
\hline 41 & 1633 & $\begin{array}{l}\text { Double-manual harpsichord, University of } \\
\text { Karl Marx, Leipzig, no. } 71 \text {. }\end{array}$ \\
\hline 2 & 1640 & $\begin{array}{l}\text { Double-manual harpsichord, Hôtel de Croix, } \\
\text { Namur. }\end{array}$ \\
\hline
\end{tabular}




\section{Footnotes:}

3-1) These marks have been discussed by me in 'The Numbering System of Ruckers Instruments', The Brussels Museum of Musical Instruments Bulletin, IV (1974) 75-89. But since writing this article many more Ruckers numbers have been discovered which alter some of the conclusions arrived at in this article.

3-2) For example the number 2 is written on the lower surface of the lower jack guide of the 1640b AR, and the number 59 is also written on the lower guide of the 1639a AR child virginal.

3-3) Edwin M. Ripin, 'The 'Three foot' Flemish Harpsichord', Galpin Society Journal, XXIII (1970) 35-39, and W.R. Thomas and J.J.K. Rhodes, 'Harpsichord Strings, Organ Pipes, and the Dutch Foot', The Organ Yearbook, III (1973) 112-121, both suggest that the Flemish voet contained 11 duimen. Ripin suggests that the duim was 25.7 or $26.6 \mathrm{~mm}$ in length, and Thomas and Rhodes give $25.8 \mathrm{~mm}$. Jeannine Lambrechts-Douillez, 'Apercu historique sur la facture de clavecin a Anvers aux XVI ${ }^{e}$ au XVII ${ }^{e}$ siècles', La facture de clavecin du XV au XVIII siecle, Louvain-la-Neuve (1980) 62, gives the Antwerp voet as $0.2868 \mathrm{~m}$., so that one duim would be $26.07 \mathrm{~mm}$. The value of the duim used here is the 'large duim', one of two different measures both of which seem to have been used simultaneously in the Ruckers workshops, and has been calculated on the basis of the lengths of the extant unaltered virginals (see Appendix 1 and the beginning of Chapter 5).

3-4) Klass Douwes, Grondig Onderzoek van de Toonen der Musijk, Franeker (1699), facs. 105. (see Appendix 8).

3-5) Joos Verschuere Reynvaan, Muzykaal Kunst-Woordenboek, Amsterdam (1795) 115 (see Appendix 9).

3-6) This was kindly pointed out to me by Dr. J. LambrechtsDouillez of the Vleeshuis Museum, Antwerp.

3-7) Klaas Douwes, op. 10c. cit., 104-105.

3-8) See Nicolas Meeus, 'Épinettes et "muselars": une analyse Théorique', La facture de clavecin du XVe au XVIIIe siècle, Louvain-la-Neuve (1980) 67-78.

3-9) Sibyl Marcuse, 'Transposing Harpsichords in Extant Flemish Harpsichords', Musical Quarterly, XXXVIII (1952) 414 . 
3-10) See J.H. van der Meer, 'A Flemish 'Quint' Harpsichord', Galpin Society Journal XVIII (1965) 117.

3-11) Edwin M. Ripin, 'A 'Three Foot' Flemish Harpsichord', Galpin Soci ety Joumal XXIII (1970) 35-39. The instrument described is anonymous, is dated 1724 , and although its scalings match those of the 3 voet child Ruckers virginals, it has many non-Flemish features and its Flemish provenance has not been established.

3-12) Edwin M. Ripin, 'Antwerp harpsichord-building: the current state of research', Colloquium Restauratieproblemen van Antwerpse klavecimbels, Antwerp (1970) 12-22.

3-13) Eugène de Bricquevilie, Les Ventes d'Instruments de Musique au XVIII ${ }^{\theta}$ Siècle (Paris 1908) 15. (seo Appendix 15 p. 896) The authenticity of this instrument, of a type unlikely to have been faked in the 18th century, seems undoubted. Another harpsichord by Andreas dated 1601 (p. 11-12) is listed as being 7 pieds 3 pouces long $(2355 \mathrm{~mm})$. But this is about $10 \mathrm{~cm}$ longer than a normal Ruckers double manual harpsichord and is therefore probably unauthentic.

3-14) See no. 78 in Albert G. Hess, The Transition from Harpsichord to Piano', Galpin Society Journal VI (1953) p. 84 and R. Russell (1959) p. 152 No. 13.

3-15) See footnote 3-1). 


\section{Chapter 4 - The Stringing and Pitches of Ruckers instruments}

A number of important factors must be considered when a builder decides upon the stringing to be used for an instrument. Because of the importance of the gauges and string materials used in determining the final sound of an instrument, the role of both the diameter and the material of the string must be clearly understood. The string must provide a fundamental tone with a set of harmonics above it that are as close as possible to integral multiples of the fundamental frequency, and at the same time it must provide enough energy to cause the soundboard to radiate the resulting sound into the air surrounding the instrument.

To provide a set of harmonics as pure as possible, the string should be as flexible as possible, and under the maximum possible tension. The flexibility of the wire can be increased by making the string as thin and long as possible and by using an inherently flexible material. For any given pitch, the length of the string is increased until the tension in the string is such that the string is just on the point of breaking. Since this breaking point is unaffected by the diameter of the string for wire of uniform properties, the ideal string will have a large ultimate breaking stress and a-small stiffness or Young's Modulus. Unfortunately, of the common materials available, those of high breaking stress also have a high 
stiffness so that the desir ability of one material over another is not very great.

In order to impart enough energy to the soundboard to cause the string to radiate its sound into the surrounding air, the lighter and extremely flexible string materials such as gut and silk must be rejected in favour of the heavier metal strings, simply by virtue of the fact that they lack the inertia necessary to cause sufficient motion in the soundboard. The most suitable and readily available metal strings are the iron and copperalloy materials. Iron has a slightly lower stiffness in relation to its breaking point than the copper-alloy materials, and is therefore marginally the preferable material. The ultimate breaking stress of iron being somewhat higher than that of the strongest copper alloys means that longer strings must be used with iron in order that it be close to its breaking point. However, the use of critically stressed iron throughout the entire compass of keyboard instrument would result in unreasonably long strings in the bass of the instrument. For example, an instrument at the same pitch as a 6-voet virginal would require strings approximately 2.84 metres long for low $C$ if it were strung in steol right to the bottom. The problem is avoided by foreshortening the bass strings and using the softer copper-alloy strings up to a point permitted by their breaking strength. This results in an improvement over the continued use of the stiffer iron in this part of the compass. 
Given that the strings must be of metal, one must arrive at a compromise diameter where the energy of the radiated sound is as great as possible by using a large diameter string, which is, on the other hand, small to ensure enough that the stiffness of wire does not seriously affect the purity and musical acceptability of the harmonics produced. Choosing the gauge of the wire to be used can thus be done only by experiment, and, being subjective, will vary from individual to individual, and from time to time according to aesthetic judgement. Nonetheless certain physical constraints will affect the choice of any person carrying out the experiment.

Theory shows that in order for an acoustical radiator to be efficient, one of the requirements is that the actual physical size of the radiator should be approximately equal to or greater than the size of the wavelength of the propagated radiation. In the treble part of a harpsichord or virginal this is approximately the case so that the fundamental note in the string as well as all of the shorter wavelength harmonics are radiated by the soundboard there. But in the bass of the instrument the dimension of the radiating soundboard is only about one tenth of the wavelength of the fundamental tone being sounded. A simple experiment shows that in the bass the fundamental tone is not radiated at all. If one removes the jack of the lowest note from a harpsichord, the lowest string can then be plucked 
in the middle with the soft part of the fingers of one hand. In this way the fundamental will be excited very strongly in the string. Any weak odd harmonics also excited can be damped out by touching the string near the bridge or nut momentarily with the soft part of a finger of the other hand, leaving only the fundamental note excited in the string. The string will then be seen to be vibrating with a large amplitude, but the soundboard will radiate absolutely no sound. This simple experiment proves that the soundboard does not radiate the fundamental tone in the bass of a harpsichord or virginal. How then do we sense the fundamental tone when the string is plucked and sounded normally? The answer seems to lie in the properties of the ear itself. Because of the harmonics present in the string and excited by plucking it sharply near one end, the ear creates the impression of a fundamental from the structure of the harmonics themselves. If the harmonics are all exact multiples of the fundamental, then the fundamental is just the difference tone between successive harmonics contained in the harmonic series of the string. It is this series of difference tones which is perceived by the ear. If the harmonics are not exact multiples of the fundamental then the ear will perceive a band of difference tones rather than a single unique fundamental. Such a note will beat with itself and have' a totally unmusical character. It is thus very important that the harmonics be as pure as possible by ensuring a long, 
thin string sounding as near its breaking point as possible, and with as small inherent stiffness as possible. In order to compensate for the inefficiency of the soundboard in the bass, heavier strings must be used. Also, because of the increased elasticity of the strings in the bass caused by their increased length, a thin long string is displaced by the quill to such an extent that the pitch of the string is slightly sharpened due to the increased tension, and the pitch of the string after it is released from the quill becomes flatter as time progresses. Fortunately both the soundboard inefficeincy and the pitch instability for thin strings operate in the same direction and determine the use of thicker strings in the bass than in the treble. Calculations show that even though the bass strings are much heavier and thicker than those in the treble, the inharmonicity caused by the stiffness and thickness of the strings is more than compensated for by their length in the bass and that in fact, for any normal stringing plan, the inharmonicity of the treble strings is greater than it is for the bass strings.

As will shortly become clear, the historical instrument builders and designers, and writers on the subject had a remarkable insight into these factors even though their insight was perhaps much more intuitive than the explanation given above. Claas Douwes ${ }^{4-2)}$ although he lived some 50 years after the Ruckers family had ceased production, had considerable things to say on the subject 
and his discussion throws much light onto the instruments already under study. Douwes mentions three different types of stringing material, and lists the actual gauge numbers of the strings for different sizes of instrument, although unfortunately he does not give the diameter equivalents for these gauge numbers. In order to understand better the scalings and string gauges that Douwes gives it is necessary first to understand the pitch scheme of Ruckers instruments. It will then become clear, I think, that Douwes lists apply perfectly to Ruckers clavecimbels. An examination of the strings and gauge numbers on some extant instruments shows also that a close analysis of these may give some indication of the actual sizes of Douwes string gauges. The pitches of Ruckers instruments

Whereas the absolute pitch of a wind instrument can be determined within very narrow limits, the absolute pitch of a stringed instrument can not because any given string can be tuned up and down over a limited range and still remain musically acceptable. However, a comparison of the ratio of string lengths gives an indication of the relative pitch of two instruments, and such a comparison shows that the Ruckers/Couchet family built instruments at pitches differing by fixed amounts, corresponding to common musical intervals. The study of these pitch relationships should throw light not only on musical practice during the period contemporary with the Ruckers, but also on some of the design principles utilized, if 
not invented, by the Ruckers family.

The discussion in Chapter 3 introduced the different models of clavecimbel made by the Ruckers and Couchets.-3) Like other instruments which occur in families, the members of which are large and small, these keyboard instruments are clearly meant to sound at different pitches. Above middle c $\left(c^{1}\right)$ the Ruckers instruments exhibit a Pythagorean scaling which halves in length every octave. Thus in this region the relative pitch of two notes bears a strict mathematical relationship to the string length so that, for example, the string soundin the note $g^{2}$ is two-thirds the length of the $c^{2}$ string a fifth lower. If another smaller instrument whose $c^{2}$ key activates a string which is the same length as the $\mathrm{g}^{2}$ string in the larger instrument, then we can be fairly certain that the two instruments are meant to sound a fifth apart.

Douwes mentions 6-voet, 5-voet, 4-voet, 3-voet, and 2 voet 4 duimen instruments. Edwin M. Ripin ${ }^{4-4}$ ) has suggested pitch assignments for the first four of these instruments, based on the scalings given for them by Douwes but without reference to extant instruments. It therefore remains to examine the scalings and relative pitches of some surviving instruments.

Table 4-1 shows the length and proposed pitches of a number of Ruckers virginals. The instruments chosen for study here are of necessity those whose scalings and dimensions have remained unaltered up to the present day. 
Table 4-1

\begin{tabular}{|c|c|c|c|c|c|}
\hline \multirow[b]{2}{*}{ Instrument } & \multicolumn{3}{|c|}{ Length } & \multirow{2}{*}{$\begin{array}{l}\text { Ruckers } \\
\text { upper } \\
\text { number }\end{array}$} & \multirow{2}{*}{$\begin{array}{l}\text { Proposed } \\
\text { pitch }\end{array}$} \\
\hline & $\mathbf{m m}$ & duimen & voet en & & \\
\hline (c 1600) HR & 1709 & 66.0 & 6.00 & 6 & $\mathbf{R}$ \\
\hline $1604 \mathrm{HR}$ & 1424 & 55.0 & 5.00 & 5 & $R+2$ \\
\hline $1629 \mathrm{IR}$ & 1282 & 49.5 & $4 \cdot 50$ & $4 \frac{1}{2}$ & $R+4$ \\
\hline $1613 \mathrm{~b} A R$ & 1138 & 44.0 & 4.00 & 4 & $R+5$ \\
\hline (c 1600) HR & 820 & 31.7 & 2.88 & $\mathbf{k}$ & $R+8$ \\
\hline$(c 1610) a \mathrm{AR}$ & 711 & $27 \cdot 5$ & $2 \cdot 50$ & $?$ & $\mathrm{R}+9$ \\
\hline
\end{tabular}

This has unfortunately meant that examples had to be chosen from the workshops of both Ioannes and Andreas Ruckers, which were built at various times during their active lifespans. Despite this the degree of accuracy and standardization of the Ruckers workshop practice results in a wholly convincing comparison, which strongly suggests that the lists in Douwes are indeed applicable to Ruckers instruments.

It is important to note that an accurate pitch comparison is possible only because all of the instruments being compared belong to the same family tradition. A comparison of the scalings of, say, two Italian instruments to determine their pitch relationship is more difficult unless the two are also built by the same builder or family of builders. It is therefore extremely fortunate that such a large number of instruments of different sizes and pitches survives, all built within the same tradition. 
In making the calculations in Table 4-1, as in Chapter 3 p. 94, the Flemish voet is taken to have 11

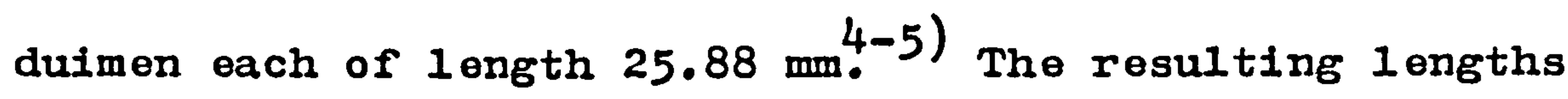
in Flemish voeten are then clearly equal to the upper half of the Ruckers number-symbol normally found on various parts of the action and elsewhere on the instrument (see Chapter 3).

Although it is not clear that there was any fixed pitched standard during Ruckers' time nor is it clear that the pitch of any one type of Ruckers instrument was considered as standard, the pitch of the 6-voet virginal has been taken as reference for the simple reason that this pitch survived into the late 17 th and the 18th centuries and is closest to our present modern pitch standard. This pitch will here be called 'reference pitch' and denoted by $R_{0}^{4-6)}$ The pitches $R+2, R+4$, $R+5, R+8$, and $R+9$ thus are a major second, a fourth, a fifth, an octave, and a ninth above reference pitch. The virginals at a pitch of $R+4$, the $4 \frac{1}{2}$-voet virginals, are absent from Douwes lists. He mentions them in terms neither of their scalings nor of their stringing. From the only basis we have of estimating the number of instruments of this type produced - namely the Ruckers number - it seems likely that fow of these virginals were made. For example, in 1629 Ioannes Ruckers had built only eleven $4 \frac{1}{2}$-voet virginals whereas he had produced thirty or more of each of the other types of instrument at this same date. Because of their 
scarcity it is quite possible that they were unfamiliar to Douwes and therefore omitted from his work.

The last entry in Table $4-1$ at a pitch of $R+9$ is mentioned by Douwes in terms of its length "een Klavecimbeltje van twee voeten en vier duimen" and its stringing list is given, without however a mention of its scalings and therefore without any implication of its relative pitch. However using the scalings of the one extant example of this type of instrument by Ruckers, this pitch assignment is confirmed just as with the larger instruments in Table 4-2. A double confirmation of this pitch assignment will be made later by a careful examination of Douwes stringing lists.

Comparison of the scalings of the various Ruckers virginals is made in Table 4-2. Here the measured length of each ' $c$ ' and ' $f$ ' throughout the compass is given. Each of these lengths has then been normalised to take into account the proposed difference in pitch between each instrument type and reference pitch. Thus in just intonation, a rise in pitch of a tone is equivalent to a foreshortening of $\frac{8}{9}$, a rise in pitch of a fourth is equivalent to a foreshortening of $\frac{3}{4}$, a fifth of $\frac{2}{3}$, and octave of $\frac{1}{2}$, and a ninth of $\frac{4}{9}$. Thus this normalisation is accomplished by multiplying by the reciprocal of the foreshortening factors, to compare the higher of the instruments to reference pitch. It is clear that the agreement between the numbers on the right hand side of each column for each ' $c$ ' and ' $f$ ' is very good, and that no other conjecture as to 
(151)

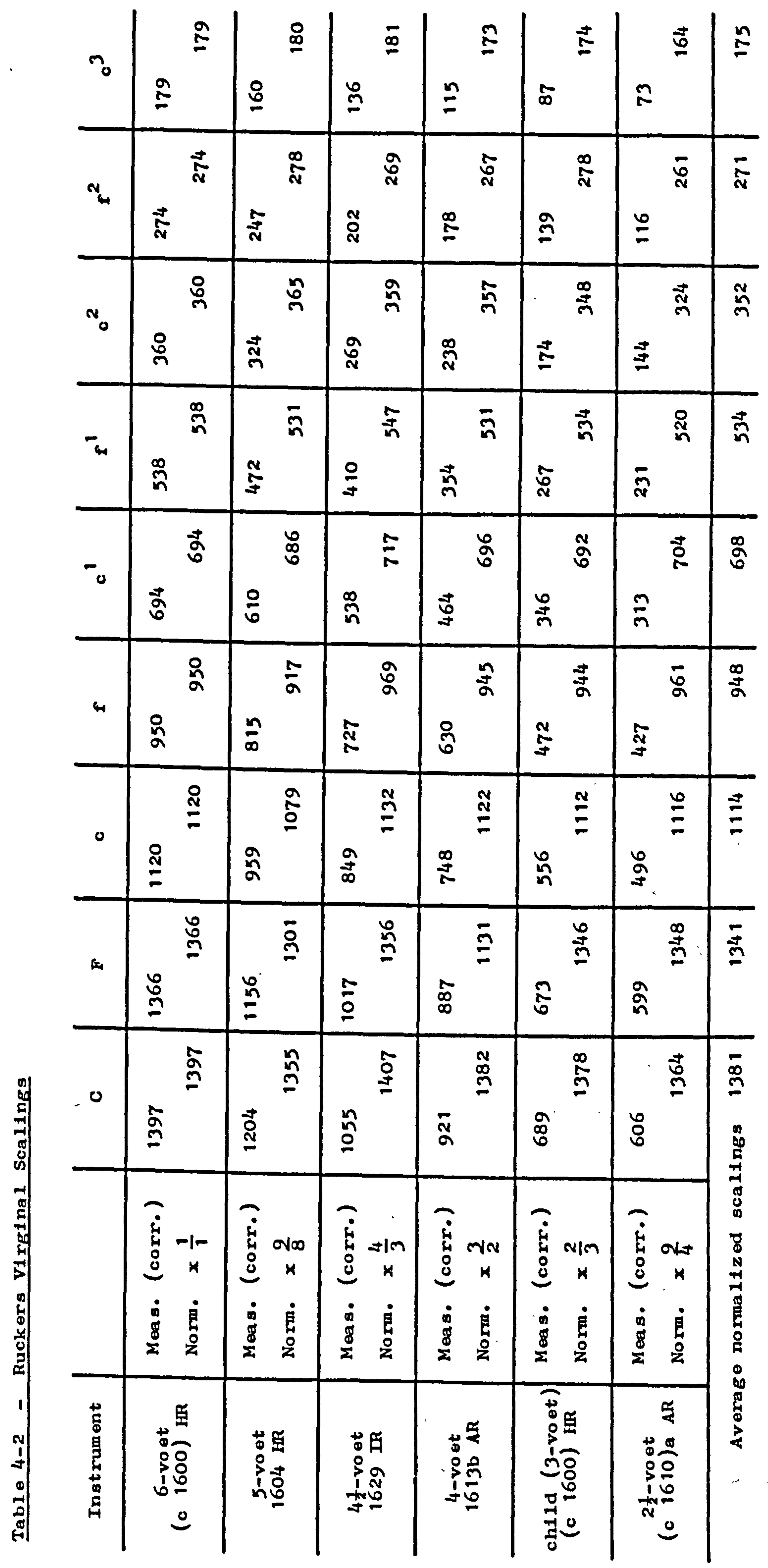


the intended pitch of any instrument would yield as good agreement throughout the entire compass. Thus the pitches proposed for each instrument in Table 4-1 can be taken as the pitch intended for the instrument by the Ruckers.

It is important to note that the scalings of the various sizes of virginal are in proportion to the instrument's pitch, not only in the treble part of the compass, where is is normally strung with iron, but also in the tenor and bass where copper alloy strings are used. The full significance of this will be pointed out in the discussion of the stringing materials. It should also bo realised that the scalings of alternate notes in a virginal are slightly longer and shorter than the 'average' in the part of the compass being considered.. This is because the alternate strings have to be moved slightly apart to make room for the jacks which are placed between the successive pairs of strings. In the case of all Ruckers virginals the 'c' strings are slightly too long, and the 'f' strings are slightly too short. Calculation shows that the 'average' string lengths for the 'c's and 'f's in a Ruckers virginal can be computed by applying the following correction factors to the ' $c$ ' and ' $f$ ' strings from $c^{1}$ to $c^{3}$ :

\begin{tabular}{l|c|c|c}
$\begin{array}{l}\text { Type of } \\
\text { Virginal }\end{array}$ & Correction & $\begin{array}{c}\text { Reduction factor } \\
\text { for 'c' strings }\end{array}$ & $\begin{array}{c}\text { Elongation factor } \\
\text { for 'f' strings }\end{array}$ \\
\hline 6-vo et & $2.0 \%$ & 0.980 & 1.020 \\
5-vo et & $1.8 \%$ & 0.982 & 1.018 \\
$4 \frac{1}{2}$-vo et & $2.0 \%$ & 0.980 & 1.020
\end{tabular}




\begin{tabular}{l|l|l|l} 
4-voet & $1.8 \%$ & 0.982 & 1.018 \\
3-voet & $2.3 \%$ & 0.977 & 1.023 \\
$2 \frac{1}{2}$-voet & $2.1 \%$ & 0.979 & 1.021
\end{tabular}

The corrected measured scalings in Table 4-2 are plotted in Graph 4-1 in such a way that the actual sounding pitch of each type of virginal has been taken into account. Thus the scalings of the 5-voet virginal are plotted two semitones higher in pitch than the 6-voet one, the $4 \frac{1}{2}$-voet virginal a fourth higher, the 4-voet virginal a fifth higher, the child virginal an octave higher and the $2 \frac{1}{2}$-voet virginal a ninth higher than reference pitch. In each of these plots the curve becomes Iinear above the played note $c^{1}$. The best straight line was fitted to these points by the method of least squares subject to the restriction that the line gave points whose scalings decreased by $\frac{1}{2}$ with each octave increase in pitch. This gives an average treble scaling converted to reference pitch for these six virginals of $c^{2}=$ $354.8 \pm 4.2 \mathrm{~mm}$.

In an analogous way the scalings of three harpsichords are treated in Table 4-3. The instruments under consideration are the following:

1) The lower manual of the $1638 \mathrm{~b}$ IR double-manual harpsichord at sub-quart pitch and its octave at quint pitch;

2) The 1644a AR at reference pitch and its octave;

3) The 1627 AR 4-voet single-manual harpsichord at quint pitch and its octave a twelfth above reference pitch. 


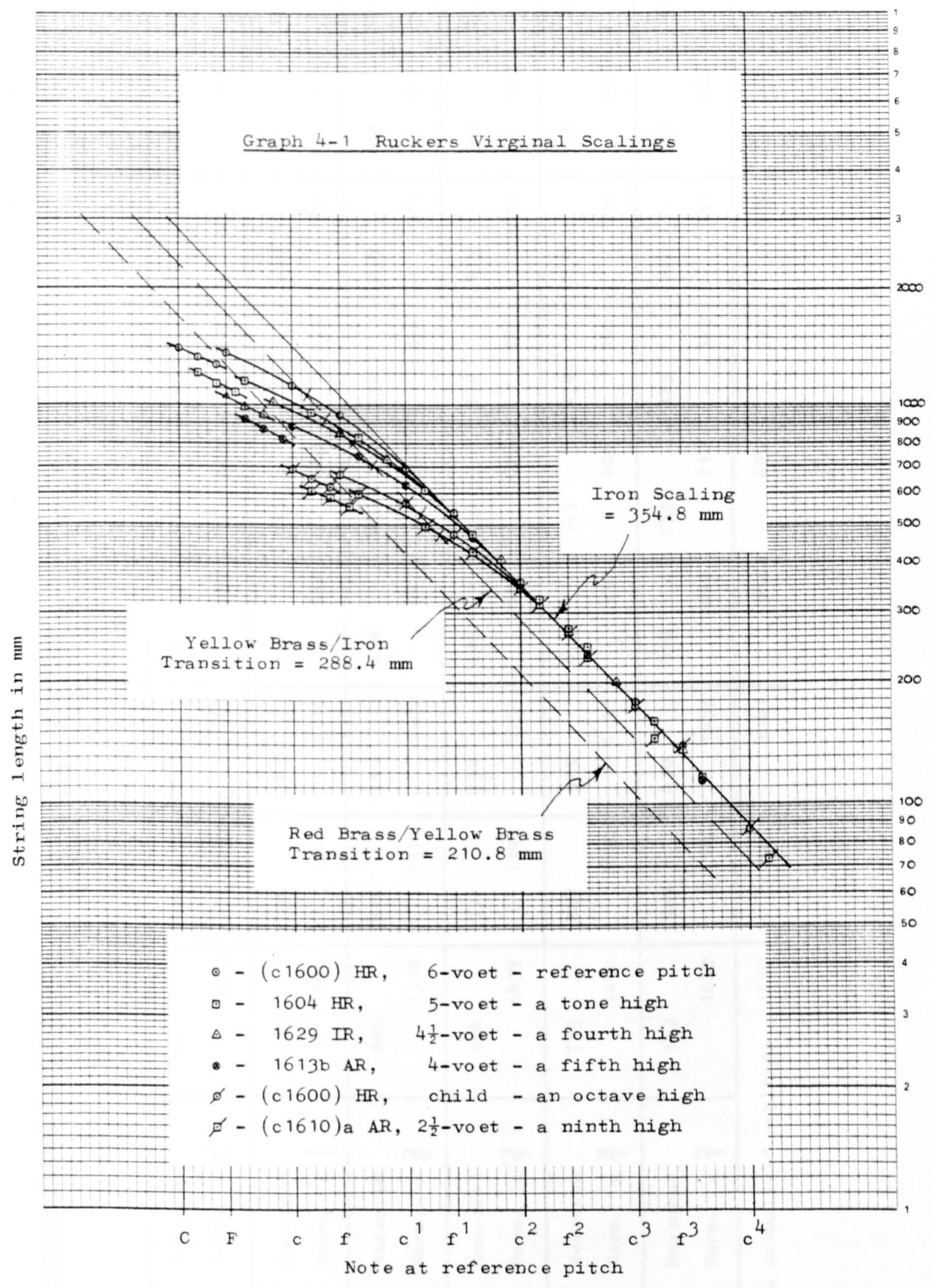




\begin{tabular}{|c|c|c|c|c|c|c|c|}
\hline$n_{0}$ & $\stackrel{\mathscr{\alpha}}{\underline{\alpha}}$ & $\underline{\Xi}$ & $\bar{\Phi}^{\stackrel{\infty}{\infty}}$ & $\stackrel{\varrho}{\cong}$ & 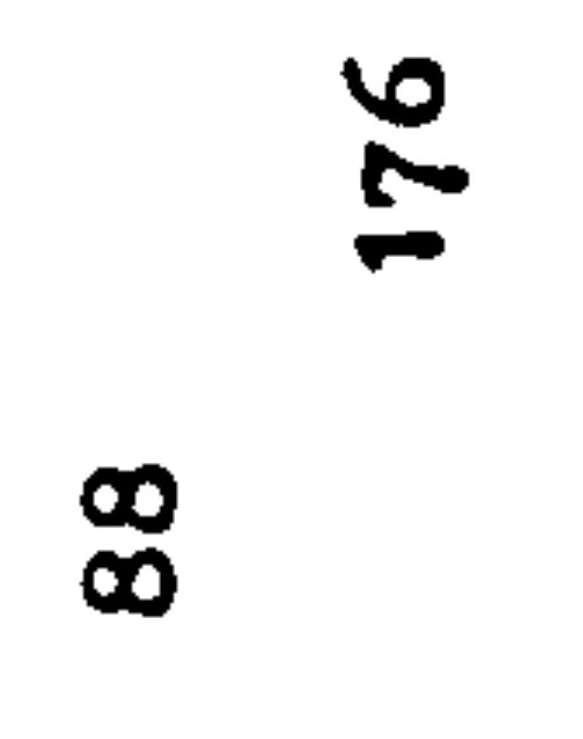 & $\stackrel{\infty}{\stackrel{\circ}{\circ}}$ & 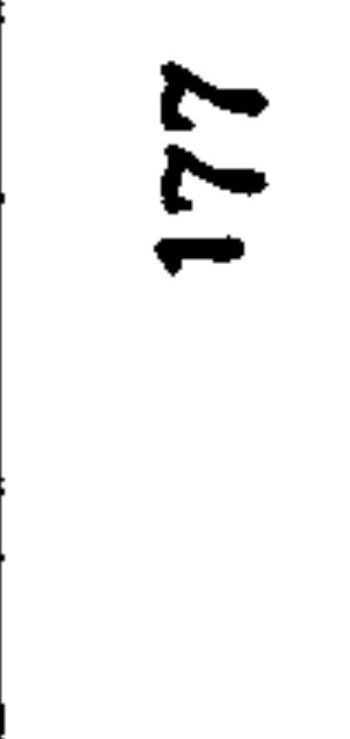 \\
\hline$N_{\omega}^{N}$ & 葛 & 옷 & 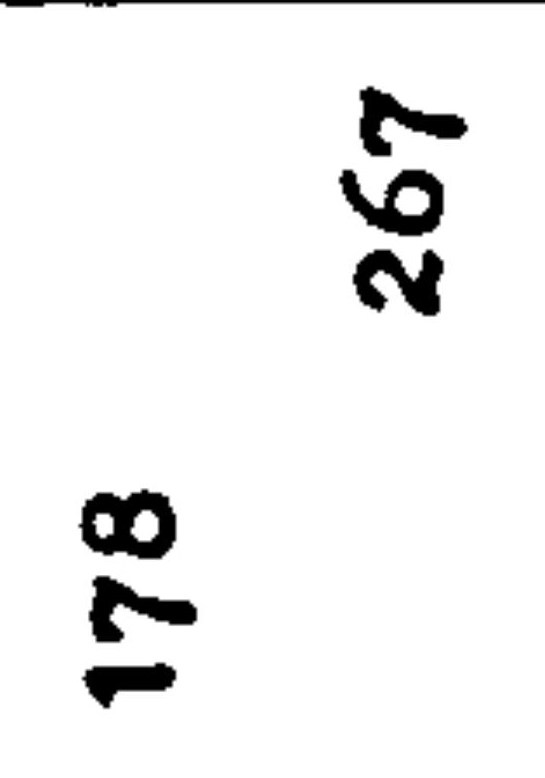 & $\stackrel{\hat{\sigma}}{\stackrel{0}{a}}$ & $\stackrel{\circ}{\stackrel{\alpha}{\sigma}}$ & ${ }_{\infty}^{\hat{\sim}}$ & స్రి \\
\hline $\boldsymbol{v}_{0}$ & $\stackrel{\infty}{\xi}$ & min & 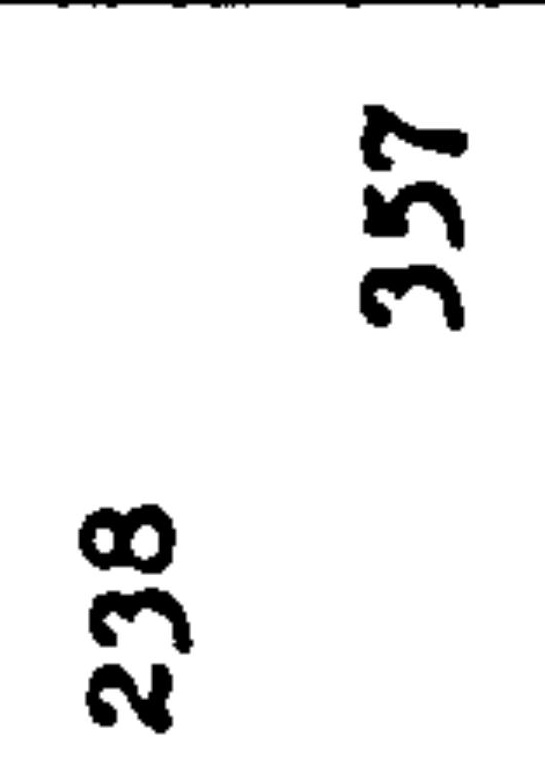 & مิ & $\stackrel{\infty}{n}$ & $\Xi^{\bar{n}}$ & 足 \\
\hline- & $\begin{array}{l} \\
\\
\stackrel{\infty}{*}\end{array}$ & 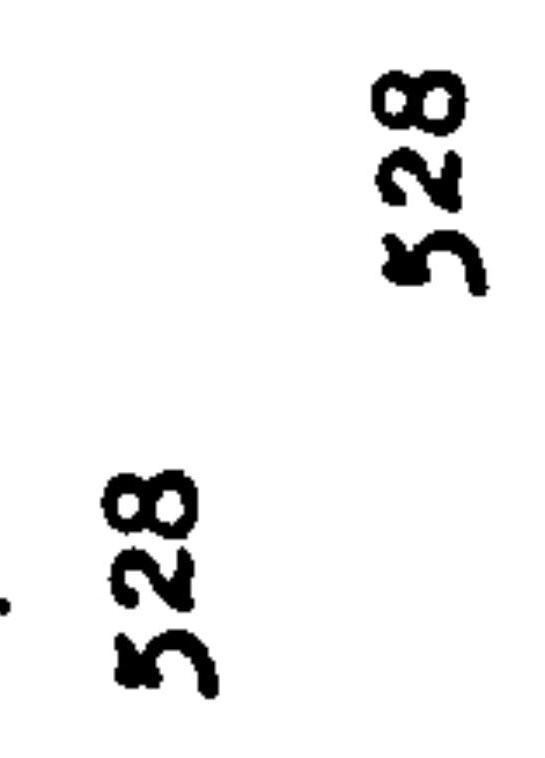 & 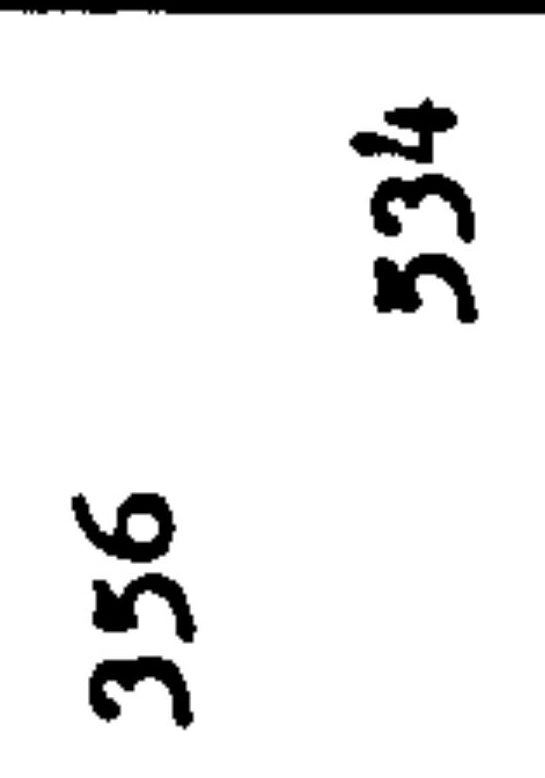 & ${ }_{\substack{\tilde{N} \\
\text { N }}}$ & 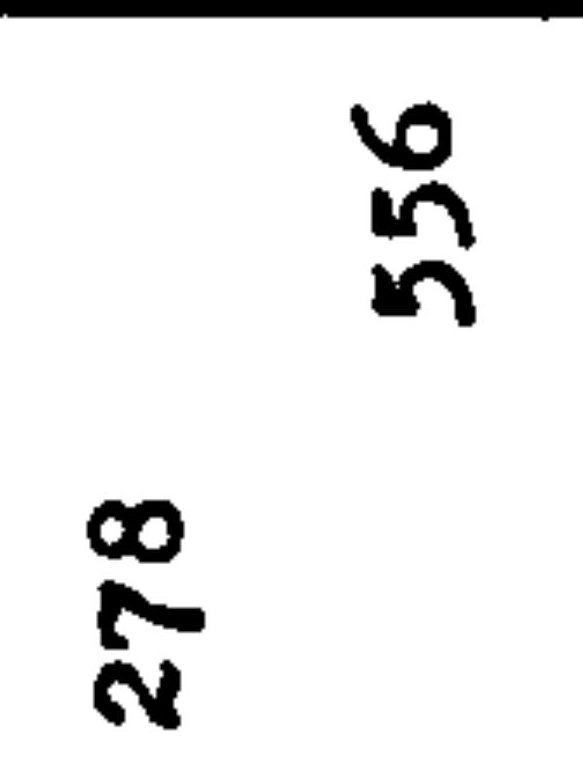 & 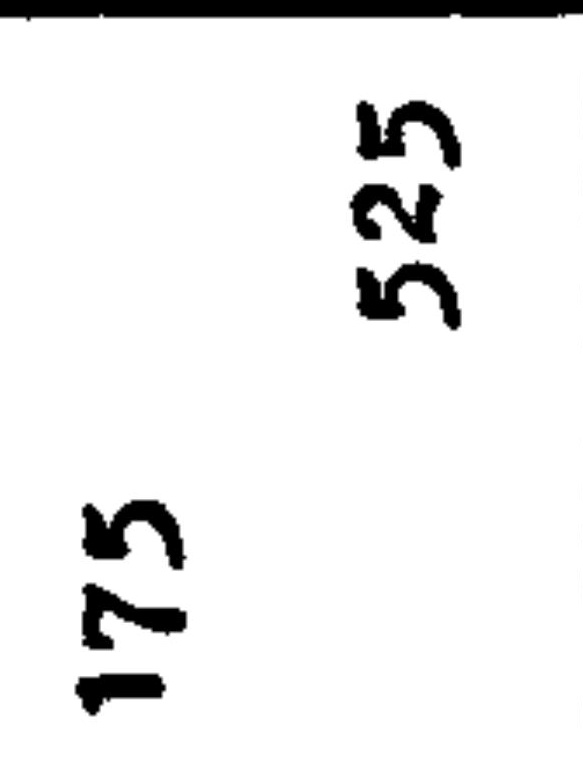 & స̃ \\
\hline$-_{0}$ & 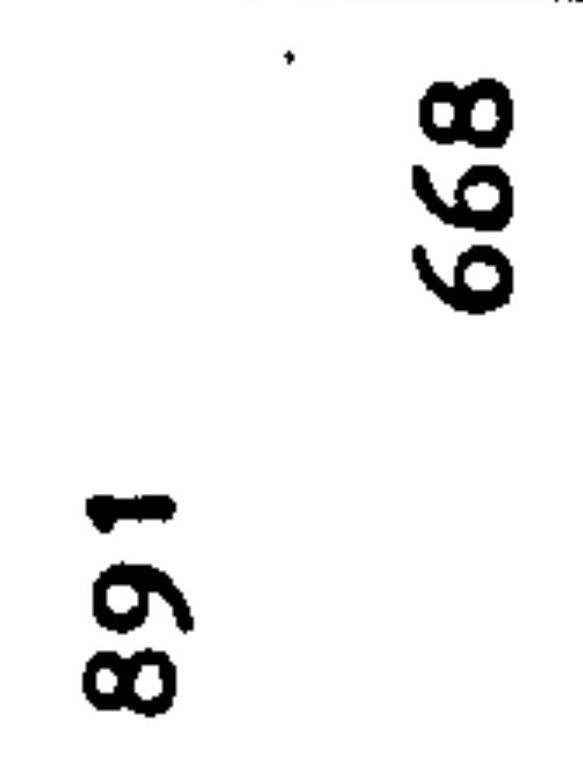 & $\underbrace{\infty}_{\mathscr{\infty}}$ & $\begin{array}{l}\text { Sू } \\
\bar{\sigma}\end{array}$ & 占 & 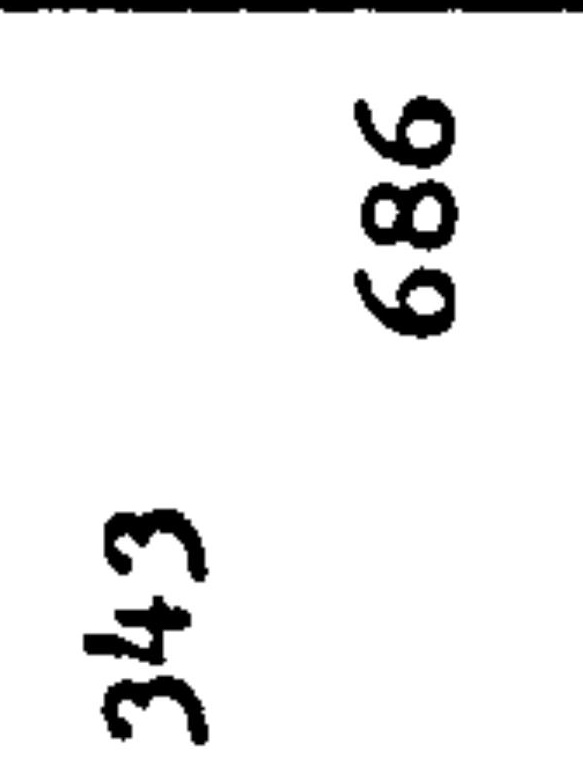 & $\overline{\bar{\alpha}}$ & : \\
\hline$\omega$ & 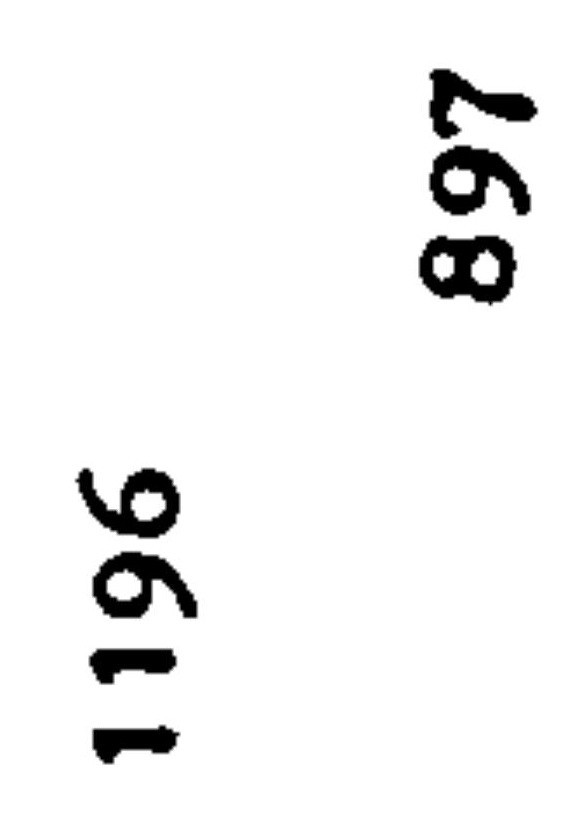 & $\begin{array}{l}\text { व̊ } \\
\text { 웡 }\end{array}$ & 疋 & $\bar{\delta}_{\tilde{\sigma}}$ & 品 & $\stackrel{\tilde{\rho}}{\underline{0}}$ & 吕 \\
\hline 0 & $\stackrel{8}{\Xi}$ & $\stackrel{\stackrel{n}{\underline{N}}}{\underline{\underline{N}}}$ & 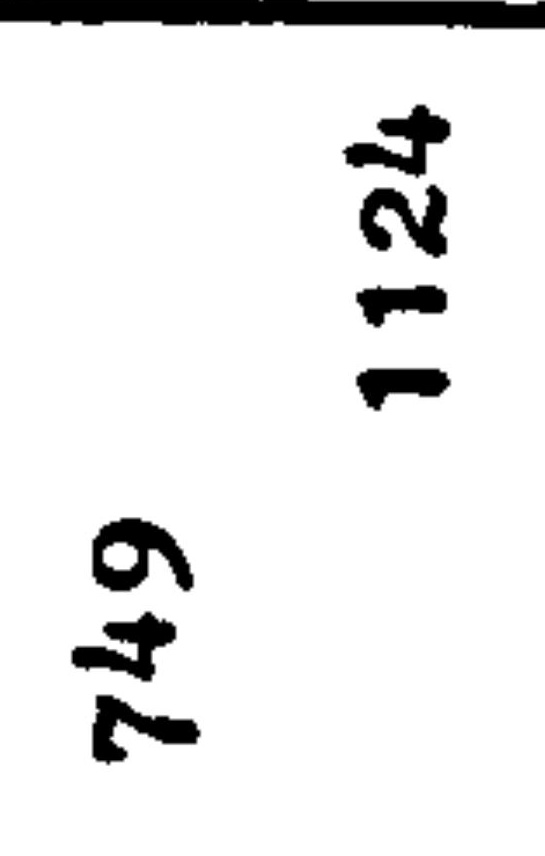 & $\stackrel{\bar{m}}{\underline{\underline{n}}}$ & $\stackrel{0}{\stackrel{2}{z}}$ & 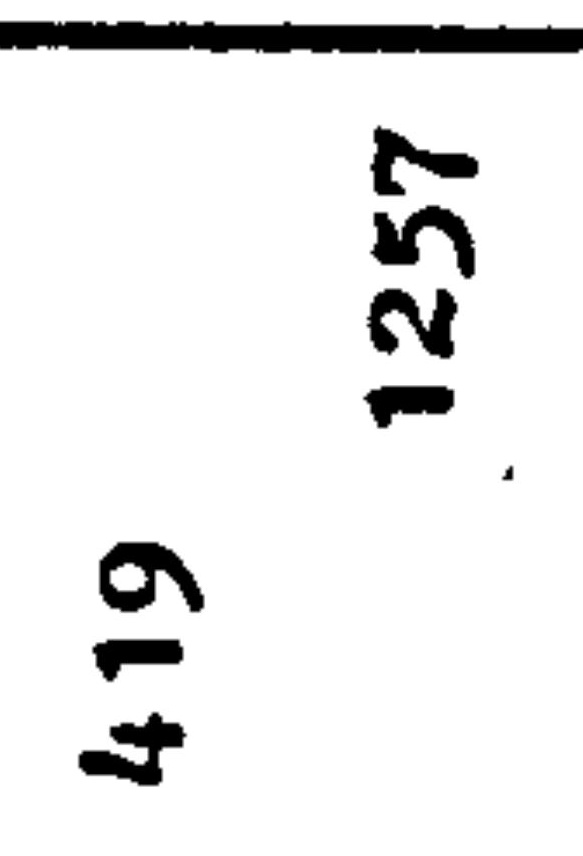 & $\Xi$ \\
\hline w & 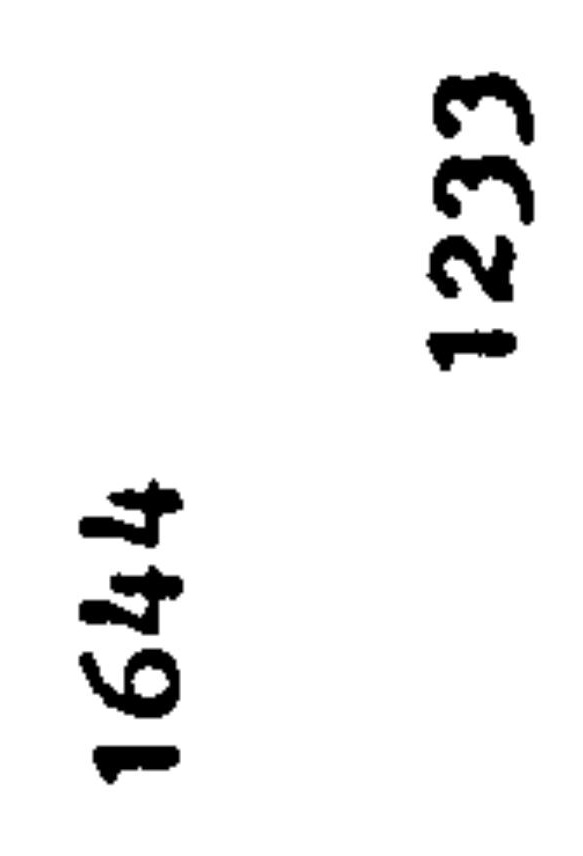 & 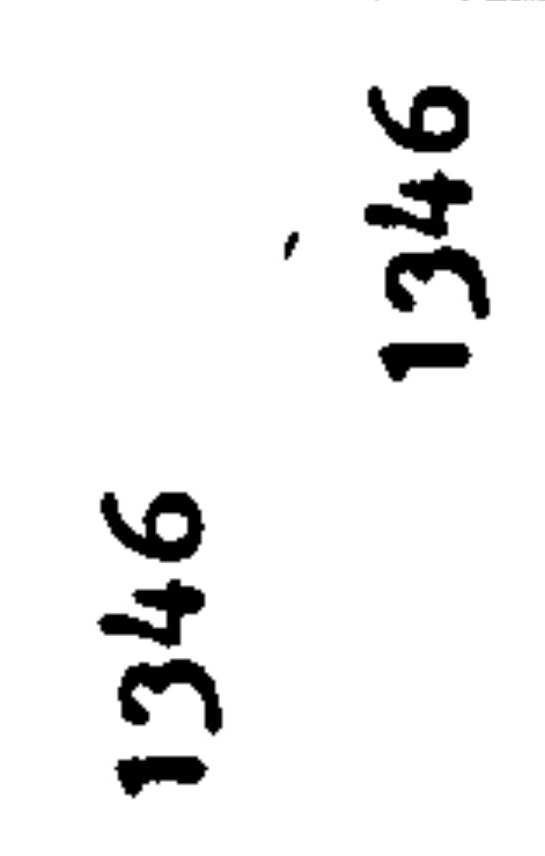 & 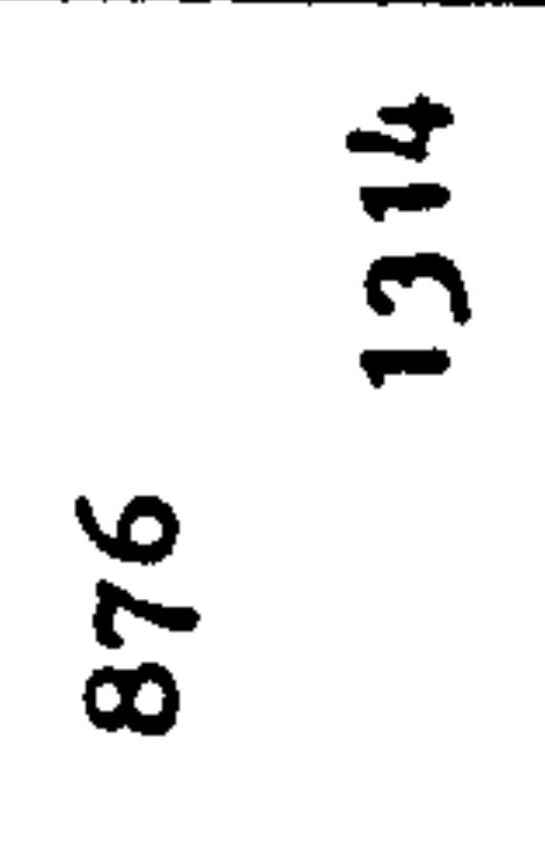 & Бू & 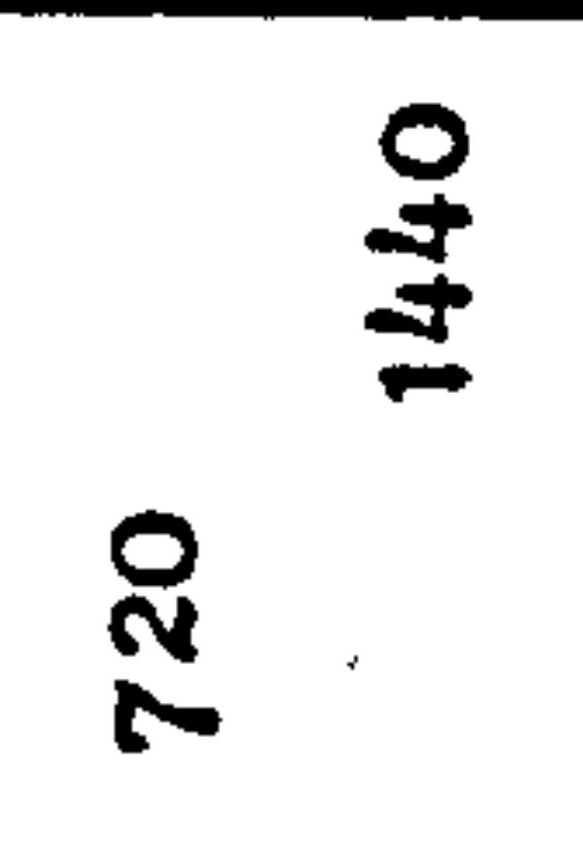 & 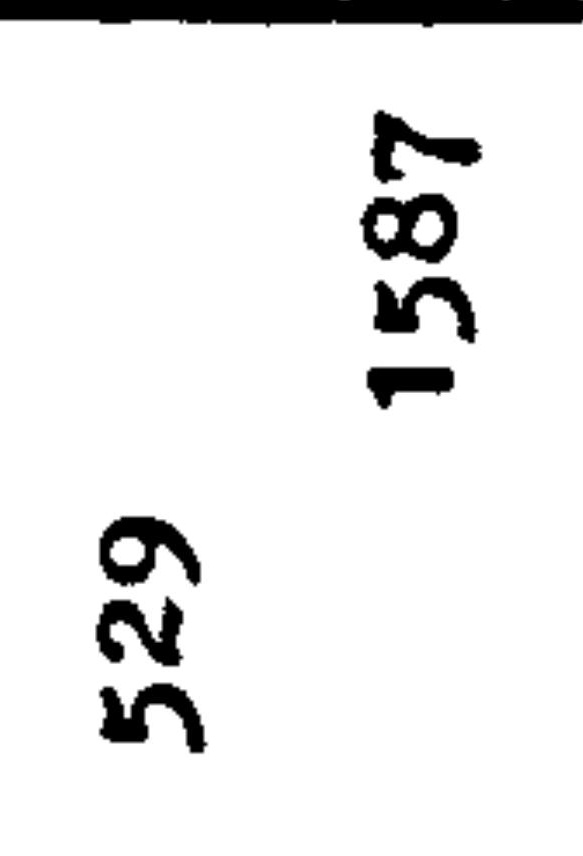 & 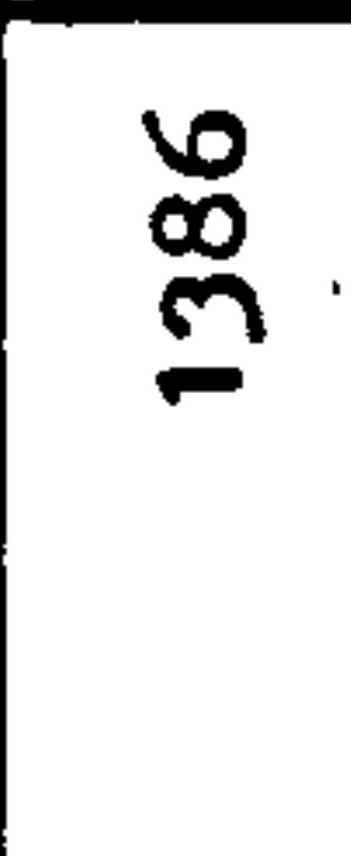 \\
\hline 0 & 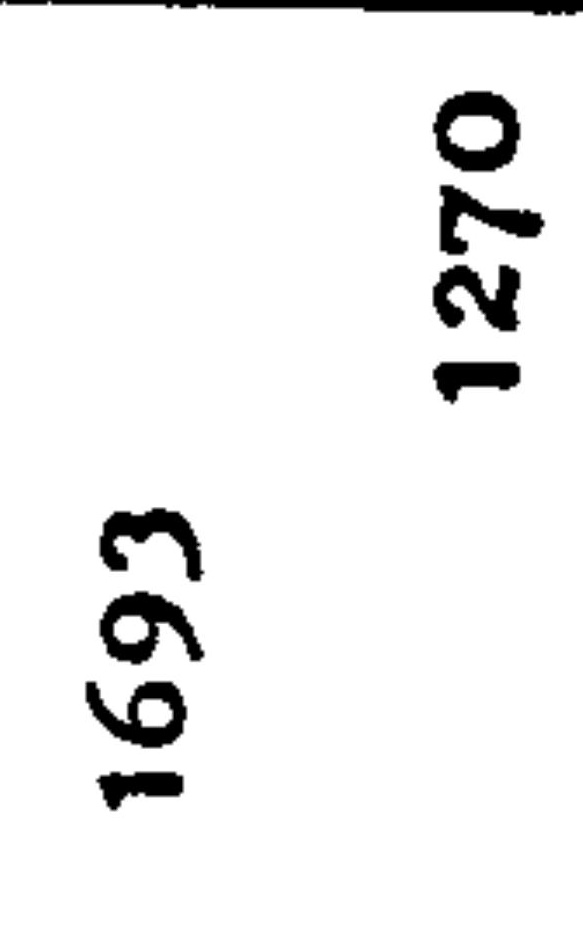 & $\stackrel{n}{\stackrel{n}{n}}$ & 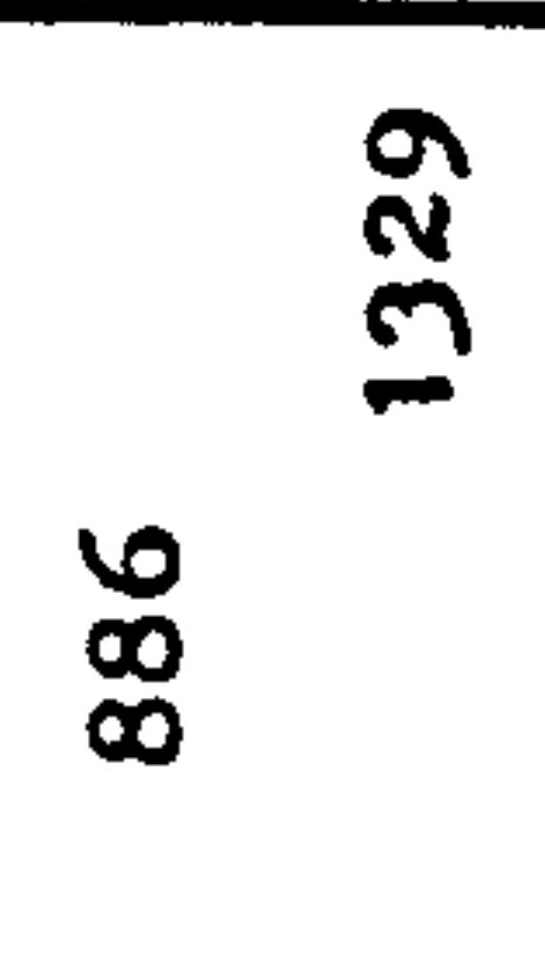 & 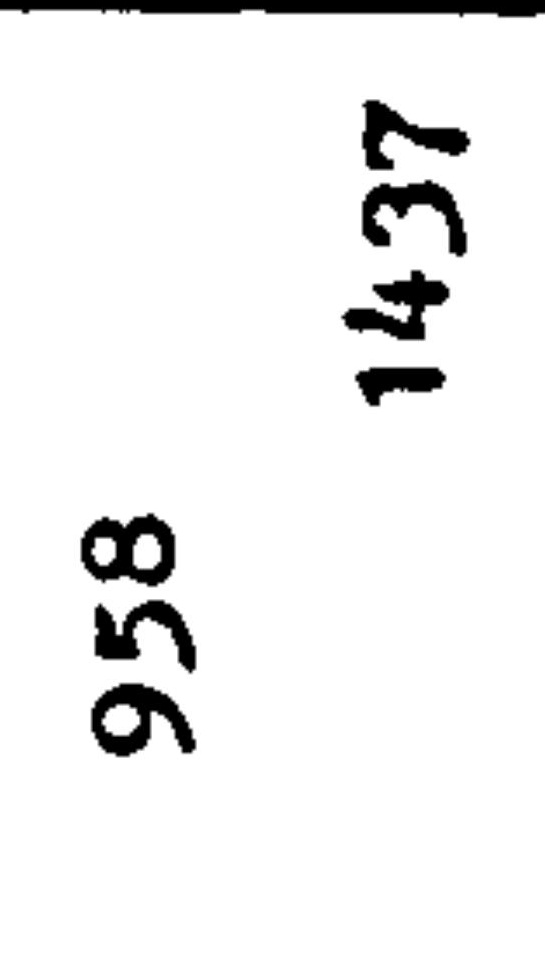 & 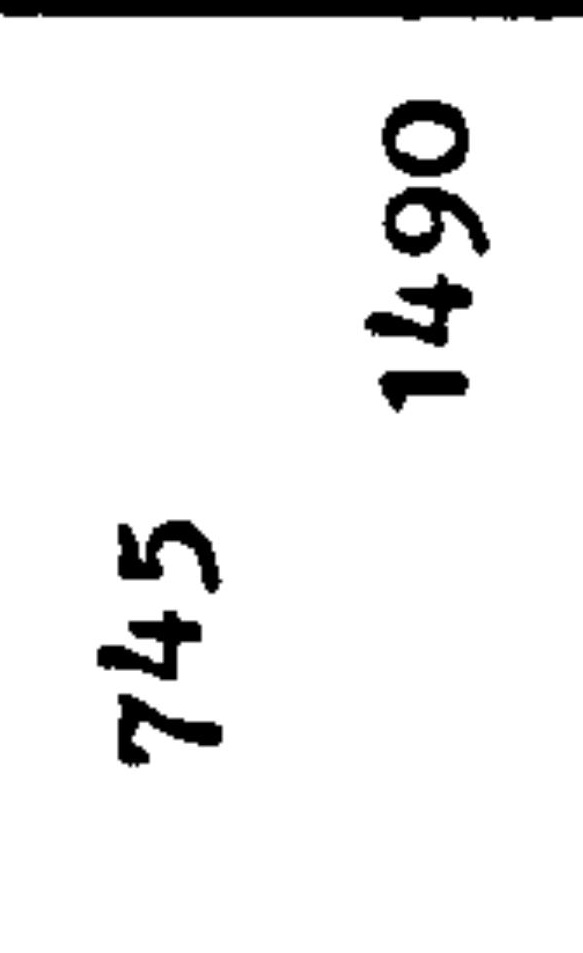 & 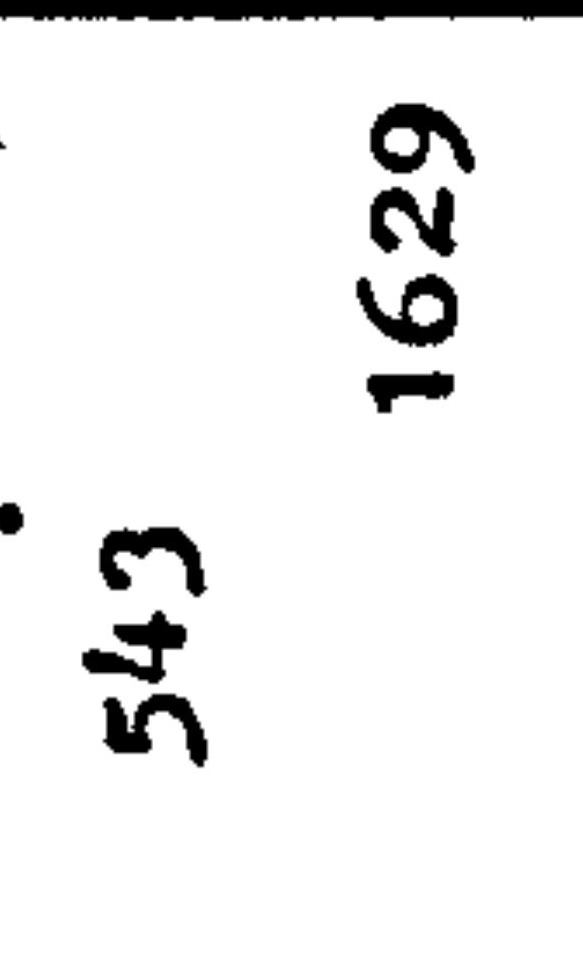 & 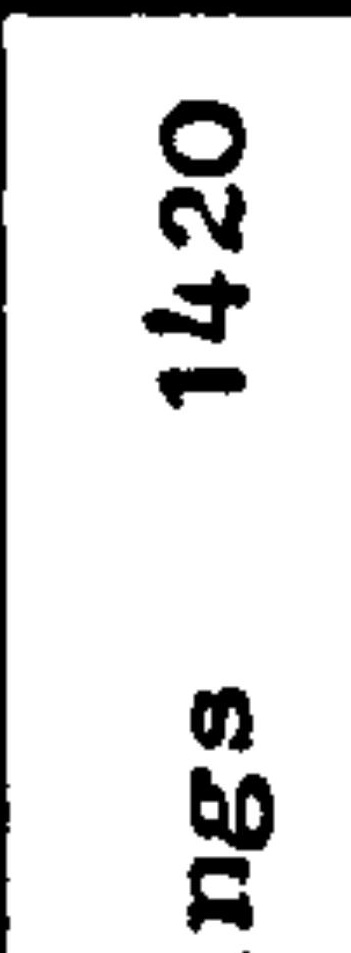 \\
\hline & 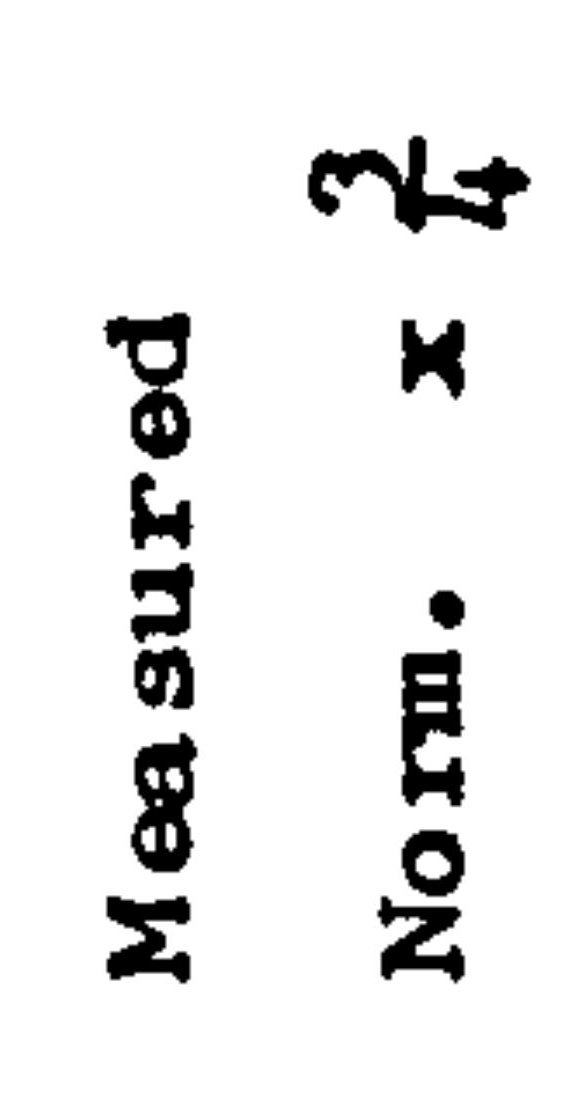 & 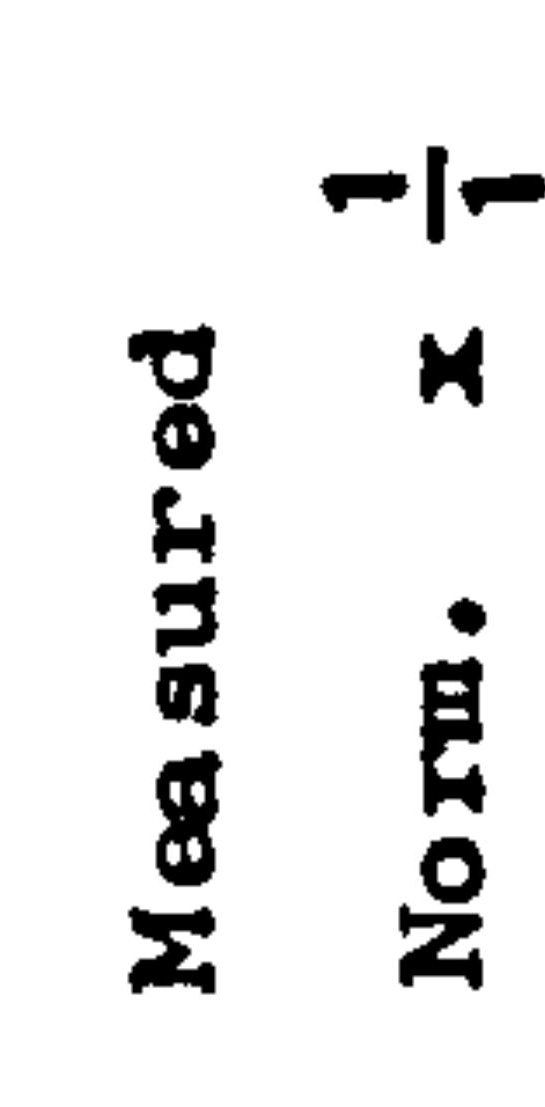 & 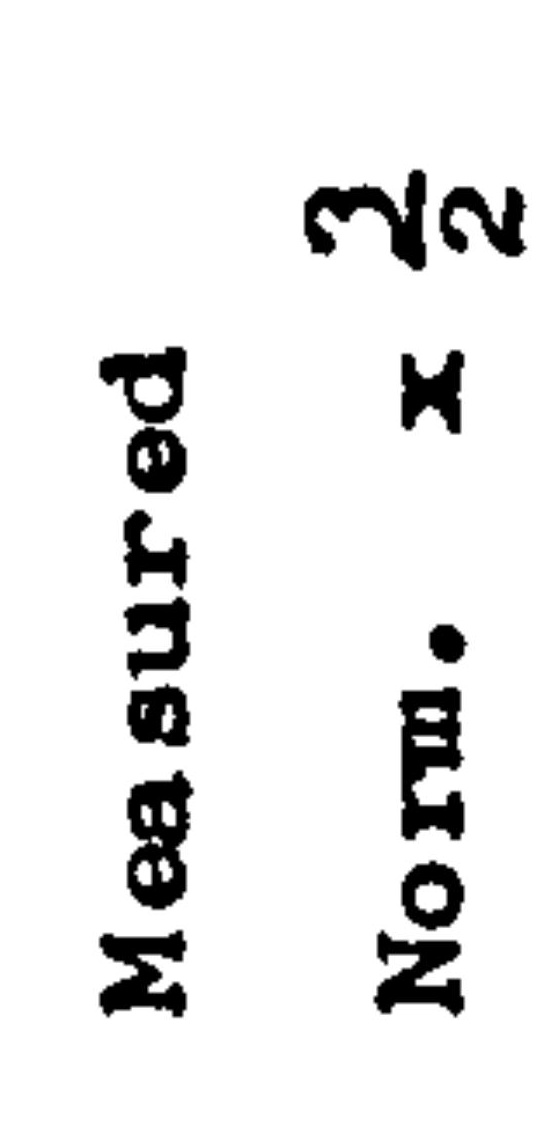 & 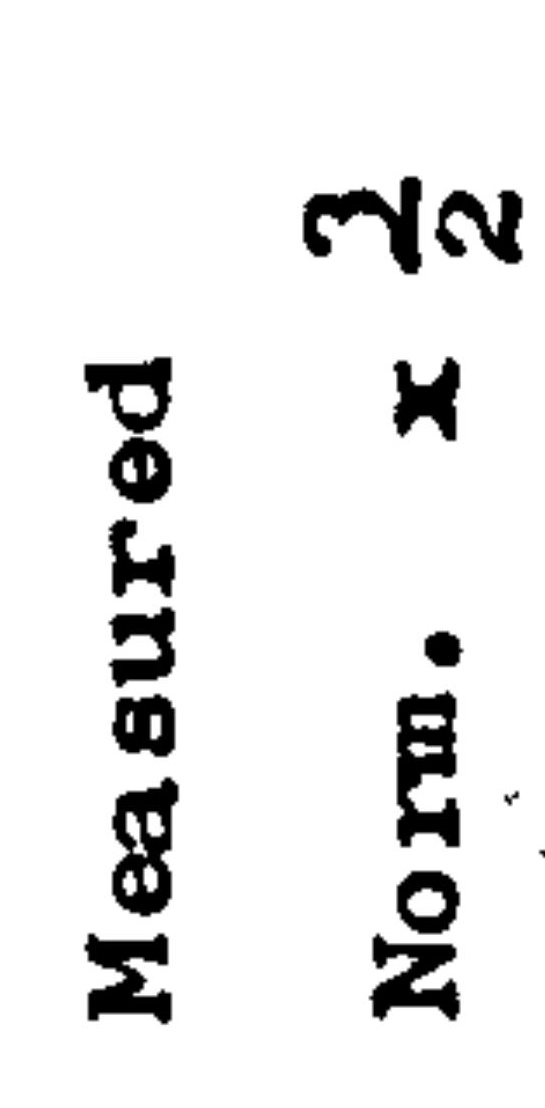 & 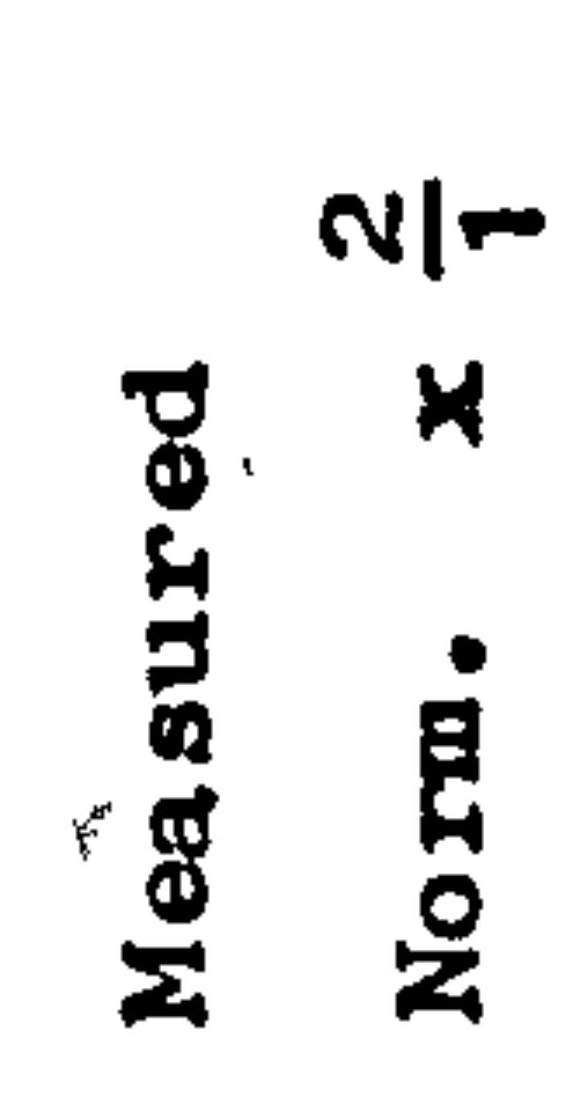 & 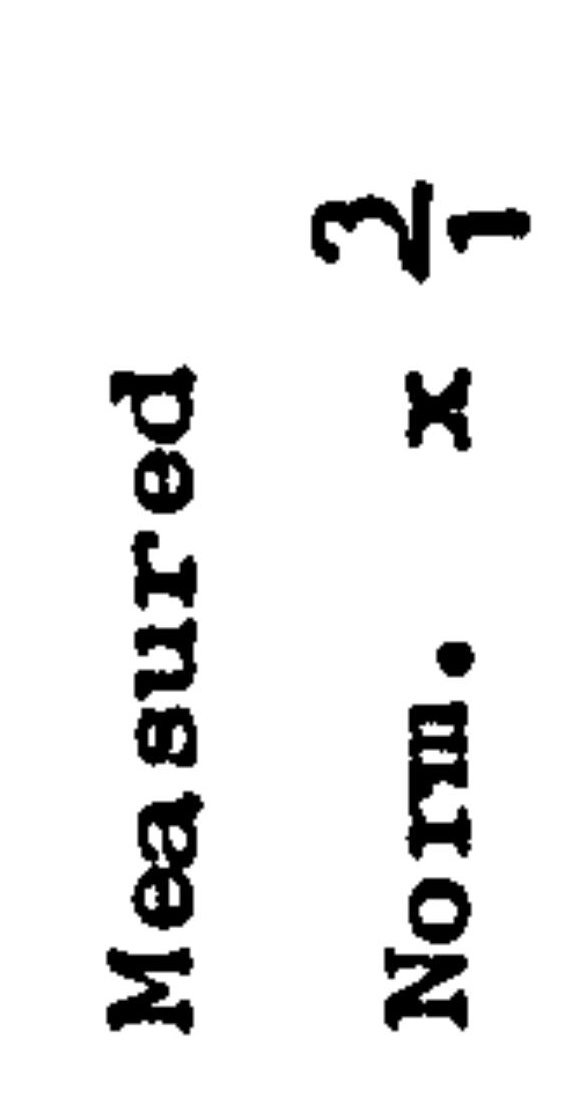 & 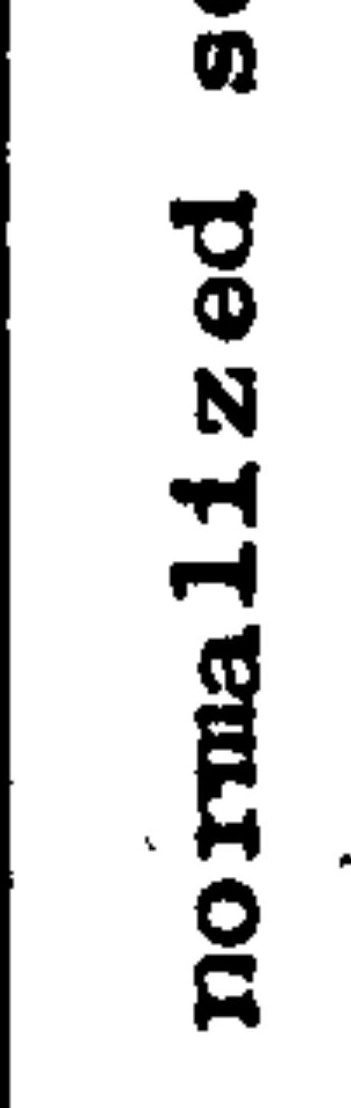 \\
\hline 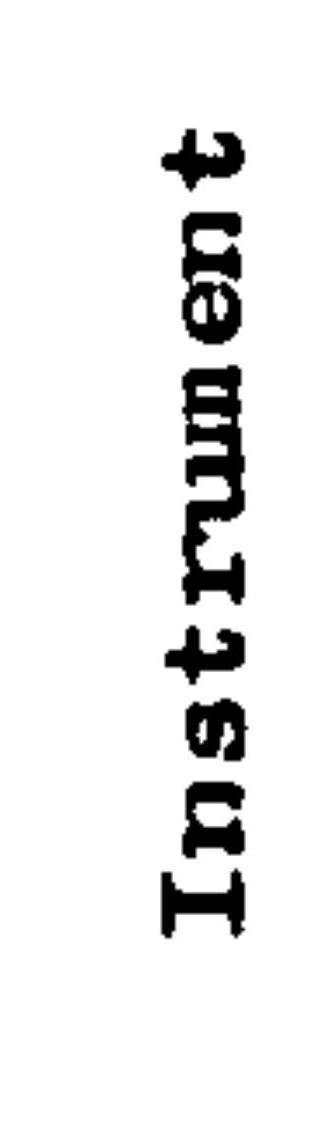 & 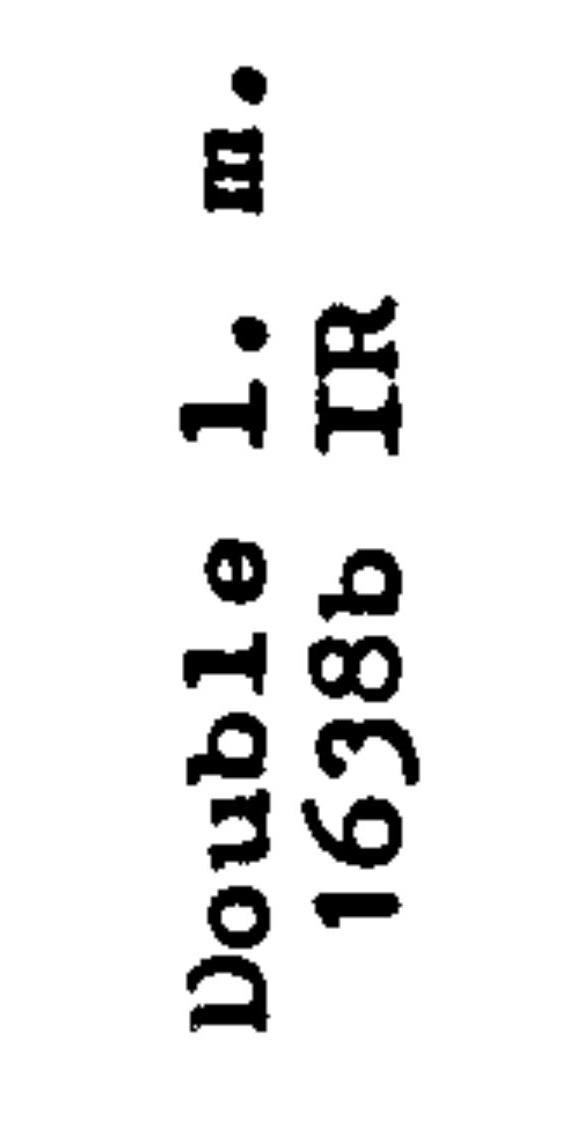 & 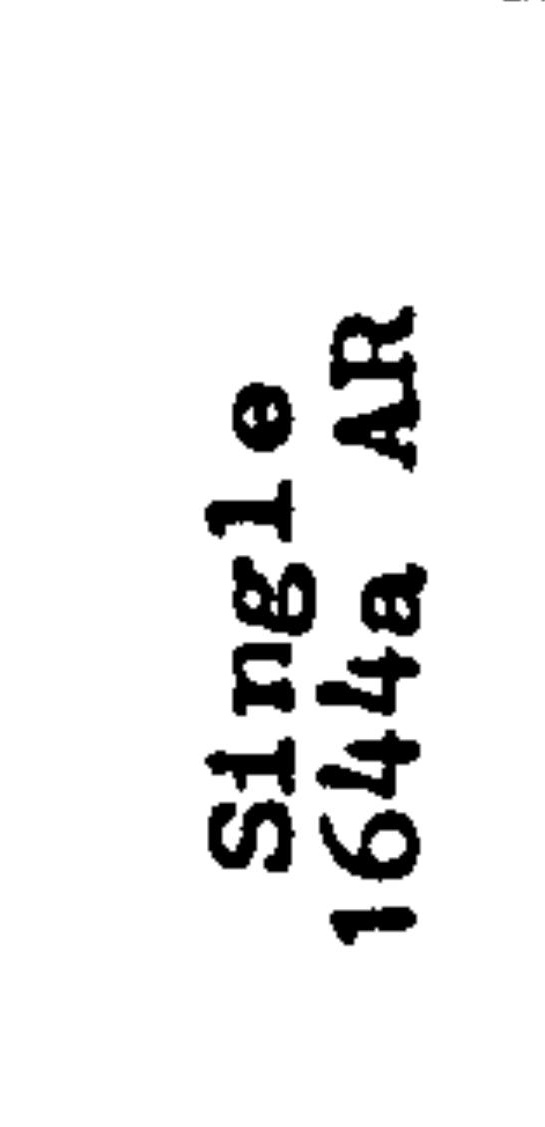 & 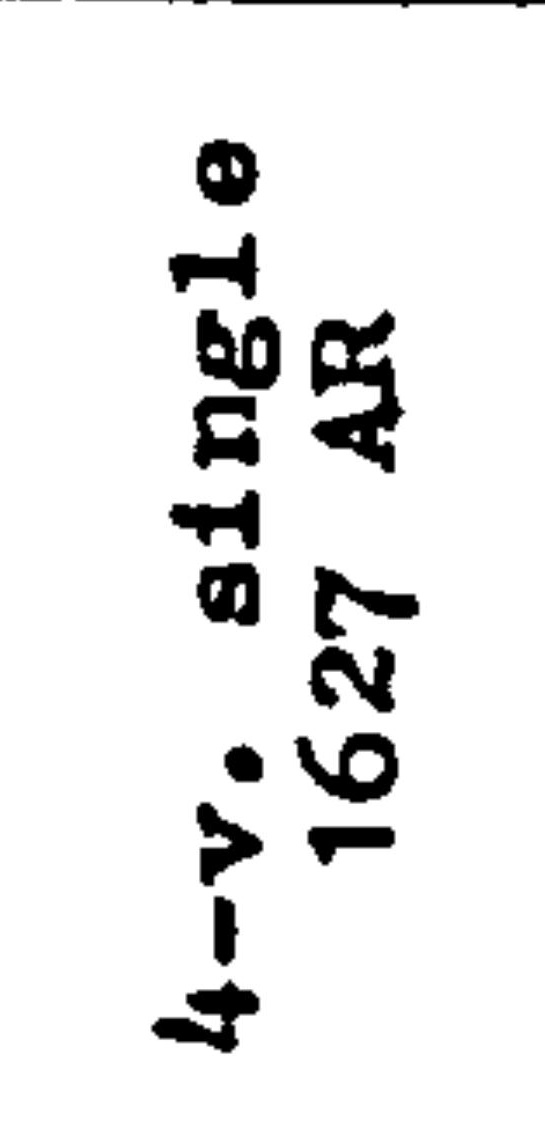 & 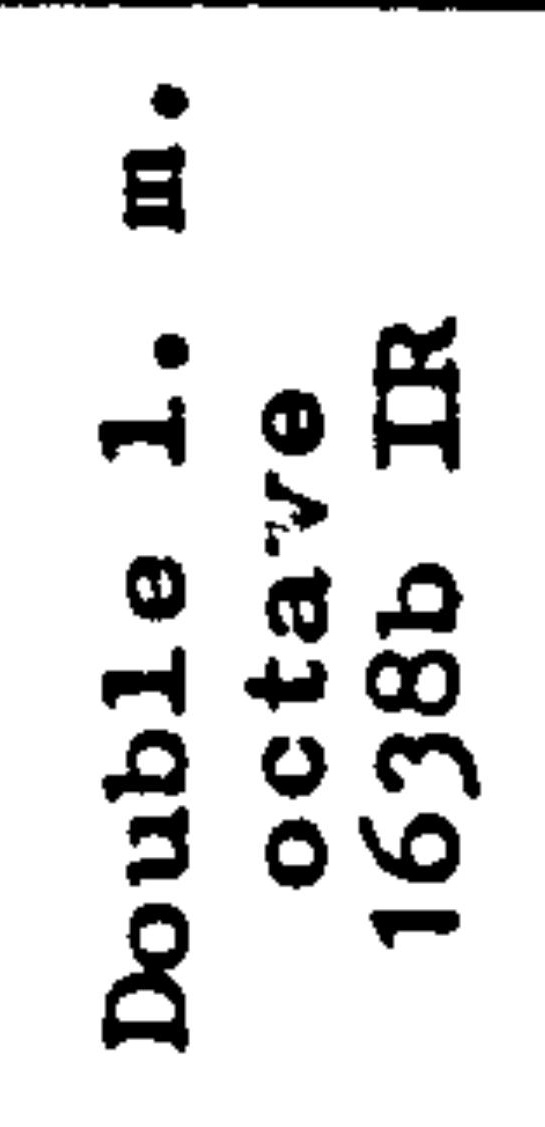 & 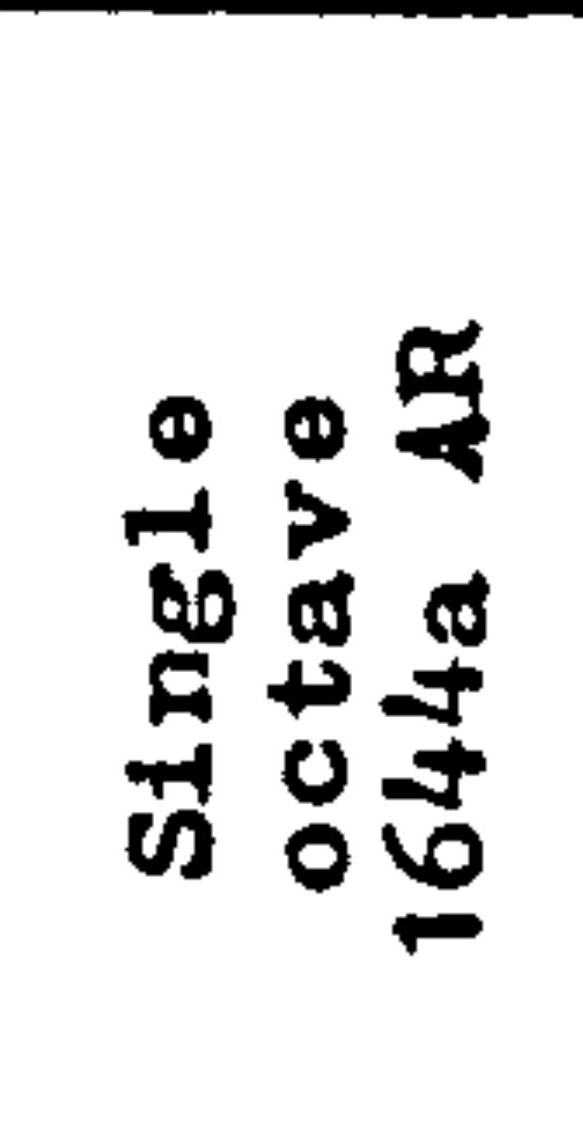 & 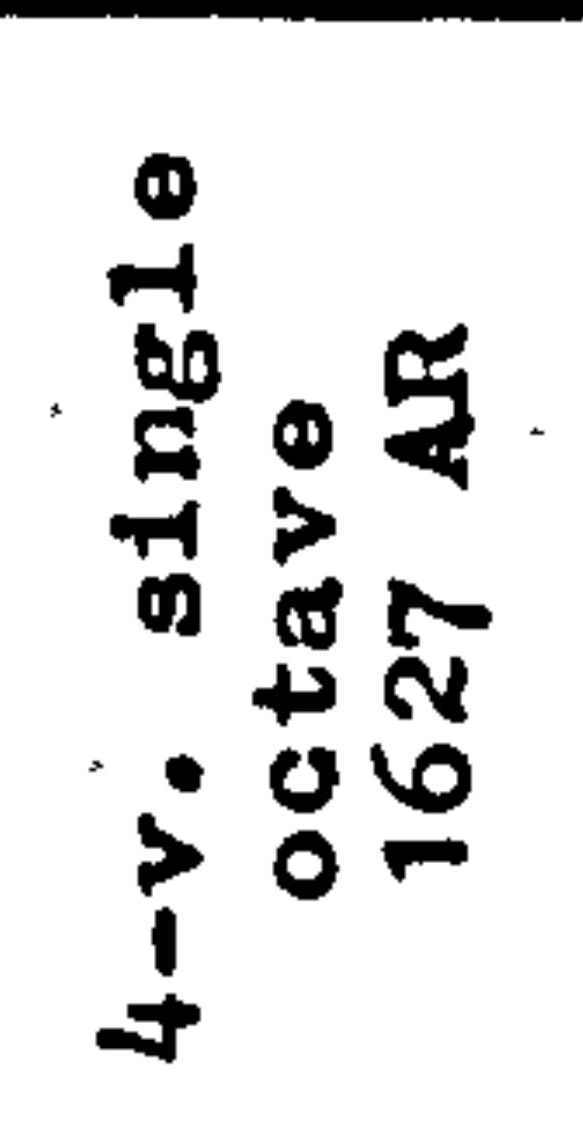 & $\begin{array}{l}0 \\
0 \\
2\end{array}$ \\
\hline
\end{tabular}


Here again the measured scalings have been normalised to account for their pitches, and the resulting standardisation to reference pitch shows that the pitch-assignments are correct. The agreement is very good in the treble, and the normalized values of the bass scalings of the longer harpsichord strings are roughly the same as those of the virginals. The bass scaling of the octave stops of these harpsichords are all notably longer in comparison with the unisons, especially that of the quint harpsichord. This seems to be because space constraints are less serious for the octave stop of a harpsichord, requiring less foreshortening in the bass. Surprisingly for comparable instruments the $8^{\prime}$ bass scalings of the virginals are longer than those of the corresponding strings of the harpsichords.

The measured scalings of Table 4-3 are plottid in Graph 4-2 in a manner similar to that carried out for the virginals. As before the curves are linear above the played note $c^{1}$, and again the points were fitted to the line of slope $-\frac{1}{2}$ by the method of least squares. The resulting average scaling at reference pitch is $c^{2}=$ $355.2 \pm 0.8 \mathrm{~mm}$. Weighting equally the harpschord and virginal results gives an average scaling at reference pitch of $c^{2}=355.0 \pm 2.5 \mathrm{~mm}$. This scaling could be thought of as the design-scaling used by the Ruckers, from which they calculated the scalings of the treble strings of all of their instruments, both virginals and harpsichords. Obviously because of workshop techniques and simple problems of geometry - for example, the curved bridges which 


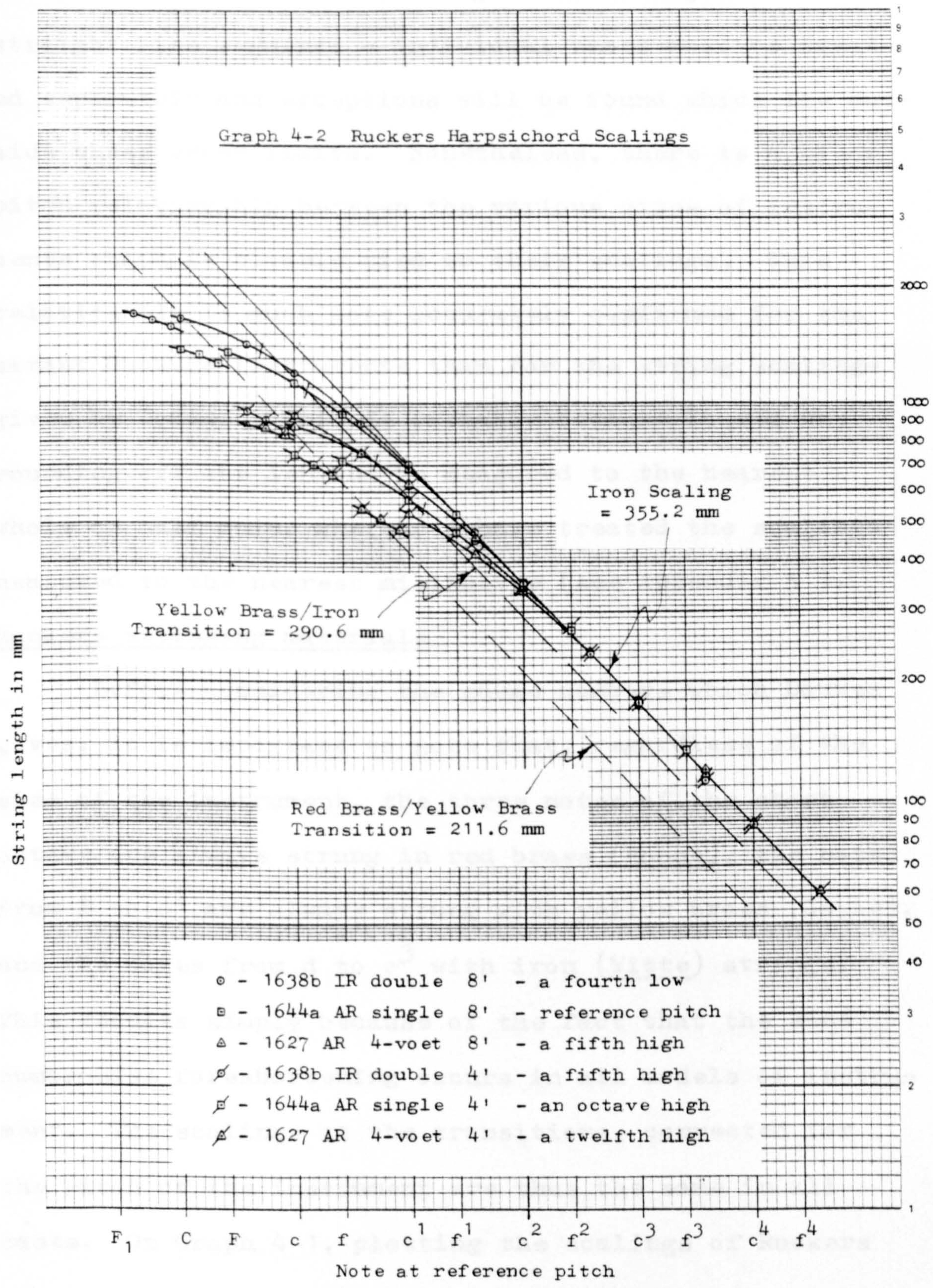


one would expect on the small instruments at $R+8$ and $R+9$ are approximated by bridges consisting of two straight line segments - individual cases must be treated separately and exceptions will be found which lie outside these error 1imits. Nonetheless, there is a clear pitch relationship between the various sizes of instruments which is closely tied to their scalings. This relationship is much more accurately confirmed for the extant Ruckers instruments than for the string scalings given by Douwes. This is probably because Douwes was rounding off the lengths he measured to the nearest whole or half duim, whereas I have treated the scalings measured to the nearest milimetre (see Appendix 5 ). Ruckers stringing materials

Before considering the gauge numbers which Douwes gives, it is important to note that, regardless of the size of the instrument, the three notes of the short octave are always strung in red brass (Roode), the notes from $F$ to $c \#$ are always strung with yellow brass (Geele), and the notes from $d$ to $c^{3}$ with iron (Witte) strings. This results simply because of the fact that the same compromise foreshortening occurs in all models of instrument. The scalings at the transitions, corrected for the pitch of the instrument are thus the same in all cáses. On Graph 4-1, plotting the scalings of Ruckers virginals corrected for their pitch, the transitions from yellow brass to iron between notes $c$ and $d$ have been marked with a short diagonal, and these points have 
been fitted to a line of slope $-\frac{1}{2}$ which, like the line for the iron scalings, halves with each octave rise in pitch. The resulting long-dashed line passes through pitch $c^{2}$ at a scaling of $288.4 \mathrm{~mm}$ so that each point on this line can be thought of as having a scaling, referred to pitch $c^{2}$, of $288.4 \mathrm{~mm}$. Similarily the transitions between red and yellow brass all occur at approximately the same scaling given by the short-dashed line, which, referred to pitch $c^{2}$ has a value of $210.2 \mathrm{~mm}$.

Carrying out a similar procedure assuming the same transition notes for the harpsichords (Graph 4-2), gives results which are less consistent than those for the virginal scalings. This is mainly because of the scalings with the longest and shortest values: the bass scalings of the double manual harpsichord are slightly too much foreshortened, and the octave scalings of the quint harpsichord are longer than expected. Nonetheless, it would appear that the transition from one string material to another should occur at the same played notes for the harpsichords as for the virginals, and this further confirms the common design scaling and bass foreshortening compromise for all Ruckers instruments.

The question then arises as to whether Douwes lists are specifically for virginals, or whether they apply equally well to harpsichords.

There are a number of factors which point to the lists being intended for virginals.' Harpsichords were built of length approximately 6 feet, 4 feet and 3 feet, 
but the inclusion of the 5-voet and the 2 voet 4 duimen instrument points to virginals being intended here. Also Douwes refers elsewhere $e^{4-7)}$ to the six-voet instruments:

"But I should also say that such clavecimbels as are called six-voet are not fully 6 feet long, but are approximately $1 / 3$ of a foot shorter. Then in a similar way the 5,4 , and 3 -voet also have not the full length, but are normally a bit shorter..."

It seems clear that the confusion here arises because Douwes is using the Dutch foot with 12 inches instead of the Flemish foot used by Ruckers with only 11. Thus an instrument labelled by the Ruckers as being 6 feet long would be somewhat shorter than the 6 Dutch feet. If Douwes were thus talking about harpsichords this confusion would not have arisen, and in fact the harpsichords, being somewhat Ionger than the equivalent virginals, are almost exactly 6,4 and 3 Dutch feet in 1 ength.

Now, despite the fact that Douwes seems to be referring specifically to virginals, there seems no reason to suppose that the stringing lists he gives cannot be applied to harpsichords as well. Douwes does not mention any difference in the stringing of the centre plucking muselar and the left plucking spinett virginals, and even the Ruckers themselves did not seem to distinguish between the two when numbering their instruments (see p. 118). Since the plucking ratios of the harpsichords are roughly the same as those of the spinett virginals, it would seem that the gauge lists are equally applicable to the harpsichords. Thus these stringing lists should apply. equally well to the 6,4 and 3-voet harpsichords as to 
the corresponding virginals, if only the gauge equivalents were known.

\section{Ruckers string gauges}

Having carefully examined most of the Ruckers family instruments in Europe and America, I have come to suspect that two of the instruments that $I$ have seen, al though both have been slightly altered, reflect 17 th century stringing practice and may be of some help in.determining an approximate value for each of the gauge sizes given by Douwes. In both cases the surviving strings were obviously not original, but I feel that the sizes were copied from the original, or at least 17 th century, strings and show a remarkable correlation with Douwes tables. Further, the $1612 \mathrm{~b} \mathrm{HR}$ double in Amiens was aligned in France, and the gauge numbers of the strings to be used were marked on the instrument. These markings are in good agreement with the string sizes found on the two instruments with old strings and seem to confirm that the person who carried out the alignment tried to copy the Ruckers stringing with the equival ont 18th century French gauges.

The first instrument found which seemed to represent 17th century stringing practice was the 1644a AR single manual harpsichord in the Vleeshuis Museum, Antwerp. This harpsichord was extended by two notes in both the treble and bass to widen its compass to $\mathrm{C}$ to $\mathrm{c}^{3}$ chromatic; and the 4' register was replaced by an 8' one. But other than this very little has been done to it and it retains most of its original decoration, many original jacks some of which 
still have their original dampers, some original cloth in the keyboard rack, etc. However, all that remained of the strings were a few loops of wire on the tuning pins and most of these were relatively recent and either 0.25 mm or $0.33 \mathrm{~mm}$ in diameter and used without discretion throughout the entire compass. But the present short string $f^{2}$ tuning pin, or the original $g^{2}$ tuning pin, had about 10 coils of wire of very old age rusted to it - see Photograph 4-1. The approximate diameter of this wire could be measured and it was found to be $0.31 \mathrm{~mm}$. Wrapped over the coils rusted to the tuning pin was more recent wire of diameter $0.305 \mathrm{~mm}$, apparently copying the string gauge size of the earlier wire and, as will be shown, it seems likely that this is the original 17 th century wire, and probably the only bit of original wire left on any Ruckers instrument.

It was also noted that the lowest note was strung with brass wire of diameter $0.63 \mathrm{~mm}$, and that the tongue axles in some of the broken jacks were of brass wire of diameter $0.64 \mathrm{~mm}$. It seems probable then that the 0.305 mm wire wound over the rusted wire on the tuning pin, and the 0.63 wire in the bass were an attempt to copy the original sizes of 0.31 and $0.64 \mathrm{~mm}$ respectively. If these then correspond to gauge 10 and gauge 1 , the intermediate sizes can be calculated by assuming a logarithmic relationship between successive gauge numbers. ${ }^{4-8}$ The ratio between the successive diameters is then

$$
r_{g}=\sqrt[9]{\frac{0.64}{0.31}}=1.0839
$$



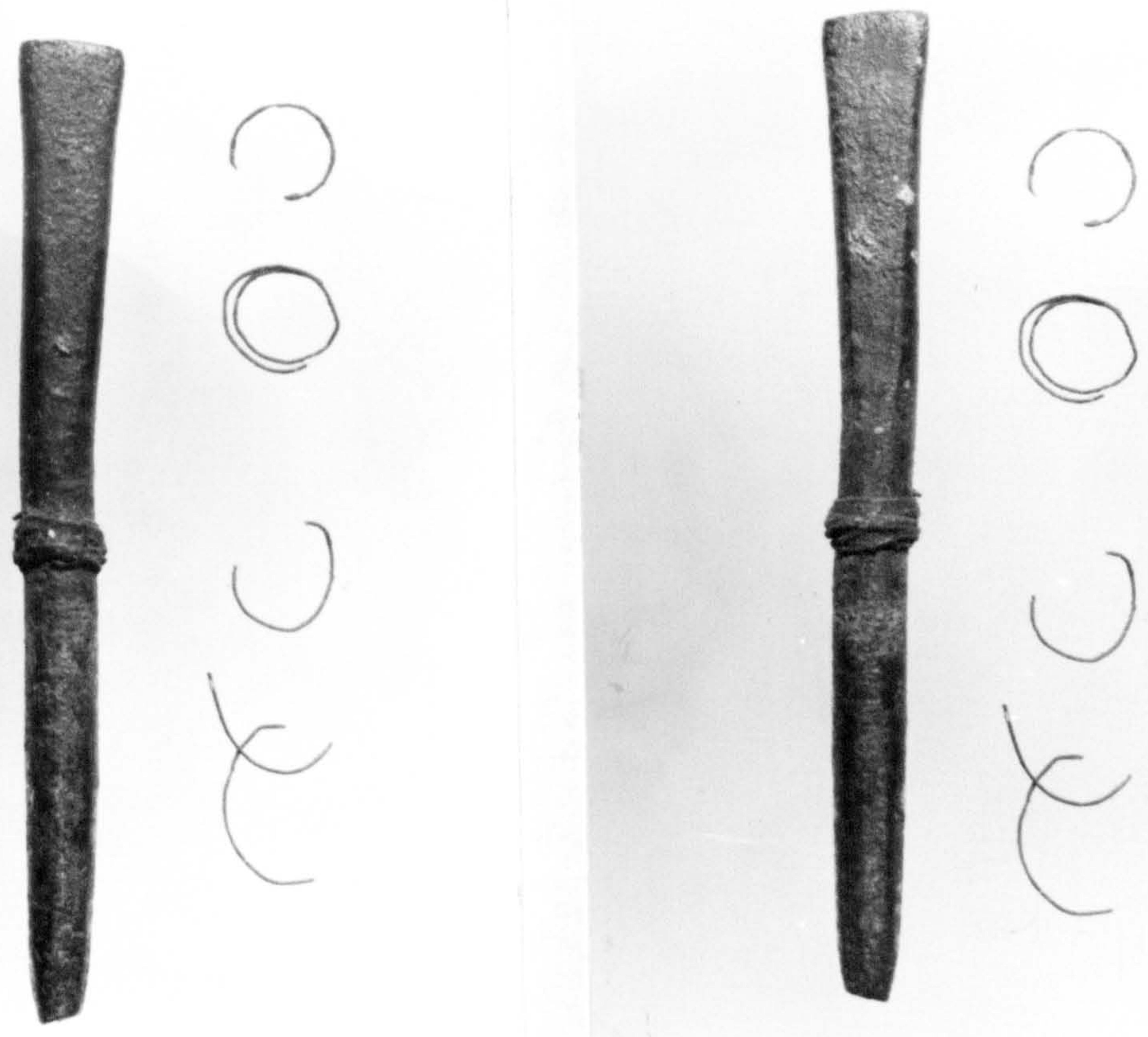

Photo 4-1 Tuning pin and wire from the 1644a AR singlemanual harpsichord. The wire in loose fragments and the wire rusted to the pin is of diameter $0.31 \mathrm{~mm}$. 
and the gauges above gauge 1 can be obtained by successive1y multiplying $0.640 \mathrm{~mm}$ by this factor. The results of this can be seen in Graph 4-3 which plots the sizes of the intermediate gauges. Wires of: some of these intermediate sizes were found to exist on the instrument and some gauge transitions occured at the same notes as those given in Douwes lists for 6-voet clavecimbels. But there were too few old strings on the instrument to support a convincing argument. Clearly the assumptions made about these few strings on the 1644a AR harpsichord are not sufficient in themselves to base a whole system of gauge diameters on, and more evidence is required before these can be accepted. This evidence is found, I believe, on the $1618 \mathrm{~b}$ IR doublemanual harpsichord in Schloss Cappenberg, Westphalia. This harpsichord originally had the usual unaligned keyboards, similar to those on the 1638b IR double-manual harpsichord in Edinburgh. The keyboards on this harpsichord have now been aligned and the treble compass extended to $\mathrm{d}^{3}$, giving the present compass of $\mathrm{G}_{1} / \mathrm{B}_{1}$ to $\mathrm{d}^{3}$. Other than this the instrument has been very little altered and it retains many of its original jacks which also have some original dampers, the original keyboard rack and balance rail cloth, etc. In the case of this instrument, many more of the strings have survived than on the 1644b AR instrument, so that the hitchpin loops as well as the tuning pin coils could be examined, and the workmanship of these compared, so that some obviously recent strings could be identified. The problem associated with this 
instrument is that, being a double-manual instiment, it is not included in the gauge lists given by Douwes. However, because the upper part of the compass of the upper manual has the same compass and scalings, it seems most probable that the gauges used in the treble were the same as those used in the 6-voet virginal and harpsichord. In the bass one might then expect the use of gauges perhaps one or two larger than in the 6-voet instrument, the additional length of the double-manual instrument adequately compensating for the lower pitch. With this in mind assignments to the measured values of the string diameters given below in Table 4-5 were made. The values in brackets indicate that the corresponding strings were clearly not old and $a$ ' $b$ ' after a measurement indicates that it is of brass or an ' $I$ ' indicates a string of iron where a string of this material would not normally be expected. Each of the strings was measured a number of times where possible to account for the possible oval nature of the string cross-section, and to arrive at the best possible average for each string diameter.

The average diameters for each gauge are plotted on Graph 4-3 where it can be seen that they are in good agreoment with the results proposed for the single manual 1644a AR harpsichord. Assuming then that these results are logarithmic as before, the logarithm of each of the above diameters was taken and the results fitted by the usual regression analysis to a linear equation (a first order polynomial), weighting each diameter according to the 


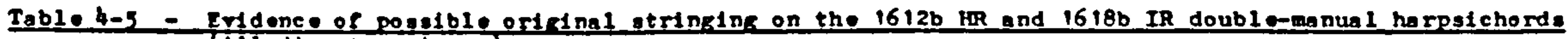

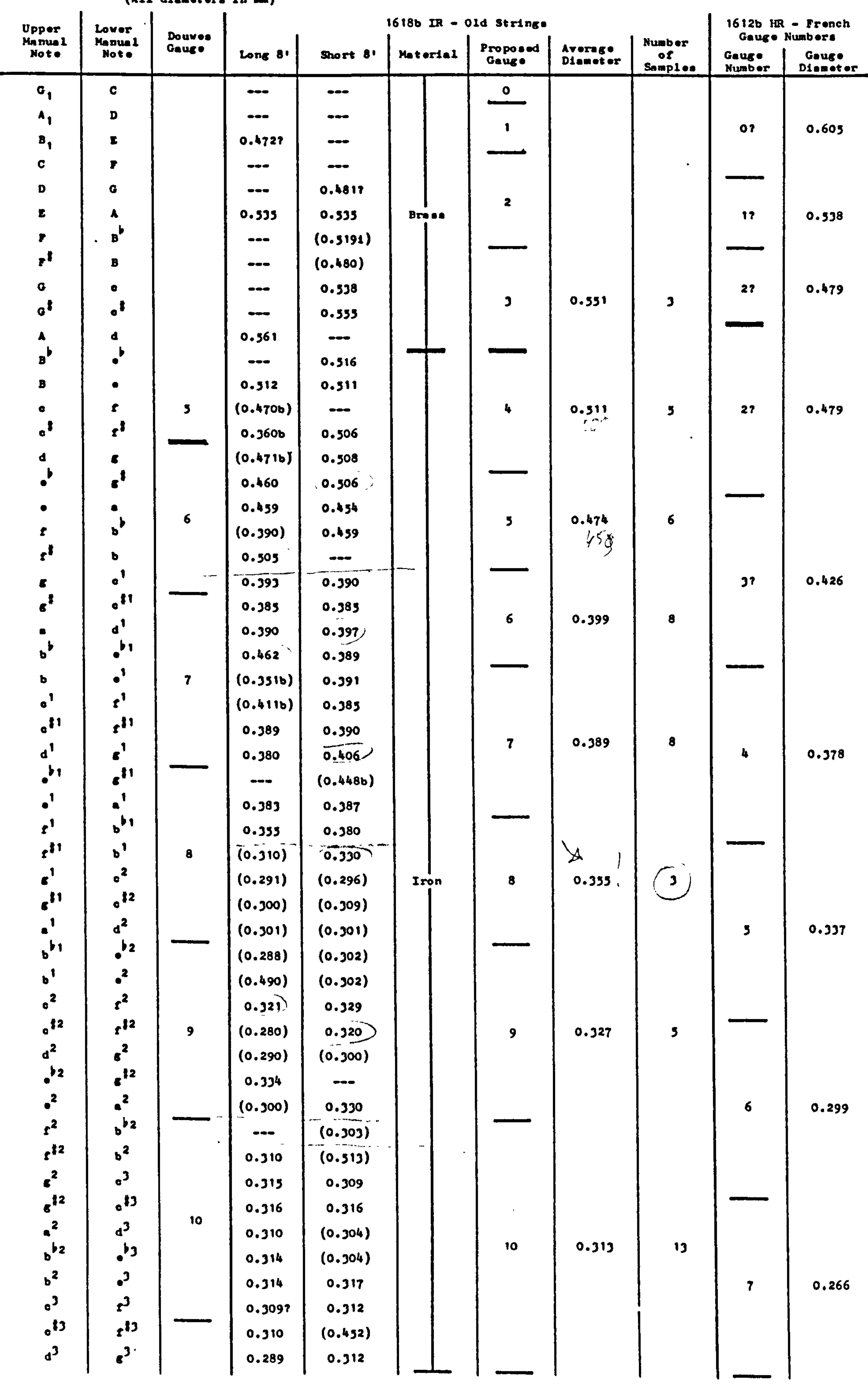




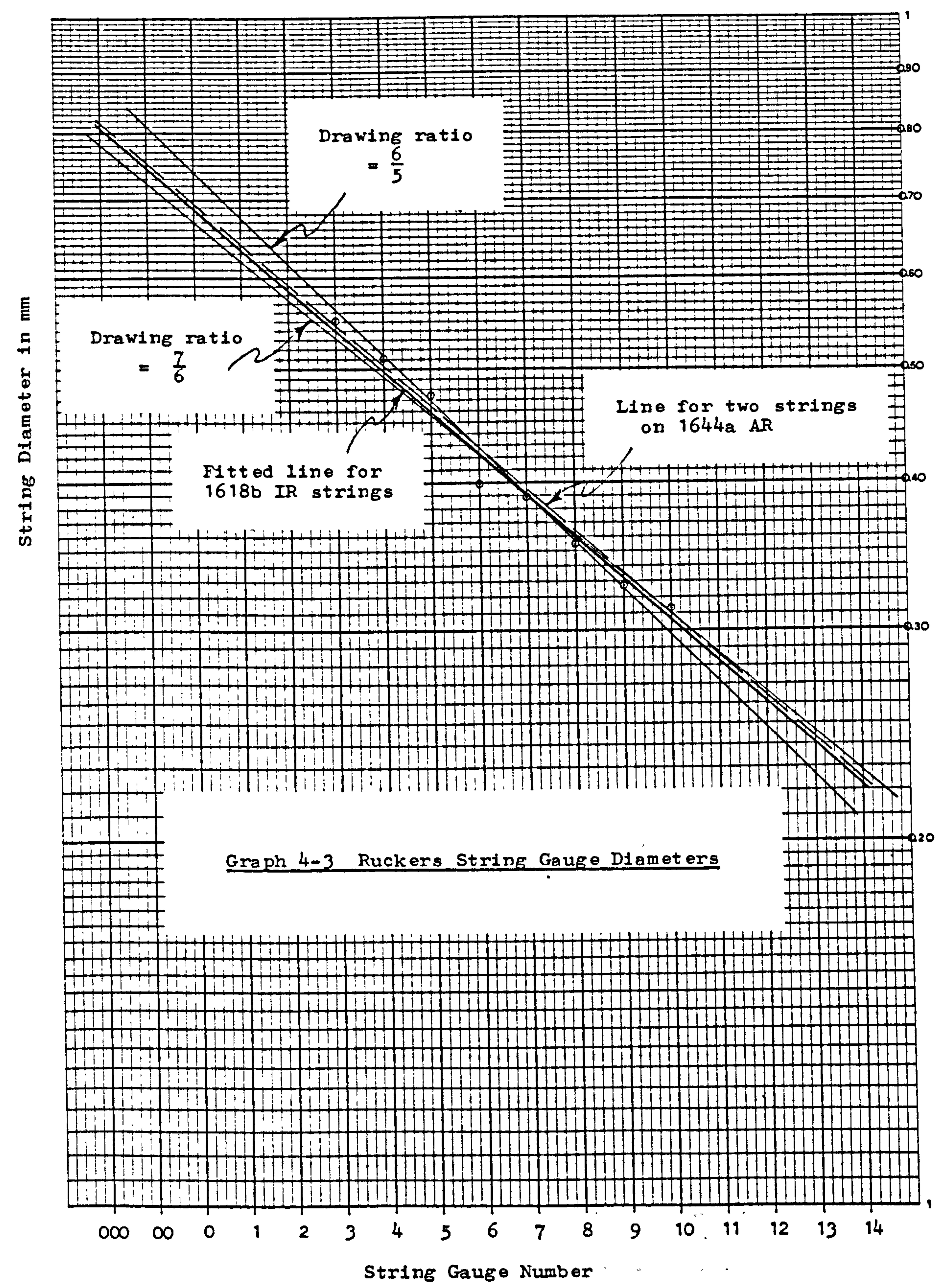


number of strings from which the average diameter was calculated. The result of this calculation gives the gauge sizes listed in Table 4-6 which have been extrapolated to both heavier and lighter diameters than those given by the results themselves.

These diameters thus represent the gauge sizes suggested by the extant strings on two instruments. These are probably the only two instruments with extant strings on which any evidence of Ruckers stringing practice is likely to be found, since there are no other Ruckers instruments known to me which have strings of any age. ${ }^{4-9)}$ But the gauge markings on the $1612 \mathrm{~b} \mathrm{HR}$ double in Amiens tend to confirm the string sizes found on these two instruments.-10) This double was given a very conservative alignment and petit ravalement in France in 1730. The keyboards were aligned and the compass extended from 50 to 53 notes by adding a split $B_{1} / E^{b}$ key and the two top notes $c^{\# 3}$ and $\mathrm{d}^{3}$. The disposition was left with only $1 \times 8^{\prime}$, $1 \times 4$ on each manual and no manual coupler. The gauge numbers were marked on the bridges and these are shown in Table 4-5 along with their 18th century French equivalents. Comparing the string diameters on the $1618 \mathrm{~b}$ IR and the $1612 \mathrm{~b}$ HR doubles gives fairly close agreement. It would indeed appear that both instruments were strung at some later period using strings which came from different gauge systems, but which both attempted to copy the original Flemish stringing found on the instruments before they were altered. Other evidence which will throw 
Table 4-6 Ruckers String Gauges based on the extant strings on the $1618 \mathrm{~b}$ IR double-manual harpsichord.

$$
\begin{aligned}
& \text { Gauge } 00-0.745 \mathrm{~mm} \\
& \text { Gauge } 0-0.687 \mathrm{~mm} \\
& \text { Gauge } 1-0.634 \mathrm{~mm} \\
& \text { Gauge } 2-0.585 \mathrm{~mm} \\
& \text { Gauge } 3-0.539 \mathrm{~mm} \\
& \text { Gauge } 4-0.498 \mathrm{~mm} \\
& \text { Gauge } 5-0.459 \mathrm{~mm} \\
& \text { Gauge } 6-0.424 \mathrm{~mm} \\
& \text { Gauge } 7-0.391 \mathrm{~mm} \\
& \text { Gauge } 8-0.361 \mathrm{~mm} \\
& \text { Gauge } 9-0.333 \mathrm{~mm} \\
& \text { Gauge } 10-0.307 \mathrm{~mm} \\
& \text { Gauge } 11-0.283 \mathrm{~mm} \\
& \text { Gauge } 12-0.261 \mathrm{~mm}
\end{aligned}
$$

$$
\begin{aligned}
& \text { Gauge ratio } r_{g}=1.0839 \\
& \text { Drawing ratio } r_{d}=r_{g}{ }^{2}=1.1749
\end{aligned}
$$


further light on these results may be found later, perhaps in the form of 17 th century Flemish wire-drawing plates, or spools of 17 th century wire with their gauge number given on them.

The gauge ratio of the strings found on the $1618 \mathrm{~b}$ IR Cappenberg harpsichord is $r_{g}=1.0839$. This gives the drawing ration $r_{d}=r_{g}^{2}=1.1749$. This is very close to the ratio $\frac{7}{6}=1.167$ and suggests that the ratio of the 1 ength of the. wire after drawing to the length before drawing was given by this simple ratio. It is clear that this is the drawing ratio of the gauge system which replaced the Ruckers system and not of the original Ruckers wires. However, to the extent that the gauge transitions occur at roughly the points for the Douwes lists as on this harpsichord, this is then also approximately the same gauge ratio as for the Ruckers wire.

It is extremely important to point out that the string diameters given by the list above, when applied to the instruments given by Douwes, are much heavier than would be suggested by the original strings found on a number of 18 th century instruments. An 18th century English or French harpsichord would typically be strung with strings of diameter $0.21 \mathrm{~mm}$ for the note $\mathrm{c}^{3}$, whereas a Ruckers 6-voet clavecimbel would be strung with strings of approximately $0.31 \mathrm{~mm}$. Assuming for the time being the same pitch standard, this implies a tension approximately 2.3 times higher in the 17th century instrument. This increased tension would result in a large increase 
in the volume of sound produced, and this may explain much of the iconographic evidence which shows harpsichords being played with their lids closed, and be in keeping with the rather raucous nature of a number of $17^{\text {th }}$ century wind instruments.

The increased tension puts a greater strain on the case of the instrument, which is partly offset by the fact that the 17 th century harpsichords had only one set of $8^{\prime}$ strings whereas the later ones had two sets. However, I feel it necessary to stress that the data on which the calculated diameters are based are open to considerable question. They are at best the only evidence that seems to exist of what the 17 th century gauges in the Low Countries might have been. Before using these diameters to string an historical instrument, it must be completely clear that the instrument is able to stand the strain imposed upon it, and in no case would I recommend that any Ruckers or Flemish instrument be strung with these gauges if it has been altered to the disposition with two $8^{\prime}$ sets of strings from its original disposition of $1 \times 81$ and $1 \times 4^{\prime}$, as this could result in an excessive overall tension which might well lead to permanent damage to the instrument.

Each of the three materials used by the Ruckers family to string their instruments was utilised at a pitch and tension such that it was just on the point of breaking, allowing for some margin of safety. Even 
if one knew the ultimate breaking strength of the materials used by Ruckers, it is impossible to estimate what this safety margin was, whereby one could calculate the pitch to which the instruments were intended to be tuned. By way of comparison, however, the scalings used on a number of instruments by Pascal Taskin in the late 18th century in. France are known: 4 -12)

Table 4-7 Comparison of Taskins' and Ruckers' Scalings

\begin{tabular}{c|c|c|c|c} 
& & \multicolumn{3}{|c}{ Ruckers' Scalings } \\
Material & $\begin{array}{c}\text { Taskins' } \\
\text { Scalings }\end{array}$ & Virginals & Harpsichords & Average \\
\hline Iron & $364.0 \mathrm{~mm}$ & $354.8 \mathrm{~mm}$ & $355.2 \mathrm{~mm}$ & $355.0 \mathrm{~mm}$ \\
Yellow brass & $292.6 \mathrm{~mm}$ & $288.4 \mathrm{~mm}$ & $290.6 \mathrm{~mm}$ & $289.5 \mathrm{~mm}$ \\
Red brass & $231.4 \mathrm{~mm}$ & $210.8 \mathrm{~mm}$ & $211.6 \mathrm{~mm}$ & $211.2 \mathrm{~mm}$
\end{tabular}

These results indicate in all cases that Taskin's scalings were longer than Ruckers', corresponding to a lower pitch. The difference may of course be due to the manufacture in 18th century France of stronger wire. However, until the the breaking strengths of some of these wires is determined, nothing definite can be said about the absolute value of Ruckers pitch standard, although Taskin's pitch is known to have been $409 \mathrm{~Hz}^{4-13)}$ If one assumes for the moment that both Ruckers and Taskin used wire of the same breaking strength, and that they chose scalings which gave the same safety factor between the working stress and the ultimate breaking stress of the strings, then the scalings would reflect a true difference in pitch standard. Ignoring the value of the Ruckers copper scaling because of 
the inaccurate way in which it is determined, as well as the apparent variable quality of the material itself, then compared with Taskins's pitch and scalings, Ruckers' iron and brass scalings correspond to pitches of $419 \mathrm{~Hz}$ and 413 Hz respectively. This is a pitch roughly one semitone flat to modern pitch at $440 \mathrm{~Hz}$.

The ratio of Ruckers iron to brass scalings is $355.0 /$ 289.5=1.226. Considered in terms of the corresponding musical interal the ratio of these two scalings is somewhere between a major third $\left(\frac{5}{4}=1.25\right)$ and a minor third $\left(\frac{6}{5}=1.20\right)$. Considering van Blankenburg's suggestion $\left.{ }^{4-14}\right)$ that copper (alloy) strings were sometimes used in the treble, a Ruckers 6-voet instrument strung throughout in brass would then sound between a major and a minor third lower than reference pitch. Similarly a 5-voet instrument would sound between a tone and a semitone lower than reference pitch, and this seems to contradict van Blankenburg's claim that the 5-voet virginals were suitable for copper (alloy) stringing ${ }^{4-15}$ ) Calculation of the pitch which would be sounded by the treble strings of the other sizes of Ruckers instruments leads to a new set of pitch levels for brass stringing which do not relate in any simple way to the pitch levels established by assuming iron stringing in the treble and the applicability of Douwes lists to Ruckers instruments. The internal consistency which has already been shown to result from making these assumptions seems to lead to no other possible pitch assignments or stringing possibilities.. (On a strictly 
practicaly level, however, it should be noted that copies of the little $4 \frac{1}{2}$-voet virginal, tuned to modern pitch approximately a semitone higher than the pitch which Ruckers seems to have used, are ideally sutted for brass stringing in the treble, although the bass strings are then much too short to sound well at the new pitch about a major third lower than that originally intended.)

\section{The pitch scheme of Ruckers instruments.}

Although Douwes gives approximate scalings for each of the other clavecimbels in his list, there are no scalings for, nor any indication of the pitch of, the $2 \frac{1}{2}$-voet instrument (i.e. Douwes 2 voet 4 duimen clavecimbel). As we have seen, assuming a pitch for these instruments of R+9 places their scalings in the correct relation to the scalings of the other sizes of Ruckers clavecimbels. But a further confirmation of this pitch assignment comes from Douwes stringing lists. Table 4-8 presents Douwes' gauges above $f^{1}$ in terms of actual pitch rather than of key names, and it is noticeable that the smaller instruments change gauge close to the same pitch. The last line shows the stringing list for the 2 voet 4 duimen instrument assuming that its pitch should be a whole tone above that of the 3-voet instrument. It will be seen that the positions of the transitions confirm this assumption, i.e. that the pitch should be $R+9$ or a ninth above reference pitch. Thus the instruments under study here represent, in all, seven different pitches. I have also been able 


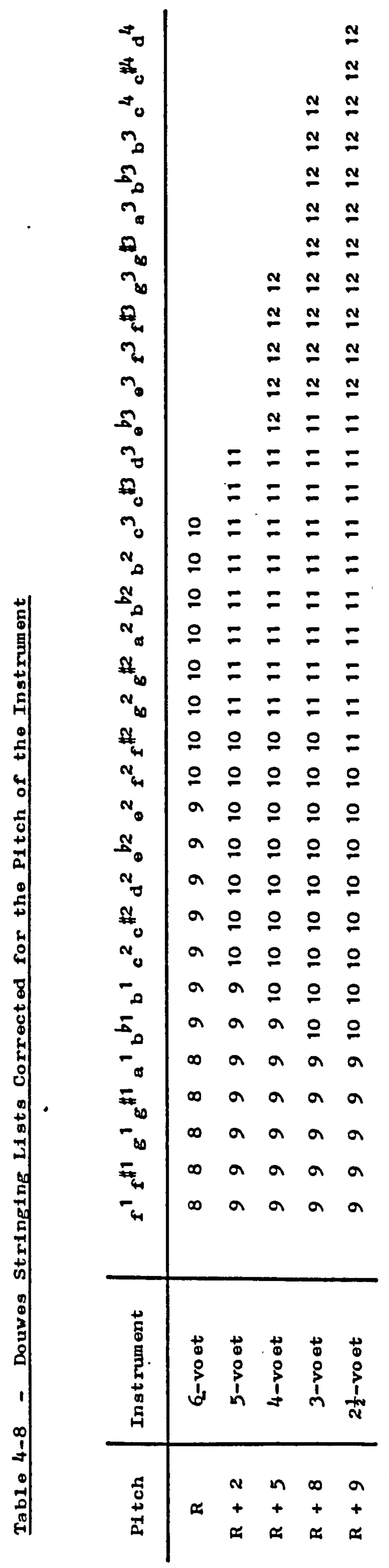


to show that the $1612 \mathrm{a} \mathrm{HR}$ was originally a double-manual harpsichord scaled so that one manual would sound at a pitch of $R-5$, a fifth below reference pitch, and that it had a compass of $\mathrm{C} / \mathrm{E}$ to $\left.\mathrm{d}^{3} \cdot 4-16\right)$ This compass is unusual for Ruckers instruments which usually had a compass of $\mathrm{C} / \mathrm{E}$ to $\mathrm{c}^{3}$. However, the 1629 IR $4 \frac{1}{2}$-voet virginal with a pitch already found to be at $R+4$, an octave higher than this, has its original keyboards and also has an original compass of $\mathrm{C} / \mathrm{E}$ to $\mathrm{d}^{3}$. This means that Ruckers made instruments at eight different pitches, with basic intervals of a tone, a fourth, a fifth and an octave between them.

These eight pitches group very naturally into the following scheme shown in Table 4-9.

It thus appears that these instruments belong to two families, each having members separated from one another by fourths and fifths, the two families being one tone apart. If this is valid, then one family consists of instruments pitched at $R-5, R, R+4$ and $R+8$, and the other family, a tone higher, at $R-4, R+2, R+5$ and $\mathrm{R}+9$

The analogy between the scheme suggested and a consort of say, recorders, viols or lutes is obvious. But although lute music is now coming to light which is intended for a consort of lutes, the idea of a consort of keyboard instruments poses certain theoretical problems involving tunings and the limited number of tonalities in which the music could bo written. Also there soems not to be a single piece of music which survives which indic- 


\section{Table 4-9 The Pitch Scheme of Ruckers Instruments.}

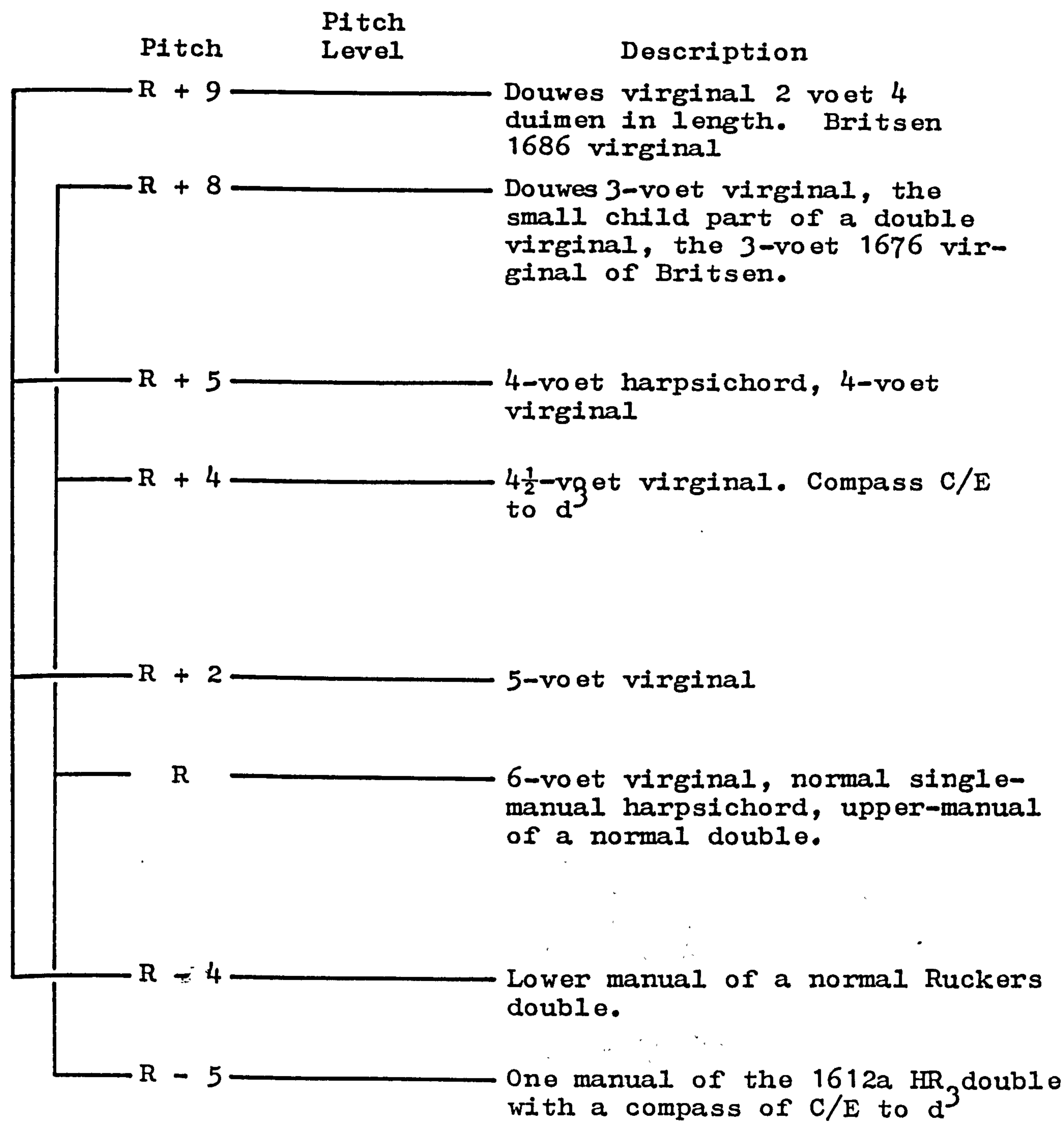


ates that four differently pitched keyboard instruments were meant to play together. It is thus not clear how the various pitches and the instruments were used in the daily musical life of the 16 th and 17 th centuries. It is probably important to the analysis of this problem that the $R+4$ and $R-5$ instruments both have compasses reaching to $\mathrm{d}^{3}$ so that. the top notes of these instruments sounded the same pitch as the top notes of the instruments a tone higher. Also important is the fact that, seen from the point of viow of this scheme, the double manual instrument bridges the gap between the two consorts, and would be looked upon as a combination of two instruments in. one, with each manual belonging to its respective consort. Needless to say, there is still much to be learned of the daily musical practice during this period.

\section{Footnotes:}

4-1) For a more complete discussion of the acoustics of soundboards and stringingfincluding the important effect of the string's internal damping, see my monograph, 'Historical Harpsichord Stringing', which is due for publication by Cambridge University Press in the near future.

4-2) Claas Douwes, Grondig Ondersoek van de Töonen der Musijk, Franeker (1699) Facs. Amsterdam. (1971) 104124. See Appendix 8 .

4-3) The instrument models to be discussed here are only related to those discussed by Frank. Hubbard in Three

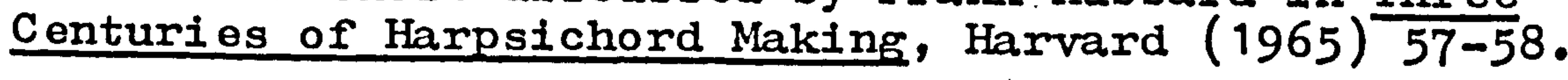

4-4) Edwin Ripin, 'The 'Three Foot' Flemish.Harpsichord', Galpin Society Journal XXIII (1970) 35ff..

4-5) See footnote 3-3).

4-6) Calling this pitch standard ' $R$ ' gives it an apparent 
importance which is completely anachronistic since it soems as though $R$ was a desired standard or norm, which it was not. This disadvantage is, I think, offset by the graphic clarity and ease with which one can then refer the other pitches to this. Note that $R+1$ and $R-1$ do not exist.

4-7) Claas Douwes, op. 1oc. cit. p. 107 .

4-8) The reason for the logarithmic nature of these results has been pointed out by W.R. Thomas and J.J.K. Rhodes, 'Harpsichords and the Art of WireDrawing', Organ Yearbook, Vo 1. X (1979) 126-139. At each stage of drawing the ratio of the length of the wire before and after drawing was kept constant. Thus the ratio of the cross-sectional area. before and after drawing, the drawing ratio $r_{d}$, is also a constant. The gauge ratio $r_{f}$, the ratio of successive gauges is thus related to ${ }^{\circ}$ by the simple equation:

$$
r_{\mathrm{d}}=r_{\mathrm{g}}^{2}
$$

4-9) The $1581 \mathrm{HR}$ virginal may have come to the Metropolitan Museum, New York with at least some 16th or 17 th century strings, but all traces of these were lost in a recent restoration. My thanks are due to Stewart Pollens, of the Metropolitan Museum, for his patient help in pursuing this matter.

4-10) Hubert Bedard, 'Harpsichord of 1644 by Andreas Ruckers: on putting it in playing condition', Colloquium: Ruckers Klavecimbels en Copieün, Antwerp (1978) 109-118.

4-11) See G. Grant O'Brien, 'Some Principles of $18 \mathrm{th}$ Century Harpsichord Stringing and their Application', organ Yearbook, Vol. XII (1981) 160-176.

4-12) See footnotes 4-1) and 4-11).

4-13) Hermann Helmholtz, on the Sensations of Tone, London (1855) facs. New York (1954): p. 495, gives the frequency of Pascal Taskin's tuning fork measured by Lissajous in 1783 as $409 \mathrm{~Hz}$.

4-14) Quirinus van Blankenburg, Elementa. Musica, 's-Gravenhage (1739) facs. Amsterdam (1972) 175, see Appendix 10.

4-15) The results given here also strongly contradict the pitch assignments of W.R. Thomas and J.J.K. Rhodes, 'Harpsichord Strings, Organ Pipes and the Dutch Foot', Organ Yearbook, Vo1. III (1973) 112.

4-16) See chapter 8, p. 506 . 


\section{Chapter 5 - The Construction of Virginals}

\section{Introduction}

Except for the wrestplank, the structural part of all Ruckers instruments is of poplar (Populus, probably Populus canescens or Populus nigra). This wood is used for the baseboard, case sides and internal framing as well as for the lid, lid flap, front flap, keys, keyblocks and jackrail. Although technically a hardwood, poplar is a soft open-textured wood, very susceptible to indentation and scratching. It is very light and extremely tough. The wood used in Ruckers instruments has sometimes mistakenly been identified as lime (Tilia vulgaris) which is, however, much heavier and denser and more close-grained than poplar, although similar in that both lack any strong distinction between the spring and summer growth woods. The timber used in Ruckers instruments often has streaks of grey and a reddish or reddish-brown tinge suggesting that the species involved is Populus canescens which has a characteristic reddish-brown heartwood.

All joins in the case, lid, baseboard and action are glued with hot glue. Hot glue consists mostly of gelatin and is made from animal bones, skins and intestines. The glue is dissolved in water and usually kept hot in a water bath. When hot the glue is watery and runny, but at room temperature it becomes rubbery and jelly-like. Any join made with hot glue must be made 


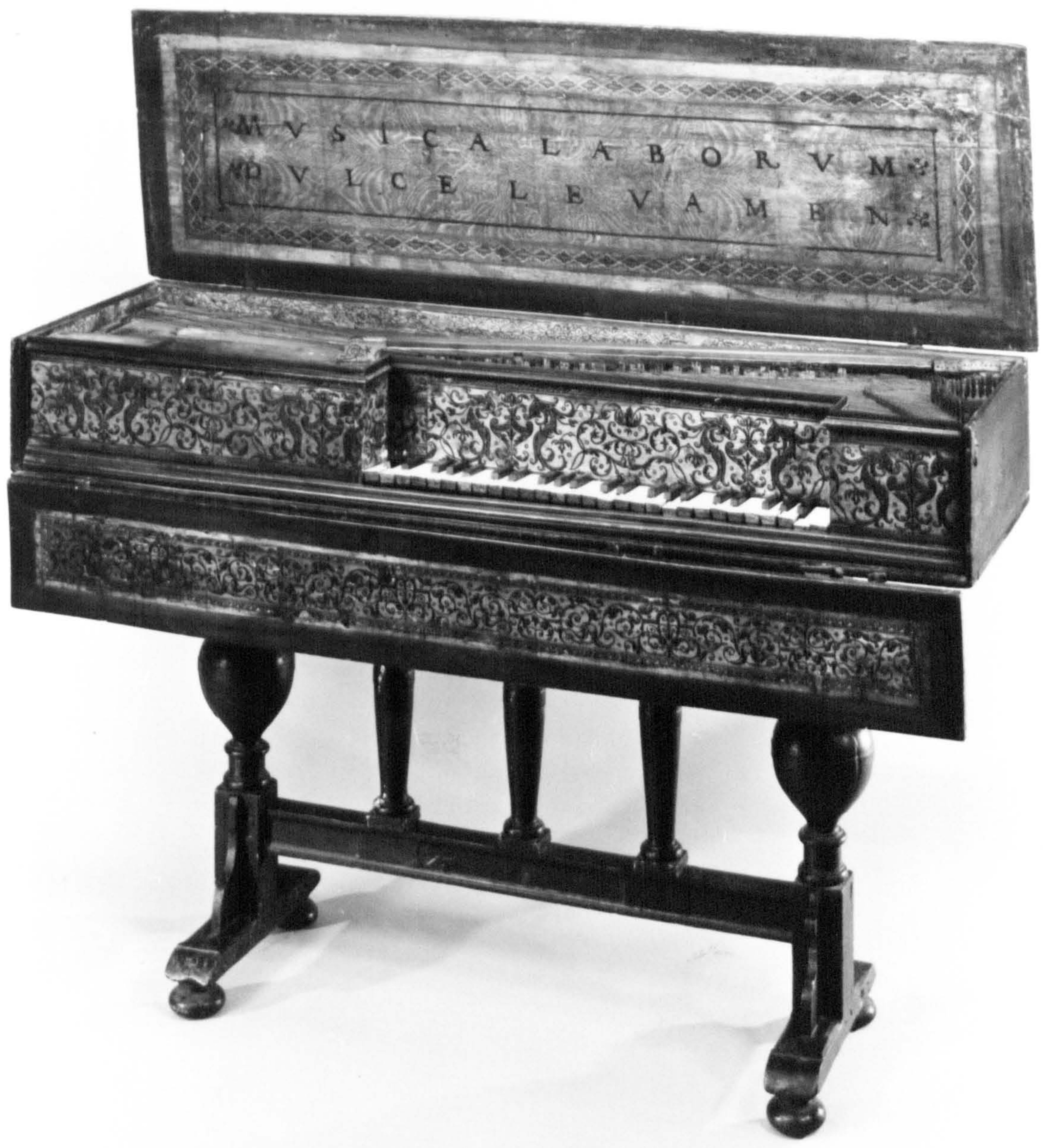

Photo 5-1 The 1640a IR 5-voet muselar virginal, now in the Gement emuseum, gives a good idea of the original appearance of a Ruckers virginal. 
before the glue cools down to its jelly consistency, otherwise a great deal of the strength of the glue-joint is lost. This means that, after applying the glue to the wood, the joint must be clamped or secured very quickly and if possible the surfaces to be glued should be preheated in order that the glue remain liquid while the join is fixed. The short working time before the initial 'set' of the glue is strongly reflected in the methods used by the Ruckers in the construction of their instruments. In particular, much use is made of wooden pegs in securing joints between two members. The thin film of glue between the sides of the peg and the hole it is driven into cools, sets and begins to dry within a few seconds so that the peg cannot be driven further into its hole nor extracted from it, and the joint being pegged becomes completely solid and without any further need of clamping. Once a joint is pegged any initial clamping used can be removed and the next joint clamped and pegged. Clearly, pegging two surfaces or joins is not always necessary or possible and individual methods of glueing surfaces together will be discussed as they arise.

All parts of the Ruckers instruments were made by hand and this is also reflected in their construction, dimensions and finish. The wood was hand sawn, joints and surfaces were planed by hand and the individual parts were assembled, glued and finished by hand. This results in a variability in the case dimensions and wood thicknesses, especially in the non-acoustical parts of the 
instrument such as the case, internal framing, and lid. It also means that many of the internal invisible surfaces are left with saw marks not planed away, large knots, wavy grain with chip marks, corners not square, etc. Although the Ruckers workmanship has been debased by many, it must also be pointed out that the actual joinery is tight and sound and the skill and craftsmanship exhibited in the making of the soundboard, bridges and registers is unisurpassed. The disparity in the attention paid to the different parts of the instrument can only be explained by the Ruckers' intuitive or learned knowledge of what parts of the instruments were important to the sound and action, and which were not, and therefore which were to be handled carefully and which not. It is clearIy a question of the attitude of the builders and not their inherent skill. They were primarily interested in the sound and action of their instruments and not in their static non-resonant parts.

In studying the Ruckers instruments it must be remembered that they were built without the aid of drawings or stable templates. This, coupled with the dimensional variability resulting from the hand work itself, is also reflected in the construction and marking out of the instruments. Generally it means that, as the construction progresses, each part is marked out from those parts already made. Any variability and lack of standardization is compensated for by matching the parts to be made to those already existing. One must then only get 
the order of construction right.

Therefore in studying what follows on the construction of Ruckers virginals and harpsichords one must try as much as possible to adopt a 17 th century frame of mind. One must remember that these instruments were made entirely by hand, without a technical drawing as a standard reference, and using hot glue. Within this framework, which almost certainly did not seem limiting to them, the Ruckers worked quickly and efficiently and turned out a surprisingly large number of some of the most beautiful sounding instruments in the history of keyboard instrument making. Virginal baseboards

One of the important characteristics of the Flemish school of harpsichord and virginal building is that the edge of the baseboard extends right to the edge of the instrument with the case sides resting on 1 t, rather than over-lapping it as is usual with instruments built in the Italian tradition. Naturally, this reflects a difference in the order and way in which the parts of the instrument were assembled.

Like the rest of the case, the baseboard is made of poplar. The grain of the wood runs lengthwise so that the maximum strength is achieved paralled to the direction in which the string tension acts. At the same time the dimensional stability is optimised since the humidity coefficient of expansion is least along the direction of the grain of the wood so that under changing conditions of humidity the instrument is most stable along an axis 
parallel to the strings.

The thickness of the baseboard varies considerably from about 11 to $14 \mathrm{~mm}$ in different instruments, but is usually near the nominal $\frac{1}{2}$ duim $(12.7 \mathrm{~mm})$. After planing, the inside surface of the baseboard was probably left completely untreated. It is possible, however, that the outer lower surface was sized with glue or shellac since the characteristic brown discoloration normally found on the baseboard of Ruckers instruments is greater than what would be expected from a completely untreated surface. The upper interior surface of the baseboard is marked out with double scribed lines to indicate the positions of the casesides, the keywell and keywell braces, the nameboard liner and the lower keywell moulding.

The positions of these lines on the baseboard were punched with a sharp awl at several places along the lines. Once the lines were scribed, the baseboard could be used as a plan and base onto which the instrument could be built. Holes were drilled between the double scribed Iines, and, as the case sides and braces were fitted to the scribed plan, wooden pegs.into these and matching holes along the lower edge of the casework pieces held the framework temporarily in position as it was being assembled on the baseboard. After the case was assembled and the soundboard was glued in position, the baseboard was fixed permanently in position and its edges were planed flush with the case sides.

The baseboard was fixed to the case of the instru- 
ment by means of the wooden pegs and was only lightly glued in place. The pegs used for fixing the case-sides to the baseboard have pointed ends, are about 2 duimen (52 mm) in length and $5 \mathrm{~mm}$ across, and seem originally to have been made either square and tapered or rather irregular in section. But being of soft poplar they assume the rounded shape of the hole after they are driven into position. The pegs were usually, but not always, glued in place and sometimes the glue near the peg holes has spread, thus strongly attaching the baseboard to the case-sides and framing.

Except for the little child virginals which fit inside the case of the larger mother virginals, the keywell flap was attached to the front edge of the baseboard by means of wire hinges. The number, position and nature of these hinges will be discussed later. Also attached to the baseboard at the front edge of the keybed are two blocks of wood with chamfered edges, the keyboard holddown blocks. Turnbuttons fixed to these blocks are used to hold the keyboard firmly in position. The top surface of the baseboard in the keywell including these blocks was painted black so that this area became unobtrusive under the keys.

Virginal outer case and framing

An analysis of the length of the poplar case of the various sizes of Ruckers virginal, coupled with a knowledge that the foot unit used in Antwerp at the time of the Ruckers contained 11 units instead of the expected 12, 
leads almost immediately to a solution of the way in which the members of the Ruckers family numbered their instruments (see Chapter 3). But knowing the number of sub-divisions in the voet, and knowing that the virginals were labelled according to their length in voeten also enables one to calculate the length of the duim and voet in use in tho Ruckers workshop. In Appendix 1, I have taken the length of all of the extant unaltered virginals and divided this by the length of the instrument in duimen. For the sixvoet virginals, for example, this means that the length is divided by 66 duimen. Obviously a few of the 6-voet instruments have lengths which are not exactly 6 voeten, the $1598 \mathrm{HR}$ and $1617 \mathrm{AR}$ spinett virginals are 2 duimen shorter, and the mother virginals are one to three duimen longer than 6 voeten. However, averaging over all of these instruments including those shorter than 6 voeten and correcting the length where it is obviously greater or less than the nominal value as above, one gets a value of $25.880 \mathrm{~mm}$. This I have called the large duim.

The large duim, when applied to the width of the various sizes of virginal, gives measurements which are integral or half-integral multiples of this unit (see Table 5-1)

It would seem equally plausible to expect that the case heights, the frame dimensions and the spacings of the various parts of the instruments should also be integral or half-integral units of the same duim unit. However all such distances turn out to be slightly less than an integral number of the large duim. 
Table 5-1 - Lengths and widths of Ruckers virginals expressed in duimen.

\begin{tabular}{c|c|c|c|c|c}
\multirow{2}{*}{ Instrument } & \multirow{2}{*}{ Type } & \multicolumn{2}{|c|}{ Length } & \multicolumn{2}{c}{ Width } \\
\cline { 3 - 6 } & & mm & duimen & mm & duimen \\
\hline $1620 \mathrm{~d} \mathrm{AR}$ & 6 -voet & 1708 & $66.00=66$ & 492 & $19.01=19$ \\
$1604 \mathrm{HR}$ & 5 -voet & 1424 & $55.02=55$ & 470 & $18 \cdot 51=18 \frac{1}{2}$ \\
$1629 \mathrm{IR}$ & $4 \frac{1}{2}$-voet & 1282 & $49 \cdot 54=49 \frac{1}{2}$ & $478 *$ & $18.47=18 \frac{1}{2}$ \\
$1613 \mathrm{~b} \mathrm{AR}$ & 4-voet & 1138 & $43.97=44$ & 441 & $17.04=17$ \\
(1626) AR & child & 801 & $30.95=31$ & 300 & $11.59=11 \frac{1}{2}$
\end{tabular}

*Only one other $4 \frac{1}{2}$-voet virginal exists (1610b AR). It is $452 \mathrm{~mm}$ or about $17 \frac{1}{2}$ duimen wide. The difference in the dimensions of these two virginals almost certainly arises because the 1629 IR is a spinett virginal, whereas the $1610 \mathrm{~b} A R$ is a muselar virginal.

The slight discrepancy cannot be explained by assuming that the case planks came to the workshops in dimensions which were exact integral multiples of the $25.88 \mathrm{~mm}$ duim, and that these were then reduced in width by planing in the process of finishing. The main evidence against this is that the scribed lines on the baseboards of Ruckers instruments are also separated by distances which are slightly less than integral multiples of this dimension. Since it is unlikely that awkward units of length would be used for what are otherwise highly arbitrary distances, one is led to the conclusion that there were two standards of length in use in the Ruckers workshop at the same time.

The large duim equal to $25.88 \mathrm{~mm}$ was used to measure large distances great or than 1 voet such as case lengths 
and widths; the other, the short duim $=25.48 \mathrm{~mm}$ was calculated from small measurements of less than 1 voet. In all some 75 measurements of the case heights, the width of the wrestplank, framing dimensions, soundbar spacings, spacings of scribed lines on baseboards and other dimensions of about or less than 1 voet were averaged to arrive at the value of the small duim. Although it might seem inconvenient and confusing to use two different standards of length in the same workshop, I see no other way of resolving the discrepancy in the measurement of long and short distances. It was obviously not a problem to the Ruckers: the same situation obtained in all of their workshops over a time span of more than 100 years. They must have had short measuring sticks and long measuring sticks and the two were not calibrated to quite the same standard. In units of the $25.48 \mathrm{~mm}$ small duim the height of the case sides (not including the thickness: of the baseboard) are close to:

$$
\begin{aligned}
& \text { Mother virginals - } 10 \text { duimen }-255 \mathrm{~mm} \\
& \text { 6-voet virginals - } 9 \text { duimen - } 229 \mathrm{~mm} \\
& \text { 5-voet virginals - } 8 \text { duimen - } 204 \mathrm{~mm}
\end{aligned}
$$

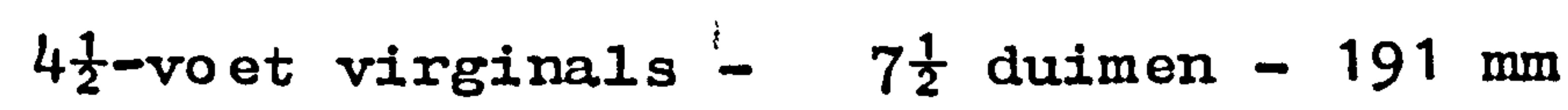

$$
\begin{aligned}
& \text { 4-voet virginals - } 7 \text { duimen }-178 \mathrm{~mm} \\
& \text { child virginals - } 5 \text { duimen }-127 \mathrm{~mm}
\end{aligned}
$$

Other measurements which are integral multiples of the small duim will be discussed as they arise.

It is important to notice that the nameboard and faceboard of the mother, 6-voet, and 5-voet virginals are 
always about $\frac{1}{2}$ duim (about $13 \mathrm{~mm}$ ) lower than the outer case sides. But they are the full height in the smaller $4 \frac{1}{2}$-voet, 4-voet, and child virginals. Also, being hand finished, the thickness of the case sides, the front flap, and lid are variable from about 13 to $15 \mathrm{~mm}$, or sometimes even less for the small sizes of virginal. The nameboard and faceboard are always somewhat thinner than the case sides and are about 11 to $12.5 \mathrm{~mm}$.

The top edge of the case sides is decorated with a characteristic moulding profile. The depth of this moulding varies with the different members of the Ruckers family, and according to the date of the instrument. But it is always of the same basic profile, and this was among many features of the Ruckers instruments which were later used by builders in other countries in the late 17th and 18th centuries. The smaller virginals with their thinner case sides usually have the moulding profile standing on its edge as it would otherwise leave only an extremely narrow ledge of wood along the top of the side of the instrument. The virginal nameboard and faceboard have a double profile with the two mouldings placed back to back (see fig. 5-1). The lower angled surface of the added moulding is sometimes rounded in the early instruments of Hans Ruckers.

The basic strength and rigidity of a virginal is provided almost entirely' by the basebaord, case sides and soundboard liners. In addition, the sides of the keywell, reduced in height, extend to and are let into 
Case moulding on the larger sizes of Ruckers clavecimbel.

Case moulding on the Ruckers clavecimbels $4 \frac{1}{2}$-voet in length or less.

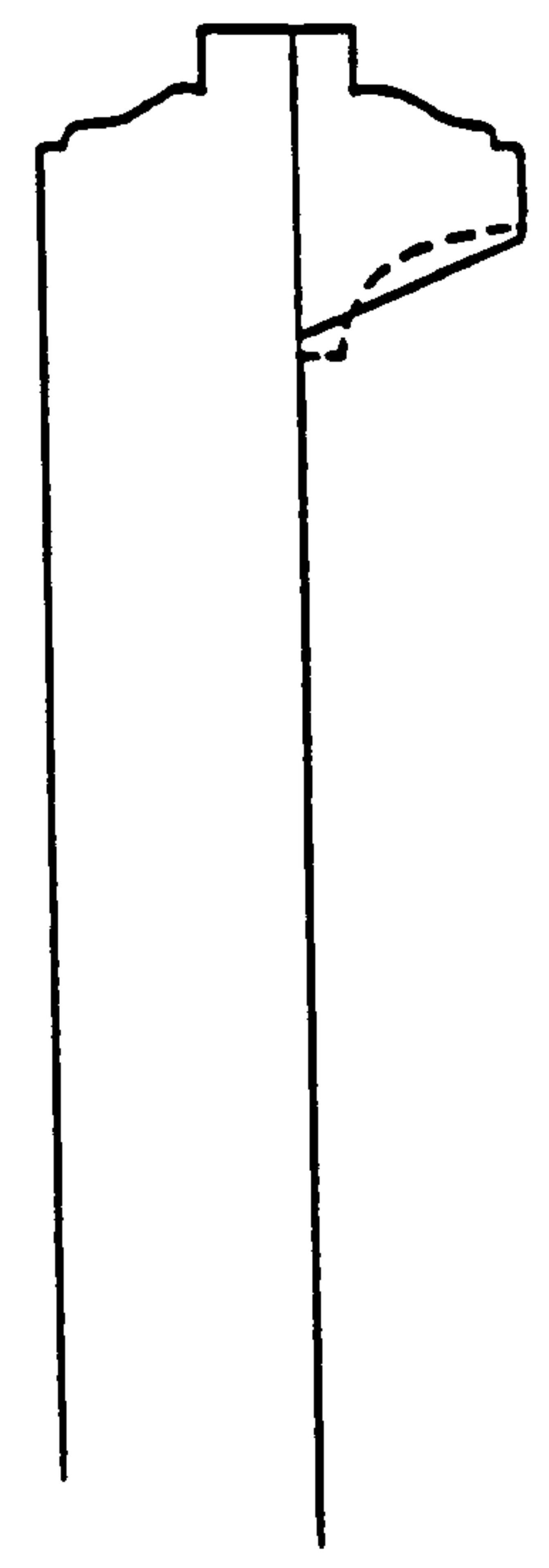

Nameboard and faceboard mouldings. The dashed line shows the shape of the curved lower surface of the nameboard moulding found on some early Hans and Ioannes Ruckers instruments.

Fig. 5-1 Case mouldings and nameboard/faceboard mouldings on Ruckers clavecimbels. 
the spine of the instrument. The nameboard liner extends to the left-hand side of the instrument and is let into the left-hand soundboardliner, and also helps to provide some rigidity. Otherwise the case sides and liners support the string tension unaided by any other interior bracing.

The corner joints in the case and the keywell/faceboard joints of Ruckers virginals are simple $45^{\circ}$ mitred joins and are not dovetailed or otherwise joined in a complicated way. The faceboard is let into the sides of the ends of the case with simple mortices. In the smaller sizes of virginal where the case sides and faceboard are the same height, the top part of the faceboard is mitred into the case ends so that the moulding at the top of the case matches the moulding of the faceboard and runs continuously around the inside of the instrument with a $45^{\circ}$ mitre at each corner. All case, faceboard/case and faceboard/keywell joins are pegged with small (about 3mm in diameter) wooden pegs for stability during glueing and to increase the ultimate strength of the join.

Except for the nameboard liner, the soundboard liners onto which the soundboard is glued are usually about 2 small duimen (about $51 \mathrm{~mm}$ ) high and about 15 to $20 \mathrm{~mm}$ in width. Behind the nameboard, the nameboard liner is about 5 small duimen (127 mm) narrower than the total case height. The left extension of the nameboard liner is usually about the same hight as the other liners in the instrument. This extension supports or provides part of 
the framing of the little toolbox in the left-hand cormer of the instrument. Also, in muselar virginals, a block glued to the side of the nameboard liner extension braces the soundboard under the left-hand jackrail support. The upper surface of the liners is placed 2 small duimen (about $51 \mathrm{~mm}$ ) below the top of the case in all sizes of virginal (and harpsichord), and the lower outer edge of the liner is characteristically chamfered off.

The liners are glued and secured to the case sides and to one another with wooden pegs. The ends of the keywell braces, in addition to being let into the spine are also further secured with wooden pegs. The rear vertical edges of the higher front part of the keywell braces are let into the nameboard liner, and nails driven into the back of the latter fix it in position.

The nameboard itself is not a structural part of Ruckers virginals, but is removeable. It slides in and out of two slots in the keywell braces which are mitred at the top and are just in front of the keywell liner. In Ruckers virginals it is necessary to take out the nameboard before the keyboard can be removed. Some nonRuckers Flemish virginals, however, have a fixed nameboard which does not extend down to the level of the top of the keys, but which has instead a removeable moulded batten just over the keys which allows the keys to be extracted. The notable exceptions to this are the Ruckers child and $2 \frac{1}{2}$-voet virginals. In the child virginals the nameboard does not exist as such since the keysiproject 
from the case, and the front of the case is one continuous straight board. So all Ruckers child virginals have a removeable batten above the keys which is held in place with two small wooden pegs. Also the keybed is not removeable in child virginals since the balance rail is fixed to the baseboard. Therefore the keys may be removed only one at a time after removing the papered batten from its position above the keys. In the $2 \frac{1}{2}$-voet virginals (see Appendix 3) a removeable keyframe, held in position with turnbuckles on the keyboard hold-down blocks, is provided. The keyframe and keyboard are removed only after lifting out a batten (like the namebatten in harpsichords) which fits into appropriate slots in the keyb1ocks.

Virginal wrestplanks and hitchpin rails

Unlike the rest of the structural part of a Ruckers instrument, the wrestplank is made of oak rather than the softer and weaker poplar. In the larger virginals of the spinett type the wrestplank consists simply of a long piece of oak about $2 \frac{1}{2}$ by $1 \frac{1}{4}$ small duimen (about 64 by $32 \mathrm{~mm}$ ) running diagonally across the rear left of the instrument roughly parallel to the direction of the bridge. This is lap-jointed to a short extension for the bass tuning pins which runs parallel to the right side of the case, and ends at the back of the faceboard. With the smaller 4-voet and $4 \frac{1}{2}$-voet spinett virginals and all sizes of muselar virginals (the 4-voet, child, and $2 \frac{1}{2}$-voet virginals are only of the spinett type) the wrestplank is composed of 
three sections jointed together in such a way that the shape of the wrestplank closely follows that of the bridge. This results in a lap joint in the wrestplank which is well away from the side of the case and about halfway from the front to the spine of the instrument. This lap joint is supported by a poplar post which is nailed at its top end to the lap joint itself and whose other end stands on the baseboard. The wrestplank support post is used to withstand any downward thrust on the tuning pins when they are put in position and during tuning. The wrestplank

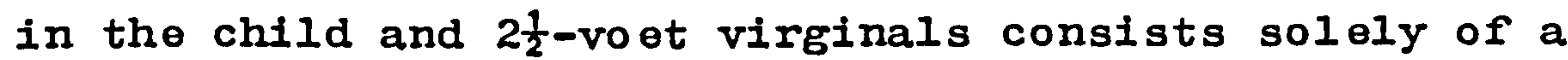
single piece of oak parallel to and attached to the righthand side of the case.

The wrestplank is let into the liners in such a way that the wrestplank sections extend right out to the case sides. The sections are glued and pegged to both the case sides and the liners, thus anchoring them firmly to withstand the tension of the strings. The soundboard is then glued to the top surface of the wrestplank as well as to the liners. Because the bass end of the right-hand bridge would, in most sizes of muselar virginal, extend over the upper surface of the bass section of wrestplank, the wrestplank is cut away at the soundboard level to allow the bass end of the bridge to vibrate freely. For the same reason, the wrestplank is also cut away near the treble end of the bridge in the spinett virginals.

The tuning pins are placed alternately in two rows along the length of the wrestplank. The tuning pin dia- 
meter is chosen in proportion to the length of the string smaller tuning pins are used for the shorter, higher pitched strings to provide greater ease and accuracy of tuning. Thus, normally, different sized tuning pins are used in the treble and bass of any one instrument and the smaller, higher pitched virginals have smaller tuning pins than the larger instruments. Typically the bass tuning pins in a 6-voet virginal are about $4.1 \mathrm{~mm}$ in diameter and the treble pins about $3.4 \mathrm{~mm}$, with the change in diameter occuring at about $c^{1}$ to $a^{1}$. The treble tuning pins in the smallest dild virginals are, by comparison about $3.0 \mathrm{~mm}$ or slightly 1ess.

The tuning pins themselves are round pieces of wire rod flattened slightly (probably cold) at one end for the tuning hammer, and slightly tapered over a length of about $10 \mathrm{~mm}$ at the other. The holes for the tuning pins are drilled at a slight angle away from the bridge to a depth of about $20 \mathrm{~mm}$. Unlike the tapered tuning pins and holes in a viol, lute or violin, these holes have parallel sides and are slightly smaller than the untapered shank of the tuning pin. By bruising and slightly compressing the wrestplank wood, the tuning pin itself forms its own tapered hole. Because of this taper and because the tuning pin is placed only about $12 \mathrm{~mm}$ deep in the hole, the tuning pin never works loose even after centuries of repeated tunings.

The tuning pin locations in a number of virginals are lettered in in ink with the note name of each pin. 
Although evidence of this has disappeared in most virginals it was probably an original feature of all Ruckers instruments.

The spinett virginals have a wide piece of poplar about 1 small duim (about $25.5 \mathrm{~mm}$ ) thick running diagonally across the rear left-hand corner of the instrument parallel to the register. This is used both as a hitchpin rail for the strings and to support the left nonsounding bridge.

In the muselar virginals where the left-hand bridge is the main sounding bridge, the spine and left-hand soundboard Iiners act as the hitchpin rail. The lowest bass strings in the muselar virginals are raised slightly at the hitchpin end on a block of wood glued to the soundboard and left-hand case side. Thus the downward pressure exerted by the heavy bass strings, which are under approximately twice the tension of the treble strings, is great1y reduced. Despite this the downward string pressure has caused the soundboard and bridge in a number of Ruckers muselar virginals to sink to such an extent that the sounding portion of some of the strings touches the soundboard or the register 1 eather.

\section{Virginal lid and keywell flap}

Except for the little child, all models of Ruckers virginal have a lid and a keywell flap. The lid is hinged along the spine, and the keywell flap is hinged to the front edge of the baseboard. Although axle hinges were sometimes used for harpsichord lids, both the lid and key- 
well flaps on virginals seem invariably to have used only wire hinges. The keywell flap was thus not removeable, and although this seems inconvenient to many modern players, it therefore gets in the way of the knees unless a a standing position or high sitting position is adopted. The wire hinges used for the lid and keywell flap consist simply of two short sections of wire bent in half across one another. Angled holes are drilled at the edges of the pieces being hinged and the paired wire ends of the hinge are inserted into them. The wire ends left projecting out of the hole are then bent over and hammered into the grain of the wood flush with the surface, thus preventing the hinge from pulling out. These wire hinges were apparently positioned after the instrument was decorated since the splayed ends of the spine hinges are visible on top of the block-printed papers araund the soundwell of the instrument, and above the inside painted surface of the lid and keywell flap.

Four wire hinges were normally used on both the lid and keywell flap of the 5- and 6-voet virginals, and only 3 hinges on the 4 - and $4 \frac{1}{2}$-voet instruments.

The keywell flap is recessed into the left- and right-hand case sides so that when closed it is flush with the front of the sides. It is held in the closed position by a brass or wire retaining hook fastened to the side of the keywell nearest the middle of the virginal. The hook engages a wire eye on the inside of the keywell flap which is made and secured like the wire hinges. Unlike the rest. 
of the case sides, the keywell flap has no moulding.

The lid usually overhangs the case sides about 10 to $12 \mathrm{~mm}$ on the sides, 6 to $8 \mathrm{~mm}$ along the front, and is flush along the spine. The lid was normally held closed with two hooks on the keywell flap entering into two wire eyes in the front lid overhang. But at least one virginal (1643 AR) had a lock and hasp similar to that normally found on double manual harpsichords.

The lid was retained in the open position with a cord running from the lid to the case side. The holes for this cord are to be found about 1 duim (about $25 \mathrm{~mm}$ ) below the top near the middle of the side of the case, and in a matching position in the lid. The holes for the lid cord are about $3 \mathrm{~mm}$ in diameter; however no direct evidence of the size or the material of this cord in virginals has been found in my investigations. Virginal toolbox

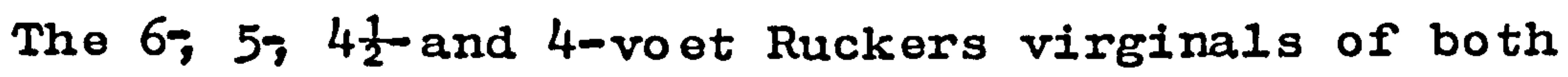
the muselar and spinett types are provided with a small toolbox. This toolbox is placed to the left of the keywell behind the faceboard and is usually, but not always, against the left-hand case side. The lid on the toolbox is pivoted along one of its long edges and is tapered in thickness from about 12 to $13 \mathrm{~mm}$ at the pivoted edge to 8 to $9 \mathrm{~mm}$ at the free edge.

On muselar virginals the soundboard provides the bottom of the toolbox. Two walls of the toolbox are built onto the soundboard and the other two walls are provided 
by the case side and faceboard. One of the walls built onto the soundboard which is perpendicular to and let into the faceboard, is moulded on top like the rest of the case walls and faceboard. The other wall is lower and acts as a stop under the thinned free edge of the toolbox lid.

The toolbox in spinett virginals is a ready-made part of the construction of the virginal and consists of the well imediately to the left of the key touchplates. Here, the tapered lid is positioned to pivot at the soundboard level. In some spinett virginals the toolbox is provided with a floor above the level of the baseboard, but in others the toolbox extends right down to the basebaord level.

Virginal soundboards

The soundboard in all Ruckers instruments is made of European spruce (Picea abies or more properly Picea excelsa). Nothing seems to be known of the country of origin of this wood except that it was not the Low Countries themselves. The annular rings, marked by the contrast between the light springwood and the darker summerwood are both highly prominent and closely spaced for this species, indicating that the country of origin was colder and drier than Flanders and had an extreme variation between the summer and winter average temperatures. It seems likely therefore that the wood came from central or northern Europe. The Alps or Carpathian Mountains are possible sources but have obvious problems of transportation to Antwerp. The Antwerp city records indicate, however, that there was an enormous timber shipping trade in Flanders in both 
softwoods and hardwoods with the Baltic countries, and this seems to be the most likely source of the wood used by Ruckers and the other Flemish builders.

The soundboard wood is usually accurately quartered, although there are instances when the grain is as much as $20^{\circ}$ off the quarter. Individual boards often consist of both widely and closely spaced annular rings and there seems to be no consistent pattern in the way in which these are used. Often it is clear that adjacent planks are successive slices from the same tree, there being no tendency to use close-grained wood for, say, the treble part of the compass, reserving the wide-grained wood for the bass. It was simply used as it came, and this had the additional advantage that the direction of the grain was the same in each plank and did not give rise to problems when planing the soundboard down to thickness.

However, although the Ruckers family seem to have placed less importance on the spacing of the annular rings and the accuracy of the quartering of the soundboard wood, they took great care with its thicknessing. Comparison of instruments by any one maker over his entire lifetime shows that the soundboards were thicknessed across their entire area consistently to an accuracy of a few tenths of a millimetre.

Comparison of the $1611 \mathrm{HR}$ and 1643a AR muselar virginals (see Fig. 5-2) shows that the soundboards were about $3.5 \mathrm{~mm}$ thick under the tenor part of the left-hand bridge. From here the soundboard was thinned in all 

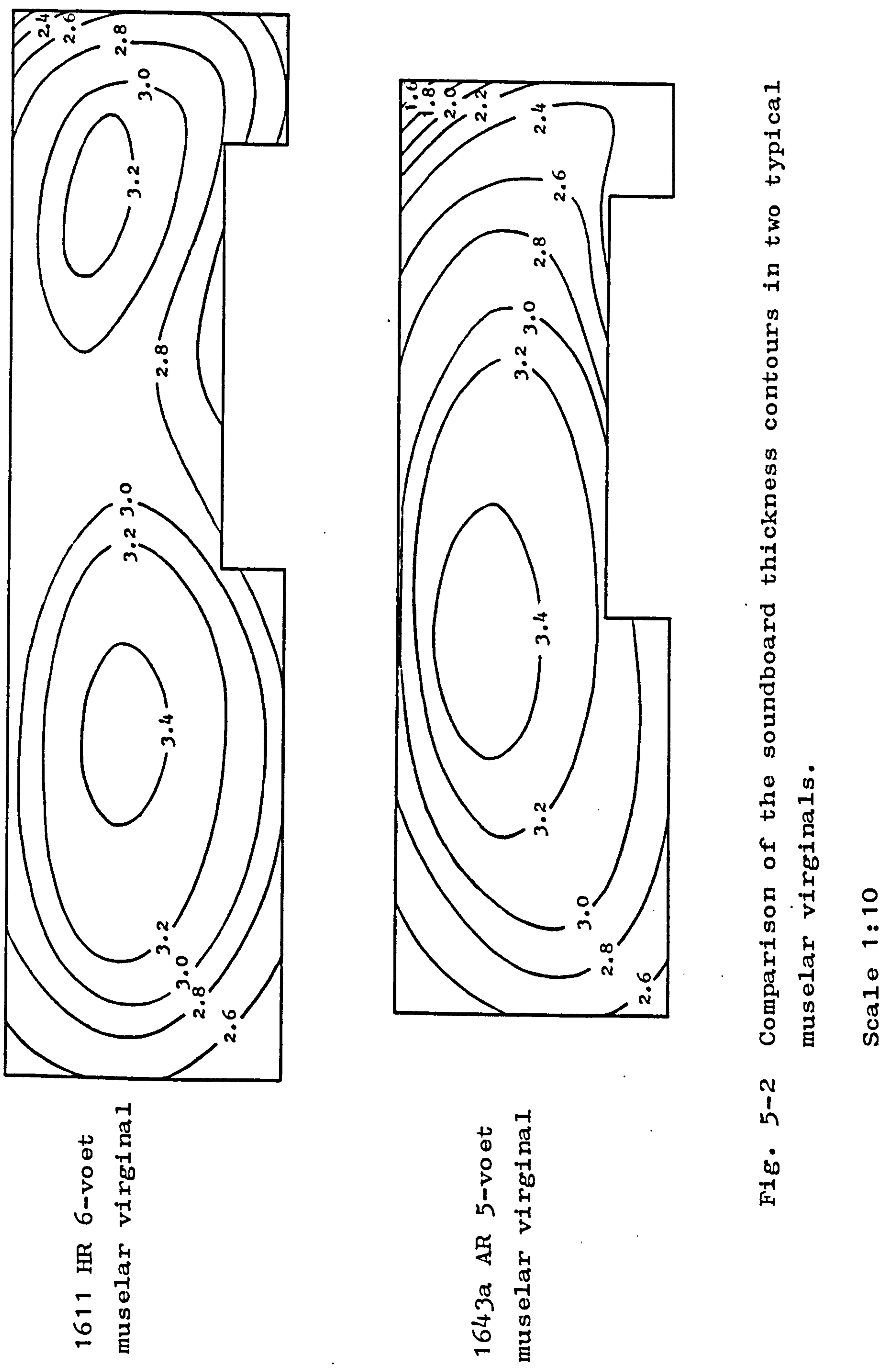
directions to about $2.8 \mathrm{~mm}$ along the outer edge of all of the sounding part of the left-hand bridge, being about 2.6 mm under most of the bridge itself, and tapering to about $1.8 \mathrm{~mm}$ at the rear right corner. The soundboard is thickest and stiffest near the tenor and bass, and is most flexible in the treble parts of the soundboard.

The upper touch bar on the keyboard rack, and the lower register guides are often made of poor quality soundboard wood of thickness 4.5 to $5.0 \mathrm{~mm}$. It is quite probable therefore that this was the original thickness of the soundboard wood as bought by the Ruckers. This was then reduced in thickness probably using a plane. The final thicknessing and finishing of the soundboard was, however, done with a furniture scraper.

A scraper works more slowly than a plane, removing only a small amount of wood with each stroke. In the final finishing of the soundboard, a scraper could be used to thickness the soundboard very accurately since it would be difficult to remove a large amount of wood. Also, the scraper is virtually insensitive to the direction of the grain of the wood, so that the soundboard cannot be damaged in the final thicknessing, as might happen with a plane.

Used on a softwood such as spruce, a scraper produces an immediately recogniseable effect. Compared to the harder summerwood, the softer springwood is only partially removed in scraping. Because of its soft spongy nature, the springwood, which is removed to the same extent as the 
summerwood in planing and sanding operations, is slightly compressed in the scraping operation. Left to 'relax' for a day or so, or if the wood is dampened slightiy, this compressed wood rises up slightly above the summerwood, and stands proud in ridges along the soundboard. This slightly ribbed texture is one of the immediately recogniseable features of a genuine Ruckers soundboard.

Before the soundboard was painted it was sized to fill the porous wood and prevent the paint from running along the grain of the wood beyond the intended edge of the painted surface. The material used as a size is not known, but it was probably something simple and readily available in the workshop such as diluted glue or shellac. The subsequent breakdown of the organic material in the size, together with the discoloration of the wood itself, has contributed to the present mellow amber brown colour of the surface of the Ruckers soundboards. Virginal soundboard barring

The effect of the barring in all Ruckers instruments is to restrict the vibrating soundboard in such a way that the free treble soundboard area is much less than that of the bass. This is in accordance with the physical requirement that, in order for an acoustical radiator to bo efficient, the physical size of the radiator must be roughly the same as the wavelength of the propagated radiation. In this case the size of the radiating soundboard should be of the same order as the wavelength in air of the note being played. In the treble part of the 
compass this is roughly true, and the wavelength of the notes being radiated (about $30 \mathrm{~cm}$ ) is of the same order of magnitude as the soundboard dimension. In the bass region, the radiating area of soundboard is much less than the wavelength of, say 'cello C in air (about $5 \mathrm{~m}$ ); but the increased stiffness of the soundboard and the heavier bridge crosssection in the bass, coupled with the heavier bass stringing, ensures that as large an area as feasible is caused to radiate in this part of the compass.

Despite this, for the very lowest notes the fundamental tone is not radiated enough to be audible by itself. For the low notes the impression of a sounding fundamental is created in the ear of the Iistener from the ear's analysis of the harmonics which are radiated by the soundboard, and which 11 e above the fundamental frequency. The centre-plucked muselar is very weak in upper harmonics in comparison with the end-plucking spinett virginals, and this means that it is necessary for the muselar to radiate the few low harmonics it produces with a greater efficiency than that which is necessary for the spinetts. This is done by alloting a much larger soundboard area in the bass region of the muselars than that found in spinetts. The barring of a typical muselar virginal is shown in Fig. 5-3. The soundboard area immediately behind the keyboard is deadened by soundbars running perpendicularly from the nameboard liner to the lower guide brace. In order to avoid the soundboard radiating the noise made by the jacks moving up and down in the register, it is cover- 


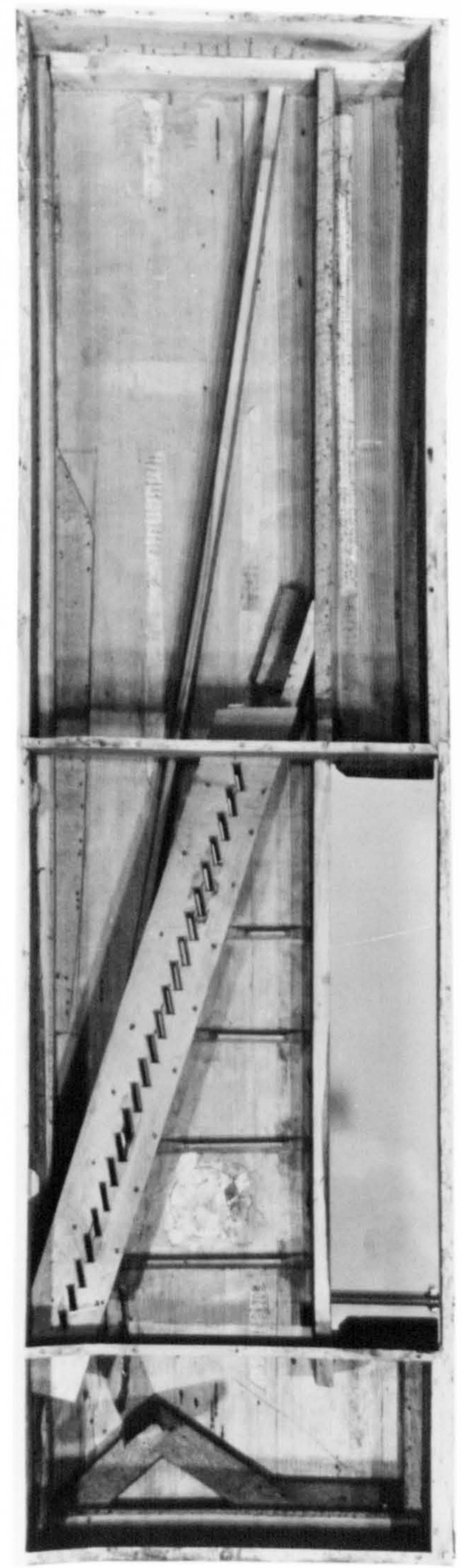

1
1
0
0

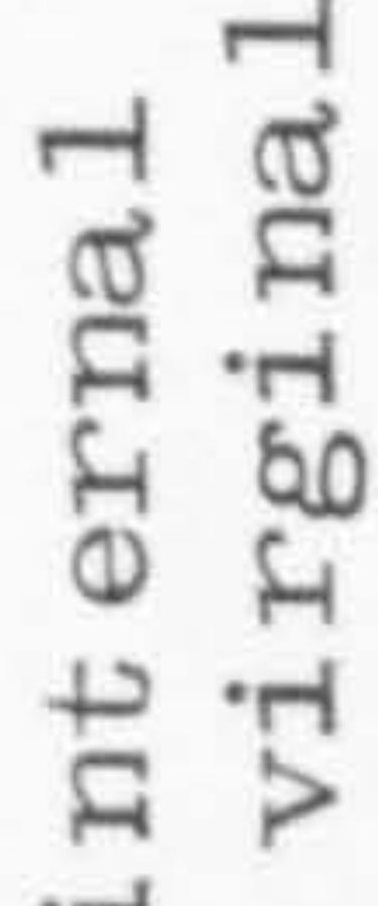

तु

疑

-

प्रे

๑)

ช 6

\&

ธี

है

כ)

on

(1)

岳案品

1 घํํ

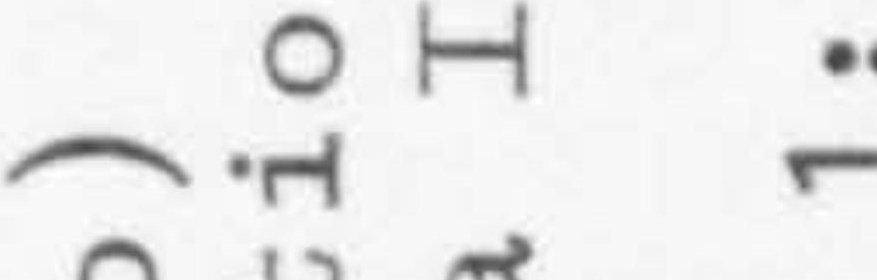

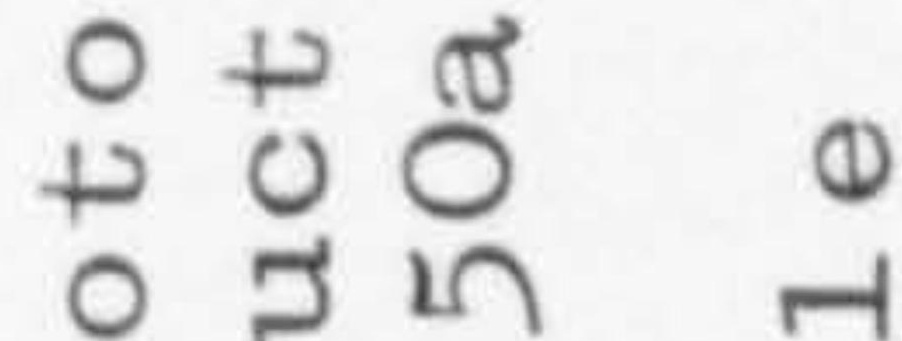

द्वे

员苟

I

$\dot{8}$ 
ed with leather against which the jacks move, and also the soundboard is stiffened by the cut-off bar running behind it and the lower guide brace in front of it. So as not to run too close to the right-hand bridge, the right end of the lower guide brace is cut away so that it does not touch the soundboard (shaded area). The radiating area of the right-hand bridge soundboard is controlled by the righthand soundbar and the lapped wrestplank whose shape roughly matches that of the bridge. Since the bass end of the right-hand bridge would otherwise sit solidly on it, the wrestplank is cut away at the soundboard level under this part of the bridge, as has been mentioned before.

The left-hand bridge radiating area is controlled by the cut-off bar and a shàped block of wood normally about $25 \mathrm{~mm}$. high which reduces the alto-tenor soundboard area. Only the two earliest muselar virginals, the $1581 \mathrm{HR}$ and the (1591)b HR virginals have a much lighter piece of wood about $6 \mathrm{~mm}$. thick restricting the tenor soundboard area similar to that found in the c.1570 Iohannes Grauwels virginal (Brussels Museum of Musical Instruments No. 2929). The cut-off bar extends in the treble right to the spine in the earliest Hans Ruckers instruments, but stops short of the spine and rapidly tapers in height in the later instruments of his sons. The left-hand end of the cutoff bar extends to (and is often let into) the left side soundboard liner. Typically the cut-off bar is about 45 $\mathrm{mm}$ high and $20 \mathrm{~mm}$ wide at the base with sides angled at close to $10^{\circ}$, and the soundbars are usually about $15 \mathrm{~mm}$ 
high and 10 to $15 \mathrm{~mm}$ wide at the base, with their sides angled either at $10^{\circ}$ or $15^{\circ}$ (see p. 295).

Fig. 5-4 shows the barring of a typical 6-voet spinett virginal. Here also the area immediately behind the nameboard liner is deadened by soundbars running to a cut-off bar placed immediately beside the jack register. The rear right soundboard area is deadened with soundbars running from the wrestplank to the spine soundboard liner. The register noise is eliminated both by the use of leather on the top surfaces of both the upper guide and lower guide and by the position of the soundbar, cut-off bar and hitchrail which are placed immediately alongside the register. The left-hand bridge does not sound on a spinett virginal since it is placed above the massive hitchpin block. Since the treble section of the right-hand bridge is located directly above the end of the wrestplank, a section of the wrestplank is cut away under the bridge to free the soundboard and bridge and allow them to vibrate free1y there. The radiating soundboard area of the righthand bridge is controlled by the shape of the wrestplank, the right extension of the nameboard liner; and the two soundbars to the left of the treble part of the bridge. Normally the soundbars in a 6-voet spinett virginal are about $15 \mathrm{~mm}$ high and 10 to $11 \mathrm{~mm}$ wide at the base and, as usual, the sides are angled at close to either $10^{\circ}$ or $15^{\circ}$. The cut-off bar beside the register slots is usually only marginally bigger than the soundbars in the spinett virginals. In both the spinett and muselar virginals the 


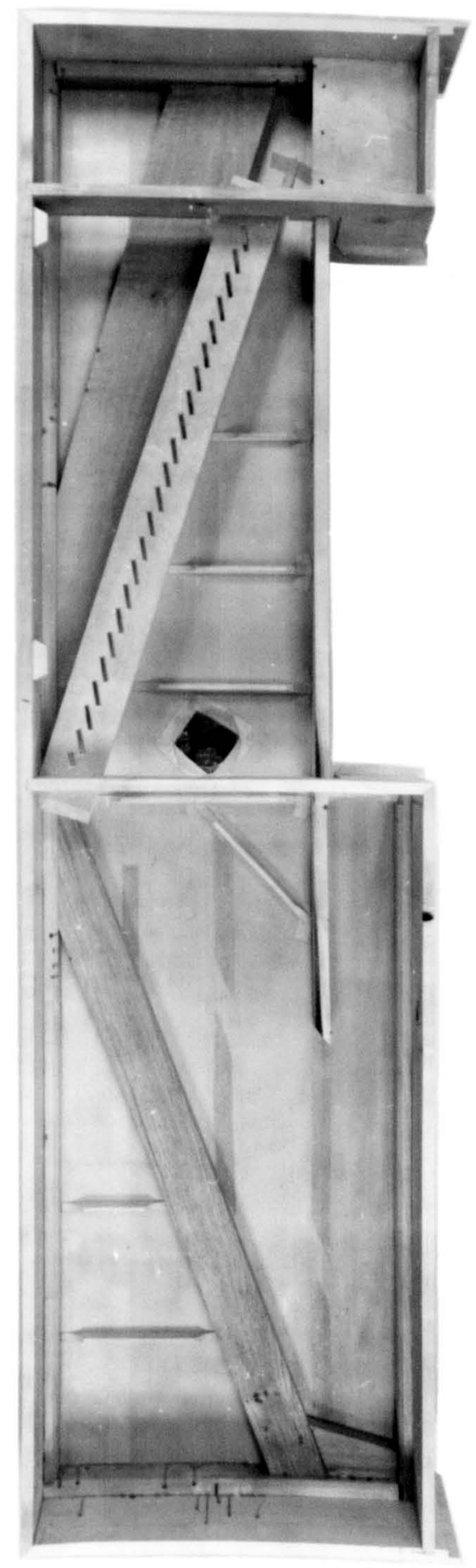

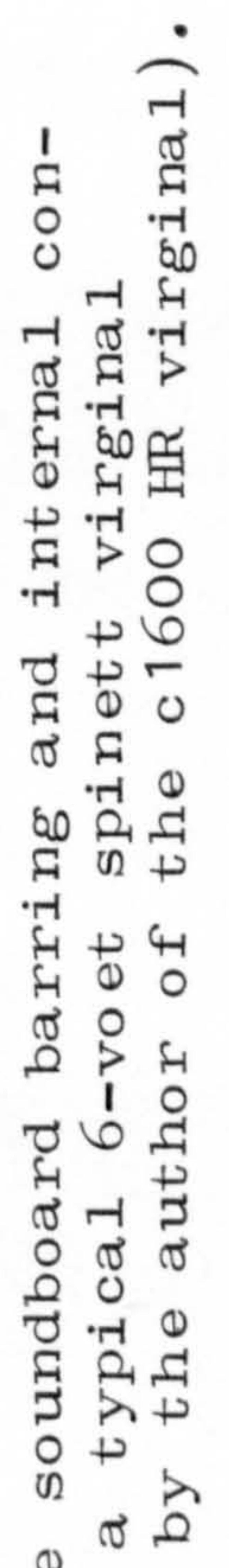

青㟔全

1 वृ० 응

开年

눙-

鱼药是

เ

80
.4
4 
larger soundboard bars such as the cut-off bars and the large register bars have rounded scallops removed from their ends which are about 2 duim (51 mm) in length, and the smaller soundbars such as those behind the nameboard liner have shorter scallops only 1 duimen (25 mm) 1ong. Because of these scallops the extreme ends of the soundboard bars are almost flush in height with the soundboard, and often Iinen tapes are glued over the scalloped ends of the bars to prevent the bars from breaking loose from the soundboard. In addition to restricting and controlling the vibrating soundboard area, the sound- and cut-off bars help to hold the soundboard flat and level, and prevent the distortions which would be produced as a result of the down- and side-draught of the strings. Virginal bridges

The material of the left-hand bridge is, in both muselar and spinett virginals practically always of beech (Fagus sylvatica). The right-hand bridge is usually also made of beech but is sometimes of cherry (Prunus avium) especially in the large spinett type of virginals where the bridge is a continuous curve sawn from the plank. In a $f$ ew rare cases cherry is used for both bridges. The righthand bridge of the muselar virginals consists of two separate sections. The treble section for $f^{\# 1}$ to $c^{3}$ is slightly curved, and this is mitred to a straight section in the tenor-bass for the notes from $C / E$ to $f^{1}$. It is along this straight section that the harpichordium stop slides. The virginal bridges have the same cross-sectional 
shape as the harpsichord bridges (see Fig. 6-7, p. 304) $5-1$ ) and were almost certainly made in the same way since the angles of the faces to the horizontal and vertical are the same as those of harpsichord bridges (see p. 305). Both the right-hand and left-hand bridge have a larger cross-sectional area in the bass than in the treble, and this factor coupled with the soundboard tapering and barring helps to ensure that a greater area of soundboard is set in vibration in the bass than in the treble as is necessary for efficient acoustical radiation.

The bridges were positioned on the soundboard by means of pairs of pins driven into the soundboard and placed on either side of the bridge. These pins not only located the bridges in their correct position, but also ensured that the bridges did not slide around on the soundboard while they were being glued in place. After the bridges were glued to the soundboard they were fixed in position with iron nails $5-2$ ) which were placed from below the soundboard between the paired positioning pin holes.

The bridge pins are made of brass wire sharpened at one end, and are slightly heavier in the large virginals than in the small ones. The 5-and 6-voet instruments usually have bridge pins of diameter 1.1 to $1.2 \mathrm{~mm}$, and the 4 -and $4 \frac{1}{2}$-voet and the child virginals have pins 0.9 to $1.0 \mathrm{~mm}$ in diameter.

There is a slight difference in the nature of the bridge pinning and the hitchpin arrangement between the spinett and muselar type of virginals. The muselar vir- 
ginals alone are equipped with a harpichordium on the right-hand bridge. Because of the relatively large amount of space occupied by each of the hooks on the harpichordium, they must be almost uniformly spaced, and the strings and bridge pins on the right-hand bridge must therefore also have a uniform spacing. In order to allow space between the strings for the jacks, alternate strings diverge, with a consequent close spacing of successive pairs of strings on the left-hand bridge.

In muselar virginals the bass end of the left-hand bridge sits on a very large and flexible soundboard area. In order to relieve the downward string pressure on the soundboard in this region the bottom octave of strings, that is the 9 notes from $\mathrm{C} / \mathrm{E}$ to $\mathrm{C}$ inclusive, are backpinned. These strings run, without any side-draught, back to hitchpins on a raised block, roughly the same height as the bass end of the bridge. There is therefore neither downward nor sideways pressure on the bridge due to the heavy bass-octave of strings.

The harpichordium is never found in spinett virginals and the strings in this type of instrument run almost completely parallel to one another, spaced in pairs along both bridges so as to allow clearance for the jacks between them. The left-hand bridge in spinett virginals sits on a solid plank of wood which runs diagonally under the bridge, and which serves both to deaden this bridge and as a hitchpin rail. Since there is no problem of the left-hand bridge sinking in a spinett virginal, it is not 
backpinned, and there is no hitchpin block to raise the strings in the bass.

In both spinett and muselar virginals, side-draught is provided by angling the strings toward the spine at both bridges. This side-draught is usually of the order of 7 to 11 degrees. Except for the bass octave in the muselar virginals, there is also a slight down-draught in the strings since the hitchpins are driven directly into the soundboard, forcing the ends of the strings down from bridge height to the soundboard level.

The harpichordium stop

As previously mentioned the harpichordium stop ${ }^{5-3}$ ) is found only on muselar virginals. Why it is not found on spinett virginals is not absolutely certain. Practical experience shows, however, that the harpichordium operates reliably only when the amplitude of vibration of the string is large 1.e. especially in the bass. Since the endplacking spinett virginals do not produce such a large amplitude of vibration in the strings as muselar virginals, even in the bass, the operation of a harpichordium in a spinett virginal may have been found to be too uneven because of the critically small tolerances required. This may also explain why, after its early appearance there on the early $1581 \mathrm{HR}$ virginal, the harpichordium was not used on the treble section of the later surviving muselar virginal bridges.

The stop operates by sliding beside the straight bass portion of the mitred bridge on the notes from $\mathrm{C} / \mathrm{E}$ to $\left.f^{1} \cdot 5-4\right)$ It consists of a bar of poplar or beech into 
which hooks of lead $5-5)$ have been fixed (see Photo 5-2). The bar is tapered so that its upper surface runs parallel to the top of the bridge about 6 to $7 \mathrm{~mm}$ below the strings, and the bar extends beyond the strings in the bass to allow a fingerstop to be fixed to it, by means of which it is operated. The bar is held in position against the bridge, and its range of motion is constrained at either end by small chamfered blocks of wood. The bar is also held down against the soundboard by 3 iron pins placed horizontally into the side of the bridge; these pins extend out of the bridge to press against the upper surface of the bar containing the hooks, and are usually located above or near the chamfered blocks.

The hooks themselves are 1.8 to $1.9 \mathrm{~mm}$ in diameter and, being of lead, are easily regulated by bending them slightly so that they just touch the strings. The point of contact of the hooks with the strings is about $12 \mathrm{~mm}$ at $\mathrm{f}^{1}$ and $15 \mathrm{~mm}$ at $\mathrm{C} / \mathrm{E}$ from the bridge pin. At this distance the amplitude of vibration of the string is sufficient to cause a buzzing sound when the stop is pushed into position. Each hook is then directly underneath its respective string, and the top horizontal surface of the hook lightly touches the string producing a snarling sound which is probably more novel to the modern ear than it was in Ruckers' time.

Praetorius ${ }^{5-6)}$ refers to this stop as an Arpichordium to be found in virginals and consisting of brass (sic) hooks below the strings. He says that the sound produced 
Photo 5-2 A typical harpichordium batten and hooks (1604 HR 5-voet muselar virginal).

Scale $1: 2$ 
in a virginal was similar to that produced on a harp and was clearly referring to the bray which was common on the Renaissance harp. and which caused the harp of this period to produce a buzzing snarling sound.

The musical use of the harpichordium is not clearly understood. The effect is to produce a snarling accompaniment to the open, rather flute-like treble sound. The C/E to $f^{1}$ compass covered by the harpichordium covers most of the bass accompaniments one finds in the literature of the period. But pieces whose melody line does not cross into the region below $f^{\# 1}$, are difficult to find. Clearly, the stop is not intended to be used in every piece one finds, and it is certainly not appropriate to slow dances or fantasias. A piece in which the use of the harpichordium stop would be possible, and fitting as well, is given below. (1) $^{-7}$

\section{Corranto.}
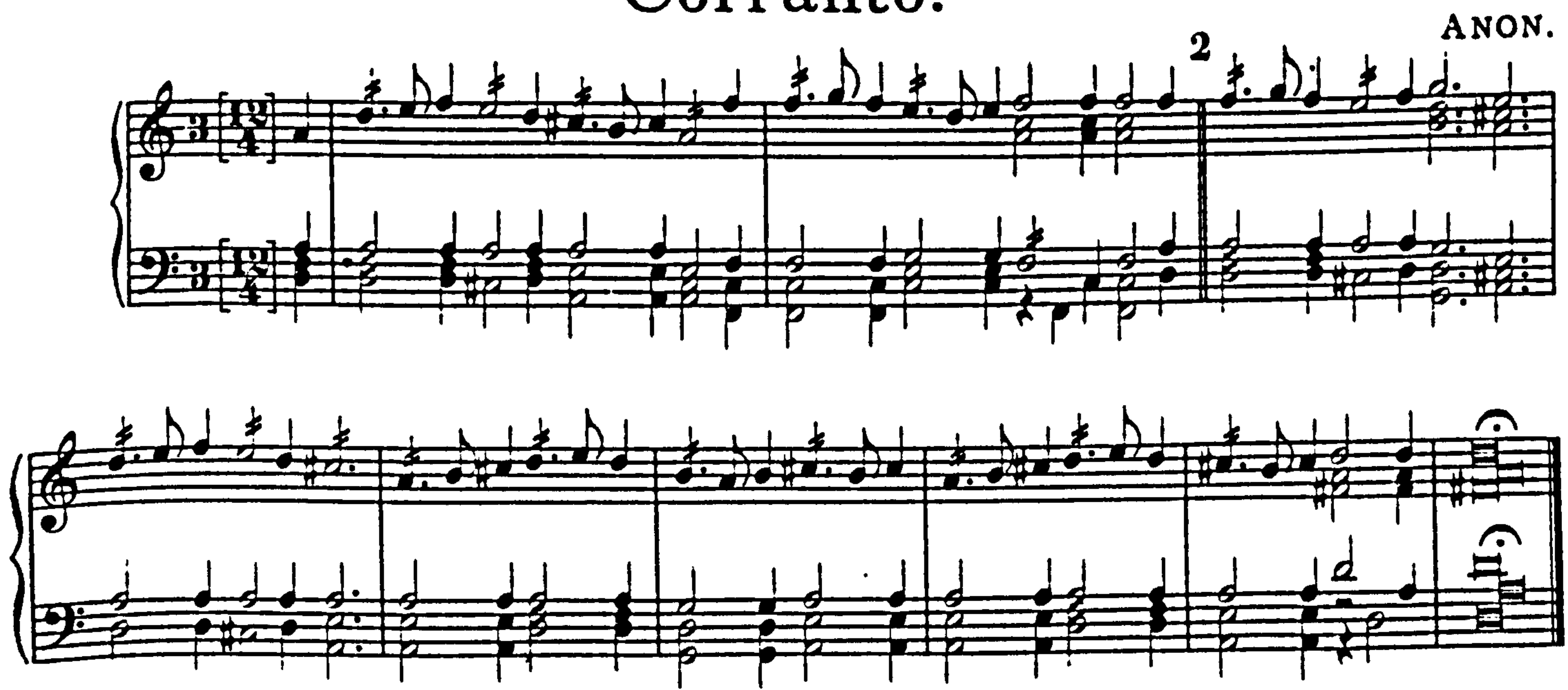

Virginal registers

The virginal jack registers consist simply of holes pierced in the soundboard. Both the lower guide and the 
soundboard registers are covered with sheepskin leather about 30 to $33 \mathrm{~mm}$ wide, and the soundboard wood and the wood of the lower guide is cut away so that the jacks bear only on the leather. This, in conjuction with the barring and framing under the soundboard, results in an extremely quiet action.

Unlike most of the contemporary virginals made in Italy, and the slightly later spinets and virginals made in England for example, the jacks in Ruckers virginals are placed two to a slot, rather than each jack having its own slot. This means that the jacks rub against one another slightly as the keys are depressed. In the usual 45 note $C / E$ to $c^{3}$ compass there are therefore 22 double slots taking the jacks from $C / E$ to $b^{2}$, plus one narrow single jack slot at the top for the $c^{3}$ jack.

Since the space occupied by one octave of keys at the tails is the same as that of the touchplates, the space occupied by one octave of jacks in a direction parallel to the spine (or parallel to the keyboard) must be the same as that of the keys. This means that the three-octave spacing of the jackslots is also $500 \mathrm{~mm}$ parallel to the long direction of the instrument. Therefore the 18 paired. slots in 3 octaves must be spaced at an interval of $\frac{500}{18}=$ $27.78 \mathrm{~mm}$. The total spacing of the 45 notes in the $\mathrm{C} / \mathrm{E}$ to $c^{3}$ compass is then $22.5 \times 27.78=625 \mathrm{~mm}$. The total space occupied by the 27 naturals at the front of the keyboard is $27 \times \frac{500}{21}=643 \mathrm{~mm}$, to which must be added about 3 to $4 \mathrm{~mm}$ clearance at both sides. The width of the key- 
well is then about $650 \mathrm{~mm}$ wide - the actual width varies from 645 to $652 \mathrm{~mm}^{5-8)}$ The keywell is therefore about 25 mm or 1 duim wider than the total space occupied by the jacks and jackslots.

Looking at the way the Ruckers marked out the virginal jckslots, one sees lines scribed on the soundboard corresponding to the inside of the keywell and keywell braces. There are also two more scribed lines about 12 to $13 \mathrm{~mm}$ ( $\frac{1}{2}$ duim) in from these keywell lines which coincide with the outside edges of the $\mathrm{C} / \mathrm{E}$ and $\mathrm{c}^{3}$ jackslots, and are $625 \mathrm{~mm}$ from one another. These construction lines often run underneath the bridges and indicate that the marking out, and probably the cutting of the jackslots, was done before the soundboard was encumbered with bridges or cut-off soundbars.

Into the two construction lines at the outside edge of the $\mathrm{C} / \mathrm{E}$ and $\mathrm{c}^{3}$ jackslots and just behind the front edge of the register leather there are invariably two nail holes. These were made by nails which were used to fix the lower guide in position under the soundboard so that the slots in both could be cut simultaneously. The corresponding nail holes in the lower guide are sometimes covered by the leather layer indicating that the leather of the lower guide was not always cut at the same time as the wood. Thus in some cases the leather was glued to the lower guide after the slots were cut in the wood, and then cut from the underside using the holes in the wood as a guide. Either way, there are no construction marks on the 
lower guide to aid in the cutting out of the jackslots.

The jackslots in the soundboard are marked out with scribed lines uniformly $27.8 \mathrm{~mm}$ apart, for the notes from $C / E$ to $b^{2}$ and half this for the top $c^{3}$. In addition to this two long lines 17.0 to $17.5 \mathrm{~mm}$ apart and running parallel to its length are scribed onto the leather strip. These two sets of lines then determine the extremes of the ends of the jackslots. The sides of the slots are cut at a constant angle to the spine of the instrument such that the angle of the jackslots is about $5^{\circ}$ steeper than the angle of the strings. This ensures a longer plectrum length than if the jackslots ran parallel to the string direction.

Like the slots in the wooden part of the lower guide in harpsichords, the sides of the jackslots in the soundboard and lower guide were probably cut with a chisel sharpened to a very small angle (see p: 334). Since a chisel will not cut soft leather satisfactorily without tearing, the leather shows clear signs of having been first cut out with a knife held vertically. After the holes in the wood have then been punched the wood is cleared away underneath, so that the jackslot opens out, ensuring that the jack touches only the leather without coming into contact with the wood.

Usually the lower guide was reinforced underneath with a layer of parchment which was glued to the guide before the slots in the wood were opened out. This seems to have been done to prevent the splitting of the short- 
grained wood between the guide slots. The soundboard slots were not so reinforced since the grain of the soundboard, running diagonally past the slots, is always much longer than the short grain of the longitudinal wood of the lower guide.

In muselar virginals the lower guide is attached both to the lower guide brace and to the top of the keywell braces - often a shallow slot is made in the keywell braces specifically for the lower guide. The guide is nailed to the upper surface of the keywell braces and to the lower edge of the lower guide brace which extends up to support and deaden the soundboard near the soundboard registers. The free edge of the lower guide is stiffened with a small bar about $14 \mathrm{~mm}$ by $18 \mathrm{~mm}$ in cross-section, leaving a space about 30 to $35 \mathrm{~mm}$ wide for the leather between the guide brace and the stiffening bar.

The lower gulde in the spinett virginals has two small stiffening bars on either side of the leather strip and fackslots, and is nailed to the upper surface of the keywell braces.

Bridge-pinning in virginals.

The bridge pins on a virginal must position the strings under the constraints of two factors. Firstly, the pins must be located so that the lengths of the strings correspond to the usual scalings for the pitch of the instrument concerned. Secondly, the strings must be the correct distance from the jacks to ensure the proper mechanical functioning of the instrument; the plectra must be 
neither too short nor too long, and the strings must not. come into contact with the neighbouring jacks or strings. The method by which the Ruckers decided the correct scalings of the strings is not entirely clear. The marking of the pin positions on the bridge was probably done beforethe top edge of the bridge was chamfered away, and thus any marks to locate the bridge pin positions have disappeared.9-9) Indeed, if the marking out were very accurate and done on the chamfered top surface of the bridge, the marks would be where the bridge pins are now located. The paired holes beside the bridges in the soundboard used to locate the bridge during glueing do not seem to bear any fixed relationship to any note or pitch, and are usually at different note positions on the left-and right-hand bridges. This is in marked contrast to the role that the positioning holes beside the bridges played in the laying out, positioning and pinning of the harpsichord bridges. The position of the right-hand bridge seems to have been determined previous to glueing the bridge by means of scribed lines indicating the position of its right edge. The location of this scribed line must have been made either in relation to the case sides or, more likely, in relation to the left-hand bridge.

The position of the string relative to the jacks is usually marked on the soundboard register leather. A sma11' pin prick in the leather indicates the position of the string in relation to the back surface of each jack. This locates the strings about $2.0 \mathrm{~mm}$ from the rear of the 
jacks and ensures that the strings will not touch them. It also, in conjunction with the angle of the jackslots relative to the strings, determines the plectrum length. In most virginals this length is found to be about $3.6 \mathrm{~mm}$, measured from the jack surface to the outside edge of the string. The total plectrum length depends upon the amount the fack tongue is recessed behind the front of the jacks, plus the amount the plectrum projects beyond the string. Once the jackslots have been cut in the soundboard and leather register, and the string positions marked on the register, the bridges could be positioned and glued to the soundboard. Since the strings run parallel to one another (the deviation even in muselar virginals is not great) a jig fixing the angle of the strings to the spine could be used to mark the string and bridge pin position on the two bridges. Such a jig might consist simply of a board or light framework with two sides or edges at the same angle as the angle of the strings to the spine edge of the soundboard. The edge corresponding to the string position must be long enough to reach from the left to the right-hand bridge at $\mathrm{C} / \mathrm{E}$. If this edge is positioned over the string position marks on the leather registers, then the two bridges will intersect the edge of the jig, and the bridge pin positions can be marked, one note at a time, on the two bridges.

Clearly a slight error in positioning either bridge, but especially the left bridge, will result in a deviation from the desired value of the string scale. Comparing 
virginal scalings one finds variations within one instrument type of up to $15 \%$ (more than two semitones, or plus or minus one semitone). The average deviation is much less than this, but the fact that such deviations do occur itself reflects the method of marking out the bridge pin positions. Also these scaling variations provide information which sheds light on two other aspects of the building of these instruments.

Firstly, it was of prime importance to the Ruckers that the instrument operated well. That the strings were neither too close nor too far away from the jacks, was more important than consistently accurate scalings. Secondly, the magnitude of the scaling variation is at least an approximate measure of the safety factor represented by the difference between the working stress and the ultimate breaking stress of the wire material used for the strings. The large variations quoted above occur in the foreshortened bass part of the scale. In the treble these variations amount to at least $7 \%$, this representing slightly more than a semitone in pitch variation. Therefore the spread between the working and ultimate breaking stress must have amounted to at least $7 \%$, and obviously a somewhat larger safety factor would have to have been used to avoid string breakages due to humidity variations, etc. Glueing the virginal soundboard into the case

After the jackslots had been cut in the soundboard, the cut-off bar and soundbars glued in position, and the bridges glued down and marked and drilled for pinning, the 
soundboard had to be glued into the case. The procedure used immediately preceding the actual glueing of the soundbard to the liners must have been slightly different for muselar than for spinett virginals.

For the muselar virginals the lower guide support with the attached lower guide had to be glued to the soundboard and fixed to the keywell braces at more or less the same time as the soundboard was glued into the instrument. It is not clear whether the lower guide and support were fixed to the keywell braces and the soundboard glued to the top of the lower guide support at the same time as the soundboard was glued to the liners, or whether the lower guide support with the lower guide attached were first glued to the soundboard and then, after the soundboard was glued into position, the lower guide was nailed to the keywell braces. The first possibility is easiest and would involve a method similar to that used to glue the soundboard to the wrestplank. Also in muselar virginals the bass end of the large cut-off bar for the left-hand bridge is usually let into the left cheek liner, and the recess for this would have to be made before the soundboard could be glued into position.

In the spinett virginals the lower guide is not attached to the soundboard and therefore would almost certainly have been fixed to the keywell braces before the soundboard was glued down. But, aside from the end-plucking of the strings, the feature which most distinguished the spinett virginals from the centre-plucking muselar 
virginals is the heavy hitchpin plank across the near lefthand corner of the instrument. This plank must have been let in, glued, and pegged to the liners before the soundboard was glued in place.

It seems likely that, aside from the differences in the details just mentioned, the basic method of glueing the soundboard into the case was the same for both muselar and spinett virginals. The soundboard in both types of virginal is pegged to the liners along its outer edge except along the nameboard liner in the keywell. Here it would have been possible to hold the soundboard down against the liner with ordinary clamps thus making pegging unnecessary. Along the rest of the edge of the soundboard it seems most likely that the soundboard was held in place during glueing with stiff battens nailed over the edge of the soundboard into the liners. A similar system seems to have been used for glueing the soundboard to the wrestplank and hitchplank in the spinett virginals and to the lower guide brace in muselar virginals. The spacing between the pegs in the soundboard is too great ( 4 to 5 duimen $=105$ to $130 \mathrm{~mm}$ ) and the soundboard is too thin to ensure proper glueing of the soundboard by means of the pegs alone. These pegs, then, are probably just filling the nail holes left after removing the battens used to hold the soundboard against the liners and other structures below it. Virginal keybeds and keyboards

The keylevers, keybed, balance rail and rack in all Ruckers virginals are made of poplar. The keybed consists 
of four pieces of wood which form an irregular polygonal shape and which are joined together with pegged half-lap joints. The sides of the keybed are parallel to one another and are a fow millimetres narrower than the width of the keywell of the instrument into which the keybed and keyboard will fit. The front of the keybed runs approximately parallel with the angled balance rail, and the rear of the keybed is roughly parallel with the rack and thus with the angled lower guide and jackslots. The rack and keybed touch the spine of the instrument on the treble side, and the board forming the bass side of the keybed extends beyond the rear of the rack to the case spine. The boards of the keybed are 12 to $14 \mathrm{~mm}$ thick.

The balance rail consists of a piece of poplar about $34 \mathrm{~mm}$. wide and tapered in height from about $12.5 \mathrm{~mm}$ to 9 or $10 \mathrm{~mm}$, so that the top surface of the balance rail is approximately parallel to the bottom surface of the keys. Because the bass keys are much shorter than the treble keys, the balance rail is angled so that the lever ratio of the bass and treble keys is roughly the same. This produces in the keys the same mechanical advantage throughout the compass so that the player experiences a uniform touch from bass to treble. Considering only the natural keylevers and taking the ratio of the distance from the end of the natural touchplate to the natural balance point, to the distance from the natural balance point to the end of the keylever, one gets an average balance ratio or mechanical advantage of about 0.53 to 

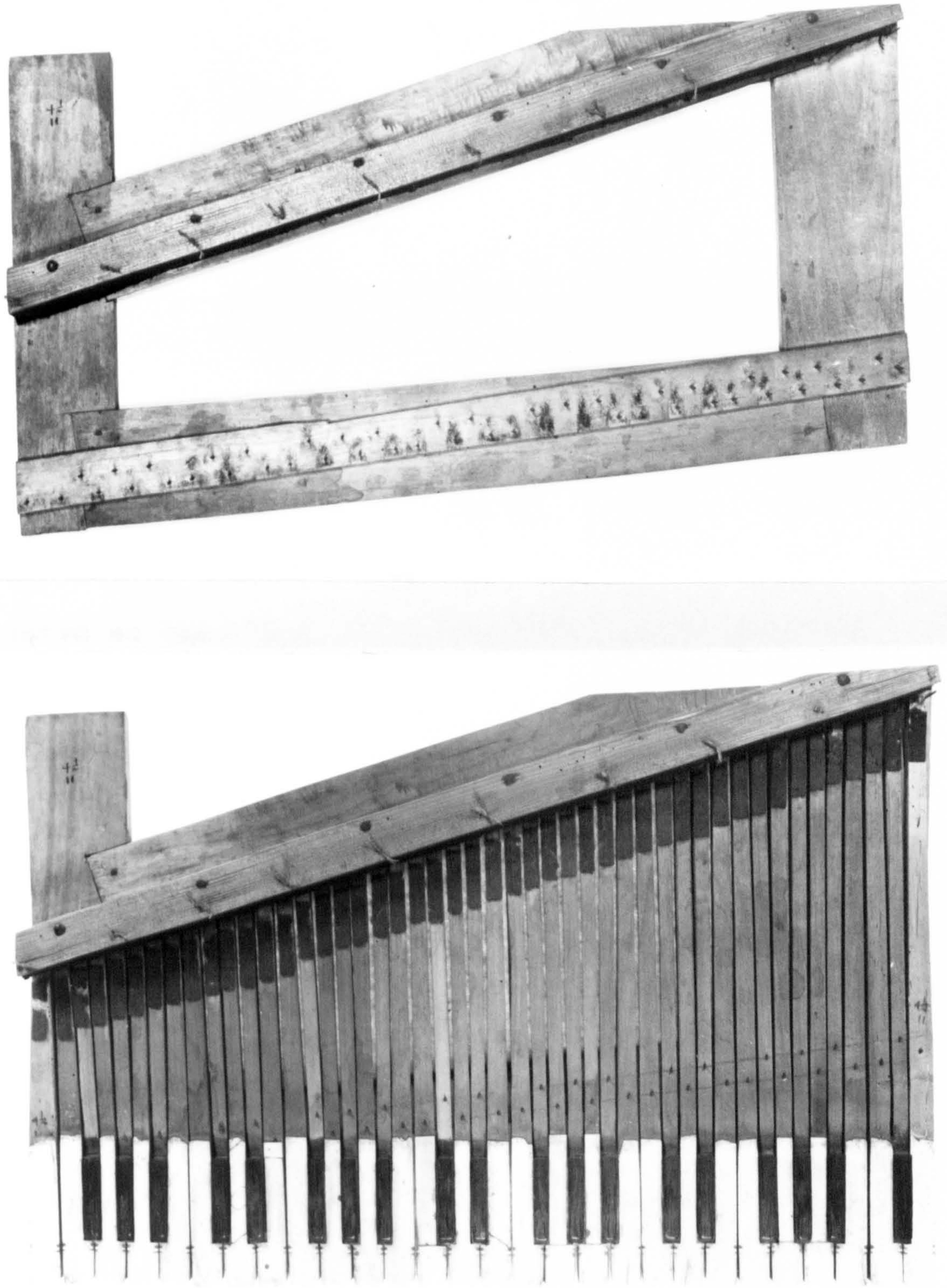

Photo 5-3 Keyframe and keyboards from the 1629 IR 4 $\frac{1}{2}$-vo et spinett virginal.

Scale $1: 5$ 
0.56. Values both above and below this average do occur, and particularly the smaller $4^{\prime}$ and child instruments have keys with a somewhat greater mechanical advantage (about 0.63) than the larger instrument, corresponding to a greater distance from the front of the keylever to the balance point. The balance point of the sharps is about half a duim (12.7 mm ) behind that of the naturals. The balance pins are made of iron wire about 1.8 to $2.1 \mathrm{~mm}$ in diameter and are long enough to just protrude above the tops of the keylevers. In fact, in the bass, the balance point is so far forward that the balance pins are underneath the natural keyplates, in which case the balance pin length is adjusted so that they just clear the lower keyplate surface.

The poplar board from which the keylevers are cut is about half a duim (12.7 mm) in thickness, and 6 to $10 \mathrm{~mm}$ narrower than the keywell of the instrument into which the keyboard will fit. Both the front and rear edge of the keyboard were angled at about $10^{\circ}$ to the perpendicular so that the lower surface of the keylever is shorter than the upper one. Before the keys were cut apart the keylever board was fixed in both the treble and bass to the balance rail - the holes for the nails used to fix the keyboard in position are sometimes visible both in the top and bottom keys and in the ends of the balance rail, although usually the keyboard was fixed, apparently by nailing it at the position of the balance pin for the top and bottom keys. The keybed and keyboard were then inserted into the instrument and fixed temporarily in their final position. A 
punch having the basic dimensions of a jack, but with an oval or rectangular end, was inserted successively into each jack slot and jack position to make a punch mark on the keyboard. These punch marks accurately locate the future position of the jack centre on the end of the key and could be used to mark the position of the rack pin in the end of the key, as well as the saw line between the ends of the keylevers.

It is probable that, after removing the keybed with the attached keyboard from the instrument, a series of short Iines to locate the position of the rack guide pin ${ }^{5-10}$ fere scribed near the rear edge of the keyboard at a point corresponding to the centre of each punch mark. Naturally, there is no evidence left of the lines scribed between the punch marks to guide the sawing out of the keylevers. Likewise all evidence of the scribed lines to guide the sawing of the keyfronts has disappeared except for the line delineating the rear edge of the natural fronts, and the front end of the sharps. This line can be seen when a natural plate has been removed or has come loose. This line is reproduced underneath the natural keylevers at a point which is the same distance from the angled keyfront below the key as above it.

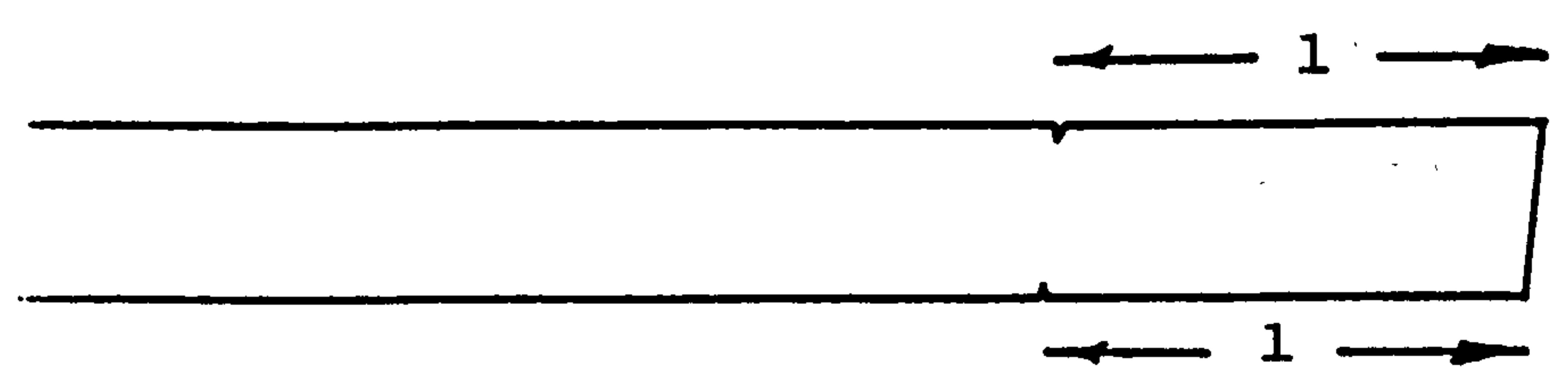

In whatever way the keyfronts were marked out, it was done such that the 3-octave span averages about $500 \mathrm{~mm}$ (one 
octave $=166.7 \mathrm{~mm})$. The origin of this octave span is obscure, but it may well have arisen by giving the 24 natural notes of the earlier $F$ to $a^{2}$ compass $a$ width of 2 Flemish feet. ( 2 voeten have a length of $569 \mathrm{~mm}$, and this compares with the width of 24 naturals with a 3-octave span of $500 \mathrm{~mm}$. which have a width of $571 \mathrm{~mm}$ ). The space between the natural tails and the sharps is divided up to give wide tails to the c's, $e^{\prime} s, f^{\prime} s$ and b's. The tails of the d's, $g^{\prime} s$ and $a^{\prime} s$ are some 3 to $4 \mathrm{~mm}$ narrower making it very difficult for a player to get his fingers between the sharps to depress these keys.

It seems clear that, before removing the nails into the balance rail, the holes for the balance pins were drilled through the keyboard into the balance rail. Also it would seem that the slots in the rack were marked out at this stage by offering the block to be used for the rack up to the rear edge of the keyboard and marking the rackslot positions from the lines already scribed to locate the guide pins. In this way any irregularities in the position of the guide pins is copied in the rack so that the two eventually match one another.

The rack consists of a block of poplar about 1 duim $(25.5 \mathrm{~mm})$ thick into which the rackslots are cut. Each rackslot is about $8 \mathrm{~mm}$ deep and opens out into the rack block so that the rackslots as seen from above have a triangular section. The top of the rack block is tapered downwards from front to back and is capped with a thin (5 mm.) piece of poplar or soundboard wood which projects 
out in front of the rackslots about $16 \mathrm{~mm}$, and which in conjunction with the cloth strips tied to it, limits the upward motion of the key and jack. Usually the top at the very ends of the key levers (about $\frac{1}{2}$ duim $=13 \mathrm{~mm}$.) has been sloped to match the upward slope of the rack upper touch limit bar. This means that the marks made to position the rack guide pins have been chiselled away, except where the occasional key has been missed and remains flat at the end. The overall height of the rack block is not tapered from bass to treble, unlike the harpsichord keyboard rack (see p. 399). The rack is glued to the keybed and held in place at either end with wooden pegs driven in from underneath.

Once the keyboard was removed from the balance rail for sawing out, the keybed alone was placed back in the instrument and the position of the top and bottom jacks (usually $\mathrm{C} / \mathrm{E}$ and $\mathrm{c}^{3}$ ) was punched on the keybed. These two keybed punch marks seem to have been used to position the rack by lining them up with the top and bottom rackslots.

The natural touchplates are made of bone - probably from beef. Since the bone plate overhangs the wood of the keylever by 3 to $4 \mathrm{~mm}$. at the recesses for the sharps, it is clear that the bone was glued to the keylevers after the keys were cut apart. The plates are about 2 to $2.5 \mathrm{~mm}$ thick at the near end and they taper to about $1 \mathrm{~mm}$. at the far end. Each keyplate is decorated with four lines scribed across the plate just in front of the sharps. An 
elliptical nick, made with a small round file, is made on each side of the key between the two middle scribed lines. Flattish bevels are made along the sides of the touchplate in front of the nearest scribed line, and the front of the touchplate is slightly rounded. The top of the bone plate was smoothed rather incompletely (apparently with a furniture scraper) and then buffed to polish it. The buffing compound remains as dark deposits in the blood pores of the bone giving the keyboard a rich and variable texture. Most instruments with their original keyboards and with keys which have not received too much use show that the tails of the naturals where lettered with their note name in red (possibly sanguine). The practice of lettering the natural names was common on Italian instruments in the period contemporary with the Ruckers. In fact the practice was so widespread that it can hardly be attributed as a guide to help: the learning child, but seems better to reflect the transition from solmisation to the modern "one pitch to a note" system.

Although they have disappeared on most Ruckers and Couchet instruments even when the original keyboards survive, decorative embossed arcades covered the near ends of the keylevers. The bone plates overhang the keylever at the front by 2 to $3 \mathrm{~mm}$ so as to protect the arcade below it. The arcade consists of a pierced design incorporating Gothic arches and trefoils embossed on heavy paper glued to a red stained or dyed parchment. The red pigment used to colour the parchment is highly light-sensitive and has 
often faded completely. Hebrew script is clearly visible through the pierced embossed paper on the parchment used on the two earliest Ruckers virginals ( $1581 \mathrm{HR}, 1583 \mathrm{HR}$ ).

Two types of arcades must be distinguished. In the first type, apparently used exclusively by Hans Ruckers, Ioannes Ruckers and Ioannes Couchet, the embossing is rounded and smooth in texture. The second type of arcade, used only by the two Andreas Ruckers, is more angular and the foliate parts of the design are indented (see Photo 5-4). A third arcade design, found only on the 1643 AR 5 voet virginal, consists of a head surrounded by two wings embossed on thin paper and without any piercing whatsoever. This is the same arcade as is found on the 1605 Artus Gheerdinck virginal (MINe 95, Neupert Collection) in the Germanisches Nationalmuseum, Nuremberg. This winged head design is not found on any other Ruckers virginal or harpsichord. Although there is no proof one way or the other, this design seems spurious and it is felt that the arcades were removed from another instrument and re-used on the 1643 AR virginal.

The sharps on Ruckers keyboards are made from bog oak or bog chestnut. This wood is obtained from a peat bog or moor, from trees (sometimes partly petrified) which have lain for centuries saturated with the dark alkaline water of the moor. The wood is cut so that the annular rings run parallel to the top of the keylever. This results in a smooth upper surface, with the pores of the wood on the vertical sides of the sharps. The early 

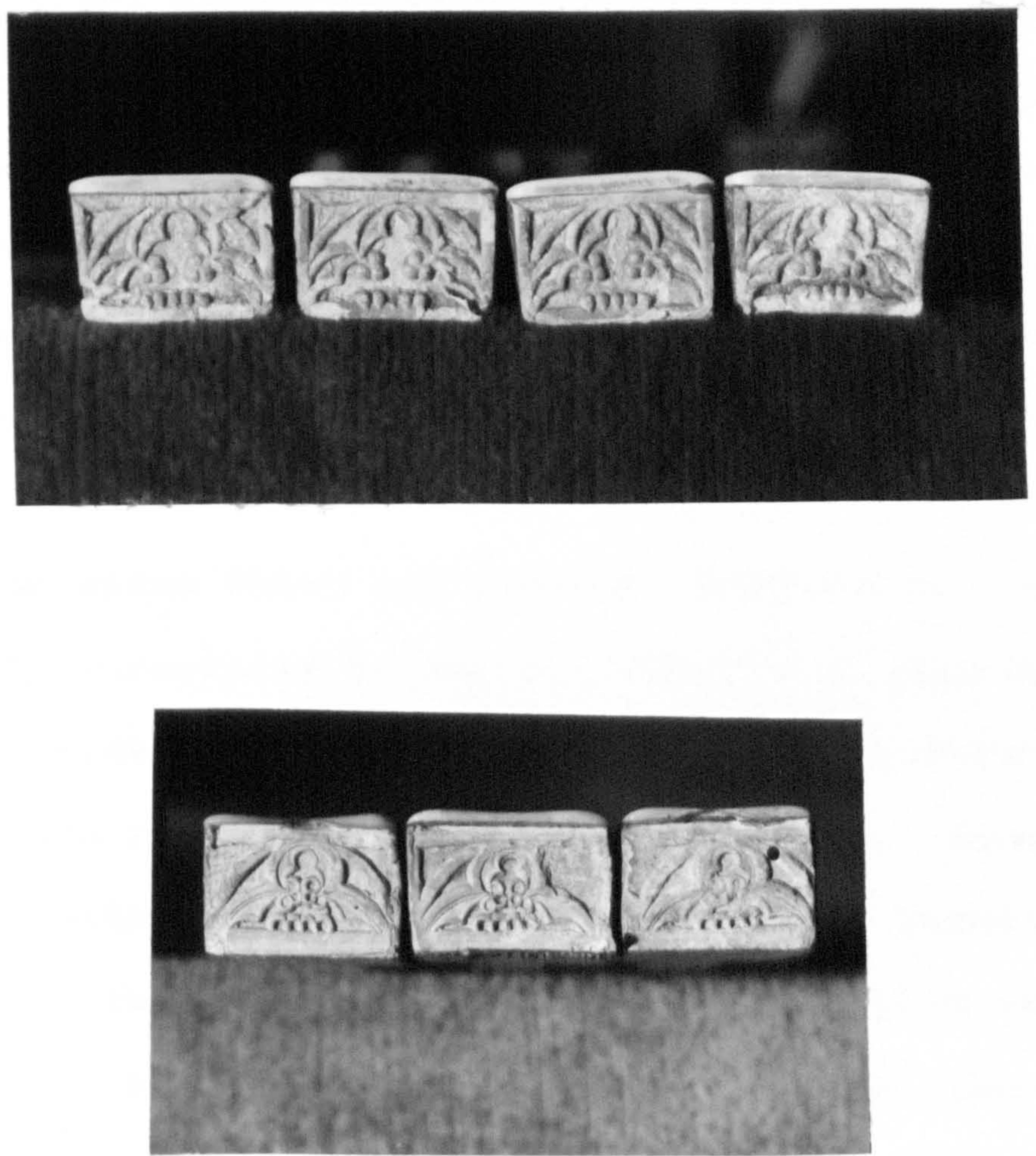

Photo 5-4 Key arcades on Ruckers clavecimbels.

Top: Type A arcade found only on instruments by Hans Ruckers, Ioannes Ruckers and Ioannes Couchet.

Bottom: Type B arcades found only on Andreas Ruckers instruments.

Scale 1: 1 
Hans Ruckers virginals, like most of the other 16 th century Flemish virginals, had sharps decorated with scribed lines and nicks similar to the naturals. But the later instruments had sharps without any decoration.

The usual type of sharp had a slightly sloping front surface and parallel vertical sides. Because of the width of the sharps and the narrowness of the natural tails, it is impossible for a player to get his fingers between the sharps, a detail of clear implication on the type of fingering used by the contemporary instrumentalists. Sharps with sloping sides which are somewhat narrower are sometimes found, especially on the instruments by Andreas Ruckers the Elder, and these just allow the players' fingers enough room to play the natural tails. Usually the top and bottom surfaces of the sharps run parallel, but the later instruments of Ioannes Couchet have sharps which taper in height, being lower at the back than at the front.

In all Ruckers instruments the sharps were initially made longer than their final length. After the sharps had been glued in place, the keys and keybed were placed in the instrument in their final position. When the nameboard was slid into position it would be stopped from dropping into its normal position by the over-long sharps. However, a scribed line or cut along the top of the sharps along the front surface of the nameboard could be used to indicate the correct length of each sharp. The sharps were then sawn to length in position on the key- 


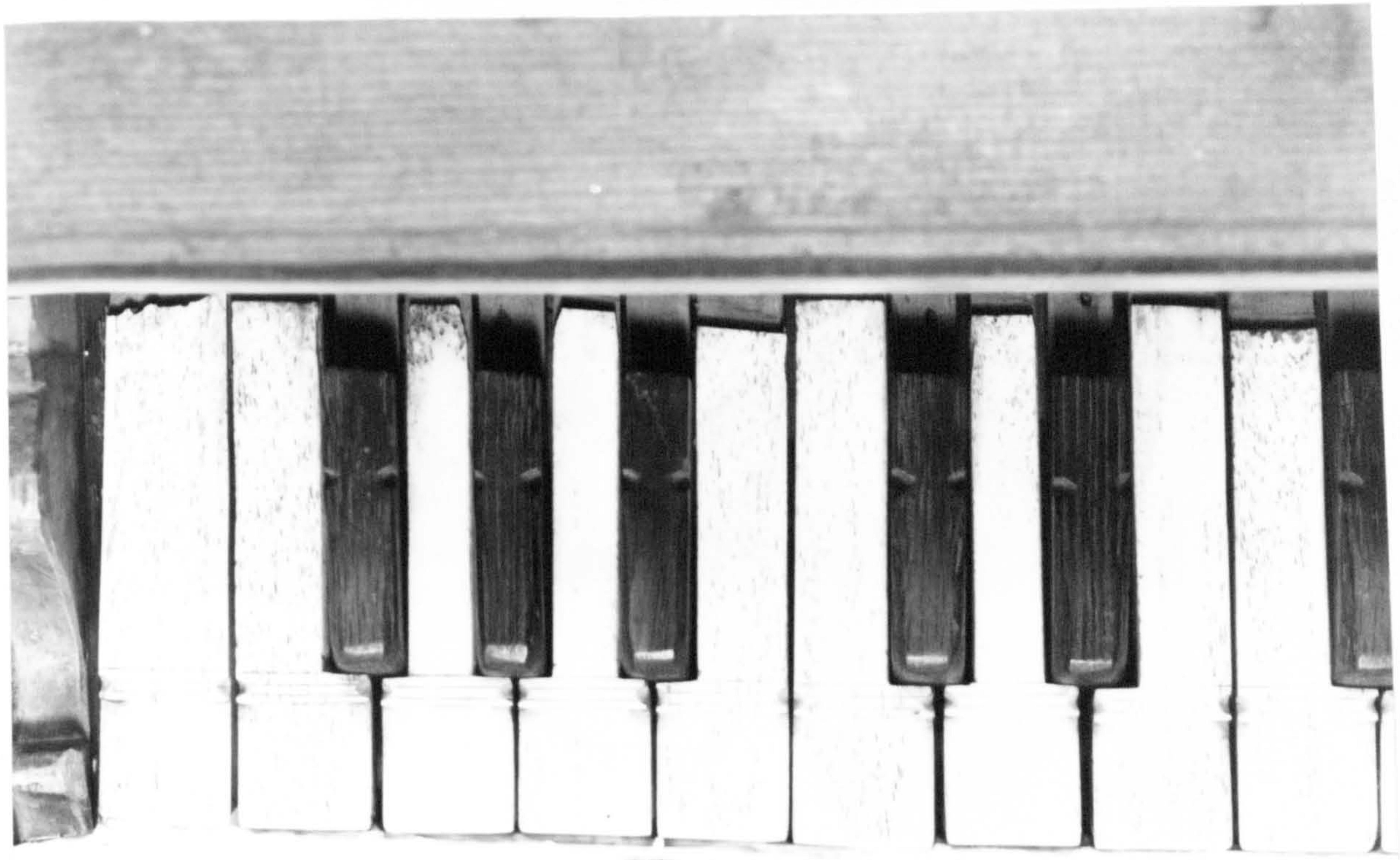

Photo 5-6 Keys of the 1581 HR virginal showing the decorated sharps found on many early Flemish instruments by Hans Ruckers and his contemporaries. 
lever, and the excess length was chipped away. The slight sawcut in the keylever at the rear of the sharp, and the clearing of the upper surface of the keylever just behind the sharp with short chamfered edges, are among the distinguishing characteristics of the genuine Ruckers keyboard.

Because the keys, jacks and jackrail were made specifically to fit each particular instrument, it was important to number (or otherwise identify) the parts and instrument so that they could be matched up. The very fact that the instruments and parts were so numbered must indicate that there were numerous instruments of many different types all in the Ruckers workshops concurrently, and that this distinguishing feature was required to keep the parts and cases together.

The sharp keylevers were recessed underneath in front of the balance pin so that the key would rock at the balance pin and not pivot at the near edge of the balance rail. Also, because of the width of the jacks and keylevers and the closeness of the jacks to one another, there is a problem of interference between adjacent keys and jacks. To avoid this, both the keys and the lower part. of the jacks were narrowed, so that each key would operate only its respective jack. The keylevers are further tapered in cross-section being' narrower underneath than on top, apparently in an effort to lighten them. Usually the top edges of the tails of the keylevers are slightly chamfered. 
The keybed is held in position at the rear by two chamfered blocks which are glued to the case spine and under which the keybed slides and fits snugly. At the front near edge two chamfered blocks are each equipped with a turnbutton to hold the keybed down, and the blocks themselves hold the keybed tightly in position against the spine. The baseboard and turnbutton blocks are painted black underneath the touchplates and sharps. Also the top of the keylever behind the sharps is painted black.

As with all keyboard instruments, cloth or felt is used in the keyboard to keep action noise to a minimum. Ruckers instruments use a felted wool cloth. The material has been tightly woven, combed to draw the fibres out of the material, matted and pressed. The result is a firm durable material of great resilience which, used as an action cloth in the keybeds, gives a firm, crisp touch, quite unlike the spongy effect produced by modern pianoaction felt. The same material appears to have been used as a damper cloth in the jacks since, because of its firmness and of its being strongly matted together, the individual fibres and threads of the material do not pull apart with repeated contact with the strings.

The warp and weft of this material are of the same thickness of yam and it is woven in a simple, tight "over one, under one" tabby weave with about 22 to 26 warp threads per $2.5 \mathrm{~cm}$. and with a weft beaten to 10 to 15 threads per $2.5 \mathrm{~cm}$. There are two distinct types of cloth used in the Ruckers action which can be distinguished by their appear- 
ance and thickness.

The thicker type of cloth is used, for example, as a single layer on the balance rail. Compressed tightly between the jaws of a vernier caliper the thickness of this cloth is about $1.8 \mathrm{~mm}$. Long fibres more than $15 \mathrm{~mm}$ long all lying in one direction which were pulled out of the woven fabric in the combing process are characteristic of this type of clath. It is cut to the full width and is held in place only by the balance pins. Additional square bits of leather or folded card about 0.9 to $1.1 \mathrm{~mm}$ thick are used on top of the cloth underneath the sharps to raise the sharp keylevers to the level of the natural levers. This is necessary because the sharp balance point is lower than that of the naturals because of the slope of the balance rail surface.

The same heavy cloth is used on the keylever top surface underneath the jacks. These cloth pads are postioned over the punch marks used in the marking out of the tails of the keylevers, but only the ends of the pads are glued so that there is actually no glue under the pad where the foot of the jack makes contact. Because of the pairwise positioning of the jacks, two to a jackslot, a pairwise pattern is produced in the positioning of the jack pads.

The thinner type of cloth is about $0.9 \mathrm{~mm}$ thick when tightly compressed, and the fibres on the surface are relatively short and not combed to lie only in one direction (i.e. it has no nap). This cloth is used both 
above and below the keylever tails in the rack, in the jackrail and as dampers in the jacks. In the rack it is usually used in three layers tied at regular intervals with coarse linen thread to the upper touch limit bar of the rack. Underneath the keylever tails 2 layers of cloth about 1 duim ( $25 \mathrm{~mm}$ ) wide are used. These lower layers of cloth are tacked at the ends with small tacks, and usually at positions about $\frac{1}{3}$ and $\frac{2}{3}$ along the length of the cloth strips as well. The depth of touch is determined by the thickness and number of cloth strips in the rack in conjunction with the keylever thickness and the height of the rack itself. In Ruckers virginals which retain their original keyboard cloths the depth of touch is found to be about 9 mm. in the bass and $8 \mathrm{~mm}$. in the treble, measured at the end of the natural keylevers. This is slightly more than the depth of touch in harpsichord keyboards.

There are not many instruments which retain their original action cloths, but among those that do, the action cloth is usually dyed black. Two Ruckers harpsichords (1618b IR, 1640b AR) have apparently original cloth dyed red in the rack, but otherwise only black cloth seems to have been used in virginal keyboards. on the other hand only red cloth seems to have been used for the jack dampers. (The damper cloths in the child part of the Marten van der Beist double virginals of 1580 in the Germanisches Nationalmuseum, Nuremberg (M1 85) appear to be original and they are dyed green.) Often the outside layer of the cloth in the rack and jackrail has lost its outer matted 
felting through wear or insect damage, and the threads of the weft and warp are clearly visible. The interior surfaces of such cloth should be carefully examined before it is condemned as being non-original.

Virginal jacks and jackrail

Like the jacks used in the harpsichords, the jacks used in Ruckers virginals are made of quartered beech and have oval damper holes instead of the morticed slots common in 18 th century instruments (for a detailed descripion of Ruckers jacks see p. 362).

The virginals have the same rounded 'mouse ear! type of damper cloths as the harpsichord jacks. The use of this type of damper is particularly important for the larger muselar virginals. If a damper with a flat lower edge (which is found only rarely even in 18th century instruments) is used in the bass section of the larger centreplucking muselars, the amplitude and inertia of the string is great enough to throw the jack up again and again until the energy of the string is dissipated. If the lower edge of the damper is angled or rounded, however, the string is gradually, but rapidly damped as the edge of the damper approaches the string and the jack returns to its rest position.

The ability to absorb the energy of the string is enhanced by using two dampers instead of just one. The 'problem of the rapid absorption of the energy of the string is clearly not as great in spinett virginals and harpsichords, but even here doubled dampers with rounded or 


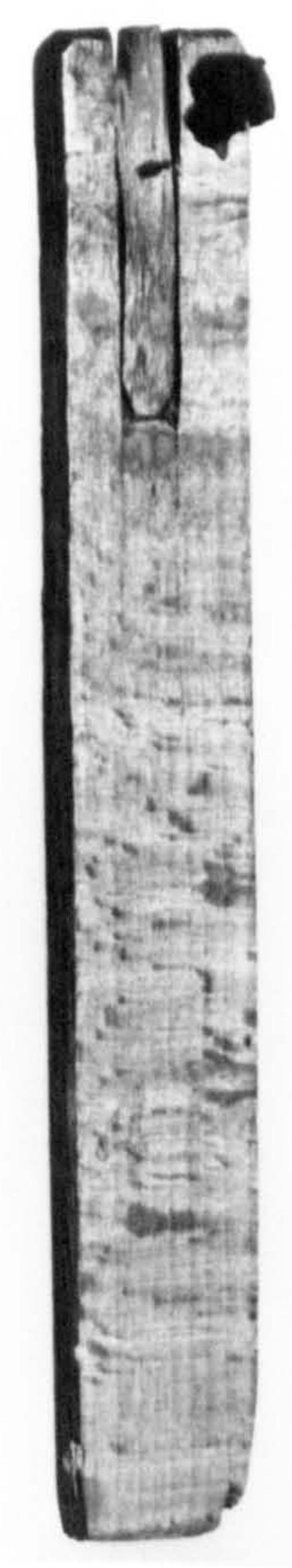

Photo 5-7 A typical Ruckers virginal jack and tongue made of quartered beech wood (1581 HR). The (slightly damaged) damper is probably original. 
sloping lower edges are normally used. However, the small

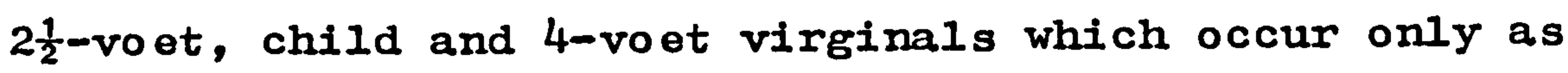
spinett types (and the 4' stops in harpsichords) have jacks with only one damper.

Since the upper touch limit bar on the rack controls the depth of touch of the keys, the jackrail in a Ruckers instrument serves only to prevent the jacks from jumping out of their slots and to rebound them as quietly and quickIy as possible back into their playing position. The jackrail is made of a solid piece of poplar with moulded upper edges, and sides which overhang the recess into which the jacks enter. To my knowledge only one Ruckers virginal survives with its original jackrail cloths, the 1622 IR 6-voet muselar virginal in the Metropolitan Museum, New York. Like the harpsichords this virginal jackrail had 2 layers of the thinner action cloth already described (compressed thickness of each layer $=0.9 \mathrm{~mm}$ ) tacked with pairs of tacks at both ends and along $\frac{1}{3}$ and $\frac{2}{3}$ of the length of the jackrail.

A tongue in the bass end of the jackrail fits into a blind groove in a decorated and carved block glued to the spine side of the instrument (except for the little $2 \frac{1}{2}$ voet and child virginals where the blind groove is located just below the moulding on the right-hand side of the case and is cut directly in the case itself). With the spinett virginals the jackrail fits into a recess in the left-hand case side. A small mortice in the jackrail fits around a wire loop fixed into the case recess, and a wire 
or brass hook nailed to the top of the jackrail engages in the wire loop to fix the jackrail in position.

In the muselar virginals a heavy block is glued to the left extension of the nameboard liner so that its upper surface is just at the soundboard level. The soundboard is glued to this block and a carved block which serves as the bass jackrail support is glued to the soundboard at this point!-11) A tongue in the bass end of the jackrail fits into a recoss in the bass jackrail support. A turnbutton on the jackrail support turns to cover the tongue in the recess, holding the jackrail in position.

The jackrails of the muselar virginals are usually slightly tapered, being somewhat wider in the bass than in the treble; the spinett virginals usually have parallel sided jackrails. The overhanging sides of the jackrail are carved with gently curved arches at both ends, gradually cutting the overhang away to the level of the top of the padded recess.

Since there is no nambatten on a virginal, the Ruckers signature is found on the jackrail, replacing the decorative block-printed papers found on harpsichord jackrails. The signature - IOANNES RUCKERS ME FECIT ANTVERPIAE - without the date is typical.

\section{Footnotes:}

5-1) The left-hand bridge of the $1581 \mathrm{HR}$ muselar mother virginal follows the tradition of many mid-sixteenth century instruments in having slightly curved faces. The right-hand bridge of the mother, and both bridges of the child have the usual flat-sided bridges. 
Photo 5-8 A typical signature on a virginal jackrail (1638a IR).

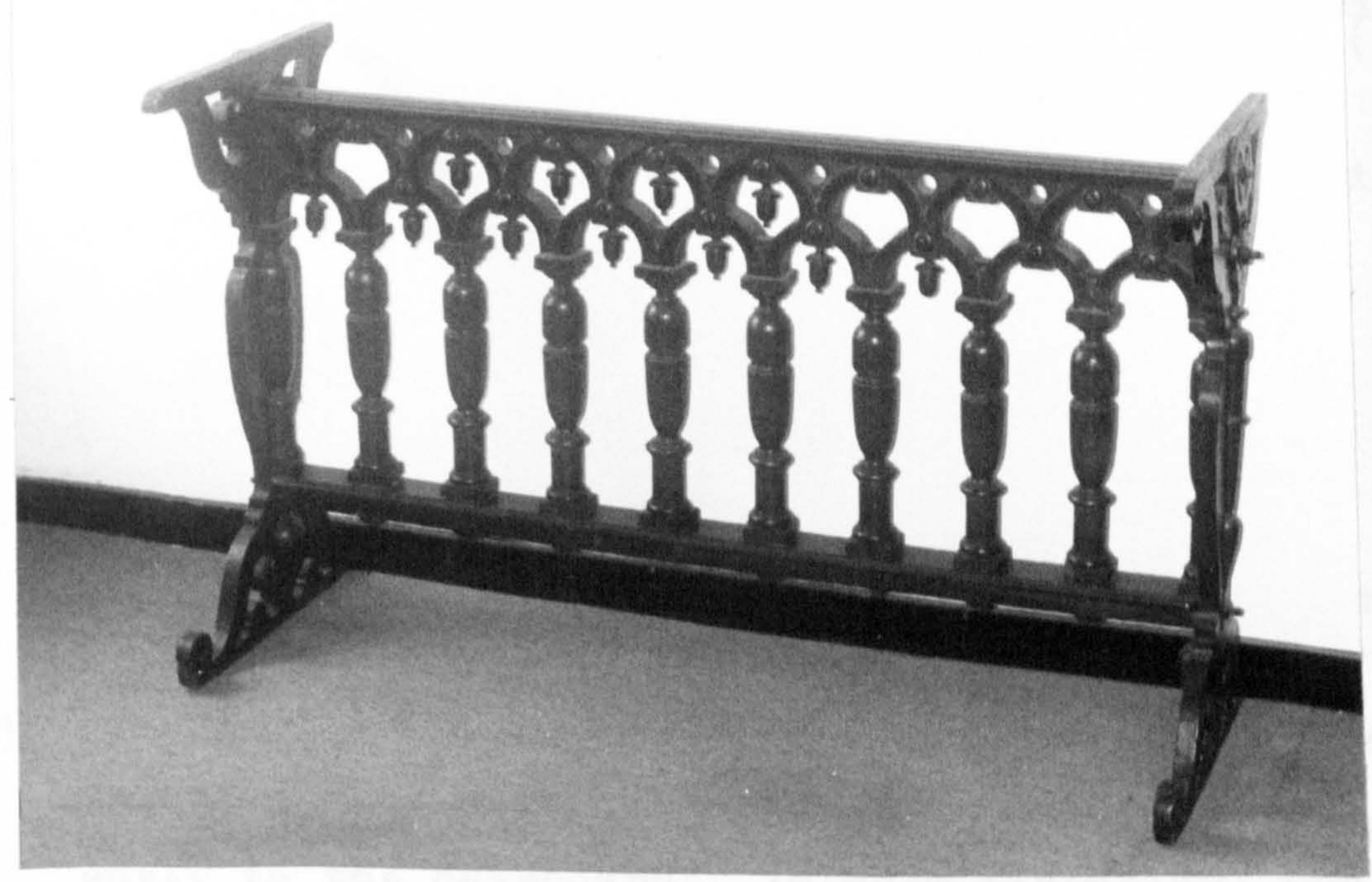

Photo 5-9 The double-arcaded stand from below the $1611 \mathrm{HR}$ 6-vo et muselar virginal. 
5-2) The virginal part of the $1594 \mathrm{HR}$ instrument used sharpened pieces of brass wire bent over against the soundboard instead of the usual iron nails. I am indebted to Martin-Christian Schmidt for pointing this out to me.

5-3) Here the word harpichordium is used to mean a stop and not an instrument. Seo, however, A. Neven, 'L'Arpicordo', Acta Musicologica, 42 (1970) 230-235, and L. Cervelli, Italiensiche Musikinstrumente in der Praxis der Generalbass-Spiels: Das Arpichord', Bericht ther den siebenten internationalen Kongress, Kdln, 1958, Kassel (1959) 76-78.

5-4) As mentioned, the $1581 \mathrm{HR}$ mother virginal in the Motropolitan Museum, Now York is an exception. It has a split harpichordium covering the entire range of the instrument. The bass section covers $\mathrm{C} / \mathrm{E}$ to $e$; the curved treble part covers $f$ to $c^{3}$.

5-5) N. Meeùs of the Brussels Museum of Musical Instruments has had the metal of the $1604 \mathrm{HR}$ harpichordium analysed by the Koninklijk Instituat voor het Kunstpatrimonium; the analysis showed that the harpichordium hooks were more than $99 \%$ lead with small traces of tin.

5-6) Michael Praetorius, 'De Organographia', Syntagma Musicum II, Wolfenbuttel (1619), (facs. Kassel (1958)) p. 67 .

5-7) Taken from the Fitzwilliam Virginal Book, Leipzig (1899), facs. New York (1963)p. 268.

5:8) The Hans and Ioannes Ruckers instruments have a keywell about 645 to $648 \mathrm{~mm}$. wide; Andreas Ruckers instruments are 650 to $652 \mathrm{~mm}$. wide.

5-9) The virginal part of the $1594 \mathrm{HR}$ instrument in Schloss Kopenick, ${ }_{1}$ East Berlin, has the intended position of the $c$ bridge pin marked on the rear surface of the right-hand bridge.

5-10) This procedure must have been slightly different for the child virginals which do not have a keybed, but in which the balance rail and rack were fixed permanently to the baseboard. In this situation, the baseboard must have been fixed temporarily in position so that it and the keyboard could be detached from the rest of the case during the various stages of the marking out of the keyboard and rack.

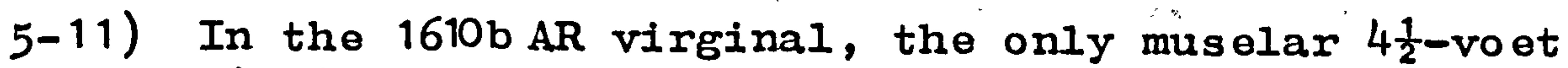
virginal, the bass end of the jackrail fits into an extension out over the soundboard, of the left-hand keywell brace, and it is secured with a turnbutton. 
Chapter 6 - Construction of Ruckers Harpsichords

\section{Harpsichord Baseboards}

As with Ruckers virginals, the harpsichord baseboards are made of poplar and are usually near or slightly less than $\frac{1}{2}$ duim $(12.9 \mathrm{~mm}$.) in thickness. The grain of the wood runs parallel to the length of the instrument except at the near end under the keyboards. Here a plank about 10 duimen ( 250 to $260 \mathrm{~mm}$.) in width whose grain runs at right angles to the long direction is jointed to the longways planks by means of an oblique scarf joint. This achieves dimensional stability and strength where it is needed most: parallel to the direction of the strings under the body of the instrument, and parallel with the long axis of the action under the keyboards. The lower outside surface of the baseboard seems to have been sized with glue or shellac although the interior surface is completely untreated. As with the other instruments of the Flemish school, the baseboard is flush with the outside case sides, and the instrument is built up onto the baseboard. The layout of the instrument is punched onto the baseboard and the punch marks joined up with scribed Iines.

The case sides and nameboard, the baseboard braces (including the toolbox braces), the keyblocks, and the keywell moulding are all marked on the baseboard. In addition, single-manual harpsichords have 3 scribed lines 


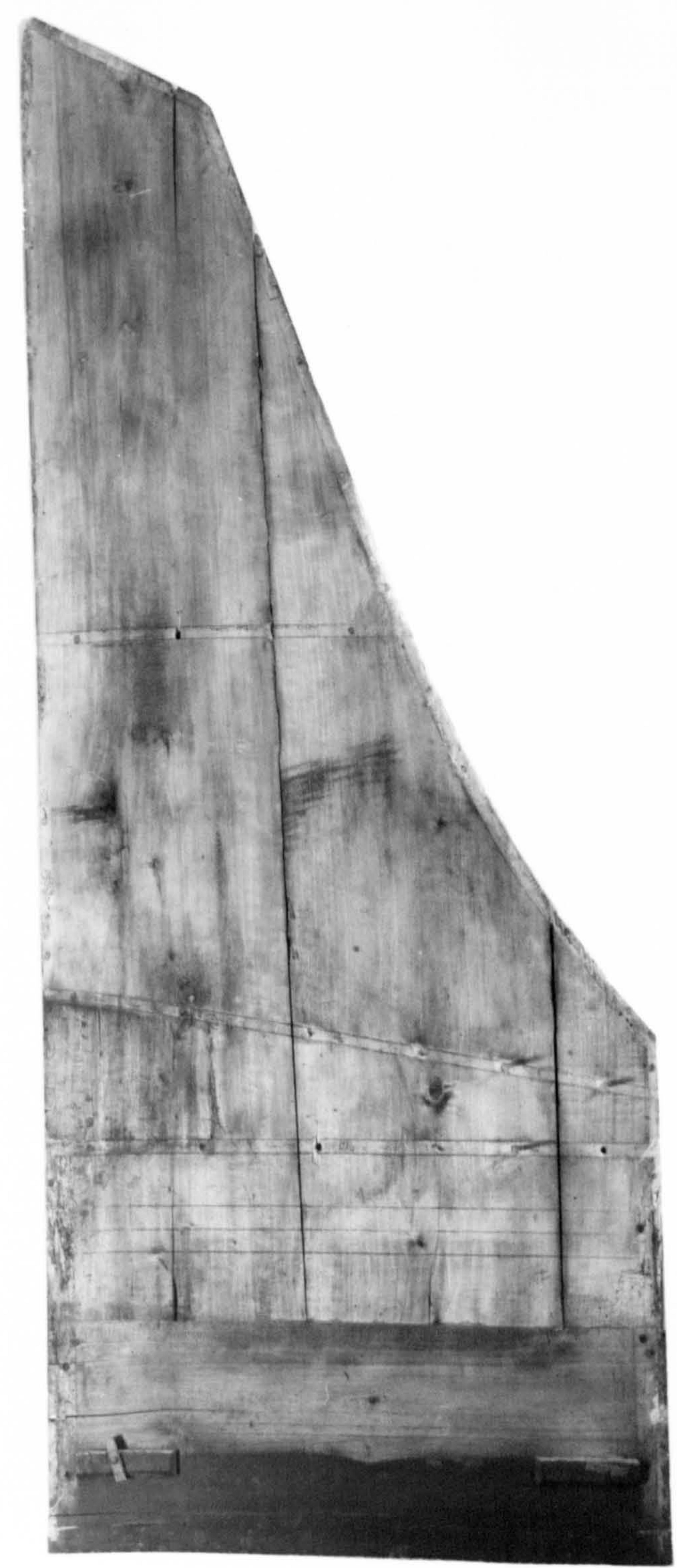

Photo 6-1 The interior surface of a single-manual harpsichord baseboard. The scribed lines for the baseboard braces and case-sides, and the 3 scribed lines marking the gap can be clearly seen.

Scale $1: 10$ 
under the gap representing, but not exactly positioning, the two registers, and doubles have five lines indicating the four registers in the gap in a similar way. The near line under the gap coincides with the far edge of the wrestplank. This line is 8 duimen (206 to $207 \mathrm{~mm}$ ) from the front face of the nameboard in both single-and doublemanual harpsichords, the only extant exception being the little quint harpsichord (1627 AR). The rear line scribed under the gap is further back than the rear edge of the gap itself. The upper belly rail is, however, always sloped in Ruckers harpsichords (see p.265 and 337) and the rear line coincides with a line projecting down from the front surface of the belly rail to the baseboard. This line, in conjuction with the position of the rear edge of the top of the gap, thus determines the slope of the upper belly rail. The central scribed line under the gap in double-manual harpsichords indicates the position of the rear ends of the upper manual keys. In addition to the extra lines under the gap, double-manual harpsichords also have two additional lines to position the papered batten in front of the upper-manual keyboard.

For instruments of any given member of the Ruckers family, the spacing of the scribed lines on the baseboard for the internal bracing, the gap lines, and the cheok, spine, and nameboard are remarkably consistent from one instrument to another. The position of these lines was thus probably punched using a marking out rod or template of some type, which was different for each member of the 
family. The shaping of the bentside, on the other hand, is somewhat erratic and it appears that no two Ruckers instruments had the same curvature of bentside. The scribed Iines on the baseboard for the bentside do, however, follow the bentside shape quite closely. Hence it would appear that the bentside scribed lines were made on the baseboard using the bentside itself as a template. But because it was impossible to expose each bentside to exactly the same heat treatment and because of the variable nature of the bentside wood, the shape of the bentside was not consistent. For each instrument, it was therefore necessary to use the bentside itself to mark out the baseboard, rather than a standard template.

As with virginals the harpsichord baseboards are fixed by means of wooden pegs onto the case sides. Indeed the scribed lines on the baseboard, as well as serving as a plan from which the instrument could be built, also serve to locate the holes for the pegs in the baseboard centrally in the case sides and baseboard braces. Harpsichord baseboards too are only lightly glued to the case sides and braces although the glue used on the wooden pegs sometimes spreads causing localized secure glueing of the baseboard to the case. The keyblocks are glued to the inside of the case and are also pegged to the baseboard from below. Keybed hold-down blocks with turnbuttons are glued to the baseboard at the sides of the keywell to fasten the keybed in position, and these and the baseboard under the keys are painted black. The key- 
well flap, hinged at the bottom to the near edge of the baseboard, seems to have been a universal feature of both double-and single-manual harpsichords. The front edge of the baseboard originally carried three wire hinges for this flap. In addition, the little toolbox flap on the spine is also fixed with wire hinges to the spine edge of the baseboard.

Harpsichord case sides and internal framing

Excepting the deviations caused by the extra length needed in the mother virginals and the slightly reduced lengths of the spinett virginals, the lengths of the virginals are relatively standard, and this standardisation is reflected in the identification of the instrument type in the numbering system used by the Ruckers. No such standardisation seems to occur in the length of the single-and double-manual harpsichords. The single-manual harpsichords vary in length from about 70 to 72 duimen (1813 to $1864 \mathrm{~mm}$ ) and doubles from about $85 \frac{1}{2}$ to 88 duimen (2210 to $2274 \mathrm{~mm}$ ). Although the latter dimension is almost exactly equal to 8 voeten $^{6-1}$ ) there is only one harpsichord of this length $(1628 \mathrm{~b} I R)$, so that no particular significance can be attached to this. Most doubles in fact measure close to 87 duimen or about $2250 \mathrm{~mm}$. Indeed, even the little 1627 AR quint harpsichord which is identified by Ruckers as "4 St", that is presumably 4-voet Staertstuk, is about 48 duimen (1232 mm ) long or 4 duimen longer than 4 voet. The widths of the harpsichords, being determined basically by the compass of the instrument, are much more 
standardised than the lengths because of the small number of different compasses used by the Ruckers in their instruments. The usual $\mathrm{C} / \mathrm{E}$ to $\mathrm{c}^{3}$ single-manual harpsichord had an inside case width of about $690 \mathrm{~mm}$ and the standard double with a lower manual compass of $C / E$ to $f^{3}$ had an inside case width near $760 \mathrm{~mm}$. The larger, less common singles and doubles, with chromatic basses had inside case widths in proportion to their compasses (see p. 493). The height of the case was also very standard with Ruckers harpsichords. The single-manual harpsichords were either 9 or $9 \frac{1}{2}$ duimen high (229 or $242 \mathrm{~mm}$ ) measured excluding the baseboard thickness.6-2) The double-manual instruments seem universally to have been built with case sides which, excluding the thickness of the baseboard, are 10 duimen high (254 mm). Clearly, one can therefore determine the original number of manuals of an instrument which has been Ereatly altered simply by measuring the case height, providing of course that this has not also been altered. Of those single-manual instruments which still retain their outer decoration those which are 9 duimen high have a marbled exterior, those which are $9 \frac{1}{2}$ duimen high have a strapwork exterior decoration. Thus in the situation of the single-manual harpsichords one may also be able to say something about the type of original decoration. However, the number of instruments which retain their original decoration is rather too small to be able to make a statistically valid rule about the universality of the strapwork decoration on the $9 \frac{1}{2}$ duimen instruments. At best ose can say that both the surviving 


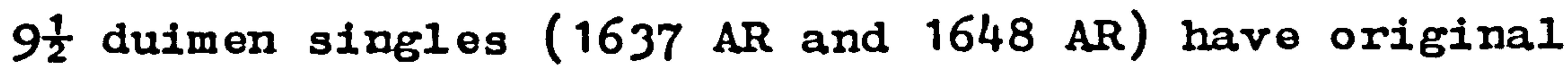
strapwork exterfor decoration, and all six of the surviving 9 duimen singles with their original case paint are marbled.

The reason for the higher case sides on instruments with a strapwork outer decoration is not clear, but is probably because the strapwork pattern would appear unduly cramped with a case height of only 9 duimen, Whatevor the reason it is clear that the Ruckers attached little acoustical significance to the height of the case since they were willing to alter this basic dimension solely on the basis of the outer decoration. The choice of the case height was at any rate more-or-less arbitrary since only integral or half-integral units of the duim were used. There seems to have been no attempt to control the volume of the internal cavity of their instruments by using smaller, or more complicated fractions of the duim unit. However, the volume of the instrument is not a function of the case height alone since it also depends upon the length and width of the harpsichord. The standard short-octave and the large 'French' double-manual harpsichords have a range of notes covering exactly the same pitch, but the volume of the two types of instrument is much different. No attempt was made to equalise the volume of the two types of instrument by changing the case height or the length in order to compensate for the larger width of the 'French' double. $6-3$ )

The thickness of the poplar case sides varies from 
instrument to instrument between about 12.5 to $16 \mathrm{~mm}$. The double-manual instruments sometimes have slightly thicker case sides than the singles but the usual thickness in both doubles and singles is from 14 to $15 \mathrm{~mm}$. The bentside, unlike the other case sides in Ruckers harpsichords, is variable in thicknoss along its length. Usually it is about $15.5 \mathrm{~mm}$ thick near the tall, and this thins to about $12.5 \mathrm{~mm}$ at the point of strongest curvature, and then thickens again to almost the original $15.5 \mathrm{~mm}$ at the cheok. The variation in thickness seems to reflect the way in which the bentsides were constructed and bent. The three combined virginals and harpsichord (1594 HR, 1619 IR and n.d. IR) provide the best clues of the way the Ruckers made the bentsides. These instruments have an internal bentside which forms a partition between the harpsichord part and the virginal part of the instrument and which is used as a hitchrail for the strings of both parts of the instrument. (This partition reaches in height only to the soundboard level and the soundboard runs over the top edge of the partition for the full length of the instrument.) Because, in this type of instrument, the bentside is completely hidden and requires no finishing or decoration, it was left completely untreated after the bending had been carried out. All three of these combined instruments show that the concave surface of the internal bentside was strongly heated over an open fire to such an extent that, in the region of strongest curvature, the surface of the wood is slightly charred. 
The ends of the bentside show streaks of black soot indicating that the fire may have been of pitch, oil or wax, although a rapid fire of wood shavings would produce a similar offect.

After heating the bentside over the fire it was bent, either over a former or perhaps simply by compressing the two ends of the bentside together between two walls, or by drawing the ends together with a twisted rope. Whatever method was used to give the curvature to the bentside there seem to be no traces of the procedure remaining on any of the surviving instruments, Also, although the curvature of the bentside is relatively shallow, I have not found any two Ruckers harpsichords which have bentsides with even approximately the same shape. This is certainly a result of the variable nature of the wood used for the material of the bentside, but is probably even more a reflection of the method used in bending. The amount of heating produced by the fire must have varied over wide Iimits, and the place along the bentside which received maximum heating, and was therefore most readily bent, must also have varied. Also if the ends of the bentside were drawn together by compression or rope tension to produce the curvature, rather than using a former, the shape of the bentside could be very variable indeed. Interestingly, comparing the scribed lines on the baseboard with the present position of the bentside on the 1644aAR singlemanual harpsichord, it is clear that the bentside has slightly straightened out between the time the baseboard 
Iines were scribed and the time when the bentside was fitted to the rest of the case sides and secured to the baseboard in its final position. This 'relaxing' or straightening is characteristic of wood which has been bent using heat. The amount that the bentside straightens will depend at least in part on the length of the time interval between when it was used to scribe the lines on the baseboard and when it was fitted and secured into the instrument.

The interior bentsides in the harpsichord/virginal combinations have a uniform thickness along their length. However, in the more usual harpsichords the bentside was an external case side and had to be prepared to take the paint for the outer decoration. The soot and charred wood had to be planed away from the surface and this was probably done with a round-bottomed compass plane. The strong heating in the region of the greatest curvature necessitated the removal of a considerable amount of wood, and thus the bentside is much thinner here than at its ends. The original exterior decoration of the $1618 \mathrm{~b}$ IR double-manual harpsichord has been completely removed, and replaced with a plain varnished finish. The discoloration produced by the heating of the bentside previous to bending is clearly visible under the varnish, showing that this particular bentside still had some discoloured, heat-affected wood remaining after the maker had removed the badly charred parts in preparation for a painted finish.

The bentside is fitted to the tail and cheek with a 


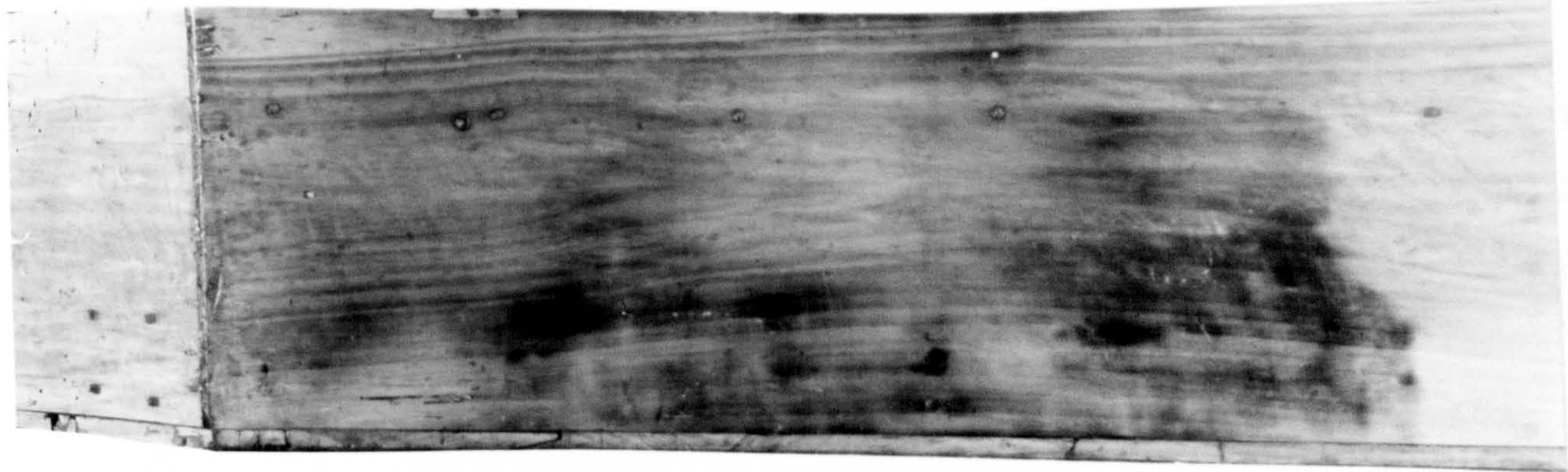

Photo 6-2 The treble section of the bentside on the 1618b IR double-manual harpsichord, which has had its outer decoration removed. As well as showing the scorching of the bentside wood, the dowells used to fix the internal baseboard braces and case-joins, and to fix the bentside liner are also visible. 
characteristic join (see Fig.9-2), which differs from the usual 18th century mitred and dove-tailed case joins. In the Ruckers bentside joins, only the moulded part of the case side forms a mitred join. In all Ruckers and most 16th and 17th century Flemish harpsichords, the tail piece overlaps the bentside and the bentside overlaps the cheek. This characteristic construction is one of the distinguishing features of a genuine Ruckers instrument which may be of help in identifyling a counterfeit instrument.

The tail/spine join is a simple mitre joint and it and all other joins are pegged together during glueing with $3 \mathrm{~mm}$ pegs. The pegs are placed in the over-lapping side at the bentside joins - i.e. in the tail at the tail/bentside join, and in the bentside at the bentside/check join (see Figs. 9-1 and 9-2).

The ends of the wrestplank are let about $6 \mathrm{~mm}$ into the cheek and spine, and secured with large oak pegs about 5 to $6 \mathrm{~mm}$ in diameter driven through the case-side into the wrestplank. In addition the wrestplank is pegged along the near edge to the nameboard with small $3 \mathrm{~mm}$ pegs.

The entire top edge of the case is decorated with an ogee moulding identical with that used in the virginals. The nameboard is somewhat thinner than the other case sides (11 to $12 \mathrm{~mm}$ ) and, like the faceboard and nameboard in the virginals, is capped with two opposing ogee mouldings (see Fig.5-1). The nameboard is let into the spine and cheek on either side, and the opposing ogee mouldings are 
mitred into the moulding on the spine and cheek. The nameboard is secured with $3 \mathrm{~mm}$ pegs from the outside of the case into the ends of the nameboard.

A11 Ruckers harpsichords, whether doubles or singles, seem originally to have had upper registers which extended and projected through the cheek. The projecting ends of each register could be grasped by the player and moved back and forth to engage or disengage the jacks of that register. The hole for the register in the cheek is the width of the gap and the height of the register plus the thickness of the bone plates glued to the top surface of the ends of the registers. The cheek usually, but not always (.1637 AR), also contained a hole through which the end of the buff stop projected and was operated.

The lid was hinged to the top of the spine side of the instrument. Most single-manual instruments used wire hinges to hinge the main lid to the instrument. Like the wire hinges used on the lid and keywell flap of the virginals, these consisted simply of two pieces of wire bent in half across each other. The paired wire ends were then inserted into angled holes in the lid and case side, splayed apart and hammered into the grain of the wood to prevent them from pulling out. The same type of hinge was used for the front keywell flap and the spine toolbox lid, and in single-manual harpsichords, for the lid flap hinged to the main lid. A few singles (e.g. $1637 \mathrm{AR}$ ard 1651b AR) and all double-manual harpsichords, used an axle strap hinge of a characteristic pattern (see photo 7-41) to hinge 
the main lid to the spine. The use of strap hinges in doubles seems to have been necessary simply because of the weight of the large heavy lids on the double manual instruments - the wire hinges would have been too flimsy. These hinges were nailed to the lid and case side with short, stubby, round-headed brass nails. Double manual harpsichords also had small decorative axle hinges to hinge the lid flap to the main lid instead of the wire hinges used on singles. These hinges (see Photo $7-41$ ) were also held in place with small brass nails.

Wire hooks, which fitted into wire loops in the overhanging edge of the lid, were nailed to the bentside and served to keep the lid firmly closed. The keywell flap was also secured from the inside with wire hooks which were nailed to the spine and cheek in the keywell, and which mated into wire loops in the keywell flap itself. Normally a lock on the outside of the keywell flap mated to a hasp attached to a strap hinge on the lid flap. But on those instruments which did not have a lock and hasp, two wire hooks on the keywell flap mated into wire loops in the overhanging edge of the lid flap.

Ruckers virginals have no specific internal framing or bracing, but rely on the case sides and structure of the instrument itself for the stability and the strength necessary to resist the tension of the strings. The harpsichords on the other hand have a clearly worked out method of internal framing and bracing which adds to the strength and stability provided by the case sides and 
joints. Since the $8^{\prime}$ strings are hitched to the bentside and tail liners the tendency is naturally for the bentside and tail to collapse inwards, and any framing system must provide bracing which prevents this from happening.

The internal framing in Ruckers harpsichords occurs at two levels: the lower level baseboard braces at and above the baseboard, and the upper level braces just below the liners. The lower level braces consist of poplar boards placed vertically on the baseboard at right angles to the spine. These boards are about 3 duimen (77 mm) high and are let about 6 to $7 \mathrm{~mm}$ into both the spine on one end, and the bentside or cheek on the other. The ends of the baseboard braces are pegged to the case side and the lower edge is pegged to the baseboard with $5 \mathrm{~mm}$ pegs. The baseboard brace nearest the player forms the lower belly rail. The keyframe (the lower-manual keyframe in double-manual harpsichord) butts against this brace, and two chamfered blocks glued to its side hold the rear edge of the keyframe firmly against the baseboard. Immediately behind the lower belly rail, another baseboard brace makes a small angle with the bellyrail. This angled brace is usually about $\frac{1}{2}$ voet (140 mm) to $7 \frac{1}{2}$ duimen (191 mm ) from the belly rail at the spine end, and only one duim (26 mm) at the cheek end.

A rectangular opening in the spine allows access to the space between the two braces in which tools, the tuning key, spare quills, strings, etc. were probably stored. Usually this toolbox space did not extend right 
along to the cheek, but was stopped with a wall glued between the two toolbox braces bout halfway along the width of the instrument. A lid over the top of the toolbox is provided by a chamfered board nailed to the top edge of the toolbox braces. A small flap hinged to the baseboard provides a closure for the toolbox opening. A wooden turnbutton nailed to the spine holds the toolbox flap closed, and a loop of leather passing through a hole near the centre of the flap and glued or nailed to the inside of the flap provides a tab which may be grasped to open the flap. In order to prevent the toolbox flap from hinging past its normal closed position and becoming wedged between the two toolbox braces, a stop is glued to the spine on the inside of the case of the instrument: This flap stop hangs about $6 \mathrm{~mm}$. below the top edge of the toolbox opening and stops the flap so that it is flush with the rest of the spine in the closed position.

Behind the toolbox braces, and running from the spine to the bentside, are two more baseboard braces in doublemanual harpsichords and one in single-manual harpsichords. These baseboard braces function to keep the baseboard flat, to hold the bentside, cheek and spine at a constant distance from one another, and to hold the case sides at a right angle to the baseboard.

The upper level braces consist of boards running from the bentside to the spine which are placed flat underneath the lower edge of the soundboard Iiners. Each brace is about 2 duimen ( $50 \mathrm{~mm}$ ) wide and is nailed at each end 


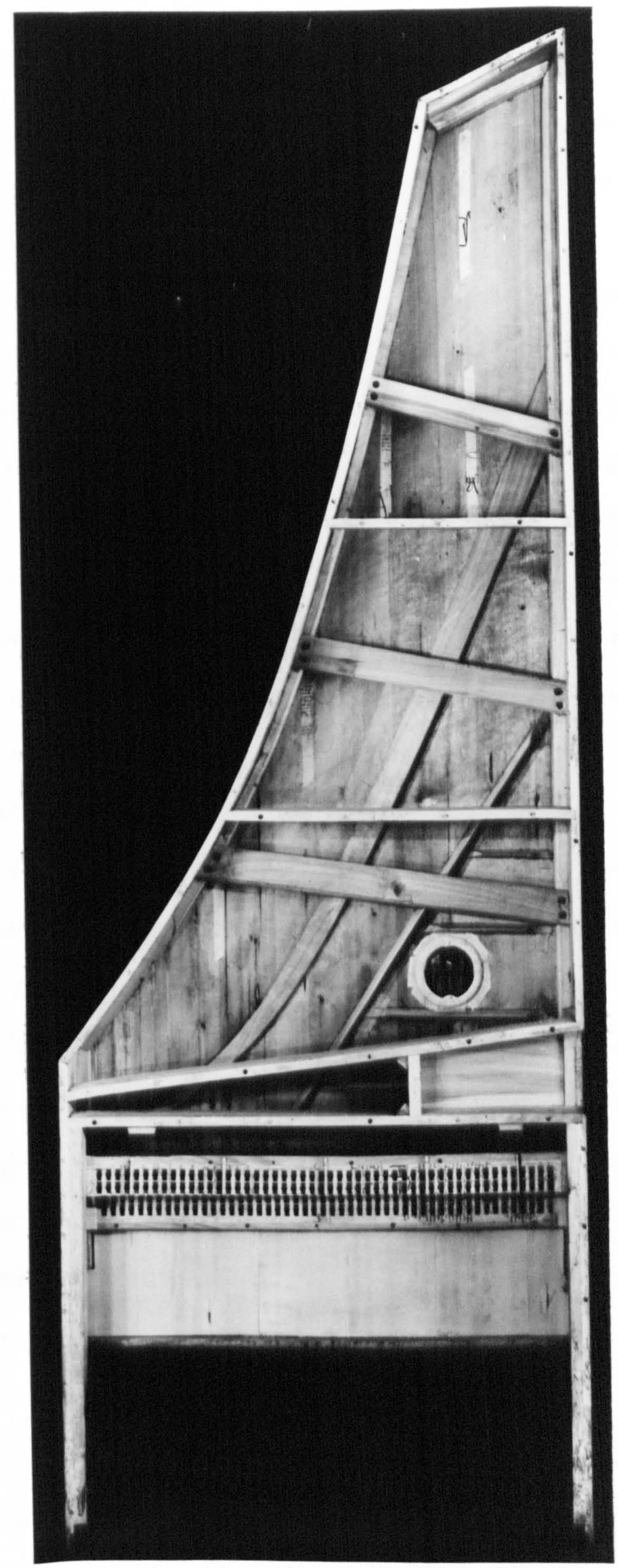

Photo 6-3 The internal framing and soundboard barring of a typical Ruckers double-manual harpsichord (1640b IR). The method of fixing the soundboard rose, and the veneer on the lower surface of the wrestplank are not original. Scal e $1: 10$ 
with two nails into the liners. The lower edge of each of these braces is chamfered in a way which seems characteristic of the Ruckers family, and which also seems completely aesthetic and non-functional (see Fig. 9-3). The upper level braces are perpendicular to the spine in some instruments or they run obliquely across the instrument, being not quite perpendicular either to the bentside or the spine. The upper level braces - two in single-manual harpsichords, and three in doubles - maintain the integrity of the upper section of the bentside. Any tendency of the bentside to collapse inwards is prevented by buttressing the bentside against the spine at a level which is close to that in which the string tension is acting.

In addition to supporting the soundboard, the liners also add to the strength and rigidity of the instrument. The liners are varied in their dimensions, but are usually about 45 to $52 \mathrm{~mm}$ wide and 15 to $20 \mathrm{~mm}$ thick. The tail liner which has to withstand the tension of the heavy bass strings is usually both wider and thicker than the other liners. Like the bentside, the bentside liner is thinner near the region of maximum curvature. It seems likely therefore that the bentside liner was also bent by heating over an open fire, and later thinned to remove the charred wood where the bending was the most pronounced. The top surface of the wrestplank, excluding the wrestplank veneer, and all of the liners along the spine, tail, bentside and cheek, are placed 2 duimen (51 mm) below the top edge of the case. The liners are glued to 
the case sides, and the bentside liner is, in addition, pegged to the bentside with $5 \mathrm{~mm}$ pegs placed at intervals of about 5 to 6 duimen (125 to $155 \mathrm{~mm}$ ). The joins in the liners at the case-side corners are all simple mitred joints. The liners in Ruckers harpsichords and the harpsichords of most of the other Flemish builders of the 16th and 17th centuries, extend right on past the upper belly rail into the gap and continue on under the wrestplank at both the spine and cheek sides. In some examples, the liners even extend under the wrestplank right to the name-. board, although they usually stop slightly short of it. Beyond the gap, the liners are cut away to fit around the (sometimes rather irregular) shape of the wrestplank. The upper belly rail is let into the liners about 6 to $8 \mathrm{~mm}$ at either end, and therefore it does not extend to the spine and cheek case sides, but is left with an air gap at either end below the liners.

The belly rail is usually 15 to $16 \mathrm{~mm}$ thick, and is positioned at an angle to the vertical so that its lower edge is further to the rear of the instrument than the top edge. This is necessary to accommodate the jacks which are splayed apart at their feet; which in turn is a result of the way that the lower guides are constructed (see p. 337). As mentioned earlier a line projecting down from the front surface of the belly rail coincides with the rear transverse line scribed on the baseboard under the gap. It is however not entirely clear how the gap width was determined since there is no construction mark either on the baseboard 
or liner to indicate this.

The upper edge of the belly rail is planed flush and paraliel to the top of the Iiners, and the front edge of the soundboard is glued and pegged to this upper surface. Two pairs of wires which support the registers straddle the gap between the wrestplank and the top of the beliy rail, one wire underneath the registers and one above them in each pair.

The lower guide is attached to the lower edge of the upper belly rail with a number of nails along its length. The lower guide in turn, is attached to the rear top surface of the bass and treble keyblocks, and may, in doublemanual instruments, be let into the keyblocks so that the top of the lower guide is flush with the top surfaces of the keyblocks. This allows the upper-manual keybed to slide part way over the top of the lower guide as far as is necessary to line the upper-manual keys under the upper-manual lower guide and jacks. The upper belly rail thus extends from the top of the keyblocks to the soundboard, and serves as a means of support and attachment for both the soundboard and the lower guide.

In double-manual instruments, the extra lower jack guide for the upper manual is attached underneath the liners on the cheek and spine sides. In order to increase the distance between the registers and the lower guide, an additional strip of wood 10 to $15 \mathrm{~mm}$ deep is sometimes glued to the lower surface of the liners, and the lower guide is attached to this strip instead of to the liner 
itself. The strip usually extends under the wrestplank in one direction, and beyond the belly rail in the other so that the belly rail is let into the strip as well as into the liner. In some doubles the cheek liner is made specially wide, and the additional strip is not then necessary on this side.

The keyblocks at the bass and treble ends of the keyboards are glued to the case sides and pegged to the baseboard. A characteristic moulding, which I have called the keywell moulding (see Fig.6-1) runs along the baseboard between the spine and the cheek just in front of the keys, and the keyblocks extend from the back of this moulding to the lower belly rail or first toolbox brace. Besides supporting the lower jack guide and the upper manual in double-manual harpsichords, the keyblocks also have an indirect function which strongly affects the acoustical performance of a harpsichord.

Since the octave spacing of the strings and of the keys in a Ruckers harpsichord are the same, the keyboard width essentially determines the total width of the string band. If there were no keyblocks the case sides would be adjacent to the top and bottom keys and very close to the top and bottom strings. Because of the width of the liners, the bridges at both their treble and bass ends would be very close to or sitting on top of the liners, and this would seriously impair the quality of the lowest and uppermost notes. By adding keyblocks whose width is equal to or greater than the width of the soundboard liners, the case 


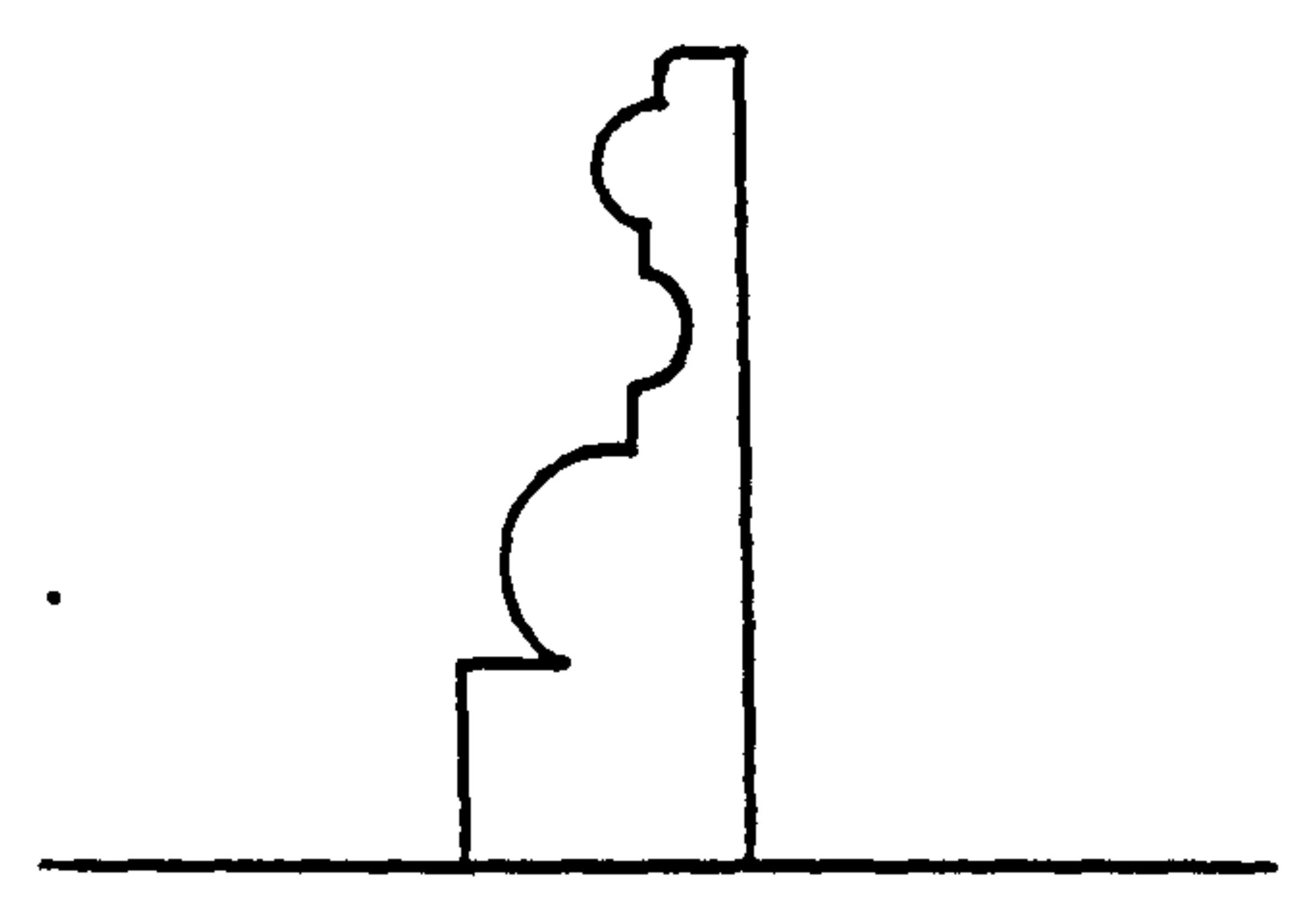

Fig. 6-1 Profile of the keywell moulding used on the baseboard in front of the keys in both harpsichords and virginals.

Scale 1:1 
sides are pushed further apart and away from the ends of the string band and bridges, thus maintaining the quality of the notes into the extreme treble and bass by allowing the bridges and soundboard to vibrate freely there. The main lid, lid flap and keywell flap in harpsichords

Like the rest of the case of the instrument, the main 1id, lid flap and the keywell flap are all of poplar wood, and are usually 12 to $14 \mathrm{~mm}$ thick. The main lid on both single-manual and double-manual harpsichords overhangs the tail and bentside by 10 to $15 \mathrm{~mm}$ and is flush along the spine. The break between the lid and lid flap occurs just behind the gap, and the edge of the main lid is stiffened by two transverse bars with ovolo mouldings, one bar on the top surface and one bar on the lower surface of the lid (see Fig.6-2). These bars have functions, however, in addition to that of stiffening the lid.

The bar on the outer surface of the lid has an ovolo moulding along only one edge, the other edge being flush with the edge of the 1id. Three hinges attach the lid flap to the main lid and are placed along the edge of this bar. The bar on the inner surface of the main lid has ovolo mouldings along both edges, and one edge of the moulding projects beyond the ecife of the lid to overlap the break between the main lid and the lid flap. The purpose of this lower overlapping moulding seems to be to prevent dust and dirt from falling through the small gap at the lid break onto the soundboard, and especially into the jacks and registers. I have therefore called this lower batten 

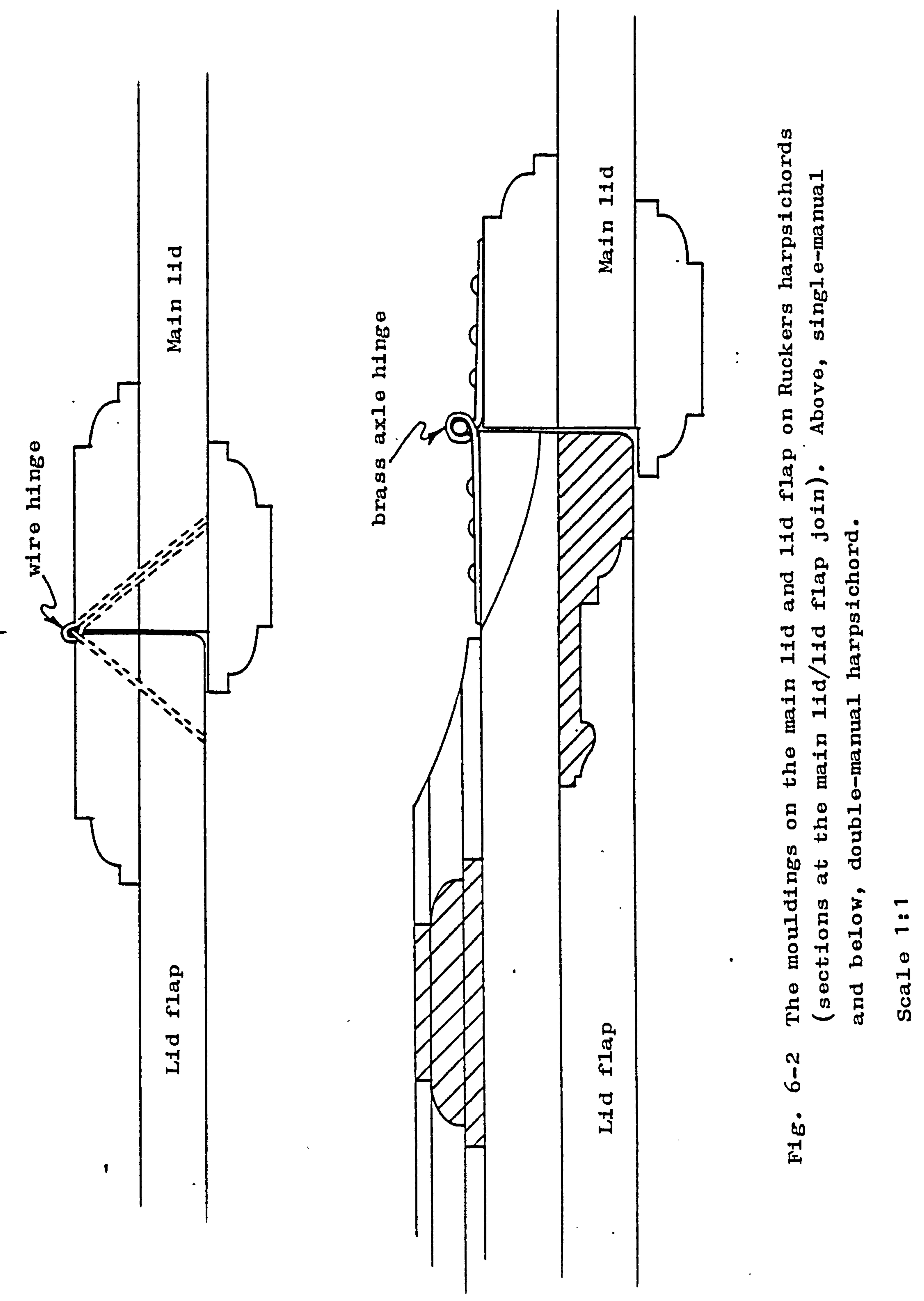
the dustcatcher moulding.

The lid flap design varies slightly between singlemanual and double-manual harpsichords. On singles the lid flap cunsists simply of a jointed board stiffened only along the edge hinged to the main lid with a bar with a single ovolo moulding which also takes the hinges. In addition to being larger, the double-manual lid flap is stiffened differently from the lid flap used on singles. Here the jointed board used for the flap is stiffened on the outside at the spine and cheek edges with ovolo moulded bars and framed on the inside surface with mitred bars bearing an elaborate moulding (see Fig.6-2). The effect of the inner mouldings, especially, if the inside of the lid is painted rather than decorated with block printed papers, is that of a framed painting. Because of the way the flap is hinged (see Fig.6-2), the surface of the frame and the inside of the lid are flush when the lid is closed. Thus the inside surface of the lid flap and the main lid are in the same plane in single-manual harpsichords but are offset in doubles. Also, because of the additional size of the double-manual main lid, and extra transverse stiffening bar with ovolo mouldings along both edges was added to the top of the lid at about the mid-point along the length of the instrument.

Unlike the main lid, the lid flap overhangs the case sides along the spine as well as along its other two outside edges in both double-and single-manual harpsichords. The Ruckers never seemed to have used a single large lid 
without the break between the main lid and the lid flap (see however the catalogue entry for n.d. IC). Although a number of 17 th century paintings show instruments built very much in the style of Ruckers harpsichords with a single-piece lid, there are usually other features which are also uncharacteristic of Ruckers instruments visible in the paintings, leading to the conclusion that the instruments depicted were not made by any of the Ruckers family.

The harpsichord lids were, held open, not with a lid stick, but with string cords. With the main lid closed, the lid flap could bo hinged back and held in position by a cord running from a $3 \mathrm{~mm}$ hole in the spine above the wrestplank and just behind the nameboard, to a hole about half-way along the spine side of the lid flap. The lid flap is held back at an angle to the vertical by gravity and can be used in this position as a music support by resting the music on the jackrail. The main lid could also be hinged back past the vertical and was held open in this position by a cord running from another $3 \mathrm{~mm}$ hole in the bentside above the soundboard to a hole in the bentside portion of the lid. The stability of the main lid in the open position is increased by the lid flap which, hinging freely on the main lid, falls back and increases the tendency of the lid to overbalance and therefore also increases the tension in the main lid cord. These lid cords can be seen in a number of contemporary paintings, as for example, in the 'Music Lesson' by Jan Steen (see Photo6-4). This lid arrangement prevents the harpsichord from being 


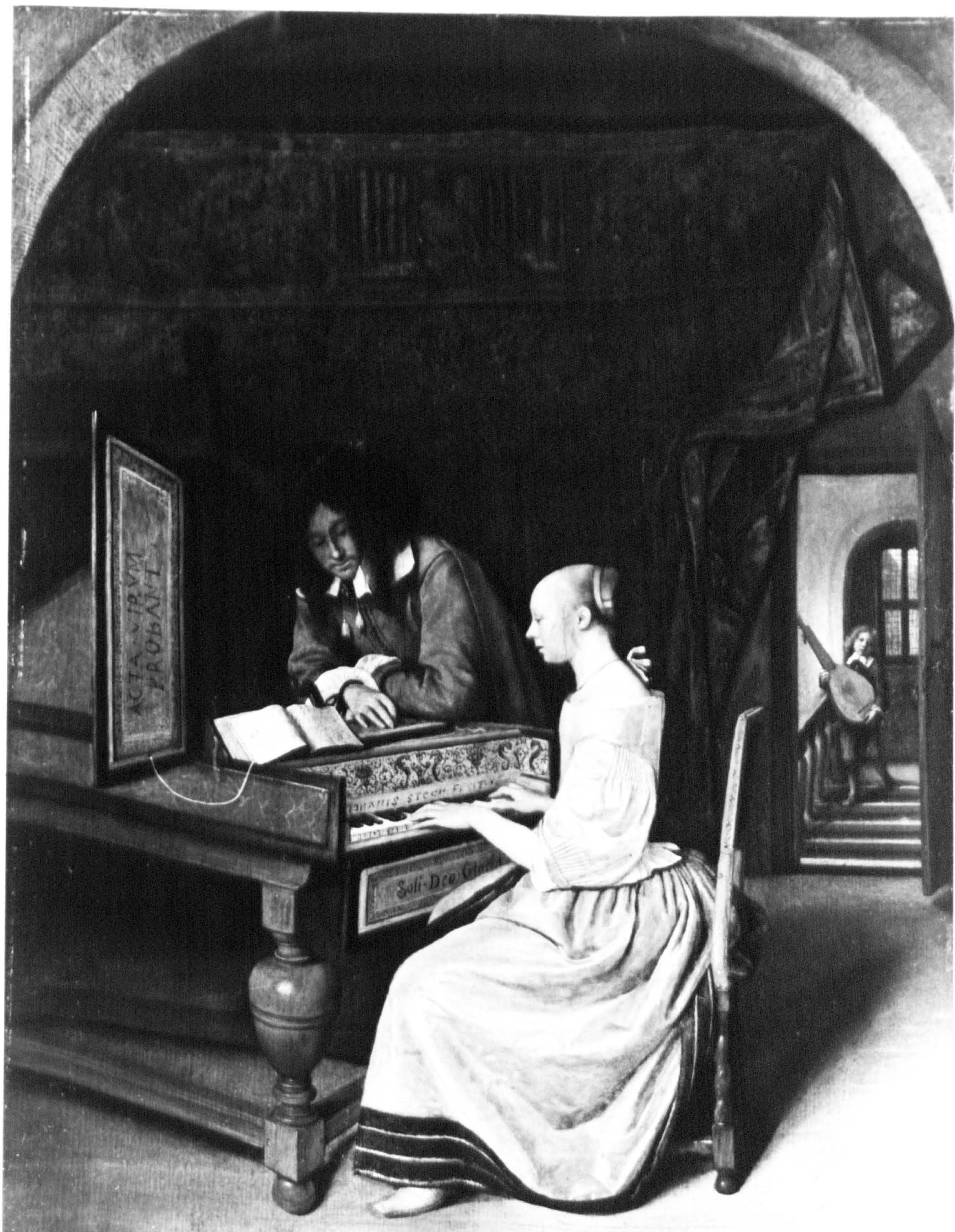

Photo 6-4 'The Music Lesson' by Jan Steen (1626 - 1679). The main lid of the harpsichord is held open with a lid cord (not visible). The cord for the lid flap, which can be used to hold the lid flap open with the main lid closed, can be seen hanging below and to the left of the music. 
placed close to a wall. In turn, this leaves the toolbox accessible and means that, unlike most 18 th century harpsichords, the spine side is decorated.

The keywell flap is a simple unmoulded board hinged in both double-and single-manual harpsichords with three wire hinges to the baseboard. It fits into a recess in the front edge of the spine and cheek and is held closed by one or two hooks in the inside of the keywell on the cheek and spine which engage wire loops on the inside of the keywell flap. Some harpsichords have a pin (often a tuning pin) projecting out of the case side in either or both of the case recesses. for the keywell flap. This pin. fits into a small slot in the keywell flap when it is in the closed position. This pin would prevent the keywell flap from being pulled up, and prevent any strain on the keywell flap hinges, if an inadvertent attempt were made to open the lid flap without first unlocking it or unhooking it from the lid flap.

The harpsichord wrestplank

Although the rest of the structural part of the Ruckers harpsichord is made of poplar, the wrestplank is made of oak (quercus). It is let about $6 \mathrm{~mm}$ into the spine and cheek and pegged and glued to the nameboard, spine and cheek, as well as being. glued to the shaped extensions of the spine and cheek liners. The wrestplank in both double-and single-manual harpsichords is about $45 \mathrm{~mm}$ thick near the player and about $26 \mathrm{~mm}$ ( $1 \mathrm{duim}$ ) thick near the gap. It is cut very close to the quarter 
so that the-lower surface always shows a very strong figure with the characteristically wide rays. The fact that the wrestplanks are tapered in thickness and cut almost exactly on the quarter strongly suggests that they were obtained by splitting an oak butt radially and then discarding the thin central wedges. Indeed, the 1608 AR doublemanual harpsichord has a wrestplank which, where it has not been planed smooth, shows clear signs of splintering and splitting. While the lower surface of the wrestplank of some later Ruckers harpsichords often shows saw marks indicating that it was sawn from the log and not split, the tapered shape and the fact that it is so accurately quartered are almost certainly the result of the way in which it was cut from the log, whother it was split or sawn as a radial section of the treo.

The shape and grain direction of the wrestplank have a number of important consequences. The thickest, strongest part of the wrestplank is located near the $8^{\prime}$ nut and tuning pins where the stress on the wrestplank from the 8' strings is greatest, leaving the thinner part to support the lesser forces of the lighter 4' strings. The tuning pin holes are drilled parallel to the annular rings in the oak which takes advantage of the greater resistance to splitting of the wood in the tangential direction. Also the wrestplank as a whole is less likely to split under the tension of the strings for the same reason. The other advantage of the quartered wrestplank is that the humidity coefficient of expansion is greater in the tangential than 
in the radial direction. Thus the movement of the wood under conditions of changing humidity is minimized in the direction of the strings. This obviously contributes to the overall tuning stability.

The wrestplanks in both double-manual and singlemanual instruments have the same width of 193 to $196 \mathrm{~mm}$ (about $7 \frac{1}{2}$ duimen) and, since they also have the same thickness, they are indistinguishable except in their length. Because the nuts are in the same relative positions in doubles and singles, and because singles, with only one set of $8^{\prime}$ and $4 '$ registers instead of two, have a narrower gap, the soundboard bridges are much further away from the belly rail in the treble in singles than in doubles for any given pitch of string. All other things being equal, the increased area of free soundboard around the bridges should produce more responsive top notes in single-manual harpsichords than in doubles, although I have not been able to confirm this.

The wrestplank is covered on its upper surface with a veneer of soundboard wood about 3 to $3 \frac{1}{2} \mathrm{~mm}$ in thickness. The veneer overhangs the gap edge of the wrestplank by about $2 \mathrm{~mm}$ and this overhanging soundboard wood partly covers the edge of the near register. The direction of the grain of the veneer wood is the same as the direction of the soundboard wood, and the use of this veneer on the wrestplank seems to carry on from the very early tradition of Mtiller and Theeuwes. In this tradition the jackslots were cut through the soundboard wood as in the virginals, and 
the soundboard wood carried on beyond the jacks, under the freely vibrating nuts to the wrestplank at the back of the nameboard. At sometime between 1579 to 1594 , probably becase they were more accessible and easier to engage and to disengage than the earlier enclosed moveable lower registers, moveable upper registers were introduced, and the wrestplank extended out under the nuts to the edge of the registers. But the traditional appearance of the soundboard wood extending to the nameboard was maintained in the later instruments and carried on into the 18th century in most Flemish and French instruments.

In Ruckers harpsichords the soundboard veneer is pegged with very small (2 mm) wooden pegs to the wrestplank. These pegs are spaced regularly across the surface of the wrestplank at an interval of about 4 duimen (102 mm) which is unrelated to the width of the soundboard planks used to make up the veneer. This suggests that the sections of the veneer were first jointed together and cut to length and the whole veneer was then glued to the wrestplank. This was probably done by nailing a board or several strips of wood over the veneer to press it to the wrestplank while the glue cooled and dried. The boards and nails were removed and the veneer was pegged to the wrestplank with pegs which filled the holes left by the nails.

After the veneer was glued and pegged to the wrestplank, lines were scribed on its surface marking the position of the tuning pins and nuts. The nuts mun 
obliquely across the wrestplank, being further from the gap in the bass than in the treble. The 4' nut is completely straight but the $8^{\prime}$ nut is curved such that the concave edge is nearest the player. The $8^{\prime}$ tuning pins run in a line parallel to the nameboard and about $14 \mathrm{~mm}$ from it. But because of the oblique placement of the 8' and 4' nuts, the 4' tuning pins also run obliquely and in a straight Iine about half-way between the two nuts. The name of each key to which the string belongs is written in Flemish handwriting near the location of each tuning pin. In the case of the normal double-manual harpsichords, the note name written on the wrestplank corresponds to that of the lower manual.

The 4' tuning pins in Ruckers harpsichords are smaller than the 8 ' pins (the one exoeption that $I$ know of is the 1627 AR quint harpsichord, where both the 8' and 4' tuning pins have a diameter of $3.7 \mathrm{~mm}$ ). The smaller size of the 4' tuning pins makes the $4^{\prime}$ easier to tune accurately than if it had large tuning pins. Unlike the virginals where the size of the tuning pins is graded within one register, as well as being graded according to the pitch of the instrument, the harpsichord tuning pins of any given register are all of the same diameter. In the harpsichords, the 8' tuning pins are usually about $4.2 \mathrm{~mm}$ in diameter and the $4^{\prime}$ pins about $3.4 \mathrm{~mm}$, but variations of 3.8 to $4.6 \mathrm{~mm}$ for the $8^{\prime}$ and 3.2 to $3.7 \mathrm{~mm}$ for the $4^{\prime}$ tunings pins do occur. The 8' tuning pins are usually about $55 \mathrm{~mm}$ long and are about $5 \mathrm{~mm}$ longer than the 41 tuning pins. 
The tuning pins are of iron wire rod, and their outer surface is usually striated with marks left by the drawing plate used to pull the wire rod down to the required diameter. The sharp edges left on these striations help to prevent slippage when the wire is being coiled on the tuning pins during stringing. This makes the holes drilled in some modern smooth tuning pins to aid in starting the tuning pin coil unnecessary.

The top section of the tuning pin has been hammered lightly to provide a flat bearing surface for the tuning hammer. The lower portion of the tuning pins used by Ruckers, and for that matter, by all of the builders of the classical period, were tapered. This tapered section was driven into a parallel sidedhole in the wrestplank which was slightly smaller than the untapered shank of the pin bruising and compressing the wood into a shape exactly right to fit the tapered shape of the tuning pin, Usually the bottom $13 \mathrm{~mm}$ ( $\frac{1}{2}$ duim) of the pin are tapered and the pin is put in the wood to a depth of about $19 \mathrm{~mm}$, thus ensuring that the pin lines up in its hole. The hardened compressed wood around the tapered shank of the pin onsures a tight-fitting, long-wearing bearing surface which will not loosen even if the pin slowly wears its way deeper • into the hole.

The holes drilled in the wrestplank for the tuning pins are placed at a slight angle to the vertical. Both the $4^{\prime}$ and $8^{\prime}$ tuning pins are angled at about $5^{\circ}$ to $6^{\circ}$ such that the top of the tuning pin leans away from its 
corresponding nut. Drilling the $4^{\prime}$ tuning pins at an angle presents no problems, but drilling the 8 ' tuning pins with the wrestplank in the instrument, even vertically, requires an exceptionally long drill bit. This suggests that the tuning pin holes were drilled in the wrestplank before it iwes positioned and glued into the case sides. Further weight is given to this hypothesis by the fact that the lower surface of the tapered wrestplank is at an angle of about $5 \frac{1}{2}^{\circ}$ to the upper surface. Thus with the wrestplank placed on a horizontal surface drilling vertically into the wrestplank would automatically angle the holes at the angle at which the tuning pins have indeed been found to exist. If the wrestplank was drilled before being positioned in the instrument, this implies that the wrestplank veneer was glued to the wrestplank, the nuts were glaed in position and the nut pins were marked out in order that the tuning pin positions relative to the strings could be determined and marked out. Having the wrestplank out of the instrument would also facilitate the glueing and clamping of the nuts in position.

Like the soundboard bridges and the bridges in virginals, the harpsichord nuts have a characteristic crosssection with angled faces. Also, like the bridges, the nuts are tapered in height and cross-section from bass to treble. For a complete description of the angles of the faces and the probable method of making the bridges and nuts see p. 303. Table 6-i/gives typical values of the dimensions of the nuts in a single-manual and in a double- 
manual harpsichord. Also, like the bridges, the nuts are positioned prior to glueing with pairs of pins on either side of the nut. Usually these positioning pins are placed at or near the notes $c$ and $\underline{f \#}^{\#}$, and the holes left by these pins may therefore be of some help in detemining the original pitch and compass of the instrument. They are, as well, a characteristic feature of Ruckers and at least some of the other Flemish builders. Normally, the holes left by the positioning pins in the wrestplank have been filled with small wooden plugs cut off flush with the top of the wrestplank veneer

All Ruckers harpsichords seem originally to have had a buff stop; a stop in which soft buff leather pads touch the strings near their ends, producing a sound which is rapidly damped away like that of the harp or lute (it is sometimes called the harp stop or the lute stop). In Ruckers harpsichords the buff stop comprises a bar of beech or poplar placed against the $8^{\prime}$ nut with soft buff pads(probably oil-tanned ox or moose leather) about $5.5 \mathrm{~mm}$ thick, glued to its top surface. The pads are usually about $10 \mathrm{~mm}$ high in the bass and about $8 \mathrm{~mm}$ high in the treble. They are also tapered in width, and are about $4 \mathrm{~mm}$ wide at the top and $6 \mathrm{~mm}$ wide at their base. The doubled $e^{b} / \mathrm{g}^{\#}$ strings on double-manual harpsichords (see p. 314) require special buff pads which are higher than normal and specially shaped so that the edge of the buff pad comes in contact with both strings similtaneously. The buff "stop on Ruckers harpsichords is split near the middle - the treble section 
profects through the cheek like the registers and can be operated by reaching around to the side of the instrument. The bass section of the buff stop was operated by a finger stop like that on the virginal harpichordium, or by a pin in a block, either of which was glued to the top of the buff bar near the spine. ${ }^{6-4}$ ) Both sections of the stop are turned on by pushing the buff bar toward the centre of the instrument, that is, the treble buff pads are on the right of the strings and the bass pads are on the left of the strings. This means that the special pads for the $e^{b} / g^{\#}$ strings have to be differently shaped on the bass buff bar than those on the treble bar; it also means that the two sections of the buff bar cannot be joined together to operate as one, as has been suggested by Hubbard (p. 63). Further it means that the original split-buff system is not readily adaptable to the instruments which have later had a second 8' set of strings added. In this case the left and right hand strings belong to different registers so that each section of the split buff would operate on only half of each register. For this reason the original buff stop survives only on those instruments which have not been changed from their original $1 \times 8^{\prime}$ disposition, and clear1y not in those situations where the spacing of the strings has also beén reduced.

The buff stop is held in place in a manner similar to that used for the harpichordium stop in virginals. Small chamfered blocks of wood hold the bar against the $8^{\prime}$ nut, and horizontal wires placed in the nut hold the bar 
down against the wrestplank veneer. The friction between the bar and these wires and chamfered blocks, which is necessary to hold the stop in position, is increased by the bend introduced in the buff bar by the curvature of the nut. In the "on" position the buff bar is stopped partly by the resistance of the pads against the ends of the strings and partly by a small carved block of wood placed at the position of the split in the buff stop (see Photo 6-5). At one end this small block is let into a 'V' shaped recess in the nut, and at the other, one of the 4' tuning pins passes through its low tapered end. The existence of the ' $V$ ' shaped nick in the 8' nut proves the former existence of a split buff in those instruments which have lost their original buff, and also reveals where the split in the buff occurred. Also the border of the scalloped decoration on the wrestplank was usually painted round the chamfered blocks holding the buff bar against the nut and round the carved bumper block at the split in the buff stop. This painted decoration provides further proof of the original existence of a buff stop and whether or not it was split. If the nut is original, the holes for the wires used to hold down the buff stop will also indicate whether or not the instrument originally had a buff $(6-5)$

The split between the two sections of the buff stop occurs in single-manual harpsichords between the notes $f^{1}$ and $f^{\# 1}$. The two manuals of the Ruckers double are at different pitches so that the split in the buff occurs at 


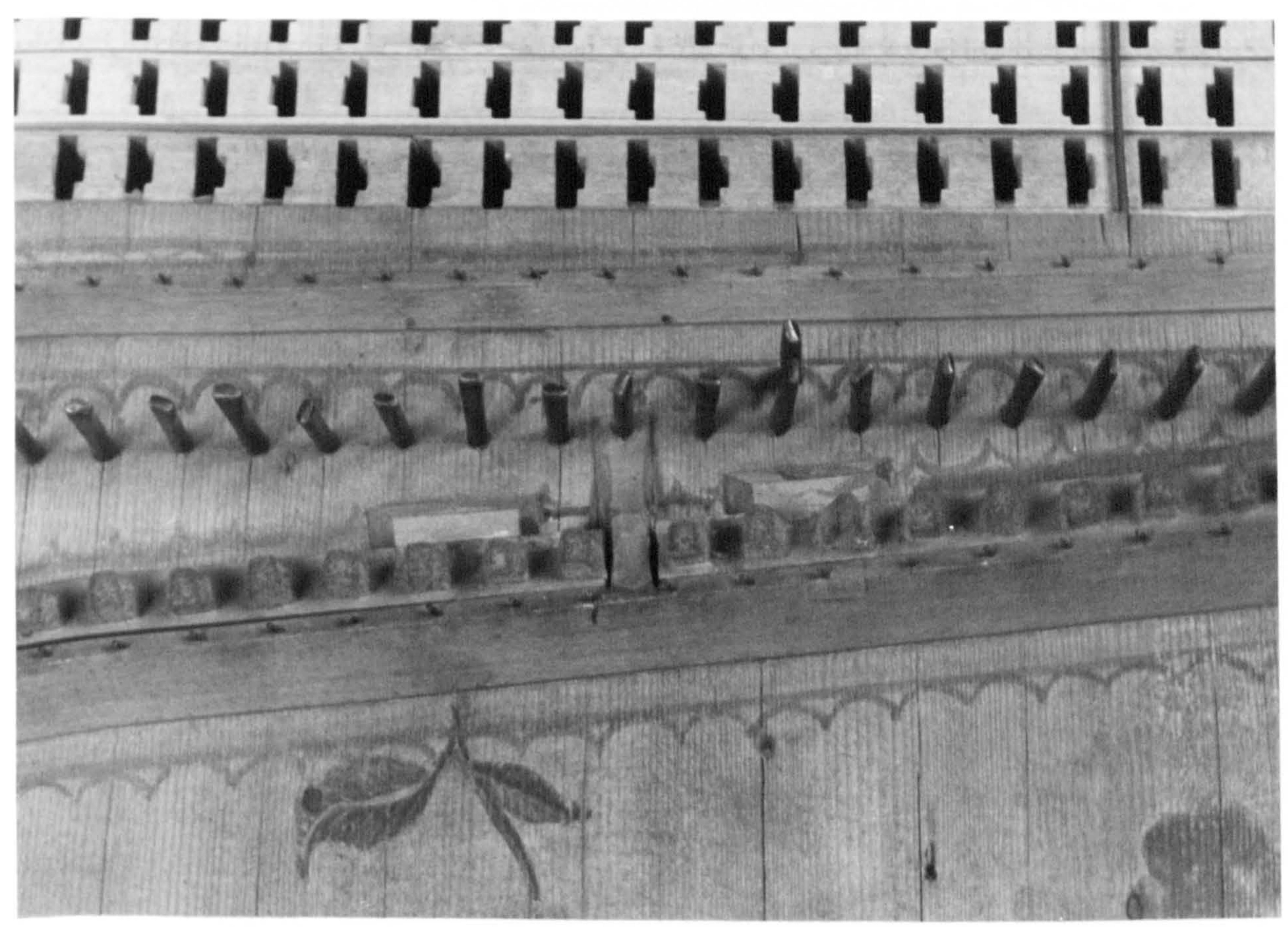

Photo 6-5 Detail of the wrestplank of the 1638b IR showing the position of the split in the buff stop and the carved block between the bass and treble sections of the buff battens. 
a different note (but the same pitch) on each manual. On doubles the split in the buff occurs at $f^{1} / f^{\# 1}$ on the ' $f$ ' keyboard and at $c^{1} / c^{\# 1}$ on the ' $c$ ' keyboard. That is, the split occurs at $f^{1} / f^{\# 1}$ on the lower manual of the usual double, and at $c^{1} / c^{\# 1}$ on the lower manual of the extended compass Ruckers 'French' harpsichord (seo p. 515).

As with the harpichordium stop in the virginals, the musical use of the split buff stop is not clearly understood. The virginal harpichordium extends from $C / E$ to $f^{1}$, and the buff stop splits between $f^{1}$ and $f^{\# 1}$, so that there is a strong musical relationship between the harpichordium and buff stop. The intention must have been to try to produce the effect of two different timbras from the one instrument. Unlike the harpichordium stop which operated only on the bass and tenor strings (except for the $1581 \mathrm{HR}$ ) the buff effect could be interchanged between bass and treble. As with the harpichordium the use of a markedly different type of sound in the treble and bass does not seem appropriate to pieces like fantasias or pavan es, and was probably used more for fast, light dance pieces. However, although it is difficult to say that the split buff stop was analogous with the relatively common organ stops split near the middle of the keyboard, it is possible that marked contrasts between the treble and bass sounds were acceptable to the 17 th century ear even in the more serious and ecclesiastical pieces.

Harpsichord soundboards

The major acoustical element in any Ruckers instru- 
ment is obviously the soundboard. The extreme importance of the soundboard to the final sound of the instruments seems to have been clearly understood by all of the members of the Ruckers family, for the soundboard and bridges are made and finished with a delicacy, accuracy and care that is not generally typical of the rest of the instrument. It is almost as though the case was prepared by an entireIy different person from the soundboard, bridges, registers and jacks, as may indeed have been the case in a busy shop training apprentices.

The soundboard is made of softwood which has been identified microsocopically as picea, or spruce (probably picea abies, or more properly picea excelsa) $)^{6-6)}$ The wood is cut on the quarter so that one sees the edges of the annular rings and the silvery shimmer of the sides of the rays on the surface of the wood. The reason for the quartering of the wood is not clear. The velocity which a compression vibration travels in the wood is greater in the radial than in the tangential direction in the wood, but preliminary research on the vibrations of harpsichord soundboards $6-7$ ) shows clearly that the soundboard is acting as an acoustical radiator, and not an acoustical resonator. This means that the soundboard is acting as a whole like a large piston driving the air above it up and down. In this way the soundboard converts the energy of vibration of the string into sound energy around the instrument. The soundboard does not break up into small sections with nodes and antinodes whose dimensions and energy are 
controlled by the velocity of the wave in the soundboard, the frequency, the stiffness, and the other factors which affect a resonant system. Therefore since the soundboard is a radiating system and not a resonating system, the velocity of travel of a wave in the soundboard is not an important acoustical factor. The absorption of sound energy in the two directions in spruce has not been investigated and may well be important. It must be remembered that many early Italian harpsichords and virginals used plank sawn cypress, and although there seems to be no acoustical disadvantage in doing so, I know of no Italian instruments which, when using spruce or fir, did not use it cut on the quarter. One clear non-acoustical advantage of using quartered soundboard wood is that the humidity coefficient of expansion is lower for quartered than for plank-sawn spruce, so that a quartered soundboard is dimensionally more stable under conditions of changing humidity. The soundboard is also therefore less subject to splitting when cut on the quarter since the internal forces of tension (or compression) due to change in humidity are also reduced.

The width of the individual planks of wood are usually integral multiples of the small duim, although one does, rarely, encounter half-integral widths as well. Usually adjacent planks in a soundboard show the same pattern of annular rings indicating that they are successive slices cut from the tree. This was probably done to ensure that the grain of the wood in each plank in the 
soundboard was lying in the same direction. This is important when planing the soundboard to thickness to avoid the grain rising in one or more planks and being lifted by the plane. This means however that no attempt was made to use, say, wide-grained wood in the bass and narrow-grained wood in the treble. Although the wood is usually close and straight grained, there are many cases where the wood is open grained (1646 IC) or rather variable in texture. The same applies to the accuracy of the quartering. The wood often shows a fine shimmering silvery quartered figure, but this is sometimes lacking, and the wood may be up to $20^{\circ}$ off the quarter. Also, as is characteristic of spruce, the soundboard wood often has pitch pockets found in it, and these are usually disguised underneath the soundboard painting.

But although the Ruckers apparantly did not pay much attention to the accuracy of the quartering or the density of the grain lines in their soundboard wood, the same does not apply to the amount of attention they paid to the thicknessing of the soundboards. After glueing the individual planks together, the soundboard was carefully and accurately planed to thickness to achieve a definite flexibility and weight distribution. The soundboards are much thicker under the tenor/bass part of the bridge than elsewhere and they taper away across the rest of the soundboard becoming thinnest near the tail/spine corner and in the extreme treble part of the compass. The instruments of Couchet and the late instruments signed by Ioannes 
Ruckers even seem to thickness the tenor/bass regions of the 4' bridge separately from the 8' bridge. Fig.6-3 shows the thicknessing of the soundboard of the 1640b AR doublemanual harpsichord. The soundboard of Ioannes Ruckers harpsichords are even more strongly tapered, being about $4.3 \mathrm{~mm}$ thick under the tenor part of the bridge and less than $2 \mathrm{~mm}$ in the treble $e^{6-8)}$

Whatever the intention of the Ruckers might have been, the effect of the thicknessing and tapering is quite definite. In the treble the bridges lie almost at right angles to the grain of the soundboard. This, coupled with the small distance of the bridges from the 4 ' hitchpin rail and the belly rail in the treble, tends to make the soundboard and bridges very stiff. This is offset by thinning the soundboard here. Clearly the opposite is true in the tenor and bass, both where the angle between the bridge and the soundboard grain is small, and the distance of the bridges to the case sides and hitchpin rail is large, thus producing a much more flexible system. A thicker, stiffer soundboard here avoids the 'banjo effect' where the sound energy of the string is radiated very quickly and dies away almost immediately. It also helps to support the heavier bass strings and, being stiffer, a larger part of the soundboard is set in motion, thus increasing the effective area of the soundboard. This in turn, increases the strength of the fundamental component and lower harmonics of the radiated sound. As with the virginals the soundboard wood was 


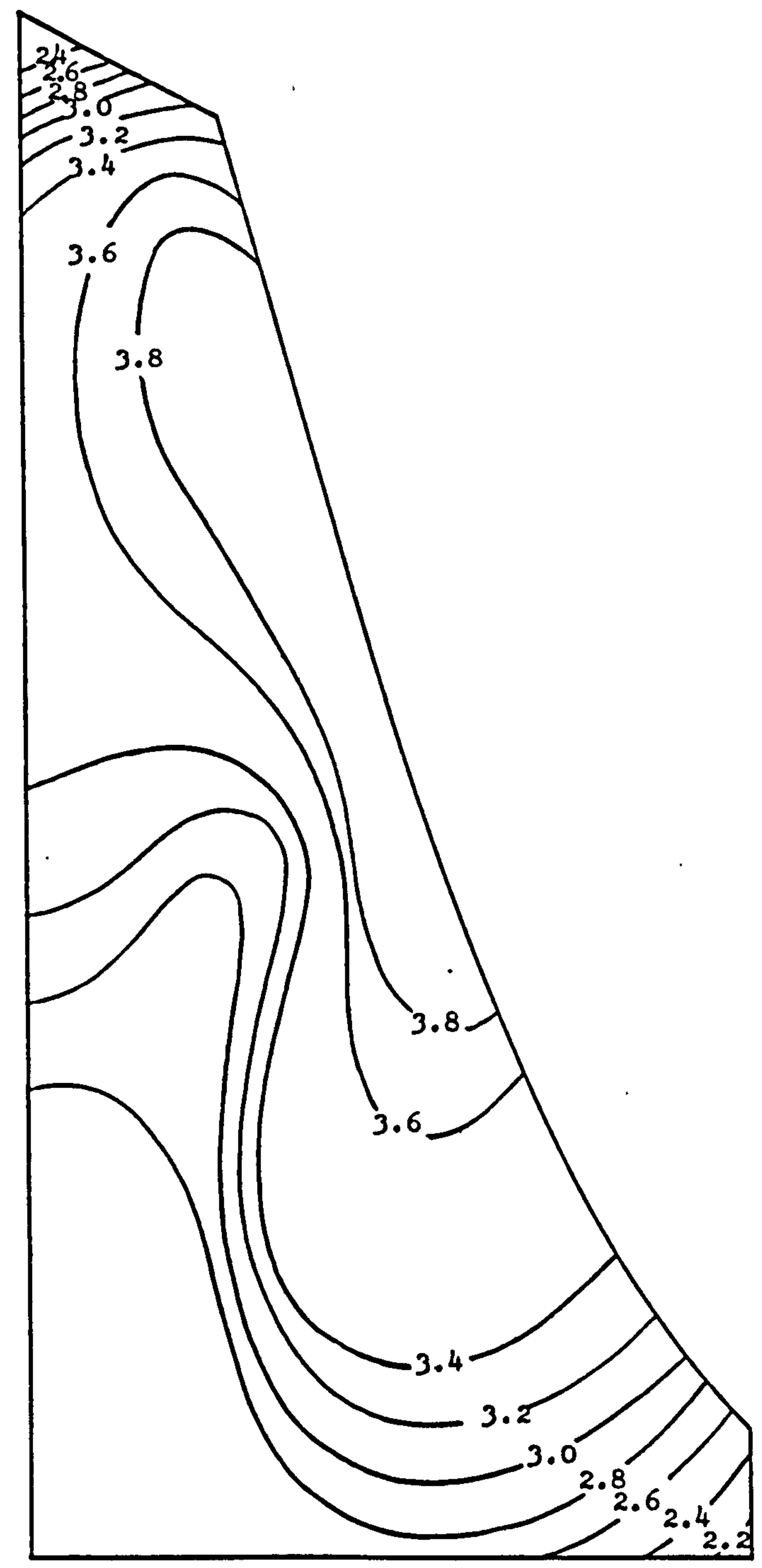

Fig. 6-3 The soundboard thickness contours for the 1640b AR double-manual harpsichord.

Scale $1: 10$ 
probably reduced from a thickness of about $5 \mathrm{~mm}$ initially by using a plane and then the final thicknessing was done with a scraper. The characteristic ribbed texture of the soundboard surface in Ruckers instruments, and in those of a number of other $16 \mathrm{th}$ and $17 \mathrm{th}$ century Flemish makers, is the result of the use of a scraper on the upper surface of the wood (see p. 203).

After thicknessing, the upper surface of the soundboard was sized as a preparation for the soundboard painting. The material(s) used to size the soundboard has become a rich golden brown colour and has produced a fairly shiny surface. This brown coloration is probably the result of the degradation of the organic matter in the size preparation. It seems likely that the material used was a simple, easily accessible material commonly found in the workshop, and not a complex special preparation. Gum arabic, egg white (glair), or varnish might have been used, but the most likely and readily available materials were thinned shellac or glue size made by thinning down the glue used for glueing the instrument together. Since the surface of the soundboard is not sticky when touched by the moistened finger it seems likely that the final size at least was not glue or gum arabic. It therefore seems most likely that thinned shellac was used for sizing the soundboard.

Soundboard barring and hitchpin rails in harpsichords

There are two separate hitchpin rails in harpsichords, one for the 4' strings and one for the $8^{\prime}$ strings. The 
8' strings are hitched to the bentside and tail soundboard liners. A thin moulded strip about $\frac{1}{4}$ duim (6.5 mm) high sits on the soundboard adjacent to the case walls, and the 8' hitchpins are driven into this moulding, through the soundboard and into the liners. Since the soundboard moulding is everywhere the same height there is a large down-draught especially for the heavy bass $8^{\prime}$ strings, where the bridge is very high and the distance from the bridge to the hitchrail is relatively short. The 4' hitchpin rail consists of a curved piece of poplar placed between the $4^{\prime}$ and $8^{\prime}$ bridges under the soundboard. The 4' hitchpin rail was let into the spine Iiner at the bass end so as to make the top surface of the hitchrail flush with the level of the top of the 1iners. At the treble end the hitchrail was either let into the cheek liner in a manner similar to the bass end, or it was supported by and usually let into a block glued to the cheek liner or belly rail.

The 4' hitchpin rail tapers very little in height from bass to treble and is usually about 20 to $25 \mathrm{~mm}$ high along most of its length. It is, however, much wider in the bass than in the treble, tapering from 50 to $60 \mathrm{~mm}$ in the bass to 13 to $18 \mathrm{~mm}$ in the treble. The 4' hitchpin rail seems always to be of one piece of wood sawn from the plank.

The position of the 4' hitchpins on the upper surface of the soundboard relative to the 4' hitchpin rail underneath was probably determined according to the following 
procedure which has been deduced from construction marks on the soundboard itself. The 4' hitchpin rail was placed temporarily in position and then the soundboard was positioned temporarily in the instrument above the 4 ' hitchpin rail. With the baseboard removed and the instrument on its side, a line was scribed along the whole length of the near edge of the 4' hitchpin rail on the lower surface of the soundboard. 6 ) The soundboard was then removed and a fine pointed object (a fine nail or pin?) was driven from the lower to the upper surface of the soundboard so that the point just pierced the top of the soundboard. This was repeated so that in all there were holes at 4 or 5 positions spaced along the scribed line. The soundboard was turned over and the 4' hitchpin rail was laid on the top of the soundboard and lined up with the holes that had been pierced through. Short lines were scribed along the edge of the 4' hitchpin rail on the top surface of the soundboard so that each line passed through one of the holes pierced from below. At this stage the hitchpin rail was in the same position above the soundboard that it would normally occupy below the soundboard. The hitchpin rail was then drawn back slightly toward the tail and bentside by an arbitrary amount which was, however, always less than half the width of the hitchpin rail at each point along its length. Another line was scribed along the entire length of the player side of the hitchpin rail. The 4' hitchpins were driven into this line. Because of the way the position of the hitchpin rall was transferred to the top of the 
soundboard, and the way the line of hitchpins was marked out from this, the maker was certain that all of the $4^{\prime}$ hitchpins would find their way firmly into the wood of the hitch rail, and not miss it on one side or the other. The line scribed underneath the soundboard along the edge of the 4' hitchpin rail could also be used to locate the hitchpin rail when glueig it to the lower surface of the soundboard. As well as carrying the 4' hitchpins and helping to support the tension of the 4' strings, the 4' hitchpin rail forms a natural soundbar and barrier between the 4' and 8' bridges. The vibration of the soundboard around the 8' bridge is limited on one side by the tail and bentside, and on the other by the spine and $4^{\prime}$ hitchpin rail. Similarly the vibration of the $4 '$ soundboard area is limited between the 4' hitchpin rail, and the spine and cutoff bar on the other side. The amount of soundboard area allotted to each part of the compass is very important to the final tone of the instrument. Thus the position of the 4 ' hitchpin rail and the cutoff bar relative to the bridges and case sides has an important acoustical effect.

The cutoff bar runs diagonally under the soundboard and is placed so that the $4 '$ bridge is more or less halfway between the $4^{\prime}$ hitchpin rail and the cutoff bar. Behind the cutoff bar a number of smaller soundbars running perpendicularly to the spine stiffen and deaden the area of soundboard between the cutoff bar and spine. Naturally the soundbars, cutoff bar and 4' hitchpin rail, in additon to acting as acoustical barriers, also perform an import- 
ant structural duty in helping to hold the soundboard flat. The inherent rigidity of these bars glued to the soundboard helps to counteract distortions in the soundboard caused by the down- and side-draught in the strings. Despite the rigidity provided by these bars under the soundboard, the unsupported parts of the soundboard under the bridges are often considerably distorted by sizeable undulations in the soundboard surface. Also there seems to be not a single harpsichord without the characteristic split at the treble end of the bridges. These must be accepted as part of the consequences of classical harpsichord design and construction.

The cutoff bar and soundbars each have the same basic cross-section (see Fig. 6-4). They are wider at the base than at the top and the angle of the angled sides is usually either the same for the cutoff bar and all of the soundbars in one instrument, or the bars are either of two distinctly different angles. The cutoff bars and soundbars in Ruckers instruments, whether virginals or harpsichords have sides tapered such that $\alpha$ is close either to $10^{\circ}$ or to $15^{\circ}$. This constancy in the angles of the sides of the cutoff and soundbars suggests that they were made in a jig which always produced the same angles regardless of the size of the bar.

Such a jig can easily be made as follows (seo Fig. 6-5). Beginning with a rectangular bar of wood which is the same height and has the same width as the base of the soundbar required, the bar is placed first in the left angled slot 


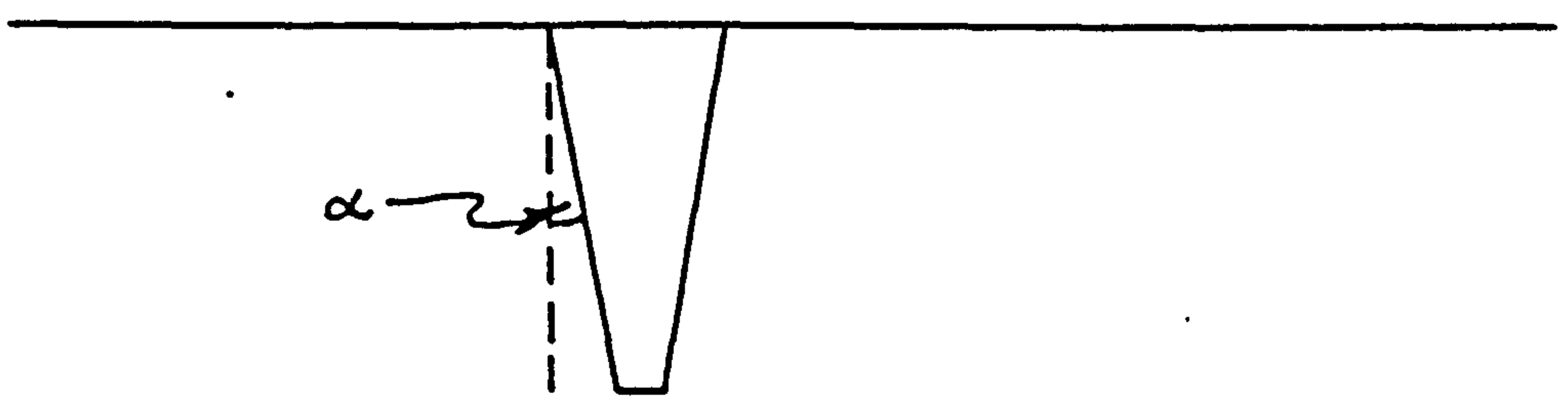

Fig. 6-4 Cross-section of typical soundbars and cutoff bars in Ruckers clavecimbels. 


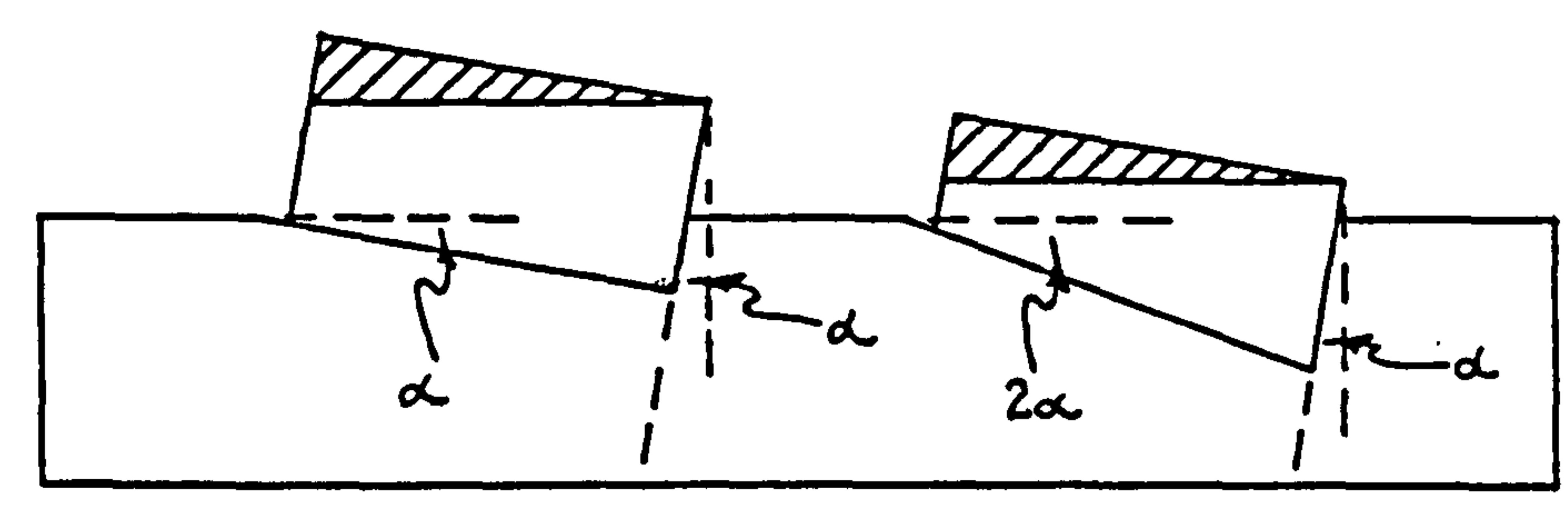

Fig. 6-5 Cross-section of a jig for making Ruckers soundbars and cutoff bars. 
and against $a$ bench stop and the shaded area planed away parallel to the top of the jig and work bench. The bar is then turned end-for-end and placed in the right-hand slot and the shaded area again planed away. It seems likely that the Ruckers used two such jigs, in some way similar to the above one with $\alpha=10^{\circ}$ and another with $\alpha=15^{\circ}$, which produced bars which were close, but not necessarily exactly equal, to these angles. This follows closely the probable procedure used in making the bridges (see p. 303).

Arched scallops were removed from the ends of the soundbars and cutoff bars leaving the extreme ends of the bars only 1 to $2 \mathrm{~mm}$ high (see Fig.6-6). The scallops in the larger cutoff bars are about 2 duimen (51 mm.) long and about 1 duim ( $25 \mathrm{~mm}$ ) long in the smaller soundbars. The reason for the scalloped cutouts at the ends of the soundbars is probably structural rather than acoustical. If the soundbars were left full thickness at the ends they would be totally rigid throughout their entire length, and any tendency of the soundboard to distort near where the soundbars are glued in place would result either in the soundboard splitting near the end of the soundbar or the glue joint at the end of the soundbar would give way. By thinning the soundbar near its ends and making it more flexible there, the tendency of the soundboard to distort is prevented by the inherent rigidity of the soundbar, but the flexibility of the ends of the soundbars prevents concentrated areas of stress there and 

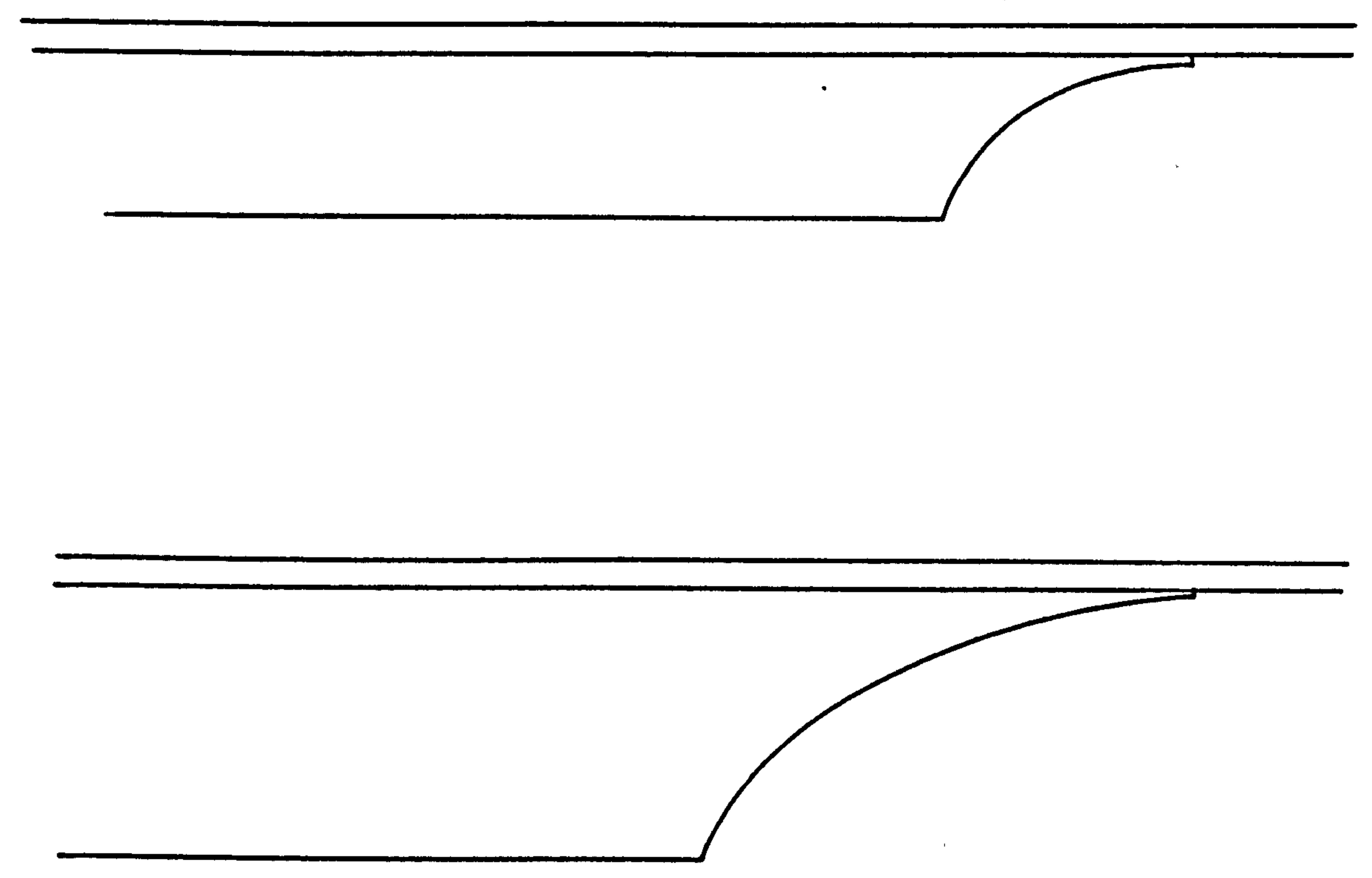

Fig. 6-6 Scalloped ends of Ruckers soundbars (above) and cutoff bars (below).

Scale 1:1 
so avoids soundboard splits, or cracks in the glue joints. Before glueing on the soundbars, their position was marked in red underneath the soundboard with a sanguine pencil. The soundbars are usually separated from one another at regular intervals which are an integral or half-integral number of duimen apart. The ends of the soundbars are angled to butt tightly against the cutoff bar at one end, but at the other there are several millimetres of clearance between the soundbars and the spine liner. Similarly several millimetres of clearance is left between the ends of the cutoff bar and the spine liner and the belly rail. This clearance was probably left to ensure that the ends of the bars did not get trapped between the soundboard and the spine liner when the soundboard was glued in place. Should this have happened the soundboard would not have been properly attached to the liner near the trapped end of the soundboard. The spine and belly rail ends of the cutoff bar and both ends of the larger soundbars are secured with linen tape glued over the scalloped ends of the soundbars to the soundboard.

The joins in the soundboard planks in much of the area of freely vibrating soundboard are covered on the lower surface with strips of parchment about 1 duim (25 mm ) wide. These parchment strips shrink slightly when the moisture of the glue used to fix them evaporates, and they tend not only to strengthen the joint but actually to tighten it. These parchment strips do not run under the bridges, 4' hitchpin rail or the cutoff and soundbars, 
and their position and length is also marked in red with sanguine previous to glueing, They are practically always found between the bentside and 8' bridge along the soundboard joins, but are sometimes lacking in those areas where there is only a short distance along the soundboard join between say, the 4' hitchpin rail and the bridges. Thus they are often not found in the treble where the belly rail, bridges and 4 ' hitchpin rail are all already very close together.

\section{Harpsichord bridges}

The 8' bridge in Ruckers harpsichords are almost always made of cherry (prunus avium - commonly called wild cherry, European cherry or gean. Rather confusingly 'bird cherry' is prunus padus). The heartwood of wild cherry has the characteristic feature that it turns dark brown on long exposure to air and light, and thus Ruckers 8' soundboard bridges, because of their age, are always a deep brown colour rather than the pale pink colour one usually associates with freshly sawn or planed cherry. There are at least four Ruckers harpsichords, however, which have original bridges not of cherry. The $1636 \mathrm{AR}, 1637 \mathrm{AR}, 165.1 \mathrm{~A}$ AR and 1645 IC single-manual harpsichords all have $8^{\prime}$ bridges of beech. Ruckers 4' bridges are, to my knowledge, always of beech. Because it has a much smaller section and no regions of sharp radius of curvature, the 4' bridge is made from a straight piece of wood which is bent and held in its bent shape solely by the glue and by the nails driven into it from underneath the soundboard. However, because of the 


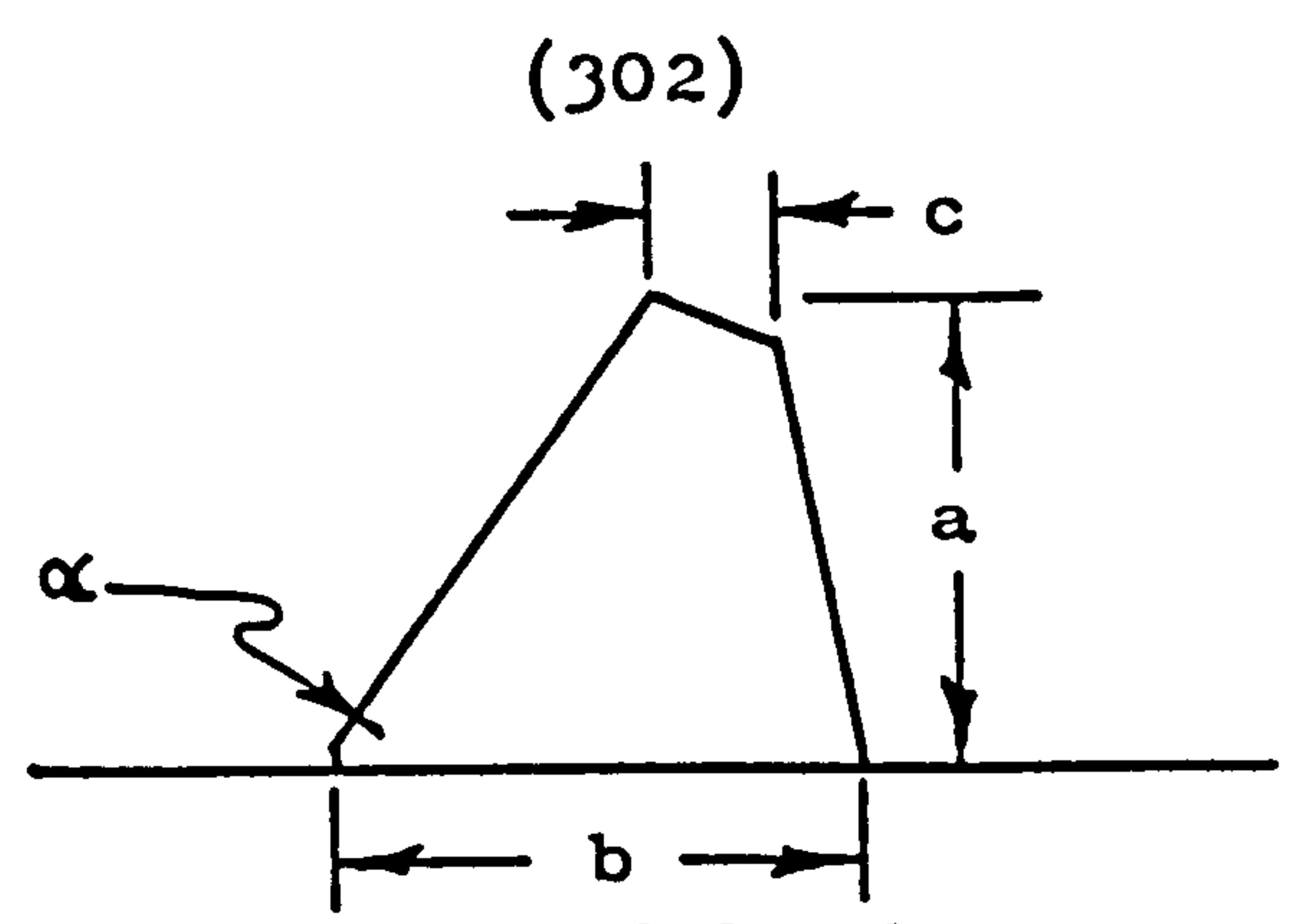

1645 IC Single-manual Harpsichord:

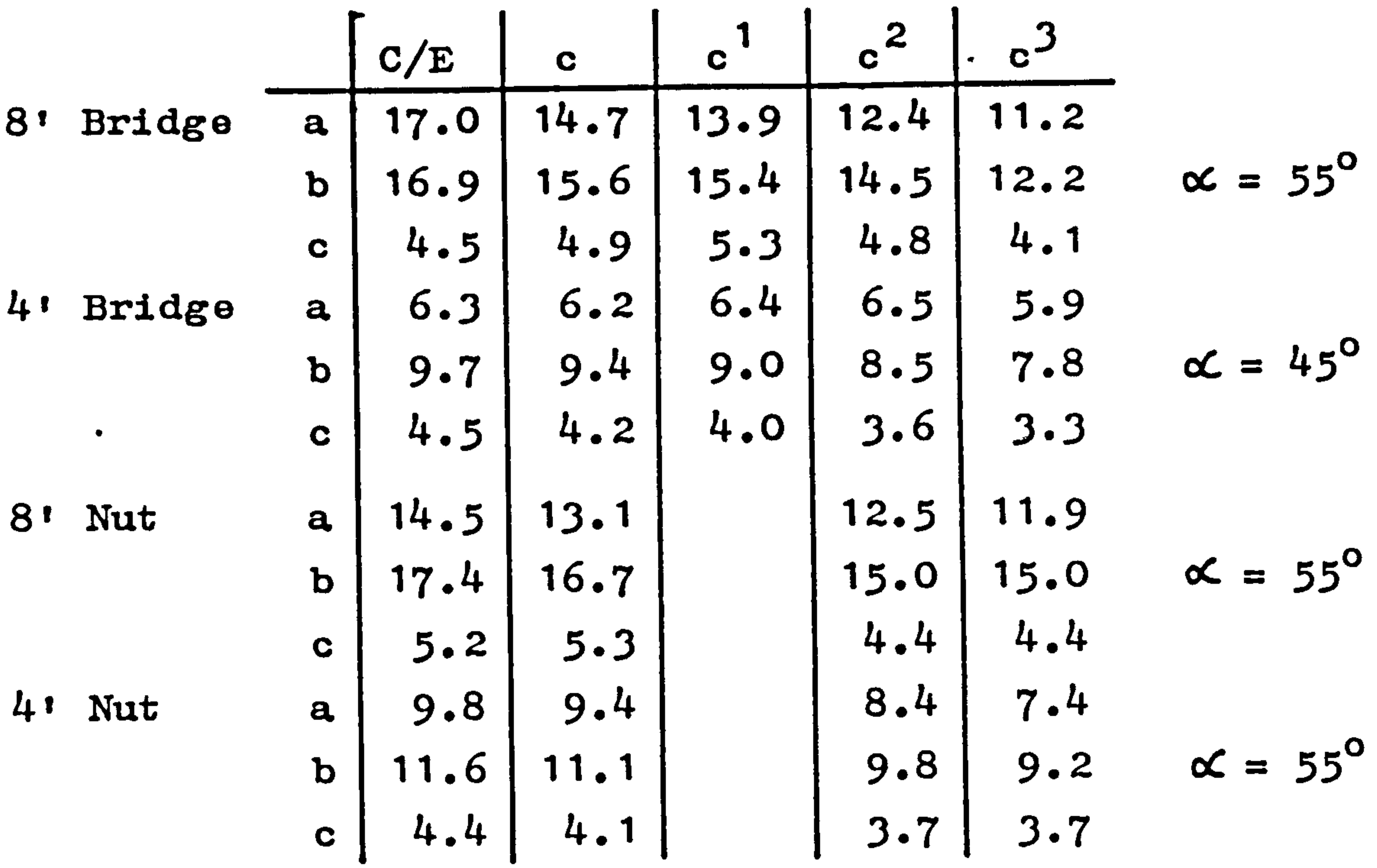

1638b IR Double-manual harpsichord:

\begin{tabular}{|c|c|c|c|c|c|c|c|c|c|}
\hline & & & $\mathrm{G}_{1} / \mathrm{B}_{1}$ & C & c & $c^{1}$ & $c^{2}$ & $c^{3}$ & \\
\hline \multirow[t]{3}{*}{$8^{\prime}$} & $\operatorname{Br} 1 d g \theta$ & $\bar{a}$ & 16.8 & 16.7 & 15.0 & 13.7 & 12.7 & 11.1 & \\
\hline & & $\mathrm{b}$ & 18.0 & 18.6 & 177 & 14.8 & 12.3 & 11.5 & $\alpha=55^{\circ}$ \\
\hline & & c & 4.5 & 4.8 & 5.0 & 4.6 & 4.7 & 4.6 & \\
\hline \multirow[t]{3}{*}{41} & $\operatorname{Br} I d g e$ & $a$ & $7 \cdot 3$ & $7 \cdot 3$ & 6.8 & 6.5 & 6.7 & 6.8 & \\
\hline & & $b$ & 11.0 & 10.8 & 10.0 & 9.3 & 8.9 & 8.8 & $\alpha=45^{\circ}$ \\
\hline & & c & 4.4 & 4.2 & 3.9 & 3.6 & 2.8 & 3.0 & \\
\hline \multirow[t]{3}{*}{$8^{\prime}$} & Nut & $a$ & 12.7 & & 11.8 & & 11.4 & 10.9 & \\
\hline & & $b$ & 17.6 & & 16.5 & & 15.1 & 14.5 & $\alpha=45^{\circ}$ \\
\hline & & c & 5.0 & & 4.5 & & .4 .1 & 3.9 & \\
\hline \multirow[t]{3}{*}{41} & Nut & $\mathbf{a}$ & 9.2 & & 8.8 & & 8.1 & $8 \cdot 3$ & \\
\hline & & $\mathbf{b}$ & 10.5 & & 10.4 & & $9 \cdot 7$ & 10.0 & $\alpha=55^{\circ}$ \\
\hline & & c & 4.2 & & 3.7 & & 3.4 & $3 \cdot 3$ & \\
\hline
\end{tabular}

Table 6-1 Dimensions of the nuts and bridges in typical single-manual ( 1645 IC) and double-manual harpsichords ( $1638 \mathrm{~b}$ IR). All measurements in mm. 
thickness of the wood in the 8' bridge and the sharp curra ture of the bass end of the bridge, the 8' bridge is sawn from the plank and not bent.

Like the nuts, the bridges are tapered in height and width from bass to treble, the 8 ' bridges and nuts having a larger cross-section than their 4' counterparts. Both bridges and nuts have a characteristic shape with angled flat surfaces (unlike the early Ruckers virginals, I know of no Ruckers harpsichords with nuts or bridges with curved faces). The dimensions and the angles of the faces of most original nuts and bridges on both harpsichords and virginals have been measured and two distinct configurations have been found (see Fig.6-7). Naturally, as with any handmade object, the angles of the faces of the nuts and bridge are not always exactly $45^{\circ}, 55^{\circ}$ and $80^{\circ}$, but there is a remarkably consistent set of data giving angles very close to these for the two configurations. (In a few rare cases the front face is at right angles to the soundboard or wrestplank instead of being angled at $80^{\circ}$.) The 4 ' bridge almost always has configuration (b), the 8 ' bridge and usually the 4' nut have configuration (a), and the 8 ' nut may be either (a) or (b).

The consistency with which the bridges and nuts are found always to have faces angled to the same extent suggests that a jig of the type used to make the soundbars was also used to make the nuts and bridges. Also the obvious relationship between the angles $45^{\circ}, 55^{\circ}$ and the $10^{\circ}$ angle from the vertical suggest that the two configurations may 
(a)

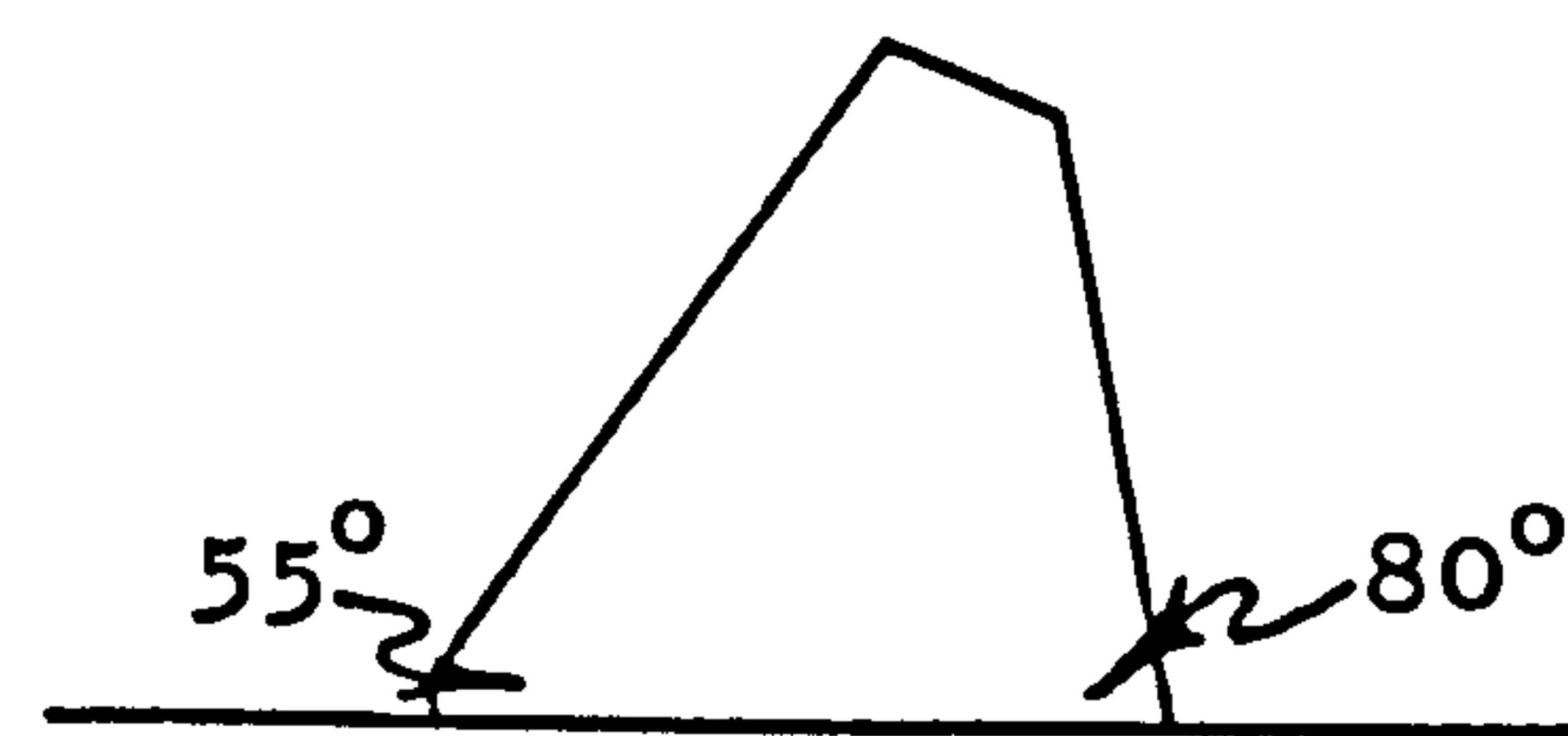

(b)

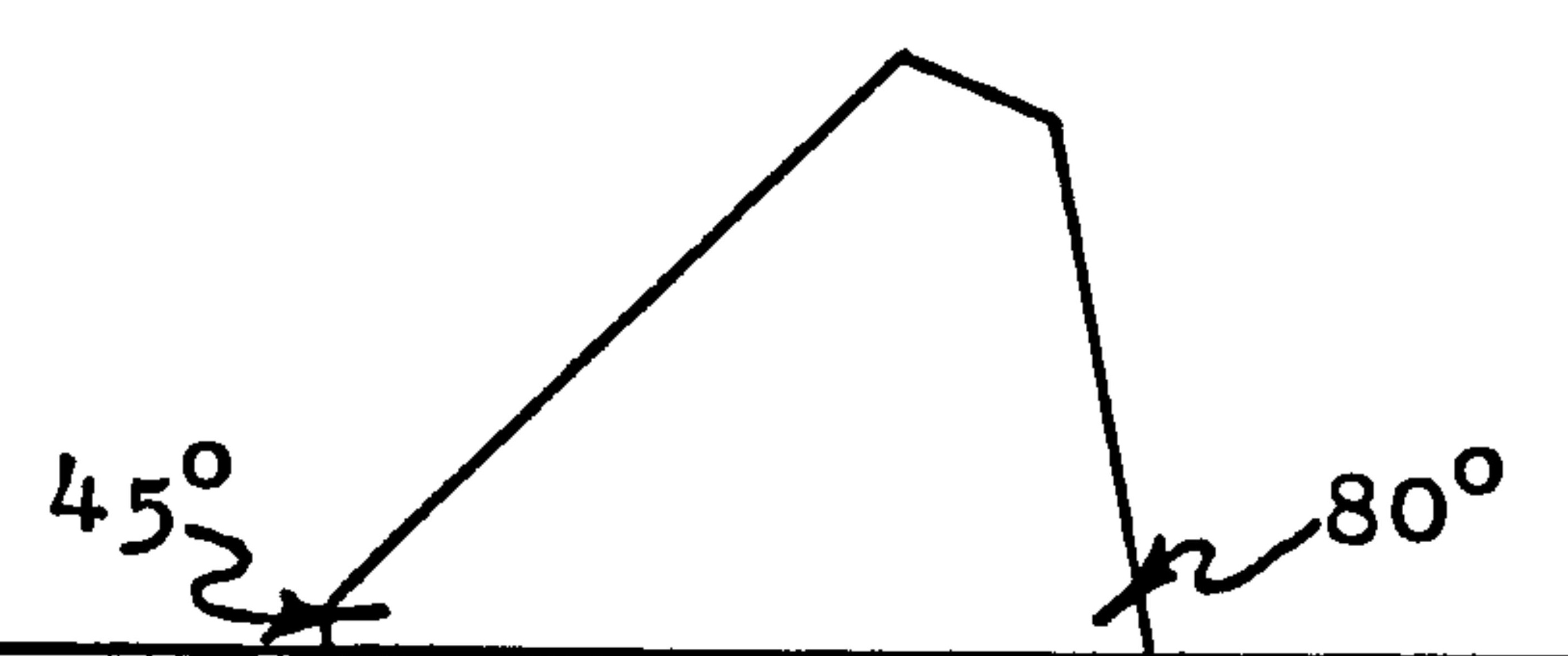

Fig. 6-7 The two configurations of Ruckers nuts and bridges.

Not to scale

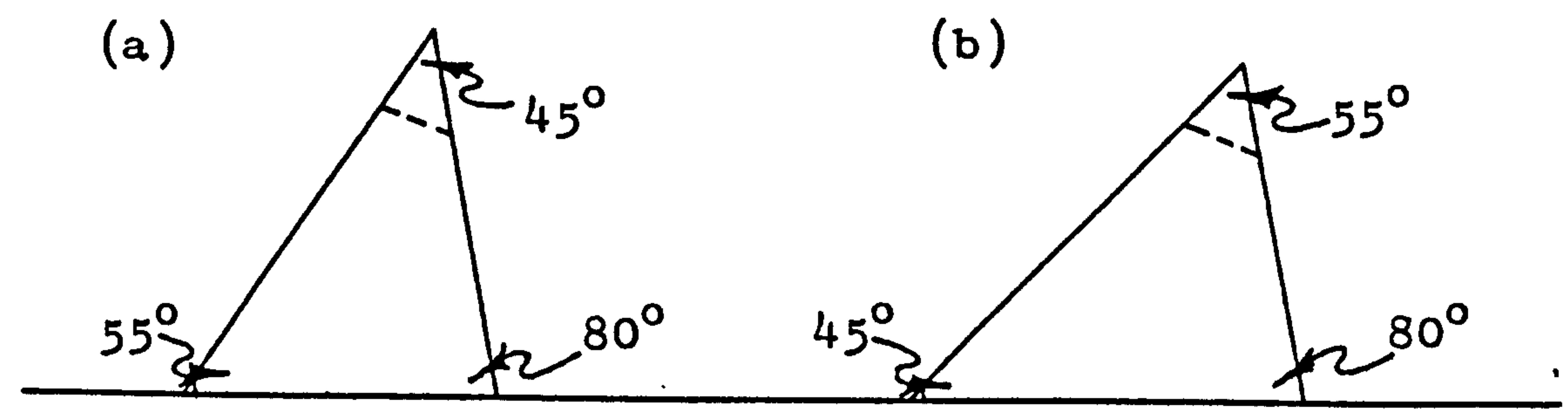

Fig. 6-8 The shape of Ruckers nuts and bridges before removing the chamfered edges.

Not to scale 
somehow be interrelated. In fact, if one ignores the chamfered top edge of the nut or bridge the relationship between the two configurations becomes obvious (see Fig. 6-8). The two configurations were clearly made using the same jig, but choosing a different surface as the eventual base of the bridge or nut.

The nuts and bridges which were made from straight pieces of wood and later bent, could be made by starting with a square piece of beech as long as the bridge or nut required, which was then cut diagonally to give two pieces with a cross-section which was a right-angled equilateral triangle. This could then be planed to the desired shape and configuration using a very simple jig, consisting of a plank of wood slotted like the soundbar jig, but with the cross-section shown in Fig. 6-9.

The piece to be used is first placed in the left hand slot and against a bench stop and, keeping the plane parallel to the top of the jig and workbench, the sawn surface is planed smooth. By planing away more wood at one end than the other the bridge or nut can also be tapered. It is then placed in the right hand slot and the $80^{\circ}$ angle is given to the piece. At this stage the decision is made about which configuration is to be used and the piece tapered to give either the left or right sloping surface the dimensions of the base of the bridge or nut being made.

The height of the piece is then established by placing the bridge or nut on its base and planing away 


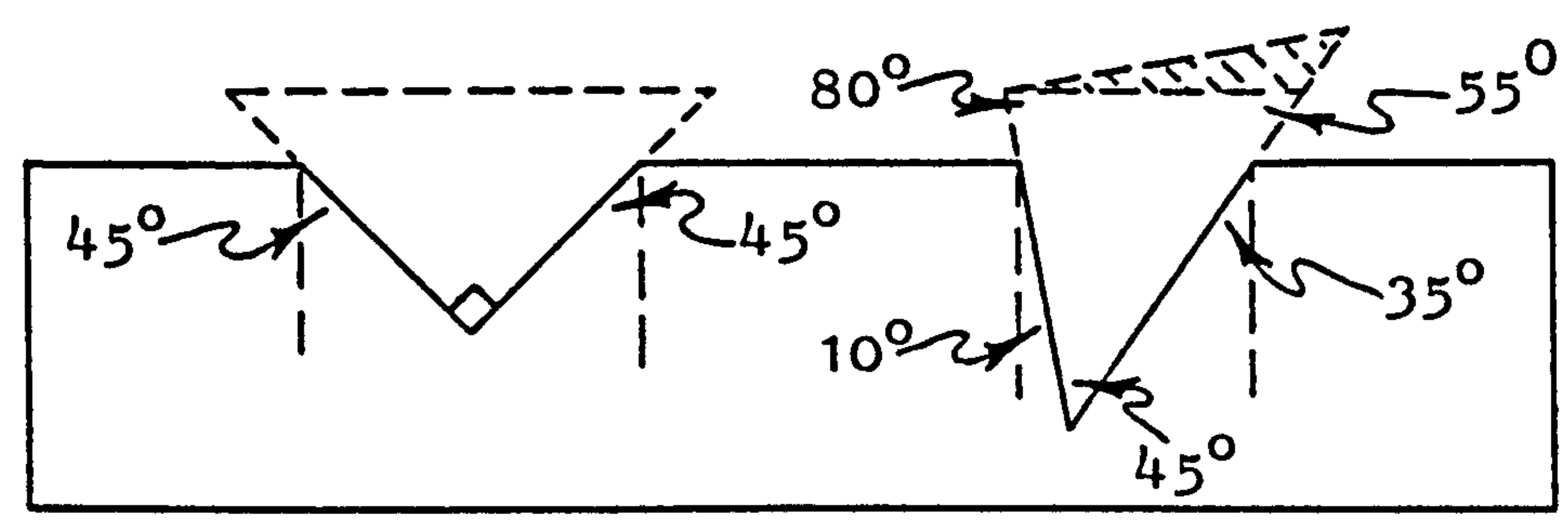

Fig. 6-9 Cross-section of a jig for making Ruckers bridges and nuts.

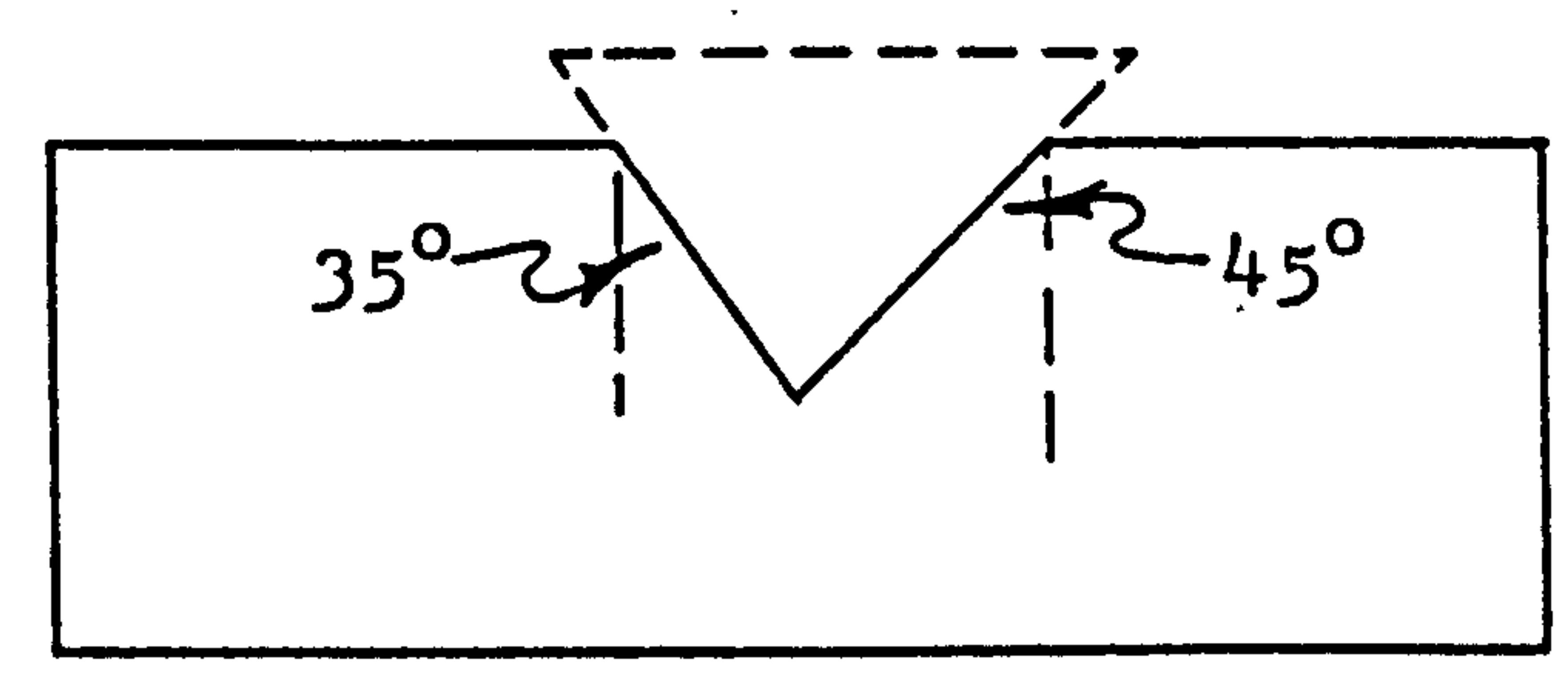

Fig. 6-10 Cross-section of the jig for shaping the sawn 8' bridges. 
the apex of the triangular cross-section until the required height was reached. It is not_clear whether the chamfer was given to the piece at this stage, or whether the top surface was. left flat and parallel to the base. The latter possibility, which would have more bearing surface for clamping to the soundboard or wrestplank, also facilitates drilling the nut or bridge pin holes. Also the lack of any construction or marking out lines on the top of the bridge may mean that the marking out and drilling of the pin holes was done when the top surface of the bridge or nut was flat, and then later chamfered away removing any construction marks in the process.

Although the sawn 8 ' bridges have surfaces angled the same as the straight nuts and $4 '$ bridges (and lefthand bridges in virginals) the use of the type of jig just described is not as convenient with a curved sawn bridge as with a straight one. However, since the only configuration which seems to have been used for the 81 sawn bridges in harpsichords and virginals is the type (a), adding one more slot to the jig as in Fig. 6-10, enables even the curved bridge to be placed in the jig and a spoke shave or compass plane used to smooth and taper the sides of the bridge after the $55^{\circ}$ surface has been sawn out.

The sharp lower edge of the rear sloping surface of the bridge or nut was removed to provide a small bearing surface for the positioning pins used to hold the bridge in place during glueing to the soundboard. Pairs of positioning pins, one on either side of the bridge or nut, 
were placed at or near the notes ' $c$ ' and ' $f$ ' intervals throughout the compass. It would seem that, even in the case of the sawn bridges, the shape of the bridge was altered slightly by bending it to give the desired scalings and then held in its final position by the positioning pins. At any rate the curved shape of the 8 ' nut and 4 ' bridges were maintained during glueing by these pins.

A number of clues exist which suggests the method used by the Ruckers to position the bridges to give the desired scalings throughout the compass of their instruments, but not enough evidence seems to exist to work out how they laid out the bridges and nuts in detail. As with the virginals there is $\dot{a}$ considerable variation in the string scalings from instrument to instrument and from one maker to another. This again suggest that, like the virginals, the bridges were positioned as well as possible to give the correct scalings, and then the pin positions were determined, not to give precisely uniform scalings, but to space the strings accurately relative to one another and to the jacks and quills to insure the correct mechanical performance of the instrument.

Ruckers harpsichords have a number of construction marks on the soundboard which seem to have been scribed before the bridges were glued in position. These marks consist of a heavy pin-prick indentation in the soundboard wood with a short scribed line running away from it. These marks can always be found corresponding to the played note 
$c^{1}$ (in the normal double manual harpsichord, the lower manual $c^{\prime}$ ) for both the $8^{\prime}$ and $4^{\prime}$ bridges. But in many instruments a number of other notes which are always either a played ' $c$ ' or ' $f$ ', are also marked on the soundboard. Sometimes the pin-prick indentation is covered over by the bridge and only the tail of the scribed line is visible. In all cases the positions of the pin-prick marks on the soundboard correspond precisely with the pin-prick on the register(s) for the notes ' $c$ ' and ' $f$ ', when the register end is held against the spine. It thus appears that, whatever their number, these marks were positioned relative to the spine and have no direct bearing on the separation of the nuts and bridges and therefore on the scalings. This is further borne out by the fact that the marks are not always covered by the bridges as they would be if they had been used to determine the scalings, when they would be directly under the bridge pin positions and therefore not visible.

After the position of the ' $c$ ' and ' $f$ ' strings. relative to the spine had been marked out on the soundboard, the intended position of the nut and bridge pins must somehow have been determined by measuring out from the nameboard, upper belly rail, or perhaps one of the rows of jacks. I have found that the bridge pin of the pitch 'c' note ( $c^{2}$ at 8 ' pitch) is always within a fow millimetres of $49 \mathrm{~cm}$ (19 duimen) from the back of the nameboard, whether the instrument is a double-or singlemanual harpsichord. This would suggest that at least 
the bridge pin postions, if not those of the nut were measured out from the rear surface of the nameboard. However, none of the other notes seems to be as accurateIy or consistently located relative to the nameboard, and certainly none of the marked ' $c$ ' or ' $f$ ', played notes in the bass has a bridge pin which seems to be in a uniformly accurate position relative to the back of the nameboard. Also in double-manual harpsichords, it is the position of the played note'c' on the lower manual which is located by the positioning holes, and not pitch 'c'.

Nonetheless, I foel that the intended bridge pin positions of the ' $c$ ' and ' $f$ ' notes were probably marked out on the soundboard relative to a seference line which may have been the back of the nameboard, and that these marks are now covered over by the bridges (unfortunately I have never had the opportunity of seeing a bridge removed from a Ruckers soundboard, nor do I know of anyone who has). It seems ilkely that the positioning holes beside the bridge were then located relative to these marks which determined the scalings to ensure that the bridge and bridge pins would be positioned as closely as possible over the marks. However, because the bridges were slightly non-uniform because of being hand made, the line of bridge pins was not always located at the same position relative to the side of the bridge. Thus when marking out the bridge pin positions relative to the spine, the pin position may have been slightly ahead of or behind its intended position, especially in the tenor and bass where the 
bridges run at a very oblique angle, and a slight sideways shift in the string position would greatly alter the position of the pin along the bridge.

This would then explain two interrelated characteristic features. Firstly, the position of the treble bridge pins (including that of the pitch 'c' bridge pin) relative to the nameboard would be relatively uniform, because of the large angle between the treble bridges and the strings. Secondly, because of the small angle between the strings and bridges in the tenor and bass, the scalings and positioning of the bridge pins relative to the nameboard is rather non-uniform. Also, for the same reason, the final position of the bridge pin may be considerably different from that actually marked on the soundboard and the actual bridge pin positions may not be exactly boside the pairs of bridge positioning holes. Hence although the positioning holes beside the bridge are always found very close to the ' $c$ ' and ' $f$ ' bridge pins in the treble, they may be a semitone or more away from these notes in the tenor and bass. The nuts seem also to have been similarly positioned on the wrestplank. There are also holes for pairs of positioning pins for each of the ' $c$ ' and ' $f$ " notes throughout the compass.

The method of clamping the bridges and nuts to the soundboard and wrestplank during glueing remains a complete puzzle. Experiments were made which combined the positioning function of the pairs of pins beside the bridges with a clamping function. This worked well for the nuts on the 
wrestplank where the pairs of pins were close together, but the interval between successive sets of pins was too great in the tenor and bass of the bridges to ensure adequate clamping in between the pairs of positioning pins. Weights may have been placed on the bridges during glueing, or deep-throated clamps may have been used. Or, the necessary pressure may have been provided by 'go-bars' similar to those used in French 18th century workshops.6-10) After glueing the bridges to the soundboard, the bridges were nailed from below to the soundboard as insurance against the glue softening or breaking loose and releasing the bridges. In the early Ruckers harpsichords (1594 HR, $1608 \mathrm{AR}$ ) the nails used for this purpose were simply bits of heavy brass wire driven through the soundboard into the bridge and then bent over and hammered into the grain of the soundboard wood. In the later harpsichords small iron tacks were used for this purpose. Whatever their type, these nails were always driven into the bridges between the pairs of positioning holes to ensure that the nail would always be located centrally and not near one edge of the bridge, where it might break through one of the upper bridge sides $\left.{ }^{6-11}\right)$ The holes left by the pairs of positioning pins beside the nuts were usually plugged with small wooden nails although the soundboard positioning holes were always left open and unplugged. This is probably because the nuts are much closer to the player and the holes in the wrestplank are therefore more likely to be noticed than those in the soundboard. 
It seems likely that the bridge pin positions in harpsichords were marked out with the soundboard removed from the instrument to avoid interference between the end of the marking-out stick and the bentside. This could easily have been done by holding the spine side of the soundboard against a wall or vertical surface (in lieu of the spine) and measuring out, perhaps with a notched bar, the distance of the bridge pins from this surface. The nuts could have been marked out in the instrument without problems, but could also have been marked out in a similar way before the wrestplank was glued in place. After marking out, the holes for the bridge and nut pins could be drilled. The pins themselves could also be driven into position at this stage, although it seems more likely that this was not done until after the soundboard was glued into the instrument and the soundboard was painted (the presence of the bridge pins makes painting the soundboard most uncomfortable!).

Throughout most of the compass the strings are basically parallel with the spine . so that the position of the nut pins relative to the spine is the same as that for the bridge pins. In the lowest octave the strings run obliquely to the spine, being pushed away from the spine at the ends of the bridges. This allows the bridges to stop well short of the spine liner and allows as much freeIy vibrating soundboard area at the bass ends of the bridges as possible. In some instruments the treble strings also angle slightly away from the cheek, probably 
for a similar reason. Not surprisingly, different instruments of a given type built at roughly the same time by the same maker have bridge and nut pins at the same relative position to the spine, indicating that the Ruckers had a standard method of spacing the strings. These instruments do not, on the other hand, have equally consistent scalings - which seems in turn to reflect the method just described used to locate and pin the bridges.

As has been mentioned before the same string is used to play the notes of the two manuals sounding a fourth apart in double-manual harpsichords (for a detailed description of the double harpsichords with manuals which were probably a tone apart, see Chapter 8, p. 505). If the instrument is tuned in meantone, eleven of the strings in each octave will be properly tuned to the correct pitches for both manuals. However, in meantone tuning with an $e^{b} / g^{\#}$ wolf, the $g$ " on the ' $f$ ' keyboard is pitched about $4 / 10$ of a semitone $\left(41\right.$ cents) below the $e^{b}$ on the 'c' keyboard. Consequently, in each octave the two keyboards require 11 shared strings plus two separate strings, one for each keyboard. If the 12 th string were shared also the player who had correctly tuned the ' $f$ ' keyboard would have an unwanted $\mathrm{d}^{\#}$ on the ' $\mathrm{c}$ ' keyboard. Correctly tuning the 'c' keyboard would involve retuning this $d^{\#}$ to an $e^{b}$ but this would produce $a^{b}$ on the 'f' keyboard. The use of two separate strings avoids the necessity of retuning when changing from one keyboard to the other.

The essential component which enabled two strings to 

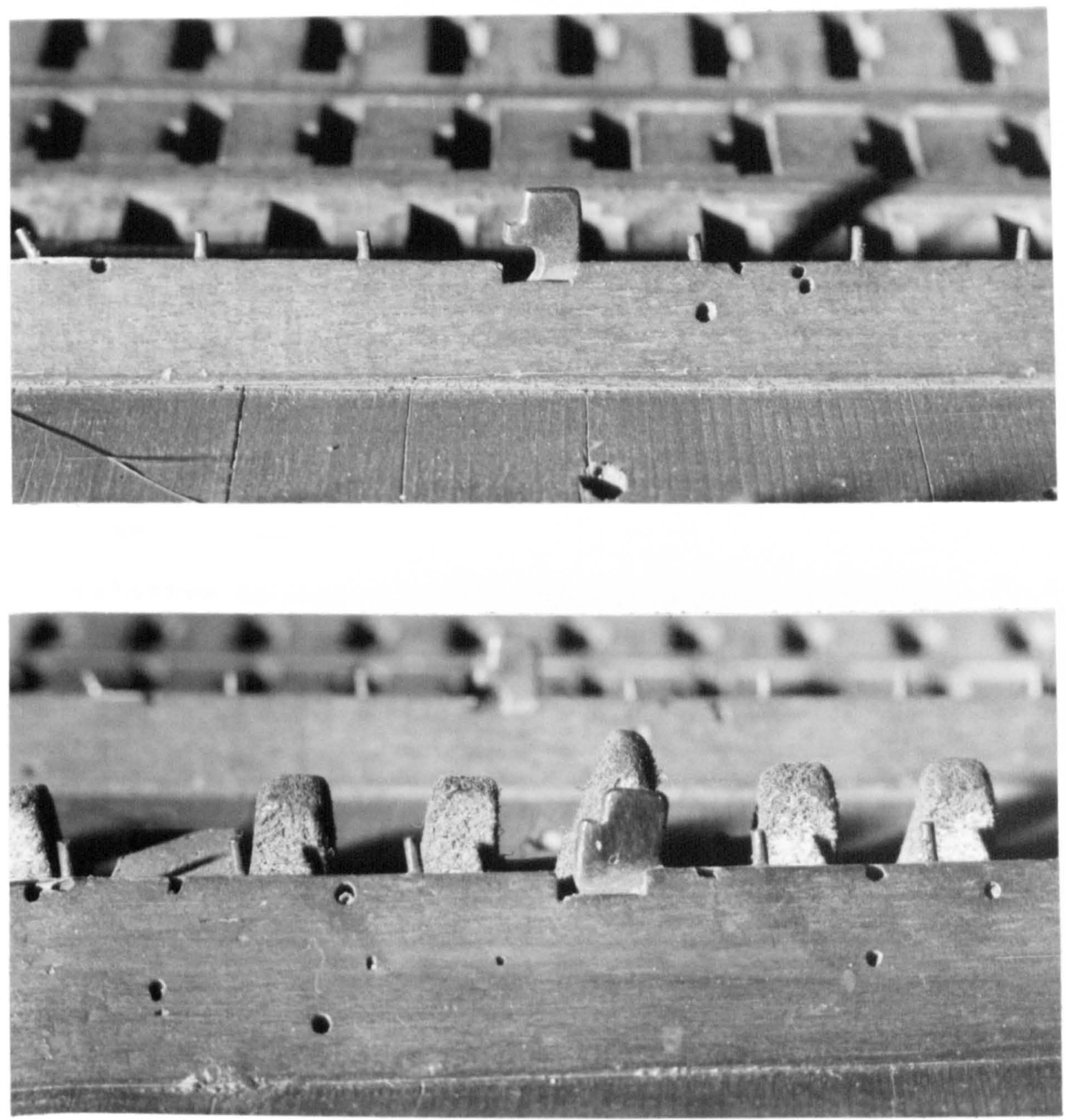

Photo 6-6 The 4' (above) and the 8' (below) transposing plates for the e/g" strings on the $1615 \mathrm{AR}$ double-manual harpsichord. 
be used for these notes and avoid the need for retuning when going from one manual to another consists of a small brass plate which is driven into a shallow notch let into the nuts at the position of the $e^{b} / g^{\#}$ strings in each octave. The brass plate is notched with indentations which are used to locate the two strings with both a slight horizontal and vertical displacement relative to one another. This displacement is greatest at the nut and gradually decreases along the length of the strings until, at the bridge, fitted with a pair of the usual bridge pins, the strings have only a slight horizontal displacement relative to one another.

since the pitch of the $e^{b}\left(a^{b}\right)$ string is slightly higher than the $\mathrm{g}^{\#}$ string (see Appendix 7), it seems 1ike1y that the $e^{b}$ string was cho sen to be the slightly shorter string placed at the right of each double pair (see Fig. 6-11). The height of the jack and the length of the quill were adjusted so that the jacks plucking the higher strings had long quills which could not drop low enough to pluck the low strings. The shorter jacks also had shorter quills which were not long enough to pluck the higher strings during the upward travel of the jack. The dampers of these shorter jacks also had to be adjusted so as not to interfere with the higher strings. In this way the jacks" of each manual pluck only the strings at the pitch appropriate to them, and the re-tuning of the $e^{b} / g^{\#}$ notes is avoided.

After the bridges were glued to the soundboard and 
4 ' nut:

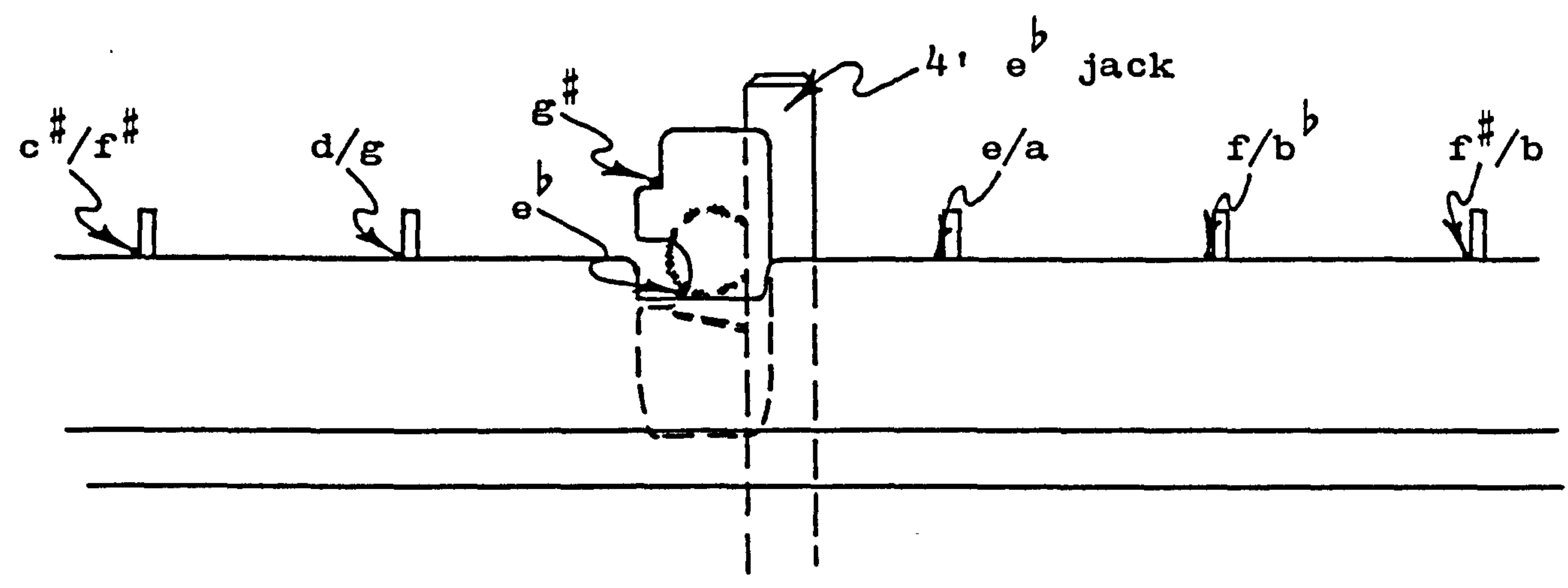

8. nut:

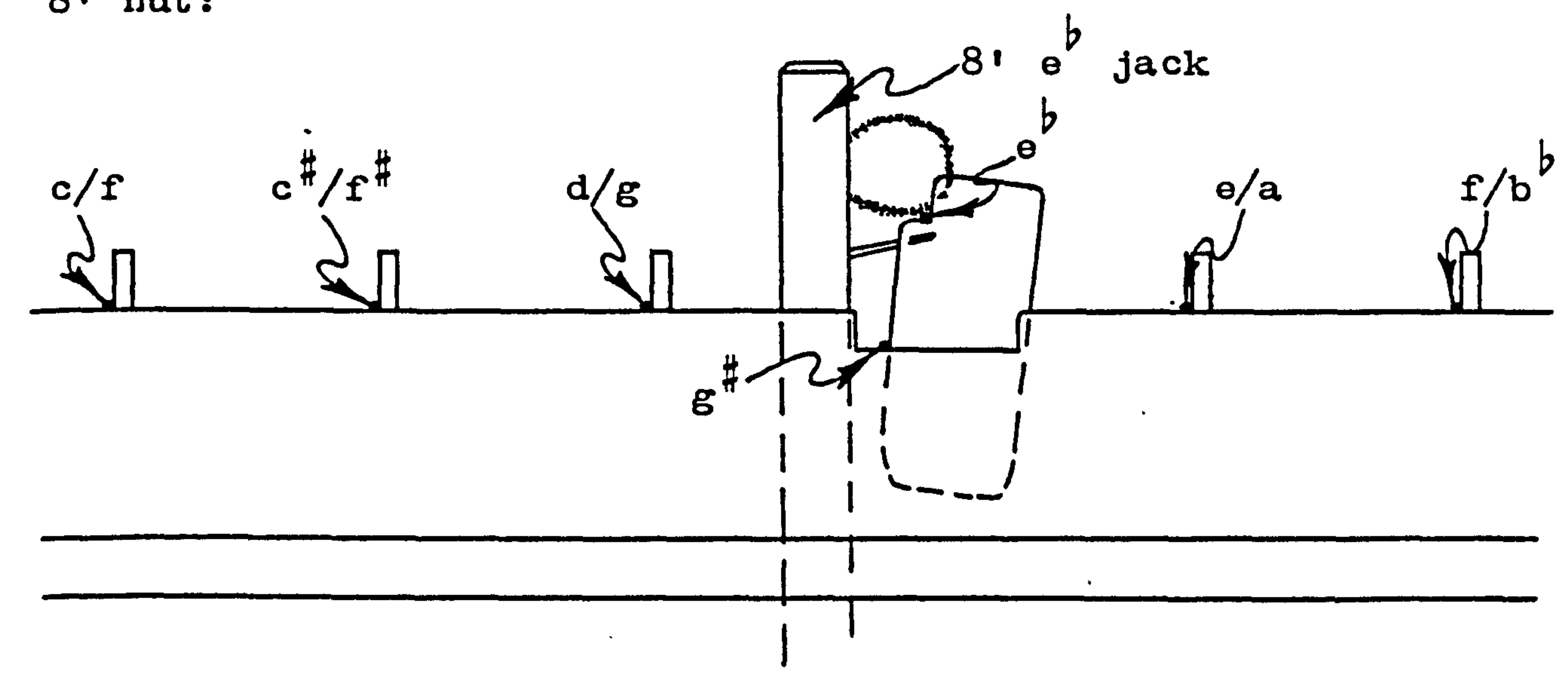

Fig. 6-11 The arrangement of the strings on the $e^{b} / g^{\#}$ transposing plates in the normal double-manual harpsif chord.ivar The figure shows the 4' nut and the 8' nut $A$ the plane of the strings. Oply the uppermanual ' $c$ ' keyboard jacks for the $\theta$ strings are shown; the lower-manual $g$ " jacks for the ' $f$ ' keyboard would be behind the jacks shown and would pluck the other string on the transposing plate.

Scale 2:1 
the bridge pin positions marked out and scribed, the soundboard was ready to be glued into the case itself. The drips of excess glue running down the insides of the case provide certain clues as to how this was done. It is clear from these glue drips that the case was the normal right-side-up when the liners were glued into position, and when the soundboard was glued to the liners and belly rail. However, the excess glue beside the edges of the 4' hitchpin rail in contact with the soundboard does not run down the sides of the hitch rail. This seems to indicate that the 4' hitchpin rail was glued onto the soundboard before the soundboard was glued into the instrument. Most Ruckers harpsichords have at least one wooden peg (usually in the treble) driven through the soundboard into the 4' hitchpin rail along the line of the 4 ' hitchpins. The hole for this peg was probably drilled after the position of the 4' hitchpins had been scribed onto the top of the soundboard (see p. 292), and after the soundboard and hitchrail had again been placed temporarily in their final position in the instrument. With the soundboard up-side-down the hitchpin rail could be glued to its lower surface using the positioning peg(s) and the previously scribed line under the soundboard along the side of the 4' hitchpin rail to locate it in the correct position. The excess glue squeezed out from between the surface of the soundboard and hitch rail would thon collect and lie beside the 4 ' hitchpin rail without moving any further as is observed. 
Before the soundboard was actually glued into its final position the cheek liner and the belly rail were cut away near the treble ends of the bridges and 4' hitchpin rail to reduce the surface in contact with the soundboard, and thus to increase the effective area of radiating soundboard in the extreme treble. The increased flexibility of the soundboard and the added area of radiating surface provided by shaving away the liner and belly rail are very important to the production of good tone in the extreme treble notes. In some instruments the spine liner is also cut away near the ends of the $8^{\prime}$ and $4^{\prime}$ bridges and this also has the effect of improving the response of the extreme bass of the instrument.

The only direct evidence of how the soundboard was glued into the instrument is provided by the wooden pegs through the soundboard into the upper belly rail. These are small (3 mm) pegs located at intervals of 5 to 6 duimen ( 125 to $156 \mathrm{~mm}$ ) along the edge of the soundboard near the gap. Because of the flexibility of the thin soundboard along the edge, these pegs could not have been the only means of holding the soundboard to the belly rail during glueing. The most likely method of doing this would seem to be to nail a batten temporarily over the edge of the soundboard to provide the necessary rigidity and stiffness to hold the soundboard against the belly rail. After the glue had dried the batten and nails could be removed and the nail holes plugged with the small wooden pegs. It has not been possible to determine whether the 
edges of the soundboard resting on the liners were glued down in a similar fashion since these are covered by the soundboard mouldings. These mouldings are also pegged every 5 to 6 duimen to the soundboard and liners, but it seems unlikely that the mouldings were glued to the soundboard at the same time as the soundboard was glued to the liners and, in the process, used to provide the stiffness and pressure necessary to hold the soundboard against the 1iners. Such a double glueing operation would be so complicated that the glue on the liners would have partially set before the soundboard mouldings could be positioned and pegged. It therefore seems most likely that the edges of the soundboard were glued to the liners with previously prepared battens nalled over the soundboard edges, and the soundboard mouldings later glued and pegged to the soundboard in a separate glueing operation. $6-12$ )

It has not been possible to determine the exact stage of construction at which the bridge and nut pins and the 4 ' and 8' hitchpins were driven in place. In both cases they are of brass and the size of the pin used is graded according to the function it has.to serve. The 4 ' bridge and nut pins are about 0.9 to $1.0 \mathrm{~mm}$ in diameter and are slightly smaller than the $8^{\prime}$ bridge and nut pins which are 1.1 to $1.2 \mathrm{~mm}$ in diameter. Similarly the 4 ' hitchpins are about 1.3 to $1.4 \mathrm{~mm}$ and the 8 ' hitchpins, 1.5 to $1.8 \mathrm{~mm}$ in diameter. The hitchpins are bent over slightly to prevent the strings from slipping off them. In double-manual instruments there are two hitchpins placed side by side 
for the $e^{b} / g^{\#}$ paired strings. Even in altered instruments, plugged holes will usually be visible in the line of 4 ' hitchpins, and the existence of these paired pins or the plugged holes for them on all Ruckers harpsichords (except the1612a HR) known originally to have been doubles is proof that the keyboards were not aligned and thus that none of the surviving Ruckers doubles originally had aligned keyboards.

There is a slight down-draught in the strings throughout the compass of both bridges since the 4' strings are hitched at the soundboard level, and the $8^{\prime}$ strings are hitched to the soundboard moulding/hitchrail, which is only about $6 \frac{1}{2} \mathrm{~mm}$ high throughout its length. Unlike many 18 th century instruments this moulding is not made higher in the bass to reduce the large downward pressure on the bridge from the heavy bass strings. The hitchpins are also usually located to give a side-draught of about 5 degrees, except for the bass octave of $8^{\prime}$ strings. The notes $\mathrm{C} / \mathrm{E}$ to $\mathrm{C}(9$ notes) in short-octave instruments, or the notes $C$ to $c$ in single or $G_{1}$ to $G$ in double (13 notes in both cases) instruments with a chromatic bass octave are back-pinned on the ' $^{\prime}$ bridge. The strings for these back-pinned notes run straight back to the hitchpins usually without any side-draught, although occasionally the very lowest bass notes are pinned so that there is á slight side-draught pulling the bridge toward the spine instead of away from it as the side-draught in the rest of the strings does. None of the 4' strings is back- 
pinned.

Harpsichord registers

The upper registers guide the jacks and position them relative to the strings. Each register consists of two parts: a "comb" between whose teeth the jacks move up and down, and a capping piece which forms one side of the register (and covers the openings at the end of the teeth in the comb). The wood used is beech (Fagus sylvatica) cut on the quarter so that the quartered wood figure is visible both on the top and bottom surface of the registers, and on the side formed by the capping piece. Because of their obvious importance to the correct mechanical operation of the instrument the registers were made with a care, skill and accuracy equal to that exhibited in the construction and preparation of the soundboard, nuts, and bridges.

The entire row of jacks may be engaged or disengaged by moving the register and with it, the jacks, toward and away from the strings. In the 'on' position the quills are positioned under the strings and pluck the string when the corresponding key is depressed; in the 'off' postion the quills are withdrawn from their position beneath the strings and the quills and dampers no longer make contact with the strings although the jacks rise and fall when the keys are depressed. The only original disposition indicated by a study of the extant harpsichords of the Ruckers family is $1 \times 8$, $1 \times 4,6-13)$ Thus the singlemanual instruments have only 2 registers while the doubles have 4 with one $8 '$ and one 4 ' on each manual! $6-14$ ) 
All the registers from one instrument were marked out together before the individual sections were cut apart. Longitudinal scribed Iines on both the top and bottom surface of the registers mark the ends of the jackslots. Pinpricks, probably made using the same notched bar postulated for the pinning of the bridges and nuts, are visible along the near edge of the near register (register 1). These pin-pricks occur in pairs and could have been made by first pricking the positions of one side of the jackslot and then moving the notched bar along by an amount equal to the width of the jackslot and then pricking the position of the other side of the jackslot, or the two pricks were made simultaneously with a double pointed marking tool. Knife cuts about $1 \mathrm{~mm}$ deep pass through these pin pricks, and these cuts were presumably made by holding a square along the edge of the register plank to ensure that the cuts were paraliel to one another and perpendicular to the long direction of the registers. Since the 4' and 8' registers were marked out simultaneously, the $4^{\prime}$ and $8^{\prime}$ jackslots (and jacks) are therefore all of the same thickness.

At this stage of the marking out the board must have been cut apart into the individual register strips, and the sawn surfaces planed flat and smooth. The sides of the jackslots were sawn so that they opened outward toward the bottom of the register at an angle to the perpendicular of about $13^{\circ}$. The sawcuts were made slightly inside the knife cut marking the two sides of the jackslot so that 

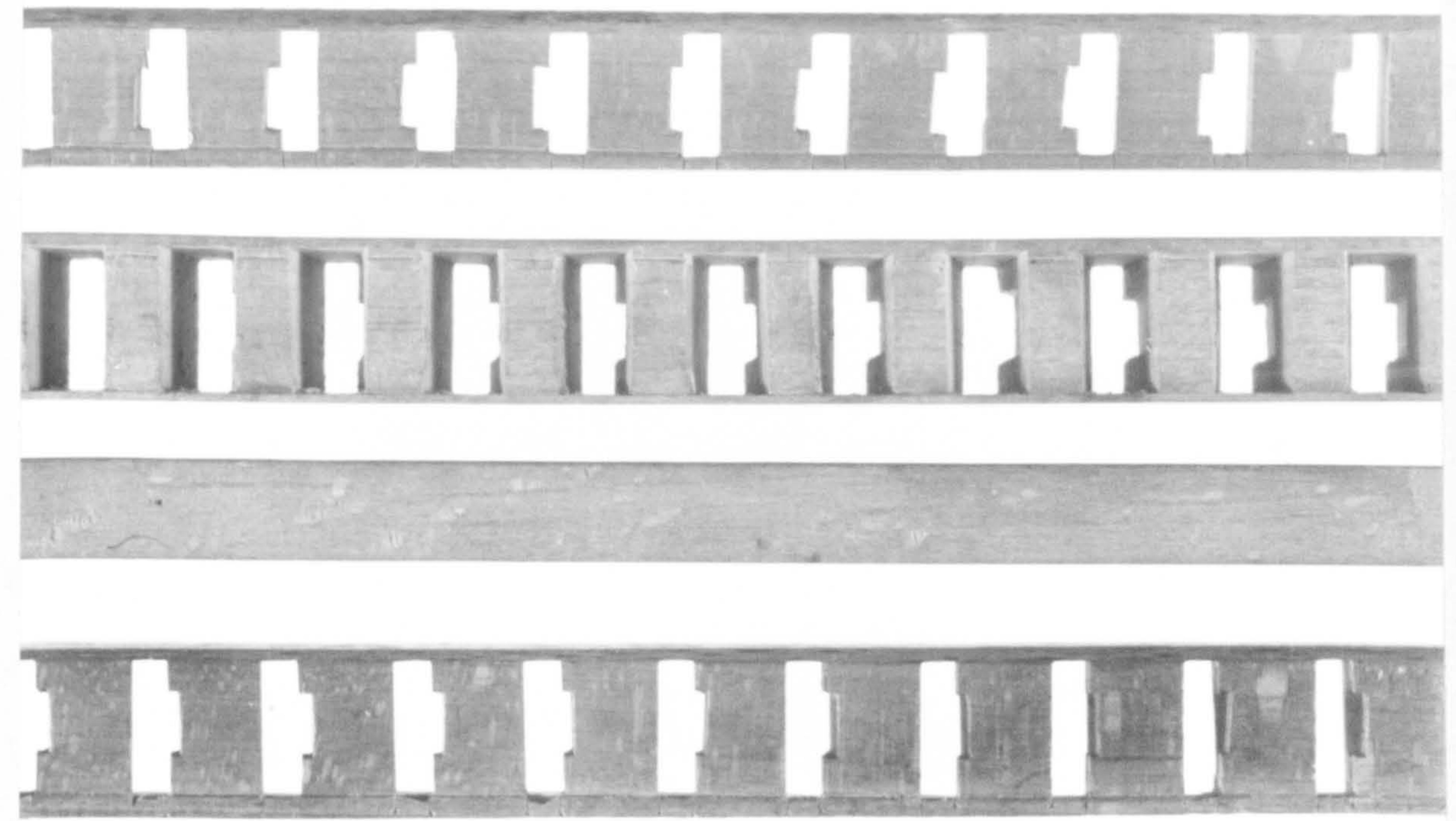

Photo 6-7 Typical Ruckers harpsichord upper registers (1638a IR). From top to bottom the photo shows: the top view of a 4' register; the bottom view of an 8 ' register; the capping piece on a 4' register; and the top view of the near $8^{\prime}$ register showing the pin pricks and knife marks used in the marking out of the registers. Scale $1: 1$

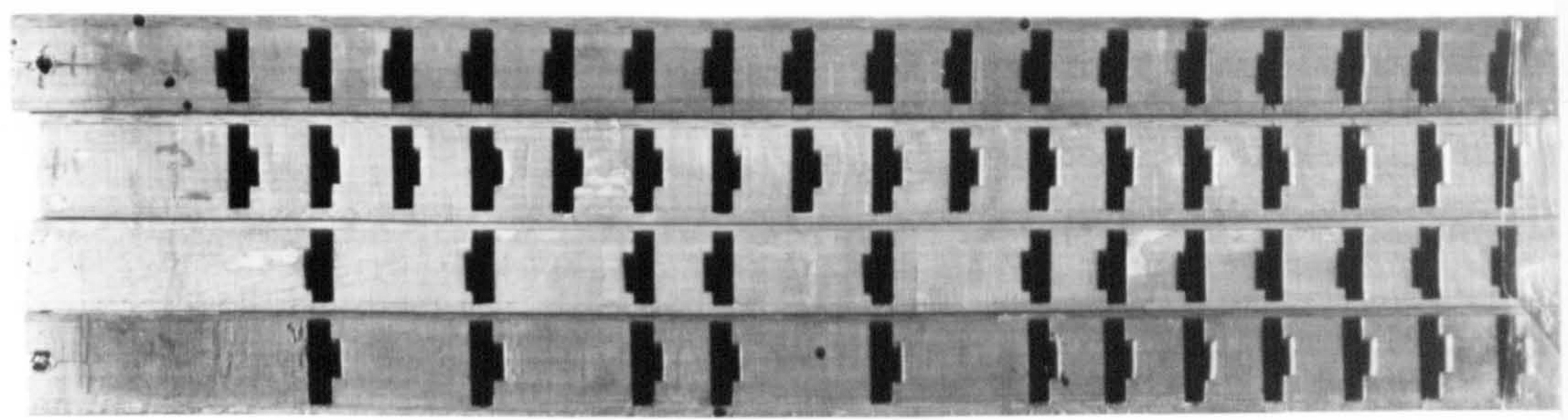

Photo 6-8 The arrangement of the bass jackslots in the registers of a normal double-manual harpsichord ( $1638 \mathrm{~b}$ IR). 
the knife cuts were not quite touched by the saw. The accuracy of the width of the jackslot opening is therefore determined by the accuracy of the marking out with the knife and not the accuracy of the sawing. The width of the jackslot openings is thus very constant along the register, and this width even from instrument to instrument and maker to maker varies between the relatively narrow limits of 3.6 to $3.8 \mathrm{~mm}$. The block remaining between the two sawcuts in the middle of the jackslot was cleared away and the side of the slot cleaned out to bear against the edge of the jack.

Because of the way in which the lower guides are constructed (see below) the space between the rows of jacks at the level of the lower guide is greater than that at the level of the registers. Thus the rows of jacks converge into the jackrail and are splayed apart at the level of the keys. Because each row of jacks rises at a different angle through the registers, the ends of the jackslots in each register are angled to suit the angle of the jacks passing through them. In a double-manual harpsichord, for example, the outer ends of the jackslots of the first and fourth registers are more steeply angled than those of the two inner registers.

The wrestplank veneer overhangs the far edge of the wrestplank and the soundboard overhangs the near edge of the upper belly rail by about $2 \mathrm{~mm}$. The registers in the gap between the wrestplank and the upper belly rail are partly covered by this overhang on each side. In order to 
prevent the jacks from binding against the wood overhanging the gap, the near and far sides are made wider than the other sides of the registers.

Thus, because of the as ymetrical way in which the registers are constructed, it is possible to determine the original order in which the registers were placed in the instrument. Also the registers were 'numbered' by a series of punch marks near the left-hand end of the registers. The near register has one punch indentation, the second has two, and in doubles the third has three and the fourth - the farthest from the player - has four indentations. Each. jackslot is recessed on one side with an almost vertical slot opposite the jack tongue, which ensures that the tongue does not bind on the side of the jackslot when the jack returns to its rest position. These tongue recesses are placed in the middle of the jackslot for the 81 jacks with 2 dampers and near to one end of the jackslot for the as ymetrical 4 ' jacks with only one damper. The difference in the positioning of the tongue recess as well as the narrower nature of the 4 ' registers enables one to distinguish the 4 ' from the 8 ' registers.

In all cases in which the original registers remain it is clear, both from.the punch indentations on the ends of the registers and the angling and width of the end wall of the jackslot, that the 4 ' register was placed nearest the soundboard and the 8 ' register nearest the player, A!so, the rogue recesses (as well as the original pinning of the bridges and nuts) indicate that the 4' jacks plucked 
to the left and the $8^{\prime}$ jacks plucked to the right. This then establishes the original disposition of Ruckers harpsichords which is, in single manual instruments:

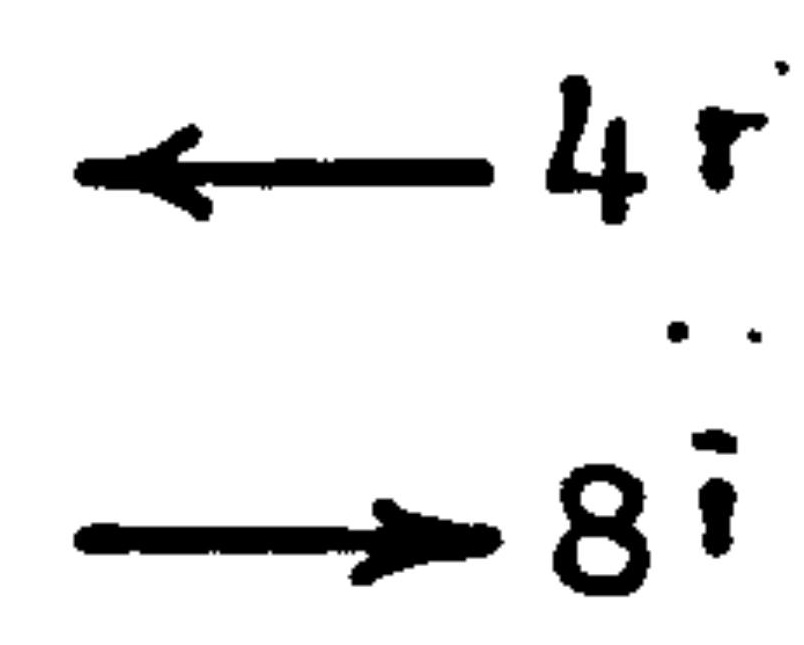

and in doubles:

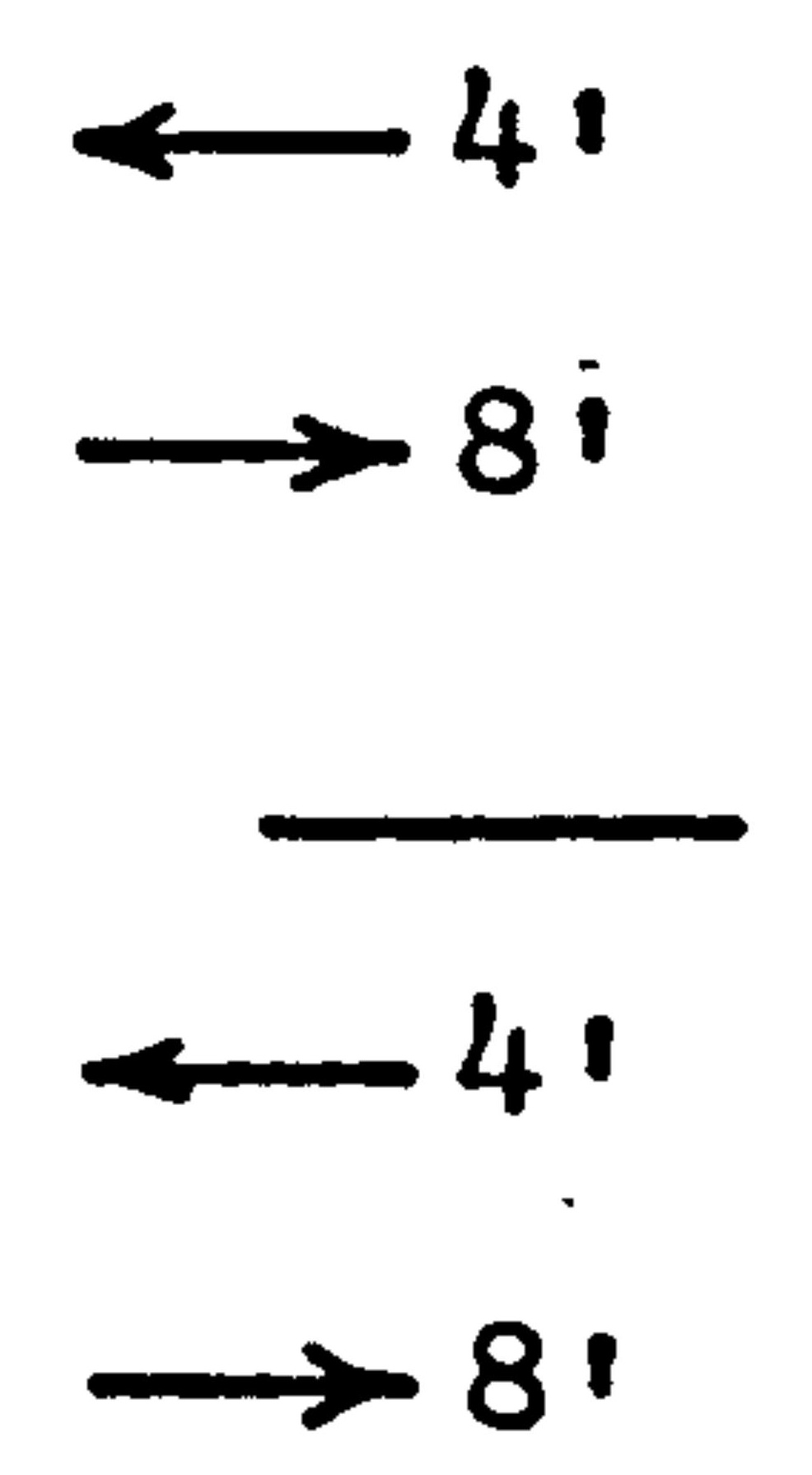

Except perhaps for the $1612 \mathrm{a}$ IR double (see p. 509), no original Ruckers instrument is known to me which indicates an original disposition other than these, although some of the late Couchet instruments are obviously exceptions

Because of the cranking down of the keys in the upper manual of the normal double-manual harpsichord (see p. 343), caused by the interweaving of the short-octave on the two manuals, the upper-manual registers have to be made specialIy to suit the particular note arrangement found here. The upper-manual and lower-manual pitches are compared in the diagram below;

Lower-manual register:

C F D G E A B B c $\mathrm{B}^{b} \mathrm{~d} \boldsymbol{\theta}^{b}$ ef $\mathrm{f}^{\#} \mathrm{~g}^{\#} \mathrm{a} \mathrm{b}^{b} \mathrm{~b}$ c... Upper-manual register:
C D $\quad E$ F $\quad$ G $A B^{b} B c \cdot c^{\#} d e^{b}$ e $f f^{\#} g \cdot \cdot \cdot$

Thus the slots of the upper-manual registers are interspersed with blank spaces in what at first appears 
to be a random pattern, (see Photo6-8). This arrangement is necessary only on the normal short-octave instruments and would not have been necessary on the extended compass instruments (1616 HR, 1627c IR, 1628b IR and 1646b AR) with a chromatic bass octave, although the original registers have not survived on any of these latter instrument. A possible arrangement of the register slots in the instrument postulated to have its keyboards a tone apart in pitch on $p .510$ and (1612a HR) is given in Appendix 7 .

A detail found on most, but not all, sets of original registers is a number of pin-pricks on the top of the register near the tongue recess for selected notes throughout the compass. The 1638 IR and the 1640b AR doubles have pin-pricks on the lower manual 8' register for the played notes $c, f^{\#}, c^{1}, f^{\# 1}, c^{2}, f^{\# 2}, c^{3}$ and $f^{3}$; the 1637 AR single has pricks on both the $4^{\prime}$ and $8^{\prime}$ registers for the notes $C / E, c, f^{\#}, c^{1}, f^{\# 1}, c^{2}, f^{\# 2}$, and $c^{3}$. In the latter case the pin-pricks are each on the same side of the jackslot as the corresponding tongue recess.

These pricks are all very close to $3.6 \mathrm{~mm}$ from the position of the side of the jack on the 1638 IR double manual lower 8 ' register. Like those on the virginal registers these pin-pricks seem to indicate the position of the string relative to the jack, and thus indirectly the length of the quil1. Assuming that the same distance applies to the 4' register, then the total space between successive $4^{\prime}$ and $8^{\prime}$ strings is just equal to the space occupied by the quilis and jacks with the $4 '$ and 8 ' 
registers in exact alignment. One can check this as follows: the space between successive 8' strings is determined by the 3 -octave span and is equal to $\frac{500}{36}==13.88$ mm. The space between the $4^{\prime}$ and $8^{\prime}$ strings for adjacent notes varies between 2.8 to $3.0 \mathrm{~mm}$ and averages about 2.9 mm. Therefore if the 4' and 8' registers are accurately aligned, then the space occupied by the quills, jacks and strings 1s:-

$$
\begin{aligned}
& 3.6 \mathrm{~mm} \\
& 3.6 \mathrm{~mm} \text { space occupied by the quills } \\
& 3.8 \mathrm{~mm} \text { width of the jacks } \\
& \frac{2.9 \mathrm{~mm} \text { separation of the } 81 \text { and } 4 . \text { strings }}{13.9 \mathrm{~mm}} \text {. }
\end{aligned}
$$

Therefore with the $4 '$ and $8^{\prime}$ registers in exact alignment the jacks in a Ruckers harpsichord should be centred in the space between the $8^{\prime}$ and $4^{\prime}$ strings of the same note. This practice of aligning the registers probably is a continuation of the old tradition found in the early Germanic and Flemish harpsichords. In these instruments (e.g. the 1537 Mtller and the 1579 Theouwes harpsichords) the jack slots are pierced through the soundboard in straight rows centred between the strings for each note.

As with the virginals the total plectrum length depends upon the amount the tongue is recessed behind the side of the jack and the amount the quill projects beyond the string. The existence of the register pin pricks does, however, give at least some idea of the quill length used in that the jack-to-string distance $(3.6 \mathrm{~mm})$ is known, and this 
compares with the corresponding distance of $3.6 \mathrm{~mm}$ in most virginals.

The ends of the registers project through a hole pierced in the cheek, and the registers/engaged and disengaged by reaching around to the side of the instrument and pulling or pushing on this register extension. The extension of the register, consisting of the part inside the cheek and the part which projects about $20 \mathrm{~mm}$ beyond the cheek, is covered on its top surface with a bone plate similar to the bone used for the key touchplates. Near the very end of the register the bone and wood are pierced with two round holes of diameter 4 to $4.5 \mathrm{~mm}$. Cords or ribbons of cloth or leather passed through these holes to assist the grasp of the player turning the register on or off.

The lateral motion of the register involved in moving it from the on to the off positions is controlled at the treble end of the register. Tuning pins, usually the same size or slightly smaller than the 4' tuning pins, are positioned through the middle of each register just inside the cheek surface into the cheek liner which spans the gap and extends under the wrestplank. Slightly oval or rectangular slots in the registers around the tuning pins allow the register a small lateral motion and determine the 'on' and 'off' positions.

In order to hold the registers in the positions required by the player a beech or poplar block or register yoke covered with soft sheeps leather on its lower surface is placed over the registers next to the cheek (seo 
Photo 6-9). Notches are cut in the side of the block so that the block does not interfere with the pins driven into the registers and cheek liners. The ends of the block are slightly recessed underneath so that the lower leathercovered surface extends down to the top of the registers slightly below the level of the soundboard and wrestplank veneer. Two hand-made screws through the ends of the block into the wrestplank and cheek liner (these are the only screws that would be found in an original Ruckers harpsichord) provide a variable amount of friction between the leather and the top of the registers. This friction is regulated by turning the screws in or out until it is sufficient to hold the register in position during playing, but not enough to prevent it being moved on and off as desired by the player:

The bass ends of the registers are covered with a smaller poplar block positioned against the spine over the gap. This block is fixed permanently in position with a small brass nail at either end, This bass register yoke does not touch the registers, but serves to prevent dust and foreign objects from entering and fouling the space between the ends of the registers and the spine. The punched indentations numbering the register are normally hidden underneath this bass register block.

As well as being supported at the cheek and spine the registers are held between two pairs of wires which span the gap. The upper wire is in the shape of an inverted 'U' staple which is driven into the top surface of the 


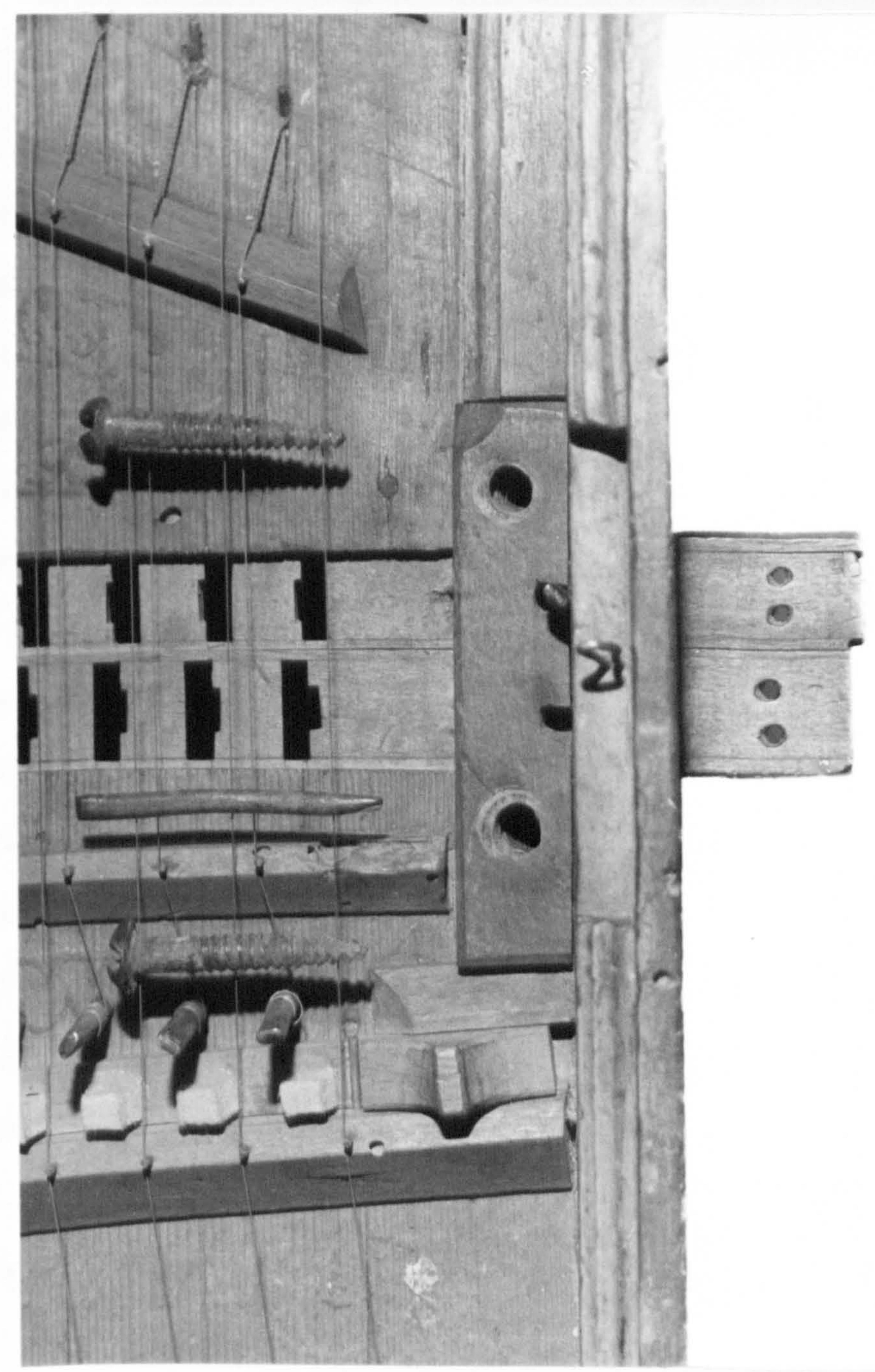

Photo 6-9 The treble arrangement of the registers in a Ruckers harpsichord (1637 AR). The bone plates normally covering the register projections are missing; otherwise the arrangement is original. 
wrestplank at one end and the top of the belly rail at the other before the wrestplank veneer or soundboard are glued into position. The lower wire is driven through a hole in the side of the belly rail into the far edge of the wrestplank at a distance below the top surface corresponding to the depth of the registers. Clearly these wires are located along the gap at positions between the jacks so as to avold interference with the mechanical operation of the instrument.

- The lower guides in Ruckers harpsichords are very similar to those already described for the virginals. They consist of a thin board of poplar or soundboard wood from 2.5 to $4.5 \mathrm{~mm}$ thick which is covered on its upper surface with sheeps leather 1.5 to $2.0 \mathrm{~mm}$ thick, and on its lower surface with parchment. The jackslots are pierced through this combination of materials. The parchment helps to reinforce the weak short-grained wood between the individual jackslots. The wood provides the basic structural rigidity of the lower guide and supports the upper layer of 1eather. The wood is cut away under the leather jackslot so that the leather alone bears on the sides of the jacks guiding them noiselessly as they move up and down.

The lower guides are marked out in a manner very similar to that of the upper registers. Longitudinal lines along the length of the leather mark out the position of the ends of the 4' and 8' jackslots. A series of paired pin-pricks along the player side of the lower guide marks the position of the sides of the jackslots, and must have 
been made using the same mothod as the pin-pricks on the near uppor rogistor which serve the same purpose. As with the sides of tho jackslots in the upper registers, the jackslot sides in tho lower guide seem to have been marked out with a kenffe gulded by a sot square held against one of the long sides of tho lower guide itself. In the case of the lower guldes however, tho knffo cuts do not extend across the whole wldth of tho guido. Tho knifo cuts are made only along the side of the jackslot itself and do not extend between tho 81 and 4 ' rows of jackslots or from the pinpricks to the 8' jackslots. Often, however, one sees a small nick in the surface of the leather through the pinprick where the knifo was linod up with the prick bofore being moved down to cut the side of each 4 ' and 8' jackslot. Often tho knife cut slightly overshoots the far end of the jackslots indicating that this side of the lower guide was nearest to tho person cutting the slots.

After the leather, and perhaps the top surface of the wood, was cut with a knife, the jackslot holes were punched through the wood and lower layer of parchment with a chisel. The upper belly rail of the 1627 AR quint harpsichord was used as a backing piece during the cutting of the lower guides, and it shows shallow chisel marks made when the jackslot holes were punched through, a fortunate accident since it gives detailed information about the cutting process. These marks show that the sides of both the $4^{\prime}$ and 8' jackslots were cut with the same chisel; two cuts were made on the sides of the wider 81 jackslots in order to 

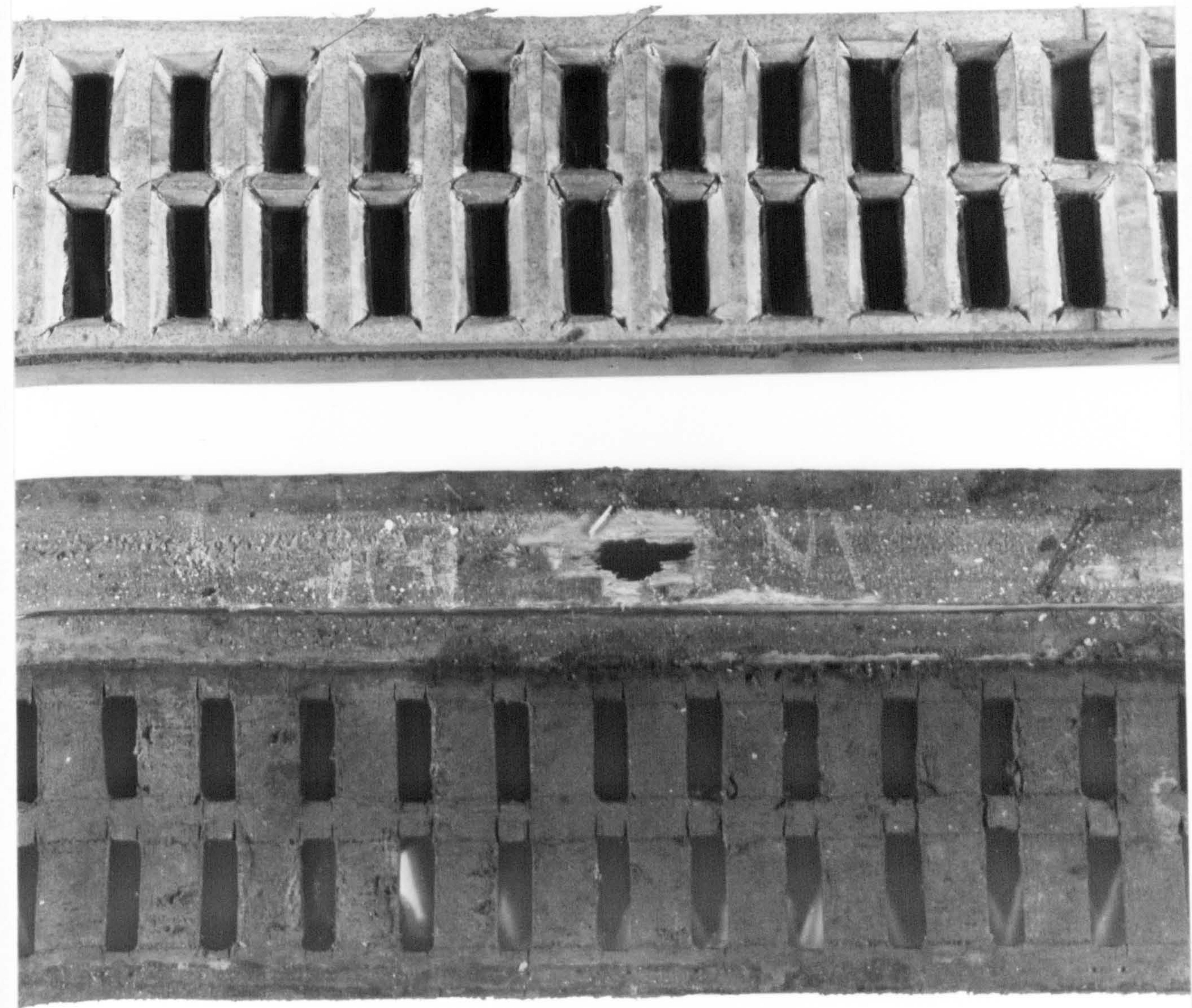

Photo 6-10 The upper-manual guide (above) and lowermanual (below) lower guides from the 1618b IR double-manual harpsichord. 
cut the full length of the jackslots. As seen on the backing piece most of the cuts for the sides of the jackslot are parallel, but a number of the jackslots appear as cuts which are not parallel and either diverge or converge in the jackslot opening. This indicates that both sides of the jackslots were not cut simultaneously with a double set of parallel chisels. Instead, each side of the jackslot was cut separately with a single chisel, and sometimes a slight rotation of either the backing piece or the lower guide itself between cutting one side of the jackslot and the other caused the observed irregularity in the backing piece marks. Clearly the knife cuts made previously in the upper leather surface would serve to guide the chisel in piercing the sides of the jackslots. The ends of the jackslots were cut separately with a narrow chisel. The pattern of chisel cuts on the backing piece suggests that the ends of the jackslots were cut in one operation, the sides in another since there is a marked misalignment of the end and side cuts at one end of the register. In both cases the cuts were made vertically however, as the width and length of the jackslot cut marks on the belly rail are the same as the width and length of the jackslots in the lower guide itself. Experience has shown that the chisel used to cut these slots must be sharpened with a cutting ard supporting edge with an angle much less than the usual $20^{\circ}$ or so, in order to avoid causing cracks in the shortgrain botween the jackslots.

After the vertical cuts were made and the wood and 
leather plugs were removed from the jackslot holes, the lower guide was turned over and the holes were opened out by angling all four sides of the jackslot, apparently with a knife. This was done so that all of the wood and the lowest portion of the leather was angled, leaving only the leather part of the jackslot with vertical sides. Thus the jack touched nothing but the leather part of the jackslot. Because the ends of the lower guide jackslots open out underneath, a certain minimum distance must be left between the rows of jacks in the lower guides in order to ensure sufficient structural strength in the wood between the jackslot rows. Usually at least $6 \mathrm{~mm}$ is left between the $4^{\prime}$ and the 8 ' row of jackslots. This is considerably more than the distance between the ends of the successive jackslots rows in the upper registers and this is the reason that the rows of jacks are further apart at their feet which, in turn is the reason that the belly rail must be angled.

The lower guide in single-manual harpsichords is glued and nailed to the lower edge of the:belly rail and sits on top of and is nailed to the keyblocks at its ends. A rectangular bar is glued to the top of the lower guide along the near edge to add stiffness and rigidity.

In double manual harpsichords also, the lower manual lower guide is nailed and glued to the lower edge of the belly rail. But in doubles the guide is let into and nailed to the top surface of the keyblocks and the stiffening bar is attached to its lower surface, both of these changes 
being necessary to allow the upper manual to slide along the top of the keyblocks and overlap the edge of the lower guide without interfering with it at the rear. Wooden pegs angled through the ends of the stiffening bar into the sides of the keyblocks under the lower guide further secure and support the lower manual guide. The upper manual guide is nailed to the lower surface of the deep cheek liner and to a block glued underneath the spine liner. Both edges of the upper manual guide are stiffened with reinforcing bars. The near bar is roughly $14 \mathrm{~mm}$ square in cross-section and similar to the one used on the lower manual guide. But the bar on the far edge of the guide, which must be squeezed between the 4 ' row of jacks of the upper manual and the 8' row of jacks of the lower manual must be very narrow to avoid interference with the jacks. It is usually only about $2.5 \mathrm{~mm}$ thick and often tapered to half this at its top edge.

Keyboards and keybeds in harpsichords

The single-manual keyboard and the lower-manual keyboard in double-manual Ruckers harpsichords are.constructed in a manner very similar to the virginal keyboards. The poplar keys, guided at the rear in a rack, are placed on a keyboard consisting of a rectangular half-lapped poplar frame. The frame is usually $12 \frac{1}{2}$ to $13 \mathrm{~mm}$ : thick, and each half-lap joint is glued and pegged together with 2 or 3 small pegs. The rack is placed near the rear edge of the frame, and is also glued and pegged to the keyframe. The slots in the rack which guide the pins, in the ends of the 
keylevers widen into the wood of the rack and are triangular in shape when viewed from above. The top of the rack is sloped upwards from back to front, and is capped with a thin ( $4 \frac{1}{2}$ to $5 \mathrm{~mm}$ ) piece of poplar or poor quality soundboard wood. This capping piece is nailed to the rear portion of the top of/thack and overhangs the front of the rack by about $12 \mathrm{~mm}$. It serves, with several layers of woollen cloth attached to its lower surface, to limit the upward motion of the tails of the keys. It has therefore been called the upper touch bar. The height of the touchbar above the keyframe is usually somewhat greater in the bass than in the treble. Because of the greater overall flexibility of the strings in the bass which is a result of their length, the jacks must raise the bass strings further before they pluck. Thus the jacks and keylever tails must move further in the bass than in the treble, and this, in turn, can only happen if the rack is also slightly higher in the bass than in the treble.

The balance rail is placed on the near board of the keyframe. A line is usually scribed on the keyframe to locate the position of one edge of the balance rail. The 1615 AR lower manual balance rail still has two metal pins beside the balance rail, driven into the scribed line, and presumably used to locate the balance rail during glueing. Similar positioning 'pins must have been used to locate the nuts and bridges during glueing, and then later removed, leaving the characteristic holes behind.

The single-manual and double-manual lower keybed are 
held in place at the rear by two chamfered blocks glued to the side of the lower belly rail (or the near toolbox brace) under which the keyframe slides when the keys and keybed are put in position in the instrument. The front of the keybed is held in position by two keybed hold-down blocks which are the same thickness as the keyframe. These are. located beside the keyblocks on the baseboard along the near edge of the keyframe, and prevent it from sliding toward the player. A turnbutton with chamfered edges is fixed with a nail to the top of the hold-down blocks, and a wing of the turnbutton can be rotated over the top surface of the keyframe to hold it firmly against the baseboard.

The upper-manual keybed in doubles is quite different from that just described. The upper manual sits on top of the keyblocks and slides in and out of the instrument like a drawer. The keyblocks are an integral part of the keyboard and are carved with a characteristic scroll pattern at the near ends. These keyblocks are approximately the same thickness as the keyblocks beside the lower manual and are pegged and glued to the keyframe which consits

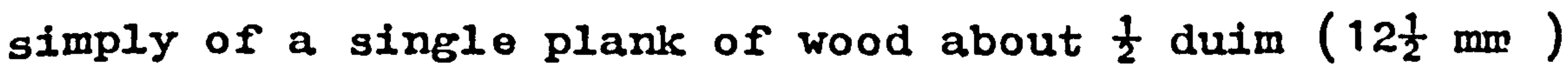
thick. The plank of wood is long enough to fit with a small clearance between the spine and cheek sides of the keywell, and extends in width from the front to the rear of the keylevers. Since there is no space at the ends of the keylevers for a rack, the upper manual keys are guided by iron pins located between the keylevers near their tails. These pins are iron wire rod about $2.0 \mathrm{~mm}$ in 


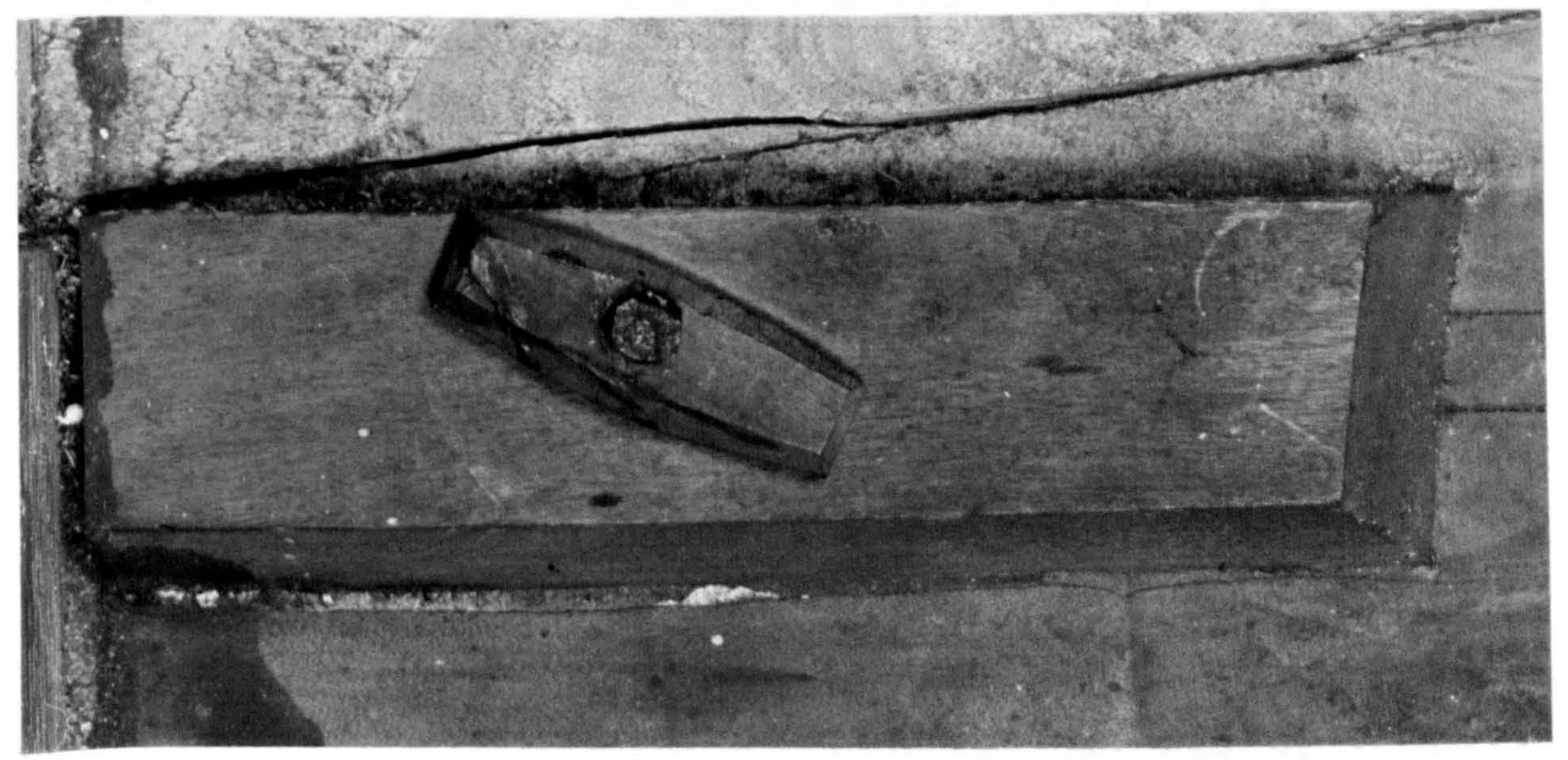

Photo 6-11 The keybed hold-down block and turnbutton for the bass end of the lower keyboard in the 1618b IR double-manual harpsichord. 
diameter driven into the keybed plank, and the sides of the keys are planed away to allow tho koylover talls just to pass between the successive pins with a small clearance. The limit of the upward motion of the tails of the keys is controlled, in the absence of the usual rack, by a rectangular bar which is lot into the top of tho upper manual keyblocks and spans the full wldth of the keybed between the keyblocks. This upper touch bar is placed over the tails of the keys, usually immediately behind the row of $2.0 \mathrm{~mm}$ guide pins between the keys. In order to prevent the middle of the rather flexible bar from bending upwards whon a large number of keys is depressed simultaneously, an additional piece of wire rod located between a pair of keys near the middle of the compass ties the upper touch bar to the keybed plank. This wire rod is bent over at its ends into the grain of the keybed plank and touch bar, thus preventing the touch bar from bending upwards.

In the normal, most common type of Ruckers doublemanual harpsichord, the upper manual is pitched a fourth higher than the lower manual. Both manuals begin in the bass with the usual short-octave and the compasses involved are $C / E$ to $c^{3}$ on the upper mamual, and $C / E$ to $f^{3}$ on the lower. Because of its more restricted compass there are 3 naturals less in the bass of the upper manual than in the lower manual, and the space for these naturals is occupied by a block of wood, moulded with an ovolo moulding and decorated with one of the larger block-printed paper 


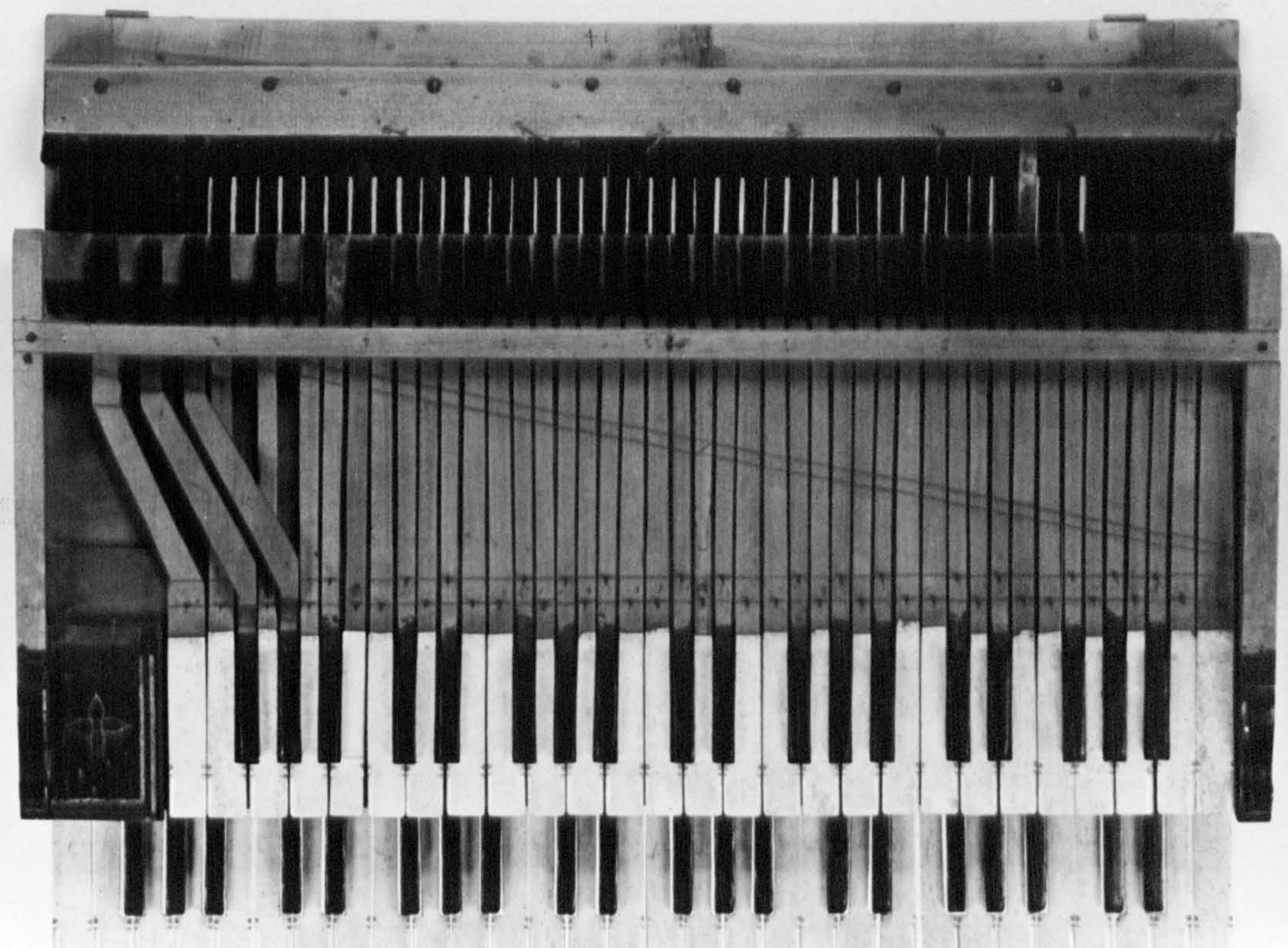

Photo 6-12 The original arrangement of the upper-and lower-manual keys in the 1638 b IR doublemanual harpsichord.

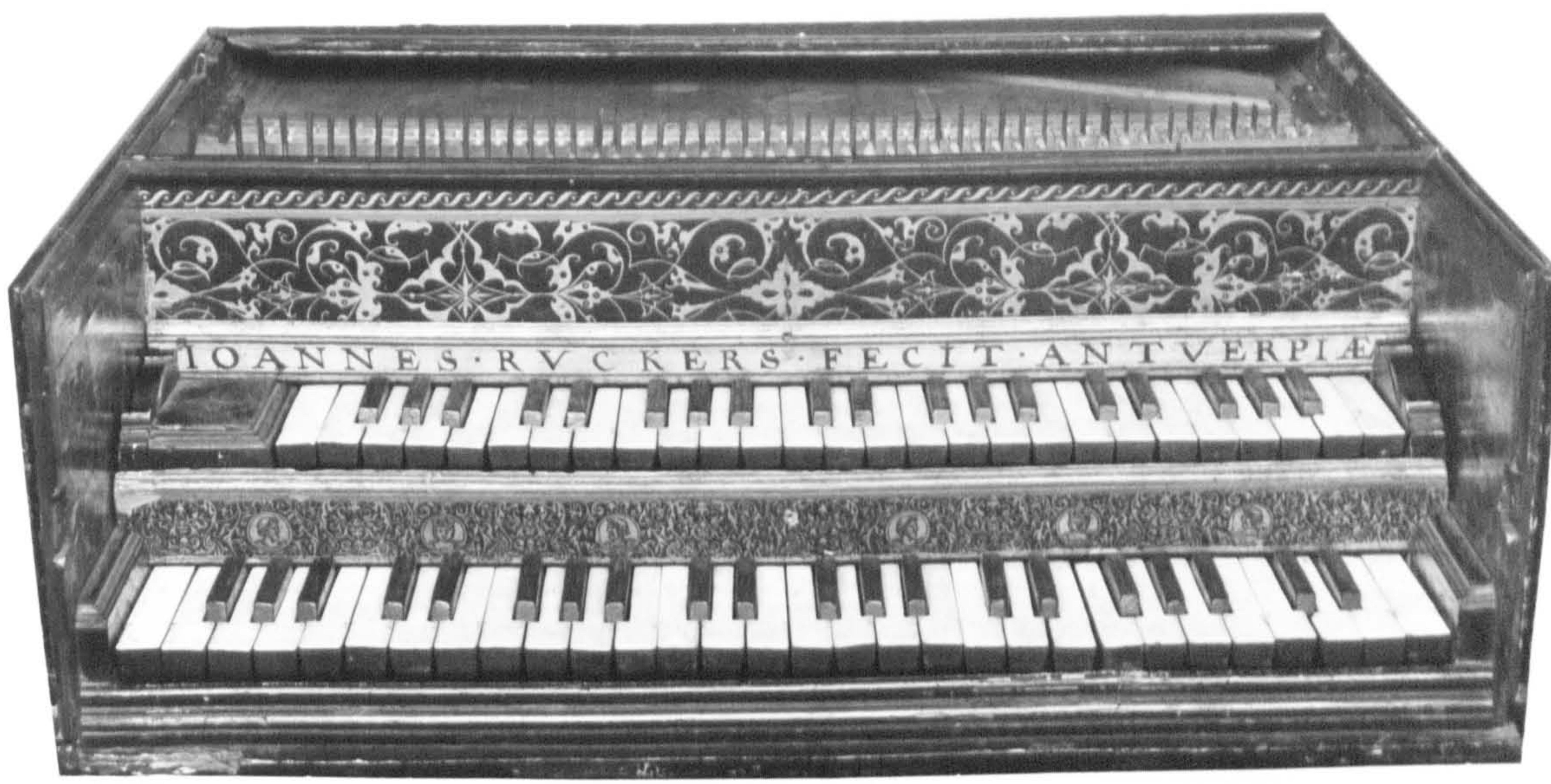

Photo 6-13 Keywell of the 1638b IR, showing the namebatten, papered lower-manual batten, the uppermanual bass block and the carved upper-manual k eyblocks. 
patterns on its upper surface.

The irregular sequence of the notes of the shortoctave on the two manuals produces a special problem in obtaining the required notes for the jacks of the upper manual from the pitches of the strings tuned to suit the lower manual. Schematically the situation at the tails of the keys of the two manuals is represented in Fig. 6-12. The notes of the lower manual with its short-octave bass tuning fills out the whole width of the keyboard. After the wooden block 3 naturals in width, the short-octave of the upper manual begins. But whereas the correct pitches for the upper manual (except for the $e^{b} / g^{\#}, s$ ) are available on the lower manual for the notes F, G, A and higher, the pitches for the upper-manual short-octave notes C, D and $E$ are found much lower down in the bass of the lowermanual keys and strings. In order that the upper-manual keys operate jacks which pluck strings at the correct pitch, they must crank down to the position of the lowermanual keys by an amount equal to the width of 4 keytails. The original arrangement used to achieve this remains only in the 1638 IR double and is shown in Photo. 6-12.

The extended compass doubles with a chromatic bass octave in both manuals ( $1616 \mathrm{HR}, 1627 \mathrm{c} I R, 1628 \mathrm{~b}$ IR and 1646b AR - the 'French' doubles) would not have required the cranked keys found in the normal double-manual harpsichords since the notes of both manuals follow in the usual sequence. A possible arrangement of the keys for the tone transposition scheme postulated for the 1612 IR double is 
(345)

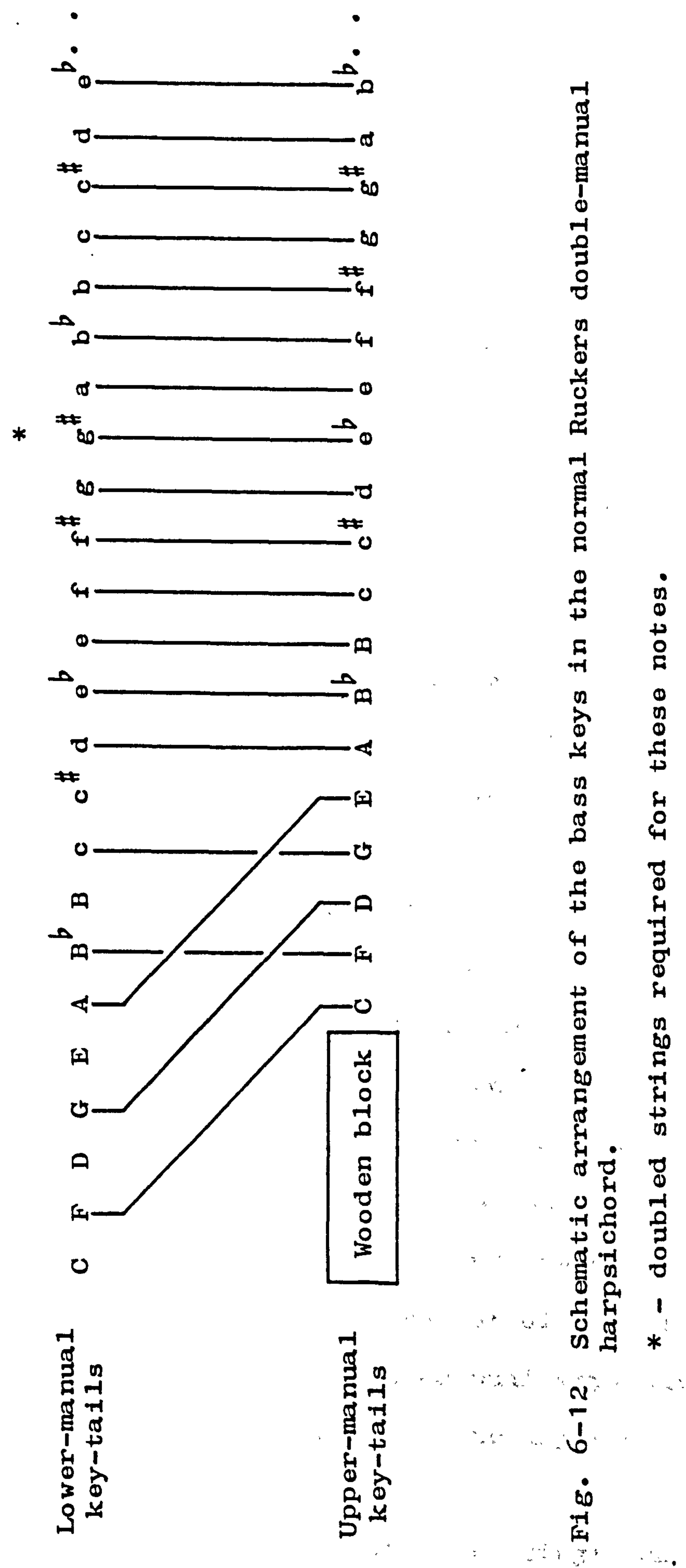


discussed in Appendix 7?

As mentioned previously, the upper manual slides in and out of the instrument on the top surface of the lower manual keyblocks. In order to prevent it from sliding too far back into the instrument a chamfered bumper block is glued to each case side under the gap and just above the lower-manual lower guide. Sometimes, a piece of the same buff leather used for the buff stop pads is glued to the edge of the bumper blocks to act as a buffer between the keybied and the bumper block. The upper mamal is prevented from sliding out of the instrument toward the player by the lower manual batten. This tapered batten, decorated with a block-printed paper pattern and a moulding, runs between the two keyblocks immediately behind and above the lowermanual keys. This batten slides into tapered slots in the keyblocks and is held in place by gravity so it is readily removeable. The back surface of the batten is located immediately in front of the upper manual keybed. Hence only when the batten is removed: can the upper manual be slid forward and out of the instrument.

The upper-manual batten, or namebatten, is similarly fitted into two tapered slots in the upper-manual keyblocks, and runs immediately above and behind the upper-manual keys. Although it is also easily lifted out of its slot, it only needs to be removed if the upper-manual keys have to be removed from the balance pins after the upper manual is slid out of the keywell.

The balance rails in double-and single-manual harp- 
sichordscan vary in width in different instruments from 35 to $50 \mathrm{~mm}$. They taper in height from the front down to the rear, at an angle which is slightly greater than the angle of the keys to the keybed in their rest position.

The single-manual and double-manual upper keylevers are made from a jointed plank of poplar about $\frac{1}{2}$ duim $(12.5$ to $13 \mathrm{~mm}$ ) thick, and the lower manual of a double, with much longer keys, is about 14.5 to $15 \mathrm{~mm}$ thick to give added stiffness to the longer keylevers. Except for the tails of the upper manual keys, both the front and rear ends of the keylevers are angled at $7^{\circ}$ to $10^{\circ}$ so as to make the top surface of the key longer than the bottom surface.

Before marking out the actual keys a number of 1ongitudinal lines were scribed on the keyplank to mark out a number of features. Lines near the front of the keyplank were used to mark, on the top and bottom surface, the cut for making the recesses in the naturals for the sharps. In single-manual harpsichords this distance y. is about

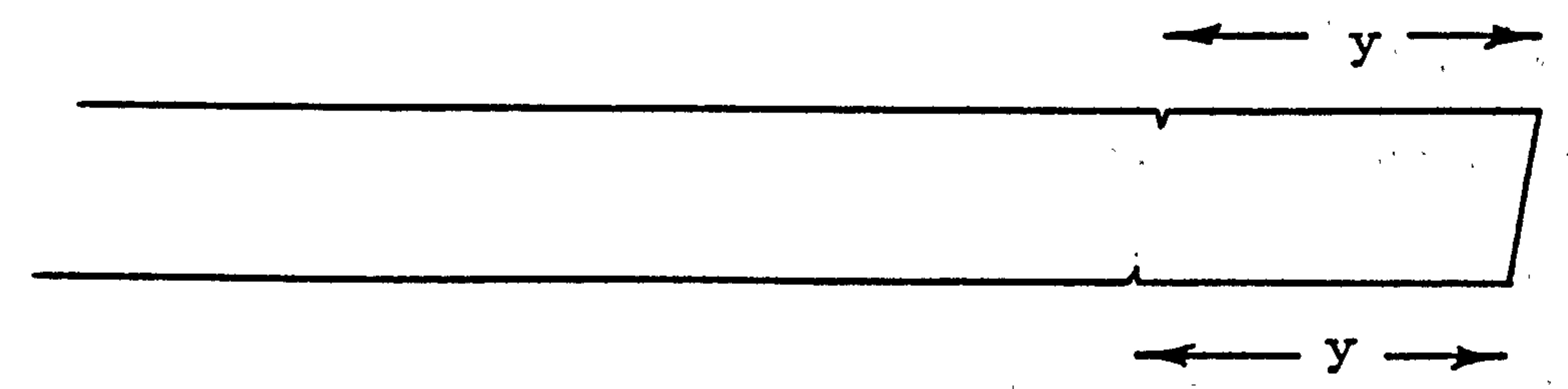

$33 \mathrm{~mm}$; in doubles $\mathrm{y}$ is about $27.5 \mathrm{~mm}$ for the upper manual and $29.0 \mathrm{~mm}$. for the lower manual, although individual harpsichords have values differing slightiy from these. Another line on the top surface, approximately 105 to 115 mm from the front of the keyplank, marks the end of the natural keyplates. 
Near the middle of the keyplank, two scribed lines mark the keylever balance points. The balance line for the sharps is about $13.5 \mathrm{~mm}$ behind the naturals balance line in singles and in double lower manuals, and about 16 to $17.5 \mathrm{~mm}$ in the upper manuals from double harpsichords. The balance pins are usually about $2.1 \mathrm{~mm}$ in diameter. The holes in the keys for the balance pins had to be enlarged to allow the balance pin to pass through readily, and to allow the keylever to rock about the balance pin. No evidence has been found to suggest how the balance hole was enlarged although the holes have been found to open out toward the top and the bottom, placing the pivot point half way up the thickness of the keylever. The location of the balance line along the length of the key is one of the most important factors affecting the feel or touch of the instrument under the fingers of the player. In order to compare the relative position of the balance point of different instruments by different makers, one can compare the balance ratio of the keylevers. "This can be defined as the ratio of the length of the front of the keylever, from the end of the natural!s touchplate to the natural's balance point, to the length of the rear of the keylever from the natural's balance point to the tail of the keylever. Defined in this way the balance ratio is just equal to the mechanical advantage of the keylever. $6-15$ ) The larger the numerical value of the balance ratio, the greater the mechanical advantage of the keylever, and the lighter the touch experienced by the finger of the player. 
For virginals the balance ratio has been found to bo botween 0.53 and 0.56 . For Ruckers harpsichords with 2 rows of jacks instead of the virginals' one row, the balance ratio must be somowhat greater to give the keys the same 'feel'. Single-manual and lower-manual harpsichord keyboards usually have a blance ratio of about 0.59 to 0.61 and the upper-manual keyboards a ratio of 0.53 to 0.58 or virtually the same as that for virginals.-16) These balance ratios have all been measured for the treble keys, but usually the balance rail and line of balance pins is slightIy angled so as to make the mechanical advantage of the bass keys less than that of the treble keys. The amount by which the balance rail is angled varies in different instruments, but the intention to angle the balance rail seems always to be present.

The reason for angling the balance rail in this way is unclear. In fact it seems the opposite of what one would logically do to achieve a uniform touch weight across the compass. The bass notes need a stronger plectrum requiring more force to cause them to pluck the string. Thus the mechanical advantage or balance ratio should be greater, not less, for the bass keys than for those in the treble in order obtain an even touch weight. One possible explanation of the angling of the balance rail in the way it has been done, is that it was an attempt to even out the depth rather than the weight of the touch across the compass of the instrument. Since the height of the rack is greater. in the bass than in the treble, the motion of the tails, 
and therefore the fronts, of the keylevers would also be greater in the bass than in the treble if the balance rail were not angled. Angling the balance rail has the effect of reducing the motion of the fronts of the keylevers in the bass, and therefore of producing the same depth of touch in the bass as in the treble. If this is indeed the reason for angling the balance rail, then the Flemish builders gave a greater importance to the uniformity in the depth of touch than to the uniformity in the force required to cause the jacks to pluck.

Behind the scribed lines for the balance pins there is usually a pair of lines running from the tails of the keys in the bass to the balance pin Iines in the treble. These lines serve to order the keys since, if one of the keys is misplaced on the keyboard when re-assembling them, its pair of oblique lines will be readily seen to be out of aligmment with the lines on the neighbouring keys. Keyboards which do not have these lines have keys which are numbered in ink behind the balance pin line for the sharps. The upper manual in the double-manual harpsichords also has a scribed line near the tails of the keylevers which marks the position of the guide pins between the keys. Usually the cloth glued to the top of the tails of the keys under the foet of the jacks begins at this line.

The keys were marked out at the front such that the 3-octave span is close to $500 \mathrm{~mm}$. Thus each of the 7 naturals in each octave occupies; on average; $\frac{500}{x 7}=23.81$ mm. The sharps are located so that the $d, g$, and " $a$ ": 
natural tails are about $11.5 \mathrm{~mm}$ wide after cutting out, and the $c, \theta, f$, and $b$ naturals are 15.5 to $16 \mathrm{~mm}$ wide. As with the virginals, this moans that it is virtually impossible for a player to get his fingers between the sharps to play the $d, g$ and a keys on the tails of the naturals. This has important implications for a study of the fingerings used by contemporary muslcians, and we must assume that such fingerings were perfectly convenient for contemporary music written for meantone temperament. Ruckers keyboards were, however, Inconvenient for later music, which explains why so many were replaced.

The tails of the harpsichord keys were marked out in a manner very simar to that used for the virginals. The keyboard plank was temporarily fixed to the keybed, probably using the balance pin holes after these had been drilled through the keyboard plank into the balance rail. The keyplank and keybed were placed temporarily in the instrument in their final position and a punch, which was inserted in both the 8' and 4' jackslots, made a double set of oblong marks along the rear of the keyplank. The

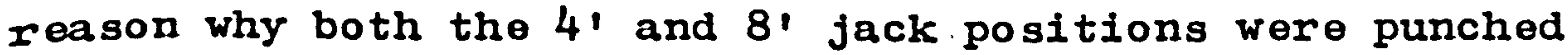
is unclear. It would be necessary to punch both only:if. there were considerable mis-alignment of the two $:$ Both w registers are alignod at the level of the lower guide, and, as has already been pointed out. (p. 328 of this section), the $8^{\prime}$ and $4^{\prime}$ upper registers seem to have been designed to be used in the aligned position. Therefore, the jacks are also completely aligned and the second punch mark 
seems to be redundant. However, the cloth strips under the feet of the jacks were glued over these marks after the keylevers were cut out. In most, but not all instruments, the cloth strips are glued only at their ends and not in the middle of the strip where the jack feet were actually resting. Perhaps both jack positions were punched simply as a gulde for gluelng these cloth strips in place. The position of the rack pin on the end of the keyIever was located along the centre line of the two punch marks on the keyplank, and the position of the slots in the rack were in turn probably marked out from the rack pin positions. This soems the most likely way to explain the fact that, although the rack slots are not uniformly spaced, they follow exactly any irregularity in the spacing of the rack pins. Presumably the lines for cutting the tails of the keylevers were marked out by spacing them midway between the punch marks made through the jackslots. But obviously any sign of this marking out has been lost in the process of cutting out and trimming the keys.

On the single-manual and lower-manual keyboards there is also a punch mark on the keyframe for the position of the 4' jacks for each of the top and bottom notes. The top and bottom rackslots line up with these marks on the keyframe and it seems likely that their purpose was in fact to position the rack and rackslots. "The position of the guide pins at the tails of the upper-manual keys must have been marked out and drilled after the key tails had been marked out, but before sawing out the keylevers. 
The sides of the keylevers were trimmed, probably with a spokeshave, after the keylevers were sawn out of the keyplank. A considerable amount of wood was shaved off the sides of the keylevers near their tails leaving relatively large gaps between the ends of the keys. More wood was removad from the lower part of the side of the key, both at the front and at the tail, giving the keylever a slightly trapezoidal cross-section. Characteristically a tiny sliver of wood was chamfered off the top edge of the tail section of the keylevers.

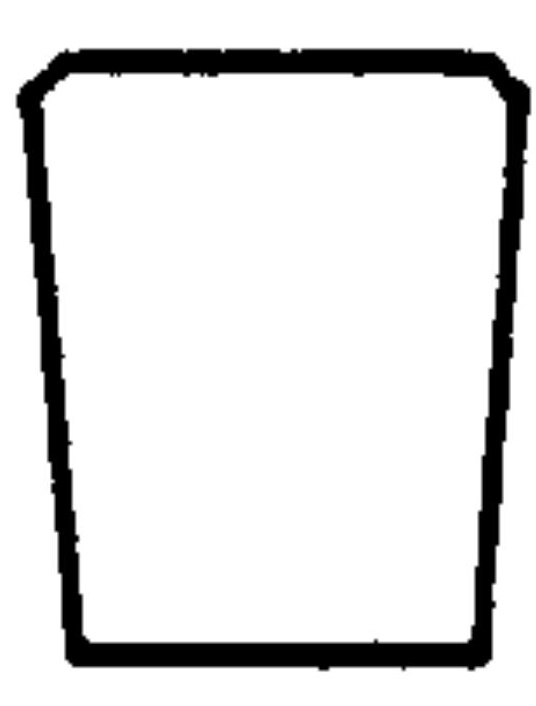

When the keys were being sawn apart and the sharp keylevers sawn out of the recesses in the natural keys a large amount of wood was removed from the near end of the recess. The absence of this wood means that the natural keyplates overhang the wood at the recess, and the sharps considerably overhang the front ends of their keylevers.

Like the virginals keys, the Ruckers harpsichord naturals keyplates are of bone and the sharps are of bog oak. The bone keyplates are 2 to $2 \frac{1}{2} \mathrm{~mm}$ thick at the front and usually taper in thickness to half this or less at the rear, and consist of one single piece of bone without a join between the head and tail sections. The front of the keyplate overhangs the wood of the keylever by about $2 \mathrm{~mm}$ and the embossed arcade (see Chapter 5, Photo 5-4) was glued to the sloping keyfront under the keyplate overhang. 

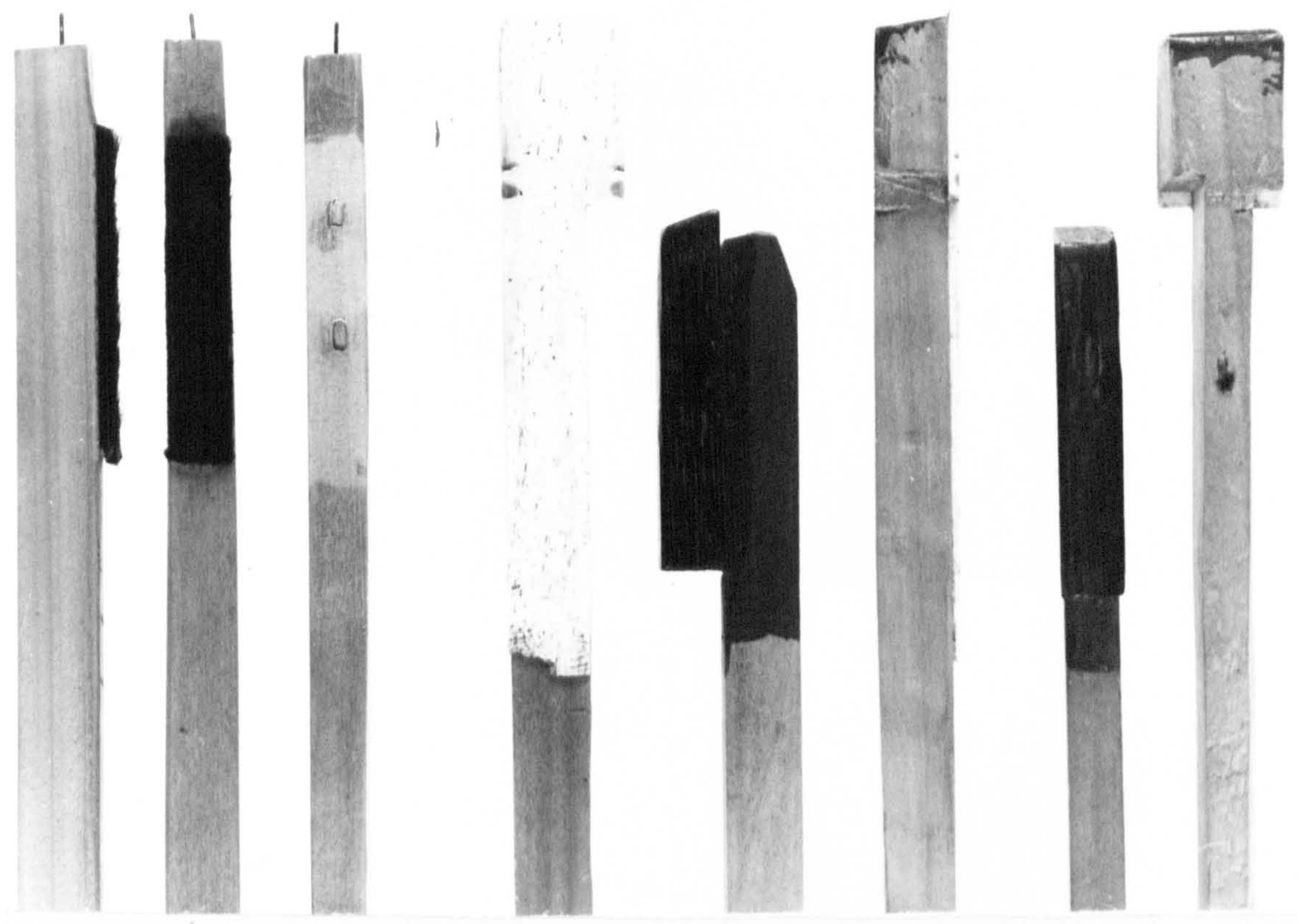

Photo 6-14 The keylever tails, natural touchplates and sharps from the lower manual of the $1638 \mathrm{~b}$ IR double-manual harpsichord. The black paint on the keylever sides below the sharps is not original - only the top of the keylever behind the sharps was originally painted black. 
Four decorative lines are scribed in the natural's keyheads just in front of the sharps, and a small elliptical nick was made with a round needle file between the middle two Iines on each side of the keylever. In double-manual harpsichords the length of the front of the touchplate, from the rear scribed line to the near edge, is about $2 \mathrm{~mm}$ greater for the lower-manual keys than for those of the upper. The top edges of the touchplates were bevelled along the front and up the side to the first decorative line, and the bevel and the front corners of the keyhead were rounded slightly before or during the buffing and polishing of the keyplates. The tails of the keypiates were lettered with the note-name of each natural key in a red material which may have been sanguine or perhaps a red dye or ink. The red pigment used to letter the keyplates was rather fugitive and evidence of the lettering of the keyplates is often difficult to find again, although traces usually exist on the littleused bass and treble keyplates. The virginal natural keyplates were also lettered with the note-names as were the naturals of most Italian instruments of this period.

The bog oak used for the sharps varies in colour from a dark brown umber to an almost black charcoal-grey, and this apparently reflects a difference in tho organic composition of the moor or bog in which the oak was found. The sharps are normally about 63 to $67 \mathrm{~mm}$ long, with very little difference botween those found in singlo-and doublomanual harpsichords except the upper-manual sharps are a few millimetres shorter than those on the lower manual. 
Like the naturals the sharps are buffed to polish them and any sharp edges and comors are rounded off.

The most usual type of sharp found on Ruckers harpsichords with their original keyboards is rectangular in cross-section. These sharps are about $12 \mathrm{~mm}$ high and 10.5 to $11.3 \mathrm{~mm}$ wide, and have a front sloping at about $15^{\circ}$ to the vertical. But a number of instruments of both Ioannes and Andreas Ruckers have sharps which are only about $9 \mathrm{~mm}$ high, and are tapered in width from $7.5 \mathrm{~mm}$ at the top of the sharp to $10.5 / \mathrm{mm}$ the base. Instruments with sharps with these sloping sides are usually dated in the period 1618 to 1627, and the standardization in the size and shape of the sharps suggest to me that they were supplied from a common source to both the Andreas and Ioannes Ruckers workshops. The sharps on the 1646 IC double are unique among the instruments of the Ruckers family. They are also made of bog oak, and the sides are very slightly sloping - botween $1^{\circ}$ and $2^{\circ}$ to the vertical. Their most distinguishing feature, however, is that they'slope in height from about $11 \frac{1}{2} \mathrm{~mm}$ at the frort to $7 \frac{1}{2} \mathrm{~mm}$ at the rear of the sharp. To my knowledge, this is the earliest:known instrument with its original sharps which slope in height from front to back. Thus either Couchet can be credited with the use of sloping sharps, or, if he bought his isharps from a supplier as seems to be the case with the other Ruckers, then this anonymous supplier must be given the credit.

The sharp as initially glued onto the keylevers was longer than its required final length (this may also argue 
for a common supplier, who produced sharps of only one 'standard' length). Since the sharps were too long, the key-board battens (lower-manual batten and namebatten) would not come to rest in their final positions in the slots of the keyblocks because they would be sitting on the ends of the sharps. Thus after the sharps were glued to the keylevers, the keys were placed on the keybed in the instrument and a scribed line was made along the tops of the sharps just in front of the keyboard battens. The sharps were then cut off to length and the excess wood at the tail of the sharp was chiselled off the keylever. The wood of the keylevers was usually penetrated. sItghtly by the saw cutting through the end of the sharp, and the wood just bohind the sharps was often slightly splintered in the process of chiselling the remaining portion of the sharp off the keylever. Characteristically, in cleaning up the keylever wood behind the sharps, two scalloped chamfers were made on the top edges of the keylever. The top of the keylever just behind the sharp including the scalloped chamfers was painted black although the sldes of the keylever under the bog oak sharp were left unpainted. The lower surface of the sharp keylevers is cut away in front of the balance point so that the keylever doesn't interfere with the balance rail or the balance rail cloth when a sharp is depressed.

The wood of the bog oak sharps was practically always cut so that the annular rings were horizontal. Thus the sides of the sharps contained the quartered ray figure of 
the oak and the yearly lines of open pores of the soft early wood. The tops of the sharps are thus relatively free of pores and otherwise rather featureless. Although the earliest Ruckers virginals had sharps which were decorated with nicks and transverse scribed lines, I know of no Ruckers harpsichord keyboards with decorated sharps.

The cloths used in the keyboards of harpsichords are of the same types as those used for virginals (seo p. 238). A heavy black cloth with long surface fibres pulled out in the matting process is used on the balance rail and on the ends of the keylevers under the feet of the jacks. The compressed thickness of this cloth is about $1.8 \mathrm{~mm}$. Because the slope of the balance rail is steeper than the angle of the keys, the sharp keylevers, which balance near the lower rear edge of the balance rail, would all be slightly bolow the level of the natural keylevers: To avoid this a piece of white leather or folded card was placed on the sharps balance points to bring the keylevers all to the same level (see Photo 6-16).

The lighter cloth used for the rack, jackrail and jacks has a compressed thickness of 0.9 to $1.1 \mathrm{~mm}$. Usually the cloth used in the rack is dyed black, but two double-manual instruments ( $1618 \mathrm{IR}$ and $1640 \mathrm{~b} \mathrm{AR}$ ) have rack cloths dyed red, like that found in the jacks. I know of only two harpsichords which have their original jackrail cloths (1624 AR and n.d. IR (Berlin)) and these cloths aro dyed black in both cases.

The number of layers of cloth used in the rack of 


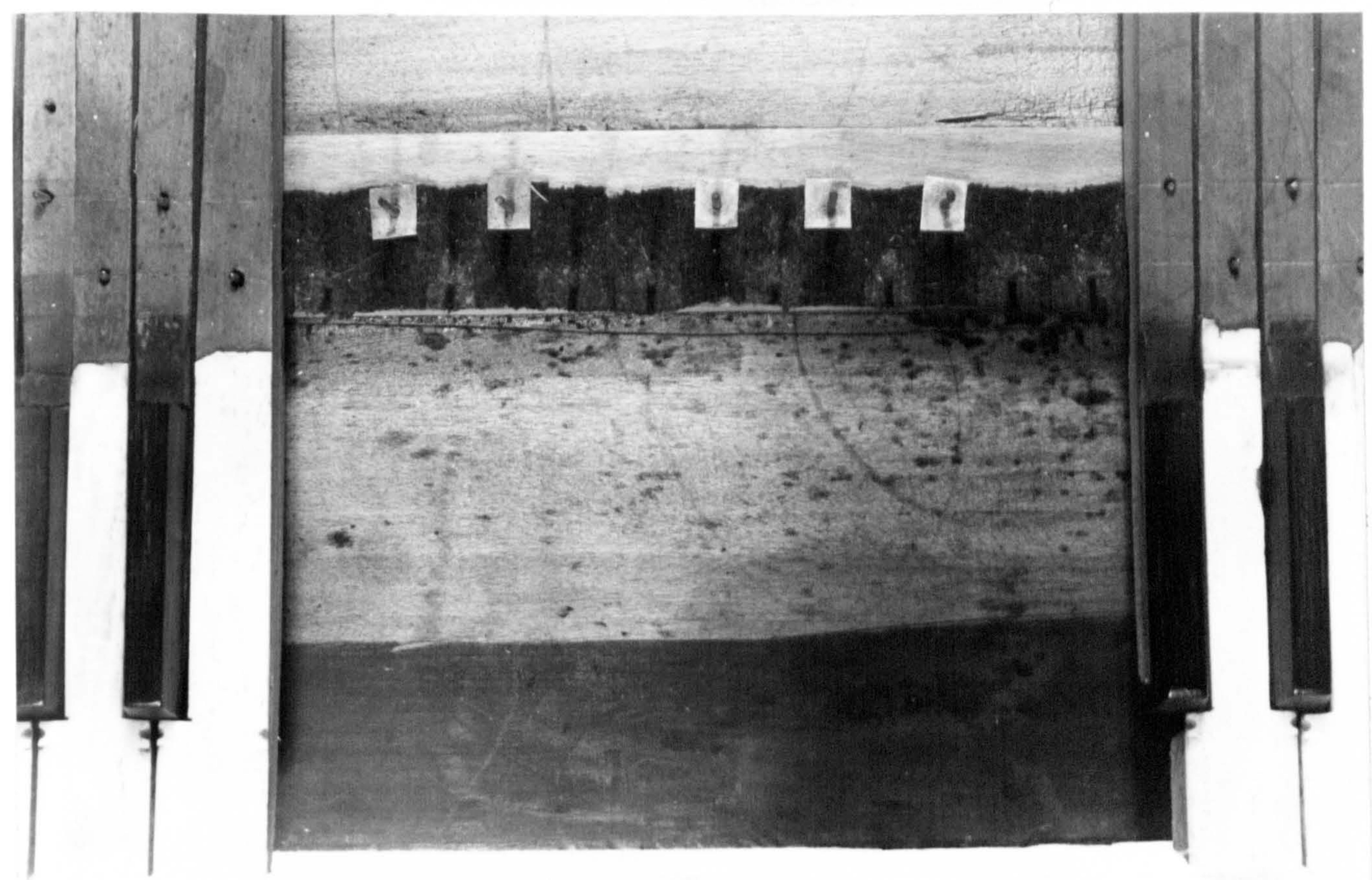

Photo 6-16 The keys and balance rail of the upper manual of the 1618b IR double-manual harpsichord. The white patches of folded playing card on the sharp balance pins is original. 
harpsichords varies slightly since the height of the rack also varies. Double upper-manual keyboards usually use 3 layers of cloth under the upper touch bar and two layers on the keyframe under the tails of the keys. The cloths are tied to the upper touch bar with loops of linen thread which pass through the cloth into small holes in the touch bar and are then tied at the top surface. The double layer under the tails of the keylevers is tacked to the keyframe with pairs of tacks at the ends and at $\frac{1}{3}$ and $\frac{2}{3}$ of the 1 ength of the cloth strips.

Single-manual and double-manual lower keyboards usual1y have 4 layers of cloth attached to the upper touchbar on the rack. These strips are rather narrow (about 12 to 15 mm ) and are tied through holes in the touchbar with linen thread in a manner similar to that used for the upper-manual upper touch cloths. The double layer of cloth under the tails of the keylevers is also attached like that of the upper manual with pairs of tacks at the ends, and $\frac{1}{3}$ and $\frac{2}{3}$ along the length of the strip.

The depth of touch has been measured of as many as possible of the harpsichords with their original rack cloths. Measuring the total motion of the near ends of the bone natural keyplates the upper manual depth of touch has been found to lie between 6.5 to $7.0 \mathrm{~mm}$ and the lower manual and single manual depth of touch is about 7.5 to $8.0 \mathrm{~mm}$. This is somewhat less than the 8 to $9 \mathrm{~mm}$ found in Ruckers virginals, and about the same as that found for 18th century English and French builders. 
The cloths used in the Ruckers keyboards are tightly woven and matted. When a keylever is depressed the woollen fibres compress to their final thickness very quickly as compared with modern piano action felts or modern artificial or composite cloths or fibres. There is enough 'give' in the cloth to bring the keys to rest quietly and quickly, and yet it is hard and resilient enough to produce a crispness to the action unlike that produced with most modern materials. This, combined with the somewhat unfavourable (compared to the 18 th century) balance ratio of the keylevers, gives the player a strong impression in his fingers of the jacks plucking the strings, and a greater feeling of contact with the instrument. "It does, however, require that the player exert a greater force and effort while playing. This is exacerbated by the fact that, unlike many 18 th century instruments which have keylevers cut away underneath to balance/the balance rail, Ruckers keys are not balanced but are quite strongly 'tail-heavy'. Although the balancing of the keys contributes little to the 1ightness of touch compared with the effect of the balance ratio, the extra effort required of the player, coupled with the impossibility of playing between the:sharps, even ignoring other unknown factors such as plectrum 'material and strength, means that a considerable alteration is necessary to the technique and fingerings used-by players accustomed to the 18 th century or most modern reproduction instruments.

Besides the decorative Iines and nicks on the bone plates, the naturals are also decorated with arcadds on 
the keyfronts under the slight overhang of the bone touchplates. These arcades consist of a design embossed onto heavy paper which is then pierced through to leave only the raised embossed pattern. Apparently the embossing and piercing were carried out simultaneously since on one instrument ( $1637 \mathrm{AR})$ a defect in the piercing of the design in one corner is reproduced on each arcade. Two slightly different embossed patterns are to be distinguished. Hans and Ioannes Ruckers and Ioannes Couchet used a rounded type of embossing; the two Andreas Ruckers used an indented type of embossing, although both patterns are essentially the same (see Photo 5-4). The embossed paper design is glued to a red-dyed parchment backing which is, in turn, glued to the front of the keylever. The dye used for the parchment backing is fugitive and is usually almost completely faded. The original red colour can therefore usually be seen only where the embossed pattern has protected the parchment from light and air and then subsequently become detached:

\section{Ruckers facks}

The material and methods of construction used in Ruckers virginal and harpsichord jacks are identical and so the two will be described here together. The length of the jacks, and the number of dampers used will be appropriate to the size and pitch of the instrument concerned.

Ruckers jacks are made of beech (Fagus sylvatica) cut on the quarter so that the quartered figure is visible on the widest face of the jack. It is not clear whether the 


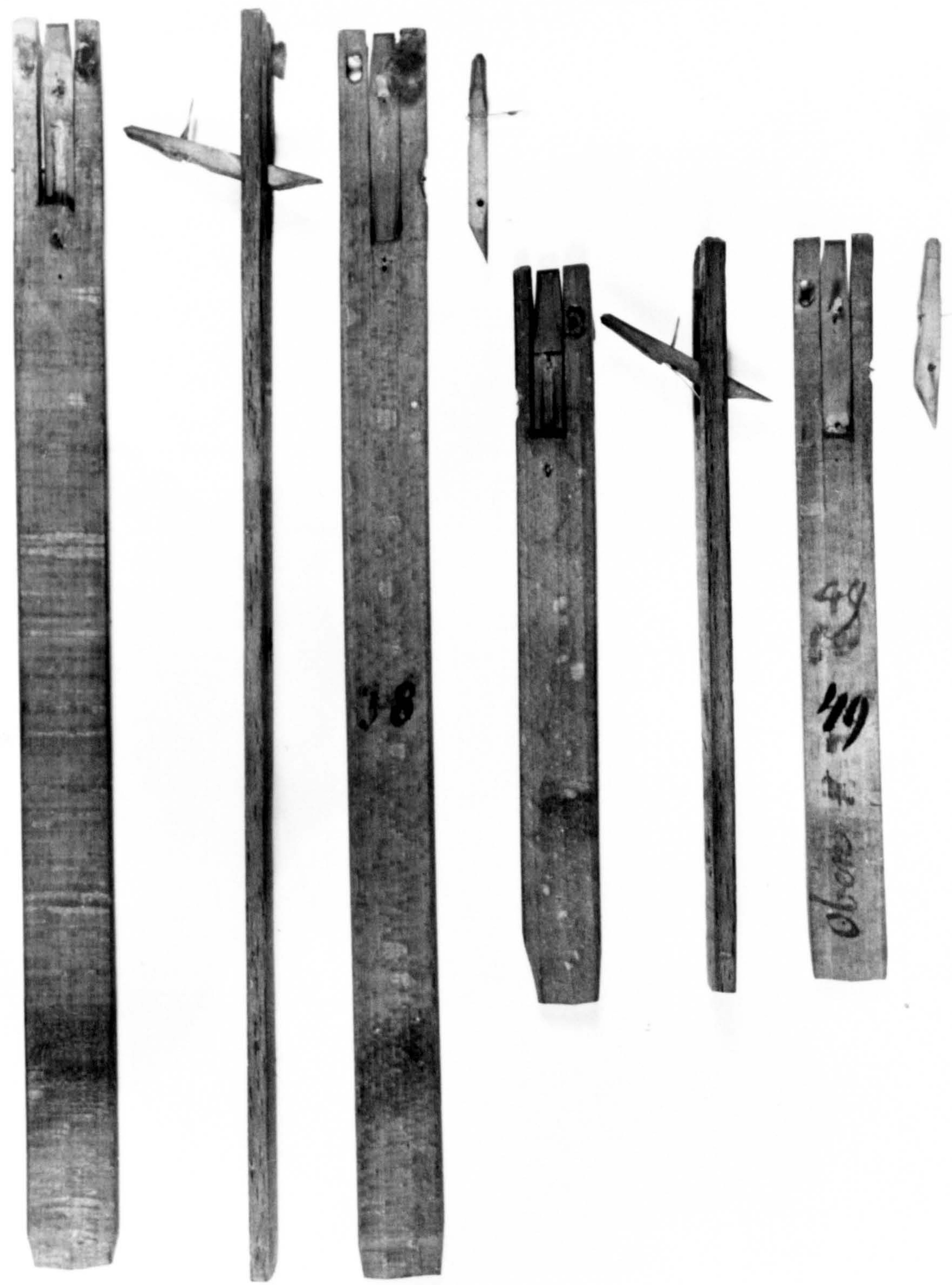

Photo 6-15 Original Ruckers jacks from a double-manual harpsichord (1618b IR).

Scale 1:1 
reason for the quartering was an attempt to achieve the maximum stability in shape and dimension in the jacks, or whether it was a result of the fact that the jacks may have boen cut apart by splitting the wood. Since beech splits cleanly and relatively easily in a radial direction it is quite possible that, to avoid the laborious task of sawing the jacks apart, they were instead split. Indeed most jacks are very accurately quartered as would be the case with jacks which wero split apart. But some instruments have jacks which are considerably off the quarter although not enough to exclude completely splitting as the method of cutting them apart. The way they are cut does, at any rate, provide the maximum strength and dimensional stability possible with wood. A disadvantage of using beech which is accurately quartered is that the extremely hard rays in beech tend, even when using a very sharp plane, to splinter slightly and provide a slightly uneven, textured surface which is quite unlike the silky smooth surface which is possible with plank sawn beech.

The jacks are dimensioned to fit the jackslides so that a fairly large amount of slack is tolerated in the long direction of the jackslot, but with a very close fit in the width. This ensures that the tip of the quill is always in the same relative position to the side of the string before plucking, although the plucking point along the string may vary a slight amount. The play botween the sides of the jack and the jackslot is only about 0.1 to $0.2 \mathrm{~mm}$, whereas in the long direction it may be between 0.5 and $1.0 \mathrm{~mm}$. 
Ruckers jacks, like the jacks of most harpsichord builders of the classical era except for the Italians, are tapered in width and thickness along the length of the jack. This means that, as it rises out of the register when a key is depressed, the jack becomes gradually looser and freer in its slot. Normally a jack is actually thicker at its top than the width of the jackslot. Even without its dampers it would thus not fall through the jackslot if the keys were removed, but would bind in the jackslot near the top of the jack. A typical 8' jack tapers in thickness from about $3.9 \mathrm{~mm}$ to $3.0 \mathrm{~mm}$ and in width from 13.7 to $13.1 \mathrm{~mm}$ and fits in a jackslot which is 3.8 by $14.4 \mathrm{~mm}$. Similarly a 4' jack with the same thickness dimensions tapers in width from 12.1 to $11.7 \mathrm{~mm}$ and fits a jackslot 3.8 by $12.6 \mathrm{~mm}$.

The dampers in Ruckers jacks fit in oval holes. These holes do not seem to have been made by drilling two holes close together and then clearing away the excess wood between them, but by means of a sharp semi-circular tool (a gouge?) which cut out the top and bottom of the hole working from both the front and back surfaces toward the middle of the jack. The hole produced in this way is longer, but not wider, at the front and rear surfaces of the jack than it is in the middle of the jack, and this pinches the damper cloth tightest near the middle of the hole (see Fig. 6-13). At the front and rear of the jack the damper holes are about $4.2 \mathrm{~mm}$ long and about $3.6 \mathrm{~mm}$ long near the middle. They are about 2.0 to $2.3 \mathrm{~mm}$ wide. 
8' jacks

4' jacks
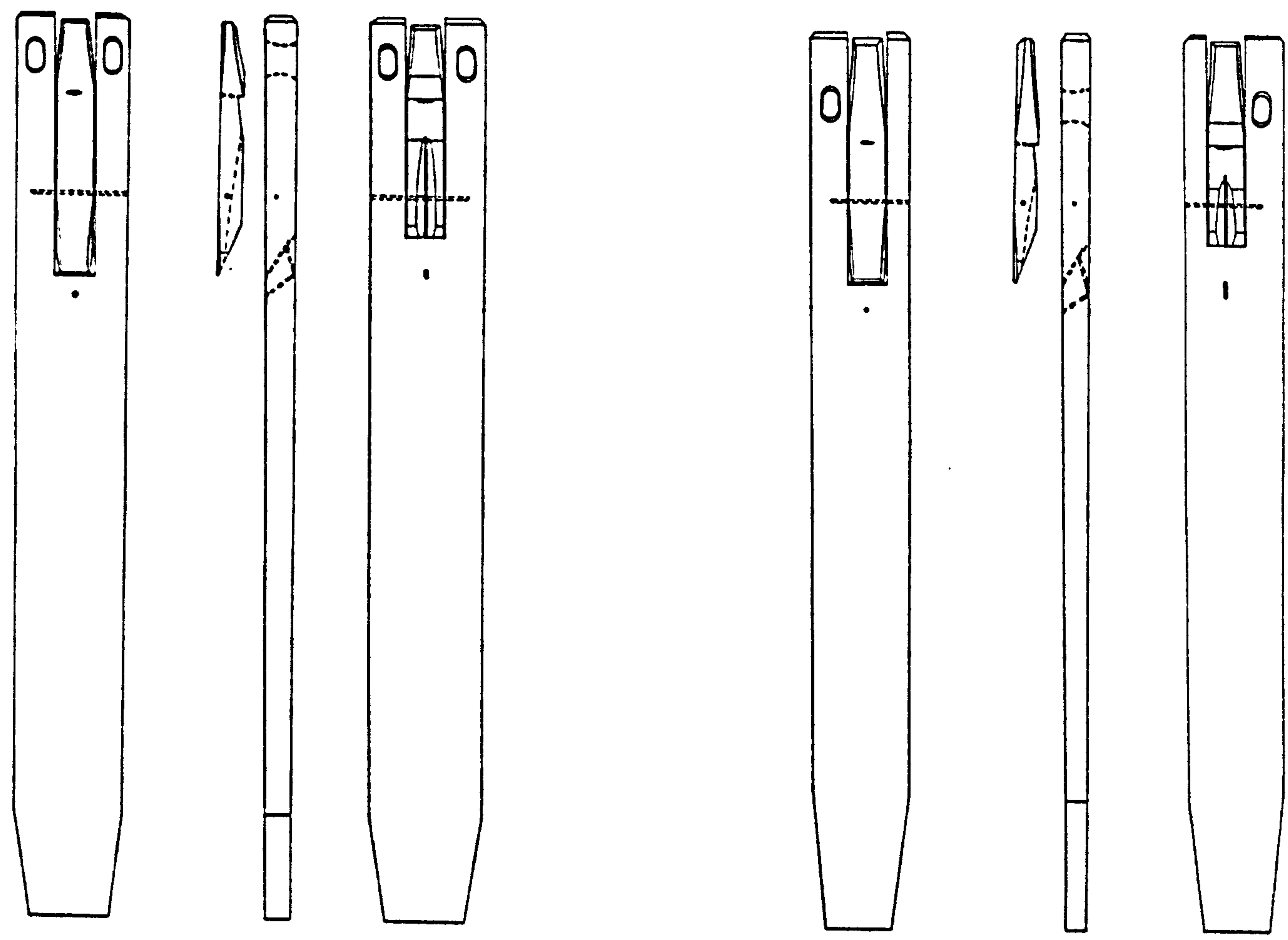

Scale $(\mathrm{cm})$
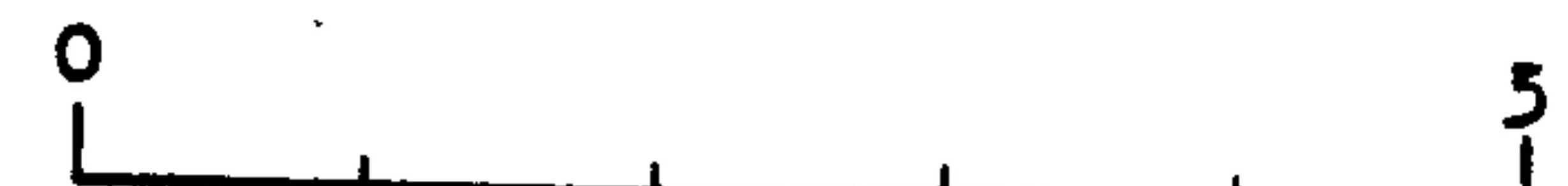

10

15

Fig. 6-13 Typical jacks from a Ruckers harpsichord (measured from the 1618b IR upper-manual jacks). 
The damper holes are often placed very close to the mortice in the jack for the tongue. Sometimes the wall between the damper hole and the tongue mortice is little more than paper thin. Because the wood in the hole must have been chiseled or gouged out, the damper holes must have been made in the jacks before the tongue mortices were cut, otherws se the wood between the damper hole and the tongue mortice would have ruptured through.

The dampers and damper holes used in Ruckers jacks are unusual to the person accustomed to the more common type of flag damper in a straight damper slot. Yet the use of this type of damper and damper slot spanned at least the period from 1579 to 1770 in instruments of Theeuwes and Delin respectively. A number of Ruckers instruments survive with their original jacks with this type of damper hole and several instruments (among them the 1618b IR, 1640b AR and 1644 AR harpsichords) retain at least traces of their original dampers. In addition, the child part of the Marten van der Biest double virginal has some original dampers and the 1651b AR harpsichord has jacks dating from.its petit ravalement which have oval damper holes and some old dampers which clearly copy the earlier Ruckers stylo.

These dampers have a characteristic rounded shape, somewhat like a large mouse's،ear! They were apparently made with a piece of wedge-shaped cloth rounded along the short side of the wedge opposite the apex. If the two side of the apex are folded together and the apex inserted 
into the damper hole holding the folded sides together, the apex may be grasped and the damper pulled up snugly into the hole. The damper itself then assumes the characteristic 'mouse ear' shape automatically, and the apex end of the damper can be cut off flush with the back of the jack. The shape of the resulting damper is such that the edge of the cloth which comes into contact with the string Is at an angle to the horizontal so that the string is brought gradually to rest as the damper lowers onto the string rather than being damped suddenly as with a flat horizontal lower surface. This is extremely important in damping the muselar virginal strings as has been explained in the previous section on virginals, but it is also a very efficient method for damping the strings of a harpsichord.

The fact that the lower edge of the damper makes contact with the string at an angle also has another important consequence especially relevant to the operation of the double-manual harpsichords. Since the damper does not rest on top of the string, it completely loses contact with the string as the register is drawn away when it is disengaged. This is an essential feature of a double-manual harpsichord since both upper-manual and lower-manual jacks operate on the same string. When one set. of jacks is engaged and the other disengaged, the dampers of the jacks in the register turned off must not make contact 'ith the strings otherwise they would permanently dampen the strings and the desired register would not sound. Thus both the dampers and the quills must be drawn away from the strings when the register is disengaged. 
The mouse ear type of damper produces an interesting effect in an instrument with two 8' strings for each note. If one 81 register is turned off, its strings are left undamped and free to vibrate in sympathy with the other 8' register. When the jack of the note being played returns to rest it will damp its own string, but the undamped $8^{\prime}$ string vibrating in sympathy will continue to sound after the key is released. Although no Ruckers harpsichord appears to have survived which was originally disposed with two $8^{\prime}$ registers, Ioannes Couchet and Ioseph Ioannes Couchet made harpsichords with the dispostion ( 1652 IC and 1671 IC). Duarte, in his letters to Huygens (seo Appendix 17) refers to an instrument made by Ioannes Couchet which had "three different strings of which 2 strings are at unison and one at the octave and which can all three be played together or each string separately, with or without the octave... . But they have a better tone because the unused string which is not played moves of its own accord, producing such a sweet quiet tone through the principal sound, which does not occur when all three strings are played together": Obviously the dampers of the 'unused string moving on its own' were not in contact with the strings, and the 'sweet quiet tone' resulted.

Virtually all harpsichords built in the 17th and 18th centuries that I have seen with jacks and dampers which seem to be original, have dampers with sloping sides. Although this classical way of cutting the dampers is much 
more efficient, virtually all modern builders use dampers with a horizontal lower surface. Most modern musicians are also unable to accept the sound of the unplucked string vibrating in sympathy, although the problem really only arises in single-manual instruments with two 8 ' registers.

The sides of the tongue mortice were scribed on the front and rear of the jack with a mortice gauge. The scribed lines are usually about $4.1 \mathrm{~mm}$ apart, but the actual tongue mortice may be up to a millimetre wider than this. The bottom of the mortice is angled at about $40^{\circ}$ to the front surface of the jack. This angled surface acts as a stop for the bottom of the tongue and a small piece of white (kid?) leather is glued to its surface to prevent the click which would otherwise result when the tongue comes to rest the instant after the string is plucked, and again when the quill passes over the string on its roturn.

The bristle which holds the tongue in position is held in the body of the jack by the friction produced between the scaly surface of the bristle and the hole for it below the tongue mortice. The amount of friction is increased by bending the bristle sharply inside the jack body to increase the force exerted on the sides of the hole by the bristle. The bristle hole angles up from below the middle of the front of the tongue mortice to emerge from the rear of the jack only to re-enter the jack body again at a shallow angle and emerge from below the top of the angled surface at the bottom of the tongue mortice (see 
Fig.6-12). These two angled holes are carefully drilled so that the bristle does not actually project from the rear surface of the jack.

The tongue pivots on an axle placed through the side of the jack and across the tongue mortice. In the 4' jacks, the axle pin always passes through the thin side of the tongue mortice, and lodges in the thicker side which has the damper hole in it. Usually the axle is a piece of brass wire of diameter $0.63 \mathrm{~mm}$ (probably gauge number 1 in the gauge system used by the Ruckers, see p. 162) which is sharpened at one end. The axle hole in the tongues, in the only two instruments where measurement of this is possible (1618b IR and $1644 \mathrm{a} \mathrm{AR}$ ) were both $0.75 \mathrm{~mm}$ in diameter. The axle hole is placed quite low on the tongue so that the point at which the bristle touches the tongue is well away from the axis of rotation of the tongue and thus. that the moment of the force of the bristle returning the tongue to its rest position is as great as possible. The sides of the tongue are chamfered near the top and bottom to avoid interference between the tongue and the sides of the mortice. The top and rear edges of the tongue are also often shaped with delicate, fine chamfers which serve only a decorative purpose. Except for these chamfers the front of the tongue is flat. The back of the tongue angles steeply at the bottom so that only the very bottom edge of the tongue touches the angled bottom of the tongue mortice. The top of the tongue is thinned at the back to reduce the amount of wood above the quill. An 
asymmetrical notch is also made in the back of the tongue with one edge of the notch coming at the edge of the quill slot. Just below this notch is the longitudinal groove for the bristle. A total of about 0.2 to $0.5 \mathrm{~mm}$ clearance was left between the tongue and the sides of the tongue mortice.

The quill slot in the tongue is a simple rectangular or lenticular shaped hole passing through the middle of the tongue. This slot is angled upwards at an angle of $10^{\circ}$ to $12^{\circ}$, and this angling of the quili has a number of significant consequences. Probably the most important is that this means, after plucking the strings, the quill will always slide past the string on its return. The weight of the jack suspended from the angled quill has a strong component which pushes the quill and tongue back allowing the quill to 'escape' over the string. This ensures that the quills and jacks do not hang on the strings as may sometimes happen with quills which are perfectly horizontal and is consistent with the general importance which seems to have been placed by the Ruckers on reliability in the action of their instruments.

Angling the quill upwards also affects the reliability of the action in another more subtle way. When a key is depressed and the jack begins to rise, the angled quill draws the jack toward the string. Thus, regardless of the amount of play between the jack and the sides of the jackslot, the jack always comes into the same position relative to the string and the amount of 'bite' of the quill is constant. 
This is, of course, not the case with horizontal quills which will project under the string by a different amount each time the key is depressed depending on the amount of play between the jack and the sides of the jackslot. The resulting unevenness is especially noticeable in the playing of trills or ornaments.

The reliability produced by angling the quill can also affect the voicing of the instrument. Since the quill automatically adjusts the position of the jack relative to the string, one may safely have less quill projecting beyond the string and still be certain that the string will be plucked. The amount of quill left projecting beyond the string is one of the important factors adjusted during volcing which greatly affects the final sound of the instrument. If a large amount of quill projects past the string, the quill displaces the string sideways as well as vertically and the string is released vibrating in a plane at an angle to the vertical. This effect is generally recognised as being detrimental to the sound produced (clearly only the vertical component of the string's vibration can be radiated by the bridges and soundboard), and thus the smaller the sideways displacement of the string the closer its plane of vibration will be to the vertical. The angling of the quill in itself aids this effect since only by angling the quill can one increase the vertical displacement in the plucking process without increasing the sideways movement of the string. Although there is no indication of how the Ruckers 
may have actually voiced their quills, these were certainly both long and angled and these are features which are recognised today as contributing to good voicing and a reliable action.

There are a number of essential differences between the 4 ' and 8 ' jacks. The 4' jacks have only one damper, as opposed to the two used in the 81 jacks. This means that one of the forks forming the sides of the tongue mortice on the jack body can be narrower than the one pierced with a damper hole. Thus the 4' jacks are narrower than the 8 ' jacks, the tongues are located as ymmetrically in the jacks, and their jackslots in the upper registers are correspondingly as ymmetrical. Also, because the 4' strings are located in a plane below the 8 ' strings, the quills and dampers on the 4 ' jacks are lower down the jacks than those on the 81 jacks. However, the difference in the distance from the top of the jack to the quills on the 8 ' and 4' jacks is less than the distance between the planes of the 81 and 4 ' strings. For example, on the 1618b IR double, the dampers and quills are about $3.7 \mathrm{~mm}$ lower on the 41 jacks than those on the $8^{\prime}$ jacks, but the average distance between the levels of the 81 and 4 ' strings is $5.5 \mathrm{~mm}$. Therefore, if the $8 '$ and 4 ' jacks are cut so that the 4' speaks first, then the length of the $4 '$ and 81 jacks will automatically be almost identical, and the two jacks will reach and rebound from the jackrail cloth together. This has been checked and corroborated on the 1640b AR double where the length of jacks has not been altered, and still 
retains a number of $4^{\prime}$ and $8^{\prime}$ jacks from the same note and manual whose length can be compared. Thus the plucking order must have boen adjusted to make the 4' jacks speak first for each note, and the position of the quilis and dampers on the jacks was chosen to give a similar mechanical motion of both types of jacks in order to achieve this. That the 4' jacks should speak first on Ruckers instriments is consistent with the later 18 th century practice in England, France and Flanders, where the 4 ' was, as far as I know, always choson to speak first with the usual $2 \times 8^{\prime}$, $1 \times 4$ disposition.

In double-manual harpsichords the length of the jacks for the $e^{b} / g^{\#}$ notes must have been respectively longer and shorter than the neighbouring jacks. Although I have kept a careful watch for original jacks which belonged to these notios (the upper-manual jacks would be numbered 12, 24 , and 36, the lower-manual ones 17,29 and 41); I have unfortunately never found any original jacks for these notes. It is of course possible, if the usual: jacks and tongues were not used for these notes, that special jacks with special tongues might have been made specifically for the unusual geometry of these notes, but $I$ have not been able to confirm or disprove this possibility.

The narrow sides of the jacks are usually cut away at the foet reducing the area of the jack touching the end of the keylovers. In virginals the sides of the jacks may be cut away for half the length of the jacks in order to avoid interference with neighbouring keys which would 
cause more than one jack to rise when any given key is depressed. Also a very characteristic feature of Ruckers jacks is that all four edges of the top of the jack are trimmed away with fine chamfered edges. This feature, as well as the quartering of the beech wood of the body of the jacks and the oval damper holes, are some of the most immedlately recognisable characteristics of original Ruckers jacks.

As the number of instruments which retain their origlnal jacks is relatively large it has been possible to compare the style and workmanship of the jacks in different instruments. As might be expected the jacks vary in the shape and chamfering of the tongues in particular, and in the chamfering of the jack body and the piercing of the damper holes as well, for the different members of the Ruckers family at different times in the course of their careors. In viow of this it is particularly surprising to find that the jacks in the two instruments $1618 \mathrm{~b}$ IR and 1618 AR have jacks which are identical in dimension and in the detail of the decorative chamfers on the tongue and jack body. This seems to suggest that, like the sharps, the Ruckers may have obtained their jacks from a common supplier rather than making them themselves. This would then explain why the jacks in the two instruments built in the same year by different builders are identical.:. Unfortunately, there are no other instances of instruments built at nearly the same time by different builders which retain their jacks for comparison. However, the fact that 
the style of the jacks varies during the course of the career of any given builder seems more likely to suggest that the supplier or workman making the jacks changed from time to time, since the building style of any given builder tended otherwise to remain very constant.

Harpsichord fackrails

Except that they are wider, the harpsichord jackrails are very similar in shape and function to the virginal jackrails. They have an inverted 'U' cross-section with a moulding profile similar to the case moulding along the top edge. The overhanging edges are carved away at the ends of the jackrail so that only the flat 'spine' of the jackrail is let into the spine and cheek case sides. Each ond of the jackrail is slotted for an iron loop which is driven into the jackrall mortice in the case side (see Photo 6-9). A flat brass hook, or an iron wire hook nailed to the top of the jackrail engages in the iron loop in the jackrail case mortice and holds the jackrail in position at each end. The extra depth of the case jackrail mortice allows for the thickness of the eye and the hook on the jackrail. Because of this the jackrail and its mouldings are lower than the case sides and case mouldings and therefore the case mortice is not mitred for the moulding in an original Ruckers harpsichord. It is instead a simple parallelsided mortice which has the same width and a slightly greater depth than the end of the jackrail.

Two layers of the thinner $(0.9 \mathrm{~mm}$ compressed thickness) black woollen cloth used by Ruckers is tacked to the 
inside lower surface of the jackrail. The tacks holding the cloth in place are located in pairs at the ends of the jackrail and roughly $\frac{1}{3}$ and $\frac{2}{3}$ along its length. This cloth damps the sound of the jacks rebounding off the jackrail so that they return quickly and quietly to their neutral position.

Whereas the Ruckers signature is always found on the jackrail of the virginals, the harpsichord signature is found on the namebatten above the keys. The jackrail is therefore decorated with a block printed paper pattern. I have found that in all instruments in which the signature is found on the jackrail, it can be shown to have been painted on the jackrail at a later period. Harpsichord stands

The number of harpsichords which still retain their original stands is very small. Those stands that do seem to be original are built in the style of the 17th century Flemish furniture and interior decoration similar to that which may be seen in the Plantin-Moretus Museum, the Rubens House, the Rockox House, or the Vleeshuis Museum in Antwerp. They are made of oak stained a very dark brown and varnished or shellacked.

Most of the original stands consist of three essential parts. The front and rear parts which go under the keywell and tail of the instrument comprise a pierced fretwork structure decorated with turned buttons, split appliques and hanging 'acorns'. Between the two end pieces is a stretcher consisting of turned columns and fretwork arcades 


\section{$10 A N N E S \cdot R V C K E R S \cdot F E C I T \cdot A N T V E R P I A$.}

Photo 6-17 A typical signature on a harpsichord namebatten ( $1638 \mathrm{~b}$ IK $)$.

Scal e $1: 5$

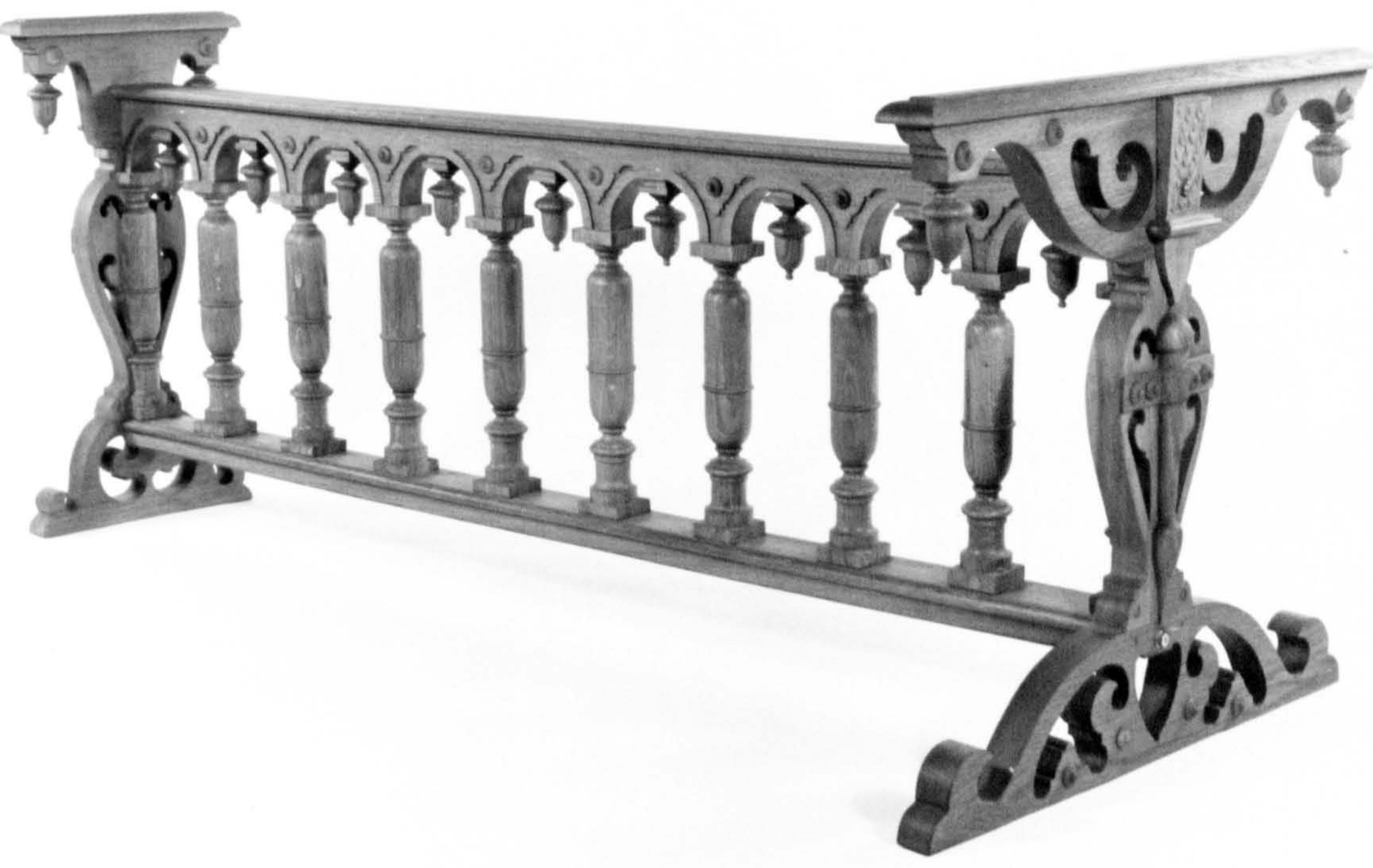

Photo 6-18 A Ruckers carved, turned and arcaded harpsichord stand (a copy by the author of the stand under the 1620c AR double-manual harpsichord 
and more turned 'acorns' hanging in the arcades - see Photo 6-18. The stands vary in height from $680 \mathrm{~mm}$ to 770 mm - the former being a comfortable height for a player seated on a chair of normal height: the latter feeling comfortable only when one is seated on a high chair such as those common in 17 th century Flanders. Instruments which retain stands of this type are the 1620c AR, 1616 HR and the 1627 AR harpsichords. The 1624 AR has a cutdown version and the '1627 IR' fake in Antwerp have parts of this type of a stand under them.

The 1640a AR single manual harpsichord has a stand (which is not original to it but is reputed to have once belonged to the 1648 AR single) with bulbous legs and plain moulded stretchers in the style of many Flemish dining tables. This stand is about $580 \mathrm{~mm}$ high. The 1608 AR double manual harpsichord has a stand which is probably almost as old as the instrument, consisting of an upper and lower frame matching the shape of the instrument, separated by carved square legs. Originally about $720 \mathrm{~mm}$ high, this stand is in the style of English 17th century furniture, so that it is likely that it was built for the instrument after the harpsichord arrived in England. Underneath the later 18 th century paint the stand is painted brick red, probably to match the original red marbling of the rest of the instrument. 
6-1) Klaas Douwes (see Appendix 8) refers to harpsichords which are 8 voeten long. He is clearly referring to harpsichords and not to virginals since he calls them Steert-stukken. These are also referred to by Duarte in his letters to Huygens (see Appendix 17) who says, "The extreme length of the large harpsichord is 8 voet more or less,...". Clearly these instruments were not usually exactly 8 voeten long.

6-2) The one exception is the 1636 AR which was originally a single with a case depth of 10 duimen.

6-3) This seems to be in basic agreement with the fact that the fundamental frequency of the internal cavity of a harpsichord or virginal is well below both the frequency of the lowest notes of the instrument and of the lowest note audible by the human ear. Further, because of the effect of the rose hole and the opening in the cavity between the upper and lower belly rails, the resonances of the higher harmonics of the internal resonant cavity would be expected to be so wide and flat as to contribute a negligible effect to the overall acoustical performance of the instrument.

6-4) Both the treble and bass sections of the buff stop are operated by finger stops on the 1637 AR single, rather than projecting the right-hand section through the cheek. Later instruments by Andreas Ruckers revert to the usual system.

6-5) The two harpsichords signed by Ioannes Couchet ( 1645 IC and 1646 IC) which retain their original wrestplanks and nuts show clearly that the buff stop was not split, but was a continuous batten covering the entire register from treble to bass. These instruments both show traces of the chamfered blocks used to hold the buff batten against the nut, and both have holes in the side of the 8' nut for the iron pins which held the batten against the wrestplank veneer. But there is no trace of the block or the ' $V$ ' notch in the 8' bridges which are necessary for a split buff.

6-6) The identification was carried out by Mrs. A. Miles of the Forest Products Research Laboratory, Princes Risborough who carried out the identification of the soundboard and 81 bridge woods (see below) for me.

6-7) See my monograph Soundboards, Strings, Acoustics and Historical Harpsichord Stringing Practice, to be published soon by Cambridge University Press, for a fuller discussion of the acoustics of soundboards and strings. 
6-8) The difference in the thickness of the soundboards in Ioannes and Andreas harpsichords may be the reason that Andreas often used a stiffening bar glued to the bentside Iiner, to increase the rigidity of the soundboard there, since, being too thin, it was otherwisefflexible in the area near the stiffening bar.

6-9) In Ioannes Ruckers instruments only the player side of the 4' hitchpin rail is scribed under the soundboard. In some of the late Andreas Ruckers instruments both sides are scribed although no use seems to have been made of the line along the far side of the rail.

6-10) Roference to go-bars are quite frequent in 18th century inventories - seo P.J. Hardouin, 'Harpsichord Making in Paris. Part I, Eighteenth Century' Galpin Soclety Journal, $x$ (1957) 13. Hubbard, who translated this article, seems to be responsible for translating 'goberge' into American English 'go-bars'. Andre Jacob Roubo, in L'Art du Menuisier (Paris 17691775) in Part IV - Vocabulaire Raisonne, p. 1285 gives "Gobergo - tringle de bois quion place entro le plafond de la boutique \& 1 louvrage, pour fixer co dernier sur l'établi."

"Go-bar - bar of wood which one places between the ceiling of the workshop and the piece being worked, to $f i x$ the latter to the workbench."

6-11) Because of the large spacing between the pairs of positioning holes in the tenor and bass, it seems unlikely that these nails were/actual means of clamping the bridge to the soundboard during glueing.

6-12) In the course of the restoration by the writer of the 1764/83 Go ermans/Taskin in the Russell Collection, Edinburgh, it was found necessary to remove the spine soundboard moulding. It was clear that Goermans in 1764 had glued the soundboard and soundboard moulding in separate glueing operations using a method similar to that described here.

6-13) The 1652 IC by Ioannes Couchet and the 1671 IC, probably by Ioseph Ioannes Couchet, were both originally singles with a $2 \times 8^{\prime}$ disposition. The use of the $2 \times 81$ disposition by Couchet is also mentioned in the correspondence between Couchet and Huygens (seo Appendix 18).

6-14) Two late instruments by the Couchets are exceptions. The 1652 IC and 1679 IC both originally had only 2 sets of strings but had 3 registers. In this case one set of 81 strings was plucked by one or other of two different sets of jacks separated by the third row. The difference in the plucking points of these 
two widely separated jacks would cause a distinct difference in the timbre of the sound produced from the same string.

6-15) To be fully accurate one should measure from the point of application of the force exerted by the finger on the natural's touchplate, and from the Iine of action of the centre of gravity of the jacks on the tails. The above definition is, however, accurate and practical enough to allow a meaningful comparison to be made.

6-16) By way of comparison the balance ratios of harpsichord builders of the 18th century are as follows:

Dulcken - 0.70 for both upper and lower manual

Taskin - 0.79 for the upper, 0.80 for the

lower manual

Kirkman - 0.85 for the upper, 0.87 for the lower manual

These are all much greater than the Ruckers balance ratios and seem to point to a desire for a much lighter touch in the 18th than in the 17th century. 
Hens Ruckers

$1381 \mathrm{hR}$ touble me. rise.

$1593 \mathrm{HR}$ L-voce ep1n. VIre.

1391. for Polyc. 6-v. op. $\mathrm{re}$.

(1391)b HR Double ans. vire.

1394 kR side. barps. a vire. Sebl. xopedick

\section{Ioennes Fuckers}

$1393 \mathrm{~kg}$ Chsle raredond

$1395 \mathrm{ER}$ Geroot epla. rare.

$1599 \mathrm{kR}$ Doviol e warpeschord

(c1600) bR Double epid. Virs.

1601 kT 5-vo ot mus. VIre.

$1610 \mathrm{kR}$ Loub2 o ans. Fla.

161: ER i-voer ous. vise.

1612A LR Doubl o mespelebord

16120 ef Double harpsichord

(1614) ER 6-voet uns. vis5.

$1616 \mathrm{HR}$ Lag5e doubl a basps.

D.e. IR SIDE. marpe. a virc.

(1612) If Ioubl a harpel chord

161? IR Iouble mepsichord

1618. IR ChS20 viscimal

1618b IR Iouble harpolchord

1618 e IR Double berpeschord

1619 IR Ioule harps. \& VIr6.

1620 IR 6-voet uns. vise.

1622 IR 6-voct was. V156.

1623 If Double mus. Viss.

1624 If Iouble harpal chord

1627. In S1pcte barpedchord

16270 IR Doubl e herpstchord

1627 II Larte double merpe.

1628a IR Motber uns. Nise.

1628 b IR Lerce double harps.

1629 IR 4jorot apdo. v1r8.

1632 IR Double berpelcbord

1636 IR 6-voet mus. Als6.

1637 I IR 510510 marpelchord

16370 IR Double barpelchord

1638. IR 6-vo ot mus. VIrc.

1638b IR Double harpstchord

1639 IR Stpele harpeichord

1640a IR j-voet wes. Fire.

1640b IR Double harpsichord

1642a IR s-voct eus. vise.

$1642 b$ IR Double harpalchord

\section{Ioannes Coucher}

1643 IC S18Ele harpsichord 1646 IC Double barpelchord 1630 IC 6-vo at wus. PIIE.

(e1630)b IC Doub2 - harpel chord 1652 IC Doubl anspichord
Mor. The ows. X.T.

T. Hoyer. Fardo

Grutiburee, Bruges

rale vost.

Clpesponed Tus.

farts Cosent.

Hedeltane

MSLas

Bruesele Musoun

Brubede menest

vecabus:

Feorod Houes

cas ene

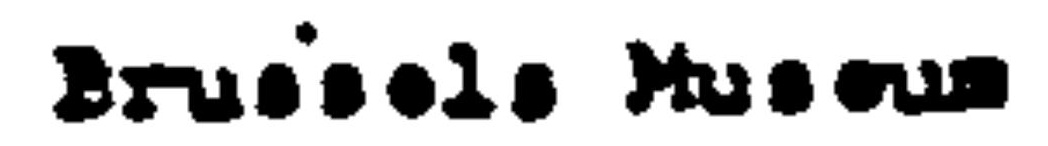

Airouer, fists

$B \cdot=210$

Pard : Codects.

R. Jobosod, L.A.

Paris Copserr.

scbl. Capporbore

Lund. Suod on

Bruse el. Mus ons

506808

Mot. Husoun, X.J.

Stuercart

Colans. Jrabce

Ber210

V1210000

Privete, Swltex.

Erusects Musers

Vorend21 os

Eruse els Hus ous

Niescbertel

Herverd

Ed: - ourch

Ros

Eruasels Husous

Edsoburch

v. L 1., Loddoz

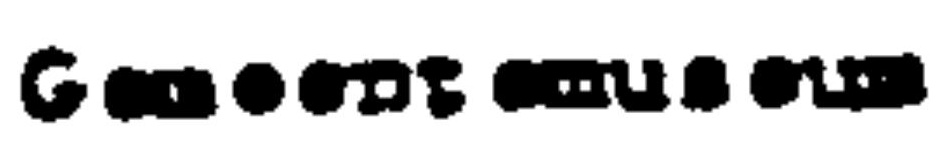

Maset or

Stockhole

H. Gough, X.X.

Ed1 Dburch

Brusesede the ous

V eenhut

Mot. Husenm, X.J.

Privete. Prance
Androes Ruckers

(1605) ar 5186de barpelchord

1608 ar toubl e barpalebore

1609 al sibele marpelebord

(e1610) as 2jevect rifciond

16100 al 4 j-vece mue. rats.

16130 al bevoer opid. Tise.

16130 ar bevoer epsD. TI5E.

If ije aR CAsld riscimal

1614 al Double barpelchord

1613 at touble barpelebord

1617 AR 6-7008 sp10. MISE.

1619 AR s1pgle marpsicbord

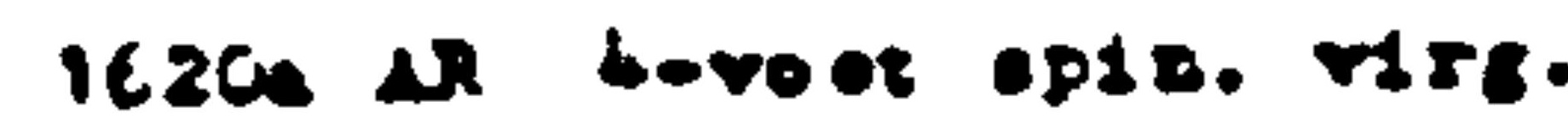

16200 ar 6rvoct wus. TIJ6.

1620e AR touble barpescbord

16200 al 6-votet auc. ress.

1621 ar Double marpsedebord

1623 AR Doutl e harpeichore

1624 as stzcte barpetchord

(1626) ar casid ristimal

1627 al Cusot sto6le batps.

1626 AR Louble barpaschord

1632 ar hevoot epdo. TI5.

1633e ar 6-voet mus. TIE.

16330 aR siogle masplichore

1634 AR Casld Tlesibal

1633 at s18cte marpadchord

1636 Af roubl e marpelebord

1637 AR strele herpedebord

1639e ar Chlla virctimal

1639b AR S10810 marpsiebord

164an AR sidede barpsicbord

1640b ar tovble marpeicbord

16430 AR 3-voet mee. Alsc.

16430 AR Doub1 - intrpsicbord

16440 AR 51082 e mespeschore

164hb AR Doubde mas. TIFE.

1646e AR 5iogle barpsicbord

$1646 b$ AR Large double harps.

1648 AR S10820 harpeschord

(1631)a AR S108lo barpaichord

1651b AR I0uble herpalchord

1634 AR Doub2 e herpsicbord

Iosear Iosnnes Coucher

D.d. IC Double herpelehord

1671 IC Doub2e meprichord

1679 IC 5incle marpalchord

1680 IC Doub2 e barpachord

Stockboln

I. G12bert

veshidertos

508000 neeshuss

EAl oburch

P. Uissiases

Ausrred10

Bosegs

Eruesele: :274

Eruesede:2928

Clpespons tus.

Elabser. Eoves

1200kuss

Musch

Ber210

beabsocted

krusecess Musure

Derdid

Labogte. G5s

SE. Irs ende

Pravere. Ioclad

Grusbuuse, sruges

Se erckebos. Dourne

Geverer cunsen

Pslktiptod, Fort.

Eruse. 10 Hus com

Ervesede Mus our

Ledpeic

Ferio Codects.

K. Jboma:

H. Tromes

- Mur aabere

Gopere consen

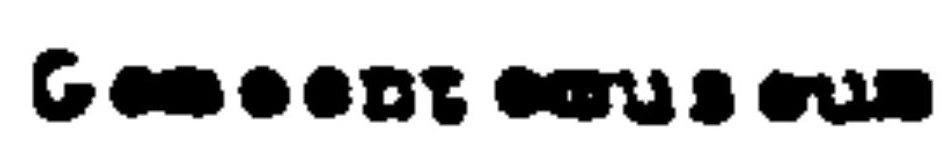

Yal * Oad T.

Nemus, Belctus

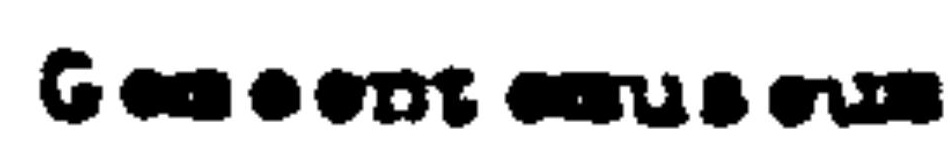

Garmed. Bostod

12 eoabus

Leipzis

17 ecshus:

Perso Codeerv.

Coperibared

Irequals House

V. L., Lododo

Mur wobers 